Frauke Streubel

\title{
Organisatorische Gestaltung und Informationsmanagement -in der lernenden Unternehmung
}




\title{
Frauke Streubel
}

\section{Organisatorische Gestaltung und Informationsmanagement -in der lernenden Unternehmung}

\begin{abstract}
„Unternehmungen müssen lernen!“ - ein vieldiskutiertes Schlagwort der aktuellen Managementliteratur. Meist bleibt jedoch unklar, was konkret unter organisationalem Lernen $\mathrm{zu}$ verstehen ist. Zahlreiche theoretische Defizite erschweren sowohl die wissenschaftliche Rezeption als auch die Umsetzung in die Praxis. Für beide Bereiche bietet die Arbeit wichtige Impulse. Sie präzisiert zunächst das Phänomen des organisationalen Lernens und zielt sodann darauf ab, den Beitrag des Informationsmanagements zur Förderung organisationalem Lernen in der Unternehmung aufzuzeigen. Dabei erfolgt die Konzeptionalisierung des Zusammenhangs zwischen organisationalem Lernen und Informationsmanagement über den Zwischenschritt der organisatorischen Gestaltung, die deshalb - neben dem Informationsmanagement - als zweites Aufgabenfeld untersucht wird.
\end{abstract}

Frauke Streubel, Jahrgang 1967, studierte von 1986 bis 1993 Wirtschaftswissenschaft an den Universitäten Essen und Bochum. Auslandsaufenthalt in Poitiers/Frankreich. Von 1993 bis 1998 wissenschaftliche Mitarbeiterin am Lehrstuhl für Wirtschaftsinformatik der Universität Bochum, Promotion 1999. Seit 1999 als Unternehmensberaterin bei der CMS Unternehmensberatung AG im Bereich Konsolidierungsmanagement in Berlin tätig. 
Organisatorische Gestaltung und Informationsmanagement in der lernenden Unternehmung 


\section{BOCHUMER BEITRÄGE ZUR UNTERNEHMUNGSFÜHRUNG UND UNTERNEHMENSFORSCHUNG}

Herausgegeben von Prof. Dr. Dr. h.c. mult. Walther Busse von Colbe, Prof. Dr. Dr. h.c. Werner H. Engelhardt, Prof. Dr. Roland Gabriel, Prof. Dr. Arno Jaeger, Prof. Dr. Gert Laßmann, Prof. Dr. Wolfgang Maßberg, Prof. Dr. Bernhard Pellens, Prof. Dr. Marion Steven, Prof. Dr. Rolf Wartmann, Prof. Dr. Brigitte Werners, Prof. Dr. Daniel Zimmer

Band 60

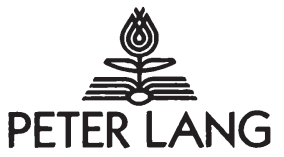

Frankfurt am Main - Berlin - Bern - Bruxelles - New York · Oxford · Wien 


\section{Organisatorische Gestaltung und Informationsmanagement in der lernenden Unternehmung}

Bausteine eines Managementkonzeptes

organisationalen Lernens

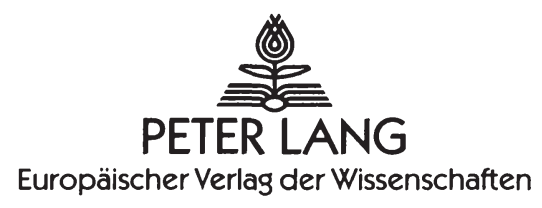


Die Deutsche Bibliothek - CIP-Einheitsaufnahme

Streubel, Frauke:

Organisatorische Gestaltung und Informationsmanagement in der lernenden Unternehmung : Bausteine eines Managementkonzeptes organisationalen Lernens / Frauke Streubel. - Frankfurt am Main ; Berlin ; Bern ; Bruxelles ; New York; Oxford; Wien : Lang, 2000

(Bochumer Beiträge zur Unternehmungsführung und

Unternehmensforschung ; Bd. 60)

Open Access: The online version of this publication is published on www.peterlang.com and www.econstor.eu under the international Creative Commons License CC-BY 4.0. Learn more on how you can use and share this work: http://creativecommons.org/licenses/by/4.0.

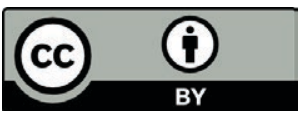

This book is available Open Access thanks to the kind support of ZBW Leibniz-Informationszentrum Wirtschaft.

Zugl.: Bochum, Univ., Diss., 1999

ISBN 3-631-36078-9

Gedruckt auf alterungsbeständigem, säurefreiem Papier.

\section{294}

ISSN 0175-7105

ISBN 3-631-36078-9

ISBN 978-3-631-75510-5 (eBook)

(C) Peter Lang $\mathrm{GmbH}$

Europäischer Verlag der Wissenschaften

Frankfurt am Main 2000

Alle Rechte vorbehalten.

Das Werk einschließlich aller seiner Teile ist urheberrechtlich geschützt. Jede Verwertung außerhalb der engen Grenzen des

Urheberrechtsgesetzes ist ohne Zustimmung des Verlages unzulässig und strafbar. Das gilt insbesondere für

Vervielfältigungen, Übersetzungen, Mikroverfilmungen und die Einspeicherung und Verarbeitung in elektronischen Systemen.

Printed in Germany 123467 
Meinen Eltern

und Dieter 
Frauke Streubel - 978-3-631-75510-5

Downloaded from PubFactory at 01/11/2019 04:00:13AM 


\section{Geleitwort}

Organisationales Lernen stellt in der Managementliteratur der ausgehenden 90er Jahre ein vieldiskutiertes Schlagwort dar. Dabei bleibt oft unklar, was organisationale Lernprozesse vom individuellen Lernen der Mitarbeiter der Unternehmung unterscheidet und damit eine eigenständige Untersuchung dieses Phänomens rechtfertigt. Das Informationsmanagement als das Management der Ressource Information bzw. Wissen in der Unternehmung steht in einem engen Zusammenhang zum organisationalen Lernen. Ziel der Arbeit von Frau Streubel ist es deshalb, den Beitrag des Informationsmanagements zur Förderung organisationalen Lernens in der Unternehmung aufzuzeigen. Dabei erfolgt die Konzeptionalisierung des Zusammenhangs zwischen organisationalem Lernen und Informationsmanagement über den Zwischenschritt der organisatorischen Gestaltung, die deshalb - neben dem Informationsmanagement - als zweites Aufgabenfeld untersucht wird.

Ausgangspunkt der Analyse ist ein Zwei-Ebenen-Ansatz des Informationsmanagements, innerhalb dessen zwischen der Gestaltung der informationellen Beziehungen in der Unternehmung als einem immateriellen Phänomen auf der einen und der Gestaltung der Informationstechnik als materiellem Phänomen auf der anderen Ebene unterschieden wird. Somit werden die Aktivitäten des Informationsmanagements über den engen Bereich der reinen Gestaltung der Informationstechnik hinaus hin zu einem auch betriebswirtschaftlich geprägten Verständnis ausgedehnt. Zugleich stellt dieser Zwei-Ebenen-Ansatz eine geeignete Grundlage für die Konzeptionalisierung des Zusammenhangs zwischen organisatorischer Gestaltung und Informationsmanagement dar.

Die Untersuchung des Phänomens des organisationalen Lernens als der Veränderung der organisationalen Wissensbasis ergibt, daß bestimmte organisationale Lernprozesse, zu denen auch die organisatorischen Tätigkeiten zählen, zur Bewältigung häufiger, schneller und diskontinuierlicher unternehmungsexterner Wandelprozesse beitragen. Die Gegenüberstellung von organisatorischer Gestaltung und Selbstorganisation zeigt, daß unter bestimmten Bedingungen Selbstorganisationsprozesse vorzuziehen sind. Deshalb muß die organisatorische Gestaltung darauf abzielen, geeignete Rahmenbedingungen zur Förderung von Selbstorganisationsprozessen zu schaffen.

Aus den entwickelten Empfehlungen für die organisatorische Gestaltung können solche für das Informationsmanagement abgeleitet werden. Auf der immateriellen Ebene wird eine stärkere Fokussierung der Informationsversorgung der unteren Hierarchieebenen der Unternehmung sowie das Einrichten eines unternehmungsweiten Informationspools in Kombination mit der verstärkten Ausrichtung der Informationsversorgung am Holprinzip gefordert. Im Mittelpunkt der auf die materielle Ebene der Informationstechnik bezogenen Gestaltungsempfehlungen stehen das Data Warehouse sowie das Knowledge Warehouse. 
Die Arbeit von Frau Streubel stellt einen hochinteressanten wissenschaftlichen Beitrag zu einem aktuellen Thema dar. Aufgrund der sorgfältigen wissenschaftlichen Aufarbeitung bietet sie dem Theoretiker insbesondere bei der Konzeptionalisierung des organisationalen Lernens und des Informationsmanagements, aber auch bei der Abgrenzung von Informationsmanagement und organisatorischer Gestaltung sowie der Untersuchung so schillernder Begriffe wie Selbstorganisation, Autopoiese und Selbstreferenz konsequent logische Argumentationslinien. Sie trägt damit dazu bei, das in diesen $\mathrm{Be}-$ reichen heute noch vielfach vorhandene Theoriedefizit zu überwinden. Mit ihrem systematischen Aufbau und der zielorientierten, sehr präzise formulierten Argumentation leistet die Arbeit einen wichtigen Beitrag zur wissenschaftlichen Diskussion. Aber auch der interessierte Praktiker wird die Arbeit mit Gewinn lesen, denn trotz der bisher vorliegenden Forschungsdefizite gelingt es Frau Streubel, fundierte Gestaltungsempfehlungen abzuleiten. Der Praktiker wird insbesondere in den gestaltungsorientierten Teilen der Kapitel 4 und 5 fündig werden und dort Anregungen finden, wie organisatorische Gestaltung und Informationsmanagement Selbstorganisationsprozesse als Prozesse organisationalen Lernens fördern können. Die Arbeit von Frau Streubel wurde mit dem vom Institut für Unternehmensführung und Unternehmungsforschung an der RuhrUniversität Bochum verliehenen Ernst-Zander-Preis 1999 für herausragende wissenschaftliche Arbeiten ausgezeichnet. Ich wünsche ihr eine weite Verbreitung.

Prof. Dr. Roland Gabriel 


\section{Vorwort}

Die vorliegende Arbeit wurde im Frühjahr 1999 von der Fakultät für Wirtschaftswissenschaft der Ruhr-Universität Bochum als Dissertation angenommen. Ein solches Projekt ist zwar phasenweise ein sehr einsames Unterfangen, wäre jedoch in dieser Form ohne die Mitwirkung einiger Menschen, denen ich dafür sehr dankbar bin, nicht möglich gewesen.

Meinem akademischen Lehrer, Herrn Professor Dr. Roland Gabriel, gebührt Dank für die vielfältige Unterstützung und insbesondere die gewährten Freiräume bei Themenwahl und Umsetzung im Rahmen meiner Tätigkeit als wissenschaftliche Mitarbeiterin an seinem Lehrstuhl. Herr Professor Dr. Wolfgang Mag hat das Korreferat übernommen.

Meine Kolleginnen und Kollegen am Lehrstuhl sowie die studentischen Hilfskräfte haben auf unterschiedliche Weise zum Gelingen dieser Arbeit beigetragen. Allen voran danke ich Dirk Beier für die stets konstruktive Zusammenarbeit im Rahmen unserer gemeinsamen Forschungstätigkeit am Lehrstuhl. Seine Bereitschaft, sich immer wieder neu mit merkwürdigen Gedankenkonstrukten auseinanderzusetzen, und die daraus resultierenden Impulse für meine Arbeit haben in mir die Überzeugung entstehen lassen, daß kollegiale Zusammenarbeit gerade bei komplexen, kreativen Aufgabenstellungen zwar nicht immer bequem ist, regelmäßig jedoch die Qualität des Arbeitsergebnisses positiv beeinflußt. Darüber hinaus danke ich Ane-Kristin ReifMosel für die gute Zusammenarbeit und ihre herzerfrischend trockenen Kommentare zu meinen Arbeitsergebnissen und meinem Gemütszustand. Marco Wallenfels hat nicht nur mit großem Engagement die Erstellung der Abbildungen übernommen, sondern in der Endphase per Telefon von Bochum aus in unnachahmlicher Art und Weise in Berlin EDV-Katastrophen gelöst und moralischen Support gewährt. Stellvertretend für alle anderen studentischen Hilfskräfte danke ich Carsten Schoene für die zahllosen Literaturrecherchen.

Den größten Dank schulde ich meinem Mann, Dieter Gloede, der alle Hochs und Tiefs, die mit der Erstellung dieser Arbeit verbunden waren, hautnah miterlebt hat und mir auch in den schwierigen Phasen immer wieder Mut gemacht hat. Ich bin froh, daß ihn all das Kreisen um konstruktivistisches Weltverständnis, komplexe Systeme, Autopoiese, Syn- und Selbstreferenz, das Fokussieren und Konzeptionalisieren nicht dazu gebracht haben, meine Dissertationsfragmente schlußendlich doch aus dem Fenster eines fahrenden Zuges auf dem Weg zwischen Ruhrgebiet und Berlin zu werfen. Ihm und meinen Eltern, Elke und Peter Streubel, die immer für mich da waren und sind, widme ich diese Arbeit. 
Frauke Streubel - 978-3-631-75510-5

Downloaded from PubFactory at 01/11/2019 04:00:13AM 


\section{Inhaltsübersicht}

\section{Einführung}

2 Grundlagen der Analyse von organisatorischer Gestaltung und Informationsmanagement in der lernenden Unternehmung

2.1 Wissenschaftstheoretische Positionierung

2.2 Abgrenzung der Aufgabenfelder organisatorische Gestaltung und Informationsmanagement

3 Unternehmungsinterner Wandel durch organisationales Lernen

3.1 Das Phänomen des Wandels

3.2 Das Phänomen des organisationalen Lernens

3.3 Der Zusammenhang zwischen organisationalem Lernen und Wandel

4 Organisatorische Gestaltung in der lernenden Unternehmung

4.1 Theoretischer Bezugsrahmen für die Ableitung von Anforderungen an die organisatorische Gestaltung in der lernenden Unternehmung

4.2 Möglichkeiten der Förderung organisationalen Lernens durch die organisatorische Gestaltung

5 Informationsmanagement in der lernenden Unternehmung

5.1 Theoretischer Bezugsrahmen für die Ableitung von Anforderungen an das Informationsmanagement in der lernenden Unternehmung

5.2 Die Gestaltung der immateriellen Ebene des computergestützten Informationssystems in der lernenden Unternehmung

5.3 Die Gestaltung der materiellen Ebene des computergestützten Informationssystems in der lernenden Unternehmung

6 Zusammenfassung und Ausblick 
Frauke Streubel - 978-3-631-75510-5

Downloaded from PubFactory at 01/11/2019 04:00:13AM 


\section{Inhaltsverzeichnis}

Abbildungs- und Tabellenverzeichnis............................................................. XIX Abkürzungsverzeichnis ..............................................................................XXI

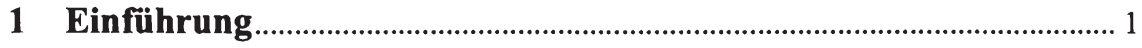

1.1 Problemstellung und Zielsetzung der Arbeit......................................... 2

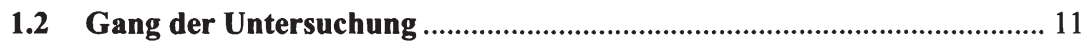

2 Grundlagen der Analyse von organisatorischer Gestaltung und Informationsmanagement in der lernenden Unternehmung........... 15

2.1 Wissenschaftstheoretische Positionierung ............................................... 16

2.1.1 Zur Notwendigkeit eines interdisziplinären Ansatzes....................... 16

2.1.2 Der Radikale Konstruktivismus als wissenschaftstheoretische Grundposition

2.1.3 Die Systemtheorie als terminologische und methodische Basis

2.2 Abgrenzung der Aufgabenfelder organisatorische Gestaltung und Informationsmanagement

2.2.1 Das Aufgabenfeld organisatorische Gestaltung

2.2.1.1 Grundsätzliche Möglichkeiten der Verwendung des Organisationsbegriffes

2.2.1.1.1 Klassifikationsschema zur Systematisierung möglicher Organisationsbegriffe

2.2.1.1.2 Verwendungsformen des Organisationsbegriffes im Rahmen der vorliegenden Arbeit

2.2.1.2 Die organisatorischen Regeln

2.2.1.3 Fremd- und Selbstorganisation als Grundformen organisatorischer Tätigkeit. 
2.2.2 Das Aufgabenfeld Informationsmanagement

2.2.2.1 Für die Konzeptionalisierung des Informations-

managements relevante Ansätze in der Literatur

2.2.2.1.1 Das Drei-Schichten-Modell des Informationsmanagements von WOLLNIK

2.2.2.1.2 Modelle der Informationssystem-Architektur .......51

2.2.2.1.3 Das Modell des Informationsmanagements von KRCMAR.

2.2.2.2 Der Gegenstandsbereich des Informationsmanagements .....60

2.2.2.2.1 Abgrenzung von Wissen, Daten und Information

2.2.2.2.2 Information als In- und Output des betrieblichen Leistungserstellungsprozesses........65

2.2.2.2.3 Materielle und immaterielle Ebene der Informationsverarbeitung .66

2.2.2.2.4 Das computergestützte Informationssystem.........70

2.2.2.3 Die Funktionen des Informationsmanagements.....................74

2.2.2.3.1 Das Management der immateriellen Ebene des computergestützten Informationssystems . .75

2.2.2.3.2 Das Management der materiellen Ebene des computergestützten Informationssystems .79

\subsubsection{Zwischenfazit: Die Konzeptionalisierung des} Informationsmanagements mit Hilfe eines Zwei-Ebenen-Ansatzes

2.2.3 Der Zusammenhang zwischen organisatorischer Gestaltung und Informationsmanagement

3 Unternehmungsinterner Wandel durch organisationales Lernen ..89

3.1 Das Phänomen des Wandels .90

3.1.1 Unternehmungsexterner Wandel als Herausforderung für die Unternehmungsführung .91

3.1.2 Die Befähigung zu unternehmungsinternem Wandel als Gegenstand der Unternehmungsstrategie .96

3.2 Das Phänomen des organisationalen Lernens .99

3.2.1 Individuelles Lernen .100

3.2.1.1 Behavioristische Lerntheorien .101

3.2.1.2 Kognitive Lerntheorien. .102

3.2.1.3 Der Stellenwert individueller Lerntheorien für ein Konzept organisationalen Lernens. 


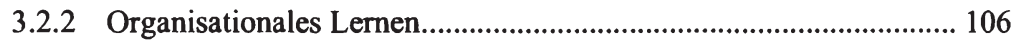

3.2.2.1 Statische Perspektive: Die organisationale Wissensbasis.. 107

3.2.2.2 Dynamische Perspektive: Organisationales Lernen als Veränderung der organisationalen Wissensbasis............... 119

3.2.2.2.1 Grundformen der Veränderung der organisationalen Wissensbasis

3.2.2.2.2 Organisationales Lernen als Veränderung der individuellen Teile der organisationalen Wissensbasis.

3.2.2.2.3 Organisationales Lernen als Veränderung der überindividuellen Teile der organisationalen Wissensbasis.

3.3 Der Zusammenhang zwischen Wandel und organisationalem Lernen 133

3.3.1 Die Notwendigkeit häufiger, schneller Prozesse organisationalen Lernens höherer Ordnung 134

3.3.2 Organisatorische Tätigkeit als organisationaler Lernprozeß höherer Ordnung.

4 Organisatorische Gestaltung in der lernenden Unternehmung .... 145

4.1 Theoretischer Bezugsrahmen für die Ableitung von Anforderungen an die organisatorische Gestaltung in der lernenden Unternehmung .. 145

4.1.1 Präsituative versus situative Regelung...... 146

4.1.2 Fremd- und Selbstorganisation als alternative Ausprägungen präsituativer Regelung

4.1.2.1 Allgemeine Bewertung von Fremd- und

Selbstorganisation

4.1.2.2 Fremd- und Selbstorganisation in der von Wandel geprägten Unternehmung.

4.1.3 Das Phänomen der Selbstorganisation als Spezialfall präsituativer Regelung

4.1.3.1 Inhaltliche Abgrenzung des Phänomens der

Selbstorganisation

4.1.3.2 Charakteristika eines Selbstorganisation fördernden Umfeldes.

4.1.3.2.1 Komplexität

4.1.3.2.2 Selbstreferenz

4.1.3.2.3 Relative Autonomie aufgrund

operationeller Geschlossenheit.

4.1.3.2.4 Redundanz 
4.1.4 Dynamisierte Mehrebenen-Betrachtung

199

4.2 Möglichkeiten der Förderung organisationalen Lernens durch die organisatorische Gestaltung

4.2.1 Organisatorische Regeln zur Arbeitsteilung ..................................210

4.2.2 Organisatorische Regeln zur Koordination....................................222

4.2.3 Organisatorische Regeln zum Leitungssystem ..............................232

4.2.4 Organisatorische Regeln zur Entscheidungsdelegation ....................241

4.2.5 Zusammenfassung der Empfehlungen für die organisatorische Gestaltung in der lernenden Unternehmung.

5 Informationsmanagement in der lernenden Unternehmung. .251

5.1 Theoretischer Bezugsrahmen für die Ableitung von Anforderungen an das Informationsmanagement.

5.1.1 Stand der Diskussion über den Zusammenhang zwischen organisationalem Lernen und Informationsmanagement in der Literatur ......253

5.1.2 Operationalisierung des Zusammenhangs zwischen organisatorischer Gestaltung als Prozeß organisationalen Lernens und Informationsmanagement.

5.1.2.1 Das Modell von WaLL zum Zusammenhang zwischen organisatorischen Regeln und Architektur der Informationstechnik

5.1.2.2 Kritische Würdigung und Modifikation des Modells von WALL

5.1.2.2.1 Grundlegende Modellannahmen

5.1.2.2.2 Dimensionaler Ansatz

5.2 Die Gestaltung der immateriellen Ebene des computergestützten Informationssystems in der lernenden Unternehmung.

5.2.1 Organisatorisch bedingte Rahmenbedingungen des Informationsmanagements

5.2.1.1 Inhaltlicher Umfang von Informationsbedarf und -bereitstellung

5.2.1.2 Bestimmtheit von Informationsbedarf und -bereitstellung

5.2.1.3 Dringlichkeit von Informationsbedarf und -bereitstellung 


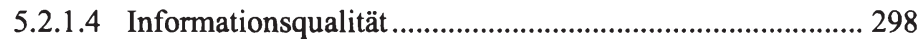

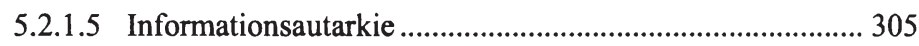

5.2.2 Die Gestaltung der Informationsstruktur ...................................... 309

5.3 Die Gestaltung der materiellen Ebene des computergestützten Informationssystems in der lernenden Unternehmung........................ 320

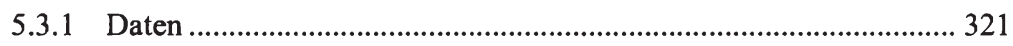

5.3.1.1 Das Data Warehouse ........................................................ 322

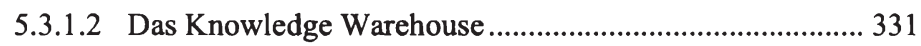

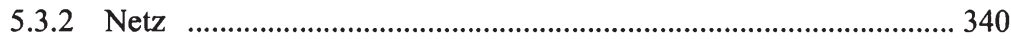

5.3.3 Anwendungsprogramme ............................................................ 343

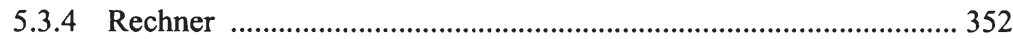

5.3.5 Zusammenfassung der informationstechnischen Gestaltungsempfehlungen in der lernenden Unternehmung .............................. 354

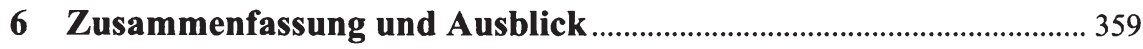

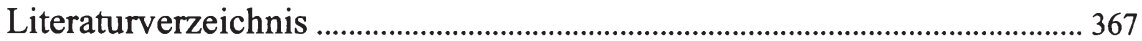


Frauke Streubel - 978-3-631-75510-5

Downloaded from PubFactory at 01/11/2019 04:00:13AM 


\section{Abbildungs- und Tabellenverzeichnis}

Abb. 1/1: Bausteine eines Managementkonzeptes organisationalen Lernens .......... 4

Abb. 1/2: Der Zusammenhang zwischen organisationalem Lernen, organisatorischer Gestaltung und Informationsmanagement.................. 10

Abb. 1/3: Die Argumentationsstruktur der vorliegenden Arbeit ............................ 13

Abb. 2/1: Die Argumentationsstruktur des zweiten Kapitels ................................. 15

Abb. 2/2: Wissenschaftstheoretische Grundpositionen mit ihren jeweiligen ontologischen und epistemologischen Annahmen.................................. 20

Abb. 2/3: Das System mit Elementen, Beziehungen und einem Subsystem ........... 24

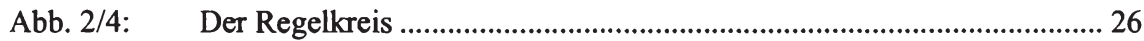

Abb. 2/5: Systematisierung institutionaler Organisationsbegriffe .......................... 32

Abb. 2/6: Die Verwendung des Organisationsbegriffes in der vorliegenden Arbeit ..................................................................................... 37

Abb. 2/7: Systematisierung der Regelungsinhalte des Organisationssystems........ 40

Abb. 2/8: Der Managementzyklus ..................................................................... 42

Abb. 2/9: Der Zusammenhang zwischen Fremd- und Selbstorganisation sowie formalen und informalen organisatorischen Regeln ............................... 47

Abb. 2/10: Mehrebenenzusammenhang der technikgestützten Informations-

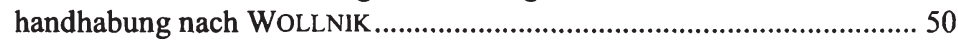

Abb. 2/11: Ganzheitliches Modell der Informationssystem-Architektur

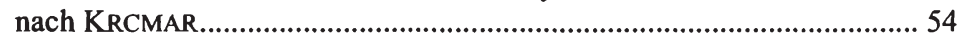

Abb. 2/12: Die Architektur integrierter Informationssysteme von SCHEER ............. 57

Abb. 2/13: Das Modell des Informationsmanagements nach KRCMAR .................... 58

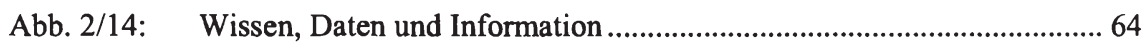

Abb. 2/15: Systematisierung der materiellen Trägermedien der Information .......... 67

Abb. 2/16: Materielle und immaterielle Ebene des computergestützten Informationssystems ....................................................................... 73

Tab. 2/17: Gegenüberstellung von organisatorischer Gestaltung und Informationsmanagement ................................................................ 83

Abb. 2/18: Der Kausalzusammenhang zwischen Organisationssystem, Informationsstruktur und Informationstechnik ....................................... 87

Abb. 3/1: Die Argumentationsstruktur des dritten Kapitels ................................... 90

Abb. 3/2: Der Zusammenhang zwischen unternehmungsexternem und -internem Wandel............................................................................. 98

Abb. 3/3: Die Systematisierung organisationalen Wissens anhand des Trägermediums.

Abb. 3/4: Die mehrdimensionale Systematisierung der organisationalen Wissensbasis 
Abb. 3/5: Die organisationale Wissensbasis als Ausgangspunkt und Ergebnis organisationalen Lernens

Tab. 3/6: Systematisierungsmöglichkeiten für Arten organisationalen Lernens ..131

Abb. 3/7: Single-loop, Double-loop und Deutero Learning .

Abb. 3/8: Der Zusammenhang zwischen unternehmungsexternem und -internem Wandel sowie organisationalem Lernen 136

Abb. 3/9: Die Beschränkung der Perspektive der vorliegenden Untersuchung auf organisatorische Tätigkeiten als Double-loop Learning. 143

Abb. 4/1: Die Argumentationsstruktur bei der Formulierung des theoretischen Bezugsrahmens.

Abb. 4/2: Grundformen der Regelung ..................................................................149

Tab. 4/3: Vor- und Nachteile von Fremd- und Selbstorganisation ........................158

Abb. 4/4: Die Schaffung eines Rahmens für Selbstorganiationsprozesse mittels organisatorischer Gestaltung....................................................164

Abb. 4/5: Gegenüberstellung alternativer Selbstorganisations-Begriffe .................167

Abb. 4/6: Arten von Selbstorganisationsprozessen ............................................168

Abb. 4/7: Synreferenz, operationelle Schließung und relative Autonomie ............185

Abb. 4/8: Synreferenz und Selbstorganisationsprozesse .....................................188

Abb. 4/9: Der Zusammenhang zwischen den verschiedenen Systemeigenschaften und dem Auftreten von Selbstorganisationsprozessen .............195

Abb. 4/10: Die Phasen des Gruppen-Lebenszyklus.................................................202

Abb. 4/11: Die Gliederung der Gestaltungsempfehlungen anhand der vier Hauptdimensionen der organisatorischen Gestaltung ...........................210

Abb. 4/12: Formen der Arbeitsteilung ...............................................................212

Abb. 4/13: Gestaltungsempfehlungen für die Arbeitsteilung in der lernenden Unternehmung

Abb. 4/14: Der komplementäre Einsatz von Koordination durch Selbstregelung, Pläne und Programme.

Abb. 4/15: Gestaltungsempfehlungen für die Koordination in der lernenden Unternehmung

Abb. 4/16: Gestaltungsempfehlungen für das Leitungssystem in der lernenden Unternehmung ...

Abb. 4/17: Systematisierung potentiell delegierbarer Entscheidungsarten

Abb. 4/18: Gestaltungsempfehlungen für die Entscheidungsdelegation in der lernenden Unternehmung

Abb. 5/1: Die Argumentationsstruktur des fünften Kapitels

Abb. 5/2: Konzeption der Homologie zwischen Organisationsstruktur und Informationssystem-Architektur bei WALL

Abb. 5/3: Die Dimensionen von Organisationsstruktur, Informationsstruktur und Architektur des Informationssystems bei WALL 
Tab. 5/4: Terminologische Unterschiede zwischen dem Modell von WALL und der vorliegenden Arbeit ............................................................ 269

Abb. 5/5: Die Dimensionen der Informationsbedarfe und -bereitstellungen......... 276

Abb. 5/6: Konsequenzen der Ausprägungen der organisatorischen Regeln für den inhaltlichen Umfang von Informationsbedarf und -bereitstellung

Abb. 5/7: Konsequenzen der Ausprägungen der organisatorischen Regeln für die Bestimmtheit von Informationsbedarf und -bereitstellung

Abb. 5/8: Konsequenzen der Ausprägungen der organisatorischen Regeln für die Dringlichkeit von Informationsbedarf und -bereitstellung

Abb. 5/9: Konsequenzen der Ausprägungen der organisatorischen Regeln für die Informationsqualität

Abb. 5/10: Konsequenzen der Ausprägungen der organisatorischen Regeln für die Informationsautarkie

Abb. 5/11: Die Dimensionen der Informationsbedarfe und -bereitstellungen sowie der Informationsstruktur.

Abb. 5/12: Zentrale Gestaltungsempfehlungen für die immaterielle Ebene des computergestützen Informationssystems

Abb. 5/13: Architekturvarianten für das Data Warehouse....................................... 326

Abb. 5/14: Das Knowledge Warehouse als Metadatenbanksystem.

Abb. 5/15: Beispielhafte Hierarchie möglicher Knowledge Maps

Abb. 5/16: Zentrale Gestaltungsempfehlungen für die materielle Ebene des computergestützten Informationssystems 
Frauke Streubel - 978-3-631-75510-5

Downloaded from PubFactory at 01/11/2019 04:00:13AM 


\section{Abkürzungsverzeichnis}

ANSI/SPARC

DV

E-mail

IM

ISO

IT

OLAP

OLTP

S-O-R-Modell

S-R-Modell

TCP/IP

WWW
American National Standards Institute/Study Group on

Database Management Systems

Datenverarbeitung

Electronic Mail

Informationsmanagement

International Organization for Standardization

Informationstechnik

On-line Analytical Processing

On-line Transaction Processing

Stimulus-Organism-Response-Modell

Stimulus-Response-Modell

Transmission Control Protocol/Internet Protocol

World Wide Web 
Frauke Streubel - 978-3-631-75510-5

Downloaded from PubFactory at 01/11/2019 04:00:13AM 


\section{Einführung}

Können Unternehmungen lernen? Glaubt man der aktuellen Managementliteratur, so ist organisationales Lernen zentrale Voraussetzung für das Überleben der Unternehmungen im Wettbewerb: „The world is changing quickly. In order to survive and grow, organizations must learn to adapt faster and faster or be weeded out in the economic evolutionary process.“" Denn: „Learning is at the heart of a company's ability to adapt to a rapidly changing environment." ${ }^{2}$ Konzepte organisationalen Lernens versprechen dem Management Lösungen für aktuelle Probleme der Unternehmungsführung. Nur die lernende Unternehmung, so wird behauptet, sei auf Dauer am Markt erfolgreich. ${ }^{3}$

Dabei profitieren Managementkonzepte organisationalen Lernens von der positiven Konnotation des individuellen Lernbegriffes. Ähnlich dem Innovationsbegriff wird Lernen nahezu automatisch mit Fortschritt, Weiterentwicklung, einer - wie auch immer gearteten - Wendung zum Besseren verbunden. ${ }^{4}$ Der positive Grundtenor wird dadurch verstärkt, daß einerseits Wissen bzw. Information ${ }^{5}$ heute in allen Lebensbereichen eine immer größere Bedeutung zukommt. Diese Entwicklung hat dazu geführt, daß schon seit einigen Jahren der Übergang von der Industrie- zur Informations- bzw. Wissensgesellschaft konstatiert wird. Andererseits sinkt die Halbwertzeit des Wissens rapide. In Schule und beruflicher Erstausbildung erworbenes Wissen muß daher regelmäßig ergänzt und aktualisiert werden. Immer mehr besteht die Notwendigkeit lebenslangen individuellen Lernens. ${ }^{6}$

Bei der Rezeption von Managementkonzepten organisationalen Lernens stellt sich die Frage, welche Bedeutung die bezüglich des individuellen Lernens gewonnenen Erkenntnisse für die Unternehmung als Institution haben. Will man den Vorwurf entkräften, hier werde ein neuer, modischer und damit publikumswirksamer Begriff für altbekannte Phänomene verwendet, so muß das postulierte organisationale Lernen klar von individuellen Lernprozessen zu unterscheiden sein. Anderenfalls wäre der Vorwurf gerechtfertigt, hier handele es sich nur um einen weiteren Modetrend der Managementliteratur, der 'alten Wein in neuen Schläuchen' präsentiert. So ist die Managementliteratur der jüngeren Vergangenheit geprägt von einer Fülle unterschiedlicher Managementkonzepte, die jedoch zum Teil erhebliche Anleihen bei Erkenntnissen der traditionellen Managementlehre nehmen. Im Rückblick läßt sich folgende Entwicklung nachzeichnen:

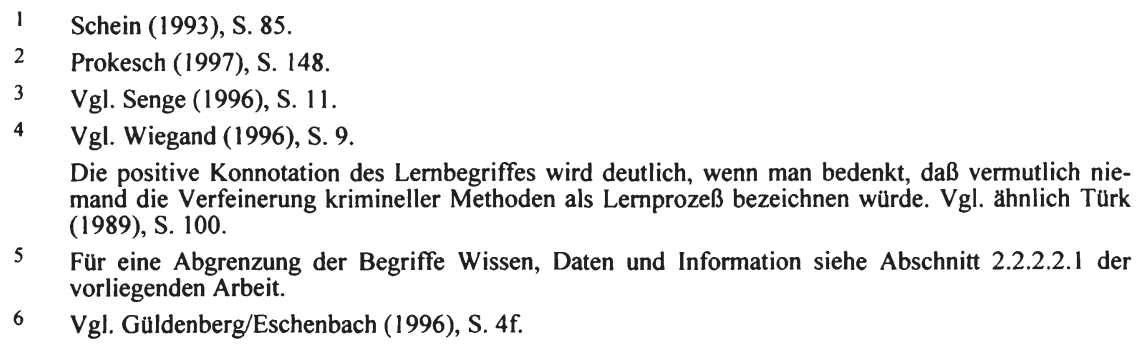
mand die Verfeinerung krimineller Methoden als Lemprozeß bezeichnen würde. Vgl. ähnlich Türk (1989), S. 100.

5 Für eine Abgrenzung der Begriffe Wissen, Daten und Information siehe Abschnitt 2.2.2.2.1 der vorliegenden Arbeit.

6 Vgl. Güldenberg/Eschenbach (1996), S. 4f. 
Dem seit der zweiten Hälfte der 80er Jahre vieldiskutierten Total Quality Management folgte zu Beginn der 90er Jahre der Lean Management-Gedanke, der wiederum Mitte der 90er Jahre durch Business Process Reengineering, die Ausrichtung am Shareholder Value sowie die Virtualisierung der Unternehmung abgelöst wurde. Speziell das Business Process Reengineering wurde dabei oft als relativ mechanistischer, allein auf kurzfristige Kostensenkungseffekte ausgerichteter Ansatz (fehl-) interpretiert, der radikale Veränderungen im Sinne eines bewußten Bruchs mit der Vergangenheit fordert, über die in Verfolgung einer Top-down-Vorgehensweise auf den oberen Hierarchieebenen zu entscheiden sei. Aktuelle Arbeiten zu Managementkonzepten organisationalen Lernens werden häufig als Reaktion auf diese Sichtweise des Business Process Reengineering angesehen, zumal sie häufigen unternehmungsinternen Wandel, der durch entsprechende organisationale Lernprozesse in Gang gehalten wird, in den Mittelpunkt der Betrachtung stellen. ${ }^{7}$

Die vorliegende Arbeit thematisiert organisationales Lernen bzw. ein auf die Förderung organisationalen Lernens abzielendes Managementkonzept. Dabei soll nicht etwa eine umfassende Theorie organisationalen Lernens entwickelt werden. Vielmehr beschränkt sich die Untersuchung auf bestimmte Aspekte, die im folgenden Abschnitt 1.1 vorgestellt werden. Ausgehend von dem dort formulierten zentralen Erkenntnisziel zeigt Abschnitt 1.2 sodann den Gang der Untersuchung auf.

\subsection{Problemstellung und Zielsetzung der Arbeit}

Die elementare Aufgabe des Managements ${ }^{8}$ in der betrieblichen Praxis besteht darin, eine günstige Wettbewerbsposition der Unternehmung zu gewährleisten, um das Überleben der Unternehmung am Markt langfristig zu sichern. ${ }^{9}$ Entsprechend hat die Managementwissenschaft als anwendungsorientierte Wissenschaft über die geeignete Begriffsbildung und die Entwicklung theoretischer Aussagen hinaus die Formulierung theoretisch fundierter Handlungsempfehlungen für die betriebliche Managementpraxis zum Gegenstand. ${ }^{10}$ Die im Rahmen von Managementkonzepten formulierten modellhaften, abstrahierenden und generalisierten Verhaltensempfehlungen sollen dabei Unterstützung leisten.

Veränderungen des unternehmerischen Umfeldes führen heute immer öfter dazu, daß traditionelle Managementkonzepte die an sie gestellten Erwartungen nicht erfüllen. Dies liegt insbesondere darin begründet, daß sie den Wandel der externen Umwelt der Unternehmung und die daraus resultierende Notwendigkeit unternehmungsinterner Verän-

$7 \quad$ Einen sehr kritischen Überblick uber das Phänomen wechselnder Managementmoden gibt Kieser (1996), S. 21 ff. Vgl. ferner Wiegand (1996), S. 9.

8 Die Begriffe Unternehmungsfuhrung und Management werden im folgenden synonym verwendet. Dieses Begriffsverständnis findet sich z.B. auch implizit bei Delfmann (1993), Sp. 3232, explizit bei Dulfer (1993), Sp. 2647, und Mag (1992), S. 60. Anders dagegen z.B. Staehle (1994), S. 69f.

9 Vgl. Reuter (1993), Sp. 2664.

10 Vgl. Chmielewicz (1994), S. 9ff. in Verbindung mit Gaugler (1994), S. $253 \mathrm{f}$. 
derungen als Ausnahmephänomen konzipieren." Zwar waren auch in der Vergangenheit schon Wandelprozesse zu beobachten. Heute ist der Wandel jedoch einerseits in vielen Bereichen zu einem sehr häufig auftretenden Phänomen geworden, andererseits ist eine deutlich höhere - und in der Zukunft tendenziell weiter zunehmende - Dynamik und Diskontinuität des Wandels der externen Umwelt der Unternehmung zu beobachten. ${ }^{12}$ Will man in dieser Situation die Wettbewerbsposition der Unternehmung langfristig sichern, gilt es, sich von traditionellen Managementkonzepten zu lösen und Wege zu finden, um die Fähigkeit zu unternehmungsinternem Wandel gezielt zu entwickeln.

Hier setzt das im Rahmen der vorliegenden Arbeit untersuchte Managementkonzept organisationalen Lernens an. Es sollen Wege aufgezeigt werden, die Fähigkeit zu flexiblem Agieren und Reagieren, die in einem hochdynamischen Umfeld von zentraler Bedeutung für das Überleben der Unternehmung am Markt ist, zu erreichen und aufrechtzuerhalten. Veränderungen werden dabei nicht länger als Ausnahme angesehen. Vielmehr sind häufige Wandelprozesse innerhalb der Unternehmung notwendig, die ihrerseits häufiges organisationales Lernen voraussetzen. Ein wichtiges Anliegen der Unternehmungsführung muß es deshalb sein, Rahmenbedingungen zu schaffen, die organisationale Lernprozesse fördern. ${ }^{13}$

Zentrales Ziel der vorliegenden Arbeit ist es, den Beitrag des Informationsmanagements zur Förderung organisationalen Lernens in der Unternehmung aufzuzeigen. Die Ausführungen zur Erreichung dieses Zieles können mittels der in Abbildung 1/1 aufgezeigten Zwischenziele strukturiert werden. Die Ausarbeitungen zu den im folgenden zu erläuternden vier Zwischenzielen bilden also die Voraussetzung für die Erreichung des zentralen Zieles. Sie können deshalb auch als 'Bausteine eines Konzeptes organisationalen Lernens' bezeichnet werden.

Als außerordentlich problematisch für die Rezeption der vielfältigen Literatur zum organisationalen Lernen erweist sich, daß das Phänomen organisationalen Lernens dort häufig nur diffus umschrieben, nicht jedoch ausreichend konzeptionalisiert wird. Trotz der in der jüngsten Vergangenheit zu einer wahren Flut angewachsenen Fülle von Veröffentlichungen existiert zur Zeit weder ein einheitlicher Begriffsrahmen noch ein darüber hinausreichender, allgemein anerkannter, theoretisch fundierter Ansatz des organisationalen Lernens. Insbesondere wird der Begriff des organisationalen Lernens in zahlreichen Veröffentlichungen als modisches Schlagwort in sehr unterschiedlichen Zusammenhängen verwendet. ${ }^{14}$ Auch ist ein Nebeneinander verschiedener Ansätze zu

11 Vgl. Gomez/Zimmermann (1992), S. 126; Kieser (1994), S. 199.

12 Vgl. Schüppel (1996), S. 4.

13 Vgl. Krüger/Bach (1997), S. 24ff.; Pawlowski (1994), S. 3ff.; Strauß (1996), S. I ff.; Wahren (1996), S. Iff.; Wiegand (1996), S. 8 f.

14 Ähnlich werten Güldenberg/Eschenbach (1996), S. 5. Dies gilt insbesondere für Veröffentlichungen, die dem Bereich praxisorientierter allgemeiner Managementliteratur zuzuordnen sind, so z.B. Reichardt (1998), passim; Rudolph (1997), passim. Eine im Herbst 1996 von der Stiftung 'Philosophisches Institut' durchgeführte Befragung ergab, daß dem Phänomen 'organisationales Lemen' in 


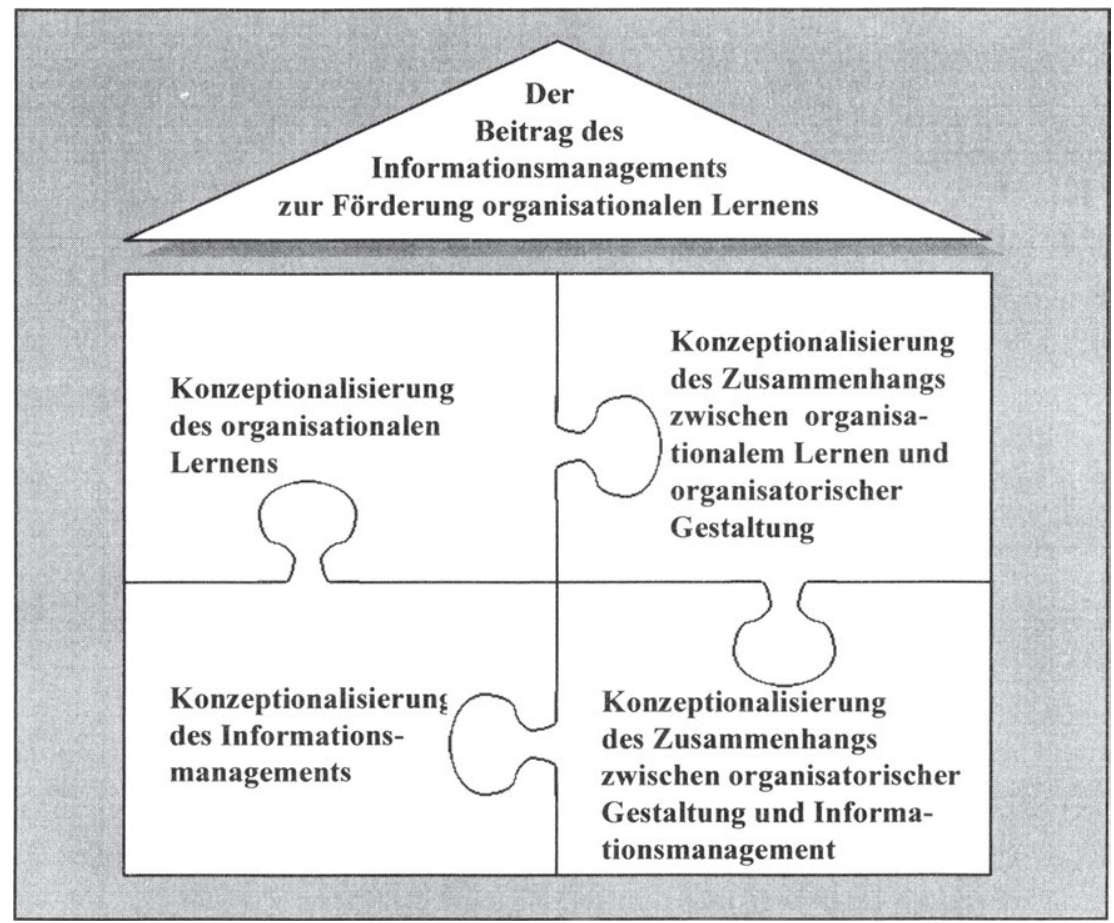

Abb. 1/1: Bausteine eines Managementkonzeptes organisationalen Lernens

beobachten, ${ }^{15}$ so daß HUBER die Forschung in diesem Bereich provokativ als (absichtlich) nicht-kumulativ bezeichnet, da Autoren oft die theoretischen und empirischen Arbeiten anderer Autoren in diesem Bereich ignorieren. ${ }^{16}$ Der somit in Teilen der Literatur zum organisationalen Lernen entstehende Eindruck der Beliebigkeit hat zur Folge, daß auf organisationales Lernen abstellende Managementkonzepte von einigen Wissenschaftlern als theoretisch nicht fundiert abgelehnt werden. Ein wichtiger Kritikpunkt ist die häufig implizierte Anthropomorphisierung der Institution Unternehmung bzw. die mangelnde Trennschärfe der Unterscheidung zwischen individuellem und organisationalem Lernen. ${ }^{17}$ Ein eigenständiger Ansatz organisationalen Lernens setzt

der Praxis zwar großes Interesse entgegengebracht wird, jedoch weitgehend offenbleibt, was im einzelnen darunter zu verstehen ist. So subsumierten die befragten Führungskrăfte Ansătze wie Kaizen, Total Quality Management und sogar Business Reengineering unter organisationales Lernen. Vgl. Hoch (1997), S. P1.

15 Vgl. z.B. die Übersicht uber die Systematisierungen 18 verschiedener Autoren bei Probst/Büchel (1998), S. 18 sowie der tabellarische Vergleich sieben wichtiger Ansătze zum organisationalen Lemen bei Wiegand (1996), S. 174ff.

16 Vgl. Huber (1991), S. 88, 95f. Hubers Aussage, die sich allein auf englischsprachige Veröffentlichungen bezieht, kann m.E. in ähnlicher Form auch auf den deutschen Sprachraum ubertragen werden.

17 Vgl. z.B. bei Bernskőtter (1997), S. 30; Beutel-Wedewardt (1991), passim, insbesondere S. 258; Garratt (1990), passim; Geyer (1997), passim, insbesondere S. 125; Pedler/Boydell/Burgoyne (1991), S. 60ff. Auf die Problematik der Analogiebildung zwischen individuellem und organisationalem Lernen verweist Wiegand (1996), S. 2. 
aber voraus, daß dieses nicht mit der Summe der individuellen Lernprozesse der Mitglieder der Unternehmung gleichgesetzt wird. ${ }^{18}$ So stellt KIM fest: „A model of organizational learning has to resolve the dilemma of imparting intelligence and learning capabilities to a nonhuman entity without anthropomorphising it."19

Einerseits verbinden sich also mit Managementkonzepten organisationalen Lernens regelmäßig Hoffnungen auf Antworten zu aktuellen Fragen der Unternehmungsführung. Andererseits erweist sich die theoretische Aufarbeitung organisationalen Lernens als eigenständigen Phänomens jedoch zumeist als mangelhaft. Ein Zwischenziel der vorliegenden Arbeit ist deshalb die Konzeptionalisierung des organisationalen Lernens. Dabei zeigt die Reinterpretation der Erkenntnisse individueller Lerntheorien für organisationales Lernen, daß solche organisationalen Lernprozesse zielführend im Sinne der Bewältigung dynamischen und diskontinuierlichen Wandels sind, die Veränderungen organisationaler Handlungstheorien darstellen.

Die Förderung organisationalen Lernens bildet den Kernpunkt bestimmter Managementkonzepte, die deshalb auch als Managementkonzepte organisationalen Lernens bezeichnet werden. Ein solches Managementkonzept organisationalen Lernens steht im Mittelpunkt der vorliegenden Arbeit. Als Managementkonzept sei hier die Gesamtheit logisch zusammenhängender Annahmen über auf bestimmte Ziele ausgerichtete Managementaktivitäten ${ }^{20}$ und die dabei wirksam werdenden Ziel-Mittel-Beziehungen verstanden. Der 'weichere' Begriff des Konzeptes - im Sinne eines 'schwachen' Vorläufers von Theorien ${ }^{21}$ - soll hier dem der Theorie vorgezogen werden. Denn in dem Forschungsbereich 'organisationales Lernen' existiert zur Zeit noch kein befriedigendes Zwischenergebnis bei der Theoriebildung im Sinne eines Geflechtes von empirisch gehaltvollen, empirisch bewährten, als Gesetzesaussagen interpretierbaren, eine vollkommene Erklärung liefernden Hypothesen (Erklärungsfunktion von Theorien), das als gedankliche Basis für Gestaltungshandlungen dienen kann (Gestaltungsfunktion von Theorien). ${ }^{22}$ Aufgrund der in diesem Forschungsbereich schon bei der Begriffs- und Modellbildung $\mathrm{zu}$ verzeichnenden großen Defizite kann die vorliegende Arbeit die empirischen Anforderungen an eine Theorie organisationalen Lernens nicht erfüllen. Vielmehr liegt der Fokus der folgenden Untersuchung auf der Konzeptionalisierung im Sinne eben dieser Begriffs- und Modellbildung. Die empirische Prüfung der dabei entwickelten Ergebnisse steht dagegen noch aus. Auch müßte eine umfassende Managementtheorie organisationalen Lernens Gestaltungsempfehlungen für alle Teilbereiche der betrieblichen Realität bzw. alle Managementaktivitäten in der

18 Vgl. Güldenberg/Eschenbach (1996), S. 5; Pawlowski (1994), S. 262; Reinhardt (1995), S. $43 \mathrm{ff}$.

$19 \operatorname{Kim}(1993)$, S. 40.

20 Für eine Definition von Management siehe Abschnitt 2.2.1.3 der vorliegenden Arbeit. Die hier vorgenommene Definition stellt dagegen auf den Begriff des Managementkonzeptes ab.

$21 \mathrm{Vgl}$. Osterloh/Grand (1994), S. 278ff., die jedoch von einem anderen Theoriebegriff ausgehen; Steinle (1985), S. 23; Ulrich (1993), S. 39ff.

22 Vgl. Kieser/Kubicek (1978), S. 13ff. 
Unternehmung umfassen. Die folgende Untersuchung beschränkt sich dagegen auf bestimmte Teilaspekte.

In der Literatur zum organisationalen Lernen finden sich traditionellerweise in erster Linie Empfehlungen für die organisatorische Gestaltung und die Personalwirtschaft. ${ }^{23}$ Eine systematische Aufarbeitung des Zusammenhangs zwischen dem Ziel der Förderung organisationalen Lernens und den Aktivitäten des Informationsmanagements als dem Aufgabenfeld, das sowohl die Gestaltung der Informationsstruktur als auch die der Informationstechnik umfaßt, fehlt dagegen bislang. Den wenigen in der Literatur zum organisationalen Lernen verfügbaren Aussagen bezüglich der Informationsstruktur und der in der Unternehmung eingesetzten Informationstechnik fehlt jede Systematik. ${ }^{24}$ Dies erweist sich als ausgesprochen problematisch, da dem Informationsmanagement bei der Unterstützung organisationaler Lernprozesse hohe Bedeutung zukommt.

Da die Qualität von Entscheidungen unmittelbar von der Qualität der verfügbaren Informationen abhängt, ${ }^{25}$ kommt einerseits den auf die Gestaltung der Informationsstruktur gerichteten Aufgaben des Informationsmanagements außerordentlich hohe Bedeutung für den Erfolg der Unternehmung zu. Das hier entwickelte Managementkonzept organisationalen Lernens definiert organisationales Lernen als Veränderung der organisationalen Wissensbasis. Entsprechend stellt es Wissen bzw. Informationen in den Mittelpunkt der Betrachtung. Die Gestaltung der Informationsstruktur als Aufgabe des Informationsmanagements steht somit in unmittelbarem Zusammenhang mit der Realisierbarkeit organisationaler Lernprozesse. Eine zweckmäßige Struktur der informationellen Beziehungen in der Unternehmung erweist sich insbesondere für diejenigen organisationalen Lernprozesse, die zur Bewältigung diskontinuierlichen Wandels erforderlich sind, als unverzichtbare Rahmenbedingung.

Betrachtet man andererseits die Informationstechnik als Objekt der Aktivitäten des Informationsmanagements, so ist festzustellen, daß weite Bereiche der betrieblichen Informationsflüsse heute computergestützt abgewickelt werden. Die gestiegenen informationstechnischen Möglichkeiten, verbunden mit sinkenden Preisen für Hard- und Software, haben zu einem hohen informationstechnischen Durchdringungsgrad des betrieblichen Geschehens geführt. Entsprechend kommt der Gestaltung der Informationstechnik als Teilaufgabe des Informationsmanagements generell eine hohe Bedeutung zu. Ferner resultieren aus den mit der Förderung bestimmter organisationaler Lernprozesse verbundenen Konsequenzen für die Gestaltung der Informationsstruktur bestimmte Anforderungen an die Gestaltung der Informationstechnik.

23 Vgl. z.B. Felsch (1996), passim; Geißler (1991), passim; Kakabadse/Fricker (1991), passim; Probst/Buchel (1998), S. $119 \mathrm{ff} ., 156 \mathrm{ff}$;; Sattelberger (1991), passim.

24 Vgl. z.B. die Beiträge in dem 1995 von Zucchermaglio/Bagnara/Stucky herausgegebenen Sammelband zum Thema 'Organizational Learning and Technological Change'.

25 Vgl. Gemünden (1993), Sp. 1725; Mag (1990), S. 145. 
Aufgrund der hohen Bedeutung des Informationsmanagements für die Förderung organisationalen Lernens erweist sich die fehlende wissenschaftliche Aufbereitung des $\mathrm{Zu}$ sammenhangs zwischen organisationalem Lernen und Informationsmanagement als äußerst problematisch. Zentrales Ziel der vorliegenden Arbeit ist es deshalb, den Beitrag des Informationsmanagements zur Förderung organisationalen Lernens zu untersuchen. Zum einen gilt es dabei, die Erfordernisse organisationaler Lemprozesse im Rahmen der auf die Gestaltung der informationellen Beziehungen gerichteten Aktivitäten des Informationsmanagements zu berücksichtigen. Zum anderen ist zu prüfen, wie die Gestaltung der Informationstechnik organisationales Lernen fördern kann.

Neben der theoretisch fundierten Operationalisierung des Phänomens organisationalen Lernens setzt die Erfüllung dieses Zieles der Arbeit eine geeignete Abgrenzung des Aufgabenfeldes Informationsmanagement voraus. Obwohl der Begriff des Informationsmanagements in den USA bereits seit zwanzig, in Deutschland seit über zehn Jahren intensiv diskutiert wird, hat sich bis heute kein Konsens über dessen definitorische Abgrenzung herausgebildet. So wird in der wissenschaftlichen Literatur zum Informationsmanagement zwar seit längerem eine Erweiterung dieses Aufgabenfeldes um betriebswirtschaftliche Aspekte - und damit über die reine Technikgestaltung hinaus grundsätzlich gefordert. Zumeist beschränkt sich die konkrete Darstellung der Aktivitäten des Informationsmanagements dann aber doch auf die technische Seite. ${ }^{26} \mathrm{Die}$ gestalterische Relevanz der so gewonnenen Aussagen leidet insbesondere dadurch, daß die Informationsstruktur von Unternehmungen als notwendiger Bezugsrahmen jeder technischen Problemlösung aus der Betrachtung ausgeklammert bleibt. Das Fehlen theoretischer Arbeiten zur Konkretisierung der betriebswirtschaftlichen Ausrichtung des Informationsmanagements kann zugleich als Grund dafür angesehen werden, daß entsprechende Überlegungen auch heute noch in der betrieblichen Praxis viel zu selten Berücksichtigung finden. Vielmehr wird Informationstechnik häufig noch isoliert, d.h. ohne systematische Berücksichtigung betriebswirtschaftlicher Belange, gestaltet. Ein Zwischenziel der vorliegenden Arbeit besteht deshalb darin, eine geeignete Konzeptionalisierung des Informationsmanagements vorzunehmen. Erst danach kann der Zusammenhang zwischen organisationalem Lernen und Informationsmanagement untersucht werden.

Die Berücksichtigung betriebswirtschaftlich orientierter, die Informationsstruktur gestaltender Aktivitäten stellt das Informationsmanagement in einen unmittelbaren

26 So definieren z.B. Österle/Brenner/Hilbers zwar Informationsmanagement zunächst umfassend als Management der Informationsverarbeitung(sprozesse), legen dann aber den Schwerpunkt auf die Gestaltung der Informationstechnik. Von den von ihnen aufgefürten drei Bereichen des Informationsmanagements 'informationsbewußte Unternehmungsfuhrung', 'Informationssystem-Management' und 'Management der Informatik' beschränkt sich ihre Arbeit über den St. Galler Informationsmanagement-Ansatz im wesentlichen auf das Management des Informationssystems. Da sich ihr Informationssystem-Begriff - im Gegensatz zur vorliegenden Arbeit - dabei im wesentlichen auf informationstechnische Aspekte beschränkt, handelt es sich hier um einen typischen Ansatz des Technik-Managements mit Schwerpunkt auf den Informationssystem-Architekturen. Vgl. Österle/Brenner/Hilbers (1992), S. 26ff. 
Zusammenhang mit übergeordneten Fragen der organisatorischen Gestaltung. Denn die organisatorischen Regeln stellen einen zentralen Einflußfaktor auf die informationellen Beziehungen als den Objekten des Informationsmanagements dar. Schon allein aufgrund der oben genannten Forschungsdefizite bei der theoretischen Abgrenzung des Informationsmanagements muß ein weiteres Zwischenziel der vorliegenden Arbeit darin bestehen, eine allgemeine Konzeptionalisierung des Zusammenhangs zwischen organisatorischer Gestaltung und Informationsmanagement vorzunehmen. Dies gilt umso mehr angesichts der Tatsache, daß Abhängigkeiten zwischen organisatorischer Gestaltung und Informationsmanagement in der Literatur zwar gelegentlich konstatiert werden, die Konkretisierung des Zusammenhangs zwischen beiden Aufgabenfeldern aber regelmäßig unterbleibt. ${ }^{27}$ Insbesondere fehlen Ansätze für eine trennscharfe Abgrenzung eines über die reine Technikgestaltung hinausreichenden, auch betriebswirtschaftlich orientierten Informationsmanagements von dem Aufgabenfeld der organisatorischen Gestaltung. Stattdessen subsumieren einige Autoren z.B. ein auf technische Aspekte beschränktes Informationsmanagement - zumindest implizit - unter die organisatorische Gestaltung. ${ }^{28}$ Andere dehnen das Aufgabenfeld Informationsmanagement soweit aus, daß es auch Aktivitäten umfaßt, die typischerweise der organisatorischen Gestaltung zugerechnet werden, wobei offenbleibt, ob dies lediglich eine Überschneidung der beiden Aufgabenfelder bedeutet oder ob das Informationsmanagement dort der organisatorischen Gestaltung übergeordnet wird.29 Aus diesen Defiziten auf der theoretischen Ebene resultiert ein entsprechender Handlungsbedarf.

Aufgrund des Fehlens theoretischer Arbeiten über die organisatorische Bedingtheit des Informationsmanagements und insbesondere die Operationalisierung dieser Beziehung wird dieser Zusammenhang in der betrieblichen Praxis auch heute noch zu wenig beachtet. Häufig wird dort nicht erkannt, daß die informationstechnische Infrastruktur der Unternehmung in weiten Bereichen eine Institutionalisierung organisatorischer Regeln darstellt. ${ }^{30}$ Wird - wie in der betrieblichen Praxis noch immer verbreitet Informationstechnik isoliert und aus einer primär technischen Perspektive heraus gestaltet, so wird gleichzeitig ein Teil der organisatorischen Regeln mitgestaltet, ohne daß ein entsprechendes Bewußtsein dafür existiert. Technisch motivierte Entscheidungen bezüglich der einzusetzenden Informationstechnik können jedoch aus betriebs-

27 Vgl. z.B. Brenner (1994), S. 13ff.; Brockhaus (1992), S. 48ff., 67ff.; Nawatzki (1994), S. 23, 26ff.; Schulze-Wischeler (1995), S. 82ff., 160ff.; Trott zu Solz (1992a), S. 27f. Zwar stellen Brockhaus und Nawatzki - aufgrund des auch von ihnen konstatierten diesbezüglichen Forschungsdefizites - die Berucksichtigung von organisatorischer Gestaltung und Personalmanagement im Rahmen eines 'integrierten Informationsmanagements' in den Mittelpunkt ihrer Arbeiten. Die ihren Ausfuhrungen zugrundeliegende Konzeptionalisierung des Zusammenhangs zwischen organisatorischer Gestaltung und Informationsmanagement kann jedoch aus der Sicht der vorliegenden Arbeit nicht überzeugen. Vgl. z.B. Krüger (1994), S. 139ff.

29 Vgl. z.B. Baumől (1998), S. 25, $91 \mathrm{ff.;}$ Brockhaus (1992), S. 48ff.; Krcmar (1997), S. 56ff. So nennt z.B. Krcmar im Rahmen seiner Ausfuhrungen uber verschiedene Verfahren zur Ermittlung des Informationsbedarfs die 'Ableitung aus einer intersubjektiv validierten Interpretation der Aufgabe' als Aufgabe des Informationsmanagements, die in der organisationstheoretischen Literatur typischerweise der organisatorischen Gestaltung zugerechnet wird.

30

Vgl. Widmer (1990), S. 148. 
wirtschaftlicher Perspektive Fehlentscheidungen darstellen. Die ungelösten theoretischen Probleme verursachen damit Probleme auf der Ebene der praktischen Gestaltungsarbeit in der Unternehmung.

Grundsätzlich ist die komplexe betriebliche Realität durch wechselseitige Einflüsse der beiden Aufgabenfelder organisatorische Gestaltung und Informationsmanagement aufeinander geprägt. Zwecks Ableitung von Anforderungen an das Informationsmanagement in der lernenden Unternehmung beschränkt sich der Fokus der vorliegenden Arbeit jedoch auf eine unidirektionale Betrachtung der Abhängigkeit des Informationsmanagements von der organisatorischen Gestaltung (siehe Abbildung 1/2, Beziehung (1)). Denn für die Konzeptionalisierung des Zusammenhangs zwischen organisationalem Lernen und Informationsmanagement ist von entscheidender Bedeutung, daß organisatorische Regeln nicht nur Einflußfaktoren des Informationsmanagements, sondern zugleich wichtige Bestandteile der organisationalen Wissensbasis sind. Jede Veränderung organisatorischer Regeln kann in diesem Sinne auch als Prozeß organisationalen Lernens interpretiert werden. Deshalb besteht ein weiteres Zwischenziel der vorliegenden Arbeit in der Konzeptionalisierung des Zusammenhangs zwischen organisationalem Lernen und organisatorischer Gestaltung.

Die Gesamtheit der organisatorischen Regeln in einer Unternehmung stellt als Teil der organisationalen Wissensbasis nicht nur das Ergebnis von Lernprozessen dar, sondern ist zugleich auch Ausgangspunkt weiterer organisationaler Lernprozesse. Bestimmten Formen organisationaler Regelwerke wohnt eine Tendenz zur Selbstverfestigung inne, die dann tatsächlich nur durch radikale Reengineering-Maßnahmen wieder aufgelöst werden kann. Dagegen begünstigen andere organisatorische Regeln zukünftiges organisationales Lernen in Form der Eliminierung nicht mehr zweckmäßiger Regeln bzw. deren Ersatz durch neue, dem gewandelten externen Umfeld besser entsprechende Regeln. Veränderung ist in diesem Fall nicht länger Ausnahme, sondern alltägliches Phänomen.

Aufgrund der Diskontinuität und der mangelnden Vorhersehbarkeit des Wandels müssen die zu seiner Bewältigung erforderlichen organisationalen Lemprozesse inhaltlich indeterminiert bleiben. Hingegen können die notwendigen organisatorischen Rahmenbedingungen für die Aufrechterhaltung solcher Lernprozesse anhand allgemeingültiger Merkmalsausprägungen beschrieben werden (siehe Abbildung 1/2, Beziehung (2)). Deshalb erweist sich die Beschränkung der Analyse des Zusammenhangs zwischen organisationalem Lernen und Informationsmanagement auf die für organisationale Lernprozesse notwendigen Rahmenbedingungen der organisatorischen Gestaltung als zweckmäßig. Der Beitrag des Informationsmanagements zur Förderung organisationalen Lernens ist also danach zu bemessen, inwieweit Informationsstruktur und Informationstechnik einer Unternehmung den Anforderungen gerecht werden, die sich aus dem organisatorischen Gestaltungsrahmen organisationaler Lernprozesse ergeben. 


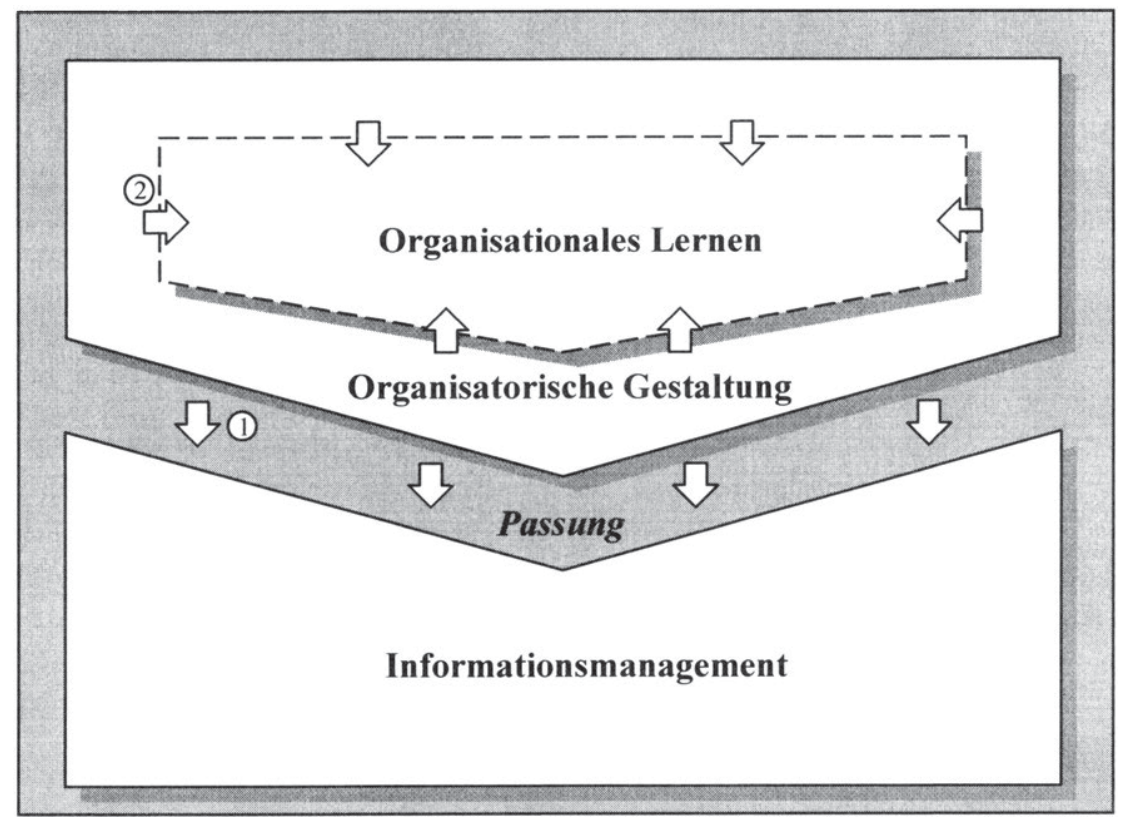

Abb. 1/2: Der Zusammenhang zwischen organisationalem Lernen, organisatorischer Gestaltung und Informationsmanagement

Die Konzeptionalisierung des Zusammenhangs zwischen organisationalem Lernen und Informationsmanagement erfolgt somit über die beiden in Abbildung 1/2 visualisierten Zwischenschritte der Konzeptionalisierung des Zusammenhangs zwischen organisationalem Lernen und organisatorischer Gestaltung (Beziehung (2) auf der einen und der des Zusammenhangs zwischen organisatorischer Gestaltung und Informationsmanagement (Beziehung (1)) auf der anderen Seite.

Da die Entwicklung einer umfassenden Theorie organisationalen Lernens angesichts des gegenwärtigen Forschungsstandes ein Fernziel bleiben muß, besteht die Aufgabe der vorliegenden Arbeit darin, vorhandene Erkenntnisdefizite zunächst im Rahmen einer Partialbetrachtung aus Sicht des Informationsmanagements zu beseitigen. Damit soll sie einen Beitrag zur Theoriebildung bzw. der 'weicheren' Vorstufe der Konzeptbildung leisten, was durch die Formulierung 'Bausteine eines Managementkonzeptes organisationalen Lernens' im Untertitel der Arbeit zum Ausdruck kommt. Der Beitrag der Arbeit bezieht sich dabei sowohl auf die Entwicklung eines konzeptionellen Rahmens als auch auf das Aufstellen konkreter Handlungsempfehlungen, so daß deutlich wird, wie organisatorische Gestaltung und Informationsmanagement organisationales Lernen in der Unternehmung fördern können. Dies setzt die theoretische Analyse des Phänomens organisationalen Lernens und die Abgrenzung des Aufgabenfeldes Informationsmanagement voraus. Die Konzeptionalisierung des Zusammenhangs zwischen organisationalem Lernen und Informationsmanagement erfolgt sodann über die beiden Zwischenschritte der Betrachtung des Zusammenhangs zwischen organisationalem Lernen und 
organisatorischer Gestaltung sowie des Zusammenhangs zwischen organisatorischer Gestaltung und Informationsmanagement.

\subsection{Gang der Untersuchung}

Voraussetzung für die Entwicklung theoretischer Aussagen und praktischer Handlungsempfehlungen ist Klarheit über die wissenschaftstheoretische Positionierung und die verwendeten Begriffe. Entsprechend werden in Kapitel 2 die wissenschaftstheoretischen (Abschnitt 2.1) und begrifflichen (Abschnitt 2.2) Grundlagen der Arbeit vorgestellt. Die Zielsetzung der Arbeit macht es notwendig, sehr unterschiedliche Themenbereiche in die Argumentation einzubeziehen, deren Aufarbeitung in der Literatur zudem oftmals ausgesprochen unpräzise ist, aus sehr unterschiedlichen Perspektiven heraus erfolgt und die über keine einheitliche Terminologie verfügen. ${ }^{31}$ Deshalb kommt der Klärung der wissenschaftstheoretischen Position der Arbeit und der inhaltlichen Abgrenzung der beiden fokussierten Aufgabenfelder große Bedeutung zu. Ein entsprechend breiter Raum wird ihnen in Kapitel 2 eingeräumt. Neben der isolierten Darstellung der beiden Managementaktivitäten organisatorische Gestaltung und Informationsmanagement wird insbesondere auch der Zusammenhang zwischen den beiden Bereichen herausgearbeitet.

In Kapitel 3 werden zunächst die beiden Phänomene Wandel (Abschnitt 3.1) und organisationales Lernen (Abschnitt 3.2) separat dargestellt. Die Ausführungen zum Wandel verdeutlichen die Ausgangsproblematik der Arbeit: Unterscheidet man Wandelprozesse in unternehmungsexterne und -interne, so resultiert aus dem unternehmungsexternen Wandel aufgrund des postulierten Fit zwischen Umwelt und Unternehmung die Notwendigkeit unternehmungsinternen Wandels. Das Managementkonzept organisationalen Lernens stellt eine Möglichkeit dar, die Befähigung der Unternehmung zu internem Wandel zu fördern. Aufgrund der mangelnden Eindeutigkeit der Verwendung des Begriffes in der Literatur muß aufgezeigt werden, was im Rahmen der vorliegenden Arbeit unter organisationalem Lernen verstanden wird. Dabei werden insbesondere die Unterschiede zwischen individuellem und organisationalem Lernen herausgearbeitet. Erst nachdem geklärt ist, was organisationales Lernen ist, kann in Abschnitt $3.3 \mathrm{der}$ Zusammenhang zwischen Wandel und organisationalem Lernen aufgezeigt werden. Da angenommen wird, daß organisationales Lernen als geistige Veränderung materiellen Veränderungen vorausgeht, gilt es, solche Prozesse organisationalen Lernens zu fördern, die häufigen, schnellen und grundlegenden unternehmungsinternen Wandel ermöglichen. Es wird also nicht undifferenziert die Förderung organisationalen Lernens

31 Dies gilt für große Teile der Literatur zu organisationalem Lernen, Selbstorganisation und Informationsmanagement. Dagegen ist die Literatur zur organisatorischen Gestaltung zwar von einer Fülle unterschiedlicher organisationstheoretischer Ansătze geprägt. Die Veröffentlichungen einzelner Autoren lassen sich diesen jedoch zumeist eindeutig zuordnen und orientieren sich in der Regel an einem gewissen Minimalkonsens bezulglich der verwendeten terminologischen Abgrenzungen. 
gefordert, sondern die bestimmter organisationaler Lernprozesse. $\mathrm{Zu}$ diesen gehören auch organisatorische Tätigkeiten.

Im Mittelpunkt von Kapitel 4 stehen sodann die organisatorischen Tätigkeiten als Teil derjenigen organisationalen Lernprozesse, die häufigen, schnellen und grundlegenden unternehmungsinternen Wandel ermöglichen und deren Ergebnis zugleich die Anforderungen an das Informationsmanagements entscheidend beeinflußt. Für die Konzeptionalisierung des Zusammenhangs zwischen organisationalem Lernen und Informationsmanagement stellt die Betrachtung organisatorischer Tätigkeiten somit den notwendigen Zwischenschritt dar. Die Gegenüberstellung von Selbst- und Fremdorganisation (bzw. organisatorischer Gestaltung ${ }^{32}$ ) als alternativer Formen organisatorischer Tätigkeiten zeigt, daß Selbstorganisation der Fremdorganisation unter den hier thematisierten Wandelaspekten tendenziell vorzuziehen ist. Da Selbstorganisation ohne Fremdorganisation nicht möglich ist und vielmehr die Ergebnisse organisatorischer Gestaltungsaktivitäten den Rahmen für selbstorganisatorische Prozesse vorgeben, gilt es aufzuzeigen, über welche Möglichkeiten die organisatorische Gestaltung verfügt, um das Auftreten von Selbstorganisationsprozessen zu fördern. Nachdem in Abschnitt 4.1 zunächst - in Ergänzung der entsprechenden Ausführungen in den Kapiteln 2 und 3 - die fehlenden Argumente zur Vervollständigung des theoretischen Bezugsrahmens für die Ableitung von Anforderungen an die organisatorische Gestaltung in der lernenden Unternehmung ergänzt werden, werden die konkreten Anforderungen sodann in Abschnitt 4.2 vorgestellt. Diese gliedern sich anhand der Dimensionen Arbeitsteilung, Koordination, Leitungssystem und Entscheidungsdelegation.

Ebenso wie Kapitel 4 gliedert sich auch Kapitel 5 in einen rein analytischen und einen gestaltungsorientierten Teil. In Abschnitt 5.1 wird zunächst der theoretische Bezugsrahmen für die Ableitung von Anforderungen an das Informationsmanagement in der lernenden Unternehmung vervollständigt. Der im zweiten Kapitel entwickelte ZweiEbenen-Ansatz des Informationsmanagements, innerhalb dessen zwischen einer immateriellen und einer materiellen Ebene des Informationsmanagements unterschieden wird, erlaubt es nicht nur, die Gestaltung der Informationstechnik in einen umfassenderen Kontext einzuordnen, sondern er ermöglicht insbesondere die unmittelbare Anbindung des Informationsmanagements an die organisatorische Gestaltung. Über den Zwischenschritt organisatorischer Tätigkeiten kann somit der Zusammenhang zwischen organisationalem Lernen und Informationsmanagement hergestellt werden. Aufbauend auf den in den Kapiteln 2, 3 und 4 vorgestellten grundsätzlichen Modellannahmen wird dieser Zusammenhang zwischen organisatorischer Gestaltung als Prozeß organisationalen Lernens und Informationsmanagement im Rahmen eines dimensionalen Ansatzes operationalisiert. In den folgenden beiden gestaltungsorientierten Abschnitten 5.2 und 5.3 werden sodann Gestaltungsempfehlungen für das Informationsmanagement in der

32 Die Begriffe Fremdorganisation und organisatorische Gestaltung werden im folgenden synonym verwendet. Fur eine ausfuhrliche Darstellung dieser Aktivităten siehe Abschnitt 2.2.1.3.1 der vorliegenden Arbeit. 
lernenden Unternehmung entwickelt. Die auf die immaterielle Ebene des Informationsmanagements bezogenen Gestaltungsempfehlungen werden dabei unmittelbar aus denen an die organisatorische Gestaltung abgeleitet, die bezüglich der materiellen Ebene resultieren wiederum aus denen für die immaterielle Ebene des Informationsmanagements.

Den Abschluß der Arbeit bildet Kapitel 6 mit Zusammenfassung und Ausblick. Die Zusammenfassung betrifft einerseits den theoretischen Argumentationsrahmen, andererseits die entwickelten Handlungsempfehlungen für die organisatorische Gestaltung und das Informationsmanagement. Die Arbeit endet mit einem kurzen Ausblick auf offen gebliebene Fragestellungen und daraus resultierende potentielle zukünftige Forschungsfelder.

Abbildung 1/3 visualisiert den geschilderten Aufbau der Arbeit.

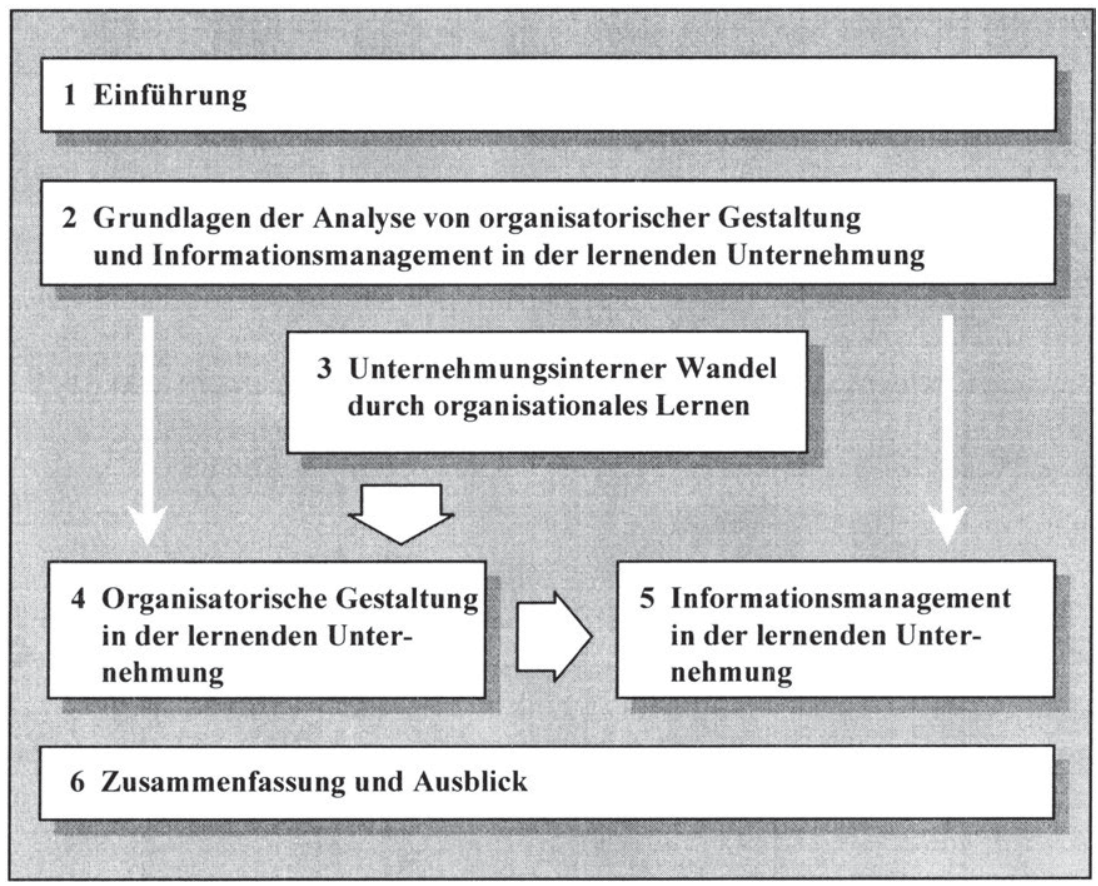

Abb. 1/3: Die Argumentationsstruktur der vorliegenden Arbeit 
Frauke Streubel - 978-3-631-75510-5

Downloaded from PubFactory at 01/11/2019 04:00:13AM 


\section{Grundlagen der Analyse von organisatorischer Gestaltung und Informationsmanagement in der lernenden Unternehmung}

Die Entwicklung theoretischer Aussagen und analytisch begründeter Gestaltungsempfehlungen erfordert die Klärung der wissenschaftstheoretischen Grundposition und der verwendeten Terminologie. Denn einerseits beeinflußt die Person des Forschenden über das von ihr verfolgte Wissenschaftsverständnis und die daraus resultierende Methodik die abgeleiteten Gestaltungsempfehlungen. ${ }^{1}$ In Abschnitt 2.1 werden deshalb einige Aussagen über das dieser Arbeit zugrundeliegende Wissenschaftsverständnis getroffen. Andererseits bildet ein konsistentes Sprachsystem mit zweckmäßigen Begriffen die notwendige Voraussetzung für jede über das Terminologische hinausreichende

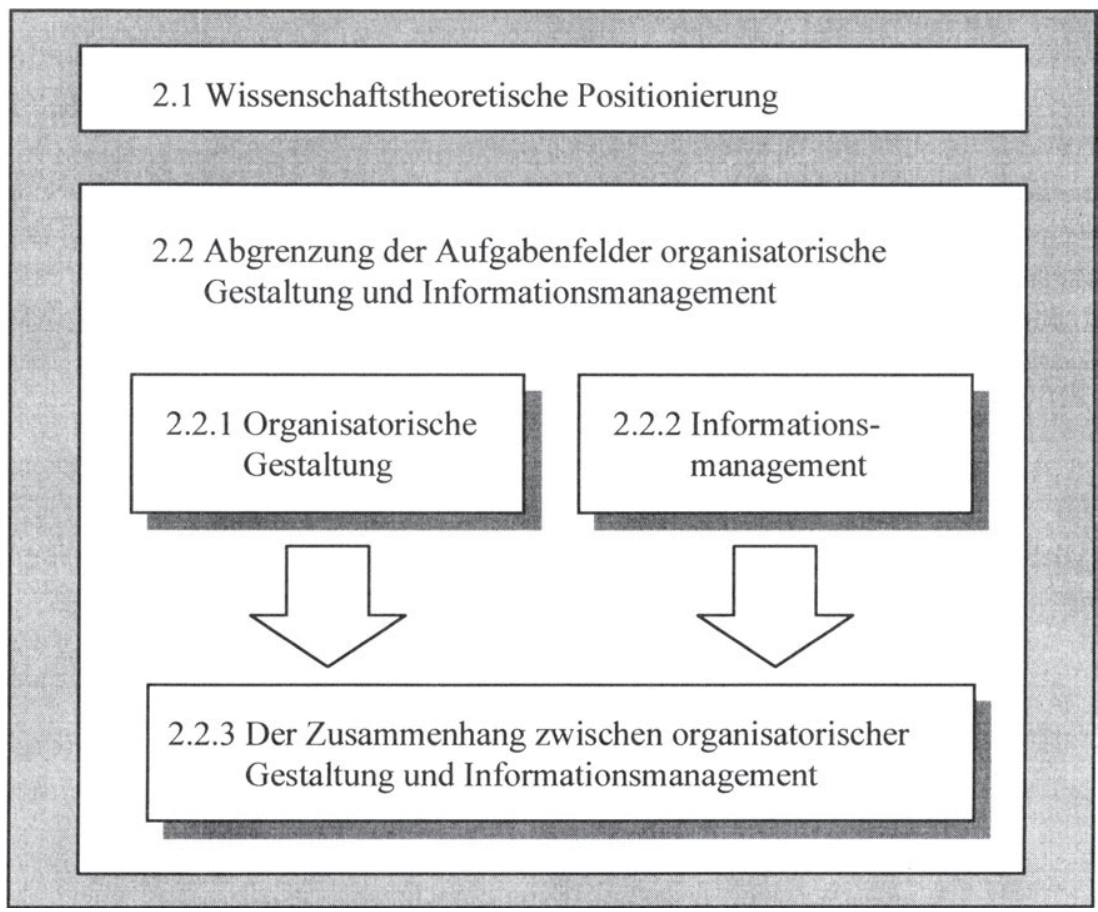

Abb. 2/1: Die Argumentationsstruktur des zweiten Kapitels

wissenschaftliche Arbeit. Ordnet man die Gesamtheit der Forschungskonzeptionen in solche mit essentialistischem, theoretischem, pragmatischem und normativem Wissenschaftsziel, so sind die im Rahmen essentialistischer Forschung erarbeiteten

1 Vgl. Frese (1992), Sp. 1708; Hill (1994), S. 131f. Morgan/Smircich stellen fest: „The development of organization theory ... would be better served if researchers were more explicit about the nature of the beliefs they bring to their subject of study.“ Morgan/Smircich (1980), S. 499. 
Begriffe die Basis aller anderen Konzeptionen. ${ }^{2}$ Sieht man von logischen Inkonsistenzen des verwendeten Begriffssystems ab, können Begriffe nicht wahr oder falsch definiert sein, sondern sich lediglich als bezüglich des angestrebten Forschungsziels mehr oder weniger geeignet erweisen. ${ }^{3}$ Im Anschluß an die Ausführungen zum Wissenschaftsverständnis der Arbeit werden deshalb in Abschnitt 2.2 die wichtigsten begrifflichen Abgrenzungen bezüglich der beiden Aufgabenfelder organisatorische Gestaltung und Informationsmanagement vorgestellt, die zur Erreichung des Zieles der vorliegenden Arbeit besonders geeignet sind. An die isolierte Darstellung der beiden Managementaktivitäten schließt sich die Konzeptionalisierung des Zusammenhangs zwischen den beiden Aufgabenfeldern an. Abbildung 2/1 zeigt die Argumentationsstruktur des zweiten Kapitels im Überblick.

\subsection{Wissenschaftstheoretische Positionierung}

Die wissenschaftstheoretische Positionierung der vorliegenden Arbeit ist durch drei zentrale Elemente gekennzeichnet: Abschnitt 2.1.1 identifiziert zunächst das Ziel der folgenden Ausführungen, den Beitrag des Informationsmanagements zur Förderung organisationalen Lernens $\mathrm{zu}$ untersuchen, als sowohl theoretisches als auch pragmatisches Forschungsziel. Es wird aufgezeigt, daß das Bestreben, theoretisch begründete Handlungsempfehlungen für die betriebliche Praxis zu entwickeln, einen interdisziplinären Ansatz erfordert. Sodann wird in Abschnitt 2.1.2 der Radikale Konstruktivismus als wissenschaftstheoretische Grundposition der Arbeit vorgestellt, auf deren Basis die in dieser Arbeit verfolgten Forschungsziele erreicht werden sollen. Der Radikale Konstruktivismus prägt vor allem das im weiteren Verlauf der Arbeit entwickelte Verständnis von Informationsmanagement. Aber auch die Forderung, im Rahmen der organisatorischen Gestaltung Selbstorganisationsprozesse explizit zu berücksichtigen, entspringt einer konstruktivistischen Grundüberzeugung. Schließlich bietet Abschnitt 2.1.3 einen Einblick in die Systemtheorie, die als Basis für einen interdisziplinären Forschungsansatz besonders geeignet ist und deren Kernideen sich entsprechend im weiteren Verlauf der Arbeit an zahlreichen Stellen wiederfinden.

\subsubsection{Zur Notwendigkeit eines interdisziplinären Ansatzes}

Jedes wissenschaftliche Arbeiten setzt die Formulierung eines spezifischen Forschungsziels voraus. Dabei können die im Einzelnen formulierten konkreten Ziele den folgenden vier grundsätzlichen Forschungskonzeptionen zugeordnet werden, wobei jede der aufgeführten Konzeptionen auf den Ergebnissen der zuvor genannten aufsetzt: ${ }^{4}$

2 Vgl. Chmielewicz (1994), S. 9ff.

3 Vgl. Hutchison (1972), S. 194.

4 Vgl. Chmielewicz (1994), S. 9 ff. 
- Forschungsprogramme mit essentialistischem Wissenschaftsziel,

die darauf abzielen, ein konsistentes Sprachsystem mit präzisen Begriffen und Definitionen aufzustellen;

- Forschungsprogramme mit theoretischem Wissenschaftsziel, innerhalb derer die Begriffsbildung nicht Selbstzweck ist, sondern die Begriffe Bausteine für zu bildende wahre und informative theoretische Aussagen (insbesondere über generelle Ursache-Wirkungs-Zusammenhänge) sind;

- Forschungsprogramme mit pragmatischem Wissenschaftsziel, die auf theoretischen Aussagen über Ursache-Wirkungs-Zusammenhänge aufbauen und sie technologisch umformen, indem die Wirkungen als Ziele angestrebt werden und dafür die Ursachen als Mittel herbeigeführt werden;

- Forschungsprogramme mit normativem Wissenschaftsziel, die auf technologischen Aussagen aufbauend Werturteile formulieren.

Trotz der Fülle an verfügbarer Literatur ist sowohl bezüglich des organisationalen Lernens als auch bezüglich des Informationsmanagements ein Mangel an präzisen Begriffsabgrenzungen zu konstatieren. Deshalb erfordert jede Untersuchung dieser Phänomene die Entwicklung eines konsistenten Sprachsystems. Über dieses essentialistische Forschungsziel hinaus verfolgt die vorliegende Arbeit ein theoretisches Forschungsziel. Es gilt, den theoretischen Zusammenhang zwischen organisationalem Lernen, organisatorischer Gestaltung und Informationsmanagement aufzuzeigen. Die Entwicklung einer geeigneten Argumentation zur Konzeptionalisierung dieses Zusammenhangs stellt einen Schwerpunkt der vorliegenden Arbeit dar. In einem nächsten Schritt dient diese wiederum dazu, theoretisch fundierte Anforderungen für die organisatorische Gestaltung und das Informationsmanagement in der lernenden Unternehmung abzuleiten. Solchermaßen entwickelte Ziel-Mittel-Aussagen stehen gleichberechtigt neben der Konzeptionalisierung des grundsätzlichen Zusammenhangs und bilden den zweiten Schwerpunkt der vorliegenden Arbeit.

Den folgenden Ausführungen liegt somit eine über ein theoretisches Wissenschaftsziel hinausreichende, letztlich pragmatische Wissenschaftskonzeption zugrunde. ${ }^{5}$ Da es sich bei den zu formulierenden Handlungsempfehlungen um solche für die Managementaktivitäten organisatorische Gestaltung und Informationsmanagement handelt, orientiert sich die Arbeit an der Perspektive des Managements, das Adressat der Arbeit bzw. Subjekt der formulierten Empfehlungen ist. ${ }^{6}$

$5 \quad$ Vgl. Kieser/Kubicek (1992), S. 58ff.; Meyer (1988), S. 199.

6 Vgl. ähnlich Gerstner (1995), S. $27 \mathrm{f}$.

Dagegen würde das Verfolgen einer mitarbeiterorientierten Perspektive eine stärkere Fokussierung von Motivation, Arbeitszufriedenheit u.ă. nach sich ziehen. Besonders deutlich zeigt sich diese Perspektive in Kapitel 4: Wăhrend die vorliegende Arbeit untersucht, wie organisatorische Gestaltung als Managementaktivität einen geeigneten Rahmen zur Förderung von Selbstorganisationsprozessen schaffen kann, würde eine mitarbeiterorientierte Betrachtung Selbstorganisationsprozesse aus der Perspektive der selbstorganisierenden Individuen untersuchen. 
Aus dem pragmatischen Forschungsziel der Arbeit, deren Themenbereich einerseits der Betriebswirtschaftslehre, andererseits der Wirtschaftsinformatik zugeordnet werden kann, läßt sich die Notwendigkeit eines interdisziplinären Ansatzes ableiten, wie ihn für die Betriebwirtschaftslehre z.B. BLEICHER, HILL, MALIK und ULRICH fordern.? ULRICH stellt fest, daß die disziplinäre Beschränkung der Betriebswirtschaftslehre auf das ökonomische Prinzip, die im Rahmen einer rein theoretischen Wissenschaft die Analyse erleichtert, für eine praxisorientierte Wissenschaft nicht angebracht ist. ${ }^{8}$ Angesichts der hohen Komplexität der betrieblichen Wirklichkeit und des Umstands, daß die dort auftretenden Probleme in der Regel a-diziplinären Charakter haben, erweisen sich disziplinäre Grenzziehungen immer dann als dysfunktional, wenn wissenschaftliche Untersuchungen auf praxisrelevante Gestaltungsempfehlungen abzielen. Die dort vorgenommene Komplexitätsreduktion, die insbesondere in den gesetzten Prämissen und den gewählten Methoden zum Ausdruck kommt, führt dazu, daß die entwickelten Aussagen oft keinerlei Praxisrelevanz besitzen. ${ }^{9}$ Diese Aussagen können über die Betriebswirtschaftslehre hinaus auf die Wirtschaftsinformatik ausgedehnt werden. Die vorliegende Arbeit ist deshalb interdisziplinär angelegt und integriert neben originär wirtschaftswissenschaftlichen und Wirtschaftsinformatik-Aspekten auch verhaltenswissenschaftliche Erkenntnisse. Dies liegt insbesondere auch darin begründet, daß weite Teile der Organisationstheorie, die für die Thematik der Arbeit von zentraler Bedeutung ist, interdisziplinär ausgerichtet sind. ${ }^{10}$ Eine so verstandene Betriebswirtschaftslehre erfährt dann eine Ausweitung zur Managementlehre. " Diese 'fachliche Mehrdimensionalität'12 entspricht der von ACKOFF bereits 1961 formulierten These, daß die (zu gestaltende) Realität eben anders organisiert sei als die wissenschaftliche Forschung. ${ }^{13}$

Es sei jedoch darauf hingewiesen, daß ein interdisziplinärer Forschungsansatz nicht zu einer 'Megatheorie' führen kann und darf, die sämtliche in der Realität zu beobachtenden Interdependenzen berücksichtigt und den Anspruch erhebt, alle Variablen zu explizieren. Eine solche 'Megatheorie' wäre von nicht zu bewältigendem Umfang und würde an ihrem eigenen Anspruch scheitern. ${ }^{14}$ Vielmehr müssen auch im Rahmen eines inter-

7 Vgl. dazu und im folgenden Bleicher (1994), S. 94ff.; Hill (1994), S. 125ff.; Malik (1989), S. 23, sowie das richtungsweisende Werk von Ulrich, das 1968 in der ersten Auflage erschien.

8 Vgl. Ulrich (1994), S. $165 f$.

9 Vgl. Bleicher (1994), S. 94.

10 Vgl. Bleicher (1994), S. 93; Picot (1993), S. 105; Schreyögg (1995), S. 9.

11 Dieses Grundverständnis von Betriebswirtschaftslehre spiegelt z.B. der Titel des von Wunderer 1994 herausgegebenen Sammelbandes 'Betriebswirtschaftslehre als Management- und Führungslehre' wider. Anders dagegen insbesondere Schneider (1995), S. $140 \mathrm{ff}$.

12 Bleicher verweist ohne Quellenbeleg darauf, daß dieser Begriff von Hans Ulrich geprăgt wurde. Vgl. Bleicher (1994), S. 97. Vgl. ăhnlich Gaugler (1994), S. 252, der die wissenschaftliche Arbeitsweise einer auf Managementaspekte ausgerichteten Betriebswirtschaftslehre als integrierenddifferenzierend' bezeichnet.

13 Vgl. Ackoff (1961), S. 37.

14 Vgl. Osterloh/Grand (1994), S. 289. Ähnlich argumentiert Kieser angesichts der Vielzahl unterschiedlicher Organisationstheorien: Da Organisationen bzw. Unternehmungen „... hochkomplexe soziale Gebilde ..." sind, sei es unmöglich, ,... alle ihre Eigenschaften und alle Beziehungen zwischen ihren Elementen in einer Theorie zu erfassen." Kieser (1993), S. If. 
disziplinären Ansatzes Eingrenzungen des betrachteten Realitätsausschnittes vorgenommen werden. Dies spiegelt sich in dem Untertitel der vorliegenden Arbeit 'Bausteine eines Managementkonzeptes organisationalen Lernens' wider.

\subsubsection{Der Radikale Konstruktivismus als wissenschaftstheoretische Grundposition}

In der Wissenschaftstheorie stehen Realismus und Idealismus einander als alternative Basisansätze gegenüber. Dabei kann man die von Wissenschaftlern unterschiedlicher Denkrichtungen vertretenen Positionen danach unterscheiden, ob sich Realismus und Idealismus auf ontologische oder epistemologische Aspekte beziehen. ${ }^{15}$

Die Ontologie als Lehre vom Sein untersucht das Wesen des Seienden bzw. der Welt. Ein ontologischer Realismus geht davon aus, daß die Welt an sich existiert. Welt wird hier somit als Wirklichkeit außerhalb des Bewußtseins des Menschen verstanden. Dagegen verneint ein ontologischer Idealismus die Existenz einer ebensolchen Wirklichkeit. 16

Die Epistemologie bzw. Erkenntnistheorie hat die Erkenntnis des Menschen zum Gegenstand. Ein erkenntnistheoretischer Realismus unterstellt, daß die Wirklichkeit als solche vom Menschen aufgrund seiner Vernunft erkannt werden kann. Eine Übereinstimmung von Denken und Sein ist prinzipiell möglich. Dagegen geht ein erkenntnistheoretischer Idealismus davon aus, daß Erkenntnis von allgemein vorhandenen Denkschemata abhängt, die jedoch nicht notwendigerweise mit der Wirklichkeit übereinstimmen. Da der Zusammenhang zwischen dem menschlichen Denken und der Realität nicht überprüfbar ist, muß offenbleiben, ob und inwieweit Denken und Sein übereinstimmen. Wirklichkeit wird nicht wahrgenommen wie sie ist, sondern vom Subjekt konstruiert. ${ }^{17}$

Abbildung 2/2 grenzt die wissenschaftstheoretischen Grundpositionen naiver Realismus, Kritischer Rationalismus, Radikaler Konstruktivismus und Solipsismus anhand ihrer jeweiligen ontologischen und epistemologischen Haltungen voneinander ab. Die Darstellung stellt dabei notwendigerweise eine starke Vereinfachung der vielschichtigen philosophischen Denktraditionen dar.

Der naive Realismus geht nicht nur davon aus, daß eine objektive Wirklichkeit existiert, sondern auch davon, daß der Mensch sie so wahrnehmen und erkennen kann, wie sie ist. Er wird heute zumeist nicht verfolgt, da in der wissenschaftstheoretischen Diskussion weitgehend Einigkeit darüber besteht, daß das Erkennen des Menschen subjektiven Einflüssen unterliegt. ${ }^{18}$

15 Vgl. Schütte (1997), o.S.

16 Vgl. Schischkoff (1982), S. 503, 572.

17 Vgl. Schischkoff (1982), S. 161, 301, 572; Schütte (1997), o.S.

18 Vgl. Vollmer (1994), S. 35. 


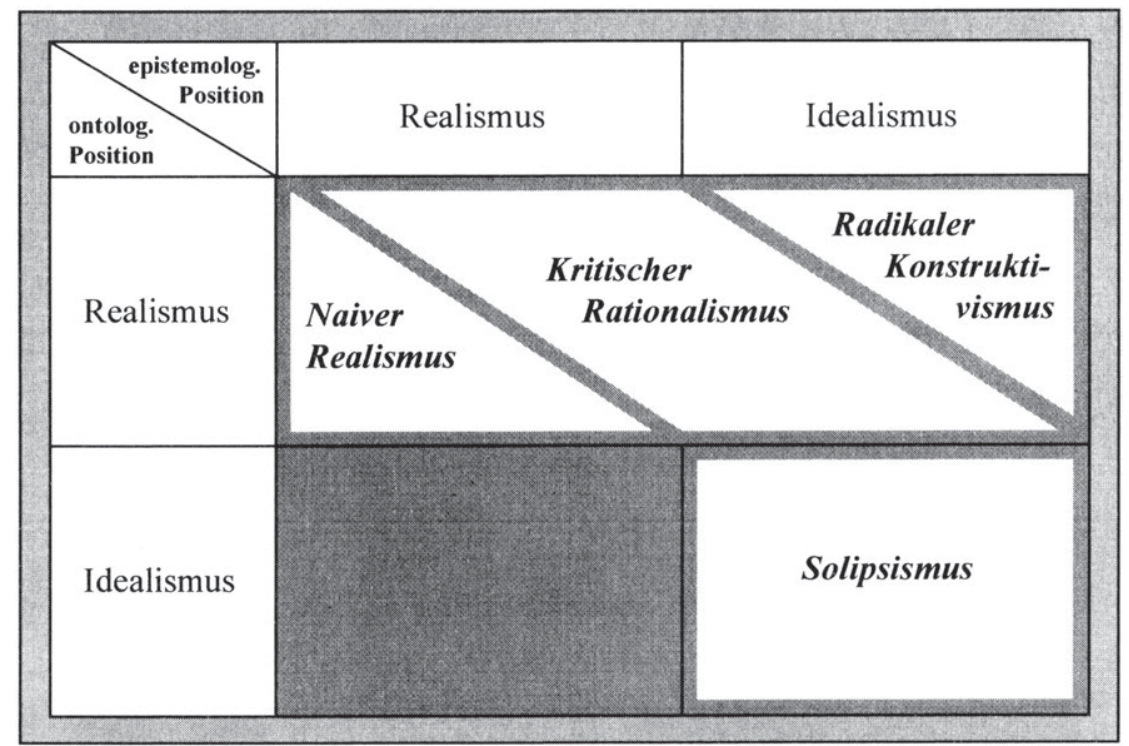

Abb.2/2: Wissenschaftstheoretische Grundpositionen mit ihren jeweiligen ontologischen und epistemologischen Annahmen

In der Betriebswirtschaftslehre hat die Position des Kritischen Rationalismus nach POPPER und ALBERT als Ausprägung eines kritischen Realismus eine weite Verbreitung gefunden. ${ }^{19}$ Dem Kritischen Rationalismus liegt die Annahme zugrunde, daß eine Wirklichkeit existiert. Bezüglich deren Wahrnehmung unterscheidet man zwischen subjektiver und objektiver Erkenntnis. Objektive Erkenntnis ist unabhängig vom erkennenden Subjekt. Da subjektive Einflüsse ausscheiden, gibt die objektive Erkenntnis die Wirklichkeit unverfälscht wieder. Dagegen ist subjektive Erkenntnis ein Bewußtseinszustand des erkennenden Subjektes und damit geprägt von subjektiven Einflüssen. ${ }^{20}$ Zwar arbeiten die Sinne des Menschen selektiv und können vielen Täuschungen unterliegen, die prinzipielle Erkennbarkeit der Welt wird hier jedoch nicht bezweifelt. ${ }^{21}$ Eine zentrale Forderung des Kritischen Rationalismus ist vielmehr, die subjektiven Einflüsse auf das Erkennen nicht nur aufzudecken, sondern zu eliminieren und damit subjektive in objektive Erkenntnis zu überführen. ${ }^{22}$

Der Solipsismus stellt die extreme Gegenposition zum naiven Realismus dar, indem er epistemologischen und ontologischen Idealismus verknüpft. Das subjektive Ich mit seinem Bewußtseinsinhalt wird hier als einzig Seiendes angesehen. Nur der Akt des Denkens und das Subjekt werden als sicher gegeben anerkannt. Da der Solipsismus als

\footnotetext{
Vgl. z.B. Schneider (1987), S. 178.

Vgl. Popper (1995), S. 112.

Vgl. Schmidt (1996a), S. 14.

Vgl. Schütte (1997), o.S.
} 
mitteilbare Lehre nicht bestehen kann, ohne sich selbst zu widersprechen, gilt er heute als überholt. ${ }^{23}$

Die vorliegende Arbeit verfolgt ein radikal konstruktivistisches Wissenschaftsverständnis. Der Radikale Konstruktivismus kann als Gegenposition zum Kritischen Rationalismus verstanden werden. Während der kritische Rationalismus im wesentlichen mit den Namen POPPER und ALBERT verbunden ist und einen vergleichsweise geschlossenen philosophischen Ansatz darstellt, bildet der Radikale Konstruktivismus keinen einheitlichen Ansatz. Vielmehr handelt es sich um einen Oberbegriff für eine Vielzahl aktueller wissenschaftstheoretischer Arbeiten, deren Positionen neben grundsätzlichen Gemeinsamkeiten auch einige Unterschiede aufweisen, die hier jedoch nicht untersucht werden. ${ }^{24}$ Die im Rahmen der vorliegenden Arbeit vorgenommene Betrachtung des Radikalen Konstruktivismus beschränkt sich vielmehr auf dessen ontologische und epistemologische Grundposition.

Der Radikale Konstruktivismus vereint einen ontologischen Realismus ${ }^{25}$ mit einem epistemologischen Idealismus: „Unsere Erkenntnis bildet nicht eine objektive Wirklichkeit $\mathrm{ab}$, sondern sie konstruiert etwas, das wir erkennend als Wirklichkeit akzeptieren“26, d.h. die „Umwelt, so wie wir sie wahrnehmen, ist unsere Erfindung.“27 Erkenntnis kann nie Repräsentation der „Welt da draußen“28 sein, sondern ist stets menschliche Konstruktion. Im Gegensatz zum Kritischen Rationalismus, der die prinzipielle Möglichkeit objektiver Erkenntnis zumindest noch in abgeschwächter Form proklamiert, verneint der Radikale Konstruktivismus ebendiese Möglichkeit objektiver Erkenntnis und somit die Überprüfbarkeit der Übereinstimmung von Denken und Sein.

Diese epistemologische Grundposition des Radikalen Konstruktivismus basiert auf neurophysiologischen Untersuchungen der 50er und 60er Jahre über menschliche Kognition. Bei der Analyse des Nervenssystems des Menschen stellte man fest, daß zwischen Außenweltereignissen und neuronalen Zuständen keine stabilen Korrelationen hergestellt werden können. Bei der Transformation von Umweltreizen in Nervenimpulse geben die Erregungszustände der Nervenzellen nicht das genaue (physikalische oder chemische) 'was' der Erregungsursache an das Gehirn weiter, sondern nur das 'wieviel', d.h. deren Intensität. Während die einzelnen Sinnesorgane spezifische Signale erfassen, da sie in ihrer Wahrnehmung auf bestimmte Signale beschränkt sind, ist die neuronale Erregung in Form daraufhin entstehender elektrischer Impulse als solche unspezifisch. Das Gehirn wiederum kann nur diese „neuronale Einheitssprache“ 29 verarbeiten. ${ }^{30}$

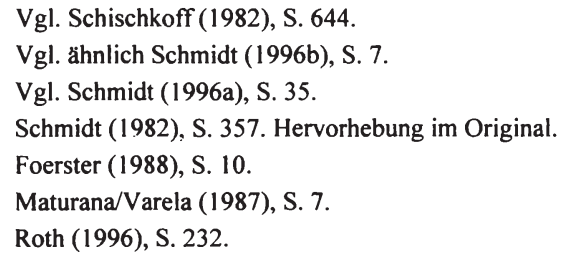


Der von den Nervenzellen dem Gehirn zugeleitete unspezifische, rein quantitative elektrische Impuls bedarf sodann der weitergehenden Verarbeitung innerhalb des Gehirns, damit Erkenntnis über den Umweltreiz entsteht. ${ }^{31}$ Dies geschieht dadurch, daß das Gehirn den Erregungszuständen der Nervenzellen auf der Basis früherer neuronaler Zustände Bedeutungen zuweist. Frühere Beobachtungen bilden dabei die Basis neuer Beobachtungen. Damit ist das Gehirn abhängig von seiner eigenen Vergangenheit bzw. 'Geschichte'. ${ }^{32}$ Dieser Konstruktionsprozeß des Gehirns hat Erkenntnis zum Ergebnis. Dabei ist das Gehirn kein umweltoffenes, sondern „ein kognitiv in sich abgeschlossenes System ist, das nach eigenentwickelten Kriterien neuronale Signale deutet und bewertet, von deren wahrer Herkunft es nichts absolut Verläßliches weiß“33. Es hat keinen direkten Zugang zur Außenwelt, sondern konstruiert Wirklichkeit als interpretative Eigenleistung. ${ }^{34}$

Der Radikale Konstruktivismus folgert daraus, daß eine Bewertung menschlicher Kognitionen anhand ihres inhaltlichen Wahrheitsgehaltes in Bezug auf eine sogenannte 'objektive' Wirklichkeit nicht möglich ist, da der Mensch eine solche nicht erkennen kann. Jedoch ist menschliche Erkenntnis unverändert auf ihre logische Widerspruchsfreiheit zu prüfen. Darüber hinaus kann sie anhand ihrer Nützlichkeit für das menschliche Leben bewertet werden. Diese Nützlichkeit können jedoch mehrere, inhaltlich unterschiedliche Konstruktionen aufweisen. ${ }^{35}$

Diese kognitionstheoretischen Grundlagen des Radikalen Konstruktivismus führen zu einem veränderten Wissenschaftsverständnis. Wissenschaft wird hier unmittelbar auf den Menschen bezogen. Das Streben nach absoluter, objektiver Wahrheit kann nicht Ziel von Wissenschaft sein, da Erkenntnis nie objektiv sein kann, sondern stets subjektiv geprägt ist. Vom Einfluß des Wissenschaftlers auf die wissenschaftliche Erkenntnis bzw. des Beobachters auf die Beobachtung kann nicht abstrahiert werden. Die Bewertung wissenschaftlicher Erkenntnis als Spezialfall menschlicher Kognition anhand ihres jeweiligen Nutzens für das menschliche Leben impliziert ein pragmatisches Wissenschaftsziel. Die Formulierung von Gestaltungsempfehlungen ist auch im Rahmen eines radikal konstruktivistischen Wissenschaftsverständnisses durchaus möglich. Denn Wissenschaft soll einen Beitrag zur Bewältigung menschlichen Lebens leisten. Pointiert formuliert dies JANTSCH: „Unsere Suche gilt letzten Endes nicht der genauen Kenntnis des Universums, sondern der Kenntnis der Rolle, die wir in ihm spielen - dem Sinn unseres Lebens.“36 Dieses Wissenschaftsverständnis ist wiederum mit bestimmten

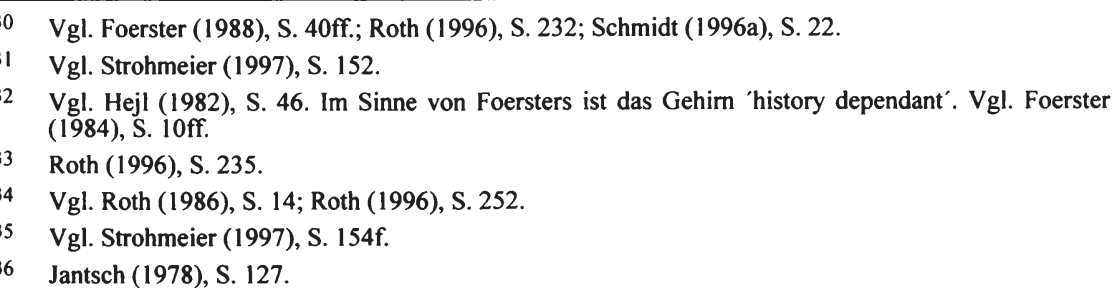


ethischen Konsequenzen verbunden. Scheidet nämlich 'objektive Wahrheit' als Bezugspunkt der Argumentation aus, muß der erkennende Mensch als Erkenntnis konstruierendes Subjekt Verantwortung für seine Kognitionen und die daraus resultierenden Handlungen übernehmen. ${ }^{37}$ Für die Ausführungen der vorliegenden Arbeit bedeutet dies, daß die aus der theoretischen Konzeptionalisierung resultierenden Handlungsempfehlungen stets als subjektiv bedingt verstanden werden müssen. Auch stellt die hier verfolgte Perspektive des Managements nur eine von mehreren Sichten auf die Unternehmung dar. Gleichzeitig darf die Unmöglichkeit 'objektiver' Erkenntnis jedoch nicht etwa dahingehend mißverstanden werden, Radikalen Konstruktivismus mit relativismusbedingter Unbestimmtheit und Beliebigkeit gleichzusetzen. ${ }^{38}$

\subsubsection{Die Systemtheorie als terminologische und methodische Basis}

Die Systemtheorie ist als Basis eines interdisziplinären Forschungsansatzes besonders geeignet. Aufgrund ihrer universal anwendbaren Terminologie und Methodik hat sie metawissenschaftlichen Charakter und kann innerhalb der unterschiedlichsten Teildisziplinen angewendet werden. ${ }^{39}$ Die disziplinenübergreifende Modellierung der Realität mit Hilfe von Systemen erleichtert den Transfer von Erkenntnissen zwischen verschiedenen Wissenschaftsdisziplinen bzw. deren Verknüpfung und unterstützt damit interdisziplinäres Arbeiten. Im Bereich der Betriebswirtschafts- und der Managementlehre trägt die systemtheoretische Fundierung wesentlich dazu bei, deren Perspektive über den rein ökonomischen Horizont hinaus für die Methoden und Erkenntnisse anderer Wissenschaften zu öffnen. ${ }^{40} \mathrm{Zwar}$ kann die Systemtheorie nicht die spezifischen Methodiken und Erkenntnisse der einzelnen Teildisziplinen ersetzen, da sie auf einem deutlich höheren Abstraktionsniveau angesiedelt ist. ${ }^{41}$ In Ergänzung anderer wissenschaftlicher Erkenntnisse stellt sie jedoch einen geeigneten Argumentationsrahmen für die folgenden Ausführungen dar. Die in diesem Zusammenhang relevanten, zentralen Begriffe des systemtheoretischen Ansatzes sind System, Subsystem, Struktur, Element, Attribut und Beziehung. Abbildung 2/3 verdeutlicht den Zusammenhang zwischen diesen Begriffen in grafischer Form.

37 Vgl. Schmidt (1996a), S. 37ff.

38 Vgl. Strohmeier (1997), S. 178. Für eine ausführliche Erwiderung auf den hăufig geäußerten Vorwurf, daß der Radikale Konstruktivismus eine selbstaufhebende Doktrin sei, vgl. Schmidt (1996a), S. $39 \mathrm{ff}$.

39 Vgl. Grothe (1997), S. 96; Hill/Fehlbaum/Ulrich (1994), S. 18.

40 Vgl. Malik (1989), S. 25.

$41 \quad$ Vgl. Bleicher (1994), S. 118; Picot (1975), S. 98; Raffée (1974), S. 88; Ulrich (1994), S. 169. 


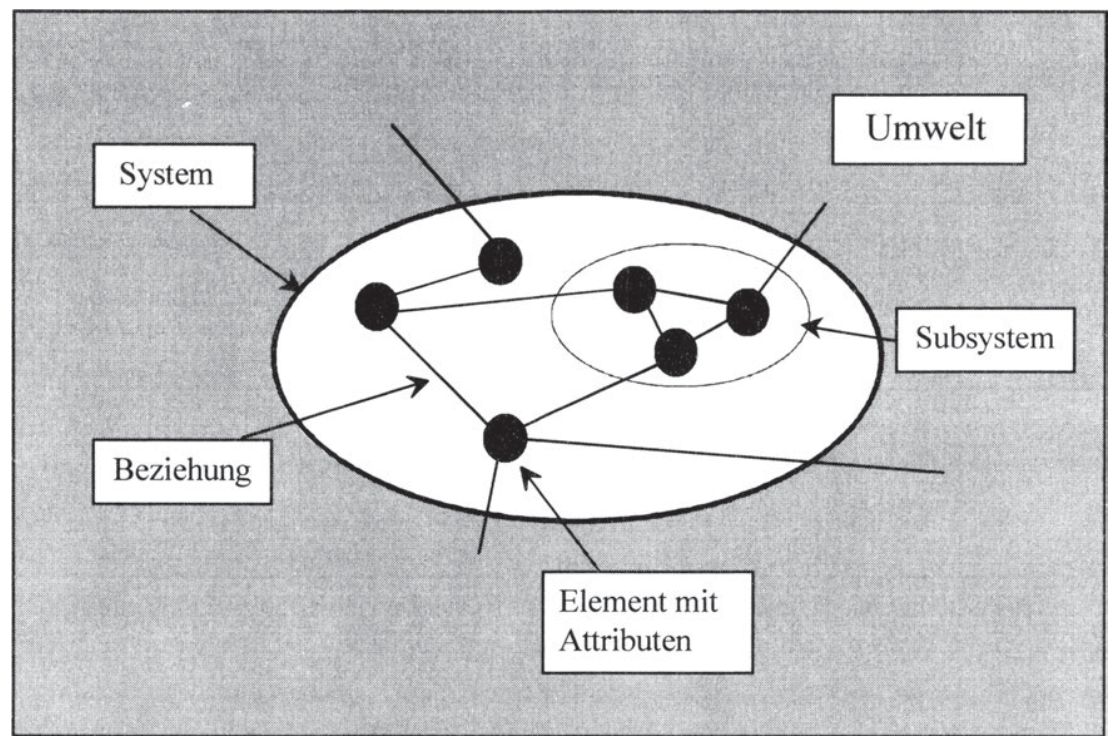

Abb. 2/3: Das System mit Elementen, Beziehungen und einem Subsystem (in Anlehnung an Schulte-Zurhausen (1995), S. 29)

Ein System besteht aus einer Menge von Elementen und den Beziehungen zwischen diesen Elementen. Es wird gegenüber der Umwelt als den nicht-zugehörigen Elementen und Beziehungen abgegrenzt. ${ }^{42}$ Das Element ist der kleinste Grundbestandteil des Systems als Gesamtheit, der entweder nicht weiter zerlegt werden kann oder im relevanten Betrachtungszusammenhang nicht weiter zerlegt werden soll. Die Definition der Elemente, die anhand ihrer Attribute beschrieben und mittels ihrer Beziehungen zu anderen Elementen in das Gesamtsystem eingeordnet werden können, hängt somit von der eingeschlagenen Betrachtungsperspektive sowie dem Ziel der Analyse ab. ${ }^{43}$ Beziehungen ergeben sich durch den Austausch von Strömungsgrößen. Anhand der Art der Strömungsgrößen kann zwischen materiellen, immateriellen und energetischen Beziehungen unterschieden werden, ${ }^{44}$ wobei energetische Beziehungen im Rahmen der vorliegenden Arbeit nicht relevant sind. Als Struktur wird im folgenden eine im Zeitverlauf relativ stabile Menge von Beziehungen bzw. ein Beziehungsmuster bezeichnet. ${ }^{45}$ Der Strukturbegriff kann sowohl auf die Gesamtheit der Beziehungen innerhalb

\footnotetext{
Vgl. Willke (1987), S. 38.

Vgl. Bertalanffy (1968), S. 38; Fuchs (1973), S. 40; Raffée (1974), S. 80.

44 Vgl. ähnlich Fuchs (1973), S. 39ff. In der Literatur wird in diesem Zusammenhang anstelle der immateriellen Beziehungen hăufig auf informationelle Beziehungen abgestellt. Der dort verwendeten Terminologie soll hier jedoch nicht gefolgt werden, da aufgrund der Abgrenzung des Informationsbegriffes im Rahmen der vorliegenden Arbeit informationelle Beziehungen einen Spezialfall der lubergeordneten Menge der immateriellen Beziehungen darstellen. Für eine ausfuhrliche Abgrenzung des Informationsbegriffes siehe Abschnitt 2.2.2.2.1 der vorliegenden Arbeit.
}

45 Vgl. Grothe (1997), S. 100, 243; Hejl (1982), S. 26; Hoffmann (1980), Sp. 1425; Miller (1978), S. 22 . 
eines Systems und zu seiner Umwelt als auch auf Teilmengen dieser Gesamtheit abstellen. Somit wird hier die Auffassung vertreten, daß ein System Strukturen hat. ${ }^{46}$

Jede Abbildung der Realität in einem System stellt ein Modell des betrachteten Realitätsausschnitts dar, weshalb man dieses auch als Systemmodell bezeichnen kann. Entscheidend für die Bildung von Systemmodellen ist es, den problemrelevanten Systemausschnitt und das geeignete Aggregationsniveau zu ermitteln. ${ }^{47}$ Entsprechend kann man einerseits das System durch Abgrenzung von seiner Umwelt unterschiedlich definieren, andererseits im Rahmen einer mehrstufigen Systemgliederung das System zwecks Komplexitätsreduktion in verschiedene Subsysteme unterteilen. Jedes einzelne Subsystem besteht wiederum aus Elementen und Beziehungen zwischen diesen Elementen und weist (neben Beziehungen zur sonstigen Umwelt) zahlreiche Beziehungen zu den anderen Subsystemen und Elementen des Gesamtsystems auf. 48 Innerhalb der entstandenen Subsystemhierarchie wird ein Subsystem einer tieferen Hierarchieebene aus der Sicht einer höheren Hierarchieebene als Black Box angesehen, deren internes Systemverhalten nicht weiter untersucht wird. Interessiert dagegen gerade dieses interne Systemverhalten, so muß man die stärker disaggregierende Sicht tieferliegender Subsystemebenen wählen. ${ }^{49}$

Sieht man von den Gemeinsamkeiten in den grundsätzlichen Erscheinungsformen von Systemen ab, die alle aus Elementen (mit Attributen) und Beziehungen bestehen, welche wiederum zu Subsystemen zusammengefaßt werden können, so existiert eine Fülle unterschiedlichster Systeme, die mit Hilfe verschiedener Klassifikationsansätze anhand ihrer zentralen Charakteristika gruppiert werden können. So kann man z.B. zwischen statischen und dynamischen, offenen und geschlossenen sowie zwischen einfachen und komplexen Systemen unterscheiden. ${ }^{50}$ Bei dem System Unternehmung als Erfahrungsobjekt der Betriebswirtschaftslehre handelt es sich um ein komplexes (und damit zugleich dynamisches), zielorientiertes, offenes, vieldimensionales, sozio-technisches System, dessen Eigenschaft der Komplexität im Mittelpunkt der folgenden Ausführungen steht. ${ }^{51}$

46 Vgl. z.B. auch Grothe (1997), S. 141f.; Kleinhans (1989), S. 28. Der Strukturbegriff wird in der Literatur in den unterschiedlichsten Zusammenhängen verwendet. Dabei wird scheinbar häufig davon ausgegangen, daß es sich hier um einen allgemeinverständlichen Begriff handelt, auf dessen Definition deshalb verzichtet werden kann. Systemtheoretisch ist jedoch sowohl eine Abgrenzung denkbar, die Struktur auf Beziehungen beschränkt (ein System hat eine Struktur), als auch eine, die den Strukturbegriff über die Beziehungen hinaus auf die Elemente ausdehnt (ein System ist eine Struktur). Die im Rahmen dieser Arbeit verwendete engere Abgrenzung vermeidet die mit der weiten Fassung einhergehende Verwendung zweier Begriffe (System und Struktur) für denselben Sachverhalt, wie sie Z.B. Biethahn/Mucksch/Ruf (1994), S. 89, und Staerkle (1985), S. 531, verfolgen.

47 Vgl. Schiemenz (1993), Sp. 4128.

48 Vgl. Raffée (1974), S. 80f.

49 Vgl. Schiemenz (1993), Sp. $4128 \mathrm{ff}$.

50 Vgl. Schiemenz (1993), Sp. 4130.

51 Vgl. Grothe (1997), S. 159; Hoffmann (1976), S. 210; Malik (1989), S. 23; Ulrich (1978), S. 277. 
Die Kybernetik als ein Teilgebiet der Systemtheorie beschäftigt sich mit der Steuerung bzw. Regelung 52 von und innerhalb von Systemen und wird deshalb auch als Regelungslehre bezeichnet. Dabei kann man zwischen zwei grundsätzlich verschiedenen Ansätzen unterscheiden, die auch als Kybernetik 1. und 2. Ordnung bezeichnet werden. ${ }^{53}$

Die Kybernetik 1. Ordnung geht - unter Rückgriff auf den Automatismus des Regelkreis- bzw. Rückkoppelungsprinzips - sowohl von der Möglichkeit der Regelung innerhalb des Systems als auch der der Regelung des Systems von außen aus. Das Regelkreisprinzip besagt, daß auf eine durch eine Störgröße bewirkte Störung des Systems, die eine Abweichung der Regelgröße von der Führungsgröße bedingt, durch eine Veränderung der Führungs- oder der Stellgröße reagiert wird, so daß die Störung nach Ablauf der Rückkoppelungsprozesse beseitigt ist und Regel- und Führungsgröße einander entsprechen. ${ }^{54}$ Diesen Zusammenhang zeigt Abbildung 2/4.

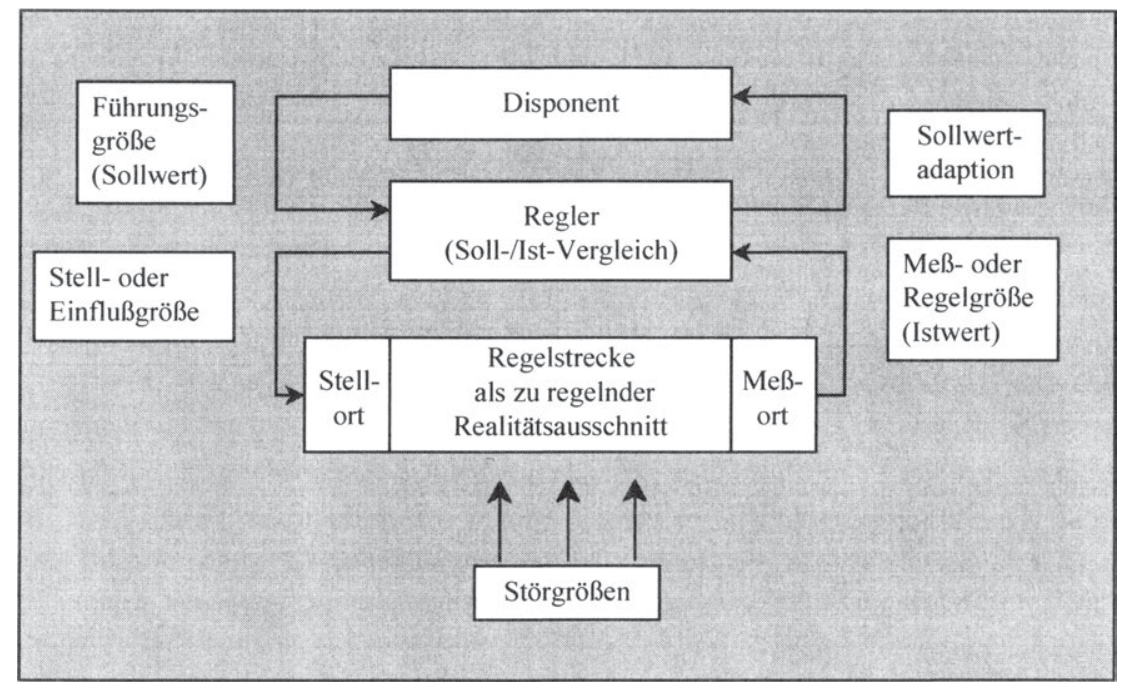

Abb. 2/4: Der Regelkreis (in Anlehnung an Busse von Colbe/Laßmann (1991), S. 91)

Die Annahmen der Kybernetik 1. Ordnung gelten für einfache Systeme bzw. sogenannte 'triviale Maschinen', bei denen invariate Ursache-Wirkungs-Zusammenhänge zwischen In- und Output bestehen, die mit Hilfe eindeutiger Transformationsregeln wiedergegeben werden können. ${ }^{55}$ Im Bereich der Technik und in Teilen der Naturwissenschaften konnten die Ideen der Kybernetik 1. Ordnung erfolgreich angewendet werden, so z.B.

52 Die Unterscheidung zwischen Steuerung und Regelung als Methoden der Systemtheorie, wie sie sich z.B. bei Baetge (1974), S. 27f., und Schiemenz (1993), Sp. 4132., findet, ist fur die Ausfuhrungen der vorliegenden Arbeit ohne Bedeutung und wird deshalb hier nicht weiter verfolgt.

53 Vgl. Glaserfeld (1997), S. 238ff.; Hejl (1983), S. 42; Probst/Gomez (1982), S. 37f.

54 Vgl. Schiemenz (1993), Sp. 4133.

55 Für eine kurze Darstellung sogenannter 'trivialer Maschinen' vgl. Foerster (1984), S. 9f. 
bei der Konzipierung von Industrierobotern oder Autopiloten in Flugzeugen, die in diesem Sinne 'triviale Maschinen' darstellen. ${ }^{56}$ In der Vergangenheit herrschte in der betriebswirtschaftlichen Literatur (zumindest implizit) häufig die Idee vor, daß sowohl einzelne Subsysteme der Unternehmung als auch diese als Ganzes im Rahmen der Aktivitäten der Unternehmungsführung vollständig plan- und steuerbar bzw. - entsprechend der Grundidee des obigen Regelkreises - prinzipiell regelbar sind. ${ }^{57}$ Die Managementaktivitäten zielten auf die vollständige Beherrschung des Systems als Idealzustand ab.

Im Gegensatz zur Kybernetik 1. Ordnung beschäftigt sich die Kybernetik 2. Ordnung mit der Regelung in komplexen Systemen. ${ }^{58}$ Komplexe Systeme zeichnen sich nicht nur durch die Vielzahl und Unterschiedlichkeit ihrer Elemente und Beziehungen (Kompliziertheit), sondern auch durch deren Veränderlichkeit im Zeitablauf (Dynamik) aus. Das Kriterium der Emergenz als drittes konstitutives Charakteristikum komplexer Systeme steht in engem Zusammenhang mit ihren dynamischen Eigenschaften. ${ }^{59}$ Emergenz ist die Fähigkeit, ,... Eigenschaften hervor[zu]bringen, die aus den Eigenschaften ihrer Elemente gerade nicht mehr erklärbar sind, die mithin neu und charakteristisch nur und erst für die Ebene des jeweiligen Systems sind.“60 Obwohl höhere Systemebenen auf den ersten Blick nur aus den bereits auf unteren Ebenen beobachteten Elementen und Beziehungen zu bestehen scheinen, kommen hier zusätzliche Strukturmuster hinzu, die aus den Funktionsbedingungen des Ganzen (der jeweiligen Betrachtungsebene) folgen und deshalb nur aus eben dieser Perspektive verständlich sind. Gliedert man das Gesamtsystem hierarchisch in mehrere Ebenen von Subsystemen, so bedeutet dies, daß bei einer synthetisierenden Sicht, die von den einzelnen Teilen (Subsystemen bzw. Elementen) ausgehend über mehrere Hierarchieebenen hinweg zum Gesamtsystem gelangt, auf jeder Hierarchieebene neue Eigenschaften der Subsysteme hinzukommen, die in deren einzelnen Teilen nicht angelegt sind. Emergenzphänomene führen in komplexen Systemen zu Übersummativität. Übersummativität bedeutet, daß das Ganze (System) mehr oder anders als die Summe seiner Teile (Elemente und Beziehungen) ist. ${ }^{61}$ Als Beispiel für ein komplexes System, in dem Emergenzphänomene auftreten, kann ein Vogelschwarm

56 Vgl. Ashby (1974), S. 287; Glaserfeld (1997), S. 240; Hejl (1983), S. 42.

57 Vgl. z.B. die Darstellung des Regelkreises in einem betriebswirtschaftlichen Lehrbuch wie dem von Busse von Colbe/Laßmann (1991), S. 91. Eine intensive kritische Auseinandersetzung mit diesem grundsătzlichen Problem unter Fokussierung des Primates der Planung vor den anderen Unternehmungsführungsaufgaben findet sich bei Steinmann/Schreyögg (1993), S. $119 \mathrm{ff}$., insbesondere S. 122. Zur Kritik mechanistischer Systemkonzeptionen der traditionellen Betriebswirtschaftslehre vgl. ferner Klimecki/Probst/Eberl (1991), S. 27ff.

58 Vgl. Malik (1989), S. 27.

59 Vgl. ăhnlich Gerstner (1995), S. 136; Probst (1987), S. 77; Wiegand (1996), S. 338. Gerstner unterscheidet ebenfalls zwischen Kompliziertheit und Komplexität. Während Gerstners Definition von Kompliziertheit mit der hier verwendeten ubereinstimmt, bezieht sich seine Definition von Komplexităt jedoch allein auf Dynamik und nicht auch explizit auf Emergenz. Dagegen stellt Wiegand ebenfalls auf Emergenz als konstitutives Charakteristikum komplexer Systeme ab. Anders dagegen z.B. Bronner (1992), Sp. 1122; Malik (1989), S. 186; Probst/Scheuss (1984), S. 481.

60 Willke (1987), S. 100. Vgl. ferner Küppers/Krohn (1992), S. 7f.

61 Vgl. Anderson (1972), S. $393 \mathrm{ff}$;; ferner Müller-Merbach (1992), S. 856f. 
angeführt werden. Das System Vogelschwarm besteht aus den einzelnen Vögeln als Elementen. Obwohl die einzelnen Vögel keine Kenntnis über das Verhalten aller anderen einzelnen Vögel haben und ihr Verhalten nicht zentral koordiniert wird, fliegen die Vögel in einer geordneten Formation. Die Bildung dieser Formation stellt ein Emergenzphänomen dar.

In der Terminologie vON FOERSTERS handelt es sich bei komplexen Systemen um nichttriviale Maschinen, die einfachen Systemen bzw. trivialen Maschinen gegenüberzustellen sind. ${ }^{62}$ Aufgrund der Existenz von Emergenzphänomenen ist das Verhalten von komplexen Systemen bzw. nicht-trivialen Maschinen im Gegensatz zu dem trivialer Maschinen nicht determiniert. Die Transformationsregeln sind hier im Vergleich zu trivialen Maschinen nicht etwa einfach nur komplizierter, sondern für weite Bereiche des betrieblichen Geschehens können keine solchen Transformationsregeln bestimmt werden. Vielmehr hängt der Systemoutput nicht nur vom Input ab, sondern auch vom jeweiligen zeitpunktbezogenen bzw. historisch entstandenen internen Zustand des Systems. Deshalb ist es wichtig, die Nicht-Durchdringbarkeit und Nicht-Reduzierbarkeit der Komplexität der Systeme anzuerkennen und ein komplexes System nicht wie ein einfaches System zu behandeln.63 Insbesondere führt eine dem Gedanken des Regelkreisprinzips folgende Regelung des Systems von außen nicht notwendigerweise zu den erwarteten Ergebnissen. Während nämlich im Rahmen der Kybernetik 1. Ordnung unterstellt wird, daß einfache Systeme tendenziell einen Gleichgewichtszustand anstreben, steht ein sogenanntes 'Denken in Ungleichgewichten' im Mittelpunkt zahlreicher Arbeiten zur Kybernetik 2. Ordnung. Diese fokussieren Rückkoppelungsprozesse, die abweichungsverstärkend wirken. ${ }^{64}$

Emergenzphänomene können sich auf unterschiedliche Eigenschaften komplexer Systeme beziehen. ${ }^{65} \mathrm{Im}$ Mittelpunkt moderner systemtheoretischer Arbeiten steht das spontane Auftreten von Ordnung bzw. Unordnung. Der Fokus der vorliegenden Arbeit liegt auf der spontanen Ordnungsbildung, wie sie VON HAYEK für den Bereich der Wirtschaftswissenschaft beschrieben hat. Zwar sind vON HAYEKS Arbeiten in erster Linie volkswirtschaftlich ausgerichtet, seine grundsätzlichen Überlegungen können jedoch auch auf die einzelne Unternehmung angewendet werden. VON HAYEK unterscheidet zwischen gemachter Ordnung (Made Order) und spontaner Ordnung (Grown Order). ${ }^{66}$ Während gemachte Ordnung nach VON HAYEK Ergebnis bewußter menschlicher Gestaltungshandlungen außerhalb des zu gestaltenden Systems ist, ${ }^{67}$ ergibt sich

\footnotetext{
Vgl. Foerster (1984), S. 10ff.; Probst (1987), S. 77; Strohmeier (1997), S. $171 \mathrm{ff}$.

63 Vgl. Strohmeier (1997), S. 171f. Probst (1987), S. 87, bezeichnet diese Problematik als „Falle der Trivialisierung“.

64 Vgl. Gebhardt (1996), S. 100.

65 So handelt es sich z.B. bei einer bestimmten Form des in Abschnitt 3.2.2.2.3 der vorliegenden Arbeit thematisierten Gruppenlernens um ein Emergenzphånomen.

66 Vgl. Hayek (1969a), S. 151.

$67, \ldots .$. it must be due to the design of some thinking mind“", „... a deliberate arrangement ...“. Hayek (1991), S. 293.
} 
spontane Ordnung zwar aus menschlichem Handeln, ist jedoch nicht etwa geplantes Ergebnis bewußter Gestaltungshandlungen. ${ }^{68}$ Vielmehr entsteht spontane Ordnung aus dem System selbst heraus im Rahmen der Interaktion mehrerer Individuen ${ }^{69}$ bzw. im eigentlichen Wortsinn 'von selbst, von innen heraus, freiwillig, ohne Aufforderung, aus eigenem Antrieb'.

Ansätze eines 'evolutionären Managements' übertragen die Erkenntnisse der Kybernetik 2. Ordnung auf die Unternehmung. ${ }^{70}$ Im deutschsprachigen Raum sind insbesondere zwei Forschungsgemeinschaften zu nennen, die sich mit der Thematik 'evolutionäres Management' auseinandersetzen. Zum einen handelt es sich dabei um den St. Galler Ansatz, dem Autoren wie Hans Ulrich, Probst, Malik, Gomez und DYLLICK zuzurechnen sind. Zum anderen ist der von $\mathrm{KIRSCH}$ und seinen Mitarbeitern, unter denen besonders ZU KNYPHAUSEN hervorzuheben ist, seit Anfang der 80er Jahre entwickelte Münchner Ansatz anzuführen. ${ }^{71}$

Die Ansätze eines evolutionären Managements interpretieren die Unternehmung als komplexes System. Das bedeutet, daß ihr Verhalten nicht determiniert und damit auch nicht vorhersagbar ist. Vielmehr treten in der Unternehmung vielfältige Emergenzphänomene auf. ${ }^{72}$ Damit muß der ausgeprägte Voluntarismus traditioneller Managementkonzepte bzw. die dort verfolgte „Illusion der Machbarkeit"73 aufgegeben werden. Da keine eindeutigen Wirkungsketten zwischen Managementaktivität und Verhalten des Systems ermittelt werden können, sondern unvorhersehbare Emergenzphänomene auftreten, stimmen intendiertes und tatsächliches Ergebnis des Managementhandelns nicht notwendigerweise überein. Trotzdem bleibt hier unbestritten, daß Managementhandeln in der Unternehmung als komplexem System prinzipiell 'wirkt'. Diese Wirkungen stellen jedoch nicht etwa deterministische Wenn-Dann-Zusammenhänge dar, sondern können teilweise oder vollständig unerwünschter Natur sein. ${ }^{74}$ Deshalb muß die sich in der obigen Darstellung des Regelkreises widerspiegelnde voluntaristische Sicht der Kybernetik 1. Ordnung im Rahmen der Kybernetik 2. Ordnung zugunsten einer Verlagerung des gestalterischen Schwerpunktes von Management auf die Potentialebene aufgegeben werden. Managementaktivitäten sollen also den Rahmen für die spontane

,.... orderly structures which are the product of the action of many men but are not the result of human design ...". Hayek (1991), S. 294. Auch thematisiert ein Aufsatz von von Hayek 'die Ergebnisse menschlichen Handelns, aber nicht menschlichen Entwurfs' bereits im Titel. Vgl. Hayek (1969b), S. 97.

69 Vgl. Malik/Probst (1981), S. 129.

70 Vgl. Hejl (1982), S. 41. Ein kurzer, prägnanter Überblick uber die zentralen Leitideen der Ansătze eines evolutionăren Managements findet sich bei Kieser (1992), Sp. 1758ff., insbesondere Sp. 1772f., sowie Knyphausen (1991), S. 56f.

71 Für eine grundsătzliche Gegenüberstellung der wichtigsten Ideen der beiden Forschungsgemeinschaften siehe Ringlstetter (1988), passim und Kieser (1994), passim.

72 Vgl. z.B. Kirsch/Knyphausen (1991), S. 76.

73 Kirsch (1992), S. 351.

74 Vgl. Strohmeier (1997), S. 172f. 
Ordnungsbildung als Emergenzphänomen schaffen. ${ }^{75}$ Ferner haben die im Rahmen von komplexitätsreduzierenden Modellvereinfachungen erarbeiteten Gestaltungsempfehlungen nicht etwa deterministischen Charakter, sondern stellen vielmehr Anregungen dar, die jedoch nur eine bestimmte Facette der komplexen Realität berücksichtigen und entsprechend vor der Übertragung in die betriebliche Praxis um weitere Aspekte zu ergänzen sind.

Angesichts der hohen Komplexität des Systems Unternehmung und der begrenzten kognitiven Fähigkeiten des Menschen setzt die Thematisierung der Unternehmung als Ganzen ein hohes Maß an Abstraktion voraus. Nur auf sehr abstrakter, grundsätzlicher Ebene beziehen sich die Aktivitäten des Managements auf die Gesamtheit dieses hochkomplexen Systems. Dieses auch als allgemeine strategische Unternehmungsführung bezeichnete Aufgabenfeld umfaßt insbesondere die Festlegung der Unternehmungsphilosophie und der allgemeinen Unternehmungsziele und zielt ab auf die grundsätzliche Beeinflussung der Wettbewerbsposition der Unternehmung am Markt. ${ }^{76}$ Über diese sehr grundsätzlichen Festlegungen hinaus besteht jedoch die Notwendigkeit, stärker konkretisierte Planungs- und Steuerungsaktivitäten des Managements auf bestimmte Teilaspekte bzw. Subsysteme des Gesamtsystems Unternehmung zu beschränken. Die vorliegende Arbeit fokussiert die Managementaktivitäten organisatorische Gestaltung und Informationsmanagement, die jeweils spezifische Sichtweisen auf das Gesamtsystem Unternehmung verfolgen und deren Tätigkeiten sich entsprechend auf bestimmte Subsysteme beschränken. ${ }^{77}$

\subsection{Abgrenzung der Aufgabenfelder organisatorische Gestal- tung und Informationsmanagement}

Im Anschluß an die Klärung der wissenschaftstheoretischen Positionierung der vorliegenden Arbeit stehen nunmehr deren begriffliche Grundlagen im Mittelpunkt. Ziel des folgenden Abschnittes ist es jedoch nicht nur, einen Überblick über die im folgenden verwendete Terminologie zu geben. Über die bloße Begriffsarbeit hinaus werden vielmehr auch die Inhalte der beiden Managementaktivitäten organisatorische Gestaltung und Informationsmanagement, für die im weiteren Verlauf der Arbeit Handlungsempfehlungen entwickelt werden, vorgestellt. Dafür werden organisatorische Gestaltung (Abschnitt 2.2.1) und Informationsmanagement (Abschnitt 2.2.2) zunächst unabhängig voneinander thematisiert. Während die Ausführungen zur organisatorischen Gestaltung relativ kurz gehalten werden können, nehmen die zum Informationsmanagement vergleichsweise viel Raum ein. Denn aufgrund des Fehlens eines geeigneten Informationsmanagement-Ansatzes in der Literatur gilt es hier, einen eigenständigen

75 Vgl. Malik (1989), S. 36ff.; Schreyögg/Noss (1995), S. 180f.; Steinmann/Schreyögg (1993), S. $119 \mathrm{ff}$

76 Vgl. Hahn (1989), S. 58ff.

77 Zur Unterscheidung zwischen allgemeiner Unternehmungsführung und dem speziellen Management bestimmter Funktionsbereiche vgl. Ulrich/Fluri (1992), S. 15. 
Vorschlag zur Konzeptionalisierung des Informationsmanagements zu entwickeln, der eine geeignete Basis für die folgenden Untersuchungen darstellt. An die isolierte Darstellung schließt sich sodann die Klärung des Zusammenhangs zwischen den beiden Aufgabenfeldern an (Abschnitt 2.2.3).

\subsubsection{Das Aufgabenfeld organisatorische Gestaltung}

Das Aufgabenfeld der organisatorischen Gestaltung stellt eine der beiden Managementaktivitäten in der Unternehmung dar, die im Rahmen der vorliegenden Arbeit unter dem Aspekt der Förderung organisationalen Lernens betrachtet werden. Die Termini 'organisatorische Gestaltung' und 'organisationales Lernen' stellen dabei nur zwei von vielen Verwendungen des Organisationsbegriffes dar. Sowohl umgangssprachlich als auch in der wissenschaftlichen - und hier insbesondere der betriebswirtschaftlichen Literatur wird der Organisationsbegriff in sehr unterschiedlichen Argumentationskontexten verwendet und ist dabei mit verschiedensten Inhalten verbunden. Deshalb wird im folgenden zunächst das im Rahmen der vorliegenden Arbeit verfolgte Verständnis des Organisationsbegriffes vorgestellt (Abschnitt 2.2.1.1). Sodann wird aufgezeigt, auf welche Bereiche sich die organisatorischen Regeln als Ergebnisse organisatorischer Tätigkeiten beziehen (Abschnitt 2.2.1.2). In Abschnitt 2.2.1.3 erfolgt schließlich die Einordnung der Managementfunktion der organisatorischen Gestaltung als Teilmenge in die Gesamtheit der organisatorischen Tätigkeiten. ${ }^{78}$

\subsubsection{Grundsätzliche Möglichkeiten der Verwendung des Organisa- tionsbegriffes}

Am Anfang einer Arbeit über organisationales Lernen und organisatorische Gestaltung muß die Klärung des Organisationsbegriffes stehen, erstaunt hier doch - zumindest auf den ersten Blick - die doppelte Verwendung des Adjektivs organisational bzw. organisatorisch. Im folgenden werden deshalb die grundsätzlichen Möglichkeiten für den Gebrauch des Organisationsbegriffes aufgezeigt. Abschnitt 2.2.1.1.1 stellt zunächst ein Schema zur Klassifikation der verschiedenen Organisationsbegriffe vor. Sodann werden in Abschnitt 2.2.1.1.2 die verschiedenen Verwendungsformen des Organisationsbegriffes im Rahmen der vorliegenden Arbeit erläutert und in dieses Schema eingeordnet.

78 Organisatorische Tătigkeiten als die übergeordnete Gesamtheit werden somit auf der vierten Gliederungsebcne (Abschnitt 2.2.1.3) thematisiert, während der Titel des Abschnittes der dritten Gliederungsebene (Abschnitt 2.2.1) auf die organisatorische Gestaltung als eine Teilmenge der organisatorischen Tătigkeiten abstellt. Diese formal problematische Lösung ist dadurch bedingt, daß auf der dritten Gliederungsebene die beiden Managementaktivităten organisatorische Gestaltung und Informationsmanagement einander gegenübergestellt werden sollen. 


\subsection{Klassifikationsschema zur Systematisierung möglicher Organisationsbe- griffe}

Zur Beherrschung der großen Vielfalt unterschiedlicher Definitionen des Organisationsbegriffes wurden verschiedene Klassifikationsschemata entwickelt, von denen im deutschsprachigen Raum die Unterscheidung in einen institutionalen, einen instrumentalen und einen funktionalen Organisationsbegriff häufig anzutreffen ist. ${ }^{79} \mathrm{Da}$ diese drei Kategorien jedoch weder untereinander trennscharf sind, noch alle in der Literatur verwendeten Organisationsbegriffe abdecken, ${ }^{80}$ sollen sie im folgenden nicht verwendet werden. Trennscharf und aufgrund seiner systemtheoretischen Ausrichtung für die vorliegende Arbeit besonders geeignet ist der Systematisierungsvorschlag von SCHARFENKAMP, der deshalb die Grundlage der folgenden Ausführungen bildet. ${ }^{81}$

Auf der obersten Systematisierungsebene ist zunächst zwischen Organisation als System (institutionaler Organisationsbegriff) und Organisation als Tätigkeit (funktionaler Organisationsbegriff) zu unterscheiden.

\begin{tabular}{|c|c|c|}
\hline $\begin{array}{l}\text { Art der System- } \\
\text { Systemgestalters }\end{array}$ & $\begin{array}{l}\text { Konkrete } \\
\text { Systemelemente }\end{array}$ & $\begin{array}{l}\text { Abstrakte } \\
\text { Systemelemente }\end{array}$ \\
\hline Natur & $\begin{array}{l}\text { Konkrete natürliche } \\
\text { Systeme } \\
\text { (z.B. einzelne Lebewesen) }\end{array}$ & $\begin{array}{l}\text { Abstrakte natürliche } \\
\text { Systeme } \\
\text { (z.B. Periodensystem der } \\
\text { chemischen Elemente) }\end{array}$ \\
\hline Mensch & $\begin{array}{l}\text { Konkrete künstliche } \\
\text { Systeme } \\
\text { (z.B. eine Unternehmung } \\
=\text { Organisation im Sinne d. } \\
\text { konkret institutionalen } \\
\text { Organisationsbegriffs) }\end{array}$ & $\begin{array}{l}\text { Abstrakte künstliche } \\
\text { Systeme } \\
\text { (z.B. organisat. Regeln } \\
\text { = Organisation im Sinne d. } \\
\text { abstrakt institutionalen } \\
\text { Organisationsbegriffs) }\end{array}$ \\
\hline
\end{tabular}

Abb. 2/5: Systematisierung institutionaler Organisationsbegriffe (in Anlehnung an Scharfenkamp (1987), S. 11)

Versteht man Organisation als System, so kann man auf einer zweiten Ebene nach der Art der Systeme unterscheiden. Dabei läßt sich die Gesamtheit der Systeme einerseits

79 Vgl. Buhner (1994), S. 1ff.; Hill/Fehlbaum/Ulrich (1994), S. 17; Hoffmann (1980), Sp. 1425ff.; Krulger (1994), S. 13; Picot (1993), S. 104f.; Schulte-Zurhausen (1995), S. Iff.

80 Vgl. Ropella (1989), S. 22.

81 Vgl. dazu und im folgenden Scharfenkamp (1987), S. 9ff., der sich auf die Ausfuhrungen von Grochla (1969), S. 2ff., Mag (1971), S. 24ff., und Hoffmann (1980), Sp. 1425, bezieht. 
anhand der Art ihres Gestalters in natürliche und künstliche (vom Menschen geschaffene) Systeme, andererseits anhand der Art ihrer Elemente in konkrete und abstrakte Systeme untergliedern. Abbildung 2/5 zeigt die beiden Dimensionen zur Differenzierung institutionaler Organisationsbegriffe in einer zweidimensionalen Matrix.

Die Elemente eines konkreten Systems sind bestimmte Objekte der dinglichen Wahrnehmungswelt, wie z.B. Menschen oder Maschinen. Die Elemente eines abstrakten Systems sind Variablen, die vom Betrachter des Systems aufgrund seines Erkenntnisziels definiert bzw. ausgewählt werden, wie z.B. bestimmte Eigenschaften von Menschen (z.B. fachliche Qualifikation) oder ein bestimmter Teil ihrer Beziehungen untereinander (z.B. Weisungsbefugnisse oder Kommunikationsbeziehungen).

Natürliche Systeme entstehen und existieren ohne Einfluß des Menschen. Natürliche Systeme sind z.B. Menschen, Tiere und Pflanzen (als konkrete Systeme), aber auch Naturgesetzmäßigkeiten (als abstrakte Systeme). Im Rahmen der vorliegenden Arbeit finden sie keine weitere Berücksichtigung. Künstliche Systeme werden vom Menschen geschaffen, so z.B. Häuser, Kühlschränke oder Unternehmungen (als konkrete Systeme) und Gesetzesvorschriften oder moralische Normen (als abstrakte Systeme).

Die in der Literatur verwendeten institutionalen Orgamisationsbegriffe sind unterschiedlich umfassend und decken entsprechend unterschiedliche Felder der Matrix in Abbildung $2 / 5$ ab. ${ }^{82}$

Die soziologisch ausgerichtete organisationstheoretische Literatur verwendet in der Regel den konkret institutionalen Organisationsbegriff, der deshalb teilweise auch als soziologischer Organisationsbegriff bezeichnet wird. ${ }^{83}$ Die Organisation ist hier ein konkretes künstliches System. Im Rahmen betriebwirtschaftlicher Arbeiten wird der konkret institutionale Organisationsbegriff auf Unternehmungen als Teilmenge der konkreten künstlichen Systeme beschränkt. Gemäß dem konkreten institutionalen Organisationsbegriff ist die Unternehmung dann eine Organisation. ${ }^{84}$

Andere betriebswirtschaftliche Arbeiten verwenden einen abstrakt institutionalen Organisationsbegriff, der die Organisation als abstraktes künstliches System auffaßt. Häufig wird dabei auf die Summe der organisatorischen Regeln in einer Unternehmung

82 Für eine Systematisierung verschiedener institutionaler Organisationsbegriffe aus der Literatur anhand der vier Felder aus Abbildung 2/5 vgl. Ropella (1989), S. 23ff., insbesondere S. 26.

83 Vgl. Henselek (1996), S. 78. In der anglo-amerikanischen Organisationsliteratur findet fast ausschließlich dieser konkret institutionale Organisationsbegriff Verwendung. Vgl. Schanz (1992), Sp. 1461. Aber auch zahlreiche deutsche Autoren definieren Organisation als konkretes sozio-technisches System. Vgl. z.B. Kieser/Kubicek (1992), S. 4ff.; Schanz (1994), S. 6ff.; Staehle (1994), S. 388ff.; Steinmann/Schreyögg (1993), S. 461, 503, 541. Staehle und Steinmann/Schreyögg verwenden in ihren jeweiligen Arbeiten neben dem konkret institutionalen jedoch auch andere Organisationsbegriffe.

Vgl. Krüger (1994), S. 13. 
abgestellt. ${ }^{85}$ Jedoch sind auch andere abstrakte künstliche Systeme denkbar. So umfaßt der Organisationsbegriff einiger wissensbasierter Ansätze zum organisationalen Lernen die Gesamtheit des Wissens der Unternehmungsmitglieder. Die Organisation wird dort dann als Wissensspeicher konzipiert. ${ }^{86}$ Entsprechend hat die Unternehmung bei Zugrundelegen eines abstrakt institutionalen Organisationsbegriffes eine Organisation. ${ }^{87}$

Hier zeigen sich die Vorteile des systemtheoretisch ausgerichteten Systematisierungsansatzes von SCHARFENKAMP gegenüber der Einteilung in institutionalen, instrumentalen und funktionalen Organisationsbegriff: Der instrumentale Organisationsbegriff stellt auf die Zweckeignung der organisatorischen Regeln als ein künstliches System zur Erreichung der Unternehmungsziele ab. ${ }^{88}$ Jedoch sind alle künstlichen Systeme als vom Menschen geschaffene Systeme ziel- bzw. zweckorientiert. Insbesondere hat auch die Unternehmung als Organisation (institutionaler Organisationsbegriff) insgesamt Instrumentalcharakter (instrumentaler Organisationsbegriff). Ferner kann das System organisatorischer Regeln (instrumentaler Organisationsbegriff) als vom Menschen geschaffene Institution (institutionaler Organisationsbegriff) angesehen werden. Beide Argumente zeigen, daß die Grenze zwischen institutionalem und instrumentalem Organisationsbegriff verschwimmt. 89

Da jedes System Ergebnis eines systembildenden Prozesses ist, kann die von SCHARFENKAMP vorgenommene Unterscheidung anhand des Systemgestalters und der Systemelemente auch auf den funktionalen Organisationsbegriff ${ }^{90}$ angewendet werden. Für die im Rahmen dieser Arbeit allein interessierenden künstlichen Systeme kann somit zwischen der Tätigkeit der Bildung abstrakter und konkreter Systeme unterschieden werden. ${ }^{91}$

\subsection{Verwendungsformen des Organisationsbegriffes im Rahmen der vorlie- genden Arbeit}

Das Konzept organisationalen Lernens, das den zentralen Gegenstand dieser Arbeit bildet, wurde ursprünglich in den USA entwickelt. Dort bezeichnet man es als 'Organizational Learning' und verwendet dabei - wie in organisationstheoretischen

85 In diesem Fall entspricht der abstrakt institutionale Organisationsbegriff dem sogenannten instrumentalen Organisationsbegriff der Autoren, die zwischen institutionalem, instrumentalem und funktionalem Organisationsbegriff unterscheiden. Einen abstrakt institutionalen Organisationsbegriff verwenden z.B. Grochla (1978), S. 10; Hill/Fehlbaum/Ulrich (1994), S. 17; Kuhn (1990), S. 136; Schanz (1992), Sp. 1460; Schulte-Zurhausen (1995), S. 2; Staehle (1994), S. 426ff.; Steinmann/Schreyögg (1993), S. 384ff.

86 Vgl. Schuppel (1996), S. 47ff.; Wiegand (1996), S. 262f.

87 Vgl. Krüger (1994), S. 13.

88 Vgl. Picot (1993), S. 104.

89 Vgl. Ropella (1989), S. 24; Scharfenkamp (1987), S. 17.

90 In der organisationstheoretischen Literatur findet sich ein funktionaler Organisationsbegriff $\mathrm{z}$. B. bei Bleicher (1991), S. 34ff.; Grochla (1978), S. 42; Kosiol (1962), S. 15; Staehle (1994), S. 641; Steinmann/Schreyögg (1993), S. 9, 377.

91 Vgl. Ropella (1989), S. 24. 
Abhandlungen des anglo-amerikanischen Sprachraums gemeinhin üblich - einen konkret institutionalen Organisationsbegriff.92 Somit bezeichnet Organizational Learning bzw. organisationales Lernen das Lernen der Institution Unternehmung. ${ }^{93}$ An die Stelle des Ziels 'Förderung organisationalen Lernens' kann damit auch die Formulierung 'Förderung des Lernens der Unternehmung' treten, und die Begriffe 'lernende Organisation' und 'lernende Unternehmung' werden synonym verwendet. Um die Übereinstimmung mit der gängigen Literatur zu gewährleisten, findet in der vorliegenden Arbeit im Zusammenhang mit organisationalem Lernen ein konkret institutionaler Organisationsbegriff Verwendung.

Der konkret institutionale Organisationsbegriff reicht jedoch nicht aus, um alle im Rahmen der vorliegenden Arbeit behandelten Aspekte adäquat zu formulieren. Einen weiteren Schwerpunkt der Arbeit bilden nämlich die organisatorischen Tätigkeiten, wobei zwischen Selbst- und Fremdorganisation (bzw. organisatorischer Gestaltung) unterschieden wird. Bereits ein intuitives Verständnis dieser Begriffe macht unmittelbar deutlich, daß der konkret institutionale Organisationsbegriff hier nicht angemessen und stattdessen ein funktionales Verständnis notwendig ist. Sowohl der Begriff der organisatorischen Tätigkeit als auch der der organisatorischen Gestaltung sind aufgrund der jeweiligen Betonung des Tätigkeitsaspektes in der Wortwahl in ihrem funktionalen Organisationsverständnis unmittelbar erkennbar und somit von anderen Organisationsbegriffen klar unterscheidbar.

Weniger offensichtlich ist dies bei den beiden Termini Selbst- und Fremdorganisation. Um das funktionale Organisationsverständnis sprachlich zu verdeutlichen, wird im folgenden - sofern dies sprachlich sinnvoll erscheint - die Formulierung 'Selbst- bzw. Fremdorganisationsprozesse' verwendet. Bei dem Terminus Selbstorganisation handelt es sich jedoch aufgrund seiner hohen Popularität in der Literatur inzwischen um einen feststehenden Begriff. Um ein zu starkes Abweichen von den gängigen Formulierungen der Literatur zu vermeiden und die Lesbarkeit des Textes zu erhöhen, wird deshalb im folgenden auch der isolierte Terminus Selbstorganisation verwendet, wobei ein funktionales Organisationsverständnis zugrunde liegt. Dasselbe gilt für Fremdorganisation als begriffliches Pendant zu Selbstorganisation.

Die Ausführungen verdeutlichen, $d a ß$ es unter Berücksichtigung des Erkenntnisinteresses und der im Rahmen dieser Arbeit eingeschlagenen Vorgehensweise nicht sinnvoll ist, einen einzigen Organisationsbegriff zu verwenden. Vielmehr werden im folgenden verschiedene Perspektiven eingeschlagen und entsprechend verschiedene Organisationsbegriffe verwendet werden. Dieser Umstand darf jedoch nicht dazu führen, daß derselbe Begriff in unterschiedlichen

92 Vgl. z.B. Porter/Lawler/Hackman (1975), S. 68ff.; Scott (1992), passim; Smircich (1983), passim.

93 Vgl. Probst/Büchel (1998), S. 17. 
Zusammenhängen bzw. mit verschiedenen Inhalten belegt verwendet wird. ${ }^{94} \mathrm{Die}$ aus einer solchen sprachlichen Unschärfe resultierende inhaltliche Verwirrung kann vielmehr dadurch vermieden werden, daß für unterschiedliche Organisationsverständnisse auch unterschiedliche Begriffe verwendet werden.

Im Rahmen der folgenden Ausführungen wird der isolierte Begriff der Organisation bei einem konkret institutionalen Verständnis stets durch den der Unternehmung ersetzt. Einzige Ausnahme stellt die adjektivische Verwendung des konkret institutionalen Organisationsbegriffes dar: Um die Nähe zur Terminologie der gängigen Literatur zum organisationalen Lernen $\mathrm{zu}$ wahren, wird im Zusammenhang mit organisationalem Lernen und der organisationalen Wissensbasis das Adjektiv 'organisational' nicht ersetzt (z.B. durch die Formulierungen 'Lernen der Unternehmung' oder 'Wissensbasis der Unternehmung'). Die Verwendung des Adjektives 'organisational' verweist damit durchgängig auf einen konkret institutionalen Organisationsbegriff.

Ein funktionales Organisationsverständnis wird durch die Wahl der explizit auf die Aktivität des Organisierens verweisenden Begriffe organisatorische Tätigkeit bzw. organisatorische Gestaltung deutlich. Wie bereits erwähnt, wird bezüglich der Begriffe Selbstund Fremdorganisation ein Kompromiß zwischen durchgängiger Begriffsverwendung und Übereinstimmung mit der Literatur zugunsten letzterer eingegangen. Sie werden zwar weitgehend durch die Begriffe ' Selbst-' und 'Fremdorganisationsprozesse' ersetzt. Zum Teil werden jedoch auch die isolierten Begriffe 'Selbst-' bzw. 'Fremdorganisation' im funktionalen Sinne verwendet.

Im Zusammenhang mit organisatorischen Regeln, deren Gesamtheit als Organisationssystem bezeichnet wird und die Gegenstand des folgenden Abschnittes 2.2.1.2 sind, findet schließlich ein abstrakt institutionaler Organisationsbegriff Verwendung.

Das Adjektiv 'organisatorisch' wird somit im Rahmen der vorliegenden Arbeit sowohl im funktionalen (organisatorische Gestaltung bzw. Tätigkeit) als auch im abstrakt institutionalen Sinne (organisatorische Regeln) verwendet, wobei jedoch die jeweilige Bedeutung im Zusammenhang mit dem begleitenden Substantiv eindeutig erkennbar ist. Das Adjektiv 'organisational' verweist dagegen durchgängig auf einen konkret institutionalen Organisationsbegriff (organisationales Lernen, organisationale Wissensbasis).

Diese grundlegende Übersicht über die verschiedenen Möglichkeiten der Verwendung des Organisationsbegriffes und die im Rahmen der vorliegenden Arbeit gewählten Definitionsansätze zeigt, daß eine isolierte Verwendung des Begriffes der Organisation im folgenden durchweg vermieden wird. Stattdessen kann der Organisationsbegriff durch entsprechende Ergänzungen (organisationales Lernen, Selbst- und Fremdorganisation,

94 Vgl. z.B. Bleicher (1991), der auf S. 34 Organisation als bestimmte Form der Strukturierung betrieblicher Zusammenhänge bezeichnet und auf S. 35 die Begriffe Aufbau- und Ablauforganisation im abstrakt institutionalen Sinne verwendet, dann jedoch zu einem konkret institutionalen Organisationsbegriff wechselt, wenn er auf derselben Seite von Aufgaben, Personen und technischen Hilfsmitteln als Organisationselementen spricht und auf S. 39 feststelit, daß Verteilungs- und Arbeitsbeziehungen die Organisation, d.h. die Unternehmung, prăgen. 
organisatorische Tätigkeiten bzw. Gestaltung, organisatorische Regeln) eindeutig als konkret oder abstrakt institutionaler oder funktionaler identifiziert werden. Abbildung 2/6 gibt abschließend einen Überblick über die verschiedenen Möglichkeiten der Verwendung des Organisationsbegriffes in der vorliegenden Arbeit.

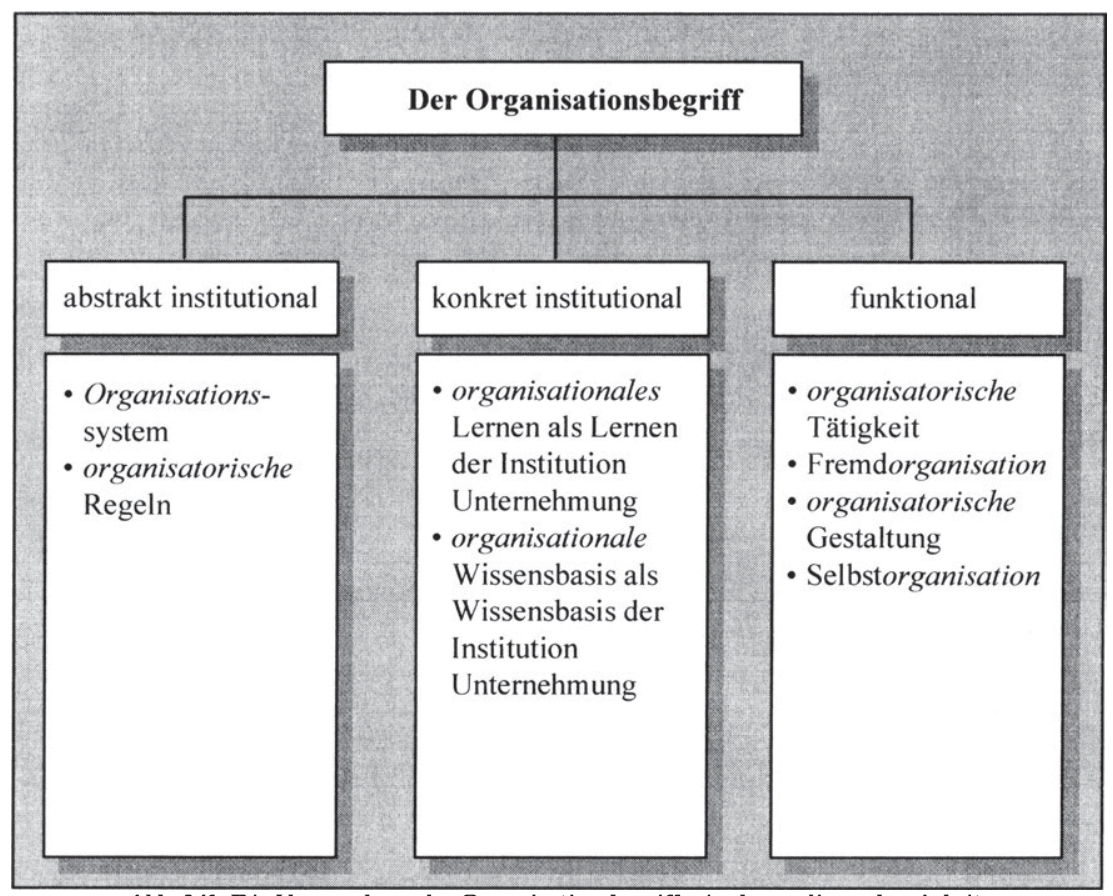

Abb. 2/6: Die Verwendung des Organisationsbegriffes in der vorliegenden Arbeit

\subsubsection{Die organisatorischen Regeln}

Der Begriff der organisatorischen Regel basiert auf einem abstrakt institutionalen Organisationsbegriff. Denn Regeln sind das Ergebnis menschlicher Entscheidungen, die die Freiheitsgrade von Handlungen im zu regelnden System beschränken und dadurch Ordnung schaffen. ${ }^{95}$ Organisatorische Regeln als Teilmenge der Gesamtheit aller die Unternehmung betreffender Regeln bestimmen das Zusammenwirken von Mensch und Technik als Elementarten des Systems Unternehmung im Rahmen der arbeitsteiligen Aufgabenerfüllung und richten es auf die Ziele der Unternehmung aus. ${ }^{96}$ So definiert NORDSIECK die organisatorische Regel als „eine spezielle und unmittelbare Regelung

95 Vgl. Grothe (1997), S. 243.

96 Vgl. Frese (1992), Sp. 1707; Scharfenkamp (1987), S. 20; Staehle (1994), S. 426. 
der menschlichen und sachlichen Zusammenarbeit im Sinn der gemeinschaftlichen Aufgabe“97.

Die Aufgabe der Unternehmung als deren Handlungsziel ${ }^{98}$ wird im Regelfall ${ }^{99}$ arbeitsteilig erfüllt. Deshalb muß sie zunächst im Rahmen der Aufgabenanalyse in geordneter Weise in Teilaufgaben zerlegt werden, die sodann im Rahmen der Aufgabensynthese zu verteilungsfähigen Teilaufgabenbündeln zusammengefaßt werden. ${ }^{100}$ Um die Ausrichtung der Teilaufgabenerfüllung auf das Handlungsziel der Unternehmung sicherzustellen, muß die Aufgabenteilung von Maßnahmen zur Koordination begleitet werden. ${ }^{101}$ Zentraler Gegenstandsbereich der organisatorischen Regeln ist somit die Aufgabe der Unternehmung bzw. die daraus abgeleiteten Teilaufgaben(bündel). Einerseits betreffen die organisatorischen Regeln dabei die Verteilung der Teilaufgaben (aufbauorganisatorische Regeln), andererseits die Art und Weise der Aufgabenerfüllung (ablauforganisatorische Regeln). ${ }^{102}$ Neben der Aufgabe betreffen die organisatorischen Regeln aber auch bestimmte Aspekte von Mensch und Technik als Elementen der Unternehmung sowie bestimmte Beziehungen zwischen diesen Elementen, die im folgenden vorgestellt werden.

Da Teilaufgaben als aus dem allgemeinen Handlungsziel der Gesamtaufgabe der Unternehmung abgeleitete Handlungsanweisungen für Personen interpretiert werden können, ${ }^{103}$ betreffen organisatorische Regeln die Menschen in ihrer Funktion als Aufgabenträger. Die Menschen, deren persönliche Ziele in der Regel nicht mit den Zielen der Unternehmung übereinstimmen, sollen in ihrer Funktion als Aufgabenträger mittels organisatorischer Regeln in ihrem Verhalten so beeinflußt werden, daß ihre Aktivitäten einen positiven Beitrag zu den Unternehmungszielen leisten. Personenbezogene Verhaltensregeln stellen somit eine Teilmenge der Gesamtheit der organisatorischen Regeln dar. ${ }^{104}$

Die menschlichen Aufgabenträger greifen bei der Erfüllung ihrer Teilaufgaben auf die Unterstützung durch Sachmittel zurück. Entsprechend beziehen sich die organisatorischen Regeln auch auf die in der Unternehmung eingesetzten Sachmittel (Fertigungs-

97 Nordsieck (1960), Sp. 4246. Der abstrakt institutionale Organisationsbegriff, der Organisation als das System organisatorischer Regeln definiert, geht auf Nordsieck zurück.

98 Vgl. Kosiol (1962), S. 43.

99 Der Spezialfall der Ein-Personen-Unternehmung wird im folgenden nicht berücksichtigt.

$100 \mathrm{Vgl}$. Schulte-Zurhausen (1995), S. 34f.

101 Vgl. Bühner (1994), S. 5.

102 Vgl. Kruger (1994), S. 13. Die Trennung in aufbau- und ablauforganisatorische Regeln hat in erster Linie analytischen Charakter. Beide stellen unterschiedliche Sichtweisen auf denselben Gegenstand, die Teilaufgaben in der Unternehmung, dar. Vgl. Hoffmann (1992), Sp. 208.

103 Vgl. Bleicher (1993), S. 116.

104 Vgl. Grochla (1978), S. 10; Krilger (1994), S. $15 f f$. 
und Informationstechnik) in ihrer Funktion als Aktionsträger. ${ }^{105}$ Diese organisatorischen Regeln werden auch als maschinenbezogene Funktionsregeln ${ }^{106}$ bezeichnet.

Neben der Aufgabe als Handlungsziel der Unternehmung sowie den menschlichen Aufgabenträgern und maschinellen Aktionsträgern als Elementen des Systems Unternehmung haben organisatorische Regeln bestimmte Beziehungen zwischen diesen Elementen zum Gegenstand. Die Summe aller organisatorischen Beziehungen innerhalb der Unternehmung wird im folgenden als Organisationsstruktur bezeichnet, da sie ein vergleichsweise stabiles Beziehungs- bzw. Anordnungsmuster zwischen menschlichen Aufgabenträgern und maschinellen Aktionsträgern herstellt. ${ }^{107}$ Die Organisationsstruktur kann in die beiden Teilmengen der Verteilungs- und der Arbeitsbeziehungen unterteilt werden.

Verteilungsbeziehungen betreffen die Zuordnung von Teilaufgaben, abstrakten menschlichen Aufgabenträgern und abstrakten technischen Aktionsträgern zueinander, wie sie als Stellenbildung im Rahmen aufbauorganisatorischer Tätigkeiten erfolgt. Somit handelt es sich bei der Definition von Verteilungsbeziehungen um eine aufbauorganisatorische Gestaltungstätigkeit. Arbeitsbeziehungen stellen Zuordnungs- bzw. Wirkungsbeziehungen dar, die die Zusammenarbeit zwischen menschlichen Aufgabenträgern und technischen Aktionsträgern regeln und entsprechende Input-Output-Beziehungen definieren. Aus ihnen resultiert der Arbeitsablauf. Entsprechend handelt es sich bei der Definition von Arbeitsbeziehungen um eine ablauforganisatorische Gestaltungstätigkeit. ${ }^{108}$ Anhand der jeweiligen Strömungsgrößen bzw. Input-Output-Beziehungen kann man zwei Arten von Arbeitsbeziehungen unterscheiden: Einerseits können die Input-Output-Ströme materieller Natur sein, andererseits können sie immaterieller Natur sein. Materielle Arbeitsbeziehungen betreffen z.B. den Austausch von gegenständlichen Rohstoffen, Zwischen- und Endprodukten zwischen Stellen. Gegenstand immaterieller Arbeitsbeziehungen ist dagegen das immaterielle Phänomen Information. ${ }^{109}$

Der Gegenstandsbereich organisatorischer Regeln umfaßt somit die Aufgabe der Unternehmung als deren Handlungsziel, die menschlichen Aufgabenträger sowie die maschinellen Aktionsträger und schließlich die Verteilungs- und Arbeitsbeziehungen als organisatorische Beziehungen bzw. Organisationsstruktur."10 Die Gesamtheit der organisatorischen Regeln wird im Rahmen der vorliegenden Arbeit auch als Organisa-

105 In der Literatur herrscht keine Einigkeit darüber, ob Maschinen Aufgabenträger sind oder nicht. Eine dies bejahende Position vertreten z.B. Hoffmann (1992), Sp. 212; Mag (1978), S. 264; Thom (1992), Sp. 2322. Die Vertreter einer ablehnenden Position, der hier gefolgt wird, argumentieren dagegen, daß zur Aufgabenerfullung die Initiativ- und die Verantwortungsfunktion gehören, die von Maschinen nicht übernommen werden können. Vgl. z.B. Bleicher (1991), S. 35, 38.

106 Vgl. Grochla (1978), S. 10.

107 Bezüglich der systemtheoretischen Definition von Struktur siehe Abschnitt 2.1.3 der vorliegenden Arbeit.

108 Vgl. Bleicher (1993), S. 120.

109 So nennt Bleicher die „Informations- und Kommunikationsbeziehungen zwischen Teil-Einheiten“ als Beispiel für durch Arbeitsbeziehungen geschaffene Arbeitsverbindungen. Bleicher (1991), S. 41.

$110 \mathrm{Vgl}$. ăhnlich Krüger (1994), S. $15 \mathrm{ff}$. 
tionssystem bezeichnet. Abbildung 2/7 zeigt die möglichen Regelungsinhalte des Organisationssystems im Überblick. Es sei darauf hingewiesen, daß die hier vorgenommene Unterscheidung verschiedener Regelungsinhalte eher theoretisch-konzeptioneller als praktischer Natur ist. Insbesondere betreffen die organisatorischen Regeln in der betrieblichen Praxis zumeist sowohl die Attribute der Aufgaben- und Aktionsträger als auch die organisatorischen Beziehungen zwischen ihnen.

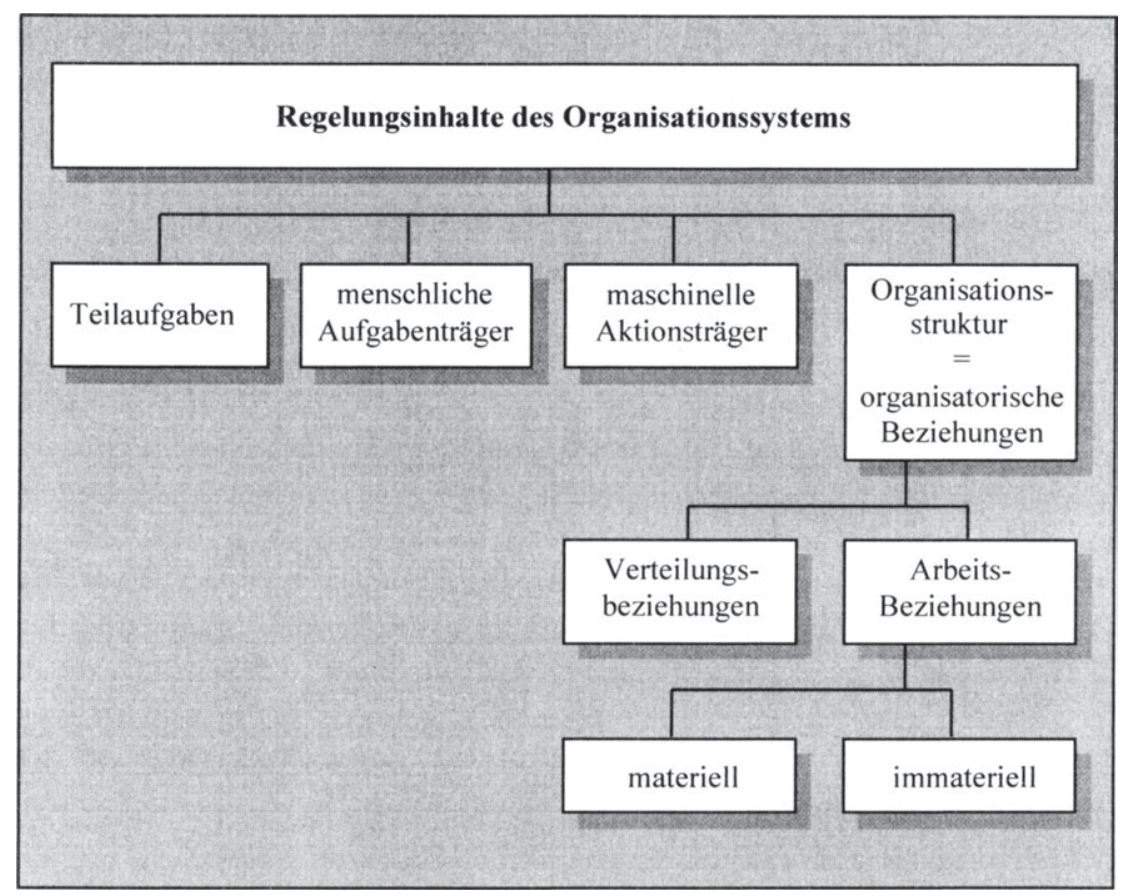

Abb. 2/7: Systematisierung der Regelungsinhalte des Organisationssystems

Das Organisationssystem als die Gesamtheit der organisatorischen Regeln ist ein Teilsystem des Systems Unternehmung. Denn es kann bezüglich seines Zieles, seiner Elemente und der Beziehungen zwischen diesen Elementen vom System Unternehmung als dem übergeordneten Ganzen unterschieden werden. Erstens umfaßt das Zielsystem der Unternehmung über die zu erfüllende Aufgabe als Handlungsziel hinaus auch andere Ziele, die nicht notwendigerweise Ziele des Organisationssystems sind. ${ }^{11}$ Zweitens sind Mensch und Technik als Elementarten des Systems Unternehmung nicht mit allen ihren Attributen dem Organisationssystem zuzurechnen. Vielmehr wird die Betrachtung hier auf diejenigen Attribute begrenzt, die für die arbeitsteilige Aufgabenerfüllung von Relevanz sind. Diese Beschränkung der Perspektive spiegelt sich in der Bezeichnung des

111 Diese Aussage steht nicht im Widerspruch dazu, daß zumindest die ubergeordneten Globalziele der Unternehmung in der Regel bei der Gestaltung aller ihrer Subsysteme - und so auch des Organisationssystems - Berucksichtigung finden. 
Menschen als menschlichem Aufgabenträger und der Technik als maschinellem Aktionsträger wider. Insbesondere betreffen die organisatorischen Regeln nur abstrakte Anforderungsprofile (Qualifikationsprofile für menschliche Aufgabenträger, Funktionsprofile für maschinelle Aktionsträger), die losgelöst von konkreten Personen und Sachmitteln grundsätzliche Bedarfe formulieren. Diese abstrakten Eigenschaften als Attribute abstrakter Aufgaben- und Aktionsträger determinieren einen Spielraum, dessen Konkretisierung nicht Gegenstand der organisatorischen Regeln ist. Drittens stellen die organisatorischen Beziehungen nur eine Teilmenge der Gesamtheit der Beziehungen in der Unternehmung dar.

Zwei Attribute der abstrakten menschlichen Aufgabenträger sind für die weiteren Ausführungen der vorliegenden Arbeit von zentraler Bedeutung: Dabei handelt es sich um Informationsbedarf und -bereitstellung. Die organisatorischen Regeln bezüglich Informationsbedarf und -bereitstellung werden vom organisatorischen Gestalter aus den sachlichen Erfordernissen der Teilaufgabenerfüllung abgeleitet und sind dabei notwendigerweise unabhängig von den individuellen Präferenzen der konkreten Person des Stelleninhabers, da diese nicht Gegenstand organisatorischer Regeln ist. Auch bewegen sich die organisatorischen Regeln bezüglich Informationsbedarf und -bereitstellung tendenziell auf einem hohen Abstraktionsniveau.

Abschließend sei hier darauf hingewiesen, daß organisatorische Regeln das Zusammenwirken der Elemente des Systems Unternehmung im Rahmen der arbeitsteiligen Aufgabenerfüllung zum Gegenstand haben. Sie betreffen somit per definitionem stets die Aufgabenverteilung zwischen den Aufgabenträgern in der Unternehmung. Die Regeln, die die stelleninterne Abwicklung der Arbeitsaufgaben des einzelnen menschlichen Aufgabenträgers - ohne Bezug zu anderen Stellen - betreffen, sind dagegen nicht organisatorischer Natur, sondern der Arbeitswirtschaft bzw. -gestaltung zuzurechnen. Bezogen auf den einzelnen Aufgabenträger sind nur diejenigen Regeln organisatorischer Art, die die Schnittstellen zu anderen Stellen bzw. die damit verbundene Einordnung des Einzelnen in einen umfassenderen, arbeitsteiligen Gesamtzusammenhang betreffen. ${ }^{112}$ Gliedert man die Unternehmung in Anwendung der systemtheoretischen Perspektive in Mikro-, Meso- und Makroebene, so ist die Mikroebene des einzelnen Aufgabenträgers somit nicht Gegenstand organisatorischer Regeln. Dagegen betreffen die organisatorischen Regeln sowohl die Meso- als auch die Makroebene. Auf der Mesoebene werden die verschiedenen Subsysteme der Unternehmung untersucht. Die organisatorischen Regeln haben hier die arbeitsteilige Aufgabenerfüllung innerhalb der Subsysteme zum Gegenstand. Die Größe dieser Subsysteme kann sehr unterschiedlich sein. Sie reicht - je nach der aufbauorganisatorischen Ausgestaltung der Unternehmung - von der Gruppe

112 Dieser Unterschied zwischen organisatorischen Regeln und solchen der Arbeitsgestaltung entspricht von der Grundidee her der Unterscheidung zwischen Organisationstheorie und Arbeitswissenschaft. Für einen kurzen Überblick über die Arbeitswissenschaft sowie bezüglich der Begriffe Arbeitswirtschaft bzw. Arbeitsgestaltung vgl. Staehle (1994), S. 105ff. Allerdings sei hier darauf verwiesen, $\mathrm{da}$ diese Abgrenzung zwischen organisatorischen Regeln und solchen der Arbeitsgestaltung ein hohes $\mathrm{Maß}$ an Interpretationsspielraum zulaßst. 
mit einigen wenigen Mitgliedern über Abteilungen und Hauptabteilungen bis hin zu Geschäftsbereichen mit mehreren Hundert oder sogar mehreren Tausend Mitarbeitern. Betrachtungsobjekt der Makroebene ist schließlich die Unternehmung als Ganzes. Gegenstand der organisatorischen Regeln sind hier aufbau- und ablauforganisatorische Aspekte zwischen den Subsystemen der Unternehmung. Abschließend ist somit festzuhalten, daß organisatorische Regeln die aufbau- und ablauforganisatorischen Aspekte innerhalb und zwischen den Subsystemen der Unternehmung zum Gegenstand haben.

\subsubsection{Fremd- und Selbstorganisation als Grundformen organisato- rischer Tätigkeit}

Dem Begriff der organisatorischen Tätigkeiten liegt ein funktionaler Organisationsbegriff zugrunde. Die organisatorischen Tätigkeiten umfassen die Gesamtheit aller auf die organisatorischen Regeln als Objekt bezogenen Managementaktivitäten. ${ }^{113}$ Damit stellen die organisatorischen Tätigkeiten eine Teilmenge der Gesamtheit der Managementaktivitäten in der Unternehmung dar. Sie sind durch ihren Gegenstandsbereich,

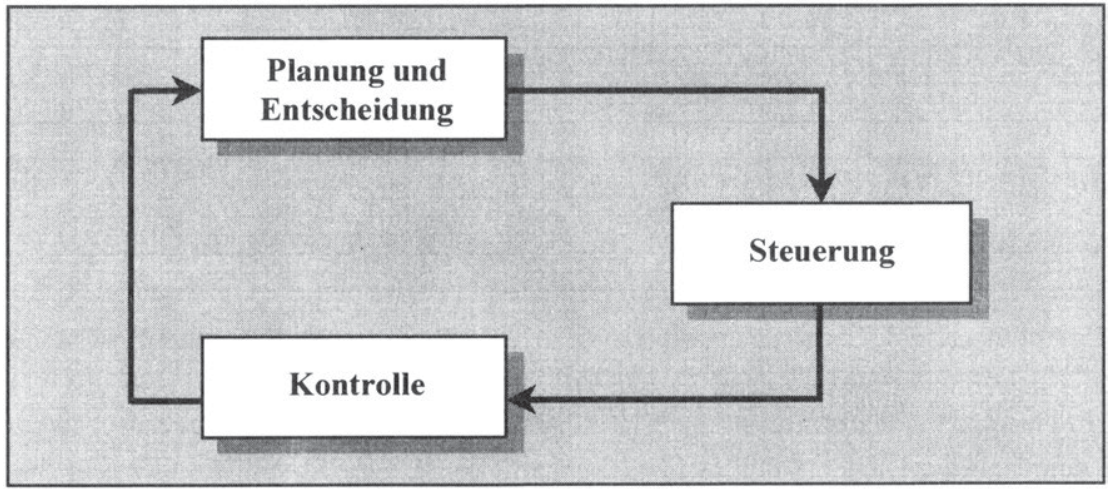

Abb. 2/8: Der Managementzyklus

die organisatorischen Regeln, spezifiziert. Der Managementbegriff umfaßt dabei die Gesamtheit der Planungs- und Entscheidungs-, Steuerungs- und Kontrollaufgaben, die den Phasen eines sich wiederholenden Managementzyklusses zugerechnet werden können, wie ihn Abbildung 2/8 zeigt.

Die Aktivitäten der Planung und Entscheidung stellen den logischen Ausgangspunkt des Managementprozesses dar. Unter die Planung als gedankliche Vorwegnahme zukünftiger Entscheidungen und Handlungen ${ }^{114}$ fallen insbesondere die Bestimmung der grundsätzlich verfolgten Ziele und die Formulierung möglicher Maßnahmen zur

113 Vgl. ahnlich Kruger (1994), S. 13; Mag (1983), S.1034ff. Aufgrund der fehlenden Unterscheidung zwischen Selbst-und Fremdorganisation (organisatorische Gestaltung) beziehen sich die Ausfuhrungen dort allerdings lediglich auf die organisatorische Gestaltung.

114 Vgl. Mag (1995), S. 2. 
Erreichung dieser Ziele. Im Rahmen der Entscheidungsfindung wird eine der formulierten Handlungsoptionen ausgewählt. Planung und Entscheidung werden dabei hier zu einer Phase (Planung/Entscheidung) zusammengefaßt. ${ }^{115}$ Bei den organisatorischen Tätigkeiten sind die organisatorischen Regeln bereits Gegenstand der Planungsphase. Nach Abschluß der rein gedanklichen Planungs- und Entscheidungsaktivitäten braucht hier deshalb nicht - wie in der Literatur zum allgemeinen Managementzyklus üblich - eine gesonderte, der Steuerung vorausgehende, als 'Organisation' bezeichnete Phase ausgewiesen zu werden, innerhalb derer organisatorische Regeln als Voraussetzung für den Aufgabenvollzug in der Unternehmung formuliert werden. Vielmehr sind die organisatorischen Regeln hier bereits Ergebnis der Phase der Planung/Entscheidung. Stattdessen folgt hier unmittelbar die Phase der Steuerung, innerhalb derer diese Ergebnisse implementiert werden. ${ }^{116}$ Die Kontrolle stellt den letzten logischen Schritt des skizzierten Managementprozesses dar. Hier werden die realisierten Ist-Ergebnisse mit den ursprünglichen Planwerten abgeglichen, eventuelle Abweichungen zwischen Ist und Plan festgestellt und auf ihre Ursachen untersucht. Mögliche Maßnahmen zur Anpassung von Soll und Ist können einerseits aus Korrekturmaßnahmen bestehen, die zu einer Anpassung der Istwerte an die geplanten führen, andererseits können mittels Planrevisionen die ursprünglichen Planwerte verändert werden. Letzteres bedeutet ein Wiedereintreten in die Planungsphase. Somit stellt die Kontrollphase nicht nur den logischen Endpunkt des Managementprozesses dar, sondern ihre Ergebnisse bilden zugleich den Ausgangspunkt für die Neuplanung und einen neuen Managementprozeß.117

$\mathrm{Da}$ in einer existierenden Unternehmung organisatorische Tätigkeiten immer auf bereits Vorhandenem aufsetzen, handelt es sich zumeist um Aktivitäten der Änderung bereits existierender organisatorischer Regeln. Diesen sind organisatorische Tätigkeiten gegenüberzustellen, die für Bereiche, die bislang situativ geregelt wurden, nunmehr präsituative - organisatorische - Regeln formulieren. Lediglich im Falle der Neugründung von Unternehmungen oder Unternehmungsteilen, der im Rahmen dieser Arbeit nicht weiter betrachtet werden soll, muß bei der organisatorischen Tätigkeit nicht auf bestehende Regelungsformen Rücksicht genommen werden. Allerdings existieren auch

115 Die Abgrenzung von Planung und Entscheidung als Phasen des Managementzyklusses wird in der Literatur nicht einheitlich vorgenommen. Einige Autoren sehen Planung und Entscheidung als klar voneinander getrennt an, andere fassen beide zusammen. In dieser Arbeit wird die zweite Sichtweise verfolgt, da hier Planung als die gedankliche Vorbereitung von Entscheidungen verstanden wird. Vgl. Mag (1993), S. 4. Da Entscheidungen daruber hinaus auch in allen anderen Phasen des Managementzyklusses anfallen, könnten sie alternativ aber auch als allen Managementfunktionen inhärente Metafunktion verstanden werden. Vgl. Steinmann /Schreyögg (1993), S. 9. Dieser Sichtweise wird hier nicht gefolgt.

116 In der Literatur findet sich anstelle des Begriffes der Steuerung teilweise der der Durchführung oder Realisation, so z.B. bei Mag (1992), S. $60 \mathrm{ff}$. Dieser Terminologie wird hier nicht gefolgt, da im Rahmen der vorliegenden Arbeit Managementaufgaben und Durchführungsaufgaben einander als disjunkte Mengen gegenubbergestellt werden.

117 Vgl. ähnlich Mag (1992), passim; Staehle (1994), S. 78; Steinmann/Schreyögg (1993), S. 8ff. 
dann i.d.R. bereits strukturkonstituierende informelle Beziehungsmuster. Die Annahme einer organisatorischen Tabula Rasa ist damit für die Praxis unrealistisch. ${ }^{118}$

Die Gesamtheit der organisatorischen Tätigkeiten kann unter Einsatz verschiedener Kriterien untergliedert werden. Eine Möglichkeit stellt die Systematisierung anhand des jeweiligen Ergebnisses bzw. Objektes der organisatorischen Tätigkeiten dar. Anknüpfend an die Darstellung der verschiedenen Arten organisatorischer Regeln in Abschnitt 2.2.1.2 kann dann z.B. mittels der betroffenen Beziehungen zwischen aufbauund ablauforganisatorischen Aktivitäten oder mit Hilfe der betroffenen Elementarten des Organisationssystems in solche bezüglich der Teilaufgaben, der menschlichen Aufgabenträger oder der maschinellen Aktionsträger unterschieden werden. Im folgenden wird anhand des Verhältnisses zwischen gestaltendem Subjekt und gestaltetem Objekt zwischen Fremdorganisation (bzw. organisatorischer Gestaltung) und Selbstorganisation als Teilmengen der Gesamtmenge der organisatorischen Tätigkeiten unterschieden. ${ }^{119}$ Die gängige Organisationsliteratur verzichtet dagegen auf diese Unterscheidung zwischen organisatorischer Tätigkeit als Oberbegriff und organisatorischer Gestaltung als Teilmenge. ${ }^{120}$ Dies liegt m.E. in erster Linie darin begründet, daß dort unter Vernachlässigung von Aspekten der Selbstorganisation organisatorische Tätigkeiten allein als Fremdorganisation untersucht werden.

Die Begriffe organisatorische Gestaltung ${ }^{121}$ und Fremdorganisation werden im Rahmen dieser Arbeit synonym verwendet. Während sie also ein und dieselbe Tätigkeit bezeichnen, stellen sie dabei auf unterschiedliche Aspekte ab: Der Begriff der organisatorischen Gestaltung hebt den funktionalen Aspekt des Gestaltens hervor. Dagegen betont der Begriff der Fremdorganisation den Umstand, daß der Gestalter außerhalb des zu gestaltenden Systems steht und stellt damit das Pendant zum Begriff der Selbstorganisation dar. Fremdorganisation liegt also vor, wenn die Person des Gestalters ${ }^{122}$ als das gestaltende Subjekt außerhalb des zu gestaltenden Systems als des Gestaltungsobjekts steht und somit nicht direkt von den eigenen Gestaltungsaktivitäten betroffen ist. ${ }^{123}$ Organisatorische Gestaltung bzw. Fremdorganisation stellt stets einen bewußten Gestal-

118 Vgl. Staehle (1994), S. 558.

119 Vgl. Gebhardt (1996), S. 93, sowie als vom prinzipiellen Ansatz her ähnlich auch Knyphausen (1988), S. 256ff., insbesondere S. 267ff., der jedoch im Detail eine von der Begriffsabgrenzung der vorliegenden Arbeit abweichende Position vertritt.

120 Vgl. z.B. Grochla (1982), S. 2, der die Begriffe organisatorische Gestaltung, Organisieren und organisatorische Tatigkeiten gleichsetzt.

121 Da die Aktivităten der organisatorischen Gestaltung hier Teilmenge der organisatorischen Tătigkeiten als der auf die organisatorischen Regeln bezogenen Managementaktivităten sind, wird der Gestaltungsbegriff hier mit dem Managementbegriff gleichgesetzt.

122 Anstelle einer einzelnen Person kann es sich grundsătzlich stets auch um mehrere gestaltende Personen handeln. Für die Ausfuhrungen der vorliegenden Arbeit hat die Unterscheidung zwischen einer und mehreren Personen jedoch keine Bedeutung. Aus Grunden der sprachlichen Vereinfachung wird deshalb im folgenden regelmaßig der Singular verwendet.

123 Vgl. ăhnlich Gebhardt (1996), S. 93; Hill/Fehlbaum/Ulrich (1994), S. 25; Knof (1991), S. 10; Seidel (1986), S. 228. 
tungsakt dar. Die aus diesen Aktivitäten resultierenden organisatorischen Regeln sind somit bewußt geschaffen. ${ }^{124}$ Sie können, müssen jedoch nicht, schriftlich fixiert sein. ${ }^{125}$

Nur Personen, die über die entsprechende Legitimation verfügen, haben das Recht, den Handlungsspielraum anderer durch organisatorische Regeln einzuschränken. In der Unternehmung sind dies die Kapitaleigner oder von diesen bestimmte Personen. ${ }^{126}$ Dazu gehören Mitglieder der Unternehmungsleitung, von dieser beauftragte Stabsabteilungen und Führungskräfte in den Funktionsbereichen. Fremdorganisation impliziert somit notwendigerweise, daß diese organisatorischen Tätigkeiten von dazu legitimierten Personen ausgeführt werden. ${ }^{127} \mathrm{Im}$ Regelfall werden organisatorische Entscheidungen von hoher strategischer Bedeutung von der Unternehmungsleitung selbst getroffen. Die verbleibenden organisatorischen Aufgaben obliegen entweder einer entsprechenden Stabsabteilung bzw. den dort tätigen Organisatoren oder aber den jeweiligen Vorgesetzten in den verschiedenen Funktionsbereichen, die organisatorische Regeln bezüglich des Aufgabenfeldes ihrer Mitarbeiter als ihres spezifischen Verantwortungsbereiches formulieren. ${ }^{128}$ Aufgrund der Legitimation der gestaltenden Personen handelt es sich bei den aus Tätigkeiten der Fremdorganisation resultierenden organisatorischen Regeln stets um formale Regeln. Konstitutiv für formale organisatorische Regeln ist also die Art ihres Entstehens als Ergebnis der organisatorischen Aktivität einer dazu legitimierten, offiziell beauftragten Person. ${ }^{129}$ Wäre das organisierende Subjekt nicht entsprechend legitimiert, nähmen die menschlichen Aufgabenträger des zu organisierenden Subsystems die mit den organisatorischen Regeln einhergehenden Beschränkungen ihres Handlungsraums nicht hin.

Im Rahmen der vorliegenden Arbeit wird eine organisatorische Tätigkeit als Selbstorganisation bezeichnet, wenn die Gestaltungsaktivitäten von Personen ausgehen, die Teil des zu gestaltenden Systems und als solche von den eigenen Gestaltungsaktivitäten unmittelbar betroffen sind. ${ }^{130}$

Stellt man diese Definition von Selbstorganisation der von Fremdorganisation gegenüber, so wird deutlich, daß die Unterscheidung dieser beiden organisatorischen Tätigkeiten anhand der relativen Position des Gestalters zum zu gestaltenden System unmittelbar von der Abgrenzung des jeweiligen Systems abhängt. Betrachtet man z.B.

$125 \mathrm{Vgl}$. Kieser/Kubicek (1992), S. 22.

$126 \mathrm{Vgl}$. Kieser/Kubicek (1992), S. 19.

$127 \mathrm{Vgl}$. Hill/Fehlbaum/Ulrich (1994), S. 25.

128 Zwecks sprachlicher Vereinfachung wird im weiteren Verlauf der vorliegenden Arbeit nicht weiter zwischen der Unternehmungsleitung, den Mitgliedern der Stabsabteilung 'Organisation' und den Führungskrăften in den Funktionsbereichen unterschieden. Vielmehr wird jede mit fremdorganisatorischen Regelungskompetenzen ausgestattete Person als Organisator bzw. organisatorischer Gestalter bezeichnet.

$129 \mathrm{Vgl.} \mathrm{Kieser/Kubicek} \mathrm{(1992),} \mathrm{S.} 22$.

130 Vgl. ähnlich Kieser/Kubicek (1992), S. 468ff., und Kieser (1994), S. 218, die diesen Sachverhalt jedoch als Selbststrukturierung bezeichnen; ferner Gebhardt (1996), S. 93; Knof (1991), S. 10; Seidel (1986), S. 228. 
die gesamte Unternehmung als das zu organisierende System, so sind sämtliche organisatorischen Aktivitäten der Unternehmungsleitung, einer Stabstelle 'Organisation' sowie der Führungskräfte der verschiedenen Funktionsbereiche als Selbstorganisation zu bezeichnen, da diese Unternehmungsmitglieder und damit Teile des zu organisierenden Systems sind.131 Geht man dagegen von einzelnen Subsystemen des Gesamtsystems Unternehmung, wie z.B. Abteilungen oder Arbeitsgruppen, aus, so handelt es sich bei denselben organisatorischen Aktivitäten um Fremdorganisation.

Während der Kreis der zu organisatorischer Gestaltung legitimierten Personen beschränkt ist, kann prinzipiell jedes Mitglied der Unternehmung ${ }^{132}$ selbstorganisierend tätig werden. ${ }^{133}$ Grundsätzlich können selbstorganisatorische Tätigkeiten dabei sowohl formale als auch informale organisatorische Regeln zum Ergebnis haben. ${ }^{134}$ Sofern den Unternehmungsmitgliedern die Legitimation zur organisatorischen Tätigkeit fehlt, haben die aus Tätigkeiten der Selbstorganisation resultierenden organisatorischen Regeln inoffziellen Charakter und werden auch als informale organisatorische Regeln bezeichnet. Verfügen die selbstorganisatorische Tätigkeiten ausübenden Personen dagegen über entsprechende Regelungskompetenz, so resultieren aus den Tätigkeiten der Selbstorganisation formale organisatorische Regeln. Dies ist einerseits immer dann der Fall, wenn die Unternehmungsleitung, eine Stabstelle 'Organisation' oder Führungskräfte in den Funktionsbereichen - als zu organisatorischer Tätigkeit legitimierte Personen - organisatorische Regeln bezüglich ihres eigenen Arbeitsfeldes definieren. Andererseits besteht die Möglichkeit, daß die Organisatoren explizit Teile ihrer Befugnis zur Formulierung organisatorischer Regeln an andere Mitarbeiter weitergeben. ${ }^{135}$ Die Organisatoren legen hier dann fest, welche Bereiche der organisatorischen Regeln durch Fremd- und welche durch Selbstorganisation abzudecken sind bzw. im Rahmen der Fremdorganisation werden die Grenzen und Rahmenbedingungen potentieller Selbstorganisationsprozesse abgesteckt. Die Mitarbeiter erhalten die offizielle Befugnis zur Festlegung der ihr spezifisches Arbeitsfeld betreffenden organisatorischen Regeln. ${ }^{136}$ Sofern der für Selbstorganisation geschaffene Freiraum durch entsprechende Prozesse ausgefüllt wird, handelt es sich dann um geplante, offiziell autorisierte Selbstorganisationsprozesse.

131 So bezeichnet z.B. Probst die Organisatoren als Teil des zu organisierenden Systems. Vgl. Probst (1986), S. 396f. Probst vertritt damit eine Sichtweise, die typisch für von den Erkenntnissen der Kybernetik 2 . Ordnung geprăgte Arbeiten ist, gemåß derer der Beobachter stets Teil des zu beobachtenden Systems ist.

132 Zur Problematik der trennscharfen Abgrenzung von Unternehmungsmitgliedern und Nicht-Mitgliedern vgl. Kieser/Kubicek (1992), S. 10ff., deren Vorschlag folgend Mitgliedschaft hier auf die Bindung durch Vertrăge (insbesondere Gesellschafts- und Arbeitsverträge) und nicht auf Kapitalverflechtungen (gemäß denen auch Fremdkapitalgeber Mitglieder der Unternehmung wăren) abstellt. Vgl. Probst (1986), S. 397.

Vgl. dazu und im folgenden ähnlich Gebhardt (1996), S. 95.

Vgl. ăhnlich Knof (1992), S. 84, die jedoch formale Regeln als Ergebnis von Selbstorganisation auf den Bereich der fallweisen Regeln beschränkt und generelle organisatorische Regeln hier explizit ausschließt.

Vgl. Kieser/Kubicek (1992), S. 469ff., insbesondere S. 474. 
Abbildung 2/9 visualisiert den beschriebenen Zusammenhang zwischen Fremd- und Selbstorganisation sowie formalen und informalen organisatorischen Regeln.

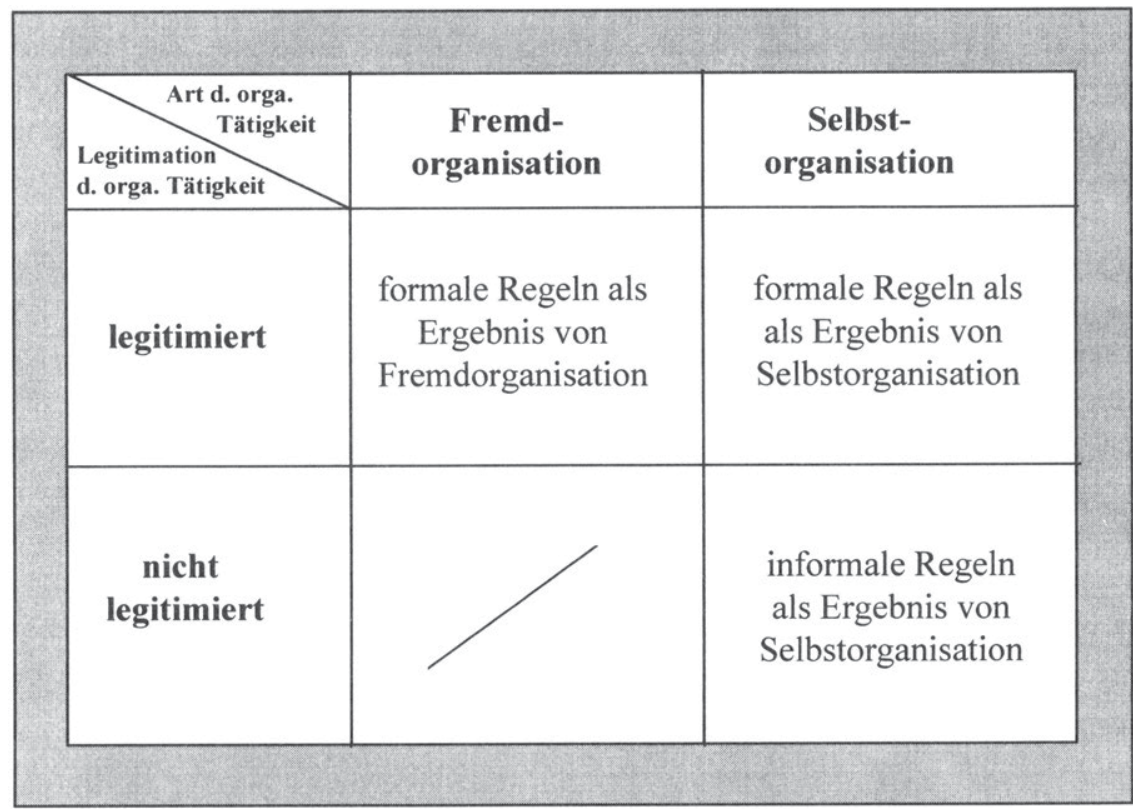

Abb. 2/9: Der Zusammenhang zwischen Fremd- und Selbstorganisation sowie formalen und informalen organisatorischen Regeln

Die Abbildung zeigt, daß die Unterscheidung zwischen Fremd- und Selbstorganisation auf der einen und die zwischen formalen und informalen Regeln auf der anderen Seite auf unterschiedlichen Systematisierungskriterien beruhen. Während fremdorganisatorische Tätigkeiten stets formale Regeln zum Ergebnis haben, können die aus Selbstorganisationsprozessen resultierenden organisatorischen Regeln sowohl formaler als auch informaler Art sein. ${ }^{137}$

\subsubsection{Das Aufgabenfeld Informationsmanagement}

Das Aufgabenfeld Informationsmanagement stellt - nach der organisatorischen Gestaltung - die zweite Managementaktivität dar, die im Rahmen der vorliegenden Arbeit unter dem Aspekt der Förderung organisationalen Lernens betrachtet wird. Zwar findet das Schlagwort 'Informationsmanagement' seit Mitte der 80er Jahre auch im deutschsprachigen Raum immer stärkere Verbreitung, ${ }^{138}$ und das Thema hat sich in der ersten

137 Für eine kritische Diskussion der Abgrenzung zwischen formalen und informalen organisatorischen Regeln vgl. Bleicher/Meyer (1976), S. 129; Grün (1980), Sp. 883; Lattmann (1975), S. 53.

138 Ursprünglich wurde der Gedanke des Informationsmanagements in den USA geprägt. Die Thematik wurde dort gegen Ende der 70er Jahre einerseits in der US-amerikanischen Bundesverwaltung andererseits in privatwirtschaftlichen amerikanischen Unternehmungen aufgegriffen und im 
Hälfte der 90er Jahre sowohl in der wissenschaftlichen Forschung als auch in der betrieblichen Praxis zu einer regelrechten Modewelle entwickelt. ${ }^{139}$ Dennoch ist die Diskussion auch heute noch von einem Nebeneinander vielfältiger, zum Teil sehr unterschiedlicher Begriffsauffassungen und entsprechender Abgrenzungen dieses Aufgabenfeldes geprägt. ${ }^{140}$ Auch fehlt vielen Arbeiten eine präzise Definition des Phänomens Informationsmanagement, so daß das exakte Begriffsverständnis häufig unklar bleibt. ${ }^{141}$ Die folgenden Ausführungen zum Informationsmanagement zielen deshalb auf die Konzeptionalisierung dieses Aufgabenfeldes ab. Dazu werden zunächst die zentralen Leitideen einiger Ansätze aus der Literatur kritisch diskutiert (Abschnitt 2.2.2.1). Die an diesen Literaturüberblick anschließenden beiden Abschnitte dienen sodann als Grundlage für die Ausarbeitung eines Zwei-Ebenen-Ansatzes des Informationsmanagements. Einerseits wird der Gegenstandsbereich (Abschnitt 2.2.2.2), andererseits werden die Funktionen des Informationsmanagements (Abschnitt 2.2.2.3) untersucht. Dabei wird jeweils zwischen einer immateriellen und einer materiellen Ebene des Informationsmanagements unterschieden. Während die Ausführungen zu den Funktionen des Informationsmanagements vergleichsweise kurz gefaßt werden können, nehmen die Ausführungen über den Gegenstandsbereich des Informationsmanagements einen relativ breiten Raum ein. Dies ist notwendig, da in der Literatur zwar weitgehend Einigkeit darüber besteht, was Management ist, nicht jedoch darüber, was genau nun im Rahmen des Informationsmanagements als eines Managementteilbereiches 'gemanaget' wird. Abschließend faßt Abschnitt 2.2.2.4 die Ergebnisse der vorangehenden Ausführungen zur Entwicklung des Zwei-Ebenen-Ansatzes des Informationsmanagements zusammen.

\subsubsection{Für die Konzeptionalisierung des Informationsmanagements relevante Ansätze in der Literatur}

Die im Rahmen der vorliegenden Arbeit verfolgte Konzeptionalisierung des Informationsmanagements steht in der Denktradition der im folgenden vorgestellten Ansätze. An erster Stelle sind dabei die Arbeiten von WoLLNIK anzuführen, der das Aufgabenfeld Informationsmanagement erstmalig mit Hilfe eines Mehr-Ebenen-Modells gliedert (Abschnitt 2.2.2.1.1). Sodann werden die mit der Entwicklung von Modellen der

wissenschaftlichen Bereich in dieser Fruhphase vor allem durch die Arbeiten von Marchand und Horton geprägt. Vgl. z.B. Marchand (1989), passim; Marchand/Horton (1986), passim. Das erste deutschsprachige Lehrbuch zu diesem Thema erschien 1987 von Heinrich/Burgholzer. Ein kurzer Überblick über die historische Entwicklung der Beschäftigung mit dem Phänomen Informationsmanagement in den USA und in Deutschland findet sich bei Streubel (1996), S. 9f.

139 Als Beispiele fur wissenschaftliche Arbeiten zum Thema Informationsmanagement seien Biethahn/Mucksch/Ruf (1994), passim, Brockhaus (1992), passim, Hildebrand (1995), passim, und Nawatzki (1994), passim, genannt. Aus der großen Fulle praxisorientierter Zeitschriftenaufsătze, die den publikumswirksamen Modebegriff 'Informationsmanagement' im Titel tragen, sei auf Angermeyer (1993), passim, Brenner/Hamm (1994), passim, Meik (1997), passim, und Reiß/Morelli (1994), passim, verwiesen.

140 Für einen kurzen Überblick uber einige Informationsmanagement-Konzeptionen vgl. Krcmar (1991), S. $177 \mathrm{ff}$; Krcmar (1997), S. 31 ff.; Seibt (1993), S. $6 \mathrm{ff}$.

141 Vgl. ăhnlich Schwarzer (1994a), S. 89. 
Informationssystem-Architektur verbundene Grundidee sowie die Vorschläge von KRCMAR und SCHEER geschildert (Abschnitt 2.2.2.1.2). Zwar werden diese in der Literatur zumeist nicht in einen logischen Zusammenhang mit dem Informationsmanagement gestellt. Dennoch bieten sie wichtige Anregungen für die Systematisierung des Aufgabenfeldes Informationsmanagement. Schließlich wird KRCMARS Verständnis des Informationsmanagements vorgestellt, das ganz wesentlich von dem von ihm entwikkelten Modell der Informationssystem-Architektur beeinflußt ist (Abschnitt 2.2.2.1.3).

Trotz einiger interessanter Grundideen ist die Anwendung dieser Ansätze im Rahmen der vorliegenden Arbeit, deren Argumentation insbesondere eine trennscharfe Abgrenzung zwischen organisatorischer Gestaltung und Informationsmanagement erfordert, mit gravierenden Nachteilen verbunden. Entsprechend eignen sie sich nicht als konzeptionelle Grundlage der folgenden Ausführungen. Vielmehr ist die Entwicklung einer eigenen Konzeption des Informationsmanagements notwendig, die die gebotenen Impulse aufgreift, gleichzeitig jedoch die mit den Ansätzen verbundenen Probleme meidet.

\subsection{Das Drei-Schichten-Modell des Informationsmanagements von WoLLNIK}

In der deutschsprachigen Wirtschaftsinformatik-Literatur stellen die Arbeiten von WOLLNIK den ersten Versuch dar, das Aufgabenfeld Informationsmanagement im Rahmen eines Mehr-Ebenen- bzw. Schichten-Modells anhand seiner Objekte und deren jeweiliger Nähe zur Informationstechnik zu systematisieren. ${ }^{142}$ Sein „Referenzmodell der technikgestützten Informationshandhabung"143 führt den in Informatik und Wirtschaftsinformatik wichtigen Schichtenbegriff in die Betrachtung des Informationsmanagements ein. Die Unterscheidung in die drei Ebenen 'Informationseinsatz', 'Informationssystem' und 'Infrastrukturen der Informationsverarbeitung' ${ }^{144}$ stellt eine Abschichtung entlang der Dimension 'Nähe zur Informationstechnik' dar. Diesen Mehrebenenzusammenhang zeigt Abbildung 2/10.

Auf der obersten Ebene bezieht sich das Informationsmanagement auf inhaltliche Fragen eines ziel- und aufgabengerechten Informationseinsatzes im Rahmen des betrieblichen Leistungserstellungsprozesses. Die zweite Ebene betrifft die Verfahren der Informationsverarbeitung, wie sie sich insbesondere in den Anwendungsprogrammen widerspiegeln. Im Mittelpunkt der dritten Ebene der Aktivitäten des Informationsmanagements steht die technische Infrastruktur. Da WoLLNIK die Anwendungsprogramme der zweiten Ebene zurechnet, muß angenommen werden, daß sein Begriff der techni-

142 Vgl. dazu und im folgenden Wollnik (1986), passim, insbesondere S. 54ff.; Wollnik (1988), passim, insbesondere S. $37 \mathrm{ff}$.

143 Wollnik (1988), S. 34

144 Im Original verwendet Wollnik die Begriffe 'Informations- und Kommunikationssystem' und 'Infrastrukturen der Informationsverarbeitung und Kommunikation', die im Rahmen der vorliegenden Arbeit aufgrund der problematischen Und-Verknüpfung von Information und Kommunikation vermieden werden sollen. Fur eine ausfuhrliche Diskussion des theoretischen Zusammenhangs zwischen Information und Kommunikation siehe Streubel (1996), S. 17ff., insbesondere S. 46. 


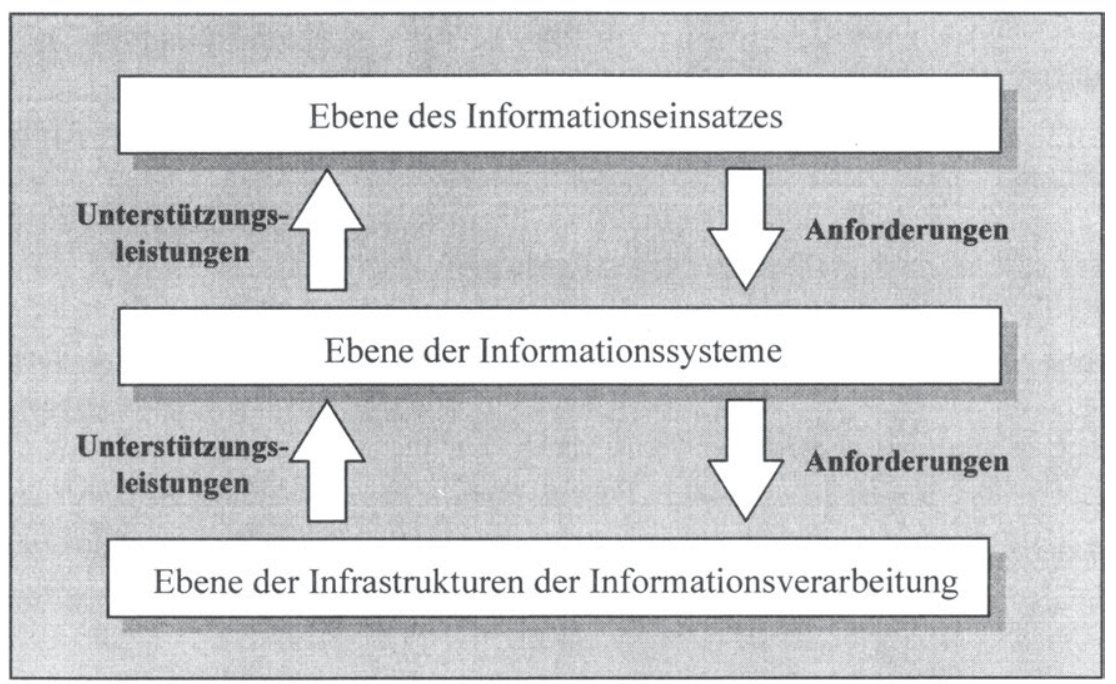

Abb. 2/10: Mehrebenenzusammenhang der technikgestützten Informationshandhabung nach WOLLNIK (in Anlehnung an Wollnik (1988), S. 38)

schen Infrastruktur diese nicht mit einbezieht, sondern auf Hardware und systemnahe Software beschränkt ist. Diese Annahme stützt auch WolLNIKS Aussage, daß die technische Infrastruktur im Gegensatz zur zweiten Ebene ein nutzungsoffenes Potential darstellt, für dessen Nutzung prinzipiell verschiedene Anwendungsmöglichkeiten in Frage kommen. ${ }^{145}$ Insgesamt sind die Ausführungen WollNIKS zur Abgrenzung der zweiten und dritten Ebene jedoch wenig präzise. ${ }^{146}$ Insbesondere weicht die von ihm gewählte Terminologie von der gängigen Literaturauffassung $a b$, wenn er die beiden Ebenen mit 'Informationssystem' und 'Infrastrukturen der Informationsverarbeitung' bezeichnet. Denn in der Literatur stellt die Informationstechnik üblicherweise ein Teilsystem des umfassenderen Informationssystems dar. Dies würde bedeuten, daß in WolLNIKS Ansatz auf der zweiten Ebene das Gesamtsystem, auf der dritten Ebene ein Teilsystem untersucht wird.

Generell ist die mangelnde Explizierung der Beziehungen zwischen den drei Ebenen in WolLNIKS Modell, die er vage mit 'Anforderungen' und 'Unterstützungsleistungen' bezeichnet, zu kritisieren. Auch bleibt offen, wie die der ersten Ebene des Informationsmanagements zuzuordnenden Aktivitäten des Managements des Informationseinsatzes von den informationsbezogenen Aktivitäten der organisatorischen Gestaltung abzugrenzen sind. Die auch von SCHWARZER und KRCMAR kritisierte fehlende Einordnung des Informationsmanagements in den Unternehmungszusammenhang bzw. die 
mangelnde Abgrenzung gegenüber anderen Managementaktivitäten erweist sich für die Argumentation der vorliegenden Arbeit als besonders problematisch. ${ }^{147}$

Trotz dieser Nachteile bietet WoLLNIKS Modell wichtige Impulse für die Konzeptionalisierung des Informationsmanagements im Rahmen der vorliegenden Arbeit. So stellt seine Grundidee der Abschichtung der Aktivitäten des Informationsmanagements entlang der Dimension 'Nähe zur Informationstechnik' den Ausgangspunkt des im folgenden entwickelten Zwei-Ebenen-Ansatzes des Informationsmanagements dar. Aufgrund der hier formulierten Kritik an WoLLNIK gilt es dabei jedoch, einerseits den Zusammenhang zwischen organisatorischen Tätigkeiten und solchen des Informationsmanagements, andererseits den zwischen den verschiedenen Ebenen des Informationsmanagements präzise herauszuarbeiten.

\subsection{Modelle der Informationssystem-Architektur}

Neben dem Informationsmanagement werden auch Informationssystem-Architekturen in der deutschsprachigen Wirtschaftsinformatik-Literatur seit Mitte der 80er Jahre verstärkt diskutiert. ${ }^{148}$ Die zeitgleiche wissenschaftliche Auseinandersetzung mit beiden Phänomenen hat jedoch nur bedingt zu deren systematischer Verknüpfung geführt. Als typische Beispiele seien hier HILDEBRAND und TULOWITZKI angeführt. HILDEBRAND stellt zu Beginn seiner Überblicksarbeit über Informationssystem-Architekturen lediglich fest, daß diese eine zentrale Rolle im Informationsmanagement einnehmen, ohne diese zu konkretisieren. Im weiteren Verlauf seiner Ausführungen erwähnt er das Informationsmanagement dann nicht mehr. ${ }^{149}$ Dagegen definiert TULOwITZKI die Planung der Informationsinfrastruktur, die er in Daten-, Anwendungssystem- und Hardware-Architekturen untergliedert, zwar als Aufgabe des strategischen Informationsmanagements. Eine systematische Einordnung in die Gesamtheit der Informationsmanagement-Aufgaben erfolgt allerdings auch hier nicht. ${ }^{150}$ Teilweise findet der Begriff des Informationsmanagements im Rahmen von Arbeiten über InformationssystemArchitekturen aber auch keinerlei Erwähnung. Eine Ausnahme stellt hier KRCMARS Lehrbuch zum Informationsmanagement dar. Sein Überblick über verschiedene Konzepte des Informationsmanagements beinhaltet neben Ebenenmodellen sowie problemund aufgabenorientierten Ansätzen auch Architekturmodelle. ${ }^{151}$

147 Für eine kritische Würdigung des Informationsmanagement-Ansatzes von Wollnik vgl. Krcmar (1991), S. 180, 187, 190; Schwarzer (1994a), S. 109.

148 Einen Überblick über die Literatur der 80er Jahre zum Thema 'Informationssystem-Architektur' geben Hasenkamp/Syring (1990), passim.

149 Vgl. Hildebrand (1993), passim, insbesondere S. 74.

150 Vgl. Tulowitzki (1991), passim, insbesondere S. 94 und 99.

151 Vgl. Krcmar (1997), S. $31 \mathrm{ff}$. Als weitere Ausnahme sei hier auf den St. Galler Ansatz des Informationssystem-Managements verwiesen, der zwischen den funf Ebenen Informationssystem-Konzept, Architektur, Informationssystem-Projektportfolio, -Projekt und -Betreuung unterscheidet. Zwar werden auf der Architektur-Ebene einige Teilarchitekturen betrachtet. Die Darstellung ist hier jedoch von einer Fülle von Detailbetrachtungen geprägt. Der Gesamtzusammenhang wird dagegen nicht ausreichend konzeptionalisiert. Dies gilt insbesondere auch für den explizit erwähnten $\mathrm{Zu}$ - 
In der Wirtschaftsinformatik besteht zwar keine generelle Einigkeit bezüglich der inhaltlichen Abgrenzung des Begriffes 'Architektur'. Sieht man von Abweichungen im Detail ab, verweist die Verwendung des Architekturbegriffes jedoch regelmäßig auf eine von Einzelheiten abstrahierende Gesamtsicht, auf Strukturbezogenheit (im Sinne der relativen Positionierung von Elementen zueinander aufgrund des zwischen ihnen existierenden Beziehungsgefüges anstelle der exakten Beschreibung der Elemente selbst) und auf planerische Aspekte. ${ }^{152}$ KRCMAR bezeichnet die InformationssystemArchitektur deshalb auch als 'Generalbebauungsplan'.153 Das von technischen Details abstrahierende Verständnis des Architekturbegriffes wird in der folgenden Formulierung von SMITH besonders deutlich: „Computer architecture concentrates on the logical aspects of computer design as opposed to physical or electronic aspects."154 Diese Abstraktion von technischen Details gewährleistet insbesondere, daß die Architektur über einen längeren Zeitraum hinweg erhalten bleibt und damit für Stabilität sorgt, gleichzeitig auf der Ebene der technischen Details jedoch ausreichend Flexibilität für Veränderungen besteht.

Ein so verstandener Architekturbegriff kann sich in der Wirtschaftsinformatik auf sehr unterschiedliche Objekte beziehen. In der Literatur finden sich z.B. Ausführungen zur Informations-, Informationssystem-, Informationstechnik-, Anwendungs-, System-, Rechner-, Daten-, Kommunikations-, Funktions- oder Netzarchitektur. ${ }^{155}$ Dabei variiert der Grad der mit der Fokussierung von Architekturen verbundenen Abstraktion in Abhängigkeit von den jeweils betrachteten Objekten. Der bei der Verwendung von Begriffen wie Informations- oder Informationssystemarchitektur regelmäßig verfolgten gesamthaften - und entsprechend stark abstrahierenden - Perspektive steht die mit Begriffen wie Daten- oder Netzarchitektur verbundene Beschränkung auf Teilaspekte gegenüber.

Charakteristisch für Architekturmodelle ist die Unterscheidung in eine Gesamtsicht und verschiedene Teilsichten. Ausgehend von der - je nach verwendeter Begriffsabgrenzung - Architektur des Informationssystems oder der Informationstechnik als Ganzem, werden in einem oder mehreren Schritten verschiedene Teilarchitekturen bzw. Sichten

sammenhang zwischen organisatorischer Gestaltung und Informations(system)management. Im Rahmen der vorliegenden Arbeit soll der St. Galler Ansatz deshalb nicht weiter berlicksichtigt werden. Vgl. Österle/Brenner/Hilbers (1991), passim, insbesondere S. 40ff., 46ff., 109ff. Eine ăhnliche Kritik an Österle/Brenner/Hilbers ubt Schwarzer (1994a), S. $116 \mathrm{f}$.

152 Vgl. Hildebrand (1993), S. 74ff.; Krcmar (1990), S. 395ff.; Scheer (1998), S. 1ff. Die Strukturbezogenheit des Architekturbegriffes wird immer dann besonders deutlich, wenn dieser als Synonym für Infrastruktur verwendet wird. Auf die Möglichkeit dieser synonymen Verwendung von Architekturund Infrastrukturbegriff verweist Krcmar (1990), S. 397. Dagegen definiert z.B. Schöne (1997), S. 14f., den Begriff der Informationsinfrastruktur ohne besondere Betonung der strukturellen Aspekte.

153 Vgl. Krcmar (1990), S. 395.

154 Smith (1989), S. 277. Eigene Hervorhebungen.

155 Vgl. Hildebrand (1992), S. 8ff.; Krcmar (1990), S. 395ff.; Mertens (1997a), S. 22; Seibt (1990), S. 13f.; Tulowitzki (1991), S. $94 \mathrm{ff}$. 
ausdifferenziert. ${ }^{156}$ Die Abgrenzung der verschiedenen Teilarchitekturen hängt unmittelbar von dem jeweils verfolgten Gestaltungsinteresse ab. Vom Grundprinzip her entspricht dieses Vorgehen der Herangehensweise systemtheoretischer Ansätze bei der Zerlegung eines Systems in Subsysteme bzw. Elemente. Im folgenden werden mit den Architekturmodellen von KRCMAR und SCHEER zwei typische Ansätze vorgestellt.

Ursprünglich entwickelte KRCMAR sein Architekturmodell ohne direkten Bezug zum Informationsmanagement. ${ }^{157}$ Seine Ausführungen über „Bedeutung und Ziele von Informationssystem-Architekturen" 158 sind vielmehr im Zusammenhang der allgemeinen Diskussion um Informationssystem-Architekturen zu sehen. Deshalb soll hier zunächst sein Architekturmodell vorgestellt werden, bevor in Abschnitt 2.2.2.1.3 KRCMARS auf diesem aufsetzender Ansatz des Informationsmanagements vorgestellt wird.

Abbildung 2/11 zeigt, daß KRCMAR für die Darstellung seines 'Ganzheitlichen Modells der Informationssystem-Architektur' die Form des Kreisels wählt. Das Bild des Kreisels verweist darauf, daß die Abstimmung der unterschiedlichen Schichten und Sichten der Informationssystem-Architektur im Sinne des Ausbalancierens aller Teile eines Kreisels von großer Bedeutung ist. 159

Die erste Schicht der Informationssystem-Architektur enthält Elemente des in der Geschäftsstrategie entwickelten Unternehmungszielsystems. Aufgrund der wechselseitigen Beeinflussung zwischen Geschäftsstrategie und allen anderen Schichten des Modells ${ }^{160}$ durchzieht sie in der grafischen Darstellung den gesamten Kreisel. Dieses explizite Einbeziehen der Geschäftsstrategie unterscheidet KRCMARS Modell einer Informationssystem-Architektur von den Ansätzen der meisten anderen Autoren.

Die zweite Schicht der Informationssystem-Architektur bezeichnet KRCMAR als organisatorische und unterscheidet zwischen Prozeß- und Aufbauorganisation. Diese werden hier zwar als zwei unterschiedliche Sichten dargestellt, in der betrieblichen Praxis sind sie jedoch regelmäßig eng miteinander verknüpft.

Der dritten Schicht werden - in Anlehnung an das von ZaCHMAN entwickelte Architekturmodell ${ }^{161}$ - die Anwendungs-, die Daten- und die Kommunikationsarchitektur zugeordnet. Während die Anwendungsarchitektur Funktionen und die Kommunikationsarchitektur die logische Dimension der Informationsflüsse beschreibt und beide dabei

156 Vgl. z.B. Österle/Brenner/Hilbers (1991), S. 41f., 109ff.; Tulowitzki (1991), S. 94ff.; Zachman (1987), S. 276ff.

157 In seinem grundlegenden Aufsatz von 1990 in einem dem Themenschwerpunkt 'InformationssystemArchitekturen' gewidmeten Heft der Zeitschrift Wirtschaftsinformatik verwendet Krcmar den auch damals schon sehr populären Begriff des Informationsmanagements nicht. Vgl. Krcmar (1990), passim.

158 So lautet der Titel seines Aufsatzes. Vgl. Krcmar (1990), S. 395.

159 Vgl. dazu und im folgenden Krcmar (1990), S. 399f.

160 Einerseits ist die Geschäftsstrategie handlungsleitend für die Gestaltungshandlungen innerhalb jeder der Schichten des Modells, andererseits können von diesen Impulse an die Gestaltung der Geschätsstrategie ausgehen.

161 Fur eine ausfuhrliche Darstellung von Zachmans Architekturmodell vgl. Zachman (1987), passim. 
eine dynamische Perspektive verfolgen, gibt die Datenarchitektur den statischen Zusammenhang zwischen den Daten in der Unternehmung wieder. ${ }^{162}$

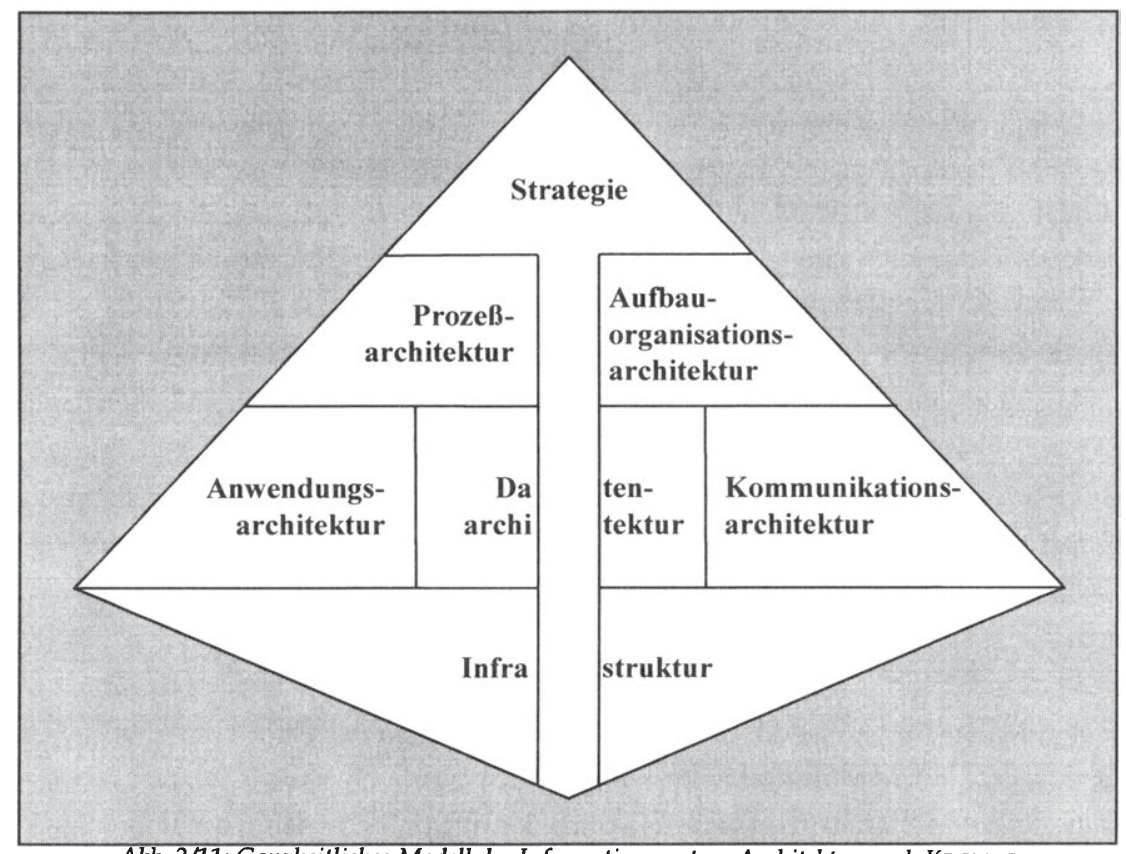

Abb. 2/11: Ganzheitliches Modell der Informationssystem-Architektur nach KRCMAR (Quelle: Krcmar (1990), S. 399)

Die vierte Schicht der Informationssystem-Architektur fokussiert die Infrastruktur. Als Infrastruktur bezeichnet KRCMAR dabei die Architektur der in der Unternehmung genutzten Informationstechnologie. ${ }^{163}$ Aufgrund der Offenheit des Begriffes der Informationstechnologie bei KRCMAR, ${ }^{164}$ der neben der Hardware auch jegliche Software umfaßt, kann die Gesamtheit aller Softwarearchitekturen der vierten Schicht zugerechnet werden. Prinzipiell ist jedoch auch denkbar, daß die Architektur der Anwendungssoftware im Rahmen der Ausführungen zur Anwendungsarchitektur der dritten Schicht zugeordnet wird. Zur Vermeidung von Überlappungen der dritten und der vierten Schicht könnte die vierte Schicht dann auf Hardware und systemnahe Software begrenzt werden. Die diesbezüglichen Ausführungen von KRCMAR sind jedoch wenig präzise, so daß keine exakte Abgrenzung zwischen der dritten und der vierten Schicht möglich ist.

162 Obwohl es theoretisch denkbar wäre, auf eine eigenstăndige Darstellung der Kommunikationsarchitektur zu verzichten, da die diesbezulglichen Aussagen unmittelbar aus der Anwendungs- und der Datenarchitektur abgeleitet werden könten, betont Krcmar die Wichtigkeit der gesonderten Betrachtung der Kommunikationsarchitektur. Vgl. Krcmar (1990), S. 400.

163 Konkret formuliert er: „Auf der vierten Schicht beschreibt die Technologie-Architektur, welche IKT [Informations- und Kommunikationstechnologie, die Verfasserin] wo im Unternehmen benutzt wird." Krcmar (1997), S. 40.

$164 \mathrm{Vgl}$. Krcmar (1997), S. 31. 
Darüber hinaus ist zu kritisieren, daß KRCMAR zwar die Abstimmung aller Schichten seines Architekturmodells fordert, jedoch keine Aussagen zur Art und Weise dieser Abstimmung trifft. ${ }^{165}$ Dies erweist sich aus der Sicht der vorliegenden Arbeit als besonders problematisch, da der Schwerpunkt der Betrachtung hier gerade auf dem Aufzeigen des Zusammenhangs zwischen der reinen Technikgestaltung und den nicht-technischen Aufgaben des Informationsmanagements sowie der organisatorischen Gestaltung liegt.

Ein weiterer Kritikpunkt betrifft die Einbeziehung der Geschäftsstrategie in die Informationssystem-Architektur. Es bleibt unklar, ob KRCMAR die gesamte allgemeine Unternehmungsstrategie der Informationssystem-Architektur zurechnet oder sich auf die Informationsstrategie als dem für das Informationsmanagement unmittelbar relevanten Teilaspekt ${ }^{166}$ beschränkt. Für erstere Sicht spricht neben der gängigen Verwendung des Begriffes der Geschäftsstrategie in der Literatur, daß KRCMAR sich in diesem Zusammenhang explizit auf den Ansatz eines Enterprise-wide Information Management nach BENSON/PARKER bezieht, die die Beeinflussung der allgemeinen Unternehmungsstrategie durch die Informationstechnologie thematisieren. ${ }^{167}$ Auch formuliert er an einer Stelle „begründet ... die explizite Aufnahme der Geschäftsstrategie in eine Informationssystemarchitektur"168 und beschränkt sich dort nicht - wie an anderer Stelle - auf einige „Elemente der Geschäftsstrategie“169. Geht man davon aus, daß KRCMAR jeden einzelnen der Teile seines Kreiselmodells als Teilarchitektur des Informationssystems als Ganzem versteht, so erweist sich das Einbeziehen der gesamten allgemeinen Unternehmungsstrategie (und nicht nur der Informationsstrategie) als höchst problematisch, da sie dann Teil des Informationssystems ist. Damit kann KRCMARS Architekturmodell nicht als Grundlage der Abgrenzung des Aufgabenfeldes Informationsmanagement verwendet werden. Hier muß KRCMARS Argumentation widersprochen werden, daß die Einbeziehung der Geschäftsstrategie in die Informationssystem-Architektur aus systemtheoretischer Sicht notwendig sei. ${ }^{170}$ Denn ein die Gestaltung eines Systems prägender Einflußfaktor muß nicht Teil dieses Systems sein. Somit würde die Beschränkung der Betrachtung auf die Informationsstrategie die theoretisch weniger problematische Interpretation des Strategiebegriffes in KRCMARS Modell darstellen. Allerdings erweist sich diese Sicht für die Einbettung der Gestaltung der Informationssystem-Architektur in den betrieblichen Gesamtzusammenhang als unzureichend, da die Art des Zusammenhangs zwischen Informations- und allgemeiner Unternehmungsstrategie von KRCMAR nicht thematisiert wird.

\footnotetext{
165 Für eine ăhnliche Kritik vgl. Schwarzer (1994a), S. 114.

166 Zum Begriff der Informationsstrategie vgl. Beier/Gabriel/Streubel (1997), S. 27f.

$167 \mathrm{Vgl.} \mathrm{Krcmar}$ (1990), S. 399. Für eine einfuhhrende Darstellung in den Ansatz von Benson/Parker vgl. Benson/Parker (1985), passim.

$168 \operatorname{Krcmar}(1990)$, S. 399. Eigene Hervorhebung.

169 Krcmar (1990), S. 399 sowie Krcmar (1997), S. 40.

$170 \mathrm{Vgl.} \mathrm{Krcmar}$ (1990), S. 399.
} 
Der wichtigste Problempunkt, der einer Verwendung von KRCMARS Informationssystem-Architektur zur Systematisierung des Aufgabenfeldes Informationsmanagement im Rahmen der vorliegenden Arbeit entgegensteht, betrifft die zweite, organisatorische Ebene seines Modells. Bei den Aktivitäten der Gestaltung von Prozeß- und aufbauorganisatorischer Architektur handelt es sich nämlich um typische Aufgaben der organisatorischen Gestaltung, die KRCMAR hier als Gestaltung der InformationssystemArchitektur bezeichnet. Da die Thematik der vorliegenden Arbeit die trennscharfe Abgrenzung von organisatorischer Gestaltung und Informationsmanagement erfordert, kann KRCMARS Architekturmodell nicht als Grundlage für die Konzeptionalisierung des Aufgabenfeldes Informationsmanagement dienen.

Als zweites Architekturmodell soll hier das von SCHEER vorgestellt werden. Denn aufgrund seiner Umsetzung in dem computergestützten Modellierungswerkzeug ARISToolset der IDS Prof. Scheer Gesellschaft für integrierte Datenverarbeitungssysteme $\mathrm{mbH}$ und deren enger Verbindung zur SAP AG handelt es sich bei der von SCHEER entwickelten 'Architektur Integrierter Informationssysteme' (ARIS) um das z.Z. im deutschsprachigen Raum in Wissenschaft und betrieblicher Praxis bekannteste Architekturmodell. Abbildung 2/12 verdeutlicht die von SCHEER verfolgte zweidimensionale Perspektive, innerhalb derer er zwischen vier Sichten und drei Ebenen unterscheidet. Während die Organisationssicht aufbauorganisatorische Aspekte wie die Stellenbildung umfaßt, verfolgt die Funktionssicht eine an Vorgängen bzw. Funktionen ausgerichtete ablauforganisatorische Perspektive. Die Datensicht fokussiert die Abbildung von Zuständen und Ereignissen, z.B. in Form von Entity-Relationship-Modellen. Die Steuerungssicht integriert die isolierten Perspektiven von Organisations-, Funktionsund Datensicht. Jede der vier Sichten wird nach der Nähe zur Informationstechnik in die Beschreibungsebenen Fachkonzept, DV-Konzept und Implementierung gegliedert. Die drei Beschreibungsebenen können auch als Entwicklungsstufen im Sinne eines Vorgehensmodells interpretiert werden. ${ }^{171}$

Durch das explizite Einfügen der Steuerungssicht verdeutlicht ScHEER den Zusammenhang zwischen den einzelnen Teilsichten bzw. -architekturen. Die diesbezüglich oben formulierte Kritik an KRCMARS Architekturmodell gilt hier somit nicht. Jedoch bezieht auch SCHEER mit der Organisations- und der Funktionssicht zwei typischerweise der organisatorischen Gestaltung zuzurechnende Perspektiven in seine Betrachtung der Architektur integrierter Informationssysteme ein. Somit kann auch sein Architekturmodell im Rahmen der vorliegenden Arbeit nicht als Grundlage für die Konzeptionalisierung eines eindeutig von der organisatorischen Gestaltung unterscheidbaren Aufgabenfeldes Informationsmanagement verwendet werden. Zwar entwickelt SCHEER selbst einen Ansatz des Informationsmanagements, der auf seinem 


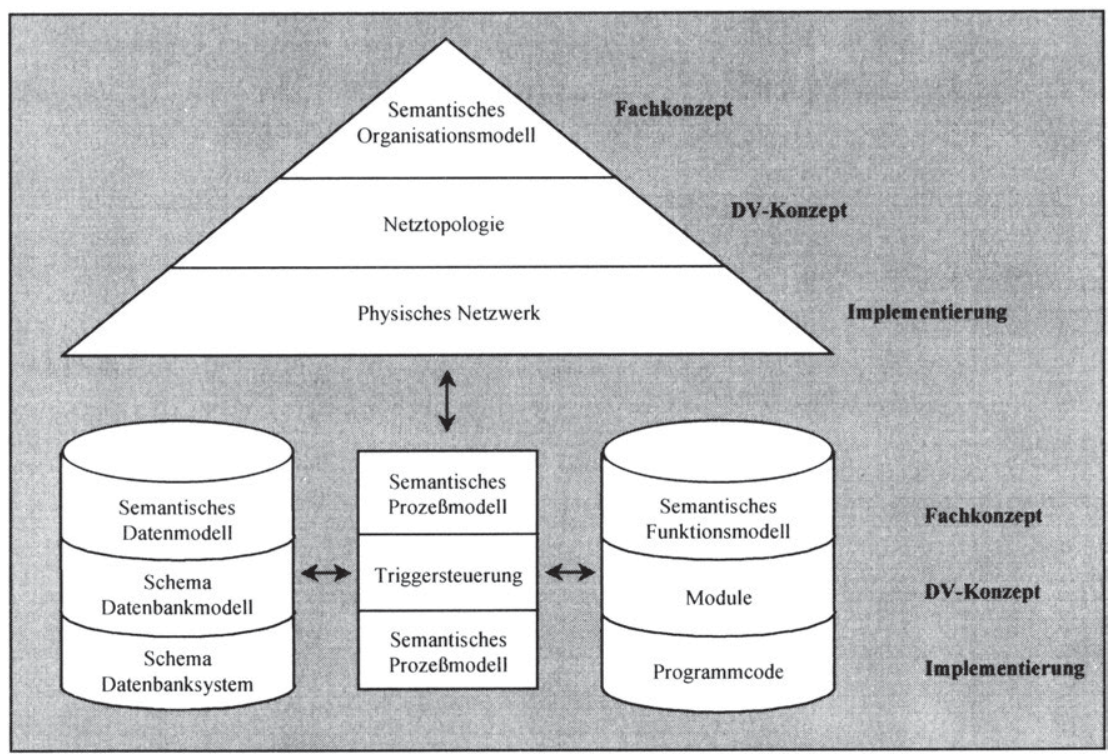

Abb. 2/12: Die Architektur integrierter Informationssysteme von SCHEER (Quelle: Scheer (1993), Sp. 401f.)

Architekturmodell und dem Drei-Schichten-Modell von WoLLNIK aufsetzt. ${ }^{172}$ Aufgrund einiger Unschärfen, ${ }^{173}$ insbesondere jedoch aufgrund der spezifischen Perspektive der vorliegenden Arbeit kann dieser jedoch nicht überzeugen und wird deshalb im folgenden nicht weiter berücksichtigt.

Trotz der genannten Kritikpunkte bieten die dargestellten Architekturmodelle wichtige Impulse für die Konzeptionalisierung des Informationsmanagements im Rahmen der vorliegenden Arbeit. Denn die Unterscheidung in eine globale Gesamtarchitektur und verschiedene Teilarchitekturen stellt prinzipiell eine Möglichkeit zur Systematisierung der auf die Gestaltung der Informationstechnik bezogenen Aktivitäten des Informationsmanagements dar. Dies setzt jedoch voraus, daß die oben angeführten Schwachpunkte überwunden werden.

\subsection{Das Modell des Informationsmanagements von KRCMAR}

In seinem 1997 erschienenen Lehrbuch entwickelt KRCMAR einen eigenen Informationsmanagement-Ansatz, in dem er die Grundgedanken seines Modells der Informations-

$172 \mathrm{Vgl}$. Scheer (1997), S. 684ff.

173 So erweist sich beispielsweise die von Scheer vorgenommene Zuordnung der Aufgaben des Informationsmanagements zu den drei von Wollnik beschriebenen Ebenen als problematisch. Z.B. weist Scheer in seinem Funktionsbaum des Informationsmanagements die Betreuung der Basissysteme der Standardanwendungssoftware dem Management der Anwendungssysteme und nicht dem der Informationsinfrastruktur zu. Ferner findet sich dort neben der Entwicklung des Fach- und DVKonzeptes zur Einfuhrung von Anwendungssystemen auch die Implementierung. Vgl. Scheer (1997), S. $684 \mathrm{ff}$. 
system-Architektur mit denen des Schichtenmodells von WOLLNIK, einer aufgabenorientierten Herangehensweise an das Informationsmanagement in der Tradition von HEINRICH ${ }^{174}$ sowie der Vorstellung von Information als Modell ${ }^{175}$ verbindet. Dabei unterscheidet er zwischen den in Abbildung 2/13 dargestellten drei Ebenen des Informationsmanagements sowie ebenenübergreifenden Aufgaben. ${ }^{176}$

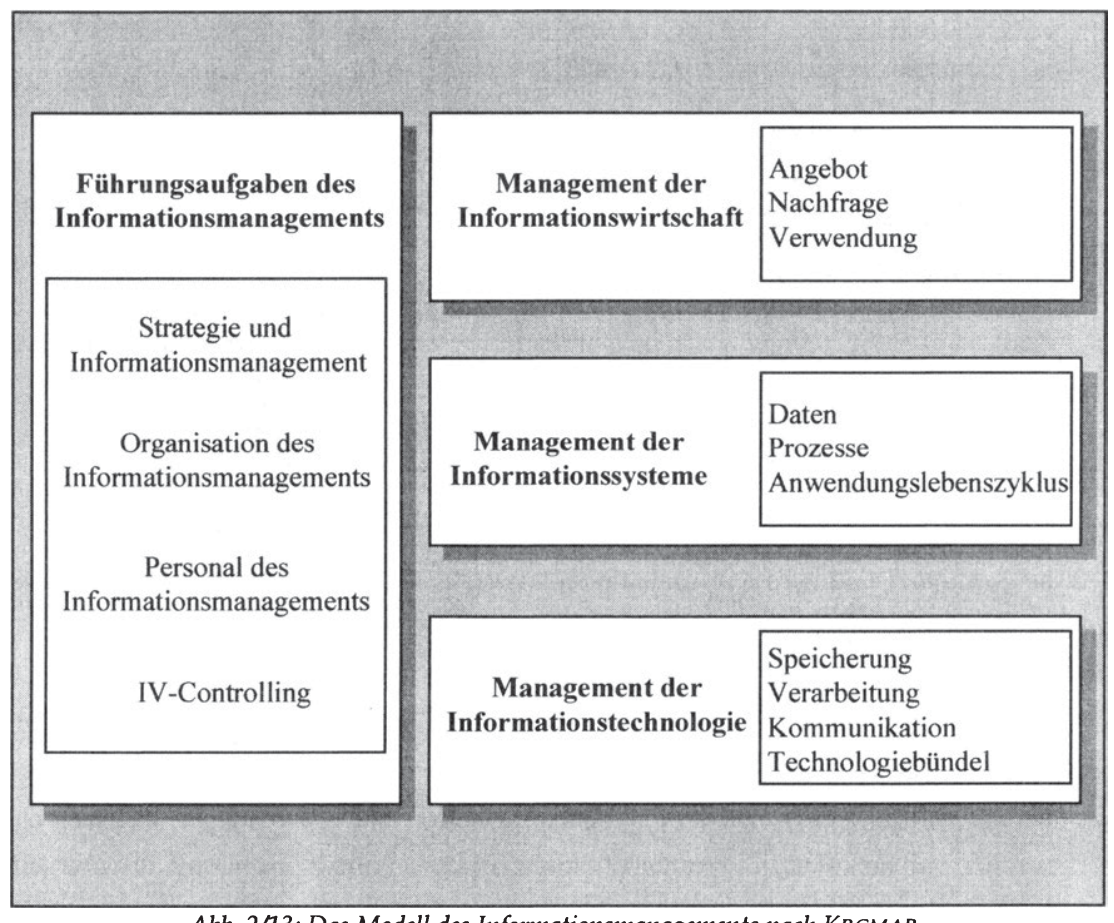

Abb. 2/13: Das Modell des Informationsmanagements nach KRCMAR

(in Anlehnung an Krcmar (1997), S. 44)

Im Mittelpunkt der Informationsmanagement-Aufgaben der obersten Ebene steht die Ressource Information bzw. ihr Einsatz als Inputfaktor des betrieblichen Leistungserstellungsprozesses. Hier wird zwischen Informationsangebot, -nachfrage und -verwen-

174 Vgl. Heinrich (1996), S. 87ff. Lange Aufgabenlisten des Informationsmanagements finden sich z.B. aber auch bei Griese (1990), S. 644, und Seibt (1990), S. 16.

175 Krcmars Verständnis von Information als Modell beruht auf den Arbeiten von Steinmuller, der Information als „,immaterielles Modell eines Originals für Zwecke eines Subjekts“ (Steinmüller (1981), S. 73) versteht. Ein Modell ist stets "Modell-wovon-wozu-für wen“ (Steinmuller (1993), S. 178), d.h. subjektrelativ (die Auswahl des Originals und der Abbildungsregeln ist auf den Erzeuger des Modells zugeschnitten), zweckrelativ (das Modell ist auf die Zwecke seines Erzeugers zugeschnitten) und perspektivisch (der Blickwinkel seines Erzeugers geht in das Modell ein). Vgl. Steinmuller (1993), S. 198ff. Krcmar entwickelt aufbauend auf diesen Grundideen ein Verständnis von Informationsmanagement als Interpretationsmanagement bzw. von Interpretation als Gegenstand des Informationsmanagements. Für eine ausfuhrliche Darstellung siehe Krcmar (1991), S. 191ff.; Krcmar (1997), S. 25ff.

176 Vgl. dazu und im folgenden Krcmar (1997), S. 43ff. 
dung unterschieden. Auf der zweiten Ebene hat das Informationsmanagement die Informationssysteme als „Systeme aufeinander abgestimmter Elemente personeller, organisatorischer und technischer Natur, die der Deckung des Informationsbedarfes dienen“177 zum Gegenstand. „Handlungsobjekt der IS-Ebene [IS=Informationssystem, die Verfasserin] sind die Anwendungen." 178 Allerdings bleibt offen, ob und wenn ja, welche Unterschiede zwischen Informationssystem und Anwendung bestehen. Innerhalb dieser Ebene unterscheidet KRCMAR dann vor allem zwischen dem Management der Daten und dem der Prozesse. Daneben stellt er hier aber auch das Management des Lebenszyklusses einer Anwendung. Die dritte Ebene umfaßt die auf die Informationstechnologie bezogenen Aufgaben des Informationsmanagements. Dabei unterscheidet KRCMAR zwischen Speicherungs-, Verarbeitungs- und Kommunikationstechnologie sowie Technologiebündeln.

Vergleicht man KrCMARS Modell des Informationsmanagements mit seinem oben beschriebenen Modell der Informationssystem-Architektur, so werden einige Parallelen, aber auch Unterschiede deutlich.

Am auffälligsten ist die Ähnlichkeit zwischen der vierten Ebene des Architekturmodells und der dritten Ebene des Modells des Informationsmanagements. Die unterste Ebene der Informationsmanagement-Aufgaben betrifft die Informationstechnologie. Die Infrastruktur als Architektur der Informationstechnologie stellt die unterste Schicht des Architekturmodells dar. Erwies sich bereits im Architekturmodell die weite Fassung des Begriffes der Informationstechnologie, die auch Anwendungssoftware umfaßt, als problematisch für eine trennscharfe Abgrenzung zwischen den untersten beiden Schichten, so gilt dasselbe nun auch für das Modell des Informationsmanagements.

Überraschend ist die unterschiedliche Einordnung der Kommunikation bzw. Kommunikationsarchitektur in beiden Modellen. War die Kommunikationsarchitektur im Architekturmodell noch auf derselben Ebene wie die Anwendungs- und die Datenarchitektur angesiedelt, so wird die Kommunikation im InformationsmanagementModell eine Ebene tiefer im Rahmen der technologiebezogenen Aufgaben behandelt. Diese unterschiedliche Einordnung verstärkt den oben erwähnten Eindruck der mangelnden Trennschärfe zwischen den untersten beiden Ebenen des Architekturmodells, der damit auch auf die untersten beiden Ebenen von KRCMARS Modell des Informationsmanagements ausgedehnt werden kann. Die von ihm selbst an WOLLNIK geübte Kritik ${ }^{179}$ läßt sich damit m.E. auch auf KRCMARS eigene Ausführungen anwenden. Nicht nur in seinem Architekturmodell, sondern auch in dem Modell des Informationsmanagements fehlt die Konzeptionalisierung des Zusammenhangs zwischen den einzelnen Schichten. In den theoretischen Ausführungen verwendet er mit 'Anforderungen' und 'Unterstützungsleistungen' dieselben vagen Formulierungen wie WoLLNIK. Aber auch

$177 \operatorname{Krcmar}(1997)$, S. 45.

178 Krcmar (1997), S. 45.

179 Vgl. Krcmar (1991), S. 180. 
im Rahmen der daran anschließenden ausführlichen Darstellung der einzelnen Ebenen wird der Zusammenhang zwischen den Ebenen nicht systematisch, sondern lediglich exemplarisch behandelt. ${ }^{180}$

Der wichtigste Kritikpunkt, der einer Verwendung des Informationsmanagement-Modells von KRCMAR im Rahmen der Thematik der vorliegenden Arbeit entgegensteht, ist auch hier wiederum die mangelnde Präzisierung des Zusammenhangs zwischen organisatorischer Gestaltung und Informationsmanagement. Dies wird einerseits auf der obersten Ebene deutlich, da Informationsangebot und -nachfrage teilweise organisatorisch bedingt sind, wie die Ausführungen in Abschnitt 2.2.1.2 der vorliegenden Arbeit zeigen. Andererseits bestehen aber auch bezüglich des Prozeßmanagements auf der zweiten Modellebene Abgrenzungsprobleme zwischen den Aktivitäten organisatorische Gestaltung und Informationsmanagement.

Insgesamt erweist sich die sehr knappe Skizzierung der theoretischen Struktur des Modells des Informationsmanagements von KRCMAR als problematisch. ${ }^{181}$ Zwar illustriert er die verschiedenen Arten von Informationsmanagement-Aufgaben anhand einer Fülle von Beispielen. Die konzeptionellen Zusammenhänge bleiben jedoch weitgehend ungeklärt. Während KRCMARS Modell des Informationsmanagements somit eine geeignete Grundlage für ein einführendes Lehrbuch zum Informationsmanagement darstellt, dessen Wert vor allem in der Fülle interessanter Beispiele aus der Unternehmungspraxis liegt, ist es als Grundlage für die Ausführungen der vorliegenden Arbeit nicht geeignet.

Trotz der genannten Kritikpunkte bietet jedoch auch KRCMARS Modell des Informationsmanagements wichtige Impulse für die Konzeptionalisierung des Informationsmanagements im Rahmen der vorliegenden Arbeit. Denn das von KRCMAR entwickelte Verständnis von Informationsmanagement reicht deutlich über die isolierte Gestaltung der Informationstechnik hinaus und bettet diese vielmehr unter Berücksichtigung betriebswirtschaftlicher Gesichtspunkte in einen umfassenderen Zusammenhang ein. Unter Vermeidung der oben angeführten Kritikpunkte - insbesondere bezüglich der mangelnden Abgrenzung zwischen den Aktivitäten organisatorische Gestaltung und Informationsmanagement - bieten die Grundideen der Arbeiten KRCMARS damit einen interessanten Ausgangspunkt für den im folgenden zu entwickelnden Zwei-EbenenAnsatz des Informationsmanagements.

\subsubsection{Der Gegenstandsbereich des Informationsmanagements}

Bereits die einfache sprachliche Zerlegung des Begriffes Informationsmanagement weist die Information als potentielles Bezugsobjekt des Informationsmanagements aus. Entsprechend stellt die Abgrenzung des Informationsbegriffes eine erste Möglichkeit dar,

\footnotetext{
$180 \mathrm{Vgl}$. Krcmar (1997), S. 43ff.

181 Die theoretische Darstellung seines Modells des informationsmanagements beschränkt sich auf zwei Textseiten. Vgl. Krcmar (1997), S. $43 \mathrm{ff}$.
} 
sich den Aufgaben des Informationsmanagements anzunähern. Als problematisch erweist sich dabei einerseits, daß der Informationsbegriff auch umgangssprachlich verwendet wird. Andererseits existieren in Betriebswirtschaftslehre und Wirtschaftsinformatik vielfältige, nicht immer exakte Begriffsabgrenzungen, die jeweils - entsprechend dem spezifischen Standpunkt und Forschungsinteresse - auf unterschiedliche Aspekte abstellen. ${ }^{182}$ Das Ziel dieses Abschnittes besteht deshalb darin, eine für die Thematik der vorliegenden Arbeit geeignete Eingrenzung des Phänomens Information vorzustellen. Dafür werden zunächst die drei Begriffe Wissen, Daten und Information, die häufig in einem ähnlichen Kontext verwendet werden, voneinander abgegrenzt (Abschnitt 2.2.2.2.1). Sodann wird die Betrachtung von Information in der Unternehmung auf deren Funktion als Inputfaktor eingeschränkt (Abschnitt 2.2.2.2.2). Somit ist nur eine bestimmte Teilmenge der Informationen in der Unternehmung Gegenstand des Informationsmanagements. Schließlich wird aufgezeigt, daß Information als potentielles Bezugsobjekt des Informationsmanagements sowohl auf der immateriellen als auch auf der materiellen Ebene zu untersuchen ist (Abschnitt 2.2.2.2.3). Daraus resultiert, daß der Gegenstandsbereich des Informationsmanagements über die Information als immaterielles Phänomen hinaus auf das computergestützte Informationssystem mit seinen immateriellen und materiellen Elementen und Beziehungen ausgedehnt werden muß (Abschnitt 2.2.2.2.4).

\subsection{Abgrenzung von Wissen, Daten und Information}

Die Definition von Information erfordert die Abgrenzung dieses Begriffes von den Begriffen Wissen und Daten, da die drei Termini häufig in einem ähnlichen Zusammenhang verwendet werden, jedoch auf unterschiedliche Phänomene abstellen. Als Systematisierungshilfe wird hier auf die Erkenntnisse der Semiotik als allgemeiner Sprach- bzw. Zeichentheorie zurückgegriffen, die zwischen den drei Ebenen Syntaktik, Semantik und Pragmatik unterscheidet. Die Syntaktik beschäftigt sich mit sprachlichen Zeichen (Wörter, Sätze) und deren Verknüpfungen, wobei allein auf die (formalen) Regeln zur Kombination dieser Zeichen abgestellt wird. Die Semantik thematisiert die Beziehungen zwischen dem sprachlichen Zeichen und dem bezeichneten realen Objekt bzw. dem Zeichen und seiner inhaltlichen Bedeutung. Gegenstand der Pragmatik sind schließlich die Beziehungen zwischen Zeichen und ihren Benutzern, d.h. die Zweckorientierung der verwendeten Sprachelemente. ${ }^{183}$

Wissen bildet den Ausgangspunkt der Betrachtung bzw. die Grundgesamtheit und sei hier definiert als die Wahrnehmungen, Erfahrungen und Kenntnisse über die Realität des Menschen und damit über Sachverhalte, Personen, Normen, Werte und Handlun-

182 Einen Überblick über die Vielfalt möglicher Abgrenzungen des Informationsbegriffes geben z.B. Krcmar (1991), S. 168ff.; Lehner/Maier (1994), S. 2ff.; Streubel (1996), S. $17 \mathrm{ff}$.

183 Vgl. Bode (1997), S. 451f.; Lehner/Maier (1994), S. $10 f$. 
gen. ${ }^{184}$ In seiner Entstehung ist Wissen unmittelbar an den Menschen gebunden. Einmal entstanden, kann es jedoch auch unabhängig und außerhalb vom Menschen als Wissensträger existieren. ${ }^{185}$ Unmittelbar an den Menschen gebunden ist Wissen als psychische Kategorie, die das Bewußtsein bestimmter Denkinhalte umfaßt. ${ }^{186}$ Außerhalb des und unabhängig vom einzelnen Menschen liegt Wissen z.B. in Form schriftlicher Dokumente vor. Der Wissensbegriff kann prinzipiell auf allen drei genannten Ebenen der Semiotik untersucht werden, wobei für die folgende Abgrenzung der Begriffe Information und Daten lediglich die syntaktische und die pragmatische Ebene relevant sind.

Auf der syntaktischen Ebene kann zwischen Wissen in maschinenverarbeitbarer (Daten) und nicht maschinenverarbeitbarer Form unterschieden werden. Konstitutives Charakteristikum des hier verwendeten Datenbegriffs ist demnach die unmittelbare Maschinenverarbeitbarkeit in Bezug auf eine bestimmte Informationstechnik, der keinerlei zusätzliche Umsetzungs- und Codierungsprozesse mehr vorausgehen müssen. ${ }^{187}$ Wissen wird dabei zunächst in Begriffe gefaßt und sodann in Symbole übertragen, die vom Computer als symbolverarbeitendem System verstanden werden. ${ }^{188}$ Ziel dieses Prozesses der Formalisierung muß es sein, formale Strukturen zu finden, die sowohl für die Repräsentation des Wissens als dessen statischen Aspekt als auch für dessen Manipulation als dynamische Dimension angemessen sind. ${ }^{189}$

Problematisch für die Abgrenzung von Daten und nicht maschinenverarbeitbarem Wissen ist, daß der bei der Informationstechnik zu beobachtende Fortschritt dazu geführt hat, daß die Anforderungen an die Formalisierung des Wissens zwecks maschineller Datenverarbeitung so sehr gesunken sind, daß fast alles Wissen prinzipiell auch maschinenverarbeitbar ist. So erlauben z.B. Scanner die Erfassung von geschriebenem Fließtext. Gerüche können über Sensoren erfaßt werden. Spracherfassungssysteme ermöglichen die Erfassung gesprochener Sprache. Diese und ähnliche Entwicklungen verschieben die Grenzen zwischen Maschinenverarbeitbarkeit und Nicht-Maschinenverarbeitbarkeit. Die Menge des grundsätzlich nicht maschinenverarbeitbaren Wissens

184 Vgl. Hesse et al. (1994), S. 42; Kluwe (1995), S. 219. Im Gegensatz dazu stellen engere Begriffsabgrenzungen, wie z.B. die von Bell, auf das Geordnetsein, die Vernünftigkeit und experimentelle Ûberprufbarkeit des Wissens ab. Vgl. Bell (1985), S. 180. Aber auch die vergleichsweise weite, offene Begriffsfassung von Segler, auf die Arbeiten zum organisationalen Lernen hăufig Bezug nehmen, erweist sich als problematisch, da Segler Wissen unmittelbar uber seine Verwendung definiert. Vgl. Segler (1985), S. 138. Im Rahmen der vorliegenden Arbeit soll Wissen dagegen als unabhängig von seiner tatsăchlichen Verwendung vorhanden definiert werden.

185 Somit wird Wissen hier nicht, wie z.B. bei Berthel oder Wild, allein als psychischer Zustand des Menschen definiert. Vgl. Berthel (1975), S. 13; Wild (1982), S. 119.

186 Vgl. Hesse et al. (1994), S. $41 \mathrm{f}$.

187 Konstitutiv fur den Datenbegriff ist damit das Potential der Daten zur Maschinenverarbeitbarkeit und nicht erst die tatsächlich vorgenommene Verarbeitung.

$188 \mathrm{Vgl}$. Albrecht (1993), S. 173ff. Dabei repräsentieren die Begriffe ein abstraktes Abbild der realen Welt, das wiederum durch Symbole dargestellt wird.

189 Vgl. Kleinhans (1989), S. 2. 
wird damit immer kleiner. ${ }^{190}$ Im Rahmen dieser Arbeit wird jedoch bei der Unterscheidung zwischen Maschinenverarbeitbarkeit und Nicht-Maschinenverarbeitbarkeit nicht auf die Gesamtheit der heute grundsätzlich am Markt verfügbaren Technik, sondern auf die im konkreten Einzelfall jeweils relevante Technik abgestellt. Der Datenbegriff wird im folgenden also nicht absolut, sondern relativ (zu einer bestimmten Informationstechnik) definiert. So stellen z.B. geschriebene Fließtexte für Scanner Daten dar, wohingegen gesprochene Sprache nicht unmittelbar mit Scannern verarbeitbar ist und deshalb diesbezüglich keine Daten darstellt, obwohl heute grundsätzlich technische Systeme zur Spracherkennung verfügbar sind.

Auf der pragmatischen Ebene kann zwischen zweckorientiertem Wissen (Information) und nicht-zweckorientiertem Wissen unterschieden werden. Der Informationsbegriff orientiert sich damit - wie heute in der Betriebswirtschaftslehre allgemein üblich ${ }^{191}$ - an der Definition WITTMANNS, der Information als zweckorientiertes Wissen bezeichnet. ${ }^{192}$ Dabei liegt der Zweck in der Vorbereitung von Entscheidungen und Handlungen, ${ }^{193}$ was den unmittelbar subjektbezogenen Charakter des Informationsbegriffs verdeutlicht. Information verbessert den Erkenntnisstand des Menschen als des Subjektes über ein Objekt und ermöglicht ihm dadurch insbesondere, einen Beitrag im Rahmen des betrieblichen Leistungserstellungsprozesses zu erbringen. Unerheblich ist, ob das Subjekt die Information tatsächlich zur Verbesserung seiner Entscheidungsgrundlage verwendet oder nicht. Entscheidend ist lediglich die potentielle Eignung bzw. Einsetzbarkeit der Information zur Unterstützung bei einer bestimmten Teilaufgabenerfüllung. 194

Zusammenfassend gilt, daß die Gesamtmenge des Wissens einerseits in Daten und Nicht-Daten, andererseits in Informationen und Nicht-Informationen unterschieden werden kann. Die Unterscheidung von Daten und Informationen basiert somit auf unterschiedlichen Systematisierungskriterien. Daten und Informationen stellen also keine disjunkten Teilmengen der Gesamtmenge des Wissens dar. Vielmehr kann Wissen sowohl Information als auch Datum sein. Dies gilt immer dann, wenn Wissen sowohl bezüglich einer spezifischen Informationstechnik - als maschinell verarbeitbar als auch bezüglich eines spezifischen Zweckes - als zweckgeeignet identifiziert werden kann. Diesen Umstand visualisiert Abbildung 2/14.

190 Beispiele für grundsătzlich nicht maschinenverarbeitbares Wissen sind Gefühle wie Angst, Glück, Liebe oder $\mathrm{Haß}$.

191 Vgl. z.B. Berthel (1992), Sp. 872; Gemunden (1993), Sp. 1725.

192 Vgl. Wittmann (1959), S. 14f.

193 Mag schildert den Zusammenhang zwischen Informationen, Handlungen und Entscheidungen folgendermaßen: „Da Unternehmungszwecke durch ökonomische Handlungen erfullt, diese wiederum durch Entscheidungen verursacht und eingeleitet werden, beziehen sich Informationen immer auf eine konkrete Entscheidungssituation und auf ein Entscheidungssubjekt, das für die Entscheidung Informationen benötigt.“ Mag (1975), Sp. 1884.

194 Vgl. Gemünden (1993), Sp. 1725; Hahn/Laßmann (1993), S. 3. 


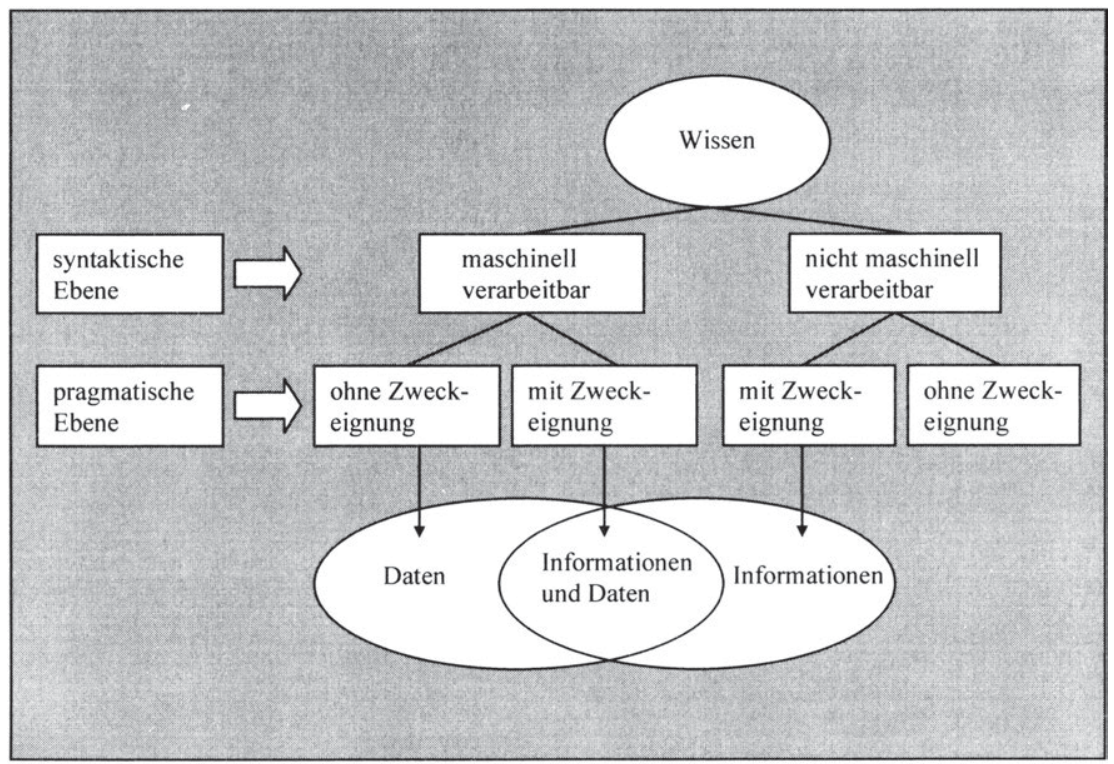

Abb. 2/14: Wissen, Daten und Information

Aufbauend auf der vorangehenden Unterscheidung von Information und Daten kann zwischen den Begriffen Daten- und Informationsverarbeitung unterschieden werden. Datenverarbeitung ist dann der technische, von der inhaltlichen Bedeutung der Daten unabhängige Prozeß. Der Bedeutungsgehalt der Daten ist nicht Gegenstand der Datenverarbeitung. Dagegen ist Informationsverarbeitung subjektbezogen und liegt immer dann vor, wenn Menschen Wissen zur Vorbereitung von Entscheidungen und Handlungen verwenden. Dabei kann zwischen einem engen und einem weiten Begriff der Informationsverarbeitung unterschieden werden. Informationsverarbeitung i.e.S. stellt allein auf die kognitiven Prozesse des Menschen ab. Informationsverarbeitung i.w.S. schließt hingegen neben diesen kognitiven Prozessen auch die ausführenden, technikgestützten Aktivitäten der Informations- bzw. Datengewinnung, -manipulation, -speicherung und -übertragung ein, die auch als Datenverarbeitung bezeichnet werden. Die Subsumtion des Begriffes der Datenverarbeitung unter den der Informationsverarbeitung i.w.S. geht davon aus, daß alle Daten in der Unternehmung zweckorientiert sind und damit auch Informationen darstellen. Datenverarbeitung ist dann immer auch Informationsverarbeitung. Umgekehrt ist jedoch nicht jede Art der Informationsverarbeitung notwendigerweise auch Datenverarbeitung. Im Gegensatz zu dem rein technisch ausgerichteten Begriff der Datenverarbeitung ist der weite Begriff der Informationsverarbeitung durch die Einbeziehung des Menschen und des von ihm verfolgten Zweckes (als dem spezifischen Verwendungszusammenhang der Information) somit umfassender ausgerichtet. Das in der Vergangenheit in Literatur und betrieblicher Praxis zu beobachtende Ersetzen des Begriffes der Daten (verarbeitung) durch den der Information (sverarbeitung) verweist auf eine Ablösung der früheren Technik- 
orientierung durch eine umfassendere Sicht auf die technische Unterstützung der Mitglieder der Unternehmung bei ihren Entscheidungen und Handlungen. 195 Entsprechend ist auch das Verständnis der vorliegenden Arbeit bezüglich des Aufgabenfeldes Informationsmanagement angelegt: Nicht die reine Technikgestaltung steht im Mittelpunkt der folgenden Ausführungen, sondern der Einsatz der Technik zur Lösung betriebswirtschaftlicher Problemstellungen.

\subsection{Information als In- und Output des betrieblichen Leistungserstellungs- prozesses}

Information als zweckorientiertes Wissen kann in der Unternehmung grundsätzlich in zwei verschiedenen Funktionen auftreten: Einerseits kann Information Input des betrieblichen Leistungserstellungsprozesses sein und damit die Funktion eines Produktionsfaktors bzw. einer Ressource erfüllen. Andererseits kann Information Output desselben sein und stellt dann einen Produktteil dar. ${ }^{196}$ Auch wenn die Autoren i.d.R. nicht explizit auf diese Unterscheidung Bezug nehmen, läßt sich die Literatur zum Thema Informationsmanagement danach ordnen, ob einer der beiden Aspekte bei der Betrachtung der Bedeutung von Information in der Unternehmung im Vordergrund steht oder ob beide Blickwinkel verfolgt werden.

Insbesondere Veröffentlichungen aus den 80er Jahren fokussieren Information als Produktteil. Im Mittelpunkt stehen dort sogenannte 'intelligente' Produkte, die vom intensiven Einsatz ausgefeilter informationstechnologischer Komponenten geprägt sind. Oder aber Informationen werden zu neuen Produkten gebündelt und eigenständig am Markt angeboten. Somit ist die Information hier wichtiger Teil des abzusetzenden Produktes oder sie tritt als eigenständiges Zusatzprodukt neben das bisherige Produkt. Entsprechend beschwören diese Veröffentlichungen häufig die 'Informationsgesellschaft', in der Information 'strategische Waffe' sei. 197 Ein Beispiel stellen elektronische Kontrollsysteme in Geschirrspülmaschinen und Autos dar. Als ein weiteres Beispiel sei auf einen Textilmaschinenhersteller verwiesen, der seinen Kunden neben Spinnereianlagen auch die Kalkulation deren laufender Betriebskosten als Zusatzprodukt anbietet. ${ }^{198}$

Andere Veröffentlichungen stellen dagegen Information als Ressource in den Mittelpunkt. 199 Sie knüpfen damit an frühe US-amerikanische Untersuchungen an, die

195 Analog konstatieren Boaden/Lockett (1991), S. 25, für den englischsprachigen Raum, daß dort der ursprüngliche Begriff des 'data processing' bzw. 'electronic data processing' mehr und mehr durch die Begriffe 'information technology' sowie 'information systems' abgelöst wird.

196 Vgl. Bode (1997), S. 449; Schüler (1989), S. $181 \mathrm{ff}$.

197 Vgl. z.B. Mertens/Plattfaut (1986), S. 6ff., die ihren Aufsatz mit 'Informationstechnik als strategische Waffe' uberschreiben.

198 Vgl. Mertens/Plattfaut (1986), S. 7ff.; Porter/Millar (1986), S. 30. Über die Bedeutung von Information bzw. Informationstechnik als Teil des Absatzproduktes hinaus thematisieren jedoch sowohl Mertens/Plattfaut als auch Porter/Millar deren Rolle innerhalb der gesamten Wertschöpfungskette und damit auch als Inputfaktor.

199 Vgl. z.B. Angermeyer (1993), S. 237; Eschenröder (1985), S. 73ff.; Otten (1993), S. 15f.; Schüler (1989), S. 184. Der Umstand, daß diese Arbeiten hier der Sichtweise 'Information als Ressource' zugeordnet werden, darf nicht dahingehend mißverstanden werden, daß sie Informationsmanagement 
aufgrund der in der amerikanischen Bundesverwaltung beobachteten Probleme bei der elektronischen Datenverarbeitung die Einführung eines 'Information Resource Management'200 für die US-Bundesbehörden forderten. Als Hauptproblem wurde dort der Umstand angesehen, daß Information als freies Gut aufgefaßt wurde und deshalb nicht dieselben Budgetierungs-, Management- und Abrechungspraktiken angewendet wurden wie bei jedem anderen Wirtschaftsgut. ${ }^{201}$ Trotz dieser Erkenntnis, die eine starke betriebswirtschaftliche Ausrichtung des Informationsmanagements unmittelbar sinnvoll erscheinen läßt, sind viele der auf dem Gedanken eines 'Information Resource Management' beruhenden Ansätze sehr stark technisch orientiert. ${ }^{202}$

Oft verknüpfen Arbeiten zum Informationsmanagement die beschriebenen beiden Sichtweisen und betrachten Information sowohl als Input als auch als Output, wobei der Schwerpunkt von Arbeit zu Arbeit variiert. ${ }^{203}$ Tendenziell ist festzustellen, daß Arbeiten zum Informationsmanagement in den 90er Jahren regelmäßig 'Information als Ressource' in den Mittelpunkt ihrer Untersuchung stellen. ${ }^{204}$ Die Perspektive 'Information als Produktteil' spielt dagegen heute in der Diskussion um das Informationsmanagement kaum noch eine Rolle. ${ }^{205}$ Auch die vorliegende Arbeit beschränkt sich auf die Untersuchung von Information als Input des betrieblichen Leistungserstellungsprozesses und vernachlässigt ihre Rolle als Output. Diese Fokussierung auf Information als Ressource bedeutet, daß Informationsmanagement hier als Teil einer Faktorwirtschaft verstanden wird.

\subsection{Materielle und immaterielle Ebene der Informationsverarbeitung}

Information als Teilmenge des Wissens ist ein immaterielles Phänomen. Sie ist nichtgegenständlicher Natur. Zugleich ist sie jedoch untrennbar von den sie darstellenden physischen Zeichen: „,information is always born on a marker“206. Die immaterielle

auch als umfassendes Management der Ressource Information definieren. Vielmehr wird hier zunächst nur auf den Gegensatz zu der Sichtweise 'Information als Produktteil' abgestellt.

200 Der Ansatz des 'Information Resource Management' geht auf Synott/Gruber (1981), passim, und Horton (1981), passim, zurilck.

201 Für eine Darstellung der US-amerikanischen Ursprünge des Informationsmanagements bzw. des Information Resource Management vgl. Schneyman (1985), S. 35ff.; Trauth (1984), S. 12ff.; Trauth (1989), S. 260f.

202 Vgl. Schwarzer (1994a), S. 100.

203 Vgl. z.B. die oben erwähnten Arbeiten von Mertens/Plattfaut (1986), passim, und Porter/Millar (1986), passim, die den Schwerpunkt ihrer Untersuchung zwar auf Information als Produktteil legen, daruber hinaus Information jedoch auch als Inputfaktor des betrieblichen Leistungserstellungsprozesses betrachten.

204 Vgl. z.B. die Beitrăge in Scott Morton (1991), passim. Dieser Sammelband stellt den Abschlußbericht eines großangelegten Forschungsprogramms der 'MIT Sloan School of Management' uber den Einfluß der Informationstechnologie auf Unternehmungen, die Abläufe ihrer Geschäftstătigkeit, ihre Strukturen etc. dar. Vgl. ferner Hildebrand (1995), S. 33ff.; Krüger/Pfeiffer (1991), S. 21, 30; Ortner (1991), S. 320ff.; Otten (1993), S. 14ff.; Schwarzer (1994a), S. 89ff.

205 Dies ist nicht dahingehend mißzuverstehen, daß Information als Produktteil heute generell nicht mehr diskutiert wird. Die Autoren ordnen ihre entsprechenden Arbeiten allerdings nicht länger dem Themenbereich Informationsmanagement, sondern z.B. dem Marketing zu.

206 Miller (1978), S. 15. Schwarzer bezeichnet diesen Umstand auch als den Dualitătscharakter der Information. Vgl. Schwarzer (1994a), S. 99ff. 
Ressource Information ist somit stets an ein materielles Trägermedium gebunden. Die Gesamtmenge der materiellen Trägermedien kann in personelle und nicht-personelle unterschieden werden. Die auf nicht-personellen Trägermedien vorgehaltenen Informationen können wiederum anhand der Art ihrer Bindung an das materielle Trägermedium unterschieden werden. Diesen Zusammenhang visualisiert Abbildung 2/15.

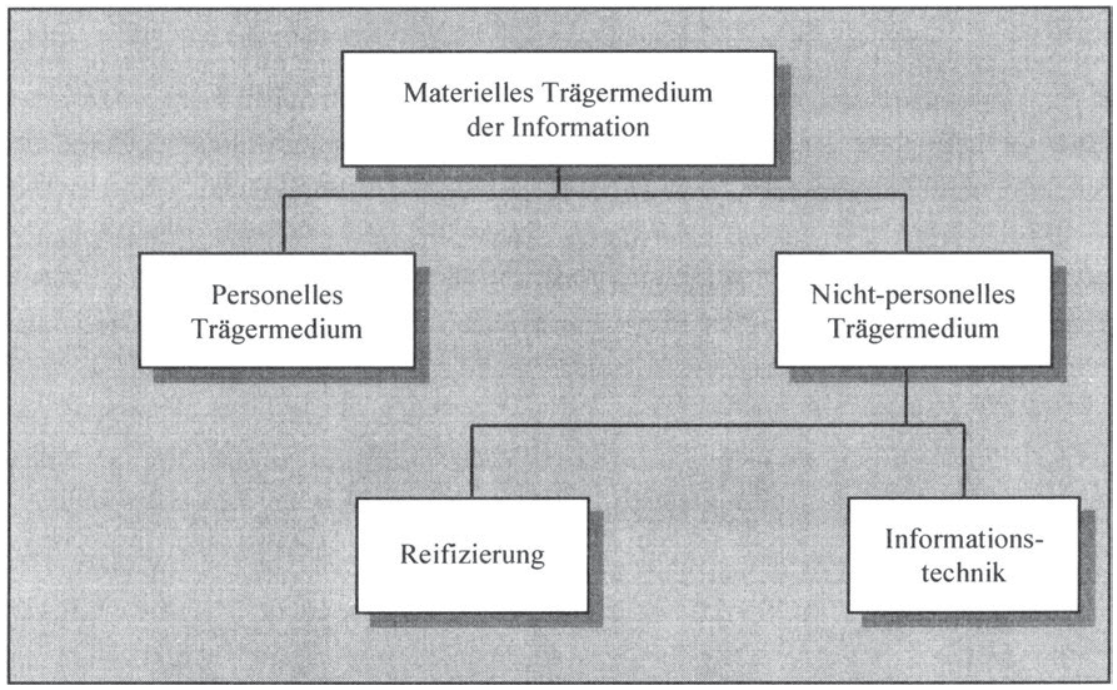

Abb. 2/15: Systematisierung der materiellen Trägermedien der Information

Der Mensch ist (personelles) Trägermedium, sofern die Information im menschlichen Gehirn vorgehalten wird. Die physischen Funktionen des Gehirns sind Gegenstand neurophysiologischer Untersuchungen. Sie unterliegen nicht dem Einfluß der Managementaktivitäten in der Unternehmung und werden deshalb auch im Rahmen des Informationsmanagements als gegeben angenommen.207 Der Mensch ist also zwar personelles Trägermedium der Information, wird im folgenden jedoch nicht dem Gegenstandsbereich des Informationsmanagements zugerechnet.

Liegt die Information außerhalb des Menschen vor, so handelt es sich um ein nicht-personelles Trägermedium. Die Gesamtheit der nicht-personellen Trägermedien wird somit als Residualgröße definiert.

207 Die neurophysiologische Perspektive auf das menschliche Gehirn und die materiellen Aspekte der menschlichen Informationsverarbeitung dürfen nicht mit den die kognitiven Fähigkeiten des Menschen betreffenden immateriellen Aspekten der menschlichen Informationsverarbeitung verwechselt werden. So sind die kognitiven Fähigkeiten des Menschen durchaus durch Managementaktivitäten beeinflußbar und insbesondere Gegenstand der Personalentwicklung als Teil des Personalmanagements. 
Eine Teilmenge der auf nicht-personellen Trägermedien gespeicherten Informationen stellen die reifizierten (lateinisch res $=$ Sache, Ding) Informationen dar. ${ }^{208}$ Es handelt sich dabei um Informationen, die verdinglicht wurden und jetzt nur noch in Form geschaffener Dinge, Werkzeuge u.ä. vorliegen. Somit sind reifizierte Informationen regelmäßig impliziter Art. ${ }^{209} \mathrm{Zu}$ den reifizierten Informationen zählen z.B. Informationen über die Art der Verarbeitung von Produkten, die sich in den Arbeitsabläufen einer Maschine widerspiegeln. Diese nunmehr reifizierten Informationen sind zwar ursprünglich durch gedankliche Tätigkeiten des Menschen entstanden, inzwischen jedoch nicht länger Gegenstand reflexiver Bewußtseinstätigkeit und auch nicht mehr unmittelbar diskursiv verfügbar. Prinzipiell können sie dies im Rahmen von Prozessen der Reflexion und Diskursivierung aber wieder werden. Letztlich beinhaltet jeder Gegenstand in der Unternehmung, der einen Zweck im Rahmen des betrieblichen Leistungserstellungsprozesses erfüllt, reifizierte Informationen. Die Menge der Trägermedien der Information umfaßt damit nahezu jedes dingliche Objekt in der Unternehmung. Da die Ausdehnung des Gegenstandsbereiches des Informationsmanagements auf die Gesamtheit der dinglichen Objekte in der Unternehmung nicht sinnvoll ist, werden reifizierte Informationen im Rahmen der vorliegenden Arbeit nicht dem Gegenstandsbereich des Informationsmanagements zugerechnet.

Im Mittelpunkt des Informationsmanagements stehen vielmehr diejenigen Informationen, die mit Hilfe von Informationstechnik als nicht-personellem Trägermedium verarbeitet werden. Informationstechnik wird dabei hier als Sammelbegriff für die Gesamtheit der in der Unternehmung eingesetzten technischen Hilfsmittel zur Informationsverarbeitung i.w.S. verstanden. Sie dienen der physischen Vorhaltung von Informationen außerhalb des Menschen und ermöglichen deren unmittelbare ${ }^{210}$ Verwendung im Rahmen kognitiver Informationsverarbeitungsprozesse des Menschen. Diese setzt insbesondere die symbolische Darstellbarkeit der Informationen voraus. Das Spektrum möglicher informationstechnischer Trägermedien der Information reicht von Papierdokumenten bis zu magnetischen, elektronischen und optischen Datenträgern. Grundsätzlich kann man zwischen computergestützter und nicht-computergestützter Informationstechnik unterscheiden. ${ }^{211}$ Der nicht-computergestützten Informationstechnik sind z.B. papiergestützte Formulare, Ablage- und Berichtssysteme sowie

208 Vgl. dazu und im folgenden Bühl (1984), S. 57, der jedoch auf reifiziertes Wissen abstellt. Seine diesbezüglichen Aussagen können jedoch auch auf Informationen als Teilmenge des Wissens übertragen werden. So resultiert die Zweckorientierung der in den Arbeitsablăufen einer Maschine verdinglichten Informationen aus deren Einsatz im Rahmen des betrieblichen Leistungserstellungsprozesses.

209 Vgl. Pautzke (1989), S. 68. Zur Abgrenzung expliziten und impliziten Wissens vgl. ferner Bühl (1984), S. 117 ff.; Oberschulte (1994), S. 67ff.; Polanyi (1985), S. $14 \mathrm{ff}$.

210 Unmittelbarkeit bedeutet hier, daß der Verwendung der Information hier - im Gegensatz zu reifizierter Information - keine Prozesse der Diskursivierung vorausgehen mulssen.

211 Somit wird hier eine weite Abgrenzung des Begriffes der Informationstechnik vorgenommen, die nicht allein auf auf moderner Mikroelektronik basierende Mittel abstellt, sondern vielmehr sämtliche technischen Hilfsmittel zur Informationsverarbeitung einschließt. Vgl. ăhnlich Hoppen (1992), S. 26; Zahn (1993), S. $231 \mathrm{ff}$. 
Kopierer, Telefon und Schreibmaschine zuzurechnen. ${ }^{212}$ Die computergestützte Informationstechnik basiert auf Mikroelektronik und umfaßt die Gesamtheit der in der Unternehmung eingesetzten Hard- und Software. Die mit ihrer Hilfe verarbeiteten Informationen stellen zugleich Daten dar. Zwar hat das Aufgabenfeld Informationsmanagement prinzipiell die Gesamtheit der in der Unternehmung eingesetzten Informationstechnik zum Gegenstand. Aufgrund deren relativer Bedeutung beschränken sich die Ausführungen der vorliegenden Arbeit jedoch auf die Teilmenge der computergestützten Informationstechnik und vernachlässigen die nicht-computergestützte Informationstechnik. Da eine Verwechslung mit der nicht-computergestützten Informationstechnik somit nicht möglich ist, entfällt aus Gründen der sprachlichen Vereinfachung im folgenden das Adjektiv 'computergestützt'. Sofern Informationstechnik thematisiert wird, handelt es sich also stets um computergestützte Informationstechnik.

Im Gegensatz zu dem Begriff der Informationstechnik, der auf die in der Unternehmung eingesetzten technischen Hilfsmittel zur Informationsverarbeitung abstellt, handelt es sich bei dem Begriff der Informationstechnologie um den die Informationstechnik und andere Aspekte einschließenden Oberbegriff. Die Informationstechnologie umfaßt die Gesamtheit der am Markt verfügbaren Methoden und technischen Hilfsmittel zur Informationsverarbeitung. So definiert z.B. ZAHN die Informationstechnologie als die „Prinzipien, Methoden und Mittel der Bereitstellung, Speicherung, Verarbeitung, Übermittlung und Verwendung von Informationen sowie der Gestaltung und Nutzung von Informationssystemen" ${ }^{213}$. Sie schließt neben den Werkzeugen auch die Verfahrensweisen ein ${ }^{214}$ und ist darüber hinaus nicht auf die konkrete Anwendung in einer Unternehmung beschränkt ${ }^{215}$. Die Informationstechnik ist somit das Ergebnis der unmittelbaren praktischen Anwendung von Teilen der Informationstechnologie in der Unternehmung. ${ }^{216}$ Zwar kann - analog zu der Unterscheidung zwischen computergestützter und nicht-computergestützter Informationstechnik - prinzipiell auch zwischen computergestützter und nicht-computergestützter Informationstechnologie unterschieden werden. Analog zu den obigen Überlegungen wird im folgenden jedoch auch die Betrachtung der Informationstechnologie auf computergestützte Phänomene beschränkt und der Begriff der Informationstechnologie hier allein für die computergestützte Informationstechnologie begrenzt. Diese Eingrenzung entspricht darüber hinaus der heute in Literatur und betrieblicher Praxis üblichen Verwendung des Begriffes.

Aufgrund des Umstandes, daß das immaterielle Phänomen Information stets untrennbar mit seinem materiellen Trägermedium verbunden ist, umfaßt der im Rahmen der vorlie-

212 Vgl. Hoppen (1992), S. 26; Zahn (1993), S. 232.

213 Zahn (1993), S. 231.

214 Vgl. Trott zu Solz (1992b), S. 73. Diese Abgrenzung von 'Informationstechnologie' entspricht weitgehend der des englischen Begriffes der 'information technology', den Boaden/Lockett als ,term used to describe all general technical developments and advances" beschreiben. Boaden/Lockett (1991), S. 29.

$215 \mathrm{Vgl}$. Specht (1993), Sp. 4155.

216 Vgl. Pfeiffer (1990), S. 13. 
genden Arbeit fokussierte Gegenstandsbereich des Informationsmanagements neben der Information auch die computergestützte Informationstechnik als Trägermedium der Information und damit sowohl immaterielle als auch materielle Phänomene. Da beide Bereiche in der Praxis untrennbar miteinander verwoben sind, ist die Unterscheidung zwar eher theoretisch-analytischer als praktischer Natur. Jedoch erweist sie sich im Rahmen der Argumentation der vorliegenden Arbeit als geeignete Möglichkeit zur Systematisierung des Aufgabenfeldes Informationsmanagement.

\subsubsection{Das computergestützte Informationssystem}

Die bisherigen Ausführungen zeigen, daß es nicht ausreicht, Information als Gegenstandsbereich des Informationsmanagements $\mathrm{zu}$ bezeichnen. Denn einerseits wird Information als Produktteil bzw. als Output des betrieblichen Leistungserstellungsprozesses aus der Betrachtung ausgeklammert. Andererseits gilt es, die Informationstechnik als untrennbar mit dem immateriellen Phänomen Information verbundenes materielles Trägermedium zu berücksichtigen. Im Rahmen der vorliegenden Arbeit wird deshalb das computergestützte Informationssystem als Gegenstandsbereich der Aktivitäten des Informationsmanagements bezeichnet. Im systemtheoretischen Sinne kann das computergestützte Informationssystem als Menge bestimmter Elemente und bestimmter Beziehungen zwischen diesen Elementen bezeichnet werden. Dabei ist wiederum zwischen einer materiellen und einer immateriellen Ebene zu unterscheiden. Auf der immateriellen Ebene besteht das computergestützte Informationssystem aus den Menschen als informationsverarbeitenden Subjekten ${ }^{217}$ sowie den informationellen Beziehungen zwischen ihnen. Auf der materiellen Ebene umfaßt es die Informationstechnik als nichtpersonelles Trägermedium sowie die mit den immateriellen informationellen Beziehungen zwischen den Menschen einhergehenden materiellen Beziehungen. ${ }^{218}$

Bezüglich der immateriellen Ebene des computergestützten Informationssystems ist festzustellen, daß informationelle Beziehungen nur zwischen Menschen auftreten.219 Denn Entscheidungen und Handlungen, deren Unterstützung der Zweck von Information ist, setzen Bewußtsein voraus und sind deshalb unmittelbar an den Menschen

217 Grundsätzlich kann der Mensch als informationsverarbeitendes Subjekt sowohl auf einer materiellen als auch auf einer immateriellen Ebene untersucht werden. Der Fokus des Informationsmanagements beschrănkt sich auf die immateriellen Aspekte des informationsverarbeitenden Menschen. Die materiellen, auf die physischen Funktionen des Gehirns abstellenden Aspekte unterliegen dagegen, wie bereits in Abschnitt 2.2.2.1.3 erwăhnt, nicht dem Einfluß des Managements und sind damit nicht Gegenstand des Informationsmanagements.

218 Für von der Grundidee bezuglich des Gegenstandbereiches dem Ansatz der vorliegenden Arbeit ahnliche Informationsmanagement-Konzeptionen vgl. z.B. Otten (1993), S. 15f., 18; Schüler (1989), S. 184; Zahn (1993), S. 279ff. Diese unterscheiden jedoch nicht systematisch zwischen einer materiellen und einer immateriellen Ebene.

219 Man kann die informationellen Beziehungen zwischen Menschen auch als Kommunikation bezeichnen. Da der Kommunikationsbegriff jedoch prinzipiell auf denselben Sachverhalt abstellt wie der der informationellen Beziehung, soll im Rahmen der vorliegenden Arbeit auf die Einfuhrung eines zusătzlichen Begriffes verzichtet werden. 
gebunden. Nur der Mensch, nicht jedoch die Technik kann entscheiden und handeln. 220 Somit ist Information als zweckorientiertes Wissen notwendigerweise subjektbezogen. Als Gegenstand informationeller Beziehungen zwischen Menschen ist die Information dabei selbst nicht Element des computergestützten Informationssystems, sondern Strömungsgröße zwischen dessen Elementen. Der Mensch als Element des computergestützten Informationssystems verfügt wiederum über bestimmte Attribute, die seine Aktivitäten der Informationsverarbeitung i.e.S. als immaterielles Phänomen betreffen. Hier ist z.B. der Informationsbedarf zu nennen, der - wie im folgenden Abschnitt erläutert werden wird - im Rahmen der organisatorischen Gestaltung bezogen auf den abstrakten Aufgabenträger formuliert wird und im Rahmen des Informationsmanagements um situative und subjektive Aspekte der konkreten Person ergänzt werden muß.221 Unterscheidet man zwischen den drei Ebenen der Semiotik, so finden auf der immateriellen Ebene des computergestützten Informationssystems Fragen der Syntax keine Berücksichtigung. Vielmehr erstreckt sich die Betrachtung hier allein auf semantische und pragmatische Aspekte. Das immaterielle Phänomen Information wird bezüglich seiner inhaltlichen Ausgestaltung und seiner Zweckorientierung untersucht, d.h. es ist zu prüfen, wer welche Informationen wie aufbereitet wann zu welchem Zweck benötigt.

Betrachtet man die materielle Ebene des computergestützten Informationssystems, so wird das menschliche Gehirn mit seinen neurophysiologischen Charakteristika als Trägermedium von Information nicht dem Gegenstandsbereich des Informationsmanagements zugerechnet. Anderes gilt dagegen für das materielle Trägermedium Informationstechnik: Einerseits reichen die geistigen Kapazitäten des Menschen angesichts der Fülle der zu bearbeitenden Informationen regelmäßig nicht aus. Deshalb greift der menschliche Informationsverarbeiter zur Unterstützung seiner individuellen Informationsverarbeitungsprozesse auf Informationstechnik zurück. Als Beispiel sei das Speichern großer Datenmengen in einer Datenbank genannt, die dem Individuum dann zu einem späteren Zeitpunkt für Auswertungen zur Verfügung stehen. Andererseits wird die Übertragung von Informationen zwischen Menschen häufig mit Hilfe computergestützter ${ }^{222}$ Informationstechnik als physischem Trägermedium abgewickelt. Als Beispiel sei hier auf das Auswerten der durch Mitarbeiter der Debitorenbuchhaltung in einer Datenbank verwalteten Umsatzdaten durch Mitarbeiter des Controlling verwiesen. Der Informationstechnik kommt dabei eine Überbrückungsfunktion zwischen den menschlichen Gehirnen als Trägermedien zu. Somit unterstützt die Informationstechnik als

220 Handeln als dem Entscheiden nachfolgende bewußte Aktivităt ist damit vom Agieren zu unterscheiden. Siehe in diesem Zusammenhang auch die in Abschnitt 2.2.1.2 der vorliegenden Arbeit vorgenommene Unterscheidung zwischen dem Menschen als Aufgabentrăger und der Technik als Aktionsträger.

221 Für eine Darstellung der organisatorischen Regeln bezüglich Informationsbedarf und -bereitstellung siehe Abschnitt 2.2.1.2 der vorliegenden Arbeit.

222 Wie oben bereits erwăhnt, findet die nicht-computergestützte Informationstechnik im Rahmen der vorliegenden Untersuchung keine Berücksichtigung. 
materielles Trägermedium sowohl die Informationsverarbeitung des einzelnen Individuums ${ }^{223}$ als auch informationelle Beziehungen zwischen Menschen. Dabei beschränkt sich die Betrachtung der Informationstechnik als Elementart des computergestützten Informationssystems auf diejenige Teilmenge ihrer Attribute, die die materielle Seite der Informationsverarbeitung i.w.S. betreffen. Über die Informationstechnik als Element des computergestützten Informationssystems hinaus sind diejenigen materiellen Beziehungen zwischen Menschen, zwischen Mensch und Informationstechnik sowie zwischen verschiedenen informationstechnischen Komponenten Gegenstand des Informationsmanagements, die unmittelbar mit den immateriellen informationellen Beziehungen einhergehen. Unterscheidet man auch hier wiederum zwischen den drei Ebenen der Semiotik, so beschränkt sich die Perspektive auf der materiellen Ebene des computergestützten Informationssystems auf die Syntax, d.h. es ist $\mathrm{zu}$ untersuchen, wie die Informationstechnik ausgestaltet sein muß, um als materielles Trägermedium eine optimale Informationsversorgung der Mitarbeiter der Unternehmung zu gewährleisten. Semantische und pragmatische Aspekte finden hier dagegen keine Berücksichtigung.

Abbildung 2/16 zeigt die materielle und die immaterielle Ebene des computergestützten Informationssystems mit ihren jeweiligen Elementen und Beziehungen. Da das computergestützte Informationssystem die Elemente Mensch und Informationstechnik umfaßt, kann es - ebenso wie das System Unternehmung als Ganzes ${ }^{224}$ - als sozio-technisches System bezeichnet werden. Diese Sichtweise hat sich auch in der WirtschaftsinformatikLiteratur weitgehend durchgesetzt. ${ }^{225}$ Betrachtet man die Elemente und Beziehungen des computergestützten Informationssystems, so sind diese zugleich Teile des Systems Unternehmung als Ganzen. Jedoch beschränkt sich die im Rahmen des Informationsmanagements verfolgte Perspektive auf das System Unternehmung auf bestimmte Aspekte: So werden bezüglich der Elementart Mensch nur diejenigen Attribute berücksichtigt, die die Informationsverarbeitung i.e.S. als immaterielles Phänomen betreffen. Die Betrachtung der Elementart Informationstechnik beschränkt sich auf diejenigen ihrer Attribute, die die Abwicklung der materiellen Seite menschlicher Informationsverarbeitungsprozesse betreffen. Die Menge der Beziehungen des computergestützten Informationssystems umfaßt einerseits die Gesamtheit der informationellen Beziehungen zwischen den Menschen in der Unternehmung als immaterielle Phänomene. Andererseits beinhaltet sie den Teil der materiellen Beziehungen zwischen Menschen, zwischen Mensch und Informationstechnik sowie zwischen verschiedenen informationstechnischen Komponenten, die aufgrund der Untrennbarkeit der Information von ihrem

223 Der Begriff der 'individuellen Informationsverarbeitung' wird hier vermieden, da er im Zusammenhang mit der informationstechnischen Unterstutzung der menschlichen Teilaufgabenerfullung in der Unternehmung regelmaßBig in einem anderen Zusammenhang verwendet wird. Vgl. Pohl (1997), S. 194f.; Stahlknecht/Hasenkamp (1997), S. 246.

224 Siehe Abschnitt 2.1.3 der vorliegenden Arbeit.

225 Vgl. z.B. König (1994), S. 80; Picot/Maier (1992), Sp. 923 (die jedoch neben personellen und technischen Elementen auch organisatorische erwăhnen); Schwarzer (1994a), S. 93. 
materiellen Trägermedium unmittelbar mit den informationellen Beziehungen einhergehen. Das computergestützte Informationssystem stellt also ein Teilsystem des Systems Unternehmung dar.

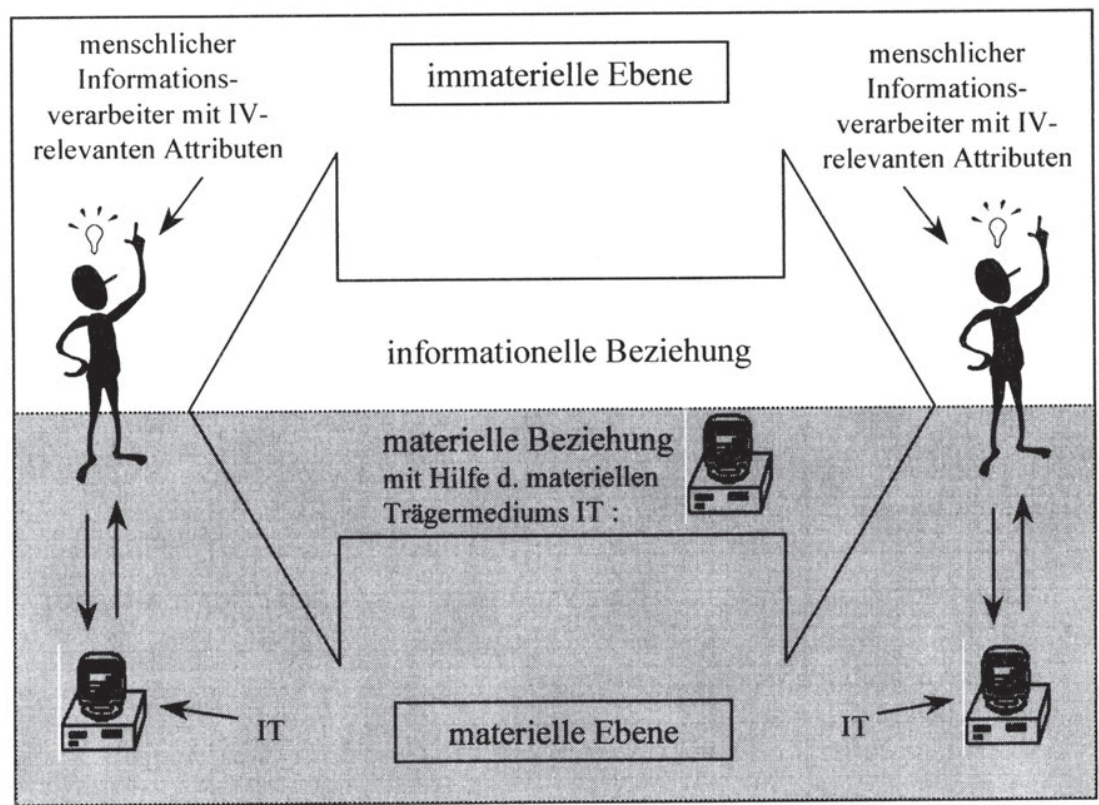

Abb. 2/16: Materielle und immaterielle Ebene des computergestützten Informationssystems

Der Begriff 'computergestütztes Informationssystem' als Gegenstandsbereich des Informationsmanagements kann auf zweierlei Art und Weise verwendet werden: Einerseits kann sich die Bezeichnung auf das Informationssystem der Unternehmung als Ganzes, andererseits auf bestimmte Teile dieses Ganzen beziehen. Im letzteren Fall wird häufig der Plural gebraucht und auf die computergestützten Informationssysteme in der Unternehmung als Subsysteme abgestellt. ${ }^{226}$ Konstitutiv für den InformationssystemBegriff in beiden Verwendungsarten ist, daß es sich um ein sozio-technisches System handelt, als Elementarten somit Mensch und Informationstechnik auftreten.

Abschließend kann festgestellt werden, daß die Fokussierung auf das computergestützte Informationssystem als Gegenstand des Informationsmanagements an sich nicht neu ist. Vielmehr stellen zahlreiche Arbeiten im Bereich der Wirtschaftsinformatik darauf ab. ${ }^{227}$ Neu ist dagegen die Unterscheidung zwischen einer immateriellen und einer materiellen Ebene des computergestützten Informationssystems, durch die sich das im Rahmen der vorliegenden Arbeit verfolgte Verständnis von Informationsmanagement von allen

226 Vgl. Schwarzer (1994a), S. 94.

227 Vgl. z.B. Gabriel/Røhrs (1995), S. 3f.; Hansen (1996), S. 67; Seibt (1997), S. 39; Trott zu Solz (1992a), S. 27. 
bisherigen betriebswirtschaftlichen und Wirtschaftsinformatik-Ansätzen in der Literatur unterscheidet. Betriebswirtschaftliche Konzeptionen, die auf dem Konstrukt der Informationswirtschaft bzw. des Informationsmanagements als betrieblicher Faktorwirtschaft beruhen, beschränken sich i.d.R. auf die immaterielle Ebene. ${ }^{228}$ Hier stehen dann inhaltliche Fragen und insbesondere die Zweckeignung der Information im Rahmen der Teilaufgabenerfüllung - und damit semantische und pragmatische Aspekte - im Mittelpunkt des Interesses. Dagegen wird Informationsmanagement in der Wirtschaftsinformatik - trotz des oft geäußerten prinzipiellen Anspruchs auf 'Ganzheitlichkeit' bzw. betriebswirtschaftlichen Bezug - auch heute noch häufig auf ein weitgehend isoliertes Management der in der Unternehmung eingesetzten Informationstechnik - und damit auf die materielle Ebene - beschränkt. Dabei liegt der Fokus dann einseitig auf den syntaktischen Aspekten der Datenverarbeitungsprozesse. Beide Perspektiven sind aus der Sicht der vorliegenden Arbeit unzureichend, da materielle und immaterielle Ebene in der betrieblichen Realität untrennbar miteinander verwoben sind. Jede Aktivität, die auf Veränderungen auf einer der beiden Ebenen abzielt, muß deshalb die jeweils andere notwendigerweise berücksichtigen. Die Begrenzung des Informationsmanagements auf die immaterielle Ebene des Managements der Ressource Information ignoriert, daß auf der materiellen Ebene greifende Beschränkungen zugleich Restriktionen auf der immateriellen Ebene implizieren. Analog können informationstechnische Innovationen über die materielle Ebene hinaus auch auf der immateriellen Ebene neue Möglichkeiten eröffnen. Dieser Sachverhalt wird in der Literatur häufig unter dem Schlagwort 'Informationstechnik als Enabler' diskutiert. 229 Umgekehrt wird die Beschränkung des Informationsmanagements auf informationstechnische Fragestellungen und damit auf das materielle Trägermedium der Information deren Ressourcencharakter nicht gerecht. Denn Daten als physische Form der Information stellen nur die Voraussetzung für die Verwendung der Information zur Unterstützung der Teilaufgabenerfüllung dar. ${ }^{230}$ Die auf der syntaktischen Ebene angesiedelten Datenverarbeitungsprozesse sind somit Mittel zum Zweck der Informationsverarbeitung i.e.S. auf der pragmatischen Ebene.

\subsubsection{Die Funktionen des Informationsmanagements}

Die inhaltliche Abgrenzung des Informationsmanagements erfordert neben der Spezifizierung seines Gegenstandsbereiches eine nähere Betrachtung seiner Funktionen. Es gilt zu untersuchen, welcher Art die das computergestützte Informationssystem betreffenden Aktivitäten des Informationsmanagements sind.

Die vorliegende Arbeit folgt einem funktionalen Verständnis von Management, das im Gegensatz zu einer institutionalen Perspektive, die die Tätigkeiten und Rollen kon-

Vgl. z.B. Eschenröder (1985), S. 23.

Vgl. z.B. Schwarzer (1994b), S. 32f.; Venkatraman (1991), S. $122 \mathrm{ff}$.

Vgl. Schwarzer (1994a), S. 101. 
kreter Personen fokussiert - auf die Managementfunktionen abstellt.231 Bereits in Abschnitt 2.2.1.3 waren Planung/Entscheidung, Steuerung und Kontrolle als Managementaktivitäten oder -phasen beschrieben worden. ${ }^{232}$ Den Managementaktivitäten als den Aktivitäten zur zielgerichteten Beeinflussung des Systems Unternehmung ${ }^{233}$ sind die Durchführungsaufgaben gegenüberzustellen, die dadurch charakterisiert sind, daß hier die wesentlichen Entscheidungen bezüglich der Ziele, Maßnahmen und Mittel schon getroffen und verbindlich vorgegeben sind. ${ }^{234}$

In Analogie zu dieser allgemeinen Abgrenzung der Managementaktivitäten wird Informationsmanagement in der vorliegenden Arbeit definiert als die Gesamtheit der auf das computergestützte Informationssystem bezogenen Aktivitäten der Planung/Entscheidung, Steuerung und Kontrolle. Einerseits handelt es sich bei der Unternehmung als Ganzem um ein äußerst komplexes System. Andererseits sind die kognitiven Fähigkeiten des Menschen begrenzt. Deshalb ist das System Unternehmung in seiner Gesamtheit nur auf einem sehr hohen Abstraktionsniveau Gegenstand von Managementaktivitäten (allgemeine Unternehmungsführung). Die konkreteren Aktivitäten des Managements werden dagegen regelmäßig auf bestimmte Gegenstandsbereiche beschränkt. ${ }^{235}$ Das computergestützte Informationssystem stellt einen dieser Gegenstandsbereiche dar. Im folgenden werden die auf diesen Gegenstandbereich bezogenen Planungs/Entscheidungs-, Steuerungs- und Kontrollaktivitäten spezifiziert. Da die Ausführungen in Abschnitt 2.2.2.2 gezeigt haben, daß das computergestützte Informationssystem einerseits auf einer immateriellen Ebene, andererseits auf einer materiellen Ebene untersucht werden kann, werden die Aktivitäten des Informationsmanagements dabei in solche bezüglich der immateriellen (Abschnitt 2.2.2.3.1) und solche bezüglich der materiellen Ebene (Abschnitt 2.2.2.3.2) des computergestützten Informationssystems gegliedert.

\subsection{Das Management der immateriellen Ebene des computergestützten In- formationssystems}

Die auf die immaterielle Ebene des computergestützten Informationssystems bezogenen Aufgaben des Informationsmanagements umfassen Planungs-/Entscheidungs-, Steue-

231 Zur Abgrenzung eines funktionalen von einem institutionalen Managementverständnis vgl. Staehle (1994), S. 69ff.; Steinmann/Schreyögg (1993), S. 5 f.

232 In der Literatur zum Managementzyklus wird über diese Phasen hinaus regelmäßig auch eine Phase 'Organisation' unterschieden. Dieses explizite Ausweisen organisatorischer Tätigkeiten als Teilfunktion des Managements ist m.E. jedoch nur für eine allgemeine Betrachtung des Phänomens der Unternehmungsführung insgesamt sinnvoll, nicht jedoch für die Betrachtung einzelner, nach dem Gegenstandsbereich abgegrenzter Managementteilbereiche, wie Informations-, Produktions- oder Personalmanagement. Wăhrend jeder dieser Managementteilbereiche nămlich durchaus Planungsund Entscheidungs-, Steuerungs- und Kontrollaufgaben umfaßt, werden dort nicht organisatorische Regeln formuliert.

233 Vgl. Kuhn (1990), S. 2; Reuter (1993), Sp. 2664.

234 Vgl. Ulrich/Fluri (1992), S. 14.

235 Weitere Beispiele fur auf bestimmte Gegenstandsbereiche beschrănkte Managementaktivităten sind Produkt-, Personal-, Produktions-, Kosten- und Qualitătsmanagement. 
rungs- und Kontrollaktivitäten bezüglich der informationellen Beziehungen zwischen den Menschen. Die informationellen Beziehungen sind geprägt von Informationsbedarf und -bereitstellung als Attributen der informationsverarbeitenden menschlichen Subjekte, die ebenfalls Gegenstand des Informationsmanagements sind. Da innerhalb der Unternehmung in der Regel kein Marktmechanismus einen Ausgleich zwischen Informationsbedarf und -bereitstellung bewirkt, werden hier die Begriffe 'Nachfrage' und 'Angebot', die in der Betriebswirtschaftslehre unmittelbar mit der Vorstellung von der Existenz eines Marktes verbunden sind, vermieden. ${ }^{236}$ Lediglich im Fall der mengenabhängigen innerbetrieblichen Leistungsverrechnung mit Hilfe von Verrechnungspreisen kommt es bezüglich derjenigen Informationen, für die variable innerbetriebliche Verrechnungspreise existieren, zu einem Ausgleich zwischen Nachfrage und Angebot. Selbst ein ausgefeiltes System innerbetrieblicher Verrechnungspreise deckt jedoch aufgrund des damit verbundenen Aufwandes in der betrieblichen Praxis regelmäßig nur einen geringen Teil der informationellen Beziehungen ab. Deshalb ist es ein Ziel der Aktivitäten des Informationsmanagements, für denjenigen Teil der Informationen, bei denen es aufgrund des fehlenden Preises nicht zu einem Ausgleich zwischen Angebot und Nachfrage kommt, einen Abgleich zwischen Informationsbedarf und -bereitstellung zu bewirken.

Informationsbedarf und -bereitstellung werden von mehreren Faktoren beeinflußt. Die Gesamtheit dieser Einflußfaktoren kann in die folgenden drei Gruppen unterschieden werden:

- organisatorische Regeln als Ergebnis der organisatorischen Gestaltung, 237

- subjektive Einflüsse der informationsverarbeitenden Personen und

- situative Faktoren.

Im Rahmen der organisatorischen Gestaltung werden organisatorische Regeln bezüglich des Informationsbedarfes und der Informationsbereitstellung formuliert. ${ }^{238}$ Sie werden aus den der Stelle zugeordneten Teilaufgaben abgeleitet, wobei grundsätzlich von den Eigenheiten konkreter Personen als Stelleninhabern abstrahiert wird. Diese Attribute der abstrakten menschlichen Aufgabenträger resultieren somit vor allem aus den sachlichen Erfordernissen der den Stellen im Rahmen organisatorischer Gestaltungsaktivitäten zugeordneten Teilaufgaben. In der Literatur werden sie deshalb häufig auch als 'objektiv' im Sinne intersubjektiv bestimmbarer Größen bezeichnet. ${ }^{239}$ Diese Argumentation ignoriert jedoch, daß die Aktivität der organisatorischen Gestaltung -

236 Dagegen ignoriert z.B. Krcmar diese mit dem Fehlen des Marktmechanismus verbundene Problematik. Vielmehr thematisiert er im Rahmen seiner Ausfuhrungen zum Informationsmanagement Informationsnachfrage und -angebot. Vgl. Krcmar (1997), S. $56 \mathrm{ff}$.

237 Organisatorische Regeln als Ergebnis von Selbstorganisationsprozessen werden im Rahmen der vorliegenden Arbeit den subjektiven Einflussen der informationsverarbeitenden Personen als der zweiten Gruppe von Einflußfaktoren zugeordnet.

238 Siehe Abschnitt 2.2.1.2 der vorliegenden Arbeit.

239 Vgl. Brockhaus (1992), S. 33f;; Picot/Franck (1988), S. 609; Schulze-Wischeler (1995), S. 9ff. 
und damit auch die organisatorischen Regeln als ihr Ergebnis - nicht von dem Organisator als dem handelnden Subjekt zu trennen ist. Aus der Perspektive des konstruktivistisch geprägten Wissenschaftsverständnisses der vorliegenden Arbeit ist die Gegenüberstellung von subjektivem und objektivem - im Sinne von 'nicht-subjektivem' Informationsbedarf bzw. subjektiver und objektiver Informationsbereitstellung deshalb abzulehnen. Denn jeder Informationsbedarf und jede Informationsbereitstellung sind subjektiv geprägt. Die organisatorischen Regeln bezüglich des Informationsbedarfes und der Informationsbereitstellung sind zwar frei von Einflüssen der konkreten Stelleninhaber, werden jedoch unmittelbar von der Person des organisatorischen Gestalters beeinflußt.

Außer durch die organisatorischen Regeln werden Informationsbedarf und -bereitstellung auch von subjektiven Einflüssen der konkreten informationsverarbeitenden Personen beeinflußt. Jeder Mensch als Stelleninhaber in der Unternehmung hat ihm eigene Vorstellungen bezüglich der Menge und Qualität von Informationen, die er als notwendig und hinreichend für die Lösung der ihm gestellten Teilaufgaben erachtet bzw. als Ergebnis seiner Aktivitäten bereitstellt. ${ }^{240}$ Er wird dabei z.B. von seiner persönlichen Arbeitstechnik, seinen kognitiven Fähigkeiten und seiner persönlichen Motivationsstruktur beeinflußt. ${ }^{241}$ Diese subjektiven, in der konkreten Person des Aufgabenträgers begründeten Einflüsse führen dazu, daß Informationsbedarf und -bereitstellung von Person zu Person verschieden sind. Die radikal konstruktivistische Perspektive der vorliegenden Arbeit bedingt, daß organisatorische Regeln als Ergebnis der organisatorischen Gestaltung und subjektive Einflüsse der konkreten informationsverarbeitenden Personen (einschließlich eventueller im Rahmen von Selbstorganisationsprozessen formulierter organisatorischer Regeln) hier als prinzipiell gleich gewichtig nebeneinander stehende Größen betrachtet werden. Allerdings ist zu beachten, daß in der betrieblichen Realität der organisatorische Gestalter in der Regel über bessere Möglichkeiten zur Durchsetzung seiner Perspektive verfügt.

Die situativen Faktoren stellen die dritte Gruppe von Einflußfaktoren auf Informationsbedarf und -bereitstellung dar. Es handelt sich hier um eine Residualgröße, d.h. dieser Gruppe werden alle Einflußfaktoren zugerechnet, die nicht organisatorische Regeln oder in der konkreten Person des menschlichen Aufgabenträgers begründet sind. Hierzu zählen z.B. rechtliche Rahmenbedingungen, wie solche zum Datenschutz.

Die auf die immaterielle Ebene des computergestützten Informationssystems bezogenen Planungs-/Entscheidungs-, Steuerungs und Kontrollaufgaben des Informationsmanagements erstrecken sich in einem ersten Schritt auf die Ermittlung von Informationsbedarf und -bereitstellung der informationsverarbeitenden menschlichen Subjekte, die aus den Einflüssen der organisatorischen Regeln, den subjektiven Einflüssen der infor-

240 Vgl. Gemünden (1993), Sp. 1726; Harbrecht (1993), Sp. 266.

241 Vgl. Berthel (1992), Sp. 882f.; Schulze-Wischeler (1995), S. 15. 
mationsverarbeitenden Personen sowie diversen situativen Faktoren resultieren. ${ }^{242}$ Denn zum einen bewegen sich die organisatorischen Regeln bezüglich Informationsbedarf und -bereitstellung regelmäßig auf einem vergleichsweise hohen Abstraktionsniveau. Zum anderen verfügen die informationsverarbeitenden Personen in der Regel nicht über das notwendige methodische Know-how zur Formulierung und systematischen Aufbereitung ihrer subjektiven Informationsbedürfnisse und der zu berücksichtigenden situativen Faktoren. Aufgabe des Informationsmanagements ist es deshalb, das Individuum bei der Formulierung und Operationalisierung bzw. Konkretisierung seines Informationsbedarfs und seiner Informationsbereitstellung zu unterstützen. Insbesondere trägt ein durch das Informationsmanagement vorgegebenes Muster zu einer Vereinheitlichung der ansonsten stark von den jeweiligen Personen geprägten Darstellung der Informationsbedarfe und bereitgestellten Informationen bei. Diese Vereinheitlichung wiederum erleichtert deren intersubjektiven Abgleich.

In einem zweiten Schritt ist es Aufgabe des Informationsmanagements, den ermittelten Informationsbedarf und die ermittelte Informationsbereitstellung $\mathrm{zu}$ modifizieren. ${ }^{243}$ Aufgrund des fehlenden Preises der Informationen kommt es zunächst nicht notwendigerweise zu einem Ausgleich zwischen Informationsbedarf und -bereitstellung. Dies ist sowohl für den Fall, in dem der Informationsbedarf größer ist als die Menge der bereitgestellten Informationen, als auch in dem Fall, in dem die Menge der bereitgestellten Informationen größer ist als der Informationsbedarf, problematisch. Denn kann der Informationsbedarf nicht durch entsprechende bereitgestellte Informationen befriedigt werden, so beeinträchtigt dies tendenziell die Qualität der Teilaufgabenerfüllung. Ist hingegen die Menge der unternehmungsintern bereitgestellten Informationen größer als der Informationsbedarf, so bedeutet dies eine Ressourcenverschwendung, da jede Bereitstellung von Informationen mit einem Ressourcenverbrauch verbunden ist. Deshalb ist es Aufgabe des Informationsmanagements zu untersuchen, wie sich die Informationskosten in Abhängigkeit von Informationsbedarfs- und -bereitstellungsniveau entwickeln. Über diese reinen Wirtschaftlichkeitserwägungen hinaus sind eine Vielzahl weiterer Aspekte, wie z.B. die Arbeitszufriedenheit der Mitarbeiter oder rechtliche Vorgaben (Datenschutz) bei der Modifikation von Informationsbedarf und -bereitstellung zu berücksichtigen.

Faßt man die Ergebnisse der Betrachtung der auf die immaterielle Ebene des computergestützten Informationssystems bezogenen Aktivitäten des Informationsmanagements zusammen, so gelten diese den Attributen Informationsbedarf und -bereitstellung der

242 Als Problemanalyse ist die Ermittlung von Informationsbedarf und -bereitstellung Teil des Planungsprozesses. Sie schafft die Voraussetzungen für die Maßnahmenplanung und die daran anschließende Maßnahmenauswahl.

243 Die Modifikation von Informationsbedarf und -bereitstellung umfaßt sowohl Planungs- und Entscheidungs- als auch Steuerungs- und Kontrollaktivitäten. Der angestrebte Ausgleich zwischen Informationsbedarf und -bereitstellung macht nämlich die Planung dieser Großen notwendig. Zur Zielerreichung sind sodann Steuerungsaktivităten notwendig, deren Erfolg im Rahmen der Kontrolle überpruft wird. 
informationsverarbeitenden Menschen als Elementen des computergestützten Informationssystems sowie den informationellen Beziehungen zwischen diesen Elementen. ${ }^{244}$ Sie betreffen die Ermittlung (im Sinne von Formulierung und Operationalisierung) von Informationsbedarf und -bereitstellung auf der einen sowie deren Modifikation auf der anderen Seite. Die Menschen als informationsverarbeitende Subjekte und die informationellen Beziehungen zwischen ihnen stellen jedoch nur einen Teilaspekt des computergestützten Informationssystems als Ganzen dar. Da Information als immaterielles Phänomen stets untrennbar von ihrem physischen Trägermedium ist, müssen die auf die immaterielle Ebene des computergestützten Informationssystems bezogenen Aktivitäten des Informationsmanagements stets auch die materielle Ebene berücksichtigen.

\subsection{Das Management der materiellen Ebene des computergestützten Infor- mationssystems}

Die auf die materielle Ebene des computergestützten Informationssystems bezogenen Aktivitäten des Informationsmanagements umfassen die Planungs-/Entscheidungs-, Steuerungs- und Kontrollaktivitäten bezüglich der Gesamtheit der in der Unternehmung eingesetzten computergestützten Informationstechnik als des materiellen Trägermediums der Information. Gegenstand des Informationsmanagements ist hier also das System Informationstechnik. Dieses System ist zugleich Subsystem des computergestützten Informationssystems als des übergeordneten Systems. Deshalb gilt für die auf die Informationstechnik bezogenen Aktivitäten des Informationsmanagements, daß diese stets den Zusammenhang zwischen materieller und immaterieller Ebene des computergestützten Informationssystems als Ganzen berücksichtigen müssen.

In der Wirtschaftsinformatik-Literatur werden häufig von der hier vorgenommenen Unterscheidung in Planungs-/Entscheidungs-, Steuerungs- und Kontrollaufgaben abweichende Systematisierungen der auf die Informationstechnik bezogenen Aktivitäten vorgenommen. Die in diesem Zusammenhang vorgeschlagenen Phaseneinteilungen wurden speziell für das Software Engineering entwickelt, ${ }^{245}$ können jedoch grundsätzlich auch über die Software hinaus auf die Gesamtheit der Informationstechnik angewendet werden. ${ }^{246}$ Sie orientieren sich am Software-Lebenszyklus bzw. dem Lebenszyklus der Informationstechnik, innerhalb dessen - sieht man von Abweichungen im Detail ab - regelmäßig zwischen den folgenden Phasen unterschieden wird:247

244 Die das (computergestützte Informations-) System konstituierenden Attribute der Elemente und die Beziehungen zwischen den Elementen sind dabei eng miteinander verbunden. Jede der beiden Größen erlaubt Rückschlüsse auf die jeweils andere: Einerseits prägen die Beziehungen die Attribute der Elemente, andererseits die Attribute der Elemente die Beziehungen.

245 Vgl. Balzert (1982), S. 15; Boehm (1986), S. 30ff.; Pomberger/Blaschek (1993), S. 17ff.

246 Vgl. Österle (1995), S. 35ff.; Schmitz (1989), Sp. 686.

247 Vgl. dazu und im folgenden Balzert (1982), S. 74ff.; Pomberger/Blaschek (1993), S. 33ff. Vereinfachend wird in Teilen der Literatur auch lediglich zwischen den Phasen Planung; Entwicklung und Betrieb unterschieden. Vgl. z.B. Hansen (1996), S. 114. 
- Systemplanung und -analyse,

- Systemspezifikation (Anforderungsdefinition),

- System- und Komponentenentwurf,

- Systemimplementierung und -verifizierung und

- Systembetrieb und -wartung.

Systemplanung und -analyse fokussieren die betriebliche Problemstellung, die mit Hilfe der Informationstechnik bearbeitet werden soll. Sie wird untersucht und beschrieben. In einem nächsten Schritt ist eine präzisere Anforderungsdefinition durchzuführen, die in einem Anforderungsdokument schriftlich zu fixieren ist. Im Rahmen des System- und Komponentenentwurfs wird sodann festgelegt, welche Komponenten des zu entwickelnden informationstechnischen Systems die in der Anforderungsdefinition beschriebenen Anforderungen erfüllen sollen und wie diese Komponenten als Gesamtsystem zusammenwirken werden. Ziel des Entwurfs ist es, eine Gesamtarchitektur bzw. mehrere Teilarchitekturen des informationstechnischen Systems zu entwickeln. Die Phase der Systemimplementierung und -verifikation umfaßt die Umsetzung und Verifikation der Ergebnisse des System- und Komponentenentwurfes. Bezogen auf die Software bedeutet das die Abbildung der angestrebten Funktionalität in einer Programmiersprache. Durch Komponententests und Systemtest wird die Arbeitsweise einzelner Komponenten und deren Zusammenwirken überprüft. Die auf die Phase des Systembetriebs bezogenen Wartungsaktivitäten betreffen Änderungen und Ergänzungen der eingesetzten Informationstechnik.

Stellt man die auf die Informationstechnik bezogenen Planungs-/Entscheidungs-, Steuerungs- und Kontrollaktivitäten des Informationsmanagements den genannten Phasen des Software-Lebenszyklusses bzw. des Lebenszyklusses der Informationstechnik gegenüber, so zeigt sich, daß es sich bei letzteren nicht ausschließlich um Managementaufgaben handelt. So stellt z.B. die Implementierung der Software eine Durchführungsaufgabe dar, da es hier darum geht, einen bereits gebildeten und schriftlich fixierten Willen in die Realität umzusetzen. ${ }^{248}$ Jeder der oben genannten Phasen können vielmehr sowohl Management- als Durchführungsaufgaben zugerechnet werden. Während das Informationsmanagement die zielorientierte Gestaltung umfaßt, dienen die Durchführungsaufgaben der Realisierung der im Rahmen des Informationsmanagements formulierten Vorgaben. ${ }^{249}$

Im Rahmen der folgenden Ausführungen wird die Betrachtung der auf die materielle Ebene bezogenen Funktionen des Informationsmanagements auf planende Aktivitäten beschränkt. Denn die aus Anforderungen an die organisatorische Gestaltung in der

$248 \mathrm{Vgl}$. Beier/Gabriel/Streubel (1997), S. 45.

249 Dieser Grundidee folgt auch die von Balzert vorgenommene Unterteilung der einzelnen Phasen des Software Engineering in die Phasenschritte Planung, Realisierung und Kontrolle. Wahrend Planung und Kontrolle dem Informationsmanagement zugeordnet werden, handelt es sich bei der Realisierung um eine Durchfuhrungsaufgabe. Vgl. Balzert (1982), S. 20. 
lernenden Unternehmung abgeleiteten Anforderungen an das Informationsmanagement beziehen sich auf der materiellen Ebene auf die Planung der Architektur der Informationstechnik bzw. einzelner informationstechnischer Teilarchitekturen. Die Steuerung und Kontrolle der eingesetzten Informationstechnik als Teilaspekte des Informationsmanagements finden in der vorliegenden Arbeit dagegen keine weitere Berücksichtigung.

\subsubsection{Zwischenfazit: Die Konzeptionalisierung des Informations- managements mit Hilfe eines Zwei-Ebenen-Ansatzes}

Faßt man die bisherigen Ausführungen zusammen, so bezeichnet der Begriff Informationsmanagement die Gesamtheit der auf das computergestützte Informationssystem bezogenen Planungs/Entscheidungs-, Steuerungs- und Kontrollaufgaben. Die Konzeptionalisierung des Informationsmanagements erfolgt dabei einerseits über seinen Gegenstandsbereich, andererseits über die Art der Aktivitäten. Bei der Betrachtung sowohl des computergestützten Informationssystems als Gegenstandsbereich als auch der Funktionen des Informationsmanagements kann zwischen einer materiellen und einer immateriellen Ebene unterschieden wird. Aufgrund dieser theoretisch-analytischen Trennung zwischen immateriellen und materiellen Aspekten, die gleichwohl nicht isoliert voneinander gestaltet werden können, kann das der vorliegenden Arbeit zugrundeliegende Verständnis von Informationsmanagement auch als Zwei-Ebenen-Ansatz bezeichnet werden. Dieser Zwei-Ebenen-Ansatz greift die ursprünglich von WoLLNIK in die Diskussion um das Informationsmanagement eingeführte Idee eines Mehr-Schichten-Modells auf. Während bei WOLLNIK und anderen Autoren, die auf seiner Idee aufsetzen (so z.B. KRCMAR), regelmäßig eine ausreichende Konzeptionalisierung des Zusammenhangs zwischen den einzelnen Schichten fehlt, dienten die Ausführungen der Abschnitte 2.2.2.2 und 2.2.2.3 der vorliegenden Arbeit der theoretischen Fundierung des hier verfolgten Zwei-Ebenen-Ansatzes.

Betrachtet man zunächst den Gegenstandsbereich des Informationsmanagements, so sind diesem nur diejenigen Informationen zuzurechnen, die Inputfaktoren des betrieblichen Leistungserstellungsprozesses darstellen. Somit ist nicht die Gesamtheit der Informationen in der Unternehmung Objekt des Informationsmanagements. Da Information als immaterielles Phänomen stets an ein materielles Trägermedium gebunden ist, ist darüber hinaus auch die Informationstechnik als ein solches Trägermedium Gegenstand des Informationsmanagements. Deshalb wird das computergestützte Informationssystem mit einer immateriellen und einer materiellen Ebene als Gegenstandsbereich des Informationsmanagements definiert.

Auf der immateriellen Ebene fokussiert das Informationsmanagement die Menschen als informationsverarbeitende Subjekte und die informationellen Beziehungen zwischen ihnen. Unterscheidet man zwischen den drei Ebenen der Semiotik, so umfaßt diese Ebene semantische und pragmatische Aspekte der Information als Strömungsgröße 
zwischen den Menschen bzw. die mit der Informationsverarbeitung i.e.S. unmittelbar verbundenen Attribute der Menschen (Informationsbedarf und -bereitstellung). Syntaktische Aspekte bleiben auf der immateriellen Ebene dagegen unberücksichtigt. Die Funktionen des Informationsmanagements umfassen hier die Planungs/Entscheidungs-, Steuerungs- und Kontrollaktivitäten zur Ermittlung (Formulierung und Operationalisierung) und Modifikation von Informationsbedarf und -bereitstellung.

Da Information als immaterielles Phänomen untrennbar von ihrem physischen Trägermedium ist, sind die immateriellen Aspekte stets auch mit materiellen verbunden. Auf der materiellen Ebene fokussiert das Informationsmanagement die computergestützte Informationstechnik als materielles Trägermedium der Informationen. Der Mensch als materielles Trägermedium und die physische Verarbeitung von Informationen im menschlichen Gehirn können dagegen nicht Gegenstand von Managementaktivitäten sein und werden deshalb im Rahmen des Informationsmanagements nicht weiter berücksichtigt. ${ }^{250}$ Während das Informationsmanagement prinzipiell die Gesamtheit der auf die Informationstechnik bezogenen Planungs- und Entscheidungs-, Steuerungs- und Kontrollaktivitäten umfaßt, beschränkt sich die Betrachtung im Verlauf der folgenden Ausführungen auf die Planung verschiedener Teilarchitekturen der Informationstechnik.

Mit der Konzeptionalisierung des Informationsmanagements mittels des vorgestellten Zwei-Ebenen-Ansatzes ist ein erstes Zwischenziel zur Erreichung des zentralen Zieles der vorliegenden Arbeit (Untersuchung des Beitrages des Informationsmanagements zur Förderung organisationalen Lernens) erreicht. Der vorgestellte Zwei-Ebenen-Ansatz des Informationsmanagements stellt einerseits eine geeignete Grundlage für die Einbettung der Gestaltung der Informationstechnik in den Gesamtzusammenhang eines umfassenderen Verständnisses von Informationsmanagement dar. Andererseits erlaubt er die exakte Abgrenzung der Aktivitäten des Informationsmanagements von denen der organisatorischen Gestaltung und erleichtert die Konzeptionalisierung des Zusammenhangs zwischen den beiden Managementaktivitäten, wie sie im folgenden Abschnitt 2.2.3 vorgenommen wird.

\subsubsection{Der Zusammenhang zwischen organisatorischer Gestaltung und Informationsmanagement}

Nachdem in den Abschnitten 2.2.1 und 2.2.2 die beiden Managementaktivitäten organisatorische Gestaltung und Informationsmanagement unabhängig voneinander dargestellt wurden, werden diese beiden isolierten Perspektiven nunmehr zusammengeführt. Dies erfordert eine exakte Abgrenzung der beiden Bereiche voneinander. Darüber hinaus ist der prinzipielle Kausalzusammenhang zwischen ihnen aufzuzeigen.

250 Dies ist keinesfalls dahingehend mißzuverstehen, daß der Mensch insgesamt keine Berücksichtigung findet. Vielmehr ist klar zwischen den immateriellen Aspekten des Menschen bzw. der menschlichen Informationsverarbeitung, die Gegenstand des Informationsmanagements sind, und den damit verbundenen physischen Prozessen in seinem Gehirn, die nicht Gegenstand des Informationsmanagements sind, zu unterscheiden. 
Sowohl die organisatorische Gestaltung als auch das Informationsmanagement stellen Teilbereiche der Gesamtmenge der Unternehmungsführungsaufgaben dar. Dabei unterscheiden sie sich von anderen Managementaktivitäten, aber auch untereinander durch die jeweils verfolgte Perspektive auf das System Unternehmung als Ganzes, die sich in ihren jeweiligen Gegenstandsbereichen und der Art ihrer Aktivitäten manifestiert. Tabelle 2/17 stellt die Gegenstandsbereiche und Aktivitäten der organisatorischen Gestaltung und des Informationsmanagements einander gegenüber.

Betrachtet man zunächst den jeweiligen Gegenstandsbereich der beiden Managementaktivitäten, so hat die organisatorische Gestaltung das Organisationssystem zum Objekt, während das Informationsmanagement das computergestützte Informationssystem mit seiner immateriellen und seiner materiellen Ebene fokussiert. Jedes dieser Systeme setzt sich aus bestimmten Element- und Beziehungsarten zusammen.

Im Mittelpunkt der organisatorischen Gestaltung steht die Aufgabe der Unternehmung, die in Teilaufgabenbündel zerlegt wird. Da die Teilaufgaben nicht Gegenstand des Informationsmanagements sind, besteht hier kein weiterer Abgrenzungsbedarf zwischen den beiden Managementaktivitäten.

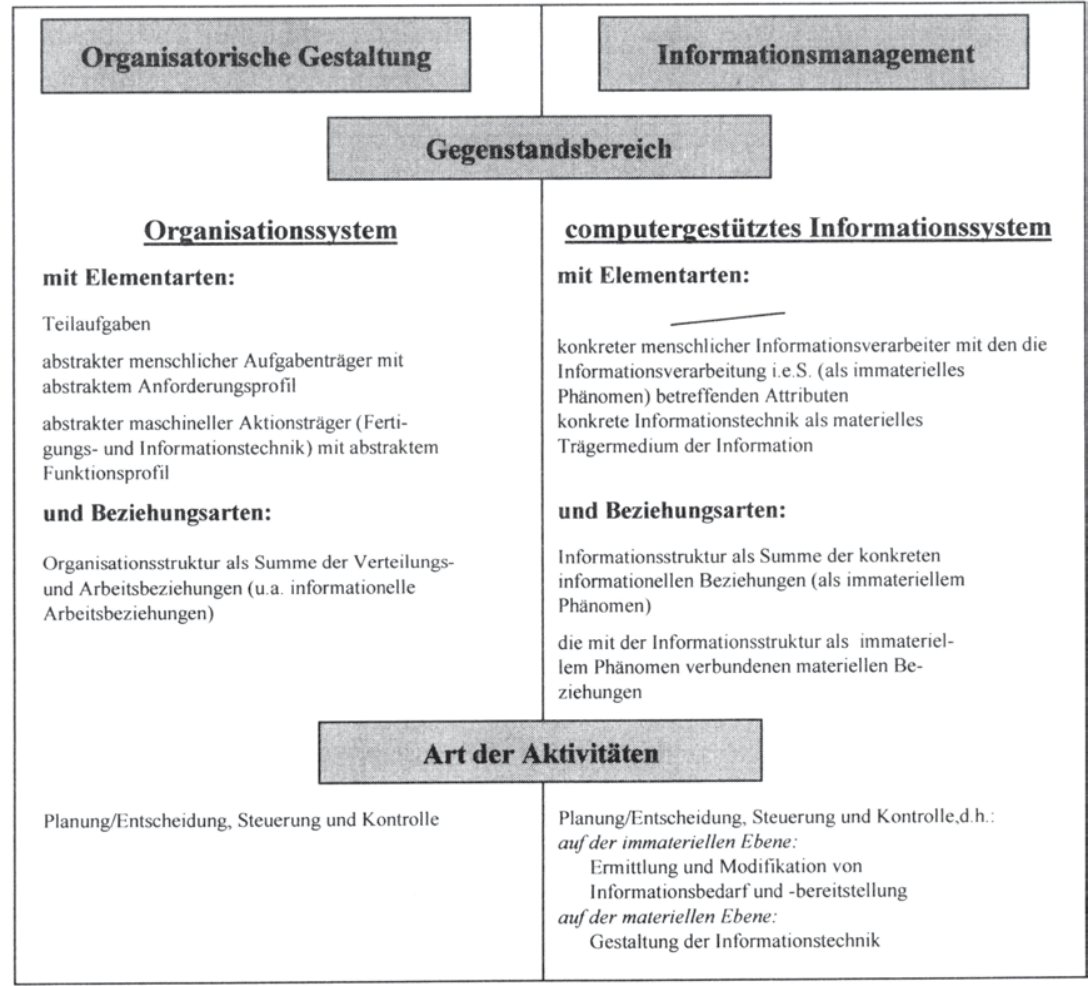

Tab. 2/17: Gegenüberstellung von organisatorischer Gestaltung und Informationsmanagement 
Neben den Teilaufgaben sind die abstrakten menschlichen Aufgabenträger und die $a b$ strakten maschinellen Aktionsträger weitere Elemente des Organisationssystems. Als Objekte der organisatorischen Gestaltung werden sie mit ihren Eigenschaftsprofilen als Attributen untersucht. Von der konkreten Person eines potentiellen Stelleninhabers bzw. der konkret eingesetzten Fertigungs- und Informationstechnik wird hier abstrahiert. Im Gegensatz dazu sind die konkreten menschlichen Informationsverarbeiter mit ihren die Informationsverarbeitung i.e.S. als immaterielles Phänomen betreffenden Attributen sowie die konkrete Informationstechnik mit ihren ihre Funktion als materielles Trägermedium der Information betreffenden Attributen Gegenstand des Informationsmanagements. Mensch und Informationstechnik werden im Rahmen von organisatorischer Gestaltung und Informationsmanagement also jeweils nicht mit der Gesamtheit ihrer Attribute als Elementarten des Systems Unternehmung, sondern nur bezüglich bestimmter Attribute betrachtet. Die Elemente von Organisations- und computergestütztem Informationssystem (als zweier Teilsysteme des Systems Unternehmung als Ganzen) unterscheiden sich somit eindeutig voneinander.

Über die genannten Elementarten hinaus besteht das Organisationssystem aus den organisatorischen Beziehungen (Organisationsstruktur), innerhalb derer zwischen Verteilungs- und Arbeitsbeziehungen zu unterscheiden ist. Die Arbeitsbeziehungen können einerseits materielle, andererseits immaterielle (informationelle) Input-OutputBeziehungen betreffen. Demgegenüber besteht das computergestützte Informationssystem aus konkreten informationellen Beziehungen (Informationsstruktur) als immateriellen Phänomenen sowie den mit diesen einhergehenden materiellen Beziehungen. Auf den ersten Blick ergeben sich hier somit scheinbar Abgrenzungsprobleme bezüglich der informationellen Arbeitsbeziehungen als Teil der Organisationsstruktur auf der einen und der Informationsstruktur auf der anderen Seite. Jedoch beziehen sich die organisatorischen Beziehungen auf menschliche Aufgaben- und maschinelle Aktionsträger als abstrakte Phänomene und vernachlässigen die konkrete Person des Stelleninhabers, die konkret eingesetzte Technik und situative Faktoren. Demgegenüber handelt es sich bei der Informationsstruktur um die konkreten informationellen Beziehungen zwischen konkreten Personen. Beispielsweise können sich organisatorische Regeln auf die Informationspflicht eines Mitarbeiters gegenüber seinem Vorgesetzten beziehen. Während im Rahmen der organisatorischen Gestaltung bei der Festlegung der informationellen Arbeitsbeziehung von den individuellen Präferenzen der konkreten Stelleninhaber abstrahiert wird, wird deren Einfluß bei der Betrachtung der konkreten informationellen Beziehungen (als Gegenstand des Informationsmanagements) berücksichtigt. Die in der konkreten Person des Vorgesetzten begründeten subjektiven Einflüsse können z.B. das Hinzufügen bestimmter im Rahmen der organisatorischen Gestaltung nicht vorgesehener Informationen oder deren veränderte Aufbereitung betreffen.

Vergleicht man abschließend Organisations- und computergestütztes Informationssystem als Gegenstandsbereiche von organisatorischer Gestaltung und Informationsma- 
nagement, so besteht der zentrale Unterschied zwischen ihnen in der Abstraktion bzw. expliziten Berücksichtigung von konkreten handelnden Personen, eingesetzten Techniken und den entsprechenden Beziehungen zwischen diesen.

Die Gegenüberstellung der Art der Aktivitäten der beiden Aufgabenfelder organisatorische Gestaltung und Informationsmanagement zeigt, daß es sich in beiden Fällen um Planung/Entscheidung, Steuerung und Kontrolle als Managementfunktionen handelt. Organisatorische Gestaltung und Informationsmanagement unterscheiden sich somit nicht aufgrund der Art ihrer Aktivitäten, sondern durch ihren jeweiligen Gegenstandsbereich.

Nachdem der Vergleich der jeweiligen Gegenstandsbereiche und Arten der Aktivitäten gezeigt hat, daß organisatorische Gestaltung und Informationsmanagement disjunkte Aufgabenfelder darstellen, ist in einem nächsten Schritt der grundsätzliche Kausalzusammenhang zwischen diesen beiden Managementaktivitäten zu untersuchen. Er wird im folgenden anhand des Kausalzusammenhangs zwischen den organisatorischen Regeln bezüglich des Informationsbedarfs und der Informationsbereitstellung (als Objekten der organisatorischen Gestaltung) auf der einen und dem Informationsbedarf und der Informationsbereitstellung (als Objekten des Informationsmanagements) auf der anderen Seite aufgezeigt.

Die organisatorischen Regeln stellen eine Gruppe von Einflußfaktoren auf Informationsbedarf und -bereitstellung als Objekten des Informationsmanagements dar. Für den Kausalzusammenhang zwischen organisatorischer Gestaltung und Informationsmanagement läßt dies schließen, daß die organisatorische Gestaltung das Informationsmanagement beeinflußt. Es bedeutet jedoch nicht, daß die organisatorische Gestaltung das Informationsmanagement determiniert. Denn neben den organisatorischen Regeln wirken in der konkreten Person des Stelleninhabers begründete subjektive sowie situative Einflußfaktoren auf Informationsbedarf und -bereitstellung. Die Aktivitäten des Informationsmanagements erstrecken sich zunächst auf die Ermittlung der aus diesen verschiedenen Einflußfaktoren resultierenden Informationsbedarfe und -bereitstellungen. Dabei müssen die organisatorischen Regeln gegebenenfalls operationalisiert werden. Diese Operationalisierung stellt jedoch selbst keine organisatorische Gestaltungsaktivität dar, sondern ist dem Informationsmanagement zuzuordnen. Als Analysetätigkeit muß sie den Aktivitäten zur Modifikation von Informationsbedarf und -bereitstellung notwendigerweise vorausgehen.

Die Aktivitäten des Informationsmanagements beschränken sich jedoch nicht auf die Ermittlung der aus den verschiedenen Einflußfaktoren resultierenden Informationsbedarfe und -bereitstellungen, sondern umfassen auch deren Modifikation. Dabei gilt es, vielfältige Aspekte zu berücksichtigen. Neben rein quantitativen Erwägungen, die insbesondere auf eine kostengünstige Informationsversorgung abstellen, handelt es sich dabei auch um qualitative Aspekte, wie z.B. die Arbeitszufriedenheit der Mitarbeiter oder datenschutzrechtliche Vorgaben. Die modifizierenden Aktivitäten des Informa- 
tionsmanagements können dazu führen, daß die daraus resultierenden Informationsbedarfe und -bereitstellungen eine Veränderung der entsprechenden organisatorischen Regeln erfordern. In diesem Fall beeinflußt das Informationsmanagement dann die organisatorische Gestaltung. Der Kausalzusammenhang zwischen organisatorischer Gestaltung und Informationsmanagement ist somit nicht uni-, sondern bidirektional. Die beiden Managementteilbereiche sind grundsätzlich interdependent.

Die obige Argumentation gilt nicht nur für die organisatorischen Regeln über Informationsbedarf und -bereitstellung als Attribute der abstrakten menschlichen Aufgabenträger und die Informationsbedarfe und -bereitstellungen als Attribute der konkreten menschlichen Informationsverarbeiter. Vielmehr kann sie analog auch auf die abstrakten informationellen Arbeitsbeziehungen als Ergebnis organisatorischer Gestaltungsaktivitäten und als eine von mehreren Einflußgrößen der konkreten informationellen Beziehungen, die Gegenstand des Informationsmanagements sind, übertragen werden.

Betrachtet man schließlich die beiden Ebenen des Informationsmanagements, so ist davon auszugehen, daß die die immaterielle Ebene betreffenden Aktivitäten grundsätzlich denen bezüglich der materiellen Ebene vorausgehen. Im Mittelpunkt des Informationsmanagements steht nämlich die optimale Informationsversorgung der Mitarbeiter der Unternehmung zum Zwecke der Erfüllung ihrer Teilaufgaben im Rahmen des betrieblichen Leistungserstellungsprozesses. Das bedeutet, daß die auf semantische und pragmatische Aspekte bezogenen Gestaltungsaktivitäten der immateriellen Ebene grundsätzlich handlungsleitend gegenüber den auf syntaktische Aspekte beschränkten Gestaltungsaktivitäten der materiellen Ebene sind. Gemäß dieser Perspektive sind die auf die materielle Ebene bezogenen Aktivitäten des Informationsmanagements 'Mittel zum Zweck'. Gegen eine einseitige Abhängigkeit der materiellen von der immateriellen Ebene des Informationsmanagements spricht jedoch, daß Veränderungen der am Markt verfügbaren Informationstechnologie zu völlig neuartigen Lösungen auf der materiellen Ebene des computergestützten Informationssystems führen können. Diese wiederum können Änderungen auf der immateriellen Ebene des Informationsmanagements möglich machen. In diesem Zusammenhang kann die Informationstechnik als 'Enabler' bezeichnet werden. Somit ist der Kausalzusammenhang zwischen der immateriellen und der materiellen Ebene des Informationsmanagements nicht uni-, sondern grundsätzlich bidirektional.

Die Interdependenz der beiden Ebenen des Informationsmanagements bedingt, daß nicht nur Veränderungen des Organisationssystems Veränderungen der Informationsstruktur und diese wiederum Veränderungen der Informationstechnik bewirken können. Gleichwohl sollte es sich dabei um die Wirkungskette mit der größten praktischen Relevanz handeln. In der Literatur wird eine solche Perspektive auch unter dem Schlagwort 'Organisation vor Technik' bzw. als 'Primat der Organisation gegenüber der 
Technik' diskutiert. ${ }^{251}$ Vielmehr ist umgekehrt auch der Fall denkbar, daß der Einsatz neuartiger Informationstechnik andere Lösungen auf der Ebene der Informationsstruktur ermöglicht, die wiederum zu Veränderungen der organisatorischen Lösungen führen. ${ }^{252}$ Diesen grundsätzlichen Zusammenhang zwischen dem Organisationssystem (als Gegenstand der organisatorischen Gestaltung) sowie Informationsstruktur und Informationstechnik (als Gegenstandsbereichen des Informationsmanagements) visualisiert Abbildung 2/18.

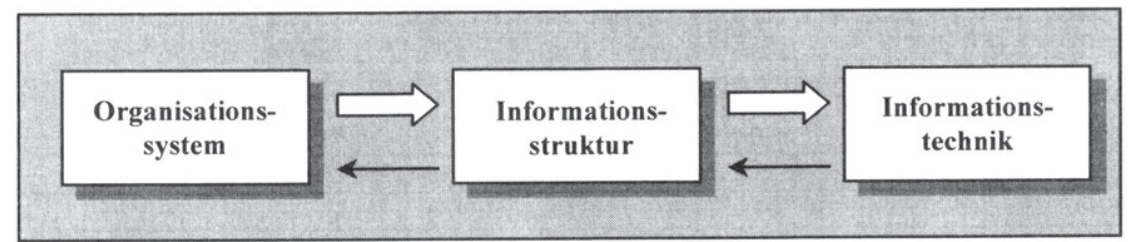

Abb. 2/18: Der Kausalzusammenhang zwischen Organisationssystem, Informationsstruktur und Informationstechnik

Mit der Konzeptionalisierung des grundlegenden Zusammenhangs zwischen organisatorischer Gestaltung und Informationsmanagement ist ein weiteres Zwischenziel als Voraussetzung der Erreichung des zentralen Zieles der vorliegenden Arbeit (Untersuchung des Beitrages des Informationsmanagements zur Förderung organisationalen Lernens) erreicht.

251 Vgl. Krüger (1994), S. 17.

252 Vgl. Widmer (1990), S. 5. 
Frauke Streubel - 978-3-631-75510-5

Downloaded from PubFactory at 01/11/2019 04:00:13AM 


\section{Unternehmungsinterner Wandel durch organisationales Lernen}

Die Diskussion um Wandelprozesse ist in der aktuellen Managementliteratur allgegenwärtig. Regelmäßig wird der Wandel dabei als problematisch für die Unternehmungsführung thematisiert, und es werden Wege aufgezeigt, diesem Problem zu begegnen. ${ }^{1}$ Managementkonzepte organisationalen Lernens postulieren die lernende Unternehmung, die besser als traditionell geführte Unternehmungen geeignet sei, den aus externen Wandelprozessen resultierenden Herausforderungen zu begegnen. Die Argumentation beruht dabei - zumindest implizit - auf zwei zentralen Prämissen: Erstens wird angenommen, daß es organisationales Lernen gibt und daß es von anderen Phänomenen, die im Zusammenhang mit Veränderungsprozessen diskutiert werden, unterschieden werden kann. ${ }^{2}$ Denn nur wenn es sich bei organisationalem Lernen um ein eigenständiges Phänomen handelt, das insbesondere nicht deckungsgleich mit der Summe der individuellen Lernprozesse in der Unternehmung ist, ist es sinnvoll, dieses zum Gegenstand einer eigenständigen Analyse zu machen. Zweitens gehen Managementkonzepte organisationalen Lernens davon aus, daß sich organisationales Lernen positiv auf die Fähigkeit der Unternehmung auswirkt, unternehmungsexternem Wandel zu begegnen. ${ }^{3}$

Die Überprüfung der beiden Prämissen erweist sich indes als problematisch: Die meisten Arbeiten in diesem Forschungsbereich basieren auf einer äußerst diffusen Begriffsbildung, die einer näheren Überprüfung nicht standhält. Die theoretische Aufarbeitung organisationalen Lernens als eigenständigen Phänomens erweist sich häufig als mangelhaft. Hierdurch wird die Konzeptionalisierung des Zusammenhangs zwischen organisationalem Lernen und Wandelprozessen von vornherein unmöglich. Dies wird in der Regel auch gar nicht versucht. Stattdessen wird zumeist undifferenziert ein positiver Zusammenhang zwischen der Gesamtheit aller organisationalen Lernprozesse und der Fähigkeit, unternehmungsexternen Wandel zu bewältigen, postuliert. ${ }^{4}$

Aus diesen in der Literatur beobachteten Defiziten leitet sich das Erkenntnisziel des folgenden Kapitels ab: Es gilt, den Zusammenhang zwischen unternehmungsexternem Wandel als Ausgangsproblematik der vorliegenden Arbeit und organisationalem Lernen als möglicher Antwort darauf zu konzeptionalisieren. Dabei ist zu prüfen, ob die Ge-

1 So stellte Hayek bereits 1945 fest, daß Wandel die Ursache aller ökonomischen Probleme sei. Vgl. Hayek (1945), S. 523. Als Beispiele für aktuelle Arbeiten, die das Phänomen des Wandels und seine Bewältigung in der Unternehmung in den Mittelpunkt ihrer Ausfuhrungen stellen, sei hier auf Bierfelder (1991), passim; Carnall (1990), passim; Gerstner (1995), passim; Gomez/Muller-Stewens (1994), passim; Meyer/Goes/Brooks (1993), passim; Perich (1993), passim; Ulrich (1994), passim und Zahn (1991), passim verwiesen.

2 Vgl. z.B. Klimecki/Probst/Eberl (1991), S. 127ff., insbesondere S. 129.

3 Vgl. Bernskötter (1997), S. 30; Probst (1994), S. 309; Probst/Büchel (1994), S. 3ff.; Wiegand (1996), S. 8.

$4 \quad$ Vgl. Bernskötter (1997), S. 30; Probst/Büchel (1994), S. 3 ff. 
samtheit der Prozesse organisationalen Lernens zielführend für die Befähigung der Unternehmung zur Bewältigung des unternehmungsexternen Wandels ist oder ob dies nur für bestimmte organisationale Lernprozesse gilt. Dies setzt einerseits die inhaltliche Eingrenzung des Begriffes des organisationalen Lernens voraus. Andererseits muß aber auch das Phänomen des unternehmungsexternen Wandels näher untersucht werden. Entsprechend ist das folgende Kapitel in drei Abschnitte gegliedert: Abschnitt 3.1 beleuchtet zunächst das Phänomen des Wandels. Sodann wird in Abschnitt 3.2 geklärt, was im folgenden unter organisationalem Lernen verstanden wird. Nach dieser isolierten Darstellung der beiden Phänomene wird schließlich in Abschnitt 3.3 der Zusammenhang zwischen Wandel und organisationalem Lernen herausgearbeitet. Während im folgenden Kapitel also zunächst ein umfassender Diskussionsrahmen aufgespannt wird, der verdeutlicht, welche Phänomene grundsätzlich unter den Begriff des organisationalen Lernens subsumiert werden können, wird dieser im weiteren Verlauf der Argumentation auf die spezifische Perspektive der vorliegenden Arbeit verengt, die nur diejenigen Prozesse organisationalen Lernens fokussiert, die zielführend bezüglich der Bewältigung bestimmter Prozesse unternehmungsexternen Wandels sind. Abbildung 3/1 zeigt die Argumentationsstruktur des dritten Kapitels im Überblick.

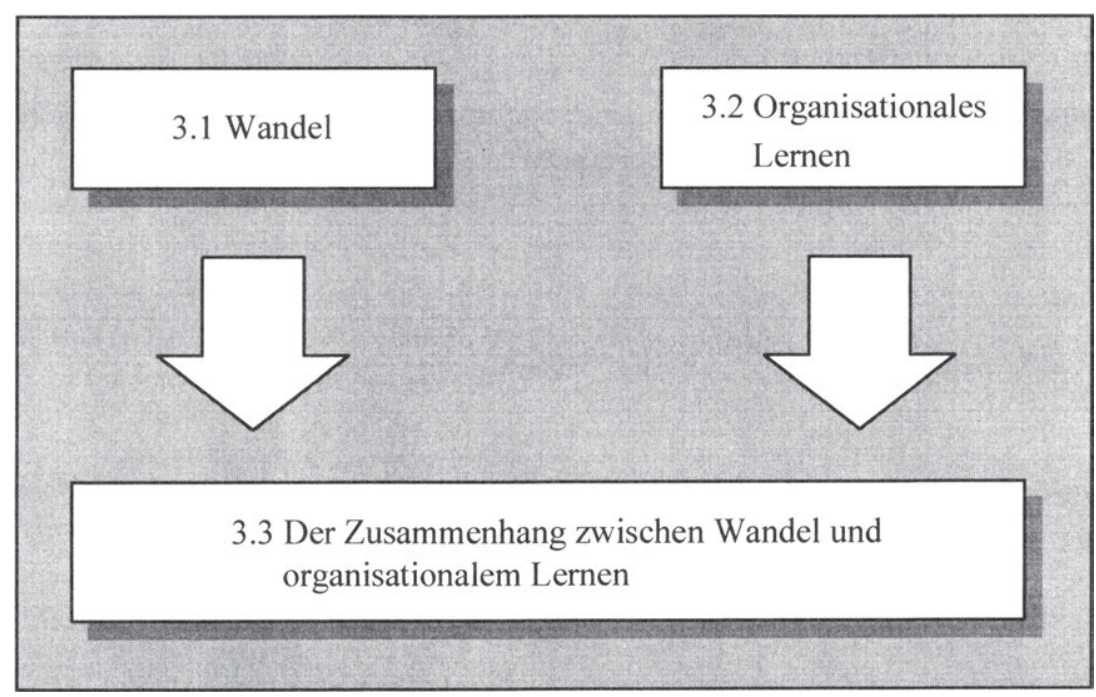

Abb. 3/1: Die Argumentationsstruktur des dritten Kapitels

\subsection{Das Phänomen des Wandels}

Im Rahmen einer komparativ-statischen Betrachtungsweise kann man Wandel als die beobachtete Differenz der Ausprägungsgrade mindestens eines Merkmals eines Bezugs- 
objektes zwischen mindestens zwei Zeitpunkten definieren. Die Beobachtbarkeit des Wandels setzt voraus, daß er sich auf materielle Objekte oder Handlungen von Menschen bezieht. Geistige Veränderungen werden dagegen in der vorliegenden Arbeit nicht als Wandel bezeichnet. Für eine dynamische Betrachtung muß die komparativ-statische Perspektive über die bloße Feststellung der Veränderung des Bezugsobjektes (als Ergebnis) hinaus um den Prozeß der Veränderung und seine Determinanten erweitert werden. ${ }^{5}$

In der Literatur werden verschiedene Möglichkeiten zur Systematisierung von Wandelprozessen genannt, so z.B. in geplanten und ungeplanten oder in inkrementalen und revolutionären Wandel. ${ }^{6}$ Im Rahmen der Ausführungen dieser Arbeit kommt der Unterscheidung zwischen unternehmungsexternem und -internem Wandel besondere Bedeutung zu. Im folgenden wird zunächst der unternehmungsexterne Wandel, d.h. der Wandel der relevanten Umwelt der Unternehmung, als Herausforderung für die Unternehmungsführung erläutert (Abschnitt 3.1.1). Sodann wird die daraus resultierende Notwendigkeit unternehmungsinternen Wandels thematisiert (Abschnitt 3.1.2). Diese spiegelt sich in dem strategischen Ziel der 'Befähigung zu unternehmungsinternem Wandel' wider.

\subsubsection{Unternehmungsexterner Wandel als Herausforderung für die Unternehmungsführung}

Zahllose Arbeiten im Bereich der Managementliteratur beschwören heute die Auswirkungen der vielfältigen und fundamentalen unternehmungsexternen Wandelprozesse auf die moderne Unternehmungsführung, die in noch nie dagewesener Weise Gesellschaft und Wirtschaft prägen. MINTZBERG kritisiert dagegen, daß ein näheres Sichten auch älterer Literatur schnell offenbart, daß es sich dabei um eine seit Jahrzehnten gepflegte Standardaussage der Managementlehre handelt. ${ }^{7}$ So bemerkte der amerikanische Philosoph und Systemtheoretiker CHURCHMAN bereits 1973:

„... Natürlich sollten wir uns um die dringendsten Probleme kümmern; wir sollten aber auch erkennen, daß wir als Individuen zwischen zweierlei stehen: einer Vergangenheit mit all ihrer Fülle und einer Zukunft mit all ihrer Fülle. Wir sollten nicht mehr sagen: zum ersten Mal in der Geschichte stehen wir vor bisher nie dagewesenen Wandlungen und Verflechtungen. Der Mensch steht eben nicht zum ersten Mal in seiner Geschichte vor nie dagewesenen Wandlungen und Verflechtungen. Er hat allerdings nicht immer gerade diese Worte gebraucht, die wir so lieben - noch nie dagewesene Wandlungen und Verflechtungen; es klingt so gut.

5 Vgl. ähnlich Steinle (1985), S. 37, 447ff.; Türk (1989), S. 52. Dagegen umfaßt der Begriff des Wandels z.B. bei Ulrich (1994), S. 15f., neben materiellen auch geistige Veränderungen.

6 Vgl. z.B. Staehle (1994), S. 849ff. Einen breiten, theoretisch fundierten Überblick über Wandelphänomene bietet Perich, der in seiner Arbeit die drei Dimensionen 'Gegenstandsbereich des Wandels' (Was?), 'Ursachen' (Warum?) und 'Verlaufsformen' (Wie?) unterscheidet. Vgl. Perich (1993), S. $120 \mathrm{ff}$.

7 Vgl. Mintzberg (1994), S. 206f. 
Aber auch andere Zeitalter haben ihre Probleme gehabt, auch jene Probleme waren in ihrer Verflechtung und Wandlung noch nie dagewesen." ${ }^{\text {" }}$

Wandel an sich ist also kein neues Phänomen. Vielmehr war und ist er Bestandteil allen menschlichen Lebens, so auch des Wirtschaftslebens. Auch in der Vergangenheit waren Menschen und Unternehmungen mit Veränderungen ihres sozialen, kulturellen, technischen und ökonomischen Umfeldes konfrontiert. Diese Veränderungen sind grundsätzlich mit Chancen und Risiken verbunden, wobei es für die einzelne Unternehmung gilt, die Chancen zu nutzen und die Risiken zu vermeiden. Die Bedeutung, die dem Wandel heute in Theorie und Praxis zugemessen wird, resultiert also nicht daraus, daß Veränderungen der Umfeldsituation für diese neu sind. Neu sind dagegen die folgenden beiden Charakteristika von Wandelprozessen.

Als erstes ist hier die in der jüngeren Vergangenheit gestiegene Dynamik der unternehmungsexternen Wandelprozesse zu nennen. Das bedeutet nicht etwa, daß die Umwelt der Unternehmung sich permanent wandelt. Vielmehr wechseln weiterhin Phasen der Stabilität solche des Wandels ab. Allerdings werden die Phasen der Stabilität immer häufiger durch Wandelprozesse durchbrochen, so daß die relative Häufigkeit von Wandelprozessen steigt. Darüber hinaus erfahren die Wandelprozesse selbst heute eine rasante Beschleunigung, d.h. sie laufen immer schneller ab. ${ }^{9}$ Zentrale Einflußfaktoren, die zu der erhöhten Dynamik unternehmungsexterner Wandelprozesse geführt haben, sind

- der zunehmende Wettbewerb auf Massenmärkten mit Marktsättigungserscheinungen, der zu einem Wandel von Verkäufer- zu Käufermärkten führt,

- die Globalisierung der Märkte, die Öffnung der osteuropäischen Märkte sowie die Schaffung des Europäischen Binnenmarktes, die zu einer deutlichen Verschärfung des Wettbewerbs führen,

- verkürzte Produktlebenszyklen, die dazu führen, daß Zeit einen zentralen Erfolgsfaktor darstellt sowie

- eine Vielzahl wichtiger Weiterentwicklungen im Bereich der Technologie und insbesondere der Informationstechnologie. ${ }^{10}$

Als zweites Charakteristikum aktueller Wandelprozesse ist ihr häufig diskontinuierlicher Verlauf zu nennen. Zwar existierten diskontinuierliche Wandelprozesse auch in der Vergangenheit, jedoch treten sie im letzten Drittel des 20. Jahrhunderts in verschiedenen Bereichen des relevanten Umfeldes der Unternehmungen immer häufiger auf." So prognostizierten EMERY/TRIST bereits 1965 eine höhere Komplexität und Unsicher-

\footnotetext{
Churchman (1973), zitiert nach Ulrich (1994), S. 6f.

9 Vgl. Klimecki/Probst/Eberl (1994), S. 6ff.; Schanz (1992), Sp. 1461; Schüppel (1996), S. 4; Ulrich (1994), S. 7.

10 Vgl. Gerstner (1995), S. 19; Perich (1993), S. $13 \mathrm{ff}$.

11 Vgl. Perich (1993), S. 1; Schüppel (1996), S. 7.
} 
heit zukünftiger Entwicklungen und DRUCKER sprach 1969 gar von einem anbrechenden 'Zeitalter der Diskontinuität'. ${ }^{12}$ Im Gegensatz zu allmählichen, kontinuierlichen Veränderungen, bei denen die Entwicklungen der Vergangenheit in die Zukunft fortgeschrieben werden können, zeichnen sich diskontinuierliche Wandelprozesse dadurch aus, daß sie vom Beobachter so nicht prognostiziert werden. Das Auftreten von Diskontinuitäten bedeutet jedoch nicht, daß keinerlei Muster in der Entwicklung der Unternehmungsumwelt zu erkennen sind. Der Beobachter ist nicht etwa ausschließlich mit - aus seiner Sicht - Zufälligkeiten konfrontiert, sondern erlebt von ihm unvorhergesehene Brüche in der Umweltentwicklung, so daß die Umwelt für ihn in bestimmten Teilen vorhersehbar, in anderen nicht vorhersehbar ist.

Einen wichtigen Grund für die Diskontinuität externer Wandelprozesse stellt die hohe Komplexität der Umwelt dar. Komplexität ergibt sich aus der Vielzahl und Unterschiedlichkeit von Elementen und Beziehungen zwischen diesen (Kompliziertheit) in Verbindung mit deren hoher Änderungsdynamik im Zeitablauf. ${ }^{13}$ Steigt die Zahl der Elemente, so steigt die Zahl der möglichen Beziehungen zwischen ihnen progressiv an. Die beschränkte Verarbeitungskapazität des wahrnehmenden Subjektes bedingt, daß dieses nicht alle Elemente und insbesondere nicht alle Beziehungen betrachten kann. Komplexität zwingt also zu Selektion. Es wird unmöglich, alle Zusammenhänge wahrzunehmen, zu verstehen und zu berücksichtigen. ${ }^{14}$ Das Fokussieren bestimmter Elemente und Beziehungen und das Ausblenden anderer führt zu einem der hochkomplexen Realität nur bedingt gerecht werdenden Modell, so daß es immer wieder zu in dieser Form vom betrachtenden Subjekt nicht erwarteten Entwicklungen kommt, die es dann als Diskontinuitäten wahrnimmt. ${ }^{15}$ Diese Begründung der Diskontinuität der unternehmungsexternen Wandelprozesse durch die Wahrnehmung des menschlichen Subjektes zeigt die konstruktivistische Grundposition der vorliegenden Arbeit: Diskontinuierliche Umweltentwicklungen sind nicht 'objektive Wirklichkeit', sondern menschliche Konstruktion.

Neben technischen Entwicklungen betreffen die beobachteten Diskontinuitäten bzw. die ihnen zugrundeliegende Komplexität vor allem die sozialen Interaktionen, die durch die hohe Wahlfreiheit von Individuen und Gruppen im Rahmen einer postmodernen Gesellschaft mit vielfältigen Lebensentwürfen und Handlungsmustern heute besonders stark ausgeprägt sind. Darüber hinaus nimmt aufgrund der enormen Vermehrung von Wissen bei steigender Vernetzung zwischen sehr unterschiedlichen Variablen der Unternehmungsumwelt die Intransparenz von Zusammenhängen zu, d.h. Ursache und Wirkung

12 So lautet der Titel des von Drucker 1969 veröfentlichten Werkes 'The Age of Discontinuity'. Vgl. Drucker (1969), o.S.; Emery/Trist (1965), S. 26.

13 Siehe Abschnitt 2.1.3 der vorliegenden Arbeit.

14 Vgl. Probst (1987), S. 29; Knyphausen (1988), S. 280ff.

15 Knyphausen (1988), S. 287 stellt in diesem Zusammenhang fest, daß es zwar ein Wissen darüber gibt, daß ,alles mit allem irgendwie zusammenhängt“. Trotzdem muß das wahrnehmende Subjekt die Komplexităt der Welt reduzieren, um sich in ihr orientieren zu können. 
sind seltener eindeutig aufeinander bezogen und Rückkoppelungsprozesse sind schwieriger zuzuordnen. ${ }^{16}$

Da die Unternehmung als offenes System in dynamischer Wechselwirkung mit ihrem Umfeld steht, wird sie durch unternehmungsexterne Wandelprozesse beeinflußt. ${ }^{17}$ Geht man - der situativen Denktradition folgend - von einem anzustrebenden Fit zwischen Unternehmung und Umwelt aus, ${ }^{18}$ so muß es Ziel der Unternehmungsführung sein, Veränderungen der Unternehmung derart zu initiieren, daß sich diese an die Veränderungen der Umwelt anpaßt oder sie gar antizipiert. ${ }^{19}$ Die situative Prägung der Argumentation ist dabei nicht etwa im Sinne der heute als überholt geltenden traditionellen situativen Ansätze zu verstehen, die von einem deterministischen, mechanistischen Zusammenhang zwischen der Situation der Unternehmung und den Aktionsparametern des Managements ausgingen. Denn eine solche isolierte und totale Anwendung des situativen Gedankens macht letztlich wissenschaftliche Aussagen zu Managementproblemen unmöglich. ${ }^{20}$ Vielmehr steht die vorliegende Arbeit verhaltenswissenschaftlich geprägten Weiterentwicklungen des situativen Gedankengutes nahe und stellt auf die allen situativ geprägten Arbeiten gemeinsame Kernthese ab, gemäß derer Managementaktivitäten in Abhängigkeit von der jeweiligen Situation unterschiedlich effizient sind. ${ }^{21}$ In dieser weiten Fassung ist die situative Relativierung ${ }^{22}$ der Managementaktivitäten mit der systemtheoretischen Argumentation, die die Unternehmung als offenes System im permanenten Austausch mit seiner Umwelt sieht, vereinbar. ${ }^{23}$ Die Forderung nach einem Fit zwischen Unternehmung und Umwelt führt dazu, daß aus den oben beschriebenen Charakteristika aktueller unternehmungsexterner Wandelprozesse die folgenden Herausforderungen an das Management resultieren:

Aufgrund der erhöhten Dynamik des unternehmungsexternen Wandels sinkt die für die Unternehmung verfügbare Reaktionszeit. Gleichzeitig steigt jedoch in der heutigen vernetzten, interdependenten Welt, die zudem von großen Mengen verfügbarer Daten geprägt ist, tendenziell die zur Bewältigung der hochkomplexen Entscheidungen benötigte Reaktionszeit. Die Tendenz zu längeren Reaktionszeiten wird - insbesondere in großen Unternehmungen - verstärkt durch die sozialen Systemen grundsätzlich innewohnenden strukturellen und kulturellen Erstarrungstendenzen. Aus diesen Einflußfaktoren resultiert eine immer weiter aufklaffende Zeitschere zwischen benötig-

16 Vgl. Klimecki/Probst/Eberl (1991), S. 108f.; Pawlowski (1994), S. 179ff.; Schüppel (1996), S. 6.

17 Vgl. Schüppel (1996), S. 7, der in diesem Zusammenhang von der Umweltkoppelung der Unternehmung spricht.

18 Vgl. Gomez/Zimmermann (1992), S. 118f.; Hahn (1994), S. 67.

19 Vgl. Bleicher (1992a), S. 21 ff.; Gomez/Zimmermann (1992), S. 112.

20 Vgl. Gaugler (1994), S. 252.

21 Für einen Überblick über situative organisationstheoretische bzw. Management-Ansătze vgl. z.B. Kieser/Kubicek (1992), S. 33ff.; Schulte-Zurhausen (1995), S. 19ff.; Staehle (1994), S. $47 \mathrm{ff}$.

22 Vgl. Meyer (1988), S. 194.

23 Im Gegensatz hierzu ist der traditionelle situative Ansatz mit den Erkenntnissen der modernen Systemtheorie prinzipiell nicht vereinbar. Vgl. ăhnlich Wiegand (1996), S. 135. 
ter und verfügbarer Reaktionszeit. ${ }^{24}$ Die Aktivitäten der Unternehmungsführung müssen deshalb darauf abzielen, diese Zeitschere so weit wie möglich zu schließen.

Auch heute noch sind in zahlreichen Unternehmungen ausgeprägte Abwehrprozesse gegen jegliche Art von Veränderungen zu beobachten. Anstelle eines aktiven Umgangs mit dem Phänomen Wandel versucht man, Wandel so weit wie irgend möglich zu ignorieren. Nahezu automatisch wird er negativ bewertet bzw. von den Betroffenen als Bedrohung empfunden und als Ausnahme vom Regelfall der Stabilität angesehen. In der Managementlehre zeigt sich diese Geisteshaltung in der Fülle statischer und komparativ-statischer Modelle, die dynamische Aspekte entweder ganz aus der Betrachtung ausklammern oder nur als Übergangsstadium zwischen unterschiedlichen Ausprägungen der Stabilität wahrnehmen. ${ }^{25}$ Die komparativ-statische Gleichgewichtslogik spiegelt sich z.B. in dem von LEWIN entwickelten, in der betriebswirtschaftlichen Literatur auch heute noch häufig zitierten organisatorischen Änderungsgesetz wider, das erfolgreichen Wandel als eine Abfolge der drei Phasen Auftauen, Verändern und Stabilisieren formuliert. In der Phase des Auftauens verläßt das System sein Ausgangsgleichgewicht, um nach der Veränderung im Rahmen der Stabilisierung in einen neuen Gleichgewichtszustand zu gelangen. Gleichgewicht wird hier als Normalfall, Veränderung bzw. Wandel als Ausnahme konzipiert. ${ }^{26}$ Die Realität sieht jedoch oft anders aus: Die gestiegene relative Häufigkeit von Phasen des Wandels gegenüber solchen der Stabilität erlaubt es nicht länger, Wandel als Ausnahme vom Regelfall der Stabilität anzusehen. Stattdessen sind dynamische Modelle notwendig, die häufige Wandelprozesse als Normalfall der betrieblichen Realität berücksichtigen.

Auch der hohe Anteil diskontinuierlicher Wandelprozesse stellt die Unternehmungsführung vor neue Aufgaben. Die mangelnde Vorhersehbarkeit zukünftiger Entwicklungen führt dazu, daß das traditionelle Managementverständnis, das von der Grundidee der 'plandeterminierten Unternehmungsführung' ausgeht, an Effektivität verliert. Im Rahmen traditioneller Ansätze, die einer analytisch-linearen Denktradition folgen, versteht man Unternehmungsführung als systematische Abfolge der Phasen bzw. Aktivitäten Planung/Entscheidung, Steuerung und Kontrolle und rechnet der Planung den geistigen Entwurf künftiger Ziele und der zur Zielerreichung zu ergreifenden Maßnahmen zu. Da alle anderen Managementaktivitäten der Erreichung dieser Ziele dienen, geht man von einem 'Primat der Planung' gegenüber den anderen Teilaktivitäten aus. Letztere haben keine eigenständige (Um-)Steuerungskapazität bezüglich der im Rahmen der Planung formulierten Ziele und Maßnahmen. Während kontinuierliche Wandelprozesse im Rahmen von Planungsaktivitäten (z.B. durch Trendextrapolation) vergleichsweise problemlos berücksichtigt werden können, führen Diskontinuitäten in der Umweltentwicklung häufig dazu, daß die tatsächlichen unternehmungsexternen

\footnotetext{
Vgl. Bleicher (1995a), S. 390f.

Vgl. Perich (1993), S. 3ff., $30 \mathrm{ff}$.

Vgl. Lewin (1958), S. $210 \mathrm{f}$.
} 
Veränderungen von den Annahmen der Planung abweichen. Die langfristige Planung wird immer störungsanfälliger und schwieriger. Moderne Managementansätze sollten sich deshalb von der Idee der plandeterminierten Unternehmungsführung abwenden und die Aufgabe des Managements eher im Schaffen von Rahmenbedingungen für flexibles Agieren und Reagieren und damit im Öffnen von Handlungsspielräumen sehen. ${ }^{27}$

Abschließend sei darauf hingewiesen, daß die geschilderten Phänome der hohen Dynamik des Wandels und des häufigen Auftretens von Diskontinuitäten keineswegs in der relevanten Umwelt aller Unternehmungen beobachtet werden können. ${ }^{28}$ Auch ist die Formulierung 'die Umwelt' mißverständlich, da keinesfalls von der Umwelt im Sinne einer Umwelt, die sich in ihrer Gesamtheit entweder verändert oder aber konstant bleibt, auszugehen ist. Vielmehr ist das Phänomen Umwelt aufzuspalten in eine Vielzahl von Teilbereichen, von denen in einigen problematische Wandelphänomene beobachtet werden, in anderen dagegen nicht. Darüber hinaus wechseln Phasen schnellen und langsamen Wandels sowie Phasen der Stabilität bzw. Kontinuität mit solchen der Diskontinuität. Die weiteren Ausführungen der vorliegenden Arbeit beziehen sich auf solche Unternehmungen, in denen das Management, an dessen Sichtweise die Arbeit ausgerichtet ist, sich mit hochdynamischen und diskontinuierlichen unternehmungsexternen Wandelprozessen konfrontiert sieht. Somit sind die nachfolgenden Aussagen relativ, d.h. sie stehen in unmittelbarem Bezug zu den getroffenen Annahmen bezüglich des beobachtenden Subjektes und dem von diesem beobachteten Umwelt-Zusammenhang.

\subsubsection{Die Befähigung zu unternehmungsinternem Wandel als Gegen- stand der Unternehmungsstrategie}

Unternehmungen stehen in einem hochdynamischen und diskontinuierlichen Umfeld immer wieder neu vor der Aufgabe, die Auswirkungen der Umwelt auf ihre Position zu erkennen und diesen zu begegnen, um den notwendigen Fit zwischen sich und der Umwelt herzustellen. Dieser Fit sichert die Wettbewerbsposition der Unternehmung am Markt und damit letztlich ihre langfristige Überlebensfähigkeit. Entsprechend muß die Bewältigung des unternehmungsexternen Wandels als strategisches Ziel in das Zielsystem der Unternehmung aufgenommen werden. Aus diesem Ziel lassen sich nunmehr verschiedene Strategien ableiten. Grundsätzlich kann man dabei zwischen folgenden drei Möglichkeiten unterscheiden:29

27 Für eine ausfuhrlichere Darstellung und kritische Würdigung der Idee der 'plandeterminierten Unternehmungsfuhrung' vgl. Ansoff/Declerck/Hayes (1986), S. 479ff.; Steinmann/Schreyögg (1993), S. $119 \mathrm{ff}$.; Sydow (1992), S. 238ff.

28 So auch Wiegand (1996), S. 473ff., der kritisiert, daß die Idee des Fit zwischen Unternehmung und Umwelt heute of ubertrieben reduziert werde, wenn man nur noch komplexe und turbulente Umwelten diagnostiziert.

$29 \mathrm{Vgl}$. dazu und im folgenden Ulrich (1994), S. 24f. 
- Strategie der Veränderung der relevanten Umwelt:

Die Unternehmung versucht, sich gegen einen Teil der externen Wandelprozesse abzuschirmen und beschränkt die Anpassung auf einige zentrale Aspekte, d.h. sie verkleinert die für sie relevante Umwelt oder aber sie versucht, stabilisierend auf ihre relevante Umwelt einzuwirken.

- Strategie des Zeitgewinns durch Frühwarnung:

Die Unternehmung versucht, durch frühzeitiges Erkennen von Wandelprozessen Zeit für die eigene Anpassung zu gewinnen.

- Strategie der erhöhten unternehmungsinternen Wandelfähigkeit ${ }^{30}$ :

Die Unternehmung versucht, ihre eigene Wandelfähigkeit zu erhöhen, so daß sie auch auf unvorhergesehene Veränderungen ihrer Umwelt mit internem Wandel reagieren kann.

Diese drei grundsätzlichen Varianten können alternativ, aber auch in Kombination gewählt werden. Die Vielzahl der die Unternehmung beeinflussenden unternehmungsexternen Wandelprozesse bedingt, daß sich in der betrieblichen Praxis in der Regel die Kombination aller drei Strategiealternativen empfiehlt. Die Untersuchung der vorliegenden Arbeit beschränkt sich auf die dritte Strategie. Es soll untersucht werden, welche Möglichkeiten sich der Unternehmung bieten, um ihre interne Wandelfähigkeit zu erhöhen.

Die Befähigung zu unternehmungsinternem Wandel sei hier verstanden als das Änderungsvermögen der Unternehmung, das im Bedarfsfall aktiviert werden kann. ${ }^{31}$ Dieses Änderungsvermögen umfaßt neben der sachlichen Dimension (die Unternehmung kann Änderungsprozesse tatsächlich durchführen) auch die zeitliche (die Unternehmung kann die Änderungsprozesse in einem bestimmten Zeitrahmen durchführen). Über die Reaktionsfähigkeit auf unternehmungsexterne Wandelprozesse im Sinne einer ex post-Anpassung hinaus kann dieses Änderungsvermögen auch antizipativer Natur sein und wird dann als Aktionsfähigkeit bezeichnet. ${ }^{32}$

Geht man einerseits von hochdynamischen und diskontinuierlichen Wandelprozessen in der relevanten Umwelt der Unternehmung und andererseits davon aus, daß zur Herstellung des Fit zwischen Unternehmung und Umwelt lediglich Strategien zur Erhöhung der internen Wandelfähigkeit betrachtet werden sollen, muß die Unternehmung mit entsprechenden internen Wandelprozessen reagieren: Der hohen Dynamik externer Wandelprozesse begegnet sie dann durch schnellen und häufigen internen Wandel, der

30 In der Literatur findet sich an dieser Stelle üblicherweise der Begriff 'Flexibilităt'. Im Rahmen der vorliegenden Arbeit werden dagegen die Begriffe 'interne Wandelfahigkeit' oder 'Befähigung zu unternehmungsinternem Wandel' als Synonyma für Flexibilităt verwendet, da dadurch der Gegensatz zwischen untemehmungsexternem Wandel als der Umweltsituation und unternehmungsinternem Wandel als der Reaktion der Unternehmung sprachlich besser zur Geltung kommt.

31 Vgl. Knof(1992), S. 67.

32 Vgl. Corsten (1988), o.S.; Schanz (1992), Sp. 1465. 
Diskontinuität der Umweltentwicklung mit grundlegendem internen Wandel. Aus der in Abschnitt 3.1.1 als Ausgangsproblematik der vorliegenden Arbeit skizzierten Umweltsituation resultiert somit die Notwendigkeit für die Unternehmungsführung, schnelle, häufige und grundlegende ${ }^{33}$ unternehmungsinterne Wandelprozesse $\mathrm{zu}$ ermöglichen. Diesen Zusammenhang zwischen unternehmungsexternem und -internem Wandel visualisiert Abbildung 3/2.

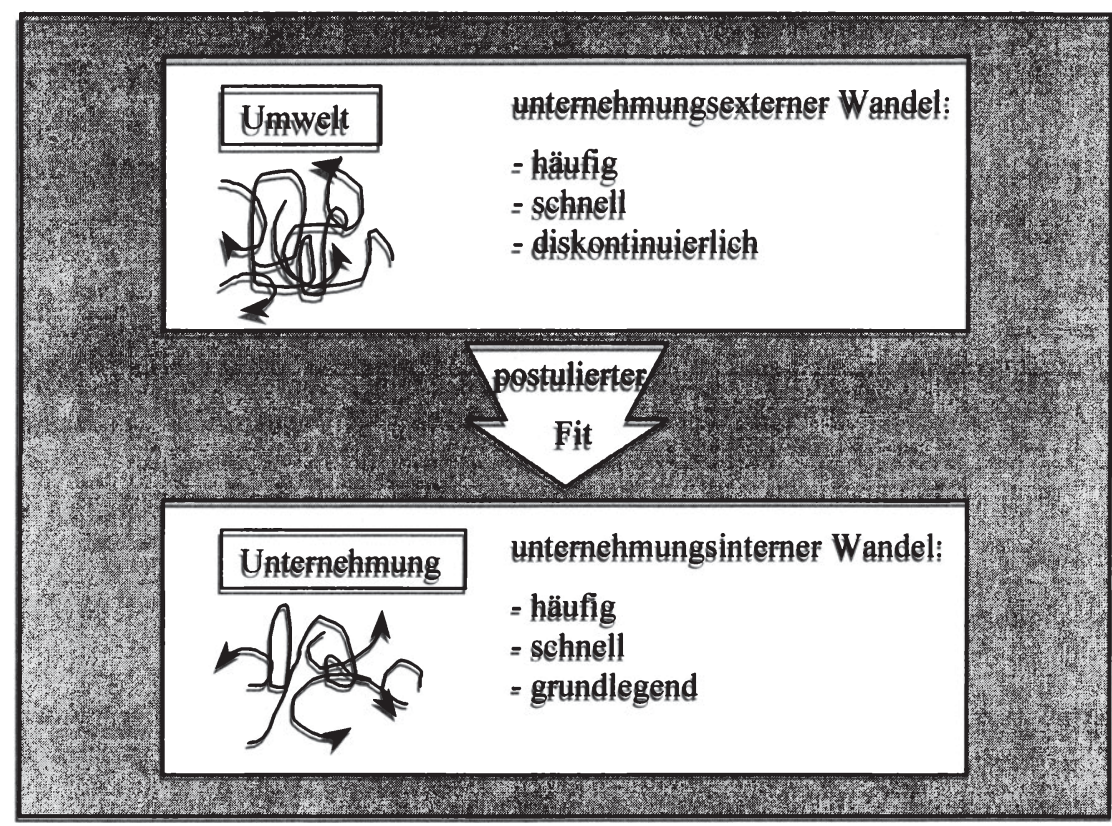

Abb. 3/2: Der Zusammenhang zwischen unternehmungsexternem und -internem Wandel

Der unternehmungsinterne Wandel kann sowohl reaktiv als auch proaktiv sein, d.h. die Wandelprozesse können nicht nur eine Reaktion auf bereits eingetretene äußere Veränderungen darstellen, sondern diese auch antizipieren. ${ }^{34}$ Inbesondere stellt die Befähigung zu unternehmungsinternem Wandel ein Potential dar, das aus der Sicht der Gegenwart zwar nicht unmittelbar verwertbar sein muß, zukünftige Handlungen jedoch erleichtert. ${ }^{35}$

Aus der Sicht des Managements kann man zwischen geplanten und ungeplanten unternehmungsinternen Wandelprozessen unterscheiden. Geplantem Wandel geht stets die

33 Die drei Adjektive beschreiben dabei nicht etwa drei disjunkte Arten von Wandelprozessen, sondern dienen der Beschreibung ein und derselben Art von unternehmungsinternem Wandel, d.h. die hier fokussierten Wandelprozesse sind zugleich schnell, hăufig und grundlegend.

34 Vgl. ăhnlich Mohr (1997), S. 34f.

35 Vgl. als vom Grundgedanken her ahnlich Klimecki/Probst/Eberl (1991), S. 110, die dort auf das Bereitstellen von Verhaltenspotentialen abstellen. 
bewußte Entscheidung dazu legitimierter Mitglieder (hier des Managements) der Unternehmung voraus, bestimmte Veränderungen vorzunehmen. Daraus resultieren dann verschiedene Managementaufgaben, die auf die Realisierung dieser Veränderungen abzielen. Ungeplanter Wandel liegt vor, wenn eine solche bewußte Entscheidung des Managements fehlt und die Wandlungsprozesse vielmehr von diesem nicht beabsichtigt, sondern - aus der Sicht des Managements - zufällig sind und sich eher unbemerkt vollziehen. ${ }^{36}$ Eine wichtige Ursache für das Entstehen vom Management nicht geplanten unternehmungsinternen Wandels ist die hohe Komplexität des Systems Unternehmung. So gehen von den Erkenntnisssen der Kybernetik 2. Ordnung geprägte Managementtheorien davon aus, daß in dem hochkomplexen System Unternehmung Prozesse ablaufen, die sich dem direkten Einfluß des Managements entziehen. ${ }^{37}$ Im Mittelpunkt der folgenden Untersuchung stehen Selbstorganisationsprozesse als eine mögliche Ursache ebensolcher Phänomene ungeplanten Wandels.

Analog den Aussagen zum unternehmungsexternen Wandel gilt für den unternehmungsinternen Wandel, daß in Unternehmungen als hochkomplexen Systemen eine Vielzahl von Größen dem Wandel unterliegen, wobei die jeweiligen Änderungsgeschwindigkeiten und -ausmaße stark variieren können. Gleichzeitig existieren konstante Faktoren. Somit besteht auch innerhalb der Unternehmung ein Nebeneinander von verschiedenen Wandelprozessen auf der einen und Konstanz auf der anderen Seite. Konstanz und Wandel stellen dabei komplementäre Aspekte dar, die beide für ein Überleben der Unternehmung notwendig sind. ${ }^{38}$ Die Befähigung zu unternehmungsinternem Wandel ist also nicht absolut zu verstehen, sondern im Rahmen der jeweiligen Situation der Unternehmung zu spezifizieren.

\subsection{Das Phänomen des organisationalen Lernens}

Seit der Mitte der 90er Jahre besteht ein stark gestiegenes Interesse an der Thematik organisationalen Lernens, das sich sowohl in der publizierten Literatur als auch in entsprechenden Weiterbildungsangeboten für Führungskräfte widerspiegelt. Frühe Arbeiten über 'Organizational Learning' wurden bereits in den 60er Jahren in den USA entwickelt $^{39}$ und fanden dort seit der zweiten Hälfte der 70er Jahre verstärkt

$36 \mathrm{Vgl}$. Staehle (1994), S. 849. Es sei ausdrücklich darauf hingewiesen, daß die hier vorgenommene Unterscheidung zwischen geplantem und ungeplantem Wandel der Perspektive des Managements folgt. Das bedeutet insbesondere, daß ungeplanter Wandel nicht etwa prinzipiell ungeplant im Sinne von zufällig und nicht zielführend ist, sondern vom Management nicht geplant ist. Aus der Sicht der Mitarbeiter kann es sich also durchaus um geplanten Wandel handeln.

37 Siehe Abschnitt 2.1.3 der vorliegenden Arbeit.

38 Vgl. Ulrich (1994), S. 17. Für eine ausfuhrliche, systemtheoretisch geprägte Diskussion der Notwendigkeit des Nebeneinanders von Konstanz und Wandel siehe Abschnitt 4.1.1 der vorliegenden Arbeit.

39 Vgl. z.B. Cyert/March (1963), passim; Cangelosi/Dill (1965), passim. 
Beachtung. ${ }^{40}$ Im deutschsprachigen Raum beschäftigen sich insbesondere KIRSCH und seine Mitarbeiter an der Universität in München sowie Autoren der Hochschule St. Gallen und hier vor allem ProBsT mit dem Phänomen organisationalen Lernens. ${ }^{41}$

Im Rückblick erweist sich der Umstand als problematisch, daß die ersten Arbeiten zum organisationalen Lernen in der Blütezeit der Forschung zum Thema 'Organisationsentwicklung' entstanden und häufig auf deren Erkenntnissen aufbauten. ${ }^{42}$ Der Bezug zur Organisationsentwicklung führte zu einer starken personalwirtschaftlichen Ausrichtung und damit einhergehend der Fokussierung individueller Phänomene. Daraus folgt, daß nicht nur in der Vergangenheit, sondern auch heute häufig keine eindeutige Abgrenzung zwischen individuellem und organisationalem Lernen gelingt. Entsprechend gilt es im Rahmen der vorliegenden Arbeit, den Bezug des organisationalen zum individuellen Lernen herauszuarbeiten, zugleich jedoch eine klare inhaltliche Abgrenzung der beiden Phänomene voneinander vorzunehmen. Deshalb wird im folgenden in Abschnitt 3.2.1 zunächst individuelles Lernen diskutiert. In Abschnitt 3.2.2 wird sodann organisationales Lernen als Veränderung der organisationalen Wissensbasis konzipiert. Diese inhaltliche Abgrenzung des Phänomens organisationalen Lernens stellt den ersten Schritt bzw. Baustein bei der Entwicklung eines theoretisch fundierten Managementkonzeptes organisationalen Lernens dar.

\subsubsection{Individuelles Lernen}

Im Mittelpunkt der Forschungsbemühungen im Bereich des Lernens stehen Untersuchungen zum individuellen menschlichen Lernen, das einen klassischen Forschungsgegenstand der Psychologie darstellt. Aber auch andere Wissenschaften, wie z.B. Soziologie, Sozialpsychologie oder Anthropologie, thematisieren Lernprozesse. ${ }^{43} \mathrm{Ob}$ wohl individuelles Lernen bereits seit langem Gegenstand wissenschaftlicher Untersuchungen ist, ist es bis heute weder ausreichend erforscht noch existiert eine einheitliche Theorie individuellen Lernens. Vielmehr steht eine Vielzahl unterschiedlicher individueller Lerntheorien nebeneinander, die jeweils bestimmte Aspekte fokussieren und andere vernachlässigen. Das führt dazu, daß sich komplexe Lernprozesse häufig erst durch die Kombination von Erkenntnissen mehrerer Lerntheorien erklären

40 Die wissenschaftliche Diskussion in den USA wurde insbesondere durch die Beiträge von Argyris/Schön (1978), passim, Duncan/Weiss (1979), passim, Fiol/Lyles (1985), passim, Hedberg (1981), passim, Jelinek (1979), passim, Levitt/March (1988), passim, March/Olsen (1976), passim, Nystrom/Starbuck (1984), passim und Shrivastava (1983), passim, geprägt. Einen guten Überblick über Veröffentlichungen zum organisationalen Lernen im englischen Sprachraum gibt Dodgson (1993), passim.

41 Vgl. Kirsch (1990), passim; Knyphausen-Aufseß (1995), S. 99ff.; Pautzke (1989), passim; Probst/Buchel (1998), passim; Ringlstetter (1988), passim.

42 Vgl. Schreyðgg/Noss (1995), S. 172ff., die die konzeptionellen Grundlagen von Organisationsentwicklung und organisationalem Lernen miteinander vergleichen. Für eine umfassende Darstellung der Organisationsentwicklung vgl. French/Bell (1994), passim.

43 Vgl. Grun (1993), Sp. 2596. 
lassen. ${ }^{44}$ Im folgenden werden zunächst mit behavioristischen (Abschnitt 3.2.1.1) und kognitiven (Abschnitt 3.2.1.2) Theorien individuellen Lernens die beiden für die Argumentation der vorliegenden Arbeit zentralen Theorieschulen vorgestellt. Sodann wird aufgezeigt, welchen Stellenwert diese individuellen Lerntheorien für das Verständnis organisationalen Lernens haben (Abschnitt 3.2.1.3).

\subsubsection{Behavioristische Lerntheorien}

Behavioristische Lerntheorien, die sich seit 1910 in den USA entwickelten, stellen auf äußerlich beobachtbare Phänomene bzw. Verhaltensweisen ab (englisch behavior = Verhalten). ${ }^{45}$ Sie beobachten den Input des lernenden Organismus in Form eines Reizes an das Gehirn (Stimulus) und den Output in Form des Verhaltens des lernenenden Individuums (Response) und werden deshalb als Stimulus-Response-Theorien bezeichnet. Dabei gehen sie davon aus, daß die eigentlichen geistigen Veränderungen des lernenden Individuums im Sinne einer Black Box nicht ergründet werden können. ${ }^{46}$ Lernen ist hier die Interpretation eines externen Beobachters und wird allein unter dieser Außenperspektive betrachtet.

Lernen wird in diesem Zusammenhang definiert als eine dauerhafte, bewußte Verhaltensänderung in einer bestimmten Situation, die auf wiederholte Erfahrungen in dieser Situation zurückzuführen ist. Angeborene Reaktionen, Ermüdung, Prozesse der Reifung u.ä. werden nicht dem Lernen zugerechnet. ${ }^{47}$ Der klassische Behaviorismus betrachtet damit allein die nach außen hin sichtbaren Resultate geistiger Prozesse und nicht die geistigen Veränderungen selbst. Entsprechend wird auch die Frage nach der Art und Weise der Aufbewahrung des Gelernten hier nicht thematisiert. Die beobachtete Reaktion (Response) wird daraufhin untersucht, ob irgendwelche Gesetzmäßigkeiten zwischen Stimulus und Response feststellbar sind. Dabei wird jedoch lediglich ermittelt, mit welcher Auftrittswahrscheinlichkeit der verschiedenen Verhaltensweisen zu rechnen ist. Man geht davon aus, daß die Reaktionen bereits im Verhaltensrepertoire des Individuums vorhanden sind. Entsprechend besteht im Rahmen dieser Theorien keine Möglichkeit, neuartige Reaktionen zu erklären. ${ }^{48}$

Im Mittelpunkt der Kritik an behavioristischen Theorien steht die Black Box-Modellierung des Menschen, dessen interne geistige Veränderungsprozesse nicht untersucht werden. Die Verarbeitungsprinzipien innerhalb des Menschen werden außer acht gelas-

44 Vgl. Heinze (1985), S. 351; Küppers (1981), S. 128 und Löwe (1974), S. 86.

$45 \mathrm{Vgl}$. Steiner (1992), Sp. 1265. Zu den wichtigsten Vertretern eines behavioristisch geprägten Lernverstăndnisses gehören Thorndike, Pawlow, Guthrie, Skinner und Hull. Für eine ausfuhrliche Darstellung ihrer Theorien vgl. Hilgard/Bower (1975), passim.

Die Begriffe Handlung und Verhalten werden im Rahmen der vorliegenden Arbeit synonym verwendet.

46 Vgl. Döring (1983), S. 105ff.

47 Vgl. Hilgard/Bower (1975), S. 16ff.

48 Vgl. Oberschulte (1994), S. 93; Pautzke (1989), S. 92, 96. 
sen. Dadurch bleiben hier all jene geistigen Veränderungen unberücksichtigt, die sich nicht im Verhalten nach außen manifestieren. ${ }^{49}$ Diese sehr restriktiven Annahmen begrenzen den praktischen Erklärungswert der behavioristischen Lerntheorien. Auch die Übertragbarkeit auf das Alltagsverhalten des Menschen ist teilweise umstritten, da die empirischen Untersuchungen, die die Basis der entwickelten Theorien bilden, in der Regel mit Tieren und als Laboruntersuchungen durchgeführt wurden. ${ }^{50}$ Einerseits ist das Lernen von Tieren jedoch mit komplexeren Formen menschlichen Lernens nicht vergleichbar, andererseits entsprechen Laborbedingungen nicht den komplexen Zusammenhängen realer Lernsituationen. Von der Vielzahl möglicher Arten menschlichen Lernens untersuchen behavioristische Theorien deshalb eher einfache Lernprozesse. ${ }^{51}$ Dort kommt ihnen gleichwohl auch heute noch durchaus Bedeutung zu. Als Beispiel sei hier auf die Theorie des Lernens durch Verstärkung (Belohnung oder Bestrafung) als implizite Führungstheorie verwiesen. ${ }^{52}$

\subsubsection{Kognitive Lerntheorien}

Die in den 60er Jahren zu beobachtende Hinwendung der Psychologie zu kognitiven Phänomenen führte zu einem grundlegend veränderten Verständnis individuellen Lernens. Während behavioristische Ansätze die internen kognitiven Prozesse des lernenden Individuums und sein Bewußtsein nicht berücksichtigen, stellen kognitive Lerntheorien das Entstehen neuer kognitiver Strukturen bzw. die Veränderung bestehender in den Mittelpunkt. ${ }^{53}$ An die Stelle der Außenperspektive behavioristischer Ansätze tritt eine Innenperspektive, d.h. das einfache S-R-Modell mit Stimulus und Response wird um die explizite Betrachtung des Menschen als wissensverarbeitendem System (Organism) zu einem S-O-R-Modell erweitert. ${ }^{54}$ Dieser 'Organism' erlangt über kognitive Prozesse zu Einsichten über die Welt. Als kognitive Prozesse werden alle im menschlichen Hirn ablaufenden Prozesse bezeichnet, die mit dem Erwerb von Kenntnissen zu tun haben, d.h. Wahrnehmung, Denken, Speichern und Abrufen von Wissen sowie das Lösen von Problemen. ${ }^{55}$

Den zentralen Ansatzpunkt kognitiver Lerntheorien stellt das Konstrukt des menschlichen Wissens dar. Nicht nur in seiner Entstehung, sondern auch in seiner weiteren Existenz wird Wissen hier als psychischer Zustand und damit als unmittelbar

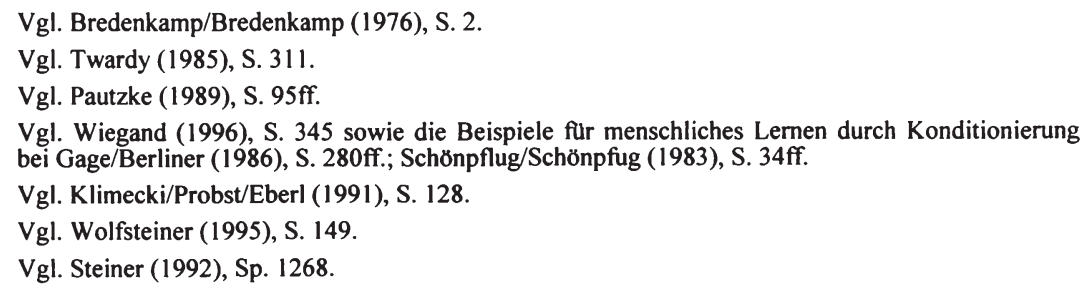


an den Menschen gebundenes Phänomen konzipiert. ${ }^{56}$ Wissen ist sowohl Ausgangspunkt als auch Ergebnis individueller Lernprozesse. ${ }^{57}$ Die Art der ablaufenden Lernprozesse hängt damit vom vorhandenen Wissen ab. So stellt MONTADA fest: „Es kann nicht alles jederzeit gelernt werden, es gibt Lernvoraussetzungen und damit eine gesetzesmäßige Abfolge aufeinanderfolgender Lernprozesse."58 Und DELHEES konstatiert: „Je mehr jemand weiß, umso mehr Wissen kann er aufnehmen und abrufen."59

Individuelles Lernen wird im Rahmen kognitiver Lerntheorien definiert als die Veränderung des Wissens des jeweiligen Individuums. Die Einführung des Konstruktes Wissen ermöglicht eine Unterscheidung zwischen Lernprozeß und Anwendung des Gelernten. Gelerntes wird als Wissen im Gedächtnis des Menschen aufbewahrt, denn der Mensch setzt nicht alles Gelernte unmittelbar in Aktivitäten um. ${ }^{60}$ Somit stehen der Erwerb, die interne Repräsentation des Wissens im Gedächtnis des Menschen, seine Veränderung durch die Integration neuen Wissens in bestehendes und schließlich die Anwendung des Wissens im Rahmen der Problemlösung im Mittelpunkt kognitiver Lerntheorien. ${ }^{61}$ Das Fokussieren des menschlichen Wissens im Rahmen kognitiver Lerntheorien führt letztendlich dazu, daß der Begriff des Lernens hier durch den der 'Wissensverarbeitung durch das menschliche Gehirn' ersetzt werden kann. ${ }^{62}$

Über diese zentralen Grundannahmen hinaus, die allen kognitiven Lerntheorien gemein sind, kann man eine Fülle verschiedener kognitiv fundierter Ansätze unterscheiden. Im Rahmen der vorliegenden Arbeit zum organisationalen Lernen sind die kognitiven Elemente in den entwicklungspsychologischen Arbeiten von Piaget für die weiteren Ausführungen von besonderem Interesse. Weite Teile der entwicklungspsychologischen Arbeiten PIAGETS können als kognitive Lerntheorie reinterpretiert werden. Sofern eine Entwicklungspsychologie nämlich nicht als reine Reifungstheorie konzipiert ist, muß sie sich mit dem Phänomen der Erfahrung auseinandersetzen und wird dann zur Lernpsychologie. ${ }^{63}$

PIAGET geht davon aus, daß sich das Gesamtverhalten von Menschen aus einer Vielzahl von Verhaltenselementen zusammensetzt. Die Summe der Verhaltenselemente bildet einen Handlungsspielraum. Die jeweilige Verhaltensweise stellt einen Ausschnitt dieses Handlungsspielraums dar, der durch eine bestimmte Kombination von Verhaltenselementen charakterisiert ist. Diese Verhaltenselemente liegen in bestimmten Strukturen

56 Diese Bindung des Wissens an den Menschen unterscheidet den Wissensbegriff kognitiver individueller Lerntheorien von dem in Abschnitt 2.2.2.2.1 der vorliegenden Arbeit vorgestellten Begriffsverständnis.

57 Vgl. Wiegand (1996), S. 350.

58 Montada (1970), S. 31.

59 Delhees (1990), S. 10.

60 Vgl. Bandura (1979), S. 37.

61 Vgl. Mandl/Spada (1988), S. 3.

62 Vgl. Wiegand (1996), S. 346.

63 Vgl. dazu das Standardwerk von Montada (1970), dessen erklärtes Ziel die Untersuchung des Zusammenhangs zwischen Lernen und Entwicklung ist. Vgl. Montada (1970), S. 11. 
vor, die als kognitive Strukturen bzw. Verhaltensmuster (Cognitive Maps) bezeichnet werden. Diese Strukturen stellen hypothetische Konstrukte dar, die es den Menschen erlauben, erworbene Erfahrungen aus ähnlichen Situationen der Vergangenheit auf das neue Problem zu übertragen. Dabei kann das neue Problem inhaltlich völlig andersartig sein als das Problem, auf dem die Erfahrung beruht. Es muß lediglich die gleiche Struktur aufweisen. ${ }^{64}$ Da die kognitiven Strukturen die Grundlage des Handelns des Individuums bilden, können sie auch als individuelle Handlungstheorien bezeichnet werden. ${ }^{65}$

Weiterhin nimmt PIAGET an, daß der Mensch nach einem Gleichgewicht zwischen sich und seiner Umwelt strebt. Seine kognitiven Strukturen als relativ stabile, generalisierte Interpretations- und Verhaltensmuster helfen ihm dabei, dieses Gleichgewicht zwischen sich und einer äußerst komplexen Umwelt zu erreichen. Die kognitiven Strukturen wirken als Wahrnehmungsfilter, da der Mensch bei jeder Wahrnehmung auf seine bereits existierenden kognitiven Strukturen zurückgreift, um mit ihrer Hilfe das neu Wahrgenommene zu erkennen, einzuordnen und zu interpretieren. Er bildet somit mit Hilfe seiner kognitiven Strukturen ein mentales Modell seiner Umwelt, das bedingt, daß er bestimmte Dinge wahrnimmt, andere hingegen ignoriert. Dabei nimmt er vorzugsweise die Dinge wahr, die seinem bisherigen mentalen Modell entsprechen und dieses bestätigen. Die mit der Filterfunktion des mentalen Modells verbundene Komplexitätsreduktion reduziert die Gefahr der Überforderung des Individuums im Rahmen seiner Interaktion mit einer hochkomplexen Umwelt. Vielmehr erlaubt sie dem Individuum, seine Wahrnehmung der hochkomplexen Welt auf ein für es verarbeitbares Maß zu reduzieren. ${ }^{66}$

PIAGET nimmt an, daß eine gesetzmäßige Abfolge aufeinanderfolgender bzw. aufeinander aufbauender Lernprozesse existiert. Der Mensch erwirbt mit der Zeit - ausgehend von bestimmten Grundmustern - immer komplexere kognitive Strukturen. ${ }^{67}$ Die unterschiedlich komplexen kognitiven Strukturen erlauben wiederum verschiedene Lernprozesse. PIAGET interessieren dabei insbesondere die Übergänge zwischen den verschiedenen Entwicklungsstufen, die er auf folgende zwei Arten von individuellen Lernprozessen zurückführt: 68

- Assimilation:

Assimilation ist der einfache Lernprozeß der Integration neuer Wissensbestandteile in die bestehenden kognitiven Strukturen. Das neue Wissen kann problemlos eingefügt

64 Vgl. Montada (1970), S. 17ff.; Weick/Bougon (1986), S. $131 \mathrm{f}$.

$65 \mathrm{Vgl}$. ăhnlich Klimecki/Probst/Eberl (1991), S. 130.

66 Vgl. Montada (1970), S. 21f.; Piaget (1983), S. 23; Weick/Bougon (1986), S. 104f., 132.

67 Vgl. Montada (1970), S. 31. Insbesondere unterscheidet Piaget in Kindheit und Jugend (von 0 bis 17 Jahren) zwischen sensomotorischer, prăoperativer, konkreter und formaler Phase. Vgl. Staehle (1994), S. 863.

68 Vgl. dazu und im folgenden Montada (1970), S. $21 \mathrm{ff}$., 38ff., 45ff.; Pautzke (1989), S. 95; Piaget (1983), S. 32ff., $70 \mathrm{ff}$. 
und angepaßt, eben assimiliert werden. Die existierenden kognitiven Strukturen bleiben unverändert. Beispielsweise handelt es sich bei dem Lernen des aktuellen Aktienkurses einer Unternehmung um Assimilation.

\section{- Akkomodation:}

Akkomodation ist ein höherer Lernprozeß, der die Veränderung der kognitiven Strukturen und des damit verbundenen Verhaltensrepertoires umfaßt. PIAGET geht von zwei zentralen Ursachen für Akkomodationsprozesse aus: Einerseits kann Akkomodation dadurch ausgelöst werden, daß sich eine Situation bzw. ein Wissensbestandteil im Rahmen der existierenden kognitiven Strukturen nicht assimilieren läßt. Andererseits kann Akkomodation dadurch angestoßen werden, daß durch den Zugewinn an neuem Wissen Widersprüche zwischen existierenden kognitiven Strukturen offensichtlich werden. Beispielsweise handelt es sich bei der Erkenntnis, daß die Aktienkurse deutscher Unternehmungen nicht nur von deren konkreter wirtschaftlicher Entwicklung bestimmt werden, sondern auch von der Entwicklung der Aktienmärkte in Fernost, Osteuropa und den USA beeinflußt werden, um Akkomodation.

Nach der Änderung der kognitiven Strukturen im Rahmen von Akkomodationsprozessen erfolgt ein weiterer Versuch, das neue Wissen im Rahmen von Assimilationsprozessen in die - jetzt geänderten - kognitiven Strukturen einzufügen. PIAGET konzipiert die Abfolge von Assimilations- und Akkomodationsprozessen als Wechsel von Gleichgewichts- und Ungleichgewichtszustầnden. Dabei strebt das Individuum immer wieder neu nach einem kognitiven Gleichgewicht, weshalb der sich aus der Verknüpfung von Assimilation und Akkomodation ergebende Entwicklungsmechanismus auch als Äquilibrationsprozeß bezeichnet wird. ${ }^{69}$ Dabei stellen Assimilation und Akkomodation nicht etwa zwei einander entgegengesetzte Lernprozesse dar, sondern Akkomodation umfaßt immer auch Assimilation. Man kann deshalb auch von unterschiedlich akkomodierten Assimilationen sprechen. Die Assimilation bzw. Einverleibung neuen Wissens in die existierenden kognitiven Strukturen kann deren mehr oder weniger starke Veränderung (Akkomodation) somit voraussetzen. ${ }^{70}$

\subsubsection{Der Stellenwert individueller Lerntheorien für ein Konzept organisationalen Lernens}

Behavioristische Lerntheorien stellen auf von außen beobachtbare Phänomene ab und rücken damit individuelles Lernen in die Nähe des Wandelbegriffes der vorliegenden Arbeit, denn individuelles Lernen stellt dort die bewußte, dauerhafte Veränderung des Verhaltens des Individuums dar. Da Wandel im Rahmen der vorliegenden Arbeit neben der Veränderung materieller Objekte auch die Veränderung beobachtbaren mensch-

$69 \mathrm{Vgl}$. Montada (1970), S. 21 ff. Piaget bezeichnet die Entwicklung als 'marche vers l'équilibre'.

70 Vgl. Montada (1970), S. 49. 
lichen Verhaltens einschließt, wäre individuelles Lernen dann Teilmenge der Wandelprozesse. Ein Teil der unternehmungsinternen Wandelprozesse würde somit als individuelles Lernen reinterpretiert. Da behavioristische Lerntheorien aber eben nicht die hinter den beobachtbaren Verhaltensänderungen stehenden - nicht beobachtbaren geistigen Prozesse untersuchen, bliebe ungeklärt, wie es zu diesen Verhaltensänderungen kommt. Der diesbezügliche mangelnde Erklärungswert behavioristischer Lerntheorien erweist sich für die vorliegende Arbeit als besonders problematisch, da die Fragestellung, wie die Unternehmung zu unternehmungsinternem Wandel befähigt werden kann, hier im Mittelpunkt der Untersuchung steht. Deshalb werden behavioristische Theorien individuellen Lernens im folgenden nicht weiter berücksichtigt.

Im Gegensatz dazu fokussieren kognitive individuelle Lerntheorien das Bewußtsein und die Denk- bzw. Problemlösungsprozesse der lernenden Individuen. Anstelle des nach außen hin beobachtbaren Verhaltens betrachten sie kognitive Prozesse, aus denen dann wiederum bestimmte beobachtbare Handlungen resultieren. Bezogen auf das einzelne Individuum zeigen sie den Zusammenhang zwischen Lernen als den (geistigen) Prozessen der Wissensverarbeitung des menschlichen Gehirns auf der einen und der Befähigung zu Wandel im Sinne von Verhaltensänderungen auf der anderen Seite. Damit ermöglichen sie - bezogen auf die individuelle Ebene - die Konzeptionalisierung des Zusammenhangs zwischen beobachtbaren Veränderungen des Verhaltens und nicht beobachtbaren geistigen Veränderungen. Da es Ziel der Ausführungen von Abschnitt 3.2 dieser Arbeit ist, den Begriff organisationalen Lernens mit Inhalt zu füllen und dabei eine eindeutige Abgrenzung zwischen individuellem und organisationalem Lernen vorzunehmen, gilt es im folgenden zu untersuchen, ob bzw. wie die grundlegenden Gedanken kognitiver individueller Lerntheorien von der individuellen auf die überindividuelle Ebene übertragen werden können.

\subsubsection{Organisationales Lernen}

Will man den Vorwurf vermeiden, Managementkonzepte organisationalen Lernens seien nichts anderes als leicht modifizierte, modisch verpackte Neuaufgüsse altbekannter Personalentwicklungskonzepte, die auf die Förderung der individuellen Qualifikation der Mitarbeiter und damit auf individuelles Lernen abstellen, so darf organisationales Lernen nicht mit der Summe der individuellen Lernprozesse der Mitarbeiter in der Unternehmung gleichgesetzt werden. Zwar setzt die folgende Konzeptionalisierung organisationalen Lernens auf den Erkenntnissen individueller Lerntheorien auf, die Eigenständigkeit eines Managementkonzeptes organisationalen Lernens setzt jedoch eine eindeutige Abgrenzung organisationalen Lernens von individuellem Lernen voraus.

Im Rahmen der vorliegenden Arbeit wird organisationales Lernen definiert als die Veränderung der organisationalen Wissensbasis. Für ein tiefergehendes Verständnis dieser Definition wird im folgenden in einem ersten Schritt eine statische Sichtweise auf die organisationale Wissensbasis als Objekt organisationalen Lernens verfolgt (Abschnitt 
3.2.2.1). Einer dynamischen Perspektive folgend werden sodann in einem zweiten Schritt die organisationalen Lernprozesse als Aktivitäten der Veränderung der organisationalen Wissensbasis untersucht (Abschnitt 3.2.2.2). Es gilt also zu untersuchen, was im Rahmen von organisationalen Lernprozessen verändert wird und wie diese Veränderungsprozesse aussehen.

\subsubsection{Statische Perspektive: Die organisationale Wissensbasis}

Mit der Definition organisationalen Lernens als der Veränderung der organisationalen Wissensbasis folgt die Arbeit der Denktradition wissensbasierter Konzepte organisationalen Lernens. Zwar thematisieren alle Konzepte organisationalen Lernens mehr oder weniger ausführlich die Bedeutung von Wissen in der Unternehmung, die wissensbasierten Ansätze rücken es jedoch explizit in den Mittelpunkt ihrer Argumentation.

Der deutsche Begriff der 'organisationalen ${ }^{71}$ Wissensbasis' geht auf den amerikanischen Terminus der 'Organizational Knowledge Base' zurück, der erstmals 1979 von DUNCAN/WeISS erwähnt und in der Folge zunächst von HEDBERG (1981) und LEVITT/MARCH (1988) aufgegriffen und insbesondere von WALSH/UNGSON (1991) und NONAKA (1994) zum Konzept der 'Organizational Memory' weiterentwickelt wurde. ${ }^{72}$ Im deutschsprachigen Raum bietet die Dissertation von PAUTZKE (1989), der sich wiederum explizit auf KIRSCH bezieht, ${ }^{73}$ eine erste umfassende Darstellung des Begriffes. In seiner Habilitation von 1994 konzipiert PAWLOWSKY ausführlich den grundlegenden Zusammenhang zwischen organisationalem Lernen und Wissenssystemen.

Da ein tiefergehendes Verständnis organisationalen Lernens als Veränderung der organisationalen Wissensbasis die Konkretisierung des Phänomens der organisationalen Wissensbasis voraussetzt, wird diese im folgenden zunächst inhaltlich abgegrenzt. Sodann werden Kriterien für die Unterscheidung verschiedener Wissensarten vorgestellt und diese werden für eine mehrdimensionale Systematisierung der organisationalen Wissensbasis verwendet, die eine Vertiefung der inhaltlichen Abgrenzung bietet.

71 In der deutschsprachigen Literatur finden - je nach Autor - im Zusammenhang mit der Wissensbasis der Unternehmung die beiden Adjektive organisatorisch (so z.B. bei Pautzke (1989)) und organisational (so z.B. bei Pawlowski (1994)) Verwendung, ohne daß dies mit inhaltlichen Unterschieden verbunden ist. Zur sprachlichen Vereinheitlichung wird im Rahmen der vorliegenden Arbeit, die 'organisationales Lernen' thematisiert, durchgehend der Begriff der 'organisationalen Wissensbasis' verwendet. Zur Verwendung der Adjektive 'organisational' und 'organisatorisch' im Rahmen der vorliegenden Arbeit siehe auch Abschnitt 2.2.1.1.2.

72 Einen umfassenden Überblick über die englischsprachige Literatur über wissensbasierte Konzepte organisationalen Lernens gibt Huber (1991), S. 88ff.

73 Pautzke erwăhnt mehrere unveröffentlichte Arbeitspapiere von Kirsch, die später in dessen umfassende Publikationen von 1990 und 1992 eingingen. Vgl. Pauzke (1989), S. $298 f$. 


\section{Definitorische Abgrenzung der organisationalen Wissensbasis}

Im Rahmen der vorliegenden Arbeit wird die organisationale Wissensbasis definiert als

- das Wissen

- innerhalb der Unternehmung,

- das den Mitgliedern der Unternehmung

- zur Lösung der ihnen übertragenen Teilaufgabenstellungen

- zum Zeitpunkt der Beobachtung zur Verfügung steht. ${ }^{74}$

Wissen umfaßt die Wahrnehmungen, Erfahrungen und Kenntnisse über die Realität des Menschen. ${ }^{75}$ Zur organisationalen Wissensbasis zählt jedoch nur der Teil des Wissens, der innerhalb der Unternehmung vorhanden ist. Dies gilt einerseits für das personengebundene Wissen der Mitglieder der Unternehmung, andererseits für all das Wissen, das innerhalb der juristischen Grenzen der Unternehmung personenungebunden gespeichert wird. Darüber hinaus muß organisationales Wissen ${ }^{76}$ zum Zeitpunkt der Beobachtung für die Mitglieder der Unternehmung verfügbar sein. Für das personengebundene Wissen bedeutet dies, daß die jeweilige Person bereit sein muß, es entweder selbst zu verwenden oder anderen Personen zur Verfügung zu stellen. Die Verfügbarkeit personenungebundenen Wissens ist dagegen daran gebunden, daß ein Mitglied der Unternehmung über Zugriffswissen bezüglich dieses Wissens verfügt. ${ }^{77}$ Ferner bildet die Zweckeignung des Wissens bei der Unterstützung der Mitarbeiter der Unternehmung im Rahmen des betrieblichen Leistungserstellungsprozesses ein weiteres konstitutives Merkmal organisationalen Wissens. Organisationales Wissen ist somit stets auch Information. Schließlich handelt es sich bei der organisationalen Wissensbasis im systemtheoretischen Sinne um eine Zustandsgröße, d.h. sie umfaßt das Wissen zu einem bestimmten Zeitpunkt.

Die Gesamtheit der organisationalen Wissensbasis läßt sich - je nach verfolgtem Zweck - in vielfältiger Hinsicht untergliedern. Zur Verdeutlichung der obigen Definition der organisationalen Wissensbasis werden im Rahmen der vorliegenden Arbeit folgende Kategorien organisationalen Wissens verwendet:

- personengebundenes und personenungebundenes organisationales Wissen,

- aktuelles und latentes organisationales Wissen,

- individuelles und kollektives organisationales Wissen,

- individuelles und überindividuelles organisationales Wissen,

- Oberflächenwissen und Tiefenstruktur des organisationalen Wissens.

\footnotetext{
74 Vgl. ähnlich Oberschulte (1994), S. 62, Pautzke (1989), S.76ff.

75 Für die Definition von Wissen siehe Abschnitt 2.2.2.2.1 der vorliegenden Arbeit.

76 Als organisationales Wissen wird im folgenden das Wissen bezeichnet, das Teil der organisationalen Wissensbasis ist.

77 Für eine ausfuhrliche Diskussion der Verfügbarkeit des Wissens siehe die folgenden Ausfuhrungen zu aktuellem und latentem organisationalen Wissen in diesem Abschnitt.
} 
Darüber hinaus läßt sich organisationales Wissen prinzipiell auch mittels anderer Kriterien systematisieren. So könnte z.B. auch zwischen explizitem und implizitem ${ }^{78}$, deklarativem und prozeduralem ${ }^{79}$ oder interpersonell übertragbarem und interpersonell nicht übertragbarem Wissen unterschieden werden. Da diese Differenzierungen jedoch weder zum weiteren Verständnis der organisationalen Wissensbasis noch zu dem organisationaler Lernprozesse beitragen, bleiben sie im folgenden unberücksichtigt.

\section{Personengebundenes versus personenungebundenes organisationales Wissen}

Information als Bezugsobjekt des Informationsmanagements ist zwar grundsätzlich immaterieller Natur, jedoch gilt: ,information is always borne on a marker“, d.h. Information ist stets untrennbar mit Phänomenen der materiellen Ebene verbunden. Die diesbezüglichen Ausführungen in Abschnitt 2.2.2.2.3 der vorliegenden Arbeit gelten auch für organisationales Wissen, da dieses aufgrund seiner Zweckeignung ebenfalls Information darstellt. Aber auch über den Spezialfall der Information hinaus gilt für die Gesamtheit des Wissens, daß es stets unmittelbar mit materiellen Phänomenen einhergeht. Das Entstehen von Wissen ist zwar unmittelbar an den Menschen gebunden.80 Einmal entstanden kann es jedoch sowohl als personengebundenes Wissen im Gedächtnis des Menschen als auch als personenungebundenes bzw. institutionalisiertes $^{81}$ Wissen außerhalb des Menschen auftreten. ${ }^{82}$ Während bei personengebundenem Wissen stets das menschliche Gehirn die Funktion des Trägermediums übernimmt, existieren vielfältige nicht-menschliche Trägermedien für personenungebundenes Wissen, von denen die folgende Untersuchung die (computergestützte) Informationstechnik fokussiert. ${ }^{83}$

\section{Aktuelles versus latentes organisationales Wissen}

Die Unterscheidung zwischen aktuellem und latentem organisationalem Wissen stellt auf die Verfügbarkeit des Wissens in einem bestimmten Zeitpunkt ab. ${ }^{84}$ Der aktuellen

78 Für eine ausfuhrliche Darstellung expliziten und impliziten Wissens vgl. Gabriel (1992), S. 34ff.; Kleinhans (1989), S. 9f.; Oberschulte (1994), S. 66ff.; Pautzke (1989), S. 65, 68; Ryle (1949), S. $25 \mathrm{ff}$.

79 Für eine ausführliche Darstellung deklarativen und prozeduralen Wissens vgl. Bühl (1984), S. 117, 121; Oberschulte (1994), S. 67; Polanyi (1985), S. $14 \mathrm{ff}$.

80 Auch moderne Expertensysteme, die selbständig lernen und entsprechend ihre Wissensbasis selbständig erweitern, tun dies im Rahmen zuvor vom Menschen festgelegter Regeln, so daß auch diese Wissensgenerierung letztendlich auf kognitive Prozesse des Menschen zurückgeführt werden kann. Für eine Darstellung der Lernkomponente von Expertensystemen vgl. Gabriel (1992), S. 83ff.

81 Die beiden Adjektive personenungebunden und institutionalisiert werden im folgenden synonym verwendet. Wahrend das Adjektiv 'institutionalisiert' dem in Arbeiten zum organisationalen Lernen üblichen Sprachgebrauch folgt, betont das Adjektiv 'personenungebunden' die explizite Gegenüberstellung zu personengebundenem Wissen.

82 Das im Rahmen der vorliegenden Arbeit verfolgte Verständnis von Wissen unterscheidet sich somit von der in Abschnitt 3.2.1.2 erwăhnten Begriffsfassung der kognitiven individuellen Lerntheorien.

83 Für eine Darstellung der verschiedenen materiellen Trägermedien von Information bzw. Wissen siehe Abschnitt 2.2.2.2.3 der vorliegenden Arbeit.

84 Für eine prinzipiell ähnliche, lediglich im Detail von der Definition der vorliegenden Arbeit abweichende Verwendung des Begriffes der latenten organisationalen Wissensbasis vgl. Pautzke (1989), S. $81 \mathrm{ff}$. 
organisationalen Wissensbasis ist das Wissen zuzurechnen, das im Zeitpunkt der Beobachtung tatsächlich verfügbar ist.

Bezogen auf personengebundenes Wissen bedeutet aktuelle Verfügbarkeit, da $\beta$ die Mitarbeiter ihr jeweiliges individuelles Wissen entweder im Rahmen ihrer eigenen Teilaufgabenerfüllung verwenden oder aber ihr Wissen anderen zur Verfügung stellen. Geschieht dies - bewußt oder unbewußt - nicht, so handelt es sich zwar um individuelles Wissen eines Mitgliedes der Unternehmung, nicht jedoch um aktuelles organisationales Wissen. Als Beispiel können hier die im Rahmen eines langjährigen Auslandsaufenthalts erworbenen Kenntnisse eines Mitarbeiters der Rechnungswesenabteilung bezüglich dieses Kulturraums und der dort anzutreffenden Konsumgewohnheiten genannt werden, die im Rahmen der Ausdehnung der Geschäftstätigkeit seines jetzigen Arbeitgebers in der Marketingabteilung von großem Wert wären, dieser jedoch nicht bekannt und damit nicht aktuell verfügbar - sind. Hier handelt es sich um latentes organisationales Wissen. Latentes organisationales Wissen ist innerhalb der Unternehmung vorhandenes Wissen, das zur Lösung betrieblicher Aufgabenstellungen verwendbar wäre, jedoch im Zeitpunkt der Beobachtung aktuell nicht verfügbar ist.

Bezogen auf personenungebundenes Wissen bedeutet aktuelle Verfügbarkeit, daß mindestens ein Mitarbeiter über Zugriffswissen auf dieses Wissen - im Sinne von (personengebundenem) Wissen über (personenungebundenes) Wissen - verfügt. Auch setzt die Unterstützung des menschlichen Aufgabenträgers bei der Erfüllung seiner Teilaufgaben durch personenungebundenes Wissen dessen Interpretation durch den Menschen voraus. ${ }^{85}$ So handelt es sich bei der Möglichkeit, die Daten aus dem Administrationssystem des Rechnungswesens mit Hilfe des Berichtsgenerators eines Führungsinformationssystems auszuwerten, nur dann um aktuelles organisationales Wissen, wenn mindestens ein Mitarbeiter diese Auswertungsmöglichkeit kennt. Fehlt dagegen dieses personengebundene Zugriffswissen, so handelt es sich lediglich um latentes organisationales Wissen.

\section{Individuelles versus kollektives organisationales Wissen}

Individuelles und kollektives organisationales Wissen können nur innerhalb der Kategorie des personenbezogenen organisationalen Wissens unterschieden werden. Die Unterscheidung betrifft also nicht die Gesamtheit der organisationalen Wissensbasis, sondern lediglich eine Teilmenge. ${ }^{86}$ Einzelne Individuen können neben rein individuellen auch über verschiedene kollektive organisationale Wissensbestandteile verfügen.

Individuelles Wissen bezeichnet das Wissen eines einzigen Individuums. Hier ist eine einzelne Person Bezugspunkt des Wissens. Kollektives Wissen dagegen umfaßt das gemeinsame Wissen einer Mehrzahl von Personen. Der Terminus 'Kollektiv' bildet

85 Vgl. Wiegand (1996), S. 330.

86 Anders Kirsch (1992), S. 501. 
dabei den Oberbegriff für unterschiedliche, jeweils zu konkretisierende Konstellationen mehrerer Personen. ${ }^{87}$ Die Abgrenzung eines Kollektivs kann auf vielfältige Art und Weise vorgenommen werden, so z.B. räumlich, rechtlich oder anhand bestimmter Merkmale der Mitglieder des Kollektivs. Im Kontext organisationalen Lernens bilden Gruppen $^{88}$ innerhalb der Unternehmung und die Gesamtheit der Mitarbeiter der Unternehmung wichtige zu betrachtende Kollektive. ${ }^{89}$

Grundsätzlich umfaßt kollektives Wissen das Wissen, das

- von allen Mitgliedern des Kollektivs bzw. deren überwiegender Mehrheit

- als identisches oder äquifinales Wissen gespeichert wird. ${ }^{90}$

Die mit der Formulierung 'allen Mitgliedern des Kollektivs bzw. deren überwiegender Mehrheit' verbundene Öffnung der Definition ist notwendig, da der Kreis der Mitglieder eines Kollektivs durch personelle Fluktuation Veränderungen unterworfen ist. Neue Mitglieder verfügen zu Beginn ihrer Mitgliedschaft im jeweiligen Kollektiv regelmäßig nicht über die Gesamtheit des Wissens der anderen, sondern erlangen dies erst nach und nach im Rahmen ihrer Mitgliedschaft in dem Kollektiv.91 Ein bestimmter Wissensbestandteil wird deshalb in der Regel nicht von allen Mitgliedern des Kollektivs, sondern nur von ihrer Mehrheit geteilt werden.

Die kollektiven Wissenbestandteile eines Individuums sind mit denen anderer Individuen identisch oder zumindest äquifinal, d.h. sie unterstützen diese bei der Bearbeitung einer bestimmten Teilaufgabenstellung auf dieselbe Art und Weise. Berücksichtigt man einerseits die Annahmen kognitiver individueller Lerntheorien, gemäß derer Wissen nicht nur Ergebnis, sondern auch Ausgangspunkt von Lernprozessen ist, und andererseits den Umstand, daß der Wissensbestand eines Individuums Ergebnis seines ganz persönlichen Lebens- und Lernumfeldes ist, so divergieren die Wissensbestände zweier Individuen in einem bestimmten Zeitpunkt in der Regel stark. Entsprechend ist es unwahrscheinlich, daß neue Lernerfahrungen von mehreren Individuen identisch wahrgenommen werden und zu identischem Wissen führen. Neuere Veröffentlichungen zur interpretativen Organisationsforschung modifizieren bzw. ergänzen deshalb das Konstrukt identischen Wissens um äquivalentes bzw. äquifinales Wissen. ${ }^{92}$ Äquifinale Wis-

87 Vgl. Wiegand (1996), S. 14.

88 Bei einer Gruppe handelt es sich um ein soziales Gebilde, das aus einer Mehrzahl von Personen besteht, die in einem unmittelbaren Interaktionszusammenhang stehen. Aus diesen beiden primären Gruppenmerkmalen, die auf die häufig zitierte Definition von Homans zurückgehen, lassen sich als sekundäre Gruppenmerkmale ein geteiltes Ziel-, Normen- und Wertesystem sowie ein Gruppenbewußtsein im Sinne eines Wir-Gefühls ableiten. Vgl. Homans (1965), S. 29; 100ff., Reif-Mosel (1999), o.S. und die dort zitierte Literatur.

89 Vgl. Oberschulte (1994), S. 88ff.; Reber (1992), Sp. 1243; Wiegand (1996), S. 336.

90 Vgl. ähnlich Oberschulte (1994), S. 190; Wiegand (1996), S. 328.

91 Ähnlich argumentieren Schein und Wiegand bezogen auf die Unternehmungskultur als einem Spezialfall kollektiven Wissens der gesamten Unternehmung. Vgl. Schein (1992), S. 12; Wiegand (1996), S. 441.

92 Vgl. åhnlich Weick (1993), S. 347f. 
sensbestände unterscheiden sich zwar inhaltlich voneinander, haben jedoch dieselben Handlungskonsequenzen. Als Beispiele für kollektives Wissen aller Mitglieder der Unternehmung sei hier auf deren Kenntnis der in der Unternehmung geltenden Gleitzeitregelung, des Firmenlogos oder der (auf der letzten Betriebsversammlung dargestellten) problematischen wirtschaftlichen Lage der Unternehmung, die Anlaß für Kürzungen des übertariflich gezahlten Weihnachtsgeldes ist, verwiesen.

Kollektives Wissen kann anhand des jeweiligen Maßes an Redundanz, das unmittelbar von der Größe des Kollektivs abhängt, geordnet werden. So weist das kollektive Wissen der Unternehmung als Ganzes (Wissen der Unternehmung) ein höheres Maß an Redundanz auf als das kollektive Wissen der Gruppe (Gruppenwissen).

\section{Individuelles versus überindividuelles organisationales Wissen}

Die Differenzierung zwischen individuellem und überindividuellem Wissen ${ }^{93}$ bildet eine Erweiterung der Unterscheidung von individuellem und kollektivem Wissen. Während letztere sich allein auf das personengebundene Wissen bezieht, wird hier nun auch personenungebundenes Wissen einbezogen. Die Kategorie des überindividuellen Wissens umfaßt all jenes Wissen, dessen Verfügbarkeit in der Unternehmung nicht nur von einer einzigen Person abhängt und somit die Person des einzelnen Individuums transzendiert. Darunter fällt sowohl die Gesamtheit allen kollektiven Wissens ${ }^{94}$ als auch das personenungebundene Wissen in der Unternehmung. Während individuelles Wissen der Unternehmung durch das Ausscheiden des Individuums oder die mangelnde Bereitschaft zur Verwendung bzw. Weitergabe an andere verloren geht, hängt die Verfügbarkeit überindividuellen (kollektiven oder personenungebundenen) Wissens nicht von einem einzelnen Individuum ab.

\section{Oberflächenwissen versus Tiefenstruktur des organisationalen Wissens}

Die Systematisierung der organisationalen Wissensbasis in Oberflächenwissen und Tiefenstruktur unterscheidet sich grundlegend von den bisher genannten Kategorien. Denn erstmals werden hier die verschiedenen Wissensbestandteile nicht als auf einer Ebene liegend konzipiert (horizontale Gliederung). Vielmehr wird eine vertikale Schichtung des Wissens vorgenommen. Dabei geht man davon aus, daß die einzelnen Wissensbestandteile unterschiedliche Funktionen erfüllen und deshalb von unterschiedlicher $\mathrm{Be}$ deutung sind.

Die Ausführungen zur Reinterpretation der Arbeiten PIAGETS als kognitiver Lerntheorie haben gezeigt, daß individuelle Lerntheorien zwischen den kognitiven Strukturen des Individuums und seinem sonstigen Wissen unterscheiden. Dieses sonstige individuelle Wissen sei hier als Oberflächenwissen bezeichnet, während die kognitiven Strukturen

93 Vgl. ahnlich Grothe (1997), S. 342.

94 Vgl. ahnlich Wiegand (1996), S. 329, der kollektives Wissen als das einzelne Mitglied der Unternehmung transzendierendes Wissen bezeichnet. 
die Tiefenstruktur des individuellen Wissens darstellen. Über ihre in Abschnitt 3.2.1.2 der vorliegenden Arbeit genannten Funktionen hinaus bilden die kognitiven Strukturen des Individuums als relativ stabile, generalisierte Interpretations- und Verhaltensmuster eine Strukturierungshilfe für das Oberflächenwissen. Die Strukturierung des Wissens erlaubt nicht nur das leichtere Einordnen neuer Bestandteile des Oberflächenwissens, sondern erleichtert auch den Zugriff auf vorhandenes Wissen. Verfügt eine Person über eine große Menge Oberflächenwissen, das jedoch nicht strukturiert ist, kann sie dieses Wissen zur Lösung einer Aufgabenstellung mitunter nur sehr begrenzt einsetzen. Umgekehrt kann eine Person, die über vergleichsweise weniger, aber gut strukturiertes Oberflächenwissen verfügt, dieses wenige Wissen in vollem Umfang zur Lösung der Aufgabenstellung einsetzen und damit u.U. eine bessere Problemlösung realisieren. Auch begrenzt die Tiefenstruktur, was an neuem Oberflächenwissen in die individuelle Wissensbasis aufgenommen werden kann. Somit bildet die Tiefenstruktur eine Art Rahmen zur Einordnung des Oberflächenwissens. ${ }^{95}$

Betrachtet man zusammenfassend die zentralen Funktionen der Tiefenstruktur des individuellen Wissens, so strukturiert dieses zum einen das Oberflächenwissen des Individuums, zum anderen filtert es die Wahrnehmung des Individuums und dient damit der Komplexitätsreduktion angesichts einer hochkomplexen Umwelt. In einem nächsten Schritt gilt es nunmehr, diese Erkenntnisse auf die Gesamtheit der organisationalen Wissensbasis zu übertragen und zu untersuchen, welche Wissensbestandteile dort dem Oberflächenwissen und welche der Tiefenstruktur zuzuordnen sind. ${ }^{96}$ Dabei werden im folgenden die Ausführungen von ARGYRIS in die Argumentation einbezogen.

ARGYRIS, dessen Arbeiten zu den bekanntesten Veröffentlichungen zum organisationalen Lernen zählen, thematisiert das Phänomen der organisationalen Handlungstheorien (im englischen Original: Theories-of-action). ${ }^{97}$ Als normative Handlungsgrundlagen beinhalten organisationale Handlungstheorien verhaltensbezogene Wenn-dannHypothesen, die Erwartungen bezüglich der Konsequenzen bestimmter Verhaltensweisen der Mitarbeiter der Unternehmung in bestimmten Situationen bzw. unter

$95 \mathrm{Vgl}$. Oberschulte (1994), S. 61; Pautzke (1989), S. 82f., 86.

96 Vgl. als vom Grundgedanken her ähnlich Pautzke (1989), S. 83ff., der jedoch im Detail zu anderen Ergebnissen gelangt. Insbesondere unterscheidet Pautzke (wie auch Kirsch (1992), S. 133ff.) zwischen Oberflächenstruktur und Tiefenstruktur des Wissens. Die vertikale Schichtung der organisationalen Wissensbasis umfaßt bei Pautzke mit Oberflächenwissen, Oberflächenstruktur und Tiefenstruktur somit drei Wissensarten. Entsprechend werden dort einige der Wissensbestandteile, die im Rahmen der vorliegenden Arbeit der Tiefenstruktur zugerechnet werden (wie z.B die Organisationsstruktur), bei Pautzke tendenziell der Oberflächenstruktur - als zusätzlicher Ebene -zugerechnet. Die im Rahmen der vorliegeden Arbeit vorgenommene Systematisierung unterscheidet sich somit von der bei Kirsch und Pautzke. Diese unterschiedlichen Konzeptionalisierungen stehen in unmittelbarem Zusammenhang mit dem jeweiligen Ziel der Arbeit: Wăhrend Pautzke einerseits in der Denktradition der evolutionären Managementkonzeption von Kirsch und andererseits der von Arbeiten zur Unternehmungskultur steht und entsprechend stärker sogenannte 'weiche Faktoren', wie z.B. Wertvorstellungen und Mythen, fokussiert, die er der Tiefenstruktur der organisationalen Wissensbasis zurechnet, zielt die vorliegende Arbeit darauf ab, den potentiellen Beitrag der organisatorischen Gestaltung und des Informationsmanagements zur Förderung organisationalen Lernens aufzuzeigen.

97 Vgl. z.B. in dem Standardwerk Argyris/Schðn (1978), S. 10ff. Eine Sammlung der wichtigsten Aufsătze von Argyris zum Thema organisationales Lernen bietet Argyris (1992), passim. 
bestimmten Bedingungen formulieren. ${ }^{98}$ Anschaulich beschreibt WIEGAND Handlungstheorien als „komplexes System .. [von] Normen, Strategien und Grundannahmen der Organisation ... , welches Kommunikations- und Kontrollmuster, die Art der Ressourcenallokation, Karrierewege, Sozialisationsmechanismen etc. beinhaltet und verknüpft."99 Entsprechend kommt den Handlungstheorien Erklärungs-, Prognose- und Kontrollcharakter zu. ${ }^{100}$ Dieses Grundverständnis organisationaler Handlungstheorien findet sich auch in den Arbeiten anderer Autoren zum organisationalen Lernen. So thematisieren JELINEK 'Shared Frames of Reference', DUNCAN/WeISS das 'Paradigma' der Organisation und KIRSCH 'Sinnmodelle'.101 Im Detail stellen diese jedoch auf vom Ansatz von ARGYRIS abweichende Sachverhalte ab. Von Unterschieden im Detail abstrahierend beschränkt sich die im Rahmen der vorliegenden Arbeit verwendete Definition auf die in allen diesen Arbeiten implizit verfolgte gleiche Grundidee: Organisationale Handlungstheorien werden als die Gesamtheit der generellen Regeln in der Unternehmung verstanden, die für mehr als einen Mitarbeiter handlungsleitend sind. Dazu gehören z.B. das Unternehmungsleitbild, die Unternehmungsstrategie, die Unternehmungskultur, inoffizielle Mythen und Weltbilder, Organigramme und Ablaufpläne.

Das Adjektiv 'organisational' wird im Zusammenhang mit organisationalen Handlungstheorien im konkret institutionalen Sinne verwendet, d.h. bei den organisationalen Handlungstheorien handelt es sich um Handlungstheorien aller oder zumindest eines Teils der Mitarbeiter in der Unternehmung und damit um Handlungstheorien in der Unternehmung oder gar der Unternehmung (als Institution). ARGYRIS läßt offen, ob sich die organisationalen Handlungstheorien notwendigerweise stets auf die Gesamtheit der Mitarbeiter der Unternehmung beziehen oder ob ihre Gültigkeit auch auf bestimmte Subsysteme beschränkt sein kann. Um eine unnötige Engführung des Phänomens der organisationalen Handlungstheorien zu vermeiden, wird im folgenden angenommen, daß in der Unternehmung organisationale Handlungstheorien mit unterschiedlich großen Gültigkeitsbereichen (d.h. für unterschiedliche Kollektive) existieren. Im Gegensatz zu den kognitiven Strukturen, die sich stets auf eine einzelne Person beziehen, handelt es sich bei den organisationalen Handlungstheorien somit um überindividuelles Wissen. Sie liegen entweder als kollektives Wissen mehrerer (im Extrem: aller) Mitarbeiter der Unternehmung oder aber als personenungebundenes Wissen - z.B. in Form schriftlicher Dokumente - vor.

Damit entsprechen die organisationalen Handlungstheorien auf der überindividuellen Ebene bezüglich ihrer grundsätzlichen Funktion den kognitiven Strukturen des einzelnen Individuums und bilden die Tiefenstruktur der überindividuellen organisationa-

98 Vgl. Wolfsteiner (1995), S. 174.

99 Wiegand (1996), S. 209, der dort auf Argyris/Schon (1978), S. 15, 25 verweist.

100 Vgl. Argyris/Schø̈n (1978), S. 4f.

101 Vgl. Duncan/Weiss (1979), S. 90f.; Kirsch (1990), S. 471 ff.; Jelinek (1979), S. XVI. 
Ien Wissensbasis. So stellt HEDBERG fest: „Theories of action ... are for organizations what cognitve structures are for individuals. They filter and interpret signals from the environment and tie stimuli to responses." 102 Handlungstheorien als 'intersubjektiv geteilte Wirklichkeitskonstruktionen'103 bilden also einen überindividuellen Bezugsrahmen innerhalb der Unternehmung.

Bereits auf der individuellen Ebene bzw. im Rahmen individueller Lerntheorien erweist sich die exakte Abgrenzung zwischen Oberflächenwissen und Tiefenstruktur des Wissens im Einzelfall als problematisch. Während nämlich davon auszugehen ist, daß Faktenwissen regelmäßig dem Oberflächenwissen zugeordnet werden kann, kann es sich bei Regelwissen sowohl um Oberflächenwissen (z.B. das Wissen darüber, daß man Besuchern zur Begrüßung die Hand schüttelt) als auch um die Tiefenstruktur des Wissens (z.B. das Wissen über die Kommunikationsgewohnheiten der Japaner) handeln. Die Zuordnung eines konkreten Wissensbestandteils zum Oberflächenwissen oder zur Tiefenstruktur des Wissens hängt hier häufig von der spezifischen Sichtweise des jeweiligen Betrachters ab. Entsprechendes gilt auch auf der überindividuellen Ebene für die Unterscheidung zwischen den als überindividueller Tiefenstruktur der organisationalen Wissenbasis verstandenen organisationalen Handlungstheorien und dem überindividuellen (kollektiven oder personenungebundenen) Oberflächenwissen der organisationalen Wissensbasis. Zwar stellt die Unterscheidung in Oberflächenwissen und Tiefenstruktur des Wissens einen zentralen Bezugspunkt der vorliegenden Arbeit dar. Für die folgende Argumentation ist jedoch lediglich die Reinterpretation der organisatorischen Regeln als Teil der Tiefenstruktur der organisationalen Wissensbasis relevant. ${ }^{104}$ Deshalb wird das überindividuelle Oberflächenwissen hier vereinfachend als Residualgröße konzipiert, die alle Bestandteile der organisationalen Wissensbasis umfaßt, die nicht deren Tiefenstruktur zuzurechnen sind.

ARGYRIS unterscheidet die Gesamtmenge der Handlungstheorien in tatsächlich im Gebrauch befindliche (Theories-in-use) und offizielle Handlungstheorien (Espoused Theories), wobei er nicht etwa auf unterschiedliche Inhalte dieser beiden Arten organisationaler Handlungstheorien abstellt. Vielmehr orientiert sich die Differenzierung an der offiziellen Legitimation der Handlungstheorien einerseits und ihrem jeweiligen Grad der Ex- bzw. Impliziertheit ${ }^{105}$ andererseits. Die Espoused Theories bzw. offiziellen Handlungstheorien dienen der offiziellen Legitimation von Verhalten. Sie stellen den Teil der Handlungstheorien der Mitarbeiter der Unternehmung dar, den diese

102 Hedberg (1981), S. 7f.

$103 \mathrm{Vgl}$. Klimecki/Probst/Eberl (1991), S. 121.

104 Siehe Abschnitt 3.3.2 der vorliegenden Arbeit.

105 Die Unterscheidung zwischen explizitem und implizitem Wissen stellt auf den Bewußtseinsgrad und die sprachliche Formulierbarkeit ab. Der Begriff des impliziten Wissens (im englischen Original: 'Tacit Knowledge') geht auf Polanyi zuruck, der davon ausgeht, „daß wir mehr wissen, als wir zu sagen wissen." Polanyi (1985), S. 14. Implizites Wissen ist eine Art Gebrauchswissen, dessen der Mensch sich im praktischen Umgang mit den Dingen und in der Sprache bedient, ohne sich dessen bewußt zu sein und entsprechend auch ohne es sprachlich formulieren zu können. Vgl. Bühl (1984), S. $117 \mathrm{ff}$; Oberschulte (1994), S. $67 \mathrm{ff}$. 
äußern bzw. nach außen hin deutlich machen. Es handelt sich hier stets um explizites Wissen. Beispiele sind das Unternehmungsleitbild, die Unternehmungsstrategie, Organigramme, Arbeitsanweisungen, Ablaufpläne, Funktionendiagramme und Stellenbeschreibungen. Tatsächlich jedoch folgt das Verhalten der Mitarbeiter nicht immer den offiziellen Handlungstheorien. Vielmehr orientieren sie sich an den Theories-in-use als den sich tatsächlich im Gebrauch befindlichen Handlungstheorien, die jedoch regelmäßig nicht offiziell legitimiert sind. Auch handelt es sich hier weitgehend um implizites Wissen. ${ }^{106}$ Somit ist ihr Einfluß auf das Verhalten einerseits den Mitarbeitern selbst oft nicht bewußt (sie glauben vielmehr, daß ihr Verhalten den Espoused Theories folgt), andererseits für einen externen Beobachter nicht unmittelbar feststellbar. ${ }^{107}$ Beispiele für Theories-in-use sind organisatorische Regeln als Ergebnis von Selbstorganisationsprozessen $^{108}$, inoffizielle Mythen und Weltbilder und andere Sozialisationsmechanismen. Ein in der betrieblichen Praxis häufig zu beobachtendes Beispiel für Diskrepanzen zwischen Espoused Theories und Theories-in-use ist eine in Führungsgrundsätzen, gruppenorientierten organisatorischen Regeln und individuellen Anforderungsprofilen manifestierte Ausrichtung an kooperativen Arbeitsformen, die oft genug im Widerspruch steht zur gleichzeitig praktizierten Bevorzugung von 'Einzelkämpfern' bei Beförderungen und ähnlichen Belohnungen.

\section{Die mehrdimensionale Systematisierung der organisationalen Wissensbasis}

Die genannten Möglichkeiten der Unterscheidung in verschiedene Arten organisationalen Wissens stellen alternative Sichten auf die Gesamtheit der organisationalen Wissensbasis dar. So kann organisationales Wissen z.B. in personengebundener oder -ungebundener Form vorliegen. Zugleich kann es sich dabei um Oberflächenwissen oder um die Tiefenstruktur der organisationalen Wissensbasis handeln. Im folgenden werden die bislang isoliert nebeneinander stehenden Kriterien zueinander in Bezug gesetzt. Dabei wird zwischen den zentralen drei Dimensionen 'Trägermedium', 'Inhalt' und 'Verfügbarkeit' unterschieden.

Betrachtet man zunächst die erste Dimension 'Trägermedium', so kann diese - wie in Abbildung 3/3 dargestellt - in mehrere Teildimensionen untergliedert werden.

Auf der ersten Ebene kann zwischen individuellem und überindividuellem organisationalem Wissen unterschieden werden. Während individuelles Wissen stets im Gehirn eines einzelnen Menschen vorliegt und damit als personengebundenes Wissen unmittelbar an diesen einzelnen Menschen gebunden ist, kann es sich bei überindividuellem Wissen sowohl um personengebundenes als auch um personenungebundenes Wissen

106 Prinzipiell kann eine Theory-in-use jedoch auch explizites Wissen darstellen. Konstitutives Charakteristikum von Theories-in-use ist somit lediglich ihre fehlende offizielle Legitimation.

107 Vgl. Argyris/Schön (1978), S. 15; Wiegand (1996), S. 208f.

108 Für eine ausfuhrliche Darstellung organisatorischer Regeln als Ergebnis von Selbst- und Fremdorganisationsprozessen siehe Abschnitt 2.2.1.3 sowie Abschnitt 4.1.2 der vorliegenden Arbeit. 


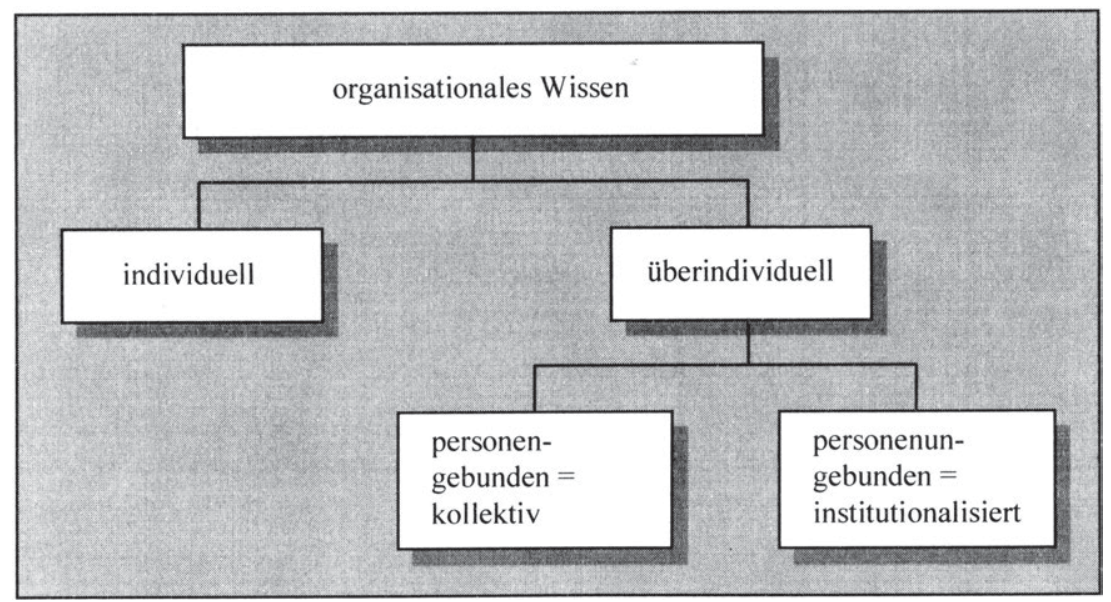

Abb. 3/3: Die Systematisierung organisationalen Wissens anhand des Trägermediums

handeln. Immer dann, wenn überindividuelles Wissen als personengebundenes Wissen vorliegt, handelt es sich um kollektives Wissen. Dieses wird in den Gehirnen mehrerer Menschen parallel gespeichert. Dagegen handelt es sich bei personenungebundenem bzw. institutionalisiertem Wissen um solches überindividuelles Wissen, das auf nichtmenschlichen materiellen Trägermedien gespeichert wird.

Die Gliederung der organisationalen Wissensbasis anhand des jeweiligen Trägermediums des Wissens in verschiedene Teilbestände erleichtert die Abgrenzung organisationalen Wissens gegenüber der Summe der individuellen Wissensbestände der Mitglieder der Unternehmung. Diese Abgrenzung ist wiederum Voraussetzung für die Unterscheidung zwischen individuellem und organisationalem Lernen im folgenden Abschnitt.

Zunächst ist die Gesamtheit des personengebundenen organisationalen Wissens der Gesamtheit der individuellen Wissensbestände der Mitglieder der Unternehmung gegenüberzustellen. Wie bereits bei der Definition der organisationalen Wissensbasis erwähnt, handelt es sich nur bei einem Teil der individuellen Wissensbestände zugleich um organisationales Wissen: Nur der Teil, der einerseits von der jeweiligen Person entweder selbst verwendet oder anderen Personen zur Verfügung gestellt wird sowie andererseits geeignet ist, diese bei der Erfüllung ihrer betrieblichen Teilaufgaben zu unterstützen, stellt organisationales Wissen dar. Da davon auszugehen ist, daß die Mitglieder der Unternehmung über mehr als das im Rahmen des betrieblichen Leistungserstellungsprozesses zweckgeeignete Wissen verfügen, reicht die Menge ihres individuellen Wissens regelmäßig über die des personengebundenen organisationalen Wissens hinaus. Nicht jeder Bestandteil der individuellen Wissensbasen der Mitarbeiter der Unternehmung ist also zugleich organisationales Wissen. Diese Argumentation kann analog auf die Unterscheidung zwischen dem kollektiven Wissen der Mitglieder der 
Unternehmung als Ganzem und der Teilmenge des Wissens, das zugleich Teil der organisationalen Wissensbasis ist, übertragen werden.

Neben individuellem und kollektivem Wissen als personengebundenem Wissen umfaßt die organisationale Wissensbasis auch personenungebundenes Wissen. Institutionalisiertes Wissen ist immer dann der organisationalen Wissensbasis zuzurechnen, wenn mindestens ein Mitglied der Unternehmung über diesbezügliches Zugriffswissen verfügt. Da das institutionalisierte Wissen nicht Teil der individuellen Wissensbasen der Mitarbeiter ist, reicht die Menge des organisationalen Wissens hier über die der individuellen Wissensbasen hinaus.

Zusammenfassend ist somit festzustellen, daß die individuellen Wissensbasen der einzelnen Mitglieder der Unternehmung auf der einen und die organisationale Wissensbasis auf der anderen Seite zum Teil übereinstimmen. Neben dieser Schnittmenge existieren jedoch auch Wissensbestandteile die der einen, nicht jedoch der anderen Menge zuzurechnen sind. Denn einerseits sind Teile des individuellen Wissens der Mitglieder der Unternehmung nicht Teil der organisationalen Wissensbasis. Andererseits handelt es sich bei Teilen der organisationalen Wissensbasis nicht um individuelles Wissen der Mitglieder der Unternehmung. Somit stellt das organisationale Wissen ein eigenständiges Phänomen dar, das eindeutig von dem der Summe der individuellen Wissensbasen der Mitglieder der Unternehmung unterschieden werden kann.

Die zweite Dimension der Systematisierung der organisationalen Wissensbasis stellt auf inhaltliche Aspekte des Wissens ab. Dabei wird zwischen Oberflächenwissen und Tiefenstruktur des Wissens unterschieden. Dieses Kriterium kann auf alle im Rahmen der Betrachtung der ersten Dimension unterschiedenen Teilmengen der organisationalen Wissensbasis angewendet werden. Somit setzen sich sowohl das individuelle als auch das kollektive und das institutionalisierte organisationale Wissen aus Oberflächenwissen und Tiefenstruktur des Wissens zusammen.

Die dritte Dimension betrifft die Verfügbarkeit des Wissens. Nur prinzipiell verfügbares Wissen wird der organisationalen Wissensbasis zugerechnet. Innerhalb der Gesamtmenge dieses prinzipiell verfügbaren Wissens wird zwischen aktuellem organisationalen Wissen, das im Zeitpunkt der Beobachtung tatsächlich verfügbar ist, und latentem organisationalen Wissen, das lediglich prinzipiell, nicht jedoch im Zeitpunkt der Beobachtung verfügbar ist, unterschieden. Auch diese Systematisierung des organisationalen Wissens kann auf alle Wissensbestandteile angewendet werden. Somit kann es sich einerseits sowohl beim Oberflächenwissen als auch bei der Tiefenstruktur der organisationalen Wissensbasis um aktuelles oder latent verfügbares organisationales Wissen handeln. Andererseits kann auch innerhalb der Systematisierung von individuellem, kollektivem und institutionalisiertem Wissen zwischen aktuellem und latentem organisationalem Wissen unterschieden werden.

Abbildung 3/4 verdeutlicht, daß es sich bei den drei Dimensionen 'Trägermedium', 'Inhalt' und 'Verfügbarkeit' um alternative Sichten auf die organisationale Wissensbasis 
als ein und dieselbe Grundgesamtheit handelt. Der Würfel umfaßt die gesamte organisationale Wissensbasis als das im Rahmen von Prozessen organisationalen Lernens veränderte Objekt. Die hier vorgenommene Abgrenzung der organisationalen Wissensbasis stellt somit einen ersten Schritt auf dem Weg zu einer umfassenden Konzeptionalisierung des organisationalen Lernens dar.

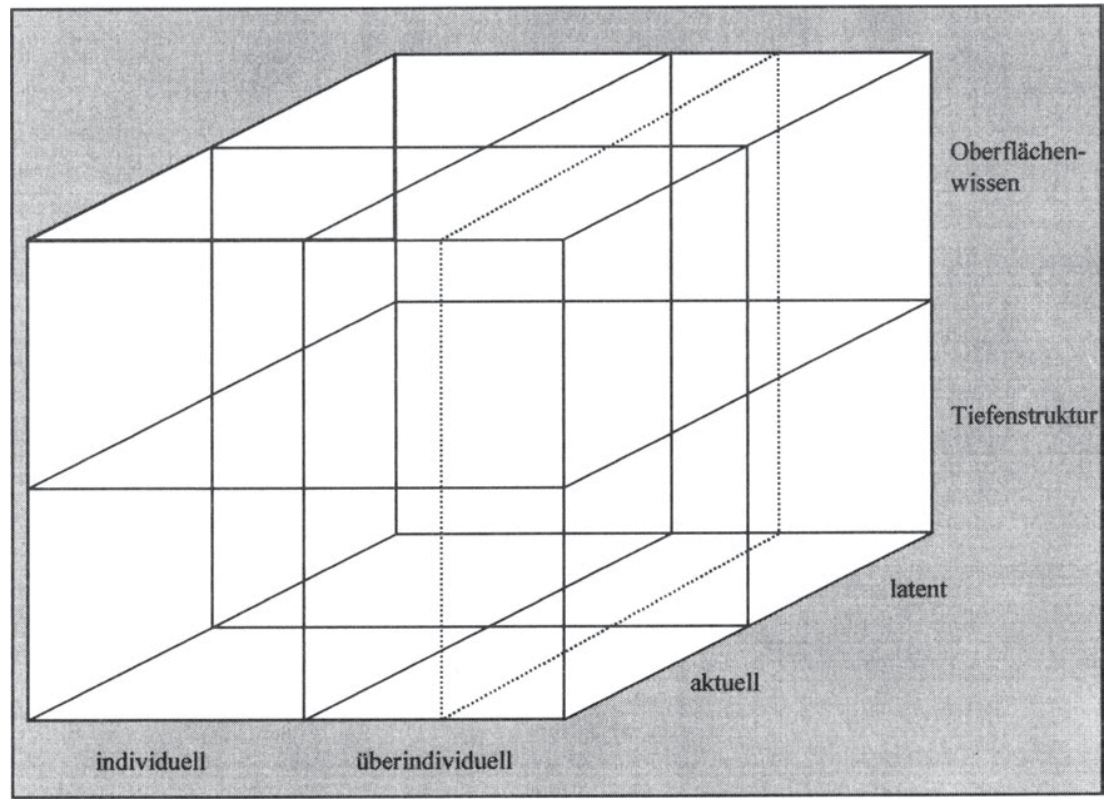

Abb. 3/4: Die mehrdimensionale Systematisierung der organisationalen Wissensbasis

\subsubsection{Dynamische Perspektive: Organisationales Lernen als Veränderung der organisationalen Wissensbasis}

Im Rahmen der vorliegenden Arbeit wird organisationales Lernen als Veränderung der organisationalen Wissensbasis definiert. Entsprechend schließt sich an die statische Betrachtung der organisationalen Wissensbasis als des Objektes organisationaler Lernprozesse eine dynamische Perspektive an, in deren Mittelpunkt die nähere Untersuchung der Aktivitäten der Veränderung steht, d.h. es ist zu klären, welche Bedeutung dem Begriff des Lernens im organisationalen Kontext zugewiesen wird.

Wie oben im Rahmen des Überblicks über behavioristische und kognitive individuelle Lerntheorien dargestellt wurde, ist der Lernbegriff traditionell unmittelbar mit dem einzelnen Individuum verbunden. Die Verwendung desselben Begriffes im Zusammenhang mit organisationalem Lernen legt eine analoge Anwendung des individuellen Lernbegriffs auf die gesamte Unternehmung bzw. die Fortführung der für die indi- 
viduelle Ebene getroffenen Aussagen nahe. Dies hat in der Vergangenheit zu vielen Mißverständnissen und Unklarheiten bei der Rezeption von Ansätzen organisationalen Lernens geführt. Die Kritiker wenden sich dabei vor allem gegen die Anthropomorphisierung der Unternehmung. ${ }^{109}$ Denn die Fähigkeit, Wissen intellektuell zu verarbeiten bzw. zu denken ist an den Menschen gebunden und kann nicht auf die Unternehmung als Ganzes übertragen werden. Zwar ist organisationales Wissen innerhalb ihrer Grenzen verfügbar, die Institution Unternehmung selbst 'weiß' jedoch nicht. Vielmehr steht das organisationale Wissen für Menschen als wissensverarbeitende Wesen bereit. Im folgenden wird aufgezeigt, was im Rahmen der vorliegenden Arbeit unter Prozessen organisationalen Lernens verstanden wird und wie diese gegenüber individuellem Lernen abzugrenzen sind.

Definiert man organisationales Lernen als Veränderung der organisationalen Wissensbasis, so ist die organisationale Wissensbasis sowohl Ausgangspunkt als auch Ergebnis organisationaler Lernprozesse. 110 Das organisationale Wissen $\mathrm{zu}$ einem bestimmten Zeitpunkt ist dann einerseits Ergebnis vorheriger organisationaler Lernprozesse, andererseits Ausgangspunkt nachfolgenden organisationalen Lernens. Diesen Sachverhalt visualisiert Abbildung 3/5.

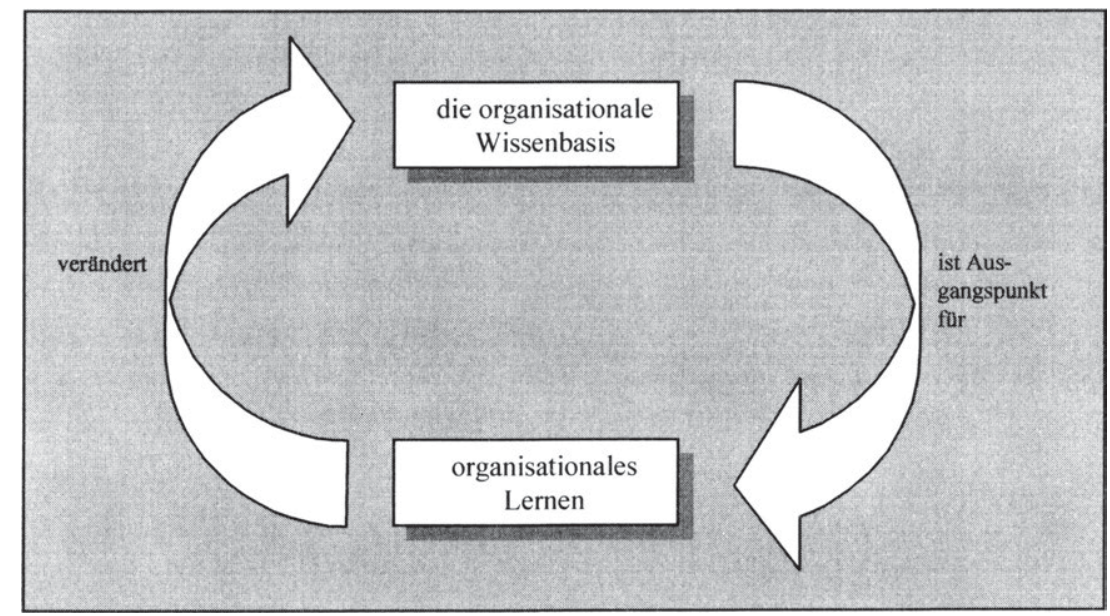

Abb. 3/5: Die organisationale Wissensbasis als Ausgangspunkt und Ergebnis organisationalen Lernens (in Anlehnung an Pawlowski (1994), S. 182)

Aufgrund dieses Sachverhalts orientiert sich die folgende Darstellung der Prozesse organisationalen Lernens an der in Abschnitt 3.2.2.1 vorgenommenen Systematisierung der organisationalen Wissensbasis. Insbesondere wird zwischen organisationalem Ler-

Vgl. Wiegand (1996), S. 2.

110 Vgl. Oberschulte (1994), S. 62. 
nen als Veränderung der individuellen (Abschnitt 3.2.2.2.2) und der überindividuellen (Abschnitt 3.2.2.2.3) Teile der organisationalen Wissensbasis unterschieden. Organisationale Lernprozesse können jedoch nicht nur anhand ihres jeweiligen Objektes unterschieden werden. Eine umfassende Betrachtung organisationalen Lernens muß vielmehr über die organisationale Wissensbasis als Objekt der Veränderung hinaus auch die verschiedenen Arten der Veränderung berücksichtigen. Deshalb werden im folgenden in Abschnitt 3.2.2.2.1 zunächst die verschiedenen Grundformen der Veränderung der organisationalen Wissensbasis vorgestellt.

\subsection{Grundformen der Veränderung der organisationalen Wissensbasis}

Betrachtet man das im Rahmen von Prozessen organisationalen Lernens zu verändernde Objekt 'organisationale Wissensbasis' als System, so kann die Veränderung dieses Systems sowohl aus dem Hinzufügen neuer als auch aus dem Ändern oder dem Entfernen bestehender Teile des Systems bestehen. Das bedeutet, daß die Veränderung der organisationalen Wissensbasis von dreierlei Art sein kann:

- Wissen, das bislang nicht Teil der organisationalen Wissensbasis war, wird in diese aufgenommen,

- ein bislang zur organisationalen Wissensbasis gehörender Wissensbestandteil wird aus dieser entfernt,

- Wissen, das Teil der organisationalen Wissensbasis ist, wird verändert.

Der Umstand, daß bisher gültiges Wissen neuem weichen muß, wird in der Literatur häufig als 'Verlernen' (im englischen Original: Unlearning) bezeichnet, wobei sich die Autoren in der Regel auf die Arbeiten der sogenannten 'Unlearning School' um Hedberg beziehen. Hedberg stellt das Verlernen dem Lernen gegenüber und postuliert eine Zweck-Mittel-Beziehung zwischen beiden: Das Verlernen vorhandenen, überholten Wissens sei die Voraussetzung für das Lernen neuen Wissens. ${ }^{11}$ Dabei bleibt unklar, ob Verlernen hier im Sinne der Zerstörung des alten Wissens oder als das Entwickeln neuen Wissens aus altem heraus zu verstehen ist. ${ }^{112}$ Folgt man den kognitiven Lerntheorien, so gilt für individuelles Lernen, daß altes Wissen nicht zerstört wird, sondern gespeichert bleibt, aber nicht mehr angewendet wird. ${ }^{113}$ Entsprechendes gilt damit auch für die individuellen Teile der organisationalen Wissensbasis. Für die Gesamtheit aller organisationalen Lernprozesse kann dagegen keine eindeutige Position vertreten werden. So kann z.B. das in einem Datenbanksystem gespeicherte Wissen im Rahmen der Aktualisierung sehr wohl vernichtet, d.h. gelöscht werden. Da die Definition organisationalen Lernens als die Veränderung der organisationalen Wissensbasis in der

111 Vgl. Hedberg (1981), S. 3ff.; Nystrom/Starbuck (1984), S. 53ff.; Wiegand (1996), S. $475 \mathrm{ff}$.

112 Gegen die Konzeption von Verlernen als der Zerstörung von altem Wissen argumentiert z.B. Lübbe (1987), S. 284ff.

$113 \mathrm{Vgl}$. Wiegand (1996), S. 477. 
vorliegenden Arbeit sowohl deren Vergrößerung durch neues Wissen als auch die Verkleinerung durch das Entfernen von Wissen umfaßt, kann HedBergs Begriff des Verlernens hier nicht verwendet werden. Vielmehr stellen die von ihm als Verlernen bezeichneten Aktivitäten hier eine Teilmenge des organisationalen Lernens dar.

Neben dem Hinzufügen und dem Entfernen einzelner Wissensbestandteile zu bzw. aus der organisationalen Wissensbasis stellt auch die Veränderung einzelner Teile des organisationalen Wissens organisationales Lernen dar.

Diese Veränderung kann einerseits inhaltlicher Art sein. Dabei werden dann z.B. als falsch oder nicht mehr aktuell erkannte Wissensbestandteile aus der organisationalen Wissensbasis entfernt und durch neu in die organisationale Wissensbasis einzufügendes Wissen ersetzt. Inhaltliche Änderungen der organisationalen Wissensbasis stellen damit letztlich keine eigenständige Kategorie neben der Aufnahme neuen Wissens und dem Entfernen überholten Wissens dar, sondern setzten sich aus eben diesen beiden Teilschritten zusammen.

Andererseits kann sich die Veränderung von Teilen des organisationalen Wissens auf deren Speicherform oder Verfügbarkeit beziehen. Bezüglich der Verfügbarkeit des Wissens gilt, daß sowohl das Überführen latenten organisationalen Wissens in aktuelles als auch das Überführen aktuellen Wissens in latentes Wissen organisationales Lernen darstellt. In der Literatur wird der Begriff organisationalen Lernens dagegen häufig auf den Prozeß des Verfügbarmachens von latentem organisationalem Wissen beschränkt. ${ }^{14}$ Dieses einseitige 'Gerichtetsein' organisationalen Lernens erweist sich in der Kombination mit dem undifferenzierten Postulat der Förderung organisationalen Lernens m.E. als problematisch: Denn ein Mehr an aktuellem organisationalem Wissen kann keineswegs pauschal positiv bewertet werden. Vielmehr sind dem Nutzen der erhöhten Verfügbarkeit des organisationalen Wissens die mit dem Prozeß des Verfügbarmachens verbundenen Kosten gegenüberzustellen. Bezüglich der Speicherform des Wissens gilt, daß jede Veränderung der Speicherform organisationalen Wissens einen Prozeß organisationalen Lernens darstellt, so z.B. die Überführung individuellen Wissens in kollektives oder die von personengebundenem (individuellem oder kollektivem) Wissen in personenungebundenes.

Bereits diese kurze Darstellung der grundsätzlich möglichen Arten der Veränderung der organisationalen Wissensbasis und damit der Arten organisationalen Lernens macht unmittelbar deutlich, daß organisationales Lernen gemäß dem Verständnis der vorliegenden Arbeit keinesfalls undifferenziert positiv (oder negativ) gewertet werden kann. Vielmehr setzt die Bewertung organisationalen Lernens bei der Weite des hier verfolgten Begriffes eine Eingrenzung der als relevant erachteten Phänomene voraus. Die Gesamtheit der Prozesse organisationalen Lernens wird hier dagegen grundsätzlich wertfrei dargestellt. 


\subsection{Organisationales Lernen als Veränderung der individuellen Teile der organisationalen Wissensbasis}

Grundsätzlich kann man die organisationale Wissensbasis anhand der Speicherform in individuelles und überindividuelles Wissen gliedern. Hier wird zunächst die Gesamtheit der organisationalen Lernprozesse betrachtet, die eine Veränderung individueller Teile der organisationalen Wissensbasis darstellen. Dazu zählen einerseits bestimmte individuelle Lernprozesse, andererseits Prozesse des (Nicht-) Verfügbarmachens individueller Wissensbestandteile.

Die Subsumtion bestimmter individueller Lernprozesse unter organisationales Lernen beruht auf der systemtheoretisch begründeten Argumentation, daß sich die Unternehmung als System ändert, sofern sich eines ihrer Elemente ändert. Lernt ein Individuum und ändert damit seinen Handlungsspielraum, so ändert sich zugleich der Handlungsraum der Unternehmung als des übergeordneten Systems. Bei individuellen Lernprozessen handelt es sich immer dann zugleich um organisationales Lernen, wenn Mitglieder der Unternehmung einen Teil ihrer individuellen Wissensbasis verändern, der zugleich Teil der organisationalen Wissensbasis ist, d.h. der zur Lösung in der Unternehmung anfallender Teilaufgabenstellungen geeignet ist und aktuell oder latent zur Verfügung steht. Somit handelt es sich nur bei einem bestimmten Teil der individuellen Lernprozesse der Mitglieder der Unternehmung um organisationales Lernen. Die Summe aller individuellen Lernprozesse in der Unternehmung ist größer als die der organisationalen Lernprozesse.

Gliedert man die individuellen Teile der organisationalen Wissensbasis anhand ihres Inhalts, so kann man zwischen Oberflächenwissen und Tiefenstruktur des Wissens unterscheiden. Die für die Gesamtheit aller individuellen Lernprozesse getroffenen lerntheoretischen Aussagen PIAGETS, die in Abschnitt 3.2.1.2 dargestellt wurden, gelten auch für diejenigen individuellen Lernprozesse, bei denen es sich zugleich um organisationale Lernprozesse handelt. Entsprechend kann organisationales Lernen als Lernen eines Individuums sowohl eine Veränderung von dessen Oberflächenwissen - im Sinne von Assimilation als einfachem Lernprozeß - als auch eine Veränderung der jeweiligen kognitiven Strukturen (als Tiefenstruktur des Wissens) - im Sinne von Akkomodation als Lemprozeß höherer Ordnung - darstellen.

Als weitere Dimension zur Systematisierung der organisationalen Wissensbasis war in Abschnitt 3.2.2.1 die Verfügbarkeit des Wissens angeführt worden. Mit Hilfe des Kriteriums der Verfügbarkeit können die individuellen Teile der organisationalen Wissensbasis in aktuelles und latentes organisationales Wissen untergliedert werden. Neben der Vergrößerung oder Verringerung der Menge des prinzipiell verfügbaren (aktuellen oder latenten) organisationalen Wissens umfaßt organisationales Lernen auch Umschichtungen zwischen aktueller und latenter organisationaler Wissensbasis. ${ }^{115}$ Bei diesen Prozes-

115 Siehe Abschnitt 3.2.2.2.1 der vorliegenden Arbeit. 
sen des (Nicht-) Verfügbarmachens individuellen Wissens handelt es sich nicht um individuelles Lernen, so daß organisationale Lernprozesse hier über die Menge der individuellen Lernprozesse hinausreichen.

Bereits diese Ausführungen zu organisationalem Lernen als Veränderung der individuellen Teile der organisationalen Wissensbasis zeigen, daß zwar bestimmte individuelle Lernprozesse zugleich organisationales Lernen darstellen. Organisationales Lernen ist jedoch keineswegs mit der Summe aller individuellen Lernprozesse in der Unternehmung gleichzusetzen, sondern reicht in manchen Teilen darüber hinaus. In anderen Teilen ist die Menge der organisationalen Lernprozesse kleiner als die der individuellen.

Frühere Ansätze zum organisationalen Lernen gingen zum Teil davon aus, daß das individuelle Lernen verschiedener Personen für die Unternehmung als Ganzes von unterschiedlicher Bedeutung sein kann. Sie definierten organisationales Lernen als das stellvertretende Lernen von Eliten (im englischen Original: Dominant Coalition ${ }^{116}$ ), so z.B. der Geschäftsführung, deren Mitglieder aufgrund ihrer Machtausstattung besser als andere in der Lage seien, ihr eigenes Wissen in die Entscheidungsprozesse in der Unternehmung einzubringen. ${ }^{117}$ Einerseits setzen diese Ansätze damit organisationales Lernen mit dem individuellen Lernen bestimmter Personen gleich und ermöglichen entsprechend keine konzeptionelle Eigenständigkeit organisationalen Lernens gegenüber individuellem Lernen. Andererseits ist aufgrund der in Abschnitt 3.1 beschriebenen hochkomplexen und -dynamischen Umfeldsituation der im Rahmen dieser Arbeit betrachteten Unternehmungen davon auszugehen, daß der relative Einfluß der Eliten zugunsten aller Mitarbeiter zurückgeht, da die Bewältigung dieser Umfeldsituation weniger durch direkte Beeinflussung der Mitarbeiter durch die Führungskräfte als vielmehr durch das Schaffen eines geeigneten Rahmens für das Handeln aller gewährleistet wird. ${ }^{118}$ Diesem Verständnis organisationalen Lernens wird deshalb im Rahmen der vorliegenden Arbeit nicht gefolgt.

\subsection{Organisationales Lernen als Veränderung der überindividuellen Teile der organisationalen Wissensbasis}

Nachdem im vorangehenden Abschnitt diejenigen Prozesse organisationalen Lernens, die sich auf die Veränderung individueller Wissenbestandteile beziehen, dargestellt wurden, soll hier nun organisationales Lernen als Veränderung der überindividuellen Teile der organisationalen Wissensbasis untersucht werden. Hierzu zählen einerseits Prozesse der Veränderung kollektiven Wissens, andererseits Prozesse der Veränderung personenungebundenen Wissens.

116 Vgl. Thompson (1967), zitiert nach Schuppel (1996), S. 18.

117 Vgl. Duncan/Weiss (1979), S. 77f.; de Geus (1988), S. 70ff. So formuliert de Geus plakativ: „The only relevant learning in a company is the learning done by those people who have the power to act ...“(de Geus (1988), S. 71).

118 Vgl. Knyphausen (1988), S. 309ff. Diese Argumentation wird in Abschnitt 4.1.2.2 der vorliegenden Arbeit wieder aufgegriffen werden. 
Die Prozesse der Veränderung kollektiven Wissens können auch als Prozesse kollektiven Lernens bezeichnet werden. Kollektives Lernen liegt vor, wenn die Mitglieder eines Kollektivs lernen und nach vollzogenen Lernprozessen über kollektives Wissen verfügen. Bei diesem kollektiven Wissen handelt es sich entweder um identisches Wissen oder aber um äquifinales Wissen. In Abschnitt 3.2.2.1 war ausgeführt worden, daß es sich bei kollektivem Wissen um das Wissen unterschiedlicher Kollektive handeln kann. Entsprechend gilt für kollektives Lernen, daß dieses die Lernprozesse der Mitglieder sehr unterschiedlicher Kollektive betrifft. Insbesondere kann die Größe des Kollektivs von einigen wenigen Mitgliedern hin zu sehr großen Kollektiven variieren und im Extrem die Gesamtheit der Mitglieder der Unternehmung umfassen.

Kollektives Lernen umfaßt einerseits das identische Lernen mehrerer Individuen. Aufgrund von Unterschieden der individuellen Wissensbestände als Ausgangspunkt weiterer Prozesse individuellen Lernens stellt identisches Wissen mehrerer Personen eher einen theoretischen Grenzfall als praktische Wirklichkeit dar. Im Rahmen der vorliegenden Arbeit wird jedoch auch das Erlangen äquifinalen Wissens als identisches Lernen mehrerer Personen bezeichnet. ${ }^{119}$ So lernen beispielsweise alle Mitglieder der Unternehmung neue Gleitzeitregelungen.

Andererseits umfaßt kollektives Lernen aber auch emergentes Lernen eines Kollektivs. Dabei handelt es sich um die Verknüpfung verschiedener, einander ergänzender individueller Wissensbestände zu völlig neuartigem Wissen, das in dieser Form bislang nicht in den individuellen Wissensbeständen vorhanden war. Als Beispiel für emergentes Lernen eines Kollektivs sei hier auf den Fall eines multidisziplinären Unternehmungsberaterteams verwiesen, innerhalb dessen jeder einzelne Berater sein individuelles Wissen zur Lösung der Teilaufgabenstellung in die Diskussion einbringt. Keine dieser Einzelpersonen kann die Teilaufgabe allein lösen. Erst durch die Kombination der verschiedenen Wissensbestände ergibt sich die Lösung als neues Wissen. Dieses Wissen entstände zwar nicht ohne individuelles Wissen, stellt jedoch nicht dessen einfache Aufsummierung dar. In dem im Vergleich zum einzelnen Individuum komplexeren System des Kollektivs bildet sich somit Wissen, das über die bloße Aggregation der individuellen Wissensbestände hinausgeht. Im Zeitpunkt seiner Entstehung wird dieses aus emergenten Lernprozessen resultierende Wissen notwendigerweise von allen Mitgliedern des Kollektivs geteilt. In der Literatur herrscht weitgehend Einigkeit darüber, daß emergentes Lernen zumindest in Kollektiven, die die spezifischen Merkmale einer Gruppe aufweisen, zu beobachten ist. Insbesondere die dort regelmäßig stattfindenden intensiven Kommunikationsprozesse sind Voraussetzung für das Auftreten emergenter Lernprozesse. Da kollektives Lernen als Emergenzphänomen auf der Verbindung verschiedener individueller Wissenbestände beruht, ist ferner deren Strukturierung von besonderer Bedeutung, d.h. es muß gewährleistet sein, daß die

119 Siehe Abschnitt 3.2.2.1 der vorliegenden Arbeit. 
jeweiligen Tiefenstrukturen der Wissensbasen der einzelnen Individuen zueinander passen. ${ }^{120}$

Gruppen bilden lediglich eine Teilmenge der möglichen Kollektive in der Unternehmung. Entsprechend stellt sich die Frage, ob über emergentes Lernen in Gruppen als Spezialfall kollektiven Lernens hinaus weitere Möglichkeiten zur Konzeptionalisierung organisationalen Lernens als Emergenzphänomen bestehen. In der Literatur existieren verschiedene Versuche, im Rahmen von Mehrebenen-Ansätzen organisationalen Lernens zwischen verschiedenen Emergenzebenen organisationalen Lernens zu unterscheiden, wobei neben Individuum und Gruppe regelmäßig auf die gesamte Unternehmung als höchste Emergenzebene abgestellt wird. Die Konzeptionalisierung emergenter Prozesse organisationalen Lernens auf dieser höchsten Emergenzebene erweist sich jedoch als problematisch. WIEGAND, dessen Arbeit zum organisationalen Lernen im deutschsprachigen Raum den zur Zeit umfassendsten kritischen Literaturüberblick zu diesem Thema bietet und der zugleich eine sehr anspruchsvolle theoretische Analyse dieses Phänomens vornimmt, untersucht die folgenden drei Möglichkeiten zur Konzeptionalisierung emergenten organisationalen Lernens auf der Ebene der Unternehmung als Ganzen:121

- organisationales Lernen als Veränderung des von allen Mitgliedern der Unternehmung geteilten (kollektiven) Wissens (auch im Sinne von Unternehmungskultur ${ }^{122}$ ),

- organisationales Lernen als Veränderung von Routinen,

- organisationales Lernen als Veränderung von Kernkompetenzen.

Der erste Ansatz, der sich in einer großen Zahl von Arbeiten zum organisationalen Lernen wiederfindet, ${ }^{123}$ definiert emergentes organisationales Lernen als die Veränderung des kollektiven Wissens aller Unternehmungsmitglieder. WIEGAND kritisiert, daß die Entstehung dieses kollektiven Wissens jedoch nicht konzeptionalisiert, sondern lediglich postuliert werde. Insbesondere in großen Unternehmungen sei die Entstehung eines

120 Vgl. Oberschulte (1994), S. 189ff.

121 Vgl. dazu und im folgenden Wiegand (1996), S. 424f. Als vierte Möglichkeit nennt Wiegand in diesem Zusammenhang sogenannte 'Wissensgemeinschaften', die er zwischen der Gruppen- und Gesamtunternehmungsebene ansiedelt. Wissensgemeinschaften sind Kollektive, deren Mitglieder über äquifinales Wissen verfügen, das fur andere Unternehmungsmitglieder nicht unmittelbar verständlich ist. Dieses kann z.B. aus der (außerbetrieblichen) berufsgruppenspezifischen Sozialisation der Mitglieder (als Techniker, Psychologen oder Kaufleute) oder dem unmittelbaren Arbeitsumfeld und insbesondere den Arbeitsabläufen resultieren. An anderer Stelle räumt Wiegand jedoch ein, daß Wissensgemeinschaften eine eigene, vierte Lernebene darstellen und damit nicht etwa mit der Emergenzebene der gesamten Unternehmung gleichzusetzen sind. Ihre Einordnung im Zusammenhang mit der Konzeptionalisierung emergenten organisationalen Lernens auf der Ebene der Unternehmung als Ganzen erweist sich damit als mißverstăndlich. Vgl. Wiegand (1996), S. 324.

122 Die Unternehmungskultur sei hier definiert als System ,gemeinsam geteilter Werte, Normen, Einstellungen, Überzeugungen und Ideale“ (Staehle (1994), S. 472) aller bzw. der Mehrzahl der Unternehmungsmitglieder. Sie dient als 'sozialer Klebstoff', der das System Unternehmung zusammenhält. Dabei hat sie u.a. Integrations-, Koordinations-, Identifikations- und Motivationsfunktion. Vgl. För/Lenz (1992), S. 138ff.; Heinen/Fank (1997), passim, insbesondere S. $141 \mathrm{ff}$.; Smircich (1983), S. 344 .

123 Vgl. z.B. Klimecki/Probst/Eberl (1991), S. 121ff.; Nonaka (1994), S. 28ff.; Pautzke (1989), S. 86ff.; Pawlowski (1994), S. 260f., 278ff.; Senge (1996), S. 251. 
solchen Wissens höchst unwahrscheinlich, da die Wissensbestände und Lernumgebungen der einzelnen Mitarbeiter (als Ausgangsbasis ihres Lernens) sehr unterschiedlich sind. Die Menge des von allen geteilten Wissens (z.B. im Sinne von Unternehmungskultur) sei deshalb in der Regel sehr klein. Wahrscheinlicher sei die Ausbildung von gemeinsam geteiltem Wissen in verschiedenen Kollektiven als Subsystemen der Unternehmung (z.B. im Sinne von Subkulturen ${ }^{124}$ ). WIEGANDS ausführliche Kritik erlaubt die Schlußfolgerung, daß sich dieser Ansatz nur sehr bedingt zur Konzeptionalisierung emergenten organisationalen Lernens auf der Ebene der Unternehmung als Ganzen eignet. ${ }^{125}$

Die zweite Möglichkeit bezieht sich bei der Konzeptionalisierung organisationalen Lernens auf Routinen, wie sie bereits 1963 von CYERT/MARCH thematisiert und in den 90er Jahren von verschiedenen Autoren erneut aufgegriffen wurden. WIEGAND kritisiert hier, daß die Definition von Routinen und ihre Erstentstehung unklar blieben, so daß Routinen letztlich als Black Box für alle möglichen Wissensformen fungierten. Offen bliebe insbesondere, ob es sich hier notwendigerweise um personenungebundenes Wissen (z.B. schriftlich fixierte Unternehmungsstrategie oder organisatorische Regeln, (Fließband-)Technik) oder auch um personengebundenes Wissen (als habitualisiertes, vorhersagbares Verhalten der Mitglieder der Unternehmung) handele. Er schlägt vor, Routinisierung und Institutionalisierung (im Sinne von (zeitlicher) Persistenz und Personentranszendenz) nicht gleichzusetzen, sondern davon auszugehen, daß Routinen unterschiedlich stark institutionalisiert auftreten können. Problematisch bliebe jedoch, daß mit dem Konzept der Routinen im Rahmen organisationalen Lernens zwar die Unterscheidung in verschiedene Emergenzebenen aufgegeben wird, eine nähere Untersuchung der Entstehung, Veränderung und Institutionalisierung von Routinen aber die emergenzebenenbezogene Differenzierung verhaltenswissenschaftlicher Konzepte notwendig mache. Deshalb erweisen sich Routinen für die Konzeptionalisierung emergenten organisationalen Lernens auf der Ebene der Unternehmung als Ganzen als ungeeignet. ${ }^{126}$

Die dritte der von WIEGAND unterschiedenen Möglichkeiten zur Konzeptionalisierung emergenter Prozesse organisationalen Lernens bezieht sich auf das Phänomen der Kernkompetenzen im Rahmen ressourcenorientierter Managementansätze. Kernkompetenzen stellen unternehmungsindividuelles technologie- und marktorientiertes Wissen dar, das von der historischen Entwicklung der Unternehmung (so z.B. früheren Investitionen oder der Unternehmungskultur) geprägt ist. Auch hier kritisiert WIEGAND, daß eine exakte Definition sowie Aussagen zur Erstentstehung von Kernkompetenzen unterblieben. Insbesondere bleibe die Abgrenzung von Routinen und Kernkompetenzen unscharf. Seine umfassende Kritik läßt WIEGAND schließen, daß auch dieser Ansatz zur 
Konzeptionalisierung emergenten organisationalen Lernens auf der Ebene der Unternehmung als Ganzen nicht geeignet ist. ${ }^{127}$

Ohne hier im einzelnen auf WIEGANDS ausführliche kritische Würdigung aller drei Möglichkeiten zur Konzeptionalisierung emergenten organisationalen Lernens auf der Ebene der Unternehmung als Ganzen einzugehen, kann als Ergebnis seiner Untersuchungen zu dieser Emergenzebene festgestellt werden, daß deren präzise Konzeptionalisierung noch aussteht. Da diese Ebene jedoch innerhalb von Mehrebenen-Ansätzen eine zentrale Position einnimmt und dort insbesondere zur Abgrenzung individuellen und organisationalen Lernens dient, erweisen sich die diesbezüglichen theoretischen Defizite als besonders problematisch. Die vorliegende Untersuchung berücksichtigt emergentes organisationales Lernen deshalb lediglich bezüglich der Gruppe.

Zusammenfassend ist festzuhalten, daß kollektives Lernen zum einen Teil der Summe identischer bzw. äquifinaler individueller Lernprozesse entspricht, zum anderen Teil ein über individuelles Lernen hinausreichendes Emergenzphänomen darstellt.

Organisationales Lernen als Veränderung der überindividuellen Teile der organisationalen Wissensbasis umfaßt über das kollektive Lernen hinaus auch die Veränderung des personenungebundenen bzw. institutionalisierten Wissens in der Unternehmung. Dabei kann es sich sowohl um die Erweiterung der institutionalisierten Teile der organisationalen Wissensbasis um neue Wissenbestandteile, ihre Verkleinerung durch das Entfernen alter Wissensbestandteile, als auch die Veränderung von Teilen des institutionalisierten Wissens handeln. ${ }^{128}$

Die Grundidee, die Unternehmung durch die Institutionalisierung von Wissen unabhängiger von dem einzelnen Mitarbeiter zu gestalten, findet sich bereits in TAYLORS Ansatz des 'Scientific Management'. Durch die genaue Beobachtung und schriftliche Aufzeichnung der einzelnen Arbeitsschritte versuchte TAYLOR, ursprünglich isoliertes individuelles Wissen über die Arbeitsabläufe in der Unternehmung beliebig replizierbar und allgemein verfügbar zu machen. ${ }^{129}$

Im Rahmen der Forschung zum organisationalen Lernen geht der Ansatz, die Institutionalisierung von Wissen als Prozeß organisationalen Lernens zu betrachten, auf JELINEK zurück, die ihr Konzept organisationalen Lernens allerdings auf die Institutionalisierung von Wissen beschränkt. Die Begrenztheit ihres Ansatzes erkennt auch JELINEK selbst, wenn sie schreibt: „Clearly some organizational learning may escape our notice within this framework. Much of what an organization 'knows' is not codified or formalized; instead, it is part of the culture, part of what is 'understood'. Yet what is codified and formalized in administrative systems does transcend the individual, it is

127 Vgl. Wiegand (1996), S. 462ff.

128 Siehe Abschnitt 3.2.2.2.1 der vorliegenden Arbeit.

129 Vgl. Pawlowski (1992), S. $201 \mathrm{f}$. 
accessible to others ..."130 JELINEK stellt jedoch die eindeutige Abgrenzbarkeit ihrer Konzeptionalisierung organisationalen Lernens gegenüber deren inhaltlicher Reichweite in den Vordergrund.

Institutionalisiertes Wissen ist nur dann zugleich auch organisationales Wissen, wenn mindestens ein Mitglied der Unternehmung das erforderliche personengebundene Zugriffswissen zur Aktivierung des institutionalisierten Wissens hat. In der betrieblichen Praxis verfügt im Regelfall sogar eine Vielzahl von Personen über das entsprechende Zugriffswissen. Dies gilt insbesondere bezüglich des im Rahmen der vorliegenden Arbeit fokussierten Wissens, das mit Hilfe computergestützter Informationstechnik gespeichert wird. Denn die Verteilung von personengebundenem $\mathrm{Zu}$ griffswissen über personenungebundenes Wissen auf mehrere Mitglieder der Unternehmung ist in der Regel einfacher zu realisieren als die Übertragung des personenungebundenen Wissens auf Individuen. Das führt dazu, daß organisationales Wissen in Form von institutionalisiertem Wissen regelmäßig ein höheres Maß an Unabhängigkeit von einzelnen Personen aufweist als individuelles Wissen, was vor allem im Falle eines personellen Wechsels von großer Bedeutung ist. ${ }^{131}$ Zwei Beispiele verdeutlichen die unterschiedliche zeitliche Persistenz institutionalisierten und personengebundenen Wissens: Das personengebundene Wissen eines Juristen aus der Rechtsabteilung geht mit dessen Ausscheiden aus der Unternehmung für diese verloren. Dagegen bleibt das institutionalisierte Wissen über die Umsatz-, Kosten- und Erlösentwicklung einer bestimmten Produktgruppe auch nach Ausscheiden des diese Produktgruppe betreuenden Mitarbeiters des Controlling erhalten, da das Zugriffswissen bezüglich dieser Daten in der entsprechenden Datenbank in der Abteilung in der Regel weit gestreut ist. Darüber hinaus hat das formalisierte Wissen, das personenungebunden mittels computergestützter Informationstechnik vorgehalten wird, aufgrund seiner leichten Reproduzierbarkeit eine relativ hohe Diffusionsgeschwindigkeit. Denn die Wissensweitergabe ist weder raumgebunden, noch ist ein persönlicher Kontakt notwendig. ${ }^{132}$ Entsprechend ist die Duplizierung personenungebundenen Wissens im Vergleich $\mathrm{zu}$ personengebundenem Wissen tendenziell mit einem geringeren Ressourcenverbrauch verbunden.

Als zweite Dimension zur Systematisierung der organisationalen Wissensbasis in Abschnitt 3.2.2.1 und hier nun der Prozesse organisationalen Lernens als Veränderungen der überindividuellen Teile der organisationalen Wissensbasis dient das Kriterium der Verfügbarkeit des Wissens. Die in Abschnitt 3.2.2.2.2 bezüglich der Veränderung der individuellen Teile der organisationalen Wissensbasis getroffenen Aussagen gelten analog für deren überindividuelle Teile, d.h. sowohl die Überführung latenten Wissens in aktuelles organisationales Wissen als auch umgekehrt die von aktuellem in latentes

130 Jelinek (1979), S. 156 (Hervorhebungen im Original).

131 Vgl. åhnlich Pawlowski (1992), S. 201.

132 Vgl. Gloede (1992), S. 144. 
organisationales Wissen stellen Prozesse organisationalen Lernens dar. Für die weitere Untersuchung der vorliegenden Arbeit spielen sie jedoch keine Rolle und werden deshalb hier nicht weiter untersucht.

Neben der Unterscheidung organisationalen Wissens anhand des Trägermediums sowie der Verfügbarkeit - und den entsprechenden Prozessen organisationalen Lernens - kann anhand des Inhalts zwischen dem Oberflächenwissen und der Tiefenstruktur der überindividuellen Teile der organisationalen Wissensbasis unterschieden werden. Dementsprechend ist auch zwischen einfachen und höheren Prozessen organisationalen Lernens als Veränderungen überindividueller Wissensbestandteile zu unterscheiden. Sie bilden das Analogon zu den individuellen Lernprozessen der Assimilation und Akkomodation nach PIAGET und können sowohl Veränderungen personengebundenen kollektiven Wissens als auch solche personenungebundenen Wissens darstellen. Die Differenzierung in einfache und höhere Prozesse organisationalen Lernens ist für die Konzeptionalisierung des Zusammenhangs zwischen Wandel und organisationalem Lernen in Abschnitt 3.3 der vorliegenden Arbeit von großer Bedeutung und wird deshalb hier ausführlich dargestellt.

In der Literatur zum organisationalen Lernen existiert eine Fülle von Ansätzen zur Unterscheidung verschiedener Formen bzw. Niveaus organisationalen Lernens. Tabelle 3/6 zeigt einen Überblick über die Systematisierungsansätze verschiedener Autoren. Sieht man von Unterschieden im Detail ab, ist allen genannten Ansätzen die Differenzierung in einfache (Lernniveau 1) und höhere (Lernniveau 2) Prozesse organisationalen Lernens gemein. Grundgedanke bei der Unterscheidung verschiedener Lernformen bzw. -niveaus ist, daß in der Unternehmung typische Muster des Lernens beobachtbar sind. ${ }^{133}$ Die Differenzierung zwischen Lernniveau 1 und 2 erfolgt anhand des jeweiligen Bezugs zur Tiefenstruktur der organisationalen Wissensbasis. In Abschnitt 3.2.2.1 der vorliegenden Arbeit war herausgearbeitet worden, daß die kognitiven Strukturen der Individuen die Tiefenstruktur der individuenbezogenen Teile der organisationalen Wissensbasis darstellen, während die organisationalen Handlungstheorien der Tiefenstruktur der überindividuellen Teile der organisationalen Wissensbasis zuzurechnen sind.

Besonders deutlich wird die Übertragung der mit der Unterscheidung zwischen Assimilation und Akkomodation nach PIAGET verbundenen Ideen auf die überindividuelle Ebene bei der Abgrenzung zwischen Single-loop und Double-loop Learning in den Arbeiten von ARGYRIS/SCHÖN, deren damit verbundene Grundgedanken deshalb im folgenden vorgestellt werden sollen. Die Unterscheidungen der anderen in Tabelle 3/6 genannten Autoren finden dagegen im Rahmen der vorliegenden Arbeit keine weitere Berücksichtigung. 


\begin{tabular}{|c|c|c|c|}
\hline Autor(en) & Lernniveau 1 & Lernniveau 2 & Lernniveau 3 \\
\hline $\begin{array}{c}\text { Argyris/Schön } \\
\text { (1978) }\end{array}$ & $\begin{array}{l}\text { Single-loop } \\
\text { Learning }\end{array}$ & $\begin{array}{l}\text { Double-loop } \\
\text { Learning }\end{array}$ & $\begin{array}{c}\text { Deutero } \\
\text { Learning }\end{array}$ \\
\hline $\begin{array}{l}\text { Hedberg } \\
\text { (1981) }\end{array}$ & $\begin{array}{l}\text { Adjustment } \\
\text { Learning }\end{array}$ & $\begin{array}{l}\text { Turnover } \\
\text { Learning }\end{array}$ & $\begin{array}{l}\text { Turnaround } \\
\text { Learning }\end{array}$ \\
\hline $\begin{array}{c}\text { Shrivastava } \\
\text { (1983) }\end{array}$ & $\begin{array}{l}\text { Adaptive } \\
\text { Learning }\end{array}$ & $\begin{array}{l}\text { Assumption } \\
\text { Sharing }\end{array}$ & $\begin{array}{l}\text { Development of } \\
\text { Knowledge-base }\end{array}$ \\
\hline $\begin{array}{c}\text { Fiol/Lyles } \\
(1985)\end{array}$ & $\begin{array}{l}\text { Lower-level } \\
\text { Learning }\end{array}$ & $\begin{array}{l}\text { Higher-level } \\
\text { Learning }\end{array}$ & \\
\hline $\begin{array}{l}\text { Senge } \\
(1990)\end{array}$ & $\begin{array}{l}\text { Adaptive } \\
\text { Learning }\end{array}$ & $\begin{array}{l}\text { Generative } \\
\text { Learning }\end{array}$ & \\
\hline
\end{tabular}

Tab.3/6: Systematisierungsmöglichkeiten für Arten organisationalen Lernens (in Anlehnung an Pawlowski (1992), S. 205)

Single-loop Learning liegt vor, wenn den Implikationen der organisationalen Handlungstheorien gefolgt wird, diese also nicht hinterfragt und geändert werden. Das Lernen beschränkt sich hier auf Anpassungen innerhalb des durch die organisationalen Handlungstheorien vorgegeben Rahmens und damit auf das Oberflächenwissen der organisationalen Wissensbasis und die daraus resultierenden Handlungen (deshalb: einfache Schleife bzw. Single Loop). Single-loop Learning kann deshalb im Deutschen als Anpassungslernen bezeichnet werden. Es dient der Stabilisierung der bestehenden Handlungstheorien. Abweichungen zwischen den tatsächlichen Handlungsergebnissen und den Vorgaben der organisationalen Handlungstheorien werden so zu modifizieren versucht, daß die realen Ergebnisse den Vorgaben entsprechen, ohne daß letztere verändert werden. ${ }^{134}$ Als Beispiel für Single-loop Learning sei auf die effiziente Gestaltung des Produktionsprozesses durch den geeigneten Einsatz von Mitarbeitern und Fertigungstechnik innerhalb eines gegebenen ablauforganisatorischen Rahmens verwiesen. ${ }^{135}$

Double-loop Learning liegt vor, wenn die Veränderungen sich nicht auf das Oberflächenwissen (einfache Schleife), sondern auf die darunterliegende Tiefenstruktur der organisationalen Wissensbasis mit den organisationalen Handlungstheorien (doppelte

134 Vgl. Argyris/Schön (1978), S. 18ff.; Pawlowski (1992), S. 206; Schüppel (1996), S. 21 ff.; Wolfsteiner (1995), S. 180ff.

135 Vgl. Klimecki/Probst/Eberl (1991), S. 132. 
Schleife) beziehen. Dies ist immer dann der Fall, wenn die von den Mitgliedern der Unternehmung erkannten Abweichungen zwischen den realen Handlungsergebnissen und den Vorgaben der organisationalen Handlungstheorien diesen als sehr groß und damit nicht im Rahmen der gültigen organisationalen Handlungstheorien lösbar erscheinen. Aus Double-loop Learning resultieren neue Verhaltensmuster, die die Grundlage einer grundsätzlich anderen Art von Verhalten bilden. ${ }^{136}$ Die Veränderung der ablauforganisatorischen Regeln zur Gestaltung des Produktionsprozesses stellt ein Beispiel für Double-loop Learning dar. Die Optimierungsbestrebungen zielen hier u.U. auf eine grundlegend andere Kombination von Mitarbeitern und Fertigungstechnik im Rahmen des Leistungserstellungsprozesses ab.

Ein drittes Niveau organisationalen Lernens bezeichnen ARGYRIS/SCHÖN als Deutero Learning. Deutero Learning liegt vor, wenn die Prozesse des Single- und Double-loop Learning selbst Gegenstand übergeordneter Lernprozesse sind. Damit steigt die Lernfähigkeit auf beiden Ebenen. Es wird gelernt, zu lernen, d.h. das Erkennen der Muster vergangener Lernprozesse beeinflußt zukünftiges Lernen. Im Mittelpunkt steht hier die Reflexion des Lernkontextes und die Analyse von Lernhindernissen und Lernerleichterungen. Problematisch ist jedoch, daß es ARGYRIS/SCHÖN nicht gelingt zu verdeutlichen, was das organisationale Deutero Learning von dem des einzelnen Individuums unterscheidet. Sie argumentieren vielmehr stets auf der Ebene der Individuen. ${ }^{137}$ Trotz dieser Probleme wird der mit der Vorstellung des Deutero Learning verbundene Grundgedanke des 'Lernens zu lernen' in der vorliegenden Arbeit aufgegriffen. Er bildet die Grundlage des in Kapitel 4 konzeptionalisierten Zusammenhangs zwischen organisatorischer Gestaltung und Selbstorganisationsprozessen.

Abbildung 3/7 visualisiert den Zusammenhang zwischen Single-loop, Double-loop und Deutero Learning als überindividuellen Prozessen organisationalen Lernens.

Zeigten bereits die vorangehenden Ausführungen zu den Veränderungen der individuellen Teile der organisationalen Wissensbasis, daß organisationales Lernen nicht mit der Summe der individuellen Lernprozesse gleichzusetzen ist, so verdeutlicht die Analyse der organisationalen Lernprozesse, die Veränderungen überindividueller Teile der organisationalen Wissensbasis darstellen, dies noch eingehender. Organisationales Lernen reicht klar über individuelles Lernen hinaus. Abschließend ist somit festzustellen, daß organisationales Lernen als eigenständiges, von individuellen Lernprozessen eindeutig unterscheidbares Phänomen konzeptionalisiert werden kann. Damit ist ein weiteres Zwischenziel (Konzeptionalisierung des organisationalen Lernens) als Voraussetzung für die Erreichung des zentralen Zieles der vorliegenden Arbeit (Untersuchung

136 Vgl. Argyris/Schön (1978), S. 24ff.; Pawlowski (1992), S. 207; Wiegand (1996), S. 212; Wolfsteiner (1995), S. 184.

137 Vgl. Argyris/Schön (1978), S. 26; Klimecki/Probst/Eberl (1991), S. 132f.; Pawlowski (1992), S. 209. 
des Beitrages des Informationsmanagements zur Förderung organisationalen Lernens) erreicht.

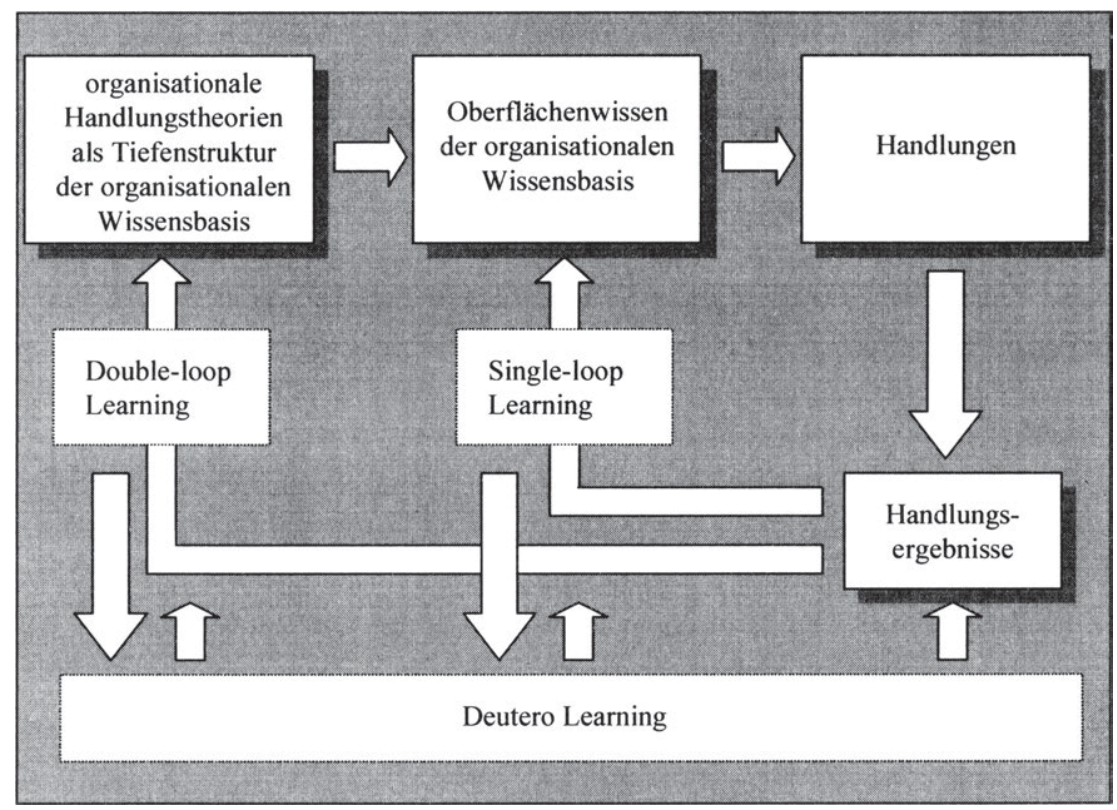

Abb. 3/7: Single-loop, Double-loop und Deutero Learning

\subsection{Der Zusammenhang zwischen Wandel und organisationa- lem Lernen}

Nach der isolierten Darstellung von Wandel und organisationalem Lernen in den ersten beiden Abschnitten dieses Kapitels wird im folgenden der Zusammenhang zwischen beiden Phänomenen herausgearbeitet. Denn es gilt zu überprüfen, ob die - zumindest implizite - Annahme von Managementkonzepten organisationalen Lernens berechtigt ist, daß organisationales Lernen positive Auswirkungen auf die Fähigkeit der Unternehmung hat, unternehmungsexternem Wandel zu begegnen. Dabei wird in der Literatur meist nicht zwischen verschiedenen Prozessen organisationalen Lernens differenziert, sondern pauschal ein Mehr an organisationalem Lernen gefordert. ${ }^{138}$ Deshalb wird im folgenden in Abschnitt 3.3.1 zunächst der Zusammenhang zwischen unternehmungsexternem und -internem Wandel sowie organisationalem Lernen näher untersucht. Aufbauend auf diesen grundsätzlichen Ausführungen wird in Abschnitt 3.3.2 sodann 
begründet, warum die weiteren Ausführungen der vorliegenden Arbeit organisatorische Tätigkeiten als Teil der organisationalen Lernprozesse höherer Ordnung fokussieren.

\subsubsection{Die Notwendigkeit häufiger, schneller Prozesse organisationalen Lernens höherer Ordnung}

Ausgangsproblem der vorliegenden Arbeit ist das Auftreten häufiger, schneller und diskontinuierlicher Wandelprozesse in der relevanten Umwelt der Unternehmung. Aufgrund des postulierten Fit zwischen Unternehmung und Umwelt machen diese entsprechende unternehmungsinterne Wandelprozesse notwendig. Aus dem Ausgangsproblem in Verbindung mit dem postulierten Fit resultiert somit das Folgeproblem, daß häufige, schnelle und grundlegende Wandelprozesse innerhalb der Unternehmung notwendig sind. Dem Management stellt sich die Frage, wie solche unternehmungsinternen Wandelprozesse erreicht werden können.

Grundsätzlich können sich Wandelprozesse als beobachtbare Phänomene auf materielle Objekte oder aber auf das Verhalten von Menschen beziehen. Auf die explizite Unterscheidung unternehmungsinternen Wandels in Veränderungen materieller Objekte und das Verhalten von Menschen wird im folgenden allerdings verzichtet, da Veränderungen materieller Objekte in der Unternehmung nur insoweit interessieren, wie sie auf Verhaltensänderungen von Menschen zurückzuführen sind.

Kognitive individuelle Lerntheorien gehen davon aus, daß die kognitiven Prozesse des Menschen als immaterielle Phänomene die zentralen Einflußgrößen seines Verhaltens als eines materiellen, von außen beobachtbaren Phänomens sind. Geistige Veränderungen betreffen die Sphäre des Denkens und Fühlens von Menschen, ihre Werte und Urteile sowie ihr Planen und Entscheiden. Einerseits bestimmt das Denken und Fühlen des Menschen sein Handeln und damit die materielle Sphäre. ${ }^{139}$ Andererseits beeinflussen materielle Gegebenheiten wiederum das Denken und Fühlen des Menschen. Geistige und materielle Veränderungen sind somit unauflösbar miteinander verknüpft und bedingen sich gegenseitig. ${ }^{140}$ Aus diesem interdependenten Zusammenhang wird zur Unterstützung der Argumentation der vorliegenden Arbeit im folgenden die Wirkungsrichtung 'immaterielle Veränderungen ermöglichen materielle' herausgegriffen. Prinzipiell können Verhaltensänderungen zwar auch ohne die entsprechenden geistigen Veränderungen auftreten. Solche u.U. zufälligen Verhaltensmodifikationen bleiben hier jedoch unberücksichtigt.

Diese Grundannahme kognitiver individueller Lerntheorien bezüglich des Zusammenhangs zwischen Lernen und Handeln wird im Rahmen der vorliegenden Arbeit über den Bereich des einzelnen Individuums hinaus dahingehend erweitert, daß geistigen Veränderungen grundsätzlich materielle folgen. So hat die Veränderung der

$139 \mathrm{Vgl}$. Klimecki/Probst/Eberl (1991), S. 130.

140 Vgl. Schüppel (1996), S. 10f.; Ulrich (1994), S. $15 f$. 
organisationalen Handlungstheorien als organisationaler Lernprozeß Verhaltensänderungen als unternehmungsinterne Wandelprozesse zur Folge. Als Beispiel sei die Modifikation einer Unternehmungsstrategie angeführt, die bisher auf Kostenführerschaft der Unternehmung abstellte. Da die Preise der Unternehmung in der jüngeren Vergangenheit mehrfach von osteuropäischen Anbietern unterboten wurden (unternehmungsexterner Wandel), wird die Änderung der Unternehmungsstrategie in Richtung Leistungsdifferenzierung und insbesondere Service-Führerschaft (organisationales Lernen) beschlossen. Die Umsetzung dieser neuen Unternehmungsstrategie bedeutet, daß Kundenreklamationen nunmehr binnen 48 Stunden bearbeitet werden (unternehmungsinterner Wandel). Organisationales Lernen als immaterielles Phänomen fördert hier somit den materiellen unternehmungsinternen Wandel. ${ }^{141}$

Der im Rahmen der vorliegenden Arbeit verfolgte Lösungsansatz für das oben genannte Ausgangs- und das daraus resultierende Folgeproblem besteht somit darin, geeignete Prozesse organisationalen Lernens zu untersuchen, die häufigen, schnellen und grundlegenden unternehmungsinternen Wandel ermöglichen. Die Förderung dieser internen Wandelprozesse stellt demnach hier das Effizienzkriterium für die Bewertung von Prozessen organisationalen Lernens dar. ${ }^{142}$ Aus dem Erfordernis häufigen und schnellen unternehmungsinternen Wandels resultiert dann die Notwendigkeit häufiger und schneller Prozesse organisationalen Lernens, aus dem Erfordernis grundlegenden internen Wandels die Notwendigkeit organisationalen Lernens höherer Ordnung. Zwar führen auch einfache Lernprozesse zu unternehmungsinternen Wandelprozessen, zur Bewältigung diskontinuierlichen unternehmungsexternen Wandels reichen sie jedoch nicht aus. Nur Veränderungen der Tiefenstruktur des organisationalen Wissens ermöglichen die in dieser Arbeit fokussierten grundlegenden unternehmungsinternen Wandelprozesse. Grundlegend andere Handlungen setzen also sowohl auf der individuellen als auch auf der überindividuellen Ebene die Veränderung der (individuellen bzw. organisationalen) Handlungstheorien - und damit Prozesse der Akkomodation (als individuelles Lernen höherer Ordnung) bzw. des Double-loop Learning (als überindividuelles Lernen höherer Ordnung) - voraus. Veränderungen des organisationalen Oberflächenwissens - im Sinne von Assimilation (individuelle Ebene) bzw. Single-loop Learning (überindividuelle Ebene) - genügen dagegen nicht. Obwohl es sich auch dabei um organisationales Lernen handelt, sind sie insofern hier nicht zielführend und werden deshalb im folgenden aus der Betrachtung ausgeklammert.

Abbildung 3/8 visualisiert den beschriebenen Zusammenhang zwischen unternehmungsexternem und -internem Wandel sowie organisationalem Lernen.

141 Diese Annahme liegt - zumeist in impliziter Form - einer großen Zahl von Konzepten organisationalen Lernens zugrunde, wie Fiol/Lyles (1985), S. 803, für die englischsprachige und Schüppel (1996), S. 13, und Wiegand (1996), S. 8, für die deutschsprachige Literatur feststellen.

142 Zur Problematik der Effizienzkriterien organisationalen Lernens vgl. Wiegand (1996), S. $470 \mathrm{ff}$. 


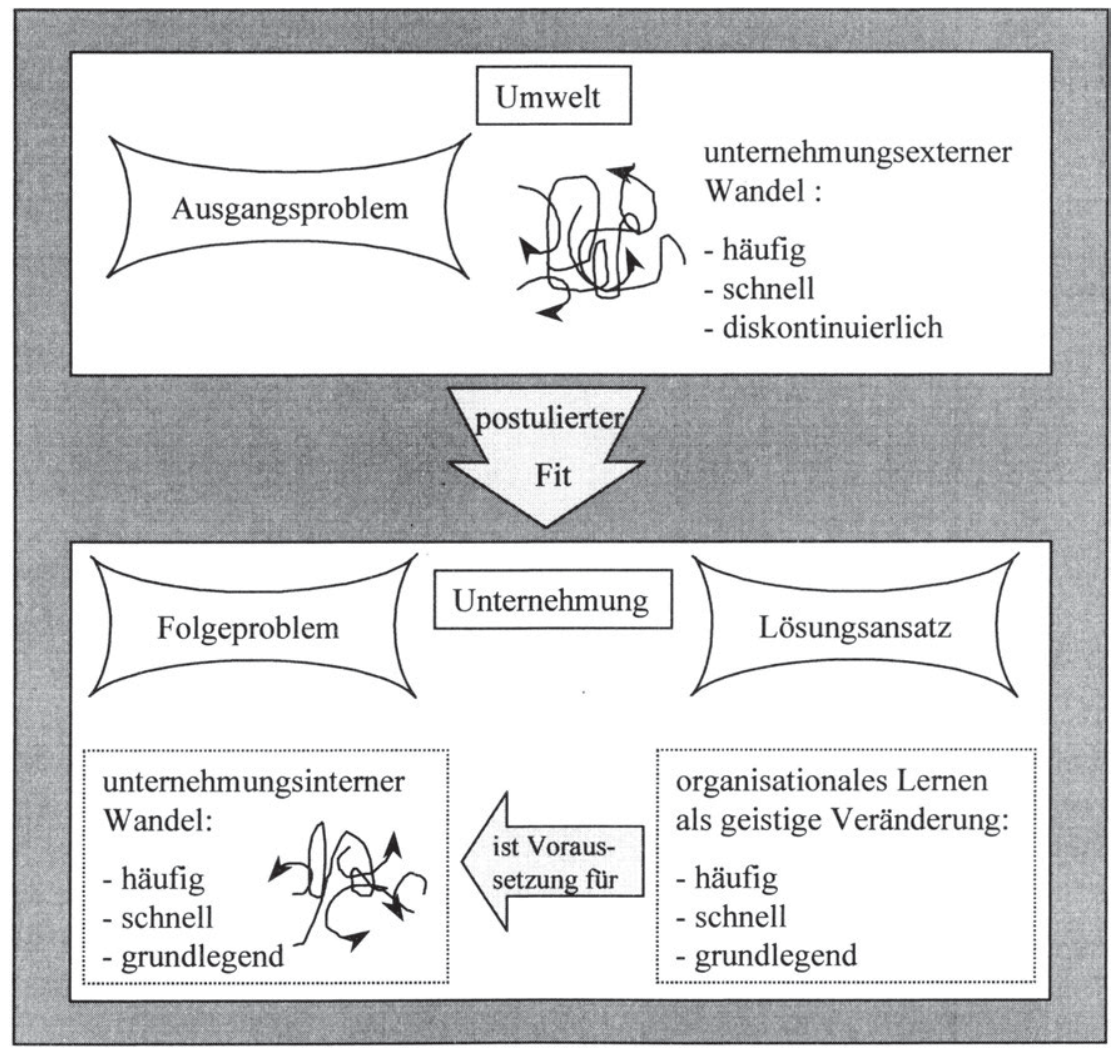

Abb. 3/8: Der Zusammenhang zwischen unternehmungsexternem und -internem Wandel sowie organisationalem Lernen

Allerdings ist der Zusammenhang zwischen geistiger und materieller Veränderung in der Praxis nicht in jedem Fall zwingend gegeben. Vielmehr können Barrieren existieren, die die Umsetzung der geistigen Veränderungen in Handlungen verhindern. So kann z.B. auf individueller Ebene ein Entscheidungsträger aufgrund machtpolitischer Erwägungen auf die Umsetzung neuen Wissens in Handlungen verzichten. Die vorliegende Arbeit abstrahiert von diesen potentiellen Barrieren. ${ }^{143}$ Ihre Untersuchung und die Formulierung von Handlungsempfehlungen zu ihrer Überwindung wäre Thema einer eigenständigen Arbeit. ${ }^{144}$

Unterscheidet man zwischen individuellen und überindividuellen Bestandteilen der organisationalen Wissensbasis bzw. zwischen individuellen und überindividuellen Pro-

143 Damit folgt die Arbeit der Forschungstradition kognitiv ausgerichteter individueller und organisationaler Lerntheorien, die in der Regel den Übergang zwischen Kognition und Aktion bzw. zwischen Wissen und Verhalten außer acht lassen bzw. als automatisch ansehen. Vgl. Weick (1991), S. 122.

144 Solche Barrieren organisationalen Lernens bzw. seiner Umsetzung in Handlungen sind z.B. Gegenstand der Arbeit von Schuppel. Vgl. Schuppel (1996), passim. 
zessen organisationalen Lernens, so fokussieren die folgenden Ausführungen lediglich überindividuelle organisationale Lernprozesse höherer Ordnung. Denn individuelle Lernprozesse höherer Ordnung als Veränderungen der Tiefenstruktur der individuellen Wissensbasis (Akkomodation) stellen zwar prinzipiell geeignete Möglichkeiten dar, grundlegenden unternehmungsinternen Wandel zu ermöglichen. Entsprechend könnte untersucht werden, wie deren häufiges und schnelles Auftreten sichergestellt werden kann. Jedoch handelt es sich dabei um Phänomene, die im Rahmen individueller Lerntheorien bereits ausreichend Berücksichtigung finden und typischer Gegenstand personalwirtschaftlicher Betrachtungen sind. Insbesondere existieren zahlreiche Untersuchungen darüber, wie diese individuellen Lernprozesse durch die Gestaltung der Informationstechnik als einer Teilaktivität des Informationsmanagements gefördert werden können. Die entsprechenden Arbeiten werden heute unter dem Stichwort 'Computer Based Training' (CBT) diskutiert. ${ }^{145}$ Bei der Förderung individueller Lernprozesse durch den Einsatz von Informationstechnik handelt es sich somit um eine in der Literatur bereits ausreichend behandelte Thematik. Im Vergleich zu dem Zusammenhang zwischen überindividuellen organisationalen Lernprozessen und Informationsmanagement ist der verbleibende Forschungsbedarf hier vergleichsweise gering. Auch würde die Eigenständigkeit organisationalen Lernens gegenüber individuellem Lernen bei der Betrachtung individueller Lernprozesse nicht deutlich. Entsprechend werden individuelle Lernprozesse als Teilaspekt organisationalen Lernens im weiteren Verlauf der Argumentation der vorliegenden Arbeit nicht weiter untersucht.

Das Ausklammern einfacher organisationaler Lernprozesse sowie individueller Lernprozesse führt zu einer Verengung der Perspektive der vorliegenden Arbeit auf solche organisationalen Lernprozesse, die Veränderungen der Tiefenstruktur der überindividuellen organisationalen Wissensbasis darstellen und auch als Veränderungen der organisationalen Handlungstheorien bzw. als Double-loop Learning bezeichnet werden. Diese im Rahmen der Argumentation der vorliegenden Arbeit als potentiell zielführend identifizierten organisationalen Lernprozesse höherer Ordnung stellen somit auf inhaltliche Veränderungen ab. Veränderungen der Verfügbarkeit des Wissens sowie Veränderungen der Speicherform bzw. des Trägermediums werden dagegen im folgenden nicht weiter untersucht. ${ }^{146}$

Aufgrund der beschriebenen Notwendigkeit häufigen unternehmungsinternen Wandels genügt es aus der Perspektive der vorliegenden Arbeit nicht, einmalige Veränderungen der organisationalen Handlungstheorien als organisationale Lernprozesse höherer Ordnung zu untersuchen. Vielmehr müssen diese organisationalen Lernprozesse auch $z u$ künftiges organisationales Lernen ermöglichen. Denn organisationales Wissen ist nicht nur Ergebnis organisationalen Lernens, sondern auch Ausgangsbasis für weitere Pro-

145 Für einen Überblick über das Forschungsfeld 'Computer Based Training' vgl. Kerres (1998), passim.

146 Fur die Darstellung der drei Dimensionen 'Trăgermedium', 'Inhalt' und 'Verfügbarkeit' zur Systematisierung der organisationalen Wissensbasis sowie der daraus resultierenden Prozesse organisationalen Lernens siehe die Abschnitte 3.2.2.1 und 3.2.2.2 der vorliegenden Arbeit. 
zesse organisationalen Lernens. ${ }^{147}$ Im Sinne eines Deutero Learning gilt es somit, Rahmenbedingungen zu schaffen, die immer wieder neue Prozesse des Double-loop Learning ermöglichen und damit im Endeffekt '(organisationales) Lernen (höherer Ordnung) zu lernen'.

\subsubsection{Organisatorische Tätigkeit als organisationaler Lernprozeß hö- herer Ordnung}

Nachdem im vorherigen Abschnitt herausgearbeitet wurde, daß häufige und schnelle organisationale Lernprozesse höherer Ordnung potentiell geeignet sind, die Unternehmung zu entsprechenden internen Wandelprozessen zu befähigen, die ihr Überleben in einer turbulenten Umweltsituation sichern, gilt es nunmehr, diese Aussage zu spezifizieren. Denn nicht jede Veränderung der organisationalen Handlungstheorien geht notwendigerweise mit einem positiven Beitrag zur Wandelfähigkeit der Unternehmung einher. Dies soll im folgenden mit Hilfe des Beispiels der Vergrößerung des kollektiven Wissens aller bzw. eines bestimmten Teils der Unternehmungsmitglieder aufgezeigt werden, die im Mittelpunkt zahlreicher Arbeiten zum organisationalen Lernen steht. ${ }^{148}$

In Abschnitt 3.2.2.2.3 der vorliegenden Arbeit wurde bereits auf WIEGANDS Kritik an der mangelnden Konzeptionalisierung des Phänomens 'kollektives Wissen aller Unternehmungsmitglieder' hingewiesen. Unter Berücksichtigung seiner Kritik kann man davon ausgehen, daß kollektives Wissen aller Unternehmungsmitglieder höchstens in stark begrenztem Umfang und beschränkt auf kleine Unternehmungen prinzipiell vorhanden sein kann. Wahrscheinlicher ist dagegen kollektives Wissen bezogen auf einzelne Subsysteme. Da Teile der Unternehmungskultur bzw. von Unternehmungssubkulturen der Tiefenstruktur des kollektiven Wissens aller bzw. eines Teils der Unternehmungsmitglieder zugerechnet werden können, ${ }^{149}$ kann hier die kontroverse Diskussion um das Phänomen der Unternehmungskultur bzw. verschiedener Subkulturen in die Argumentation einbezogen werden. ${ }^{150} \mathrm{Die}$ - zumindest implizit - häufig pauschal positive Bewertung einer starken Unternehmungskultur durch manche Autoren, die diese dazu verleitet, die Vergrößerung des kollektiven Wissens der Mitglieder der gesamten Unternehmung bzw. ihrer Subsysteme in den Mittelpunkt ihrer Untersuchungen zum organisationalen Lernen zu stellen, ist m.E. nicht sinnvoll. Starke Unter-

147 Siehe Abschnitt 3.2.2.2 der vorliegenden Arbeit.

148 Vgl. z.B. Nonaka (1994), S. 28ff.; Pautzke (1989), S. 86ff.; Pawlowski (1994), S. 260f., 278ff.; Senge (1996), S. 251.

149 Es ist davon auszugehen, daß nicht alle Teilaspekte der Unternehmungskultur als Tiefenstruktur des organisationalen Wissens bezeichnet werden können. So handelt es sich z.B. bei Vorgaben bezliglich des Firmenlogos oder bezulglich der einheitlichen Farbgebung im Verkaufsraum um organisationales Oberflächenwissen. Dagegen ist z.B. die Moglichkeit aller Mitarbeiter, die Geschäftsfuhrung - unter Umgehung der direkten Vorgesetzten - unmittelbar anzusprechen, Ausdruck eines Verstandnisses von Fuhrung, das Hierarchien keine große Bedeutung einräumt, und damit der Tiefenstruktur des organisationalen Wissens zuzuordnen.

150 Für eine Darstellung des Phănomens der Unternehmungskultur bzw. verschiedener Subkulturen vgl. Heinen/Fank (1997), passim; Pautzke (1989), S. 240; Schein (1992), passim; Schreyðgg (1989), passim. 
nehmungs(sub)kulturen weisen nämlich neben einigen Vorteilen auch grundlegende Nachteile auf. ${ }^{151}$ Aus der Perspektive der vorliegenden Arbeit, die auf die Befähigung der Unternehmung zu internem Wandel abstellt, erweist sich die mit einer starken Unternehmungs(sub)kultur verbundene einheitliche Ausrichtung des Verhaltens der Unternehmungs(subsystem)mitglieder als besonders problematisch. Denn der tendenziell statische, abschirmende Charakter der Unternehmungs(sub)kultur erschwert zukünftiges Lernen und engt damit den zukünftigen Handlungsspielraum der Mitarbeiter ein. Flexibles Agieren und Reagieren wird damit hier gerade nicht gefördert. ${ }^{152}$ Unter dem Aspekt der Befähigung der Unternehmung zu internen Wandelprozessen ist die Stärkung der Unternehmungskultur bzw. von Unternehmungssubkulturen als Teil der Tiefenstruktur des überindividuellen organisationalen Wissens somit negativ zu bewerten.

Eine Ausnahme bildet die Stärkung einer sogenannten 'Lernkultur'. Dabei handelt es sich um eine Unternehmungskultur oder Subkultur, deren konkrete inhaltliche Ausgestaltung auf die Förderung solcher Prozesse organisationalen Lernens abstellt, die die Unternehmung zu häufigem, schnellem und grundlegendem internem Wandel befähigen. Da in diesem Fall die Stärkung der Unternehmungs(sub)kultur positiv zu bewerten wäre, gälte es zunächst, die typischen Merkmale einer solchen Lernkultur zu untersuchen, um in einem zweiten Schritt die Bedeutung des Informationsmanagements für die Förderung dieser Lernkultur zu ermitteln. Da mit organisationalem Lernen und Informationsmanagement bereits zwei in der Literatur zumeist unzureichend konzeptionalisierte Bereiche Gegenstand der vorliegenden Arbeit sind und darüber hinaus die Konzeptionalisierung des Zusammenhangs zwischen Unternehmungskultur und Informationsmanagement außerordentlich schwierig ist, wird im folgenden auf die Berücksichtigung einer organisationales Lernen förderlichen Unternehmungskultur als eines weiteren hochproblematischen Forschungsbereiches verzichtet.

Die Ausführungen zur Unternehmungskultur im allgemeinen und zu einer Lernkultur im besonderen zeigen, daß die Bewertung des Zielbeitrags von Prozessen organisationalen Lernens zur Förderung unternehmungsinternen Wandels die konkrete inhaltliche Ausgestaltung der zu verändernden organisationalen Handlungstheorien voraussetzt.

Neben Teilen der Unternehmungskultur bzw. verschiedener Subkulturen umfaßt die Tiefenstruktur der überindividuellen organisationalen Wissensbasis z.B. auch die Unternehmungsstrategie. Aus der Perspektive der vorliegenden Arbeit kommt den organisatorischen Regeln als Teilmenge der Tiefenstruktur der überindividuellen organisationalen Wissensbasis besondere Bedeutung $\mathrm{zu}$. Im folgenden wird deshalb zunächst begründet, warum es sich bei organisatorischen Regeln um die Tiefenstruktur der überindividuellen organisationalen Wissensbasis bzw. bei organisatorischen Tätigkeiten um überindividuelle organisationale Lernprozesse höherer Ordnung im

151 Vgl. Schreyogg (1989), passim.

152 Vgl. Schreyøgg (1989), S. 94, 99ff., insbesondere S. $105 f$. 
Sinne von Double-loop Learning handelt. Sodann gilt es aufzuzeigen, warum die vorliegende Arbeit gerade diese Teilmenge der überindividuellen organisationalen Lernprozesse höherer Ordnung fokussiert.

Gegenstand jeder organisatorischen Tätigkeit sind die organisatorischen Regeln. Diese sind Teil der in Abschnitt 2.2.2.2.1 dieser Arbeit formulierten „Wahrnehmungen, Erfahrungen und Kenntnisse über die Realität des Menschen und damit über Sachverhalte, Personen, Normen, Werte und Handlungen" und stellen somit Wissen dar.

$\mathrm{Da}$ die organisatorischen Regeln das Zusammenwirken der Elemente des Systems Unternehmung im Rahmen der arbeitsteiligen Aufgabenerfüllung bestimmen, ihr Zweck also in der Realisierung des betrieblichen Leistungserstellungsprozesses liegt, und sie den Mitgliedern der Unternehmung innerhalb der Unternehmung prinzipiell zur Verfügung stehen, handelt es sich darüber hinaus um organisationales Wissen. ${ }^{153}$ Beruhen die organisatorischen Regeln auf mündlichen Vereinbarungen zwischen mehreren Mitgliedern der Unternehmung, so liegen sie in personengebundener Form vor, sind sie in schriftlicher Form fixiert, so stellt dies eine personenungebundene Form organisationalen Wissens dar.

Ferner sind organisatorische Regeln stets überindividueller Natur, da sie die Arbeitsteilung zwischen den menschlichen Aufgabenträgern als Elementen des Systems Unternehmung betreffen. ${ }^{154}$ Somit stellen organisatorische Regeln überindividuelles organisationales Wissen dar.

Schließlich sind die organisatorischen Regeln Teil der Tiefenstruktur des überindividuellen organisationalen Wissens, d.h. es handelt sich um organisationale Handlungstheorien. Denn im Rahmen einer systemtheoretisch fundierten Argumentation können sie grundsätzlich als Analogon zu den kognitiven Strukturen des einzelnen Individuums konzipiert werden: Als Wahrnehmungsfilter reduzieren die kognitiven Strukturen die Komplexität der von dem Individuum wahrgenommenen Umwelt und sind damit Grundlage für die Bewältigung dieser Umweltkomplexität durch das Individuum. Da die organisatorischen Regeln die Freiheitsgrade der Handlungen im System Unternehmung beschränken, haben sie ebenfalls komplexitätsreduzierende Funktion. Das Erzeugen und Aufrechterhalten eines Komplexitätsgefälles zwischen System und Umwelt und die damit verbundene Abgrenzung des Systems gegenüber der Umwelt sind konstitutiv für die Systemdefinition. Nur solange das System weniger komplex ist als die es umgebende Umwelt, ist es von dieser unterscheidbar. Diese geringere Komplexität des Systems Unternehmung erreicht man mittels Selektion, d.h. es werden nur bestimmte Aspekte der Umwelt wahrgenommen, vom verbleibenden Rest wird abstrahiert. Würde dagegen keine Selektion vorgenommen, würden sich Punkt-zu-

153 Fur die Definition der organisationalen Wissensbasis siehe Abschnitt 3.2.2.1 der vorliegenden Arbeit.

154 Vgl. ăhnlich Grothe (1997), S. 346, der dort furr generelle Regeln feststellt, daß sie als „Aktiva des gesamten betrieblichen Systems" keinem Einzelelement zugeordnet werden können. 
Punkt-Entsprechungen mit der Umwelt ergeben und das System würde sich auflösen. Selektion ist somit unabdingbar für die Systembildung und -aufrechterhaltung im Sinne des Aufrechterhaltens einer Differenz zwischen System und Umwelt. Mittels Selektion und der damit verbundenen Komplexitätsreduktion wird Orientierung in der ansonsten überwältigend komplexen Umwelt möglich. Durch die Reduktion auf ein vereinfachtes Bild entsteht für die Mitarbeiter in der Unternehmung ein leichter handhabbarer Entscheidungs- und Handlungsraum, sofern ihr Handeln den in den organisatorischen Regeln vorgegebenen Mustern folgt. 155

Da es sich bei organisatorischen Regeln um organisationale Handlungstheorien handelt, stellt jede organisatorische Tätigkeit (unabhängig davon, ob im Sinne von Selbst- oder Fremdorganisation) als Veränderung der organisatorischen Regeln Double-loop Learning bzw. organisationales Lernen höherer Ordnung im Sinne einer Veränderung der Tiefenstruktur der überindividuellen Teile der organisationalen Wissensbasis dar. Organisatorische Tätigkeiten sind somit die Voraussetzung für grundlegende unternehmungsinterne Wandelprozesse. Da diese - wie begründet - nicht einmalig, sondern häufig notwendig sind, gilt es zu untersuchen, wie organisatorische Regeln als Ergebnis organisatorischer Tätigkeiten geschaffen sein müssen, um zukünftige organisatorische Veränderungen als weitere Prozesse organisationalen Lernens zu ermöglichen.

Nachdem nunmehr aufgezeigt werden konnte, daß organisatorische Regeln organisationale Handlungstheorien und damit organisatorische Tätigkeiten organisationale Lernprozesse höherer Ordnung sind, gilt es nunmehr zu begründen, warum sich die Argumentation der vorliegenden Arbeit auf die Untersuchung der organisatorischen Regeln als einer Teilmenge der Gesamtheit der organisationalen Handlungstheorien bzw. auf organisatorische Tätigkeiten als eine mögliche Ausprägung von Double-loop Learning beschränkt.

Der zentrale Grund für die Fokussierung der vorliegenden Arbeit auf organisatorische Tätigkeiten als organisationale Lernprozesse höherer Ordnung liegt in ihrer Zielsetzung begründet, den Beitrag des Informationsmanagements zur Förderung häufiger, schneller und grundlegender Prozesse organisationalen Lernens in der Unternehmung zu untersuchen. Denn dies setzt die Konzeptionalisierung des Zusammenhangs zwischen organisationalem Lernen und Informationsmanagement voraus.

Die Aktivitäten des Informationsmanagements werden in solche zur Ermittlung und Modifikation von Informationsbedarf und -bereitstellung (immaterielle Ebene) sowie solche zur Gestaltung der Informationstechnik (materielle Ebene) unterschieden. Grundsätzlich sind die beiden Ebenen des Informationsmanagements zwar interdependent, tendenziell sind die Aktivitäten der immateriellen Ebene jedoch handlungsleitend für

155 Vgl. Bleicher (1992b), Sp. 1886f.; Luhmann (1991), S. 35ff., 47f.; Schreyögg/Noss (1994), S. 24; Steinmann/Schreyögg (1993), S. 125f., 377; Willke (1987), S. 4, 30. 
die der materiellen Ebene. Entsprechend gilt es, den Zusammenhang zwischen organisationalem Lernen und den auf die immaterielle Ebene bezogenen Aktivitäten des Informationsmanagements zu untersuchen.

Informationsbedarf und -bereitstellung als die auf der immateriellen Ebene fokussierten Objekte des Informationsmanagements werden von verschiedenen Einflußfaktoren beeinflußt, die den drei Gruppen 'organisatorische Regeln als Ergebnis der organisatorischen Gestaltung', 'subjektive Einflüsse der informationsverarbeitenden Personen' und 'situative Faktoren' zugeordnet werden. Für die Konzeptionalisierung des Zusammenhangs zwischen organisationalem Lernen und Informationsmanagement bedeutet das, daß in einem ersten Schritt zu untersuchen ist, welche Konsequenzen die Notwendigkeit schneller und häufiger organisationaler Lernprozesse höherer Ordnung auf die genannnten drei Gruppen von Einflußfaktoren hat bzw. wie diese auszugestalten sind, um entsprechendes organisationales Lernen zu fördern. In einem zweiten Schritt ist sodann der Zusammenhang zwischen den jeweiligen Ausprägungen der drei Gruppen von Einflußfaktoren, die organisationales Lernen fördern, auf der einen und dem Informationsmanagement auf der anderen Seite zu untersuchen.

Die Untersuchung des Zusammenhangs zwischen organisationalem Lernen und den subjektiven Einflüssen der informationsverarbeitenden Person ist eine typische personalwirtschaftliche Frage, die aufgrund der in Abschnitt 3.3.1 genannten Argumente im Rahmen der vorliegenden Arbeit nicht weiter betrachtet wird. Grundsätzlich unterliegen die situativen Faktoren zwar der Beeinflussung durch Managementaktivitäten, dieser Einfluß ist jedoch aufgrund fehlender Machtgrundlagen bei der Verhaltensbeeinflussung unternehmungsexterner Personen stark beschränkt. Entsprechend macht es keinen Sinn, die Förderung organisationalen Lernens durch das Informationsmanagement im Rahmen der vorliegenden Arbeit über den 'Umweg' der Umweltsituation zu konzipieren. Während im folgenden also subjektive, in der informationsverarbeitenden Person begründete, und situative Einflußfaktoren auf Informationsbedarf und -bereitstellung als den immateriellen Objekten des Informationsmanagements nicht weiter untersucht werden, fokussiert die vorliegende Untersuchung organisatorische Tätigkeiten sowie den Einfluß der organisatorischen Regeln als Ergebnis organisatorischer Tätigkeiten auf das Informationsmanagement.

Zusammenfassend ist somit festzuhalten, daß die Konzentration der vorliegenden Arbeit auf organisatorische Tätigkeiten als Teilmenge der überindividuellen organisationalen Lernprozesse höherer Ordnung darin begründet ist, daß sie die Konzeptionalisierung des Zusammenhangs zwischen organisationalem Lernen und Informationsmanagement ermöglichen. Der Zusammenhang zwischen organisationalem Lernen und Informationsmanagement entspricht dem zwischen organisatorischen Tätigkeiten und Informationsmanagement, da organisatorische Tätigkeiten hier als überindividuelle organisationale Lernprozesse höherer Ordnung (Double-loop Learning) reinterpretiert werden. Diese Reinterpretation organisatorischer Tätigkeiten (und damit auch der 
organisatorischen Gestaltung) stellt einen Teilschritt zur Erreichung eines weiteren Zwischenzieles der vorliegenden Arbeit dar: Der grundsätzliche Zusammenhang zwischen organisationalem Lernen und organisatorischer Gestaltung ist damit geklärt. Die Ausführungen in Kapitel 4 dienen sodann der Konkretisierung dieses Zusammenhangs.

Abbildung 3/9 visualisiert abschließend diese Beschränkung der Perspektive der vorliegenden Arbeit auf organisatorische Tätigkeiten als Double-loop Learning.

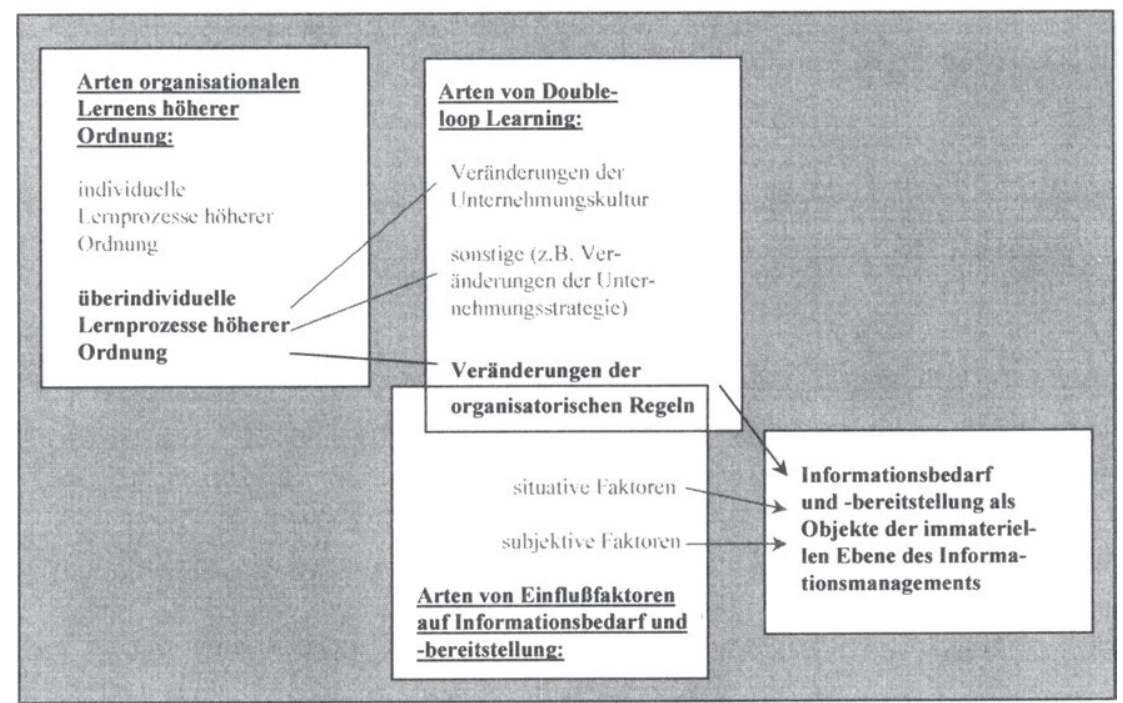

Abb. 3/9: Die Beschränkung der Perspektive der vorliegenden Untersuchung auf organisatorische Tätigkeiten als Double-loop Learning 
Frauke Streubel - 978-3-631-75510-5

Downloaded from PubFactory at 01/11/2019 04:00:13AM 


\section{Organisatorische Gestaltung in der lernenden Unternehmung}

Die organisatorische Gestaltung stellt das erste Aufgabenfeld dar, das im Rahmen der vorliegenden Arbeit bezüglich seines potentiellen Beitrages zur Förderung häufiger und schneller Prozesse organisationalen Lernens höherer Ordnung untersucht werden soll. Das setzt notwendigerweise die Konzeptionalisierung des Zusammenhangs zwischen organisationalem Lernen und organisatorischer Gestaltung (als einem der Zwischenziele der vorliegenden Arbeit) voraus. In Abschnitt 3.3.2 wurde mit der Reinterpretation sämtlicher organisatorischer Tätigkeiten als Prozessen organisationalen Lernens ein erster Teilschritt zur Erreichung dieses Zwischenzieles realisiert. Die folgenden Ausführungen stellen weitere Teilschritte dazu dar.

Die Ausgangsproblematik der vorliegenden Arbeit besteht darin, häufigen, schnellen und diskontinuierlichen unternehmungsexternen Wandelprozessen durch entsprechenden unternehmungsinternen Wandel $\mathrm{zu}$ begegnen, dem wiederum passende geistige Veränderungen vorausgehen müssen. Deshalb wird im folgenden nicht die Gesamtmenge der organisationalen Lernprozesse betrachtet. Vielmehr fokussieren die folgenden Ausführungen organisatorische Tätigkeiten als überindividuelle organisationale Lernprozesse höherer Ordnung. Im Sinne eines Deutero Learning (als Lernen zu lernen) sind dabei durch die organisatorische Gestaltung solche Rahmenbedingungen zu schaffen, die wiederholte Veränderungen der organisatorischen Regeln ermöglichen. Lernen $\mathrm{zu}$ lernen bedeutet hier, häufiges und schnelles organisationales Lernen höherer Ordnung zu lernen. Ziel des folgenden Kapitels ist es aufzuzeigen, wie organisatorische Gestaltung als organisationaler Lernprozeß höherer Ordnung zukünftige häufige und schnelle Veränderungen der organisatorischen Regeln als organisationale Lernprozesse höherer Ordnung fördern kann. Dazu wird in Abschnitt 4.1 zunächst ein theoretischer Bezugsrahmen für die Ableitung von Anforderungen an die organisatorische Gestaltung entwickelt. Darauf aufbauend werden sodann in Abschnitt 4.2 Möglichkeiten der Förderung häufigen und schnellen organisationalen Lernens höherer Ordnung durch die organisatorische Gestaltung vorgestellt.

\subsection{Theoretischer Bezugsrahmen für die Ableitung von Anforderungen an die organisatorische Gestaltung in der lernenden Unternehmung}

Grundsätzlich kommen in der Unternehmung verschiedene Regelungsarten zum Einsatz. Im folgenden wird gezeigt, daß die Fokussierung häufiger, schneller und grundlegender unternehmungsinterner Wandelprozesse Auswirkungen auf das relative Verhältnis der verschiedenen Regelungsarten hat. Zunächst werden präsituative und situative Regelung einander gegenübergestellt (Abschnitt 4.1.1). Sodann werden 
Fremd- und Selbstorganisation als die beiden Ausprägungen präsituativer Regelung näher untersucht (Abschnitt 4.1.2). Im Mittelpunkt der folgenden Ausführungen steht Abschnitt 4.1.3. Hier wird das Phänomen der Selbstorganisation als Spezialfall präsituativer Regelung näher untersucht. In Abschnitt 4.1.4 werden schließlich die Ergebnisse von Abschnitt 4.1.3 zu einer dynamisierten Mehrebenenbetrachtung erweitert. Abbildung 4/1 visualisiert diese bei der Formulierung des theoretischen Bezugsrahmens in den Abschnitten 4.1.1 bis 4.1.4 vorgenommene Verengung der Perspektive.

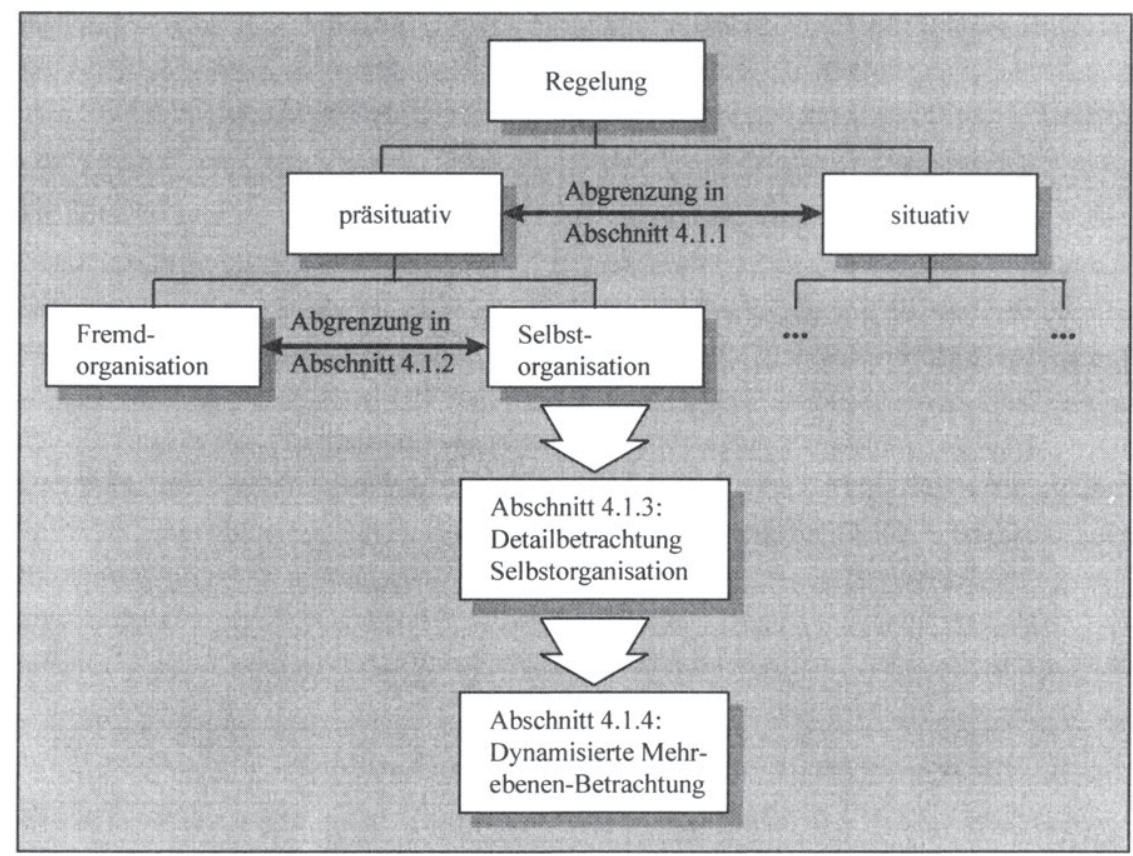

Abb. 4/1: Die Argumentationsstruktur bei der Formulierung des theoretischen Bezugsrahmens

\subsubsection{Präsituative versus situative Regelung}

Die Fokussierung des unternehmungsexternen Wandels als der Ausgangsproblematik der vorliegenden Arbeit und die daraus resultierende Notwendigkeit unternehmungsinternen Wandels sowie der diesem vorausgehenden geistigen Veränderungen lassen eine grundsätzliche Neubestimmung des Verhältnisses zwischen präsituativer und situativer Regelung notwendig erscheinen: Denn durch häufige, grundlegende Veränderungen werden die mit der präsituativen Regelung mittels organisatorischer Regeln verbundenen Generalisierungen immer schneller obsolet. Auf den ersten Blick bietet es sich hier deshalb scheinbar an, die präsituative Regelung verstärkt durch situative Regelung zu ersetzen. Tatsächlich sind Ansätze organisationalen Lernens in der Litera- 
tur häufig mit der Forderung verbunden, organisatorische Regeln als Steuerungsinstrument in ihrer Verwendung grundsätzlich stärker zu beschränken bzw. durch andere Steuerungsinstrumente zu ersetzen. ${ }^{1}$ Im folgenden wird jedoch gezeigt werden, daß es sich dabei um eine unangemessene Vereinfachung handelt, da präsituative und situative Regelung jeweils spezifische Vor- und Nachteile haben. Insbesondere erfüllt die präsituative Regelung im System Unternehmung bestimmte Funktionen, die von der situativen Regelung nicht geleistet werden können.

Im Mittelpunkt der Unterscheidung von präsituativer und situativer Regelung steht der Regelungszeitpunkt. Während präsituative Regelung mittels genereller Regeln geschieht, die vor Eintreten der zu regelnden Situation festgelegt werden, vollzieht sich die situative Regelung mittels fallweiser Regeln erst im Rahmen der zu regelnden Situation. ${ }^{2}$ Der Begriff der Regelung wird dabei im Rahmen der vorliegenden Arbeit für die Tätigkeit der Beschränkung von Freiheitsgraden verwendet, während der Begriff der Regel $^{3}$ auf das im Rahmen dieser Tätigkeit eingesetzte Instrument abstellt. ${ }^{4}$

Bei der präsituativen oder Ex-ante-Regelung bilden die Regeln das Ergebnis von Planung und zielen mittels Vorgabe von "Schemaregelungen“5 im Sinne von Verhaltensmustern auf eine vereinheitlichte Vorgehensweise bei Eintreten bestimmter situativer Bedingungen. Sie sind nicht nur für einen bestimmten Zeitpunkt, sondern über einen Zeitraum hinweg und für ganze Klassen von Handlungen gültig ${ }^{6}$ und müssen entsprechend bedingt (d.h. als 'Wenn-Dann-Klausel') formuliert werden. ${ }^{7}$ Man bezeichnet sie deshalb auch als generelle Regeln. Im Rahmen dieser Arbeit wird auf die organisatorischen Regeln als Teilmenge der generellen Regeln abgestellt. ${ }^{8}$ Wie in Abschnitt 2.2.1.3 dargestellt wurde, können diese das Ergebnis von Prozessen der Selbst- oder Fremdorganisation sein.

Vgl. Steinmann/Schreyøgg (1993), S. 452.

2 Vgl. z.B. Kruger (1994), S. 21. Die Unterscheidung zwischen fallweisen und generellen Regeln geht auf Gutenberg zurilck. Vgl. Gutenberg (1962), S. $144 \mathrm{ff}$. sowie Gutenberg (1983), S. 240.

3 Dabei sei jedoch darauf verwiesen, daß - im Gegensatz sowohl zum philosophischen als auch zum umgangssprachlichen Regelbegriff - Gleichformigkeit oder Wiederholung nicht konstitutive Charakteristika des hier verwendeten Regelbegriffes sind. Dies ist insbesondere dann von Bedeutung, wenn im folgenden fallweise Regeln behandelt werden. Zum philosophischen Regelbegriff vgl. Schischkoff(1982), S. 577.

4 Vgl. ăhnlich Grothe (1997), S. 243f. In der Literatur findet sich dagegen hăufig eine begriffliche Vermischung von Tătigkeit und Instrument, so z.B. bei Krüger (1994), S. 18ff., der einerseits von präsituativen versus situativen, formalen versus informalen sowie strukturellen und kulturellen Regelungen im Sinne des Regelbegriffes dieser Arbeit spricht. Andererseits definiert er jedoch in demselben Abschnitt (S. 21) Organisation als Tătigkeit der prăsituativen Regelung.

5 Gutenberg (1983), S. 241.

6 Vgl. Prim (1968), S. 128.

7 Vgl. Grothe (1997), S. 262.

8 Andere generelle Regeln sind z.B. kulturelle oder gesetzliche Regeln. Vgl. Krüger (1994), S. 20.

Da im Rahmen der vorliegenden Arbeit allein die generellen Regeln organisatorischer Art von Relevanz sind, wird der Begriff der generellen Regeln im folgenden vereinfachend als Synonym für organisatorische Regeln verwendet. 
Im Gegensatz zur präsituativen Regelung setzt situative Regelung, die auch als spontane oder Ad-hoc-Regelung bezeichnet werden kann, erst bei bzw. nach Handlungsbeginn und damit in der zu regelnden Situation ein. Sie geschieht anhand fallweiser Regeln. ${ }^{9}$ Die Gültigkeit der fallweisen Regeln ist auf diese eine Situation und einen bestimmten Zeitpunkt beschränkt. ${ }^{10}$ Damit ist die Singularität der zu regelnden Situation konstitutiv für den Begriff der situativen Regelung. Die Regeln entstehen spontan aus dem jeweiligen Handeln heraus. ${ }^{11}$ Sie sind unbedingt (d.h. ohne 'WennKlausel') für die aktuelle Situation formuliert. ${ }^{12}$ Analog zu der Unterscheidung in Selbst- und Fremdorganisation als Arten präsituativer Regelung kann die Gesamtheit der Aktivitäten situativer Regelung anhand des Bezugs der regelnden Person zum zu regelnden (Sub-) System in Ad-hoc-Selbstregelung und Mitarbeiterführung unterschieden werden.

Ad-hoc-Selbstregelung bedeutet, daß ein Mitarbeiter oder eine Mehrzahl von Mitarbeitern (in einem Subsystem) in einer bestimmten Situation Entscheidungen bezüglich des eigenen Arbeitsbereiches in dieser konkreten Situation trifft bzw. treffen. Selbstregelung besagt dabei, daß die Regelung durch das zu regelnde Subsystem selbst erfolgt. Für außerhalb dieses Subsystems Stehende gelten die Regeln dagegen nicht. Im Gegensatz dazu werden bei der Mitarbeiterführung die Handlungsspielräume eines Einzelnen oder mehrerer Personen durch Entscheidungen einer diesen hierarchisch übergeordneten - und damit nicht zum zu regelnden Subsystem gehörenden - Person in einer bestimmten Situation eingeschränkt. Es handelt sich dann um Fremdregelung.

Abbildung 4/2 zeigt die verschiedenen Regelungsarten. Dabei wird einerseits anhand des Bezuges des regelnden Subjektes zum zu regelnden (Sub-) System zwischen Selbstund Fremdregelung, andererseits anhand des Regelungszeitpunktes zwischen präsituativer und situativer Regelung unterschieden. Aus der Verknüpfung der beiden Dimensionen resultieren die vier Regelungsarten Selbst- und Fremdorganisation sowie Mitarbeiterführung und Ad-hoc-Selbstregelung.

Stellt man - unter Vernachlässigung der Unterscheidung anhand des Bezuges des regelnden Subjektes zum zu regelnden System - zunächst präsituative und situative Regelung einander gegenüber, so ergeben sich die folgenden Vor- und Nachteile: ${ }^{13}$

9 Die verschiedentlich in der Organisationsliteratur vorgenommene Unterscheidung zwischen Disposition und Improvisation ist für die Ausführungen der vorliegenden Arbeit ohne Relevanz und wird hier deshalb nicht vorgenommen. Vgl. z.B. Kruger (1994), S. 19.

10 Vgl. Prim (1968), S. 128. Anders dagegen z.B. Krüger (1994), S. 19, der zwischen absoluter Einmaligkeit und Mehrmaligkeit in einem kurzen, begrenzten Zeitraum unterscheidet.

11 Vgl. Steinmann/Schreyogg (1993), S. 379.

12 Vgl. Grothe (1997), S. 262.

13 Vgl. dazu und im folgenden Bleicher (1992b), Sp. 1888; Grochla (1978), S. 12ff.; Grothe (1997), S. 266; Krüger (1994), S. 19; Schreyőgg/Noss (1994), S. 19f.; Steinmann/Schreyögg (1993), S. 379; Türk (1980), Sp. 1858ff. Die folgende kritische Diskussion präsituativer und situativer Regelung beschränkt sich auf die für die vorliegende Arbeit relevanten Argumente. Für eine ausfuhrliche Gegenuberstellung von prăsituativer und situativer Regelung siehe die angegebene Literatur. 


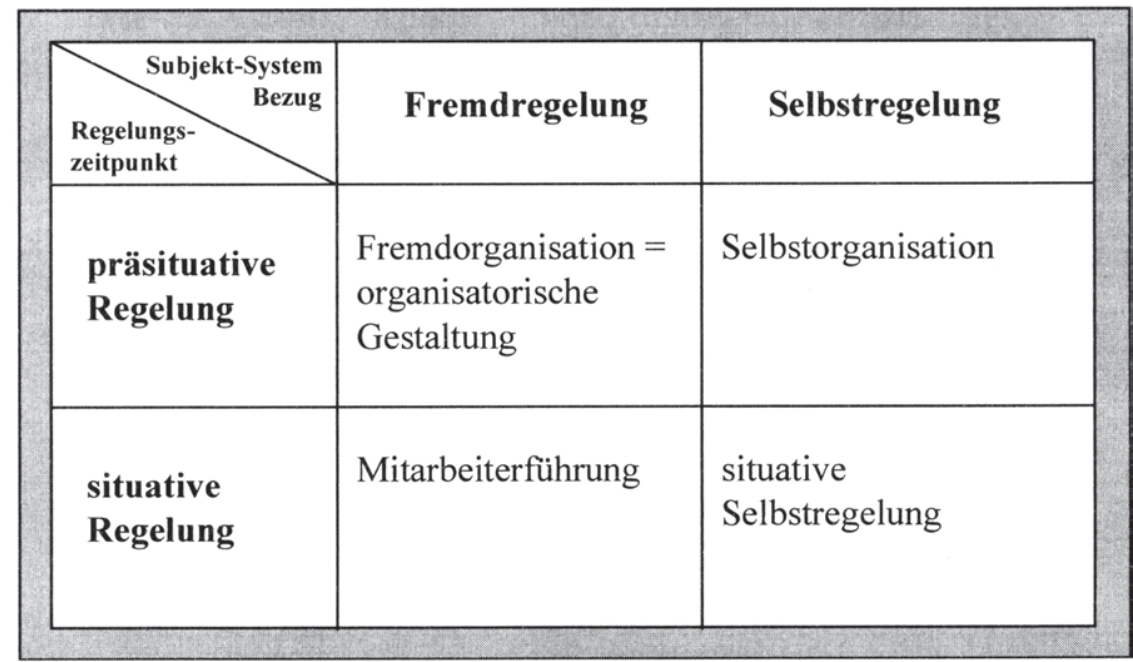

Abb. 4/2: Grundformen der Regelung

Präsituative Regelung ist im direkten Vergleich mit situativer Regelung mit Effizienzgewinnen verbunden, wenn In- und Umwelt vergleichsweise stabil sind, d.h. eine geringe Unterschiedlichkeit der anfallenden Aufgaben vorliegt oder zukünftige Veränderungen zumindest vorhersehbar sind. Dann werden die in den organisatorischen Regeln fixierten Erwartungen erfüllt. Die Effizienz präsituativer Regelung steigt mit der Geltungsdauer und der Häufigkeit des Einsatzes der organisatorischen Regeln, d.h. den Kosten des Aufstellens genereller Regeln steht ein mit der Häufigkeit ihrer Anwendung steigender Nutzen gegenüber. Die relativen Effizienzgewinne präsituativer Regelung gegenüber situativer Regelung ergeben sich vor allem durch die mit ihr verbundene Standardisierung, die wiederum eine Erhöhung der Prognostizierbarkeit und Kontrollierbarkeit des Leistungserstellungsprozesses bedingt.

Im Gegensatz zur präsituativen Regelung ist die situative Regelung an keinerlei Voraussetzungen gebunden. Vielmehr können fallweise Regeln prinzipiell überall zum Einsatz kommen. Insbesondere kann situative Regelung auch bei hoher Änderungsdynamik der In- und Umwelt der Unternehmung und daraus resultierender mangelnder Vorhersehbarkeit zukünftiger Entwicklungen Anwendung finden. Aufgrund ihres Adhoc-Charakters ist die situative Regelung grundsätzlich flexibler, d.h. sie kann den Besonderheiten der spezifischen Situation besser als ex ante festgelegte generelle Regeln Rechnung tragen. Bleiben bestimmte situative Konstellationen jedoch über einen gewissen Zeitraum konstant und sind damit die Einsatzvoraussetzungen für präsituative Regelung erfüllt, so erweist sich die situative Regelung als weniger effizient, da in jedem Zeitpunkt neu entschieden werden muß.

Das verstärkte Auftreten von Wandelprozessen, die im Rahmen der präsituativen Regelung nicht antizipiert werden, führt dazu, daß die zentrale Voraussetzung für den effizienten Einsatz präsituativer Regelung immer weniger erfüllt ist. Der Zeitraum, 
innerhalb dessen die tatsächlich eintretende Situation mit den Annahmen der in der Vergangenheit formulierten Regeln übereinstimmt, wird kürzer. Entsprechend geringer fällt der mit dem Einsatz genereller Regeln verbundene Nutzen aus. Werden die generellen Regeln gar über diesen Zeitraum hinaus angewendet, so besteht die Gefahr der Erstarrung bzw. Fehlsteuerung. Die mit der Anwendung präsituativ formulierter Regeln verbundene Generalisierung führt dann dazu, daß Probleme als gleichartig behandelt werden, zwischen denen relevante Unterschiede bestehen. ${ }^{14}$ Eine mögliche Reaktion auf diese geänderten Umfeldbedingungen besteht darin, präsituative Regelung verstärkt durch situative zu ersetzen. Dies beseitigt zwar die Gefahr der Erstarrung durch das zu lange Festhalten an überholten generellen Regeln. Gleichzeitig gehen jedoch die mit der präsituativen Regelung verbundenen Vorteile verloren. Dies erweist sich aus mehreren Gründen als problematisch: Erstens können trotz häufigen, schnellen und diskontinuierlichen Wandels in der Umweltentwicklung vielfach dennoch Muster identifiziert werden. Zweitens sind organisatorische Regeln aufgrund ihrer Stabilisierungsfunktion unabdingbar für das Bestehen des Systems Unternehmung.

Das Auftreten häufigen, schnellen und diskontinuierlichen Wandels bedeutet nicht etwa, daß in der Umweltentwicklung keinerlei Muster erkennbar sind. Vielmehr werden lediglich die Gültigkeitszeiträume der Muster kürzer, und es gestaltet sich schwieriger, die Veränderung der Muster vorherzusehen. ${ }^{15}$ So basiert die Argumentation in Abschnitt 3.3 der vorliegenden Arbeit gerade auf der Annahme, daß notwendige grundlegende materielle Veränderungen grundlegende geistige Veränderungen im Sinne eines organisationalen Lernens höherer Ordnung erfordern. Einfache Lernprozesse reichen zur Bewältigung dieses grundlegenden Wandels dagegen nicht aus. Denn 'grundlegend' bedeutet hier, daß hinter den Verhaltensänderungen Verhaltensmuster erkennbar sind. Die Veränderungen der Verhaltensmuster in der Umwelt der Unternehmung machen analog Änderungen der Muster in der Unternehmung, d.h. der organisationalen Handlungstheorien, notwendig. Zwar steht den Kosten des Aufstellens genereller Regeln aufgrund ihres kürzeren Gültigkeitszeitraumes und der damit verbundenen geringeren Anwendungshäufigkeit nunmehr ein geringerer Nutzen gegenüber. Die prinzipiellen Vorteile genereller gegenüber fallweisen Regeln gelten jedoch weiterhin. Der Verzicht auf präsituative Regelung würde bedeuten, auf die Realisierung dieser Vorteile zu verzichten.

Als zweites zentrales Argument steht die Stabilisierungsfunktion der präsituativen Regelung mittels organisatorischer Regeln im Mittelpunkt der - auch hier wiederum systemtheoretisch geprägten - Ausführungen der vorliegenden Arbeit. In Abschnitt 3.3.2 wurde bereits auf die Funktion organisatorischer Regeln als Wahrnehmungsfilter hingewiesen. Durch die damit verbundene Selektion erzeugen organisatorische Regeln ein Komplexitätsgefälle zwischen der Unternehmung und ihrer Umwelt. Dieses bildet

14 Vgl. Gutenberg (1983), S. 240.

15 Siehe Abschnitt 3.1.1 der vorliegenden Arbeit. 
wiederum die Voraussetzung für die Abgrenzung des Systems Unternehmung gegenüber seiner Umwelt und das Aufrechterhalten dieser Grenze. Der Bezugspunkt der Systembildung liegt damit außerhalb des Systems selbst, nämlich in der Relation zwischen System und Umwelt. ${ }^{16}$ Das selektive Verhalten verhindert Punkt-zu-PunktEntsprechungen zwischen System und Umwelt, die die Aufhebung der Systemgrenzen und damit die Auflösung des Systems Unternehmung bedeuten würden. ${ }^{17}$ Die systemstabilisierende Funktion organisatorischer Regeln ist damit unabdingbar für den Fortbestand der Unternehmung. Eine Unternehmung ohne generelle Regeln ist aus diesem Grund nicht vorstellbar. ${ }^{18}$

Ein sogenanntes 'Chronically Unfrozen System' kann somit nicht existieren. In Anlehnung an die Ausführungen von WEICK wäre dies ein System, in dem latente Unruhe in dem Sinne herrscht, daß jedes Signal aus der Umwelt vom System ohne Rückgriff auf bewährte Muster als vollkommen neuartiges Phänomen verarbeitet wird. Einem Maximum an organisationalen Lernprozessen stände keinerlei organisationales Nicht-Lernen gegenüber. ${ }^{19}$ Entsprechend erweist sich die in der Literatur häufig anzutreffende Forderung nach permanentem organisationalen Lernen als unangemessene Trivialisierung. ${ }^{20}$ Die Anwendung organisatorischer Regeln bedeutet nämlich, daß eine Generalisierung vorgenommen wird und bestimmte Handlungsmuster vorselektiert werden, d.h. eben nicht in jedem Einzelfall eines Umweltimpulses eine neuartige Reaktion erfolgt. Somit handelt es sich bei der Anwendung organisatorischer Regeln als zentraler systemkonstituierender Funktion um einen Prozeß des Nicht-Lernens. Permanentes Lernen im Sinne des permanenten Änderns organisatorischer Regeln bzw. ihres Ersetzens durch situative Regelung führt dagegen zur Elimierung des Phänomens der präsituativen Regelung. Da die Stabilisierung durch präsituative Regeln unabdingbar für den Erhalt des Systems Unternehmung ist, führt ihr Wegfall zur Auflösung des Systems Unternehmung. Permanentes organisationales Lernen ist damit ein theoretisch nicht konzipierbares Phänomen, da der 'permanente' Prozeß organisationalen Lernens die Eliminierung der lernenden Institution bewirken würde und sich damit selbst ein Ende setzen würde. Entsprechende Forderungen in der Literatur stellen deshalb aus der Perspektive der vorliegenden Arbeit theoretisch nicht haltbare Vereinfachungen dar.

Zusammenfassend ist festzuhalten, daß das generelle Ersetzen präsituativer Regelung durch situative Regelung auch bei häufigen, schnellen und diskontinuierlichen unternehmungsexternen Wandelprozessen keine sinnvolle Lösung darstellt. Zwar kann es im Einzelfall durchaus zu Verschiebungen des relativen Gewichtes der beiden Regelungsarten kommen. Die relative Bedeutung der beiden Regelungsarten kann jedoch nur

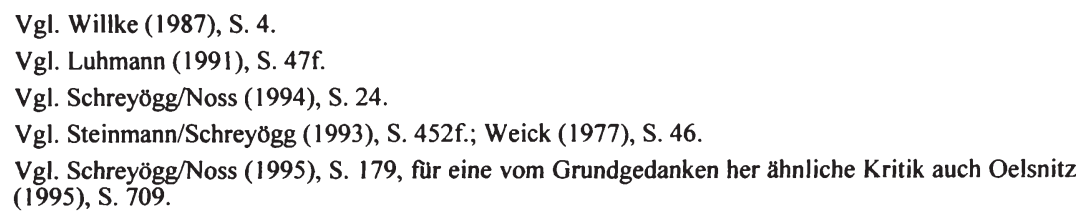


für den konkreten Einzelfall festgelegt werden. Entsprechend gälte es dann zu untersuchen, welche Rahmenbedingungen die organisatorische Gestaltung als präsituative Regelung zur Förderung situativer Regelung (in Form von Ad-hoc-Selbstregelung oder Mitarbeiterführung) schaffen kann. Die Untersuchung dieser Fragestellung wäre Gegenstand einer eigenständigen Arbeit. Im Rahmen der folgenden Ausführungen findet sie keine weitere Berücksichtigung, da hier davon ausgegangen wird, daß die unternehmungsexternen Wandelprozesse durchaus Muster aufweisen und deshalb der Einsatz genereller Regeln weiterhin sinnvoll ist. Stattdessen wird im folgenden untersucht, welche Möglichkeiten bestehen, um Veränderungen der generellen Regeln effizienter zu gestalten. Denn dadurch können die mit der organisatorischen Tätigkeit verbundenen Kosten gesenkt werden und gleichzeitig kann der mit dem Einsatz organisatorischer Regeln verbundene Nutzen realisiert werden.

\subsubsection{Fremd- und Selbstorganisation als alternative Ausprägungen präsituativer Regelung}

Organisatorische Tätigkeit als Veränderung organisatorischer Regeln ist stets präsituative Regelung. Die Gesamtmenge organisatorischer Tätigkeiten kann in Prozesse der Fremd- und solche der Selbstorganisation unterschieden werden. Beide stellen organisationale Lernprozesse höherer Ordnung dar und können damit die geistige Voraussetzung für grundlegenden unternehmungsinternen Wandel sein. $\mathrm{Da}$ der unternehmungsinterne Wandel darüber hinaus auch häufig und schnell sein muß, gilt es zu untersuchen, wie häufige und schnelle organisationale Lernprozesse höherer Ordnung bzw. organisatorische Tätigkeiten realisiert werden können. Dabei werden Fremd- und Selbstorganisation als grundsätzliche Alternativen organisatorischer Tätigkeit einander gegenübergestellt. Ausgehend von der begrifflichen Abgrenzung von Selbst- und Fremdorganisation in Abschnitt 2.2.1.3 werden in Abschnitt 4.1.2.1 zunächst allgemeine Vor- und Nachteile dieser beiden Regelungsformen dargestellt. In Abschnitt 4.1.2.2 wird diese allgemeine Bewertung von Fremd- und Selbstorganisation dann um die Bewertung unter spezifischer Berücksichtigung von Wandelaspekten sowie der Problematik der Komplexität von Umwelt und Unternehmung ergänzt, und es werden die Konsequenzen dieser Bewertung für das Verhältnis von Fremd- und Selbstorganisation in einer von Wandel und Komplexität geprägten Unternehmung aufgezeigt.

\subsubsection{Allgemeine Bewertung von Fremd- und Selbstorganisation}

Betrachtet man die Gesamtheit aller organisatorischen Tätigkeiten als Aktivitäten der Veränderung organisatorischer Regeln, so kann man diese anhand der relativen Position des Gestaltenden bezüglich des zu gestaltenden Systems in Aktivitäten der Fremdorganisation (der Gestalter steht außerhalb des zu gestaltenden Systems) und solche der 
Selbstorganisation (der Gestalter ist Teil des zu gestaltenden Systems) gliedern. ${ }^{21} \mathrm{Im}$ folgenden werden die spezifischen Vor- und Nachteile dieser beiden Arten organisatorischer Tätigkeit einander gegenübergestellt:

Den zentralen Vorteil fremdorganisatorischer Tätigkeiten bildet die mit der personellen Trennung der organisatorischen Gestaltungsaufgaben von anderen Teilaufgaben des betrieblichen Leistungserstellungsprozesses verbundene Möglichkeit der Spezialisierung. Der organisatorische Gestalter als Spezialist besitzt bezüglich organisatorischer Fragestellungen regelmäßig eine höhere methodische Kompetenz als Mitarbeiter anderer Funktionsbereiche. Während diese vor allem ihren eigenen Aufgabenbereich kennen, verfügt der Organisator ferner über vergleichsweise mehr Überblickswissen bezüglich der gesamten Unternehmung sowie bezüglich der den einzelnen Arbeitsbereichen übergeordneten Subsysteme der Unternehmung. Diesem Überblickswissen kommt bei der Koordination der verschiedenen Subsysteme in der Unternehmung bzw. der Gestaltung ihrer jeweiligen Schnittstellen besondere Bedeutung zu. ${ }^{22}$

Ein weiterer Vorteil fremdorganisatorischer Tätigkeit ist die Legitimation des organisatorischen Gestalters für seine Tätigkeit bzw. der daraus resultierende formale Charakter der organisatorischen Regeln als Ergebnis dieser Tätigkeit. Die Kompetenz zur Festlegung organisatorischer Regeln wird durch die Eigentümer der Unternehmung bzw. die von diesen mit der Geschäftsführung beauftragten Personen offiziell übertragen. ${ }^{23}$ Diese klare Kompetenzzuweisung ist nicht nur innerhalb, sondern auch außerhalb der Unternehmung eindeutig nachvollziehbar und hat verpflichtenden Charakter. Die aus fremdorganisatorischen Tätigkeiten resultierenden organisatorischen Regeln bilden somit einen verbindlichen Rahmen für die Aktivitäten aller Mitglieder der Unternehmung. Über die damit verbundene innerbetriebliche Transparenz der arbeitsteiligen Aufgabenerfüllung hinaus erfüllt die Unternehmung so bestimmte von außen an sie gerichtete Anforderungen. Dabei kann es sich beispielsweise um die Erfüllung von Vorgaben im Rahmen der Zertifizierung der Unternehmung gemäß ISO 9000 (z.B. ablauforganisatorische Regeln bezüglich der Lagerverwaltung oder der Qualitätskontrolle) handeln.

Schließlich sei hier noch die potentiell mit fremdorganisatorischer Tätigkeit verbundene Zeitersparnis gegenüber selbstorganisatorischer Tätigkeit genannt. Sie kann daraus resultieren, daß im Rahmen von Fremdorganisation auf die u.U. zeitraubende Abstimmung mit den Beteiligten und damit mit einer Vielzahl von Personen verzichtet wird. Zwar können Fremdorganisationsprozesse durchaus partizipativ gestaltet werden. Der Zeitaufwand für die Anhörung und Berücksichtigung der Interessen der Betroffenen durch den organisatorischen Gestalter dürfte jedoch insbesondere dann geringer als bei gemeinsamer Entscheidungsfindung aller Subsystemmitglieder im Rahmen von

21 Siehe Abschnitt 2.2.1.3 sowie Abschnitt 4.1.1 der vorliegenden Arbeit.

22 Vgl. Gomez/Zimmermann (1992), S. $115 f$.

23 Vgl. Oelsnitz (1995), S. 711. 
Selbstorganisationsprozessen sein, wenn es den Mitarbeitern an Know-how für die effiziente Gestaltung von Gruppenentscheidungsprozessen mangelt. ${ }^{24}$

Der wichtigste Nachteil fremdorganisatorischer Tätigkeiten resultiert ebenso wie der oben genannte Vorteil der Spezialisierung aus der personellen Trennung der organisatorischen Gestaltungsaufgabe von dem zu gestaltenden Aufgabenfeld. Da der organisatorische Gestalter nicht Teil des von ihm zu gestaltenden Subsystems ist, verfolgt er grundsätzlich eine andere Perspektive auf dieses als die betroffenen Mitarbeiter. Während für den betroffenen Mitarbeiter regelmäßig sein eigenes Aufgabenfeld - mit allen seinen Detailproblemen - im Mittelpunkt steht, ist es für den organisatorischen Gestalter als außerhalb des zu gestaltenden Subsystems Stehenden nahezu unmöglich, alle Details des zu gestaltenden Aufgabenfeldes in derselben Weise zu kennen wie ein Mitglied dieses Subsystems. Für den organisatorischen Gestalter ist vielmehr die Einordnung des einzelnen Aufgabenfeldes in das jeweils übergeordnete Ganze von zentralem Interesse. Gemäß der radikal konstruktivistischen Grundposition der vorliegenden Arbeit ist eine Bewertung menschlicher Kognitionen anhand ihres inhaltliches Wahrheitsgehaltes in bezug auf eine sogenannte 'objektive' Wirklichkeit zwar nicht möglich, da der Mensch eine solche nicht erkennen kann. ${ }^{25}$ Es ist also weder die Perspektive des organisatorischen Gestalters noch die des betroffenen Mitarbeiters 'wahrer' oder 'falscher' als die jeweils andere. Setzt sich jedoch bei deutlich divergierenden Wahrnehmungen regelmäßig die Perspektive des organisatorischen Gestalters durch, kann dies bei den betroffenen Mitarbeitern zu Akzeptanz- und Motivationsproblemen führen. Dies wird insbesondere dann der Fall sein, wenn die Mitarbeiter die mit den organisatorischen Regeln einhergehenden Beschränkungen der Freiheitsgrade ihrer Handlungen als Ausdruck einer mißtrauensorientierten Unternehmungskultur interpretieren. ${ }^{26}$ Ferner können die unterschiedlichen Sichtweisen zu Problemen bei der Interpretation der organisatorischen Regeln durch die Mitarbeiter, d.h. zu Abweichungen der tatsächlichen von den intendierten Handlungen führen. ${ }^{27}$

Ein weiterer potentieller Nachteil fremdorganisatorischer Tätigkeit ist die ihr immanente, im Vergleich zu selbstorganisatorischer Tätigkeit stärkere Tendenz zur Überorganisation. So gehen Organisationstheoretiker davon aus, daß die Wahrscheinlichkeit dafür, daß der optimale Organisationsgrad als die in einer bestimmten Situation optimale Kombination präsituativer und situativer Regelung zu Lasten der situativen Regelung verfehlt wird, bei Fremdorganisation größer ist als bei Selbstorganisation. ${ }^{28}$

24 Vgl. ăhnlich Kieser (1994), S. 211.

25 Siehe Abschnitt 2.1.2 der vorliegenden Arbeit.

26 Vgl. Gomez/Zimmermann (1992), S. 114. Für eine ausfuhrliche Darstellung mißtrauens- und vertrauensorientierter Unternehmungsstrukturen siehe Bleicher (1985), S. 2ff.; Bleicher (1995b), S. 229ff., insbesondere S. 248.

27 Vgl. ăhnlich Kieser/Kubicek (1992), S. $23 \mathrm{f}$.

28 Vgl. z.B. Bleicher (1995b), S. 230; Kieser/Kubicek (1992), S. 472. Die Frage nach dem optimalen Organisationsgrad wird in der Organisationstheorie seit langem thematisiert. Bereits Kosiol und Gutenberg stellen generelle und fallweise Regelung einander im Rahmen der Diskussion um das soge- 
Dieses übermäßige Ausdehnen der präsituativen Regelung geht mit Überkomplizierung, Übersteuerung und Überstabilisierung bzw. Erstarrung und mangelnder Flexibilität einher. ${ }^{29}$

Stellt man den fremdorganisatorischen Tätigkeiten selbstorganisatorische gegenüber, so lassen sich deren Vorteile aus den Nachteilen, ihre Nachteile aus den Vorteilen von Fremdorganisation ableiten.

Entsprechend ist der wichtigste Vorteil selbstorganisatorischer Tätigkeiten auf die Aufhebung der personellen Trennung der organisatorischen von den sonstigen Teilaufgaben im Rahmen des betrieblichen Leistungserstellungsprozesses zurückzuführen. Die aus den unterschiedlichen Perspektiven von organisatorischem Gestalter und den betroffenen Mitarbeitern resultierenden Akzeptanz-, Motivations- und Interpretationsprobleme werden vermieden bzw. in ihr Gegenteil verkehrt: Die ihr jeweiliges Arbeitsumfeld selbst organisierenden Mitarbeiter werden dies unter Berücksichtigung ihrer diesbezüglich detailreichen Kenntnisse tun. Damit kann angenommen werden, daß die aus Selbstorganisationsprozessen resultierenden organisatorischen Regeln aus der Sicht der Betroffenen deren Bedürfnissen bzw. den von ihnen wahrgenommenen Notwendigkeiten der spezifischen Arbeitssituation tendenziell besser gerecht werden, was sich positiv auf deren Akzeptanz auswirken wird. Geht man darüber hinaus davon aus, daß die Mitarbeiter einerseits intrinsisch motiviert sind, andererseits durch die Selbstorganisationsaufgaben nicht überfordert werden, so wirkt das Ermöglichen von Selbstorganisationsprozessen durch die damit einhergehende Nutzung latenter individueller Fähigkeiten tendenziell positiv auf deren Motivation. ${ }^{30}$ Dieser Effekt kann durch die Interpretation der Freiräume für Selbstorganisationsprozesse als Ausdruck eines vertrauensorientierten Managementverständnisses ${ }^{31}$ noch verstärkt werden. Schließlich treten bei Selbstorganisation weniger Interpretationsprobleme bei der Anwendung der organisatorischen Regeln auf, da diese von ihren Adressaten selbst formuliert wurden. ${ }^{32}$

Ein weiterer potentieller Vorteil von Selbst- gegenüber Fremdorganisationsprozessen besteht darin, daß organisatorische Regeln hier das Ergebnis der Entscheidungen einer Vielzahl von Beteiligten sind, deren Wirklichkeitskonstruktionen im Idealfall gleichberechtigt nebeneinanderstehen, während bei Fremdorganisation die Perspektive des organisatorischen Gestalters häufig als 'einzig richtige', 'objektive' angenommen wird. ${ }^{33}$ Denn das Einbeziehen des Wissens vieler kann aufgrund der damit verbundenen höheren Varietät der Erfahrungs- und Wahrnehmungshintergründe zu vielfältigeren und

nannte 'Substitutionsprinzip der Organisation' gegenüber. Vgl. Gutenberg (1962), S. 147; Gutenberg (1983), S. 242; Kosiol (1962), S. 30.

29 Vgl. Tük (1980), Sp. 1858f.

30 Vgl. Steinle/Bruch/Müller (1996), S. 652f.

$31 \mathrm{Vgl}$. Gomez/Zimmermann (1992), S. 116.

32 Vgl. Kieser/Kubicek (1992), S. 472.

33 Vgl. Hejl (1983), S. 58; Klimecki/Probst/Eberl (1991), S. 123. 
damit eventuell auch zu kreativeren, innovativeren Lösungen als bei Fremdorganisationsprozessen führen. ${ }^{34}$

Ferner ist - wie oben bereits erwähnt - tendenziell davon auszugehen, daß selbstorganisatorische Tätigkeiten eine geringere Tendenz zur Überorganisation haben als fremdorganisatorische. ${ }^{35}$

Schließlich kann der Umstand, daß die Betroffenen bei Selbstorganisation selbst den Einsatzort und -zeitpunkt vor allem der personellen, aber auch anderer Ressourcen bestimmen, im Vergleich zu Fremdorganisation zeit- und ressourcensparend wirken. ${ }^{36}$ Insbesondere der Umstand, daß selbstorganisatorische Tätigkeiten parallel zum Tagesgeschäft der Leistungserstellung erfolgen können und keine gesonderte Einarbeitung in die spezifischen Gegebenheiten des jeweiligen Arbeitsumfeldes erfordern, während fremdorganisatorische Prozesse stets als solche initiiert werden müssen und eine Einarbeitung des Organisators in die Details des zu gestaltenden Systems notwendig machen, kann einen Zeitvorteil von Selbst- gegenüber Fremdorganisation zur Folge haben.

Andererseits kann Selbstorganisation aber auch deutlich zeitintensiver sein als Fremdorganisation. Insbesondere wenn den Beteiligten das Methodenwissen im Umgang mit Gruppenentscheidungsprozessen und/oder organisatorischen Fragestellungen fehlt, können die Abstimmungsprozesse zwischen mehreren Personen sehr viel Zeit beanspruchen. ${ }^{37}$ Der Problematik langwieriger Selbstorganisationsprozesse kann allerdings von Seiten des Managements z.B. durch die Vermittlung von methodischen Kenntnissen oder dadurch begegnet werden, daß zeitliche Vorgaben gemacht werden, bei deren Überschreiten das Management eingreift und eine fremdorganisatorische Lösung findet. ${ }^{38}$ Das Zeitargument kann somit sowohl einen relativen Vor- als auch einen Nachteil von Selbstorganisation gegenüber Fremdorganisation darstellen.

Ähnliches gilt für den genannten potentiellen Vorteil höherer Varietät und Kreativität der gefundenen Lösungen. So kann im Rahmen von Selbstorganisationsprozessen eine deutliche Tendenz zur Beharrung auf Bewährtem auftreten. Insbesondere Vertreter des populationsökologischen Ansatzes unterstellen eine stark ausgeprägte Trägheit, die die Mitarbeiter in der Unternehmung eher in altbekannten Lösungen verharren läßt. ${ }^{39}$ Somit bleibt offen, ob das relative $\mathrm{Ma}$ an Varietät und Kreativität der gefundenen Lösung einen Vorteil oder einen Nachteil von Selbstorganisation darstellt.

Ein wichtiger Nachteil selbstorganisatorischer Tätigkeiten ist, daß das Überblicks- bzw. Zusammenhangswissen der agierenden Mitarbeiter bezüglich der gesamten Unterneh-

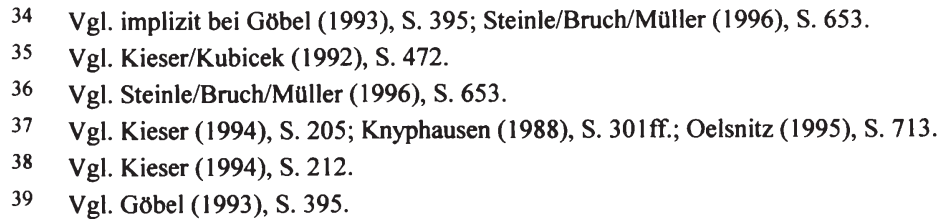


mung i.d.R. geringer ist als das des Organisators. Dies erschwert es ihnen, die spezifischen Gegebenheiten ihres Subsystems in den Gesamtzusammenhang der Unternehmung einzuordnen. Dieser Umstand ist insbesondere dann problematisch, wenn selbstorganisatorisch festgelegte organisatorische Regeln über das jeweilige Subsystem hinauswirken.

Der oben genannte positive motivationale Effekt der Förderung von Selbstorganisation in der Unternehmung kann sich bei veränderten Voraussetzungen in einen Nachteil verkehren. Fühlen sich die Mitarbeiter nämlich überlastet bzw. sind sie nicht intrinsisch motivierbar, wirkt sich Selbstorganisation negativ auf ihre Motivation aus. Ferner kann Selbstorganisation die Desorientierung der Mitarbeiter fördern und Konflikte begünstigen. ${ }^{40}$

Der Umstand, daß die Förderung von Selbstorganisation die Macht des Managements und u.U. das mit diesen Positionen verbundene Prestige senkt, kann zu Akzeptanzproblemen beim Management führen. Dies erweist sich insbesondere dann als problematisch, wenn das Management daraufhin die Förderung von Selbstorganisationsprozessen aufgibt und deren Ergebnisse konterkarrierende fremdorganisatorisch bestimmte Regeln entwirft. ${ }^{41}$

Tabelle 4/3 zeigt die genannten Vor- und Nachteile von Fremd- und Selbstorganisation im Überblick. Sie bilden die Grundlage für eine kritische Bewertung dieser beiden Alternativen organisatorischer Tätigkeit. Dabei ist zu beachten, daß die genannten Argumente für und gegen Fremd- und Selbstorganisation keinesfalls stets gegeben sein müssen. Vielmehr handelt es sich um potentielle Vor- und Nachteile, deren Grad der Ausprägung von einer Vielzahl von Kontextfaktoren abhängt. Eine allgemeine, über den konkreten Einzelfall hinausreichende Bewertung der relativen Vorziehenswürdigkeit von Fremd- und Selbstorganisation ist deshalb nicht möglich. So wurde beispielsweise zwar festgestellt, daß tendenziell die aus Selbstorganisationsprozessen resultierenden organisatorischen Regeln den Bedürfnissen der Betroffenen aus deren Sicht besser gerecht werden als solche, die Ergebnis von Fremdorganisationsprozessen sind. Weisen die informellen Machtverhältnisse innerhalb eines selbstorganisierend tätigen Subsystems jedoch starke Asymmetrien auf, so wird der Teil der Betroffenen mit einer schwachen Machtposition u.U. organisatorische Regeln als Ergebnis von Fremdorganisationsprozessen vorziehen, da er seine Interessen im Rahmen von Selbstorganisationsprozessen möglicherweise stärker gefährdet sieht. Entsprechend gilt, daß im Rahmen einer allgemeinen Bewertung von Fremd- und Selbstorganisation lediglich Tendenzaussagen möglich sind. Auch zeigen die aufgeführten Vor- und Nachteile, daß es sich bei der grundsätzlichen Frage nach Fremd- oder Selbstorganisation in der Unternehmung

40 Vgl. Göbel (1993), S. 395; Steinle/Bruch/Müller (1996), S. 652.

41 Vgl. ähnlich Steinle/Bruch/Müller (1996), S. 653. 
nicht um ein radikales 'entweder oder' handeln kann. Präsituative Regelung durch den alleinigen Einsatz von Fremd- oder Selbstorganisation ist nicht möglich.

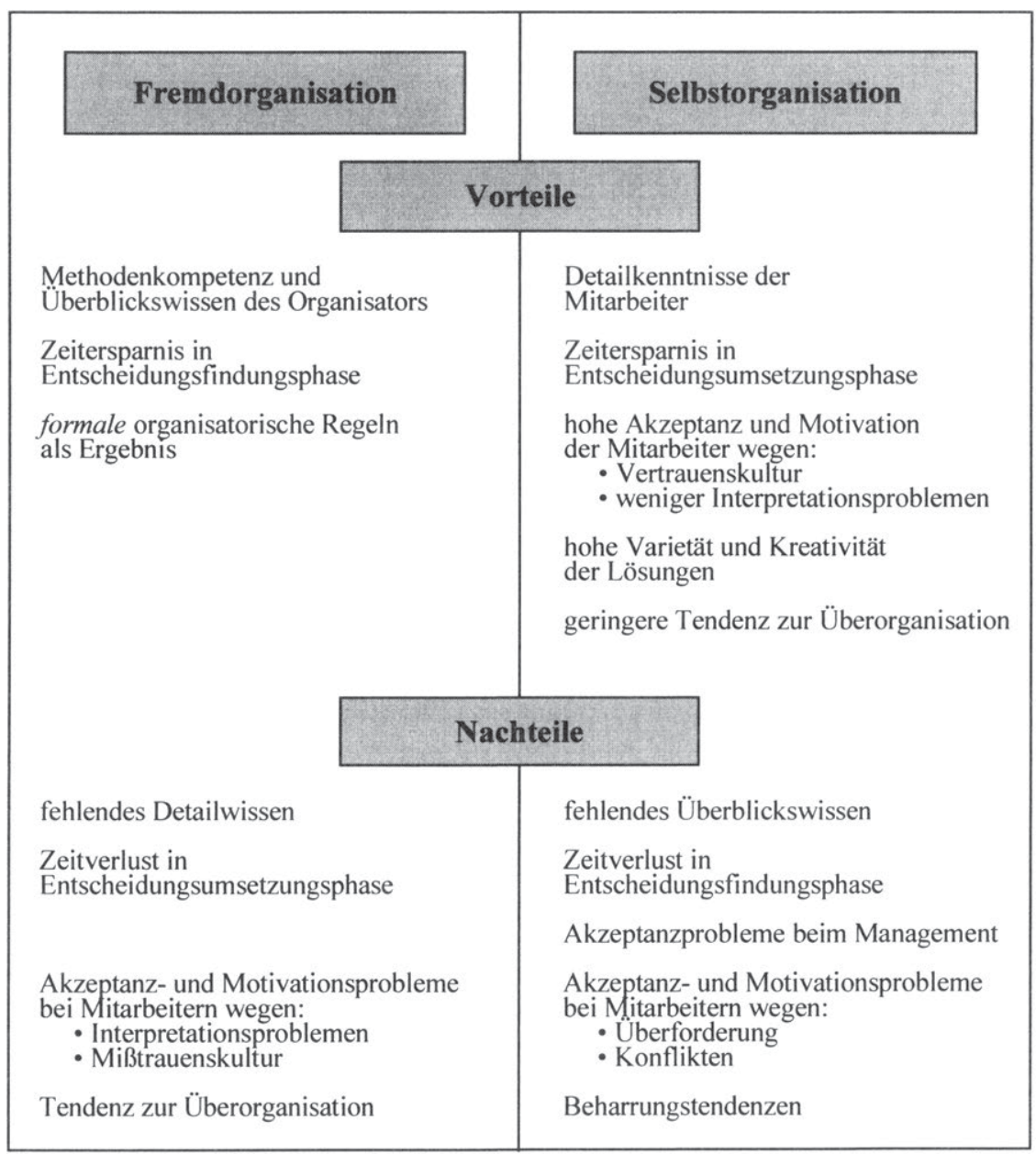

Tab. 4/3: Vor- und Nachteile von Fremd- und Selbstorganisation

Eine allein auf Fremdorganisation beruhende Lösung würde bedeuten, daß jedes noch so geringfügige präsituativ zu regelnde Detail von außen vorgegeben wird. Im Regelfall jedoch ist auf der Seite der organisatorischen Gestalter sowie der Führungskräfte weder das entsprechende Detailwissen noch die Kapazität vorhanden, um das System Unternehmung bis ins letzte Detail zu gestalten. ${ }^{42}$ Sie wären von der Umwelt- und Binnenkomplexität der Unternehmung überfordert. Darüber hinaus treten in der Unternehmung 
- unabhängig vom Willen des Managements - stets Selbstorganisationsprozesse auf. Diese sind eine zentrale Ursache für das in der betrieblichen Praxis zu beobachtende Phänomen, daß das tatsächliche Handeln der Mitarbeiter bisweilen von den Vorgaben fremdorganisatorisch formulierter organisatorischer Regeln abweicht. Selbstorganisation ist in der Unternehmung de facto also stets vorhanden. Eine allein auf Fremdorganisationsprozessen beruhende präsituative Regelung ist somit weder möglich noch sinnvoll.

Eine allein auf Selbstorganisation beruhende Lösung ist nicht möglich, da - sieht man von sehr kleinen Unternehmungen ab - die bloße Größe der Unternehmung für die in ihr spezifisches Arbeitsumfeld eingebundenen Mitarbeiter den Überblick über den Gesamtzusammenhang und über ihr jeweiliges Subsystem hinausreichende Wirkungszusammenhänge häufig unmöglich macht. Entsprechend wäre bei einem Verzicht auf jegliche Fremdorganisation die Koordination zwischen den einzelnen Subsystemen sowie deren Ausrichtung auf das Zielsystem der Unternehmung als Ganzem gefährdet, was zu Orientierungslosigkeit und letztendlich zur Auflösung des Systems Unternehmung führen würde. ${ }^{43}$ Ferner existieren - in Abhängigkeit von der Rechtsform der Unternehmung - rechtliche Anforderungen an die verbindliche Festlegung verschiedener Vertretungsrechte für die Unternehmung und der damit verbundenen Handlungszurechnungen, die zwingend fremdorganisatorische Aktivitäten voraussetzen. ${ }^{44}$ Somit ist die Reduktion jeglicher präsituativen Regelung in der Unternehmung auf Selbstorganisationsprozesse weder möglich noch sinnvoll.

Da eine unternehmungsweit allein auf Fremd- oder Selbstorganisation beruhende Lösung ausgeschlossen ist, muß die Summe aller organisatorischen Tätigkeiten in der Unternehmung stets eine Mischung beider Formen darstellen. ${ }^{45}$ Aufgrund der genannten spezifischen Vor- und Nachteile der beiden Arten präsituativer Regelung erweist es sich dabei als zweckmäßig, zunächst mit Hilfe von Fremdorganisationsprozessen die Umwelt- und Binnenkomplexität der Gesamtunternehmung zu reduzieren und innerhalb des so formulierten Rahmens sodann Selbstorganisationsprozesse zu ermöglichen. Wie die Kombination von Fremd- und Selbstorganisation konkret auszusehen hat, hängt dabei vom Ausmaß der Ausprägungen einer Vielzahl von Kontextfaktoren ab, die wiederum den Grad der Ausprägung der einzelnen Vor- und Nachteile der beiden Regelungsarten im spezifischen Einzelfall bestimmen. Im folgenden Abschnitt 4.1.2.2 wird untersucht, welche Konsequenzen häufige, schnelle und diskontinuierliche unternehmungsexterne Wandelprozesse als spezifische Kontextfaktoren für die relative Bedeutung von Fremd- und Selbstorganisationsprozessen haben.

43 Vgl. Probst/Scheuss (1984), S. 488.

44 Vgl. Kieser (1994), S. 217; Klimecki/Probst/Eberl (1991b), S. 36.

45 Vgl. ăhnlich Knyphausen (1988), S. 307. 


\subsubsection{Fremd- und Selbstorganisation in der von Wandel geprägten Unternehmung}

Ergab die allgemeine Bewertung von Fremd- und Selbstorganisation in Abschnitt 4.1.2.1 zunächst nur, daß diese beiden Arten organisatorischer Tätigkeit in der Unternehmung stets komplementär einzusetzen sind, da ihre jeweiligen Vor- und Nachteile eine allein auf Fremd- oder Selbstorganisation beruhende Lösung unmöglich machen, so soll im folgenden geprüft werden, wie diese Bewertung für den spezifischen Fall häufiger, schneller und diskontinuierlicher Wandelprozesse in der Umwelt der Unternehmung ausfällt. Die Befähigung der Unternehmung zu entsprechendem internen Wandel wird hier als Effizienzkriterium zur Bewertung der beiden Arten organisatorischer Tätigkeit verwendet. ${ }^{46}$ In der aktuellen Literatur zum Thema Selbstorganisation findet man zwar häufig Hinweise, daß Selbstorganisationsprozesse sich positiv auf die Flexibilität der Unternehmung auswirken. Eine schlüssige Begründung dieser Annahme fehlt jedoch in der Regel. ${ }^{47}$ Ziel dieses Abschnittes ist es deshalb aufzuzeigen, welche Konsequenzen die Forderung nach häufigem, schnellem und grundlegendem unternehmungsinternen Wandel als Effizienzkriterium für die Bewertung von Fremd- und Selbstorganisationsprozessen und ihre relative Bedeutung in der Unternehmung hat.

Häufige, schnelle und diskontinuierliche Wandelprozesse in der relevanten Umwelt der Unternehmung als Ausgangsproblematik der vorliegenden Arbeit betreffen nicht etwa 'die Umwelt' der Unternehmung als monolithisches Ganzes. Vielmehr setzt sich 'die Umwelt' der Unternehmung aus einer Vielzahl verschiedener Phänomene zusammen, die sich unterschiedlich entwickeln. Insbesondere betrifft der Wandel regelmäßig nicht alle für die Unternehmung relevanten Teilbereiche der Umwelt. Vielmehr stehen von starkem Wandel geprägte neben stabilen Bereichen. ${ }^{48}$ Auch reagieren die Mitglieder der Unternehmung nur auf diejenigen Wandelprozesse, die sie als solche wahrnehmen. ${ }^{49}$ Es ist davon auszugehen, daß jedes Mitglied einen anderen Ausschnitt der Umwelt wahrnimmt. Denn die subjektive Wahrnehmung ist von einer Fülle von Faktoren beeinflußt, die sich intersubjektiv unterscheiden. Als Beispiele sei hier auf berufliche Ausbildung, individuelle Interessen, persönliche Weltbilder sowie das spezifische Arbeitsumfeld verwiesen. Insbesondere wird hier davon ausgegangen, daß diejenigen Teilumwelten im Mittelpunkt der Wahrnehmung eines Subjektes stehen, die für die Erfüllung seiner spezifischen Teilaufgabe im Rahmen des betrieblichen Leistungserstellungsprozesses von besonderer Relevanz sind.

46 Vgl. åhnlich Göbel (1993), S. 395.

47 Vgl. z.B. Göbel (1993), S. 395; Steinle/Bruch/Müller (1996), S. 654. Ähnliches stellen Kieser/Kubicek (1992), S. 472, über die Vertreter eines evolutionären Managementansatzes fest, die lediglich postulieren, daß präsituative und situative Selbstregelung (dort: Selbstfuhrung und Selbststrukturierung) extensiv zu nutzen seien, jedoch keine konkreten Aussagen dazu machen, wie deren angemessenes Ausmaß zu bestimmen sei.

48 Siehe Abschnitt 3.1.1 der vorliegenden Arbeit.

49 Bezüglich der subjektiven Konstruktionen von Wirklichkeit siehe Abschnitt 2.1.2 zum Radikalen Konstruktivismus als wissenschaftstheoretischer Grundposition der vorliegenden Arbeit. 
Betrachtet man die Gesamtheit der Mitglieder der Unternehmung, so kann diese in (potentiell selbstorganisierend tätig werdende) Mitarbeiter und (potentiell fremdorganisierend tätig werdende) Organisatoren unterschieden werden, ${ }^{50}$ die jeweils unterschiedliche Wahrnehmungen haben. Im Mittelpunkt der Wahrnehmung eines in ein bestimmtes Arbeitsumfeld eingebundenen Mitarbeiters stehen diejenigen Teilumwelten, die von unmittelbarer Relevanz für seine spezifische Teilaufgabenerfüllung sind. Dagegen richtet sich das Interesse der Organisatoren stärker auf Einflüsse, die die Unternehmung als Ganzes betreffen. Daraus resultiert, daß der Mitarbeiter Veränderungen der relevanten Teilumwelt seines Subsystems in der Regel schneller und besser wahrnimmt als der Organisator. Umgekehrt nimmt der Organisator die Unternehmung als Ganzes beeinflussende Veränderungen tendenziell schneller und besser wahr als der in einen bestimmten Teilbereich eingebundene Mitarbeiter.

Geht man ferner davon aus, daß die Qualität der organisatorischen Tätigkeiten vom Informationsstand des handelnden Subjektes - und dieser wiederum von seiner Wahrnehmung - abhängt, so kann man aus dem Umstand der Wahrnehmung unterschiedlicher Wandelprozesse durch Mitarbeiter und Organisatoren ableiten, daß die relative Vorziehenswürdigkeit von Fremd- und Selbstorganisation von den jeweils wahrgenommenen Wandelprozessen abhängt. So ist Fremdorganisation immer dann tendenziell der Selbstorganisation vorzuziehen, wenn die auftretenden Wandelprozesse von Bedeutung für die Unternehmung als Ganzes sind. Umgekehrt dagegen ist Selbstorganisation immer dann tendenziell der Fremdorganisation vorzuziehen, wenn die Veränderungen die spezifische Teilumwelt eines bestimmten Subsystems betreffen. ${ }^{51}$

Zwar verfolgt die vorliegende Arbeit in ihrem Anspruch, Anforderungen an die organisatorische Gestaltung und das Informationsmanagement als Managementaktivitäten zu formulieren, die Sichtweise des Managements. ${ }^{52}$ Die Diskussion um die relative Vorziehenswürdigkeit von Fremd- oder Selbstorganisation in Abhängigkeit von den beobachteten Wandelphänomenen zeigt jedoch wiederum, daß gemäß der konstruktivistschen Grundposition der Untersuchung die Wahrnehmungen des Managements hier

50 Grundsätzlich handelt es sich zwar auch bei der Personengruppe der organisatorischen Gestalter um Mitarbeiter der Unternehmung. Aus Gründen der sprachlichen Vereinfachung soll im Rahmen der vorliegenden Arbeit dennoch zwischen den 'organisatorischen Gestaltern' auf der einen und den 'Mitarbeitern' als den nicht fremdorganisatorisch tätigen Mitarbeitern auf der anderen Seite unterschieden werden. Der Grenzfall selbstorganisierend tătiger organisatorischer Gestalter ist für die weiteren Ausfulhrungen ohne Bedeutung und wird deshalb im folgenden nicht berücksichtigt.

5I Vom Grundgedanken her ähnlich argumentieren sowohl Schäffer (1996) als auch Frese (1993): Ohne spezifischen Bezug zu Wandelphänomenen postuliert Schăffer, daß Selbstorganisation Fremdorganisation immer dann ersetzen soll, wenn der Organisator nicht über ausreichendes Wissen für diese Aufgabe verfügt, dieses Wissen jedoch beim einzelnen Handlungsträger vorhanden ist. Frese thematisiert zwar nur indirekt die relative Vorziehenswürdigkeit von Fremd- und Selbstorganisation und betrachtet vielmehr das Ausmaß der Entscheidungsdelegation in der Unternehmung. Dabei stellt er jedoch fest, daß für den Fall stark differenzierter Märkte mit einer hohen Änderungsdynamik ubergeordneten Stellen (wie Linienvorgesetzten und organisatorischen Gestaltern) tendenziell das Detailwissen bezüglich des spezifischen Arbeitsumfeldes ihrer Mitarbeiter fehlt und deshalb Selbstregelungsprozesse (und damit auch Selbstorganisation als präsituative Selbstregelung) an Bedeutung gewinnen. Vgl. Frese (1993), S. 1019; Schäffer (1996), S. 1100.

Siehe Abschnitt 2.1.1 der vorliegenden Arbeit. 
nicht als die einzig richtigen, 'objektiven' angenommen werden, denen die 'subjektiven' der Mitarbeiter gegenüberzustellen sind, wie es in traditionellen, stark hierarchisch ausgerichteten Managementkonzepten - zumindest implizit - häufig der Fall ist. ${ }^{53}$ Vielmehr wird hier davon ausgegangen, daß die Wahrnehmungen der Mitarbeiter und der Organisatoren bzw. des Managements nebeneinanderstehen. Jeder nimmt bestimmte Wandelprozesse wahr und ignoriert andere. Insbesondere gilt, daß aufgrund der unterschiedlichen Perspektiven von Management und betroffenen Mitarbeitern deren Bewertungen der organisatorischen Regeln u.U. deutlich voneinander abweichen können. Aber z.B. auch von den Unternehmungszielen abweichende persönliche Ziele oder mangelnde Fähigkeiten der Mitarbeiter können sich auf das Ergebnis von Selbstorganisationsprozessen auswirken, so daß Selbstorganisationsprozesse aus der Sicht des Managements keineswegs in jedem Einzelfall notwendigerweise zu im Vergleich zu Fremdorganisation besseren Lösungen führen. ${ }^{54}$ Akzeptiert das Management diesen Umstand, so kann es aufgrund der oben genannten Argumente sinnvoll sein, in den Bereichen, in denen Wandel schneller und besser durch die Mitarbeiter und weniger durch das Management wahrgenommen wird, auf fremdorganisatorische Aktivitäten zugunsten von mehr Selbstorganisation zu verzichten und Selbstorganisationsprozesse gezielt $\mathrm{zu}$ fördern. Häufige, schnelle und diskontinuierliche Wandelprozesse in den spezifischen Teilumwelten der Subsysteme stellen somit eine Bedingungskonstellation dar, bei deren Auftreten Selbstorganisation der Fremdorganisation tendenziell überlegen ist. Somit wäre hier der Forderung von vON DER OELSNITZ nach der Spezifizierung einer solchen Bedingungskonstellation entsprochen. VON DER OELSNITZ vermißt ebendies in weiten Teilen der Literatur zum Phänomen der Selbstorganisation. 55

Allerdings sei noch einmal ausdrücklich darauf verwiesen, daß die genannten Rahmenbedingungen nur einen Teilaspekt einer Vielzahl möglicher situativer Konkretisierungen darstellen. Prozesse unternehmungsexternen Wandels sind nur ein mögliches Argument von vielen zur Beurteilung von Fremd- und Selbstorganisation. Keinesfalls darf die hier vorgenommene kontextspezifische Bewertung der beiden Arten organisatorischer Tätigkeit als Plädoyer für einen allgemein stärkeren Einsatz von Selbstorganisation mißinterpretiert werden. Der teilweise gegenüber Arbeiten zu diesem Phänomen erhobene Vorwurf, undifferenziert und unbegründet ein Mehr an Selbstorganisation zu fordern, ${ }^{56}$ könnte sonst auch gegenüber der vorliegenden Arbeit angewendet werden.

53 Vgl. Hejl (1983), S. 58.

54 Für eine ausfuhrliche Darstellung moglicher mit Selbstorganisation verbundener Gefahren vgl. Oelsnitz (1995), S. $712 \mathrm{ff}$, wobei jedoch zu berucksichtigen ist, daß von der Oelsnitz einen geringfugig von der Terminologie der vorliegenden Arbeit abweichenden Selbstorganisationsbegriff zugrundelegt.

55 Vgl. Oelsnitz (1995), S. $715 f$.

56 Vgl. Oelsnitz (1995), S. 708. 
Auch dürfen die Ausführungen nicht dahingehend mißverstanden werden, daß die situationsspezifische relative Vorteilhaftigkeit von Selbstorganisation in einem bestimmten Subsystem bedeutet, daß Fremdorganisation dort keinerlei Anwendung findet. Zwar gilt, $\mathrm{da} ß$ eine selbstorganisatorisch festgelegte Regel nicht mit einer fremdorganisatorisch festgelegten Regel für denselben Wirkungsbereich konkurrieren sollte, wie es z.B. die Diskussion um Theories-in-use und Espoused Theories thematisiert. ${ }^{57}$ Ein konkretes Detail sollte vielmehr entweder selbst- oder fremdorganisatorisch geregelt werden. Jedoch bedeutet dies nicht, daß in Subsystemen, in denen Selbstorganisationsprozesse verstärkt zur Regelung eingesetzt werden sollen, auf Fremdorganisation verzichtet wird. Vielmehr muß dort anders als bislang fremdorganisiert werden. ${ }^{58}$ Es handelt sich dann um die Fremdorganisation eines Rahmens für Selbstorganisation. Denn Selbstorganisationsprozesse finden stets im Kontext fremdorganisatorisch festgelegter formaler organisatorischer Regeln statt. Deshalb ist es wichtig und sinnvoll, die Wechselwirkungen zwischen diesen beiden Formen organisatorischer Tätigkeit offenzulegen und - wo dies möglich ist - gezielt Einfluß auf sie zu nehmen. Hier wird der Umstand, den GidDENS mit der Formulierung 'Organisationsstruktur als duales Phänomen' bezeichnet, besonders deutlich: Einerseits sind organisatorische Regeln Ergebnis organisatorischer Tätigkeiten (hier der Fremdorganisation). Andererseits sind sie jedoch auch Ausgangspunkt weiterer organisatorischer Tätigkeiten (hier der Selbstorganisation). Nach GIDDENS bilden sie somit "both the medium and the outcome of the practices which constitute social systems" 59 . Anders formuliert ist organisationales Wissen hier nicht nur Ergebnis, sondern auch Ausgangspunkt organisationaler Lernprozesse. Im Sinne eines Deutero Learning bzw. eines Lernens zu Lernen gilt es zu berücksichtigen, daß das Ergebnis heutiger organisationaler Lernprozesse künftige fördern, beeinträchtigen oder gar verhindern kann. Abbildung 4/4 visualisiert diesen Argumentationszusammenhang.

Für die argumentatorische Verknüpfung von Fremd- und Selbstorganisation erweist sich als problematisch, daß einerseits die traditionelle organisationstheoretische Literatur das Selbstorganisationsphänomen weitgehend ignoriert bzw. lediglich im Rahmen eines kurzen Exkurses oder Ausblicks erwähnt, ohne daß dies Konsequenzen für die organisatorische Gestaltung hätte. ${ }^{60}$ Andererseits finden sich in der Selbstorganisations-Literatur zwar durchaus exemplarische Darstellungen der Möglichkeiten des Managements

57 Siehe Abschnitt 3.2.2.1 der vorliegenden Arbeit.

58 Vgl. ähnlich Kieser (1994), S. 220. Kieser formuliert allerdings m.E. überspitzt, wenn er feststellt "Es muß vor allem anders und nicht weniger fremdorganisiert werden.", denn das Einräumen von Freirăumen für Selbstorganisationsprozesse bedeutet sehr wohl, daß eben diese Regel nicht fremdorganisiert festgelegt wird, also diesbezüglich weniger fremdorganisiert wird.

59 Giddens (1981), S. 27.

60 Ähnliches stellen auch Probst/Scheuss (1984), S. 480, fest. Dies gilt aber auch für die Literatur der 90er Jahre. Zwar verweisen einige Autoren, wie z.B. Bleicher (1991), S. 916f., Kieser/Kubicek (1992), S. 467ff., und Schulte-Zurhausen (1995), S. 290, zumindest kurz auf die Existenz (und zunehmende Bedeutung) von Selbstorganisationsprozessen. Eine über die bloße Nennung einiger modischer Schlagworte hinausreichende Darstellung des Zusammenhangs zwischen Selbst- und Fremdorganisation unterbleibt jedoch auch dort. 
zur Unterstützung von Selbstorganisationsprozessen. Eine systematische Aufarbeitung des Zusammenhangs zwischen Fremd- und Selbstorganisation fehlt jedoch. ${ }^{61}$ Sie stellt deshalb den Kern der folgenden Ausführungen dieses Kapitels dar.

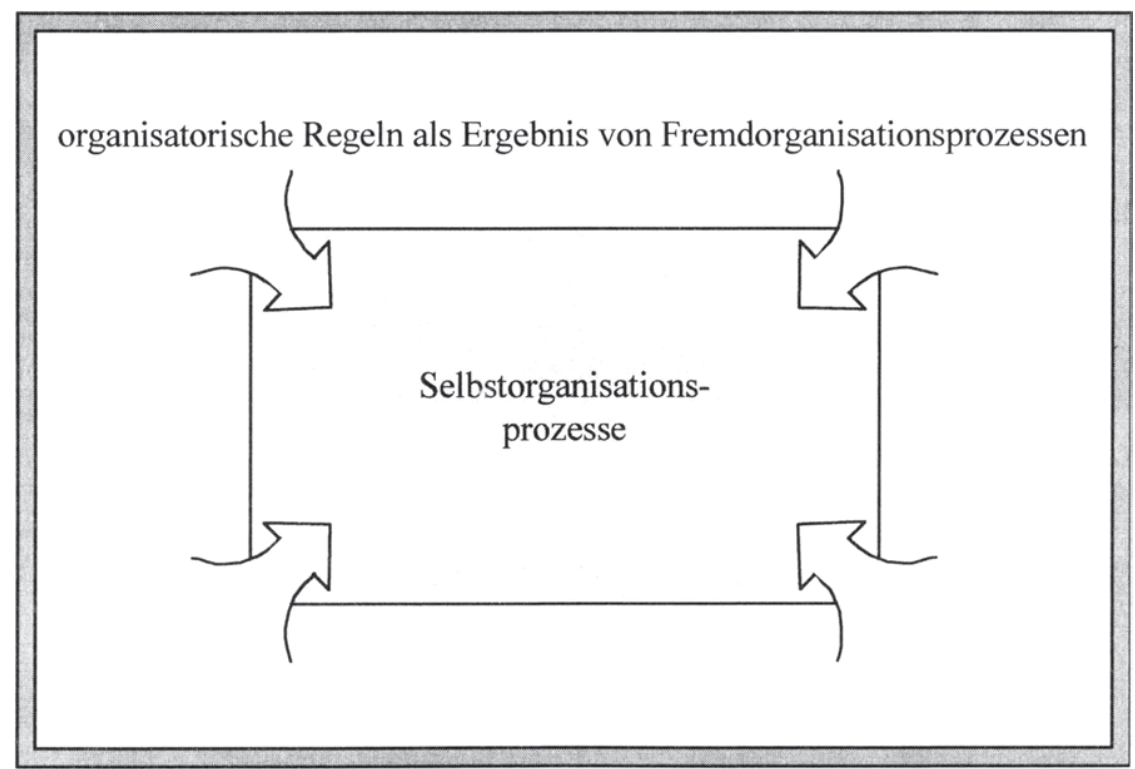

Abb. 4/4: Die Schaffung eines Rahmens für Selbstorganiationsprozesse mittels organisatorischer Gestaltung

\subsubsection{Das Phänomen der Selbstorganisation als Spezialfall präsituativer Regelung}

Die Untersuchung der Fragestellung, wie Selbstorganisationsprozesse durch geeignete Aktivitäten der organisatorischen Gestaltung im Sinne eines Lernens zu Lernen bzw. Deutero Learning gefördert werden können, setzt die intensive Auseinandersetzung mit dem Phänomen der Selbstorganisation voraus. Diese steht im Mittelpunkt der folgenden Ausführungen, die an die kurze definitorische Abgrenzung in Abschnitt 2.2.1.3 sowie die kritische Bewertung in Abschnitt 4.1.2 anknüpfen. Hierfür wird in Abschnitt 4.1.3.1 der Selbstorganisationsbegriff der vorliegenden Arbeit näher spezifiziert und der Begriffsverwendung in der Literatur gegenübergestellt. Die kritische Diskussion der in der gängigen Literatur als Charakteristika eines Selbstorganisationsprozesse förderlichen Umfeldes beschriebenen Phänomene in Abschnitt 4.1.3.2 dient sodann als Ausgangsbasis für die Ausführungen in Abschnitt 4.2, in dem konkrete Anforderungen an die organisatorische Gestaltung in der lernenden Unternehmung abgeleitet werden. 


\subsubsection{Inhaltliche Abgrenzung des Phänomens der Selbstorganisation}

Selbstorganisation wird in den letzten Jahren in Literatur und betrieblicher Praxis stark diskutiert. Der Begriff findet sich nicht nur im theoretischen Schriftum, sondern auch in zahlreichen populärwissenschaftlichen bzw. praxisorientierten betriebswirtschaftlichen Veröffentlichungen. Trotz der häufigen Verwendung fehlt es dem Begriff jedoch noch immer an Klarheit und Eindeutigkeit. Sogar in Arbeiten, die Selbstorganisation explizit in den Mittelpunkt der Betrachtung stellen, bleibt die definitorische Abgrenzung von Selbstorganisationsprozessen oft vage. ${ }^{62}$ Auch handelt es sich bei Ausführungen zum Phänomen Selbstorganisation häufig um Auflistungen diverser Maßnahmen, die sowohl dem Theoretiker als auch dem Praktiker aus anderen Argumentationszusammenhängen bereits bekannt sind. Der exemplarischen Darstellung fehlt dabei oft die Einbettung in eine theoretische Gesamtkonzeption. ${ }^{63}$ Den wissenschaftlichen Diskurs erschwert zusätzlich, daß eine Verknüpfung dieser neuen Denkrichtung mit Erkenntnissen der traditionellen Organisationstheorie unterbleibt.

Seit der Mitte der 80er Jahre ist zu beobachten, daß der Begriff der Selbstorganisation häufig zur Etikettierung einer bestimmten Forschungsrichtung innerhalb der Managementtheorie verwendet wird, in der basierend auf der empirischen Erkenntnis, daß traditionelle Managementmethoden heute immer öfter scheitern, eine radikale Abkehr von bisherigen Konzepten hin zu einem 'evolutionären Management' gefordert wird. ${ }^{64}$ Die Arbeiten zu einem 'evolutionären Management' setzen dabei auf den Erkenntnissen der überdisziplinären Forschungen der Kybernetik 2. Ordnung an. ${ }^{65}$ Dabei werden Emergenzphänomene spontaner Ordnungsbildung (nach VON HAYEK) häufig auch als Selbstorganisationsprozesse bezeichnet. ${ }^{66}$ Selbstorganisation ist demgemäß die Eigenschaft komplexer Systeme, aus sich selbst heraus Ordnung herzustellen. Dieses Gleichsetzen von Selbstorganisation und spontaner Ordnungsbildung (nach VON HAYEK), die wiederum eine zentrale Eigenschaft komplexer Systeme ist, hat dazu geführt, daß dieser

62 Dies stellen auch Knyphausen (1988), S. 264, sowie Gebhardt (1996), S. 13, fest. Siehe beispielhaft die ausfuhrliche Kritik an der Terminologie bei Probst im weiteren Verlauf dieses Abschnittes sowie in Abschnitt 4.1.3.2 der vorliegenden Arbeit.

So gilt Teubners Wertung einer "heillosen Begriffsverwirrung" in der "Galaxie auto", der er neben dem Begriff der Selbstorganisation auch damit zusammenhăngende Begriffe wie Selbstreferenz, Selbstkonstitution, Selbstbeobachtung und Selbsterhaltung zurechnet, m.E. auch heute noch. Vgl. Teubner (1987a), S. 94ff.

63 Vgl. z.B. Picot (1993), S. 173; Probst (1987), S. 91 ff.; Steinle/Bruch/Müller (1996), S. 651.

64 Vgl. Kieser (1994), S. 199; Knyphausen (1988), S. 259, 264.

65 Für eine kurze Einfuhrung in zentrale Aussagen der Kybernetik 2. Ordnung sowie des evolutionären Managements siehe Abschnitt 2.1.3 der vorliegenden Arbeit.

66 So bezeichnet z.B. Probst Selbstorganisation als "alle Prozesse, die aus einem System heraus von selbst entstehen und in diesem 'Selbst' Ordnung entstehen lassen, verbessern oder erhalten." Probst (1992), Sp. 2255. Darüber hinaus stellt Probst fest, daß allen von ihm zuvor genannten evolutionären Managementansătzen gemein ist, "daß Strukturen [im Sinne der Summe der organisatorischen Regeln, die Verfasserin] nicht nur einfach erfunden und implementiert werden können, sondern ganzheitlich aus dem System heraus entstehen" (Probst (1987), S. 66) und damit Emergenzphänomene darstellen können. Explizit bezeichnet Probst Selbstorganisationsprozesse allerdings nur an wenigen Stellen seiner Arbeiten als emergent, so z.B. Probst (1987), S. 76. 
Forschungsrichtung verpflichtete Wissenschaftler ihre Arbeiten auch als Beiträge zu einer 'Theorie selbstorganisierender Systeme' bezeichnen. Die Verwendung des Begriffes Organisation stellt dabei auf die Bildung von Ordnung (im Gegensatz zu Unordnung) als Emergenzphänomen ab. Weder VON HAYEK selbst noch die Forscher, die auf seinen Arbeiten aufbauen, differenzieren bei dieser spontanen Ordnungsbildung zwischen präsituativer und situativer Regelung. Somit umfaßt Selbstorganisation hier sowohl die präsituative als auch die situative Regelung.

Die traditionelle Managementtheorie definiert den Organisationsbegriff dagegen anders. Organisatorische Regeln als Teilmenge der Gesamtheit aller Regeln zur Ordnungsbildung in der Unternehmung beziehen sich auf die arbeitsteilige Aufgabenerfüllung. Wie in Abschnitt 2.2.1.1.1 der vorliegenden Arbeit dargestellt, kann man grundsätzlich zwischen einem abstrakt institutionalen, einem konkret institutionalen und einem funktionalen Verständnis von Organisation unterscheiden. Dem Selbstorganisationsbegriff liegt ein funktionales Verständnis zugrunde. Fremd- und Selbstorganisation sind organisatorische Tätigkeiten im Sinne des Aufstellens organisatorischer Regeln als präsituativer Regelung. Diese präsituative Regelung ist von der situativen klar zu unterscheiden. Organisatorische Tätigkeit kann per definitionem stets nur präsituative Regelung sein. Da die traditionelle Managementtheorie die Existenz von Emergenzphänomenen in der Unternehmung zumeist ignoriert, ${ }^{67}$ trifft sie regelmäBig keine Aussagen darüber, ob organisatorische Regeln emergente Phänomene sein können oder nicht. Geht man dagegen - wie im Rahmen der vorliegenden Arbeit - davon aus, daß es sich bei der Ordnungsbildung in der Unternehmung als komplexem System nicht nur um das Ergebnis bewußter Gestaltungshandlungen, sondern auch um ein Emergenzphänomen handeln kann, so umfaßt der Organisationsbegriff sowohl emergente als auch nicht-emergente Phänomene. Da die vorliegende Arbeit in der Managementtheorie wurzelt, wird hier - wie bereits in Abschnitt 2.2.1.1 definiert - deren Organisations- bzw. Selbstorganisationsbegriff gewählt. Abbildung 4/5 zeigt die Abgrenzung des Selbstorganisationsbegriffes der vorliegenden Arbeit gegenüber dem in Beiträgen zu einer 'Theorie selbstorganisierender Systeme' verwendeten Begriff.

Abbildung 4/5 zeigt, daß der Selbstorganisationsbegriff der Forschungsarbeiten zu einer 'Theorie selbstorganisierender Systeme' fundamental von der in der Managementtheorie üblichen Terminologie abweicht. Zum einen umfaßt er neben der präsituativen Regelung auch die situative, zum anderen beschränkt er sich auf das Entstehen organisatorischer Regeln als Emergenzphänomen. Dagegen schließt ein der üblichen Terminologie der Managementtheorie folgender Selbstorganisationsbegriff über Emer genzphänomene hinaus auch das Entstehen organisatorischer Regeln als Ergebnis

67 Siehe dazu auch die kurze Gegenuberstellung der Implikationen der Kybernetik 1. und 2. Ordnung für die Managementlehre in Abschnitt 2.1.3 der vorliegenden Arbeit. 


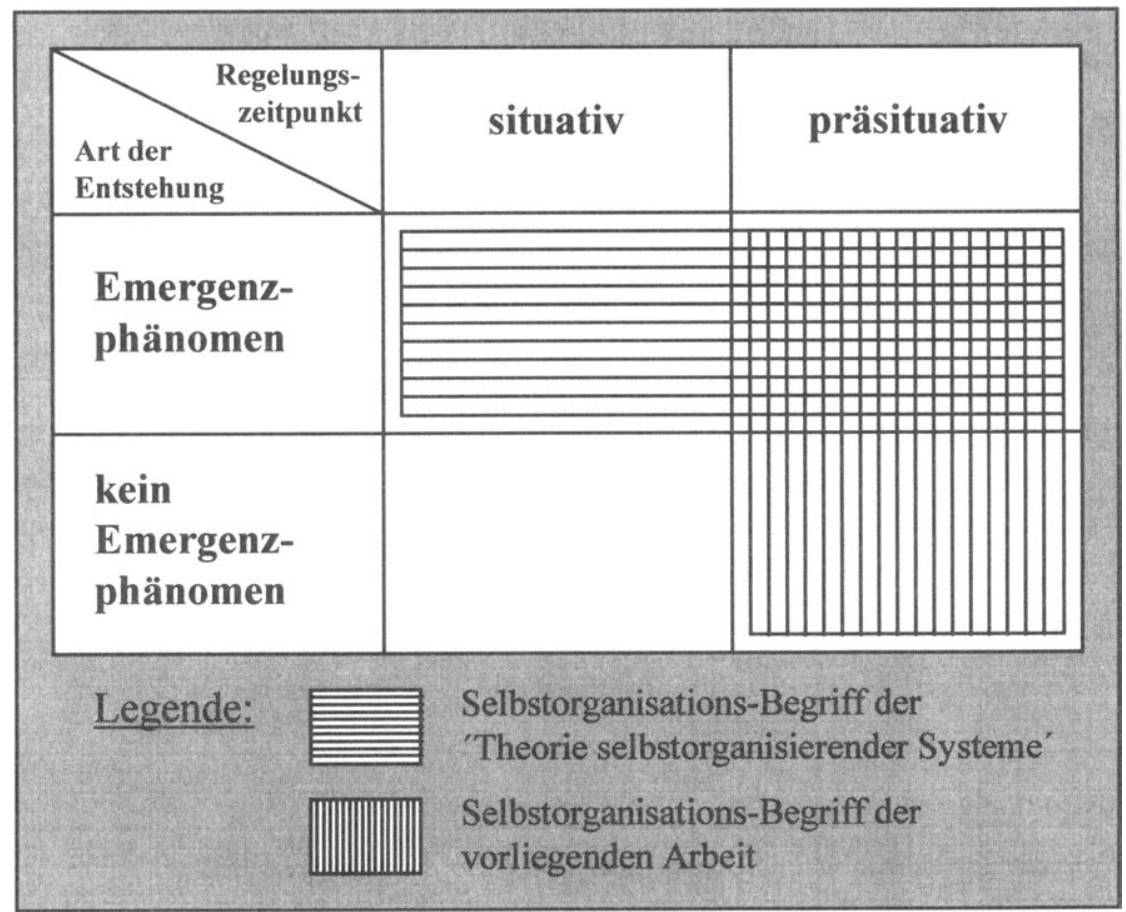

Abb. 4/5: Gegenüberstellung alternativer Selbstorganisations-Begriffe

bewußter Gestaltungshandlungen ein. Die Verwendung des Selbstorganisationsbegriffes aus Arbeiten zu einer 'Theorie selbstorganisierender Systeme' erweist sich damit als äußerst problematisch, zumal eine explizite Klärung der terminologischen Unterschiede regelmäßig unterbleibt. Die daraus resultierenden terminologischen Unklarheiten ließen sich vermeiden, würde man den Selbstorganisationsbegriff der 'Theorie selbstorganisierender Systeme' durch den Begriff der 'spontanen Ordnungsbildung' ersetzen. Der Umstand, daß moderne, dem 'evolutionären Management' zuzurechnende Ansätze eine fundamental andere wissenschaftstheoretische Grundposition einnehmen als die traditionelle betriebswirtschaftliche Literatur und entsprechend auch $\mathrm{zu}$ anderen Erkenntnissen gelangen, muß m.E. nämlich weder mit einer problematischen Unschärfe der verwendeten Begriffe noch damit einhergehen, daß dieselben Begriffe in unterschiedlichen Zusammenhängen verwendet werden. Vielmehr können traditionelle und auf den Erkenntnissen der modernen Systemtheorie basierende Managementansätze nur durch eine deutliche Offenlegung ihrer jeweiligen Grundannahmen und der daraus resultierenden Konsequenzen, die sich notwendigerweise in einer eindeutigen Terminologie widerspiegelt, einander gegenübergestellt und eventuell zusammengeführt werden.

Da der Selbstorganisationsbegriff der vorliegenden Arbeit nicht mit dem Phänomen der spontanen Ordnungsbildung gleichzusetzen ist, ist eine unmodifizierte Übernahme der 
Aussagen von Arbeiten zu einer 'Theorie selbstorganisierender Systeme' in der Regel nicht möglich. Vielmehr müssen die terminologischen und inhaltlichen Unterschiede bei jeder Bezugnahme auf die Literatur zum Phänomen der Selbstorganisation Berücksichtigung finden. Gemäß der Begriffsabgrenzung der vorliegenden Arbeit können Selbstorganisationsprozesse sowohl bewußte organisatorische Tätigkeiten der Mitarbeiter in der Unternehmung als auch Emergenzphänomene darstellen, die sich aus dem Zusammenwirken des Handelns mehrerer Individuen in der Unternehmung als komplexem System ergeben. ${ }^{68}$ Berücksichtigt man darüber hinaus, daß Selbstorganisationsprozesse sowohl offiziell autorisiert (mit formalen organisatorischen Regeln als Ergebnis) als auch nicht offiziell autorisiert (mit informalen organisatorischen Regeln als Ergebnis) sein können, ${ }^{69}$ so gelangt man zu den in Abbildung 4/6 dargestellten Arten von Selbstorganisationsprozessen. Diese Systematisierung dient nicht nur den folgenden Ausführungen in Abschnitt 4.1.3.2, sondern auch der daran anschließenden Ableitung von Anforderungen an die organisatorische Gestaltung in der lernenden Unternehmung in Abschnitt 4.2 als Grundlage.

\begin{tabular}{|l|l|l|}
\hline $\begin{array}{r}\text { Legitimation der } \\
\text { Selbstorga- } \\
\text { nisations- } \\
\text { prozesse }\end{array}$ & $\begin{array}{l}\text { Art der } \\
\text { Entstehung } \\
\text { offiziell } \\
\text { autorisiert }\end{array}$ & \multicolumn{1}{|c|}{$\begin{array}{l}\text { nicht offiziell } \\
\text { autorisiert }\end{array}$} \\
\hline $\begin{array}{l}\text { Emergenz- } \\
\text { phänomen }\end{array}$ & $\begin{array}{l}\text { geplante } \\
\text { emergente Selbst- } \\
\text { organisationsprozesse }\end{array}$ & $\begin{array}{l}\text { ungeplante } \\
\text { emergente Selbst- } \\
\text { organisationsprozesse }\end{array}$ \\
\hline $\begin{array}{l}\text { kein } \\
\text { phänorgenz- }\end{array}$ & $\begin{array}{l}\text { geplante nicht- } \\
\text { emergente Selbst- } \\
\text { organisationsprozesse }\end{array}$ & $\begin{array}{l}\text { ungeplante nicht- } \\
\text { emergente Selbst- } \\
\text { organisationsprozesse }\end{array}$ \\
\hline
\end{tabular}

Abb. 4/6: Arten von Selbstorganisationsprozessen

Sind die organisatorischen Regeln Ergebnis nicht-emergenter Selbstorganisationsprozesse, so einigen sich die Mitarbeiter eines Subsystems explizit auf diese Regeln. Es handelt sich dann um das Ergebnis willentlichen, bewußten Handelns der Mitarbeiter. Dabei kann der Prozeß der Bestimmung der organisatorischen Regeln sowohl von den normalen Arbeitshandlungen des Leistungserstellungsprozesses getrennt sein als auch in

68 Vgl. als vom Grundgedanken her ähnlich Seidel (1986), S. 229, sowie Gebhardt (1996), S. 93ff., der zwischen 'originăren', teilnehmerbezogenen Selbstorganisationsprozessen einerseits und 'derivativen', auf kulturelle Eigendynamik abstellenden Selbstorganisationsprozessen andererseits unterscheidet.

Siehe Abschnitt 2.2.1.3 der vorliegenden Arbeit. 
unmittelbarem Zusammenhang mit diesen stehen. Als Beispiel sei hier auf die Arbeitsverteilung innerhalb einer teilautonomen Fertigungsgruppe als Prozeß der gemeinsamen Entscheidungsfindung verwiesen, bei der die Mitglieder der Gruppe das anfallende Auftragsvolumen zu Wochenbeginn unter sich verteilen.

Handelt es sich bei den organisatorischen Regeln dagegen um Emergenzphänomene, so bilden sie sich innerhalb eines Subsystems der Unternehmung unabhängig vom bewußten Gestaltungswillen der einzelnen Mitarbeiter spontan aus dem Zusammenwirken ihrer Einzelhandlungen heraus. Dies geschieht in der Regel in unmittelbarem Zusammenhang mit den Arbeitshandlungen des Leistungserstellungsprozesses. ${ }^{70}$ In dem oben genannten Beispiel einer teilautonomen Fertigungsgruppe können sich z.B. über die Zeit hinweg bestimmte Rollen der einzelnen Mitarbeiter in dem Sinne herausbilden, daß eine Person im Rahmen der Entscheidungsprozesse die Meinungsführerschaft erlangt, eine andere regelmäßig die von allen wenig geschätzten Teilaufgaben übernimmt.

Zahlreiche Autoren nehmen heute an, daß emergente Selbstorganisationsprozesse in Unternehmungen bzw. in ihren verschiedenen Subsystemen ein omnipräsentes Phänomen sind. ${ }^{71}$ Geht man nämlich davon aus, daß sowohl die Unternehmung als Ganzes als auch ihre Subsysteme komplexe Systeme sind, so sind Emergenzphänomene der spontanen Ordnungsbildung konstitutiv für diese Systeme. ${ }^{72}$ In der Literatur werden solche emergenten Selbstorganisationsprozesse als Erklärung dafür angeführt, daß die tatsächlichen Ergebnisse von Maßnahmen der organisatorischen Gestaltung häufig von den geplanten Ergebnissen abweichen. ${ }^{73}$ Sie tragen dazu bei, daß das System Unternehmung und seine Subsysteme nicht vollständig durch das Management steuerbar sind. Aber auch nicht-emergente Selbstorganisationsprozesse können die Wirksamkeit des Managementhandelns beeinträchtigen.

Potentiell problematisch sind (emergente und nicht-emergente) Selbstorganisationsprozesse immer dann, wenn sie im Rahmen von Managementhandlungen keinerlei Berücksichtigung finden (sog. ungeplante ${ }^{74}$ Selbstorganisationsprozesse). Sie sind dann nicht offiziell autorisiert, d.h. die aus diesen Prozessen resultierenden organisatorischen Regeln sind stets informaler Natur. Ist der Regelungsgegenstand zugleich auch durch eine im Rahmen von Fremdorganisationsprozessen festgelegte formale Regel abgedeckt, so konterkarrieren die Selbstorganisationsprozesse u.U. die intendierten Wirkungen der organisatorischen Gestaltung. Zwar können fremdorganisatorische

70 Vgl. Kieser (1994), S. 219.

71 Vgl. z.B. Chrobok (1997), S. 114; Gomez/Zimmermann (1992), S. 129; Knyphausen (1988), S. 267f.; Seidel (1986), S. 229f.

72 Siehe Abschnitt 2.1.3 der vorliegenden Arbeit.

73 Vgl. z.B. Gobbel (1993), S. 391f.; Kirsch (1992), S. 349ff.; Klimecki/Probst/Eberl (1991), S. 125; Knyphausen (1988), S. 294; Probst (1992), Sp. $2257 f$.

74 Der Begriff des 'Ungeplantseins' stellt hier auf die fehlende Berücksichtigung im Rahmen der Managementhandlungen $\mathrm{ab}$. 
Maßnahmen emergente und nicht-emergente Selbstorganisationsprozesse behindern, vollständig verhindern können sie sie jedoch nicht. Denn einerseits treten aufgrund der Komplexität des Systems Unternehmung und seiner Subsysteme dort stets Emergenzphänomene auf. Andererseits können die Vorgaben des Managements in der betrieblichen Realität nie so eng sein, daß sie bewußte Selbstorganisationsprozesse der Mitarbeiter vollständig unterbinden können, da dies eine extrem enge Reglementierung erfordern würde, die regelmäßig mit ausgeprägten negativen Effekten auf die Motivation der Mitarbeiter verbunden wäre.

Aufgrund der geschilderten Problematik ungeplanter Selbstorganisationsprozesse sollte das Management die Existenz von Selbstorganisationsprozessen in der Unternehmung nicht nur akzeptieren, sondern systematisch einen Rahmen für diese entwickeln. Denn es ist im Sinne einer zielorientierten Steuerung der Aktivitäten innerhalb der Unternehmung besser, in bestimmten Bereichen bewußt Freiräume für Selbstorganisationsprozesse zu lassen, diese also explizit in das Managementhandeln einzubeziehen, als ihre Existenz zu leugnen und von ihren Ergebnissen überrascht zu werden. Diese Selbstorganisationsprozesse, deren Ergebnisse entsprechend formale organisatorische Regeln sind, werden im Rahmen der vorliegenden Arbeit als geplante Selbstorganisationsprozesse bezeichnet. ${ }^{75}$ 'Geplant' bedeutet dabei allerdings lediglich, daß das Auftreten dieser Selbstorganisationsprozesse geplant im Sinne von gewünscht bzw. vorhergesehen ist, nicht jedoch, daß der Ablauf dieser Selbstorganisationsprozesse oder ihre Ergebnisse geplant werden. Vielmehr sind weder der Ablauf von Selbstorganisationsprozessen noch ihre Ergebnisse durch das Management plan- bzw. vorhersehbar. Geplante Selbstorganisationsprozesse liegen immer dann vor, wenn zur Fremdorganisation legitimierte Personen ihren Entscheidungsspielraum bezüglich der Festlegung organisatorischer Regeln auf die von diesen betroffenen Mitarbeiter übertragen und diese innerhalb des ihnen gewährten Spielraumes agieren. Dabei können geplante Selbstorganisationsprozesse sowohl emergenter als auch nicht-emergenter Art sein.

\subsubsection{Charakteristika eines Selbstorganisation fördernden Umfeldes}

Nach der Spezifizierung des im Rahmen der vorliegenden Arbeit verwendeten Selbstorganisationsbegriffes im letzten Abschnitt wird im folgenden untersucht, welche typischen Merkmale des jeweiligen Systems bzw. Subsystems zur Förderung von Selbstorganisationsprozessen beitragen, wobei zwischen emergenten und nicht-emergenten Selbstorganisationsprozessen unterschieden wird.

Grundsätzliche Voraussetzung für die Sinnhaftigkeit jeder organisatorischen Tätigkeit (unabhängig davon, ob Fremd- oder Selbstorganisation) als Veränderung der Tiefenstruktur der organisationalen Wissensbasis ist - wie in Abschnitt 4.1.1 der vorliegenden Arbeit herausgearbeitet wurde -, daß es sich bei dem zu regelnden Objekt nicht nur um

Vgl. implizit bei Kieser (1994), S. 216. 
ein einmaliges Ereignis handelt, sondern daß Muster in den unternehmungsinternen und -externen Rahmenbedingungen erkennbar sind, die über einen bestimmten Zeitraum hinweg konstant bleiben. Im Gegensatz zu Fremdorganisation, bei der der Organisator über die entsprechende Legitimation verfügen muß, um den Handlungsspielraum anderer zu beschränken, ist eine solche Legitimation nicht notwendige Voraussetzung für Selbstorganisation. Emergente und nicht-emergente Selbstorganisationsprozesse können damit sowohl innerhalb eines autorisierten Rahmens als auch ohne einen solchen ablaufen, wie in Abschnitt 4.1.3.1 ausgeführt wurde.

Prinzipiell kann jedes Mitglied der Unternehmung bewußte, nicht-emergente selbstorganisatorische Tätigkeiten ausführen. ${ }^{76}$ Unabhängig davon, ob den Mitarbeitern der entsprechende Spielraum dafür offiziell eingeräumt wurde oder nicht und ob bereits fremdorganisatorisch festgelegte formale organisatorische Regeln für diesen Regelungsbereich existieren, können die Mitarbeiter bewußt organisatorische Regeln definieren und diesen entsprechend handeln. In der Literatur findet sich keine systematische Darstellung des Zusammenhangs zwischen dem Auftreten nicht-emergenter Selbstorganisationsprozesse in Subsystemen und bestimmten Eigenschaften dieser Subsysteme. Im folgenden wird deshalb von dem folgenden Argumentationszusammenhang ausgegangen: Das Auftreten bewußter Selbstorganisationsprozesse setzt Kommunikationsmöglichkeiten zwischen den an den Selbstorganisationsprozessen Beteiligten sowie die entsprechende Bereitschaft bzw. den Willen der jeweiligen Mitarbeiter voraus. Das Vorhandensein ausreichender Kommunikationsmöglichkeiten ist dabei die notwendige Bedingung, der Wille der Mitarbeiter, selbstorganisierend tätig zu werden, die hinreichende Bedingung. In Abschnitt 4.2 ist deshalb zu untersuchen, welchen Einfluß verschiedene Maßnahmen der organisatorischen Gestaltung auf die Kommunikationsmöglichkeiten sowie den Willen der Mitarbeiter haben, bewußt selbstorganisierend tätig zu werden.

Das Auftreten emergenter Selbstorganisationsprozesse ist per definitionem an die Eigenschaft der Komplexität des Systems Unternehmung gekoppelt und dabei unabhängig vom Willen der einzelnen Mitarbeiter. ${ }^{77}$ In der Literatur zum Thema 'evolutionäres Management' bzw. zu einer 'Theorie selbstorganisierender Systeme' werden im Zusammenhang mit den Emergenzphänomenen der spontanen Ordnungsbildung regelmäßig bestimmte Systemeigenschaften genannt, die deshalb im folgenden untersucht werden sollen. ${ }^{78}$ Die meisten Autoren folgen dabei der Systematisierung von ProBsT, der zwischen

76 Siehe Abschnitt 2.2.1.3 der vorliegenden Arbeit.

77 Für eine erste, kurze Erwăhnung des Zusammenhangs zwischen der Komplexităt eines Systems und dem Auftreten emergenter Selbstorganisationsprozesse siehe Abschnitt 2.1.3 der vorliegenden Arbeit. Eine ausfuhrliche Diskussion erfolgt im folgenden Abschnitt 4.1.3.2.I.

78 Diese Systemeigenschaften beziehen sich in den jeweiligen Quellen auf sogenannte 'selbstorganisierende' Systeme, wobei jedoch - wie in Abschnitt 4.1.3.1 beschrieben - Selbstorganisation dort auf das emergente Entstehen prăsituativer und situativer Regeln abstellt und somit in der Terminologie der vorliegenden Arbeit mit spontaner Ordnungsbildung gleichzusetzen ist. Im folgenden sollen 
- Komplexität,

- Selbstreferenz,

- Autonomie und

- Redundanz

als "konzeptionellen kritischen Größen" bzw. "intrinsischen Charakteristiken selbstorganisierender Systeme"79 unterscheidet. СНROBOK spricht im gleichen Zusammenhang von "kritischen Größen"80, GOMEZ/ZIMMERMANN von "grundlegenden Voraussetzungen und gleichzeitig Eigenschaften von Selbstorganisation"81. Wie PROBST selbst feststellt, sind diese "Charakteristiken ... deutlich untereinander verbunden, überlappen und definieren und produzieren sich gegenseitig"82, was die trennscharfe Abgrenzung voneinander sehr erschwert. ${ }^{83}$ Diese recht vagen Aussagen von PROBST und anderen Autoren sollen im folgenden daraufhin untersucht werden, ob es sich bei den angeführten vier Größen um notwendige Voraussetzungen für das Auftreten von emergenten Selbstorganisationsprozessen handelt. ${ }^{84}$

In den folgenden Abschnitten wird der Zusammenhang zwischen dem Auftreten von Selbstorganisationsprozessen und den Systemeigenschaften Komplexität (Abschnitt 4.1.3.2.1), Selbstreferenz (Abschnitt 4.1.3.2.2), relative Autonomie (Abschnitt 4.1.3.2.3) und Redundanz (Abschnitt 4.1.3.2.4) untersucht. Da Probst und die an seinen Arbeiten orientierten Autoren aufgrund ihrer von der vorliegenden Arbeit abweichenden Abgrenzung des Selbstorganisationsbegriffes - wie oben dargelegt - die genannten Systemeigenschaften allein im Zusammenhang mit emergenten Selbstorganisationsprozessen diskutieren, liegt darauf auch der Schwerpunkt der folgenden Ausführungen. Über emergente Selbstorganisationsprozesse hinaus soll jedoch jeweils auch der Zusammenhang zwischen den einzelnen Systemeigenschaften und nicht-emergenten Selbstorganisationsprozessen untersucht werden. In Abschnitt 4.1.3.2.5 werden sodann die Ergebnisse dieser vier Abschnitte in ihrer Bedeutung für die weiteren Ausführungen der Arbeit zusammengefaßt.

diese Eigenschaften lediglich im Zusammenhang mit präsituativer Regelung untersucht werden, während der Fall der situativen Regelung hier nicht unter den Begriff der Selbstorganisation subsumiert und deshalb nicht weiter untersucht wird.

79 Probst (1987), S. 76; Probst (1992), Sp. 2259.

80 Chrobok (1997), S. 114.

81 Gomez/Zimmermann (1992), S. 130.

82 Probst (1987), S. 76.

83 Besonders deutlich wird dies z.B. bei Gerstner (1995), S. 134ff., insbesondere S. 178f. Dort stellt Gerstner die von ihm angefuhrten Charakterstika selbstorganisierender Systeme aufgehobener Determinismus, Selbstreferenz, operationelle Geschlossenheit und Redundanz denen von Probst gegenuber und stellt z.B. fest, daß sein Verständnis von aufgehobenem Determinismus dem von Probsts Komplexităt entspricht. Daruber hinaus arbeitet er den engen Zusammenhang zwischen Autonomie und operationeller Geschlossenheit heraus.

84 Wăhrend Probsts Formulierungen in Richtung 'notwendige Voraussetzungen' interpretiert werden konnen, bleibt z.B. bei Gerstner, der Bezeichnungen wie Eigenschaften und Merkmale verwendet, offen, ob es sich um Voraussetzungen für oder Folgen des Auftretens emergenter Selbstorganisationsprozesse in bestimmten (Sub-) Systemen handelt. Vgl Gerstner (1995), S. $134 f$. 


\subsection{Komplexität}

Gemäß den Ausführungen in Abschnitt 2.1.3 der vorliegenden Arbeit handelt es sich bei der Unternehmung als sozialem System und ihren sozialen Subsystemen erstens stets um komplexe Systeme. Zweitens ist das Auftreten spontaner Ordnungsbildung als Emergenzphänomen eine konstitutive Eigenschaft komplexer Systeme. Denn immer dann, wenn mindestens zwei interagierende Menschen Elemente eines (Sub-) Systems sind, treten Emergenzphänomene auf, die im Rahmen der Interaktion von Menschen entstehen und nicht aus den Eigenschaften der Einzelnen abgeleitet werden können. Damit ist das Auftreten emergenter Selbstorganisationsprozesse konstituierendes Charakteristikum komplexer Systeme, und Komplexität ist nicht notwendige Voraussetzung für das Auftreten emergenter Selbstorganisationsprozesse, sondern beide Phänomene sind definitorisch untrennbar miteinander verwoben. Denn Komplexität beschreibt - in statischer Sichtweise - das Erscheinungsbild von Systemen, in denen gemäß einer dynamischen Sichtweise - emergente Selbstorganisationsprozesse auftreten. Einerseits ist das Auftreten emergenter Selbstorganisationsprozesse damit konstitutiv für komplexe Systeme. Andererseits können sie nur in komplexen Systemen beobachtet werden.

GERSTNER, der sich in weiten Teilen eng an PROBST orientiert, stellt - bei ähnlicher inhaltlicher Ausgestaltung der Argumentation - anstelle der Eigenschaft der Komplexität auf die des aufgehobenen Determinismus ab. ${ }^{85}$ Aufgehobener Determinismus bedeutet, daß "selbstorganisatorische Systeme als nicht vorhersagbar, als nicht bestimmbar und als nicht beherrschbar" 86 charakterisiert werden. Legt man die Annahmen der vorliegenden Arbeit zugrunde, so handelt es sich bei dem Phänomen des aufgehobenen Determinismus um eine zentrale Eigenschaft komplexer Systeme, die aus dem Auftreten von Emergenzphänomenen resultiert. Denn immer dann, wenn Emergenzphänomene auftreten, existiert kein deterministischer Kausalzusammenhang zwischen Managementhandlung und Reaktion des Systems. Der aufgehobene Determinismus ist damit nicht Voraussetzung, sondern Folge emergenter selbstorganisatorischer Prozesse in komplexen Systemen.

Gemäß den Annahmen und der darauf aufsetzenden Argumentation der vorliegenden Arbeit gilt somit, daß weder Komplexität noch aufgehobener Determinismus Voraussetzungen für das Auftreten emergenter Selbstorganisationsprozesse sind. Vielmehr tritt Emergenz nur in komplexen Systemen auf und umgekehrt weisen komplexe Systeme stets Emergenzphänomene auf. Daraus resultiert wiederum, daß komplexe Systeme nicht deterministisch sind. Entsprechend stellen Emergenz, Komplexität und aufgehobener Determinismus zwar drei Begriffe innerhalb eines größeren Argumentationszusammenhangs dar, die unmittelbar miteinander verbunden sind. Allerdings können

Vgl. Gerstner (1995), S. 134ff., $178 f$.

86 Gerstner (1995), S. 136. 
durchaus eindeutige Beziehungen zwischen ihnen abgeleitet werden, die zumal anders als bei ProBsT und anderen Autoren formuliert sind: Der aufgehobene Determinismus des Systems ist Folge - und nicht etwa Voraussetzung - emergenter Selbstorganisationsprozesse.

Die Komplexität des Systems Unternehmung und seiner sozialen Subsysteme ist durch menschliche Aktivitäten veränderbar, d.h. Komplexität wird hier als ordinal skalierbare Systemeigenschaft bzw. als gradualistisches Phänomen in dem Sinne angenommen, daß ein System bzw. Subsystem mehr oder weniger komplex sein kann. ${ }^{87}$ Beispielsweise wird die Komplexität eines Subsystems durch aufbauorganisatorische Regelungen über die Kontrollbefugnisse bestimmter Stellen gegenüber anderen oder durch ablauforganisatorische Vorgaben bezüglich typischer Routinetätigkeiten verringert. Denn die organisatorischen Regeln beschränken die Menge der offiziell autorisierten Interaktionen zwischen Systemmitgliedern und reduzieren dadurch die Komplexität des Gesamtsystems. Vollständig beseitigen läßt sich die Komplexität von sozialen (Sub-) Systemen dadurch jedoch nicht, d.h. sie werden nicht in triviale Systeme (im Sinne von nicht-komplex) überführt, solange die oben genannte Mindestvoraussetzung für das Auftreten von Emergenzphänomenen erfüllt ist und zumindest zwei interagierende Menschen Elemente des Subsystems sind (es sich also um ein soziales System handelt). Sowohl die Unternehmung als Ganzes als auch ihre sozialen Subsysteme sind und bleiben somit stets komplexe Systeme, in denen per definitionem Emergenzphänomene, wie z.B emergente Selbstorganisationsprozesse, auftreten. Diese können jedoch mehr oder weniger stark ausgeprägt sein.

Aufgrund seiner begrenzten kognitiven Fähigkeiten, die es ihm nicht erlauben, die gesamte Unternehmung in ihrer ganzen Komplexität $\mathrm{zu}$ erfassen, ist der Mensch bestrebt, die Komplexität des Systems Unternehmung zu reduzieren. Dies kann beispielsweise - wie oben bereits erwähnt - durch das Formulieren organisatorischer Regeln erfolgen. Da die Unternehmung jedoch prinzipiell ein komplexes System ist und bleibt, deren Komplexität nur in begrenztem Umfang reduziert werden kann, besteht die Gefahr, daß der Mensch sich im Rahmen seiner kognitiven Prozesse ein zu stark vereinfachtes Bild der Unternehmung macht, d.h. bei seinem internen Modell der Unternehmung handelt es sich im Gegensatz zu der Unternehmung selbst um ein einfaches, nicht-komplexes System. Als Beispiel sei hier auf die Subsystembildung verwiesen, bei der - in Abhängigkeit vom jeweiligen Erkenntnis- und/oder Gestaltungsinteresse - bestimmte Aspekte fokussiert, andere vernachlässigt werden. Dabei ist jedoch zu beachten, daß bei den vorgenommenen 'Schnitten' durch das Gesamtsystem

87 Auch Hejl (1984), S. 65, geht - dort allerdings bezogen auf lebende Systeme - von unterschiedlichen Graden der Komplexität aus.

Im Gegensatz zu ordinaler Skalierbarkeit würde nominale Skalierbarkeit nur Aussagen darüber erlauben, ob ein System komplex ist oder nicht. Intervallskalierbarkeit dagegen würde die Existenz einer Maßeinheit voraussetzen, so daß Aussagen daruber möglich wăren, um wieviel ein System komplexer ist als ein anderes. 
nicht für das Funktionieren des betrachteten Subsystems wichtige Interdependenzen vernachlässigt werden. Somit ist stets zwischen der Komplexität des Systems Unternehmung auf der einen und der Komplexität des diese abbildenden Modells als Ergebnis kognitiver Prozesse des Menschen auf der anderen Seite zu unterscheiden. Für das Management gilt, daß es zwar in einem bestimmten Umfang auf die Komplexität des Systems Unternehmung und seiner sozialen Subsysteme einwirken kann, diese jedoch nicht vollständig beseitigen kann. Während traditionelle Managementansätze häufig vor allem die Notwendigkeit zur Komplexitätsreduktion betonen, gehen moderne Ansätze dazu über, diese Komplexität grundsätzlich zu akzeptieren ${ }^{88}$ und versuchen nicht länger, komplexe Systeme auf einfache Systeme zu reduzieren.

Im Anschluß an die obige Diskussion des Zusammenhangs zwischen der Systemkomplexität und dem Auftreten emergenter Selbstorganisationsprozesse gilt es nunmehr, den Zusammenhang zwischen der Komplexität des Systems Unternehmung bzw. eines seiner sozialen Subsysteme und dem Auftreten nicht-emergenter Selbstorganisationsprozesse zu untersuchen. Da das Auftreten nicht-emergenter Selbstorganisationsprozesse einerseits den entsprechenden Willen, andererseits Kommunikationsmöglichkeiten der Mitarbeiter voraussetzt, muß dafür der Zusammenhang zwischen dem Grad der (Sub-) Systemkomplexität auf der einen und dem Willen der Unternehmungsmitglieder zur Initiierung nicht-emergenter Selbstorganisationsprozesse sowie ihren Kommunikationsmöglichkeiten auf der anderen Seite berücksichtigt werden. Bezüglich des Willens zur Selbstorganisation sind keine eindeutigen Aussagen möglich. So ist z.B. einerseits vorstellbar, daß ein hoher Grad an tatsächlicher oder wahrgenommener Komplexität des (Sub-) Systems die Einsicht der Mitglieder des (Sub-) Systems fördert, daß es einer systeminternen Person tendenziell leichter fallen dürfte als einer systemexternen Person, adäquate organisatorische Regeln zu formulieren. Entsprechend würde ein hohes Maß an Komplexität dann ihre Bereitschaft erhöhen, selbstorganisierend tätig zu werden. Andererseits kann die hohe Komplexität aber auch dazu führen, daß die Mitarbeiter sich überfordert fühlen und deshalb nicht selbstorganisierend tätig werden. Bezüglich entsprechender Kommunikationsmöglichkeiten als Voraussetzung für das Auftreten nicht-emergenter Selbstorganisationsprozesse kann auf die Definition von Komplexität ${ }^{89}$ Bezug genommen werden: Je komplexer ein System ist, durch desto mehr und desto unterschiedlichere Elemente und Beziehungen ist es charakterisiert. Da Kommunikationsbeziehungen eine Teilausprägung der Gesamtheit der möglichen Beziehungen darstellen, kann angenommen werden, daß eine hohe Komplexität eines (Sub-) Systems mit ausgeprägten Kommunikationsmöglichkeiten einhergeht. Da ausgeprägte Kommunikationsmöglichkeiten jedoch nur die notwendige, nicht jedoch die hinreichende Bedingung für das Auftreten nicht-emergenter Selbstorganisationsprozesse sind und die Auswirkungen auf den Willen der Mitarbeiter, selbstorganisierend tätig zu

\footnotetext{
Vgl. z.B. Gomez/Zimmermann (1992), S. 130.

Siehe Abschnitt 2.1.3 der vorliegenden Arbeit.
} 
werden (als der hinreichenden Bedingung), offen bleiben, kann hier insgesamt keine eindeutige Aussage über die Konsequenzen eines hohen Komplexitätsgrades für die Wahrscheinlichkeit des Auftretens nicht-emergenter Selbstorganisationsprozesse getroffen werden.

\subsection{Selbstreferenz}

In unmittelbarem Zusammenhang mit dem Phänomen der Selbstreferenz stehen Autopoiese und operationelle Geschlossenheit ${ }^{90}$, die auch in die Argumentation bei PrOBST einfließen und deshalb im folgenden ebenfalls behandelt werden. Als äußerst problematisch für die Rezeption der Ausführungen von ProBst erweist sich jedoch, daß er die drei Begriffe nicht eindeutig voneinander abgrenzt. ${ }^{91}$ Im Gegensatz zu den Arbeiten von PROBST sollen im folgenden die Unterschiede zwischen den drei Phänomenen herausgearbeitet werden, da dies die Verständlichkeit der Argumentation deutlich verbessert. Während Selbstreferenz und Autopoiese Gegenstand dieses Abschnitts sind, wird das Phänomen der operationellen Geschlossenheit erst in Abschnitt 4.1.3.2.3 dargestellt, da - wie dort gezeigt werden wird - operationelle Geschlossenheit und relative Autonomie eng miteinander zusammenhängen.

In Abschnitt 2.1.2 wurden die neurophysiologischen Grundlagen zur Untermauerung einer radikal konstruktivistischen wissenschaftstheoretischen Position beschrieben. MATURANA/VARELA fassen diese und weitergehende neurophysiologische Forschungsergebnisse $\mathrm{zu}$ einer umfassenden Theorie menschlichen Lebens und Erkennens zusammen, die heute häufig als Theorie autopoietischer Systeme bezeichnet wird. ${ }^{92}$ Dabei handelt es sich jedoch um eine sprachliche Verkürzung, da das Phänomen der Autopoiese nur ein Punkt unter mehreren ist, die Maturana/VAREla zu einem umfassenderen Theoriegebäude zusammenführen. ${ }^{93}$ Entsprechend soll hier zwischen Autopoiese i.w.S. (als Bezeichnung für die umfassende Theorie) und Autopoiese i.e.S. (als bestimmtes Teilphänomen innerhalb der umfassenden Theorie) unterschieden werden, wobei die folgenden Ausführungen auf das letztgenannte Teilphänomen abstellen. ${ }^{94}$

90 Insbesondere in den Arbeiten von Maturana und Varela sowie generell in frühen Arbeiten zu dieser Thematik findet anstelle des Begriffes der 'operationellen Geschlossenheit' auch der der 'organisatorischen Geschlossenheit' Verwendung, der aufgrund der damit verbundenen Problematik des Organisationsbegriffes im Rahmen der vorliegenden Arbeit jedoch nicht verwendet wird.

$91 \mathrm{Vgl}$. insbesondere Probst (1987), S. 79.

92 Vgl. Maturana/Varela (1979), passim; Varela (1979), passim; Maturana (1982), passim, sowie insbesondere Maturana/Varela (1987), S. 47ff.

93 So werden in dem Grundlagenwerk von Maturana/Varela neben Autopoiese auch Phänomene wie 'Metazeller', 'natürliches Driften' und 'operationelle Geschlossenheit' behandelt. Vgl. Maturana/Varela (1987), S. 14, wo diese Phänomene nebeneinander genannt werden.

94 Ähnlich müssen insbesondere die Ausführungen von Luhmann zu Autopoiese und Selbstreferenz interpretiert werden. Luhmann verwendet den Autopoiese-Begriff einerseits in einer weiten Fassung, die auch das Phănomen der Selbstreferenz einschließt. Andererseits beschränkt er Autopoiese in einer engen Begriffsfassung auf den bloßen Prozeß des Sich-Selbst-Machens. Die Rezeption seiner Ausfuhrungen erschwert, daß diese unterschiedlichen Begriffsverwendungen nicht expliziert werden. Vgl. z.B. Luhmann (1991), passim. Kasper (1990), S. 167, zeigt die widersprüchliche Begriffsverwendung bei Luhmann anhand eines Beispiels auf. Auch Gerstner (1995), S. 139, und Teubner (1987a), S. 95, kritisieren die bezüglich Autopoiese (und Selbstreferenz) unscharfe Terminologie 
Mit Autopoiese (griechisch autos = selbst; poiein = machen) bezeichnen MATURANA/VARELA die Eigenschaft lebender Systeme, nicht von außen gemacht und in Gang gehalten $\mathrm{zu}$ sein, sondern sich selbst $\mathrm{zu}$ (re)produzieren. ${ }^{95}$ Entsprechend definiert MATURANA autopoietische Systeme wie folgt:

"[Autopoietic systems]... are defined as unities as networks of productions of components that (1) recursively, through their interactions, generate and realize the network that produces them; and (2) constitute, in the space in which they exist, the boundaries of this network as components that participate in the realization of the network." 96

Autopoietische Systeme sind somit dadurch charakterisiert, daß ihre einzelnen Elemente in zirkulärer Weise zur Generierung anderer Elemente und damit letztlich auch des Systems als Ganzem in konstitutiver Weise beitragen. Ein typisches Beispiel für ein autopoietisches System ist die Zelle: "Eine Zelle ist ein Netzwerk chemischer Reaktionen, die Moleküle derart erzeugen, daß sie 1. durch ihre Interaktionen genau das Netzwerk an Reaktionen erzeugen bzw. an ihm rekursiv mitwirken, welches sie selbst erzeugte, und die 2. die Zelle als eine materielle Einheit verwirklichen. Die Zelle bleibt daher als natürliche Einheit, die topographisch und operational von ihrer Umgebung abtrennbar ist, nur so lange erhalten, als diese ihre Organisation durch fortwährenden Umsatz von Materie beständig verwirklicht wird, unabhängig von den Veränderungen ihrer Form oder der Spezifität der sie konstitutierenden chemischen Reaktionen."97 Nicht nur die Zelle, sondern auch der Mensch als Organismus ist ein autopoietisches System.

Die Erhaltung ihrer Autopoiese ist konstitutiv für die Identität autopoietischer Systeme. ${ }^{98} \mathrm{Da}$ ihre Elemente sich einerseits selbst (re-)produzieren und eben nicht von außen gemacht werden, andererseits aber auch nur für einen begrenzten Zeitraum existieren und dann untergehen, kann das System nur solange fortbestehen, wie es seine Autopoiese aufrechterhält und damit neue Elemente produziert. Die Grundeigenschaft ${ }^{99}$ der Autopoiese kann somit nicht geändert werden, ohne daß dies zur Auflösung des

Luhmanns. Trotz dieser begrifflichen Ungenauigkeiten geht die Unterscheidung von Autopoiese und Selbstreferenz in der Literatur i.d.R. auf Luhmann zurück. Das gilt auch fur die Arbeiten von Probst, bei dem das Problem unklarer Begriffsverwendungen allerdings noch deutlich stärker auftritt.

95

96

97

98

99 In Anlehnung an die ursprüngliche Terminologie bei Maturana/Varela findet sich in der Literatur in diesem Zusammenhang regelmäßig der Begriff der autopoietischen 'Organisation' lebender Systeme. Vgl. z.B. Hejl (1982), S. 45; Maturana/Varela (1987), S. 50ff., insbesondere S. 54; Varela (1984), S. 25 . Da die eindeutige Abgrenzung des Organisationsbegriffes ein wichtige Voraussetzung für die Nachvollziehbarkeit einer Argumentation ist, die so unterschiedliche Phänomene wie Selbst- und Fremdorganisation, organisationales Lernen sowie die organisationale Wissensbasis vereint, und der Organisationsbegriff im Rahmen der vorliegenden Arbeit bereits in einer anderen inhaltlichen Ausgestaltung Anwendung findet, soll er an dieser Stelle bewußt vermieden werden und durch den neutralen Begriff der 'Grundeigenschaft' ersetzt werden. 
Systems und gegebenenfalls zur Bildung eines neuen Systems führt. ${ }^{100}$ Im Gegensatz dazu können sich die aktuellen Elemente und Relationen zwischen den Elementen des Systems ${ }^{101}$ laufend verändern.

Im Gegensatz zu Autopoiese, die auf die Produktion bzw. das Selbst-Machen von Elementen des Systems als materiellem Phänomen abstellt, bezieht sich Selbstreferenz auf die Zustände der Elemente. Selbstreferenz bedeutet, daß sich die Zustände der Elemente gegenseitig bedingen. Der Zustand eines Elements ist Resultat seiner Informationsverarbeitung als immateriellem Phänomen. Die Informationsverarbeitung selbstreferentieller Systeme wiederum ist selbstbezüglich. Dies sei hier anhand des Menschen als Beispiel eines selbstreferentiellen Systems verdeutlicht: Die Selbstbezüglichkeit seiner Informationsverarbeitung liegt in der Funktionsweise des menschlichen Gehirns begründet, ${ }^{102}$ das aufgrund unspezifischer, rein quantitativer neuronaler Impulse Erkenntnis über die Umwelt konstruiert. Die neuronalen Aktivitäten als Zustände der Synapsen, die die Elemente des Systems Gehirn darstellen, basieren dabei auf den neuronalen Aktivitäten der Vergangenheit. ${ }^{103}$

Die Informationsverarbeitung selbstreferentieller Systeme ist von Selbstbeobachtung und Selbstbeschreibung geprägt. Selbstbeobachtung als permanent mitlaufendes Phänomen bedeutet, daß sich das System bei seinen Handlungen, d.h. als Aktor, stets beobachtet. Das setzt voraus, daß zwischen Handeln und Beobachten unterschieden werden kann. Nur wenn eine solche Differenz feststellbar ist, ist Selbstbeobachtung möglich. Die Omnipräsenz von Selbstbeobachtung bedingt, daß selbstreferentielle Systeme nicht beobachten können, ohne daß sie selbst Teil der Beobachtung sind. Das bedeutet insbesondere, daß bei der (Fremd-) Beobachtung der Systemumwelt nur wahrgenommen werden kann, was in den im Rahmen von Selbstbeobachtungsprozessen gebildeten Bezugsrahmen des Systems paßt. Selbstbeschreibung setzt auf Selbstbeobachtung auf. Hier sind die Beobachtungen von Handlungen nicht nur unmittelbare Ausgangsbasis für darauffolgende Handlungen, sondern werden darüber hinaus mit Hilfe von Sprache als semantischem Artefakt beschrieben. Das ermöglicht Kommunikation und Konsensbildung über Beobachtungen sowie das Überdauern der Beobachtungen im Zeitablauf. 104

Selbstbeobachtung und Selbstbeschreibung bilden wichtige Voraussetzungen für die selbstreferentielle Informationsverarbeitung des Systems. Denn die als Ergebnisse von Selbstbeobachtung und Selbstbeschreibung entstehenden vereinfachten Bilder sei-

$100 \mathrm{Vgl}$. Gomez/Probst (1985), S. 23.

101 Maturana/Varela bezeichnen diese als die 'Struktur' eines Systems und stellen die oben genannte autopoietische 'Organisation' dieser 'Struktur' gegenuber. Aufgrund der von ihrem Begriffsverstăndnis abweichenden terminologischen Festlegungen der vorliegenden Arbeit wird hier nicht nur auf Verwendung des Begriffes der 'Organisation', sondern auch dessen der 'Struktur' verzichtet. Vgl. Maturana/Varela (1987), S. 54.

102 Siehe Abschnitt 2.1.2 der vorliegenden Arbeit.

103 Vgl. ăhnlich Hejl (1984), S. 63.

104 Vgl. Gerstner (1995), S. 139f.; Kasper (1995), S. 185; Kirsch/Knyphausen (1991), S. 89; Luhmann (1991), S. 618. 
ner selbst stellen eine Komplexitätsreduktion dar und ermöglichen dem System eine Abgrenzung gegenüber seiner Umwelt, da die Beobachtung und Beschreibung der Umwelt bzw. der Interaktionen zwischen System und Umwelt an ihnen anknüpft. Beobachtung der Umwelt wiederum bedeutet, daß das System bezüglich dieser Umwelt Unterscheidungen trifft, da nicht die Gesamtheit der Umwelt für die Interaktionen des Systems mit der Umwelt relevant sind. Beschreibungen der Umwelt definieren sodann den Interaktionsbereich des Systems mit der Umwelt. Deshalb kann man hier sagen, daß die Umwelt eines selbstreferentiellen Systems nicht a priori gegeben ist, sondern im Rahmen des selbstreferentiellen Prozesses der Informationsverarbeitung erst erfunden wird. ${ }^{105}$ Die im Rahmen dieser Prozesse vorgenommenen Reduktionen ermöglichen dem System den Umgang mit einer äußerst komplexen Umwelt. ${ }^{106}$ Die Selbst- und Umweltbeobachtungen sowie Selbst- und Umweltbeschreibungen stellen dann wiederum jeweils die Basis für weitere (Selbst- und Umwelt-) Beobachtungen und Beschreibungen dar.

Untersucht man den Zusammenhang zwischen Autopoiese (i.e.S.) und Selbstreferenz als Systemeigenschaften, so gelangt man zu folgendem Ergebnis: Immer dann, wenn die Elemente eines Systems weitere Elemente produzieren und sich somit selbst reproduzieren, bestimmen sie damit zugleich die Zustände der Elemente. Ein autopoietisches System ist somit notwendigerweise stets auch selbstreferentiell. Als Beispiel sei hier auf die oben genannten Zellen verwiesen: Sie (re-)produzieren sich gegenseitig und bestimmen dabei durch die in ihnen ablaufenden chemischen Reaktionen auch ihre jeweiligen Zustände. Jedoch ist nicht jedes selbstreferentielle System autopoietisch. So sind zwar im menschlichen Gehirn als einem selbstreferentiellen System neuronale Aktivitäten Ausgangspunkt weiterer neuronaler Aktivitäten. Zugleich ist das Gehirn jedoch nicht autopoietisch, da es für sein Fortbestehen von den Organen abhängt. Die Betrachtung der beiden Systeme Gehirn und Mensch macht damit zugleich deutlich, daß die Systemabgrenzung bzw. das jeweilige Aggregationsniveau der Betrachtung unmittelbaren Einfluß auf die Systemeigenschaften hat. Während das Gehirn als Subsystem des Gesamtsystems Mensch nämlich nicht autopoietisch ist, handelt es sich beim menschlichen Organismus als Ganzem um ein autopoietisches System. ${ }^{107}$

MATURANA versteht seine Theorie autopoietischer ${ }^{108}$ Systeme als Theorie lebender Systeme und insbesondere als Theorie menschlichen Lebens und Erkennens. ${ }^{109} \mathrm{Im}$ folgenden ist nun zu untersuchen, ob und auf welche Weise es sich bei Autopoiese und

105 Siehe in diesem Zusammenhang auch die Ausfuhrungen zu der Grundüberzeugung radikal konstruktivistischer Wissenschaftspositionen in Abschnitt 2.1.2 der vorliegenden Arbeit, daß Wirklichkeit vom Menschen konstruiert bzw. erfunden wird.

106 Vgl. Gerstner (1995), S. 140; Kasper (1990), S. 171 f.; Kirsch/Knyphausen (1991), S. 80f.

107 Vgl. Hejl (1984), S. 63, 73.

108 Autopoiese sei dabei als Autopoiese i.w.S. verstanden, die dann neben Autopoiese i.e.S. auch Selbstreferenz umfaßt.

109 Vgl. Kirsch (1992), S. 195, 200ff.; Maturana (1982), S. 34ff., insbesondere S. 39. 
Selbstreferenz als typischen Eigenschaften lebender Systeme auch um Eigenschaften der Unternehmung als sozialem System und ihrer sozialen Subsysteme handelt.

Geht man - wie im Rahmen der vorliegenden Arbeit - davon aus, daß die Menschen Elemente des Systems Unternehmung sind, so würde Autopoiese bedeuten, daß diese Elemente sich selbst reproduzieren, d.h. Mitarbeiter das Ergebnis der Produktionsprozesse anderer Mitarbeiter sind. Dies ist jedoch sicher nicht gegeben, so daß die Unternehmung hier nicht als autopoietisches System bezeichnet werden kann. Entsprechendes gilt für soziale Subsysteme der Unternehmung. Betrachtet man dagegen wie LUHMANN nicht Individuen, sondern allgemein Kommunikationen und speziell Entscheidungen als Elemente des Systems Unternehmung (und seiner sozialen Subsysteme), so handelt es sich bei diesen durchaus um autopoietische Systeme. Denn Entscheidungen als zeitpunktgebundene Systemelemente sind im Moment ihres Entstehens auch schon wieder verschwunden, und es besteht ein wechselseitiger Verweisungszusammenhang zwischen den verschiedenen Entscheidungen, d.h. Entscheidungen resultieren aus anderen Entscheidungen. Der Biologismus-Vorwurf, der Vertretern einer autopoietischen Konzeption der Unternehmung als sozialem System verschiedentlich gemacht wird, ist somit immer dann unangemessen, wenn diese sich auf den von LUHMANN begründeten theoretischen Ansatz beziehen. 110

Da diese Argumentation LummanNs jedoch nicht Basis des Verständnisses der Unternehmung im Rahmen der vorliegenden Arbeit ist, können hier weder die Unternehmung noch ihre sozialen Subsysteme als autopoietische Systeme konzipiert werden. Statt autopoietisch bzw. sich selbst machend zu sein, wird die Unternehmung als Ganzes von den Eigentümern als außerhalb des Systems Stehenden gegründet. Ihre sozialen Subsysteme (wie z.B. Abteilungen) unterliegen dem Einfluß von Führungskräften, die selbst nicht Teil dieser Subsysteme sind. Die Unternehmung und ihre sozialen Subsysteme sind somit allopoietisch, d.h. fremdgemacht. Anstelle der Selbsterhaltung als oberstem Ziel ist ihnen die Produktion von Gütern und/oder Dienstleistungen als außerhalb ihrer selbst ${ }^{\prime \prime \prime}$ liegender Zweck vorgegeben.

Versucht man, das Phänomen der Selbstreferenz auf die Unternehmung und ihre sozialen Subsysteme zu übertragen, so erweist sich auch dies als problematisch. Sehr deutlich werden die Probleme, wenn man von der selbstreferentiellen Funktionsweise des menschlichen Gehirns ausgeht und versucht, ein entsprechendes Analogon für die Unternehmung als Ganzes bzw. ihre sozialen Subsysteme zu konzipieren. Die auf Selbstbeobachtung und Selbstbeschreibung basierende Selbstbezüglichkeit der Informationsverarbeitung setzt die Existenz eines Selbsts im Sinne eines 'überindividuellen

110 Für eine ausfuhrlichere Darstellung der diesbezüglichen Argumentation bei Luhmann vgl. z.B. Luhmann (1981), S. 339; Luhmann (1986), S. 166 sowie Luhmann (1991), S. 593. Vgl. ferner Kirsch (1992), S. 231 f.; Kirsch/Knyphausen (1991), S. 83f.

111 Die am Markt abzusetzenden Produkte werden hier nicht als Teil des Systems Unternehmung, sondern als diese durchlaufende Größen verstanden. 
Supergehirns' ${ }^{\prime 12}$ der Unternehmung bzw. ihrer sozialen Subsysteme voraus. Ein solches Phänomen existiert jedoch nicht. Somit existieren Selbstbeobachtungen und Selbstbeschreibungen nur auf der individuellen, nicht jedoch auf der überindividuellen Ebene. ${ }^{113}$ Auch der Versuch der Übertragung des Phänomens der Selbstreferenz auf die Unternehmung als soziales Subsystem unter Zuhilfenahme des Phänomens der Unternehmungskultur scheitert: Zwar entsteht Unternehmungskultur im Rahmen der Interaktionen der Unternehmungsmitglieder, wobei die Zustände ihrer Gehirne bzw. ihr Bewußtsein einander beeinflussen. Jedoch ist dies nicht die einzige Prägung, die diese erfahren. Denn der einzelne Mensch ist regelmäßig nicht nur Mitglied der Unternehmung, sondern einer Vielzahl unterschiedlicher sozialer Systeme, wie z.B. Familie, Freundeskreis und Vereine, die jeweils die Zustände seines Gehirns prägen. ${ }^{114}$ Die Annahme, Unternehmungen seien selbstreferentielle Systeme, stellt somit eine für Erklärungszwecke unangebrachte Übertragung neurophysiologischer Forschungsergebnisse bezüglich menschlichen Erkennens auf den Bereich sozialer Systeme dar, ${ }^{115}$ die im Rahmen der vorliegenden Arbeit nicht weiter verfolgt wird.

Stattdessen können sowohl die Unternehmung als Ganzes als auch ihre sozialen Subsysteme als synreferentielle Systeme (griechisch syn = gleichzeitig, gleichartig) verstanden werden. Synreferenz bedeutet, daß die Mitglieder eines sozialen Systems bestimmte parallelisierte Zustände ihrer Gehirne - im Sinne ähnlicher Selbst- und Fremdbeobachtungen und -beschreibungen - aufweisen, auf die sie bei ihren Interaktionen Bezug nehmen. Dies resultiert daraus, daß jedes Mitglied des Systems aus der Gesamtmenge seiner Beobachtungen diejenigen besonders betont, die es mit anderen Systemmitgliedern teilt. Denn dadurch definieren die Mitglieder miteinander vergleichbare Umwelten, in denen sie aufeinander abgestimmt und damit aus der Sicht des Systems erfolgreich handeln können. Es werden 'konsensuelle Bereiche'116 erzeugt. Die Ausbildung konsensueller Bereiche setzt voraus, daß das einzelne Systemmitglied seine eigenen Beobachtungen beobachtet ('mitlaufende Selbstbeobachtung'), um festzustellen, welche denen der anderen Systemmitglieder besonders ähneln. Die parallelisierten Zustände der Gehirne der Unternehmungsmitglieder sind dann Ergebnis ihrer Sozialisation in dem System Unternehmung bzw. in einem seiner Subsysteme. Damit können die

112 Vgl. Kirsch/Knyphausen (1991), S. 84.

113 Vgl. Kirsch (1992), S. 249.

114 Einen Extremfall, der dem theoretischen Konstrukt eines selbreferentiellen sozialen Systems recht nahe kommt, stellen Sekten und ähnliche totalitäre Lebensformen dar, die ihre Mitglieder vollständig kasernieren und von jeglicher Interaktion mit der restlichen Welt abschneiden. Die Informationsverarbeitung bzw. das Bewußtsein ihrer Mitglieder ist dann allein durch die Regeln der Sekte bestimmt. U.U. sind sich die Sektenmitglieder der Existenz alternativer Lebensformen bzw. ihrer originären Lebenswelt nicht mehr bewußt. Vgl. Kirsch/Knyphausen (1991), S. 94.

115 Vgl. Kirsch/Knyphausen (1991), S. 84.

116 Der Konsens-Begriff stellt in diesem Zusammenhang nicht etwa auf Zustimmung im Sinne einer Wertung ab. Vielmehr verweist er allein auf die Vergleichbarkeit der Wahrnehmungen bzw. Umweltdefinitionen. Denn mehrere Personen können eine Situation durchaus gleich wahrnehmen, jedoch unterschiedlich bewerten. Vgl. Hejl (1982), S. 61. 
oben genannte Unternehmungskultur sowie diverse -subkulturen zwar nicht als selbstreferentielles, aber doch zumindest als synreferentielles Phänomen interpretiert werden. 117

Abschließend ist festzuhalten, daß sowohl die Unternehmung als Ganzes als auch ihre sozialen Subsysteme im Rahmen der vorliegenden Arbeit als allopoietische und nicht als autopoietische, als synreferentielle und nicht als selbstreferentielle Systeme verstanden werden. Wenn sie aber nicht selbstreferentiell sind, kann auch kein Zusammenhang zwischen der (nicht existenten) Systemeigenschaft Selbstreferenz und dem Auftreten emergenter Selbstorganisationsprozesse untersucht werden, wie ihn PROBST ${ }^{118}$ postuliert.

Schließlich ist es aufgrund der mangelnden Selbstreferenz des Systems Unternehmung sowie seiner sozialen Subsysteme auch nicht möglich, einen entsprechenden Bezug zu nicht-emergenten Selbstorganisationsprozessen zu untersuchen.

Der Zusammenhang zwischen Synreferenz und dem Auftreten emergenter und nichtemergenter Selbstorganisationsprozesse wird im folgenden Abschnitt 4.1.3.2.3 im Rahmen der Diskussion des Phänomens der operationellen Geschlossenheit diskutiert werden.

\subsection{Relative Autonomie aufgrund operationeller Geschlossenheit}

Nicht die Erkenntnis, daß lebende Systeme autopoietisch bzw. selbstreferentiell sind, ist das eigentlich Neue an der Theorie von Maturana/Varela sowie der Arbeiten der Autoren, die versuchen, sie auf soziale Systeme zu übertragen, sondern die Schlußfolgerung, daß diese Systeme damit zugleich operationell geschlossen und partiell bzw. relativ ${ }^{119}$ autonom sind. ${ }^{120}$

Operationelle Geschlossenheit bedeutet, daß ein System in seinem Verhalten nicht von der Umwelt abhängt, d.h. nicht von dieser determiniert wird.121 Umweltreize 'perturbieren' vielmehr lediglich das System. Der im Original von Maturana/Varela verwendete Begriff der 'Perturbación' stellt darauf ab, daß Zustandsveränderungen des Systems durch Zustände in seiner Umwelt ausgelöst, nicht jedoch verursacht werden. Welcher Art die Veränderung des Systems ist, ist nicht abhängig vom perturbierenden Umweltreiz, sondern von dem System selbst. ${ }^{122}$ Damit bildet die Vorstellung von der operationellen Geschlossenheit von Systemen den Gegensatz zu traditionellen InputOutput-Modellen mit ihren Annahmen bezüglich eindeutiger Ursache-WirkungsZusammenhänge zwischen Umweltreiz und Reaktion des Systems. ${ }^{123}$ Die mit

117 Vgl. Hejl (1982), S. 52; Hejl (1984), S. 70; Kirsch/Knyphausen (1991), S. 89.

118 Vgl. Probst (1987), S. 79f.

119 Die Adjektive 'relativ' und 'partiell' werden in diesem Zusammenhang synonym verwendet.

120 Vgl. Kasper (1990), S. 167f.; Willke (1987), S. 51, 64f.

121 Vgl. Hejl (1984), S. 64.

122 Vgl. Maturana/Varela (1987), S. 27.

123 Vgl. Hejl (1984), S. 64; Varela (1984), S. $25 \mathrm{ff}$. 
operationeller Geschlossenheit als Systemeigenschaft einhergehende Beziehung zwischen Umwelt und System bezeichnen Maturana/VARELA als strukturelle Koppelung. ${ }^{124}$ Operationelle Geschlossenheit bei gleichzeitiger struktureller Koppelung bedeutet nicht etwa das völlige Herauslösen des Systems aus dem Umweltzusammenhang. Vielmehr führen Umweltveränderungen zu Veränderungen der Passung zwischen Umwelt und System. Das System hat weniger häufig - bezogen auf die Systemerhaltung - erfolgreiche Interaktionen mit der Umwelt. ${ }^{125}$ Daraus erwachsen interne Probleme. Diese internen Probleme sind es, die Handlungen der Mitarbeiter (als der Elemente des Systems) hervorrufen. ${ }^{126}$

Operationelle Geschlossenheit eines (Sub-) Systems bedeutet, daß es zugleich relativ autonom ist. ${ }^{127}$ Während absolute oder totale Autonomie eine vollständige Unabhängigkeit des Systems von seiner Umwelt bedeutet, damit aber eher ein theoretischer Grenzfall als ein in der Realität beobachtbares Phänomen ist, ${ }^{128}$ stellt relative Autonomie auf bestimmte Kriterien ab. Das (Sub-) System ist bezüglich bestimmter Aspekte unabhängig, bezüglich anderer abhängig von seiner Umwelt. ${ }^{129} \mathrm{Im}$ Rahmen der hier verfolgten Argumentationslinie stellt der Begriff der relativen Autonomie auf die Unabhängigkeit des Verhaltens des (Sub-) Systems gegenüber Umwelteinflüssen ab. Kriterium der relativen Autonomie ist an dieser Stelle somit das Verhalten des Systems: Immer dann, wenn ein (Sub-) System operationell geschlossen ist, also kein deterministischer Ursache-Wirkungs-Zusammenhang zwischen Umweltveränderungen und Zustandsveränderungen des (Sub-) Systems besteht, ist es bezüglich seines Verhaltens (und damit relativ) autonom. Der Umstand, daß operationelle Geschlossenheit zu relativer Autonomie führt, steht somit nicht im Widerspruch dazu, daß das operationell geschlossene und damit relativ autonome (Sub-) System zugleich materiell, energetisch und informationell offen gegenüber der Umwelt ist. Entsprechend ist eine Argumentation bezüglich der operationellen Geschlossenheit bzw. relativen Autonomie des Systems Unternehmung und seiner Subsysteme durchaus vereinbar mit den Erkenntnissen des (älteren) Forschungsansatzes zu einer 'Theorie offener Systeme', die davon ausgeht, daß diese Systeme Materie, Energie und Informationen aus der Umwelt aufnehmen und wieder an sie abgeben. Operationelle Geschlossenheit und materielle, energetische und informationelle Offenheit stehen nicht im Widerspruch zueinander. Vielmehr ist das System bezüglich bestimmter Aspekte geschlossen, bezüglich anderer offen gegenüber seiner Umwelt.

124 Vgl. Maturana/Varela (1987), S. 85ff.

125 Vgl. Hejl (1982), S. 47.

126 Vgl. ăhnlich Kieser (1994), S. 223.

127 Vgl. Gomez/Probst (1985), S. 22; Probst (1987), S. 82.

128 So stellt von Hayek fest: "Genau gesagt gibt es keine geschlossenen Systeme innerhalb des Universums. Wir können lediglich die Frage stellen, ob in dem betreffenden Fall die Anzahl der Kontaktstellen, durch die das übrige Universum auf das von uns zur Isolierung vorgenommene System einwirkt ..., groß oder klein ist.“ Hayek (1972), S. 14.

129 Vgl. Hejl (1982), S. 44; Probst/Scheuss (1984), S. 487; Willke (1987), S. 65 f. 
Ursprünglich bezieht sich das Phänomen der operationellen Geschlossenheit auf lebende Systeme. Lebende Systeme werden als operationell geschlossen bezeichnet, da sie autopoietisch und selbstreferentiell sind. ${ }^{130}$ Denn erstens reproduzieren sich lebende Systeme im Rahmen ihrer Autopoiese selbst und sind damit eben nicht von außen gemacht und in Gang gehalten. Zweitens bedingen sich die Zustände der Elemente lebender Systeme gegenseitig. Diese Selbstbezüglichkeit der Informationsverarbeitung bewirkt wiederum, daß das Verhalten selbstreferentieller Systeme nicht von außen determiniert werden kann. Für die Übertragung des Phänomens der operationellen Geschlossenheit auf die Unternehmung und ihre sozialen Subsysteme erweist sich als problematisch, daß soziale Systeme - wie oben erläutert - weder autopoietisch noch selbstreferentiell sind. Als allopoietischen Systemen werden ihnen ihre Zwecke von außen vorgegeben. Auch die Definition der Systemgrenzen ist keine reine systeminterne Leistung, und Teile des Systemverhaltens werden durch Vorgaben außerhalb des Systems Stehender unmittelbar beeinflußt (so z.B. im Rahmen von Aktivitäten der Mitarbeiterführung durch den Vorgesetzten). Entsprechend können hier erstens Autopoiese und Selbstreferenz nicht als Begründungen für operationelle Geschlossenheit herangezogen werden. Zweitens können die Unternehmung und ihre sozialen Subsysteme nicht als vollständig operationell geschlossen - im Sinne eines Ganz-oder-Garnicht-Phänomens bzw. nominaler Skalierbarkeit (d.h. ein System ist entweder operationell geschlossen oder nicht) - konzipiert werden. ${ }^{131}$

Berücksichtigt man jedoch die obigen Ausführungen zum Phänomen der Synreferenz der Selbstbeobachtungen und -beschreibungen der Mitarbeiter der Unternehmung und verbindet diese mit dem ursprünglich von TEUBNER vorgeschlagenen und sodann von KIRSCH/KNYPHAUSEN weiterentwickelten gradualistischen Verständnis von Autopoiese bzw. Autonomie, so gelangt man zu der Vorstellung eines Kontinuums unterschiedlicher Grade der operationellen Schließung des Systems Unternehmung und seiner sozialen Subsysteme. Operationelle Schließung ${ }^{132}$ ist dann nicht länger ein Ganz-oderGarnicht-Phänomen, sondern eine ordinal skalierbare Systemeigenschaft. TEUBNER schlägt vor, drei Stufen der Autonomie zu unterscheiden, die er 'Selbstbeobachtung', 'Selbstkonstitution' und 'Autopoiese' nennt. Da TEUBNER dabei jedoch von einem anderen als dem in der vorliegenden Arbeit verwendeten Autopoiesebegriff ausgeht, soll seine dritte Stufe der Autonomie hier als 'autonome Selbstkonstitution' bezeichnet werden. Ausgangspunkt sind 'normale' Kommunikationsprozesse zwischen mehreren Personen. Erste Tendenzen Richtung Autonomie entstehen, wenn in diesen Kommunikationsprozessen Selbstbeobachtungen auftauchen (erste Stufe), d.h. man bezieht sich im Rahmen der Kommunikation zum Beispiel auf frühere Redebeiträge in demselben

I30 Vgl. Hejl (1984), S. 63.

131 Vgl. Kirsch/Knyphausen (1991), S. 93.

132 Die beiden Begriffe 'operationelle Geschlossenheit' und 'operationelle Schließung' werden in der vorliegenden Arbeit synonym verwendet. Allerdings bringt der Begriff der Schließung den gradualistischen Aspekt besser zum Ausdruck und wird deshalb im folgenden dem der Geschlossenheit vorgezogen. 
Kreis. Auf der zweiten Stufe treten Selbstbeschreibungen zu den Selbstbeobachtungen hinzu. Diese können insbesondere dazu verwendet werden festzulegen, wer zu dem jeweiligen System gehört. Das System konstituiert damit seine Grenzen selbst. Es entsteht ein spezifisches 'Wir-Gefühl' der Mitglieder des Systems. Auf der dritten Stufe werden darüber hinaus die Bedingungen der Mitgliedschaft in dem System durch systemspezifische Normen geregelt, die nur durch Mitglieder des Systems verändert werden können. Erst wenn Systemkonstitution und -veränderung einzig durch das System selbst bzw. seine Mitglieder vollzogen werden und damit keinerlei Interventionen mehr von außen auf das System einwirken können, ist vollständige operationelle Geschlossenheit bzw. relative Autonomie realisiert. Da sowohl für die Unternehmung als auch für ihre sozialen Subsysteme als allopoietische Systeme ${ }^{133}$ gilt, daß ihre Ziele und Aufgaben ihnen von außen (von den Eigentümern der Unternehmung bzw. den Führungskräften) vorgegeben werden und Systemkonstitution und -veränderung damit eben nicht reine Leistungen der Systeme selbst sind, stellt vollständige operationelle Geschlossenheit in der betrieblichen Praxis einen unrealistischen Grenzfall von rein theoretischem Interesse dar. Partielle operationelle Schließung ist dagegen bereits auf den vorgelagerten Stufen möglich, wobei unterschiedliche Grade operationeller Schließung unterschieden werden können. Der jeweilige Grad der operationellen Schließung hängt dabei unmittelbar vom Grad der Synreferenz der Informationsverarbeitung der Mitglieder des (Sub-) Systems ab, d.h. er bestimmt sich danach, wie stark ausgeprägt die konsensuellen Bereiche der (Sub-) Systemmitglieder sind bzw. wie stark diese gegenüber ihrer originären Lebenswelt abgeschlossen sind. Entsprechend gilt, daß der Grad der operationellen Schließung sowie der Grad der relativen Autonomie eines (Sub-) Systems mit dem Maß an Synreferenz in diesem (Sub-) System steigen. ${ }^{134}$ Diesen Zusammenhang zwischen den drei graduellen Phänomenen Synreferenz, operationelle Schließung und relative Autonomie visualisiert Abbildung 4/7.



Abb. 4/7: Synreferenz, operationelle Schließung und relative Autonomie

In der Literatur wird regelmäßig ein positiver Zusammenhang zwischen den Systemeigenschaften Autopoiese, Selbstreferenz und operationeller Geschlossenheit bzw. partieller Autonomie als Ganz-oder-Garnicht-Phänomenen auf der einen und Selbstorga-

133 Siehe Abschnitt 4.1.3.2.2 der vorliegenden Arbeit.

134 Vgl. Kirsch (1992), S. 241 ff., 253ff.; Kirsch/Knyphausen (1991), S. 88ff.; Teubner (1987a), passim; Teubner (1987b), passim. 
nisationsprozessen auf der anderen Seite impliziert. ${ }^{135}$ Erzeugen die Elemente eines Systems sich nämlich gegenseitig und damit das System (Autopoiese) und bedingen gegenseitig ihre jeweiligen Zustände (Selbstreferenz), so ist die Systemkonstitution und -erhaltung eine originăre Leistung des Systems. Das System ist notwendigerweise operationell geschlossen und partiell autonom, und es finden keine direkten Aktivitäten der Systemgestaltung von außerhalb des Systems - und somit auch keinerlei Fremdorganisationsprozesse - statt. Das Aufstellen organisatorischer Regeln als Aktivität der Systemkonstitution und -erhaltung ist hier dann stets Selbstorganisation.

Geht man dagegen davon aus, daß die Unternehmung und ihre sozialen Subsysteme als soziale Systeme weder autopoietisch noch selbstreferentiell und damit auch nicht operationell geschlossen im Sinne eines Ganz-oder-Garnicht-Phänomens sind und versteht stattdessen Synreferenz und die daraus resultierende operationelle Schließung bzw. relative Autonomie als gradualistische Phănomene, so ist zu untersuchen, welcher Zusammenhang zwischen Synreferenz, operationeller Schließung und relativer Autonomie auf der einen und dem Auftreten von emergenten und nicht-emergenten Selbstorganisationsprozessen auf der anderen Seite besteht. Hierfür kann auf Aspekte der Diskussion um das Phănomen Unternehmungskultur bzw. -subkulturen sowie um Gruppenverhalten Bezug genommen werden.

Betrachtet man zunächst Synreferenz und emergente Selbstorganisationsprozesse, so kann folgender Zusammenhang konzipiert werden: Die intersubjektiv geteilten Normen und Wertvorstellungen der Unternehmungskultur bzw. einzelner Subkulturen stellen eine mögliche Ausprägung von Synreferenz als dem Auftreten von parallelisierten Zuständen der Gehirne von Subsystemmitgliedern dar. Eine ausgeprägte Subkultur wiederum fördert erstens die Interaktionen und insbesondere die Kommunikation zwischen den Mitgliedern des Subsystems. ${ }^{136}$ Die Gruppenforschung hat ergeben, daß mit der Häufigkeit der Interaktionen in der Gruppe die Gruppenkohäsion im Sinne des Zusammenhalts der Gruppe steigt. ${ }^{137}$ Zweitens bedeutet eine hohe Synreferenz in einer Gruppe in Form einer ausgeprägten Gruppenkultur, daß die Wahrscheinlichkeit für das Auftreten von Konflikten zwischen den einzelnen Gruppenmitgliedern sinkt. Mit sinkendem Konfliktpotential steigt die Gruppenkohäsion. Je höher schließlich die Gruppenkohäsion, desto wahrscheinlicher ist das Auftreten emergenter Selbstorganisationsprozesse als typischer Gruppenphänomene. Überträgt man diese gruppenspezifische Argumentation auf die Gesamtheit der potentiellen sozialen Subsysteme der Unternehmung, so gilt, daß die Wahrscheinlichkeit für das Auftreten emergenter Selbstorganisa-

135 Vgl. z.B. Probst (1987), S. 76ff.

136 Diese Annahme gilt nicht fur den Spezialfall einer Kultur des 'Nicht-Kommunizierens', der hier jedoch nicht weiter berucksichtigt werden soll.

137 Vgl. Staehle (1994), S. 264. 
tionsprozesse mit dem Grad der Synreferenz in einem Subsystem bzw. dessen operationeller Schließung und der daraus resultierenden relativen Autonomie steigt. ${ }^{138}$

Betrachtet man in einem nächsten Schritt Synreferenz und nicht-emergente Selbstorganisationsprozesse, so kann folgender Zusammenhang entwickelt werden: Erstens bedingen die positiven Effekte einer ausgeprägten Subkultur (als einer Form von Synreferenz) auf die Kommunikation und das Konfliktpotential innerhalb einer Gruppe eine Stärkung der Gruppenkohäsion. Eine hohe Gruppenkohäsion hat wiederum einen positiven Einfluß auf den Willen der Gruppenmitglieder zu präsituativer und situativer Selbstregelung und geht deshalb ceteris paribus mit dem verstärkten Auftreten von nichtemergenten Selbstorganisationsprozessen einher. Auch hier soll diese gruppenspezifische Argumentation auf die Gesamtheit der potentiellen Subsysteme in der Unternehmung übertragen werden. Zweitens geht eine Erhöhung der Synreferenz in einem Subsystem mit dessen zunehmender operationeller Schließung einher, die wiederum eine Stärkung der relativen Autonomie des Subsystems bedingt. Geht man davon aus, daß ein Mehr an Autonomie den Willen der Mitarbeiter fördert, selbst (präsituativ und situativ) regelnd tätig zu werden, so kommt es ceteris paribus zu einem verstärkten Auftreten nicht-emergenter Selbstorganisationsprozesse. Faßt man beide Argumentationslinien zusammen, so gilt, daß die Wahrscheinlichkeit für das Auftreten nicht-emergenter Selbstorganisationsprozesse mit dem Grad der Synreferenz in einem (Sub-) System steigt.

Zusammenfassend ist hier festzuhalten, daß der Grad an Synreferenz eines (Sub-) Systems positiv mit dessen operationeller Schließung korreliert, die wiederum den Grad der relativen Autonomie des (Sub-) Systems bedingt. Je ausgeprägter schließlich die relative Autonomie eines (Sub-) Systems ist, desto höher ist die Wahrscheinlichkeit für das Auftreten emergenter und nicht-emergenter Selbstorganisationsprozesse. Diesen Zusammenhang visualisiert Abbildung 4/8.

Der Umstand, daß der Grad der relativen Autonomie eines (Sub-) Systems im Rahmen der systemtheoretisch geprägten obigen Argumentation in Abhängigkeit von dessen Grad der operationellen Schließung definiert wird, steht nicht im Widerspruch zum üblichen Sprachgebrauch in der Managementlehre. Dort wird der Begriff der Autonomie in Anlehnung an seine umgangssprachliche Bedeutung allgemein als Ausdruck für die Intensität und Zahl der Beziehungen bzw. Interdependenzen zwischen einem System und seiner Umwelt verwendet. ${ }^{139}$ Autonomie ist demnach die Unabhängigkeit des Systems von systemexternen Einflüssen. Die Einflüsse auf das System bzw. die

138 Diese Argumentation widerspricht nicht der Erkenntnis der Gruppenforschung, daß ein Großteil des Vorteils von Gruppen darin begrundet liegt, daß in der Gruppe eine Verknupfung der heterogenen Wissensbestănde ihrer einzelnen Mitglieder erfolgt. Denn eine starke Subkultur als Ausprägung von Synreferenz in einem Teilsystem bezieht sich vor allem auf die Tiefenstruktur der individuellen Wissensbasen. Wahrend eine gewisse Ähnlichkeit der Tiefenstrukturen der individuellen Wissensbasen die oben genannten positiven Effekte auf die Gruppenkohäsion hat, kann das Oberflächenwissen der einzelnen Individuen durchaus variieren und dadurch innovative Problemlð̋sungen begunstigen.

139

Vgl. z.B. Hill/Fehlbaum/Ulrich (1994), S. 339. 
Interdependenzen des Systems mit seiner Umwelt können sehr unterschiedlicher Art sein. Da absolute Autonomie im Sinne einer vollständigen Unabhängigkeit der Unternehmung als System und einzelner ihrer Subsysteme in der betrieblichen Praxis nicht möglich ist, ist jede Autonomie eine relative. Anhand der Art der jeweils fokussierten Interdepenzen kann dabei zwischen verschiedenen Autonomiearten unterschieden werden.

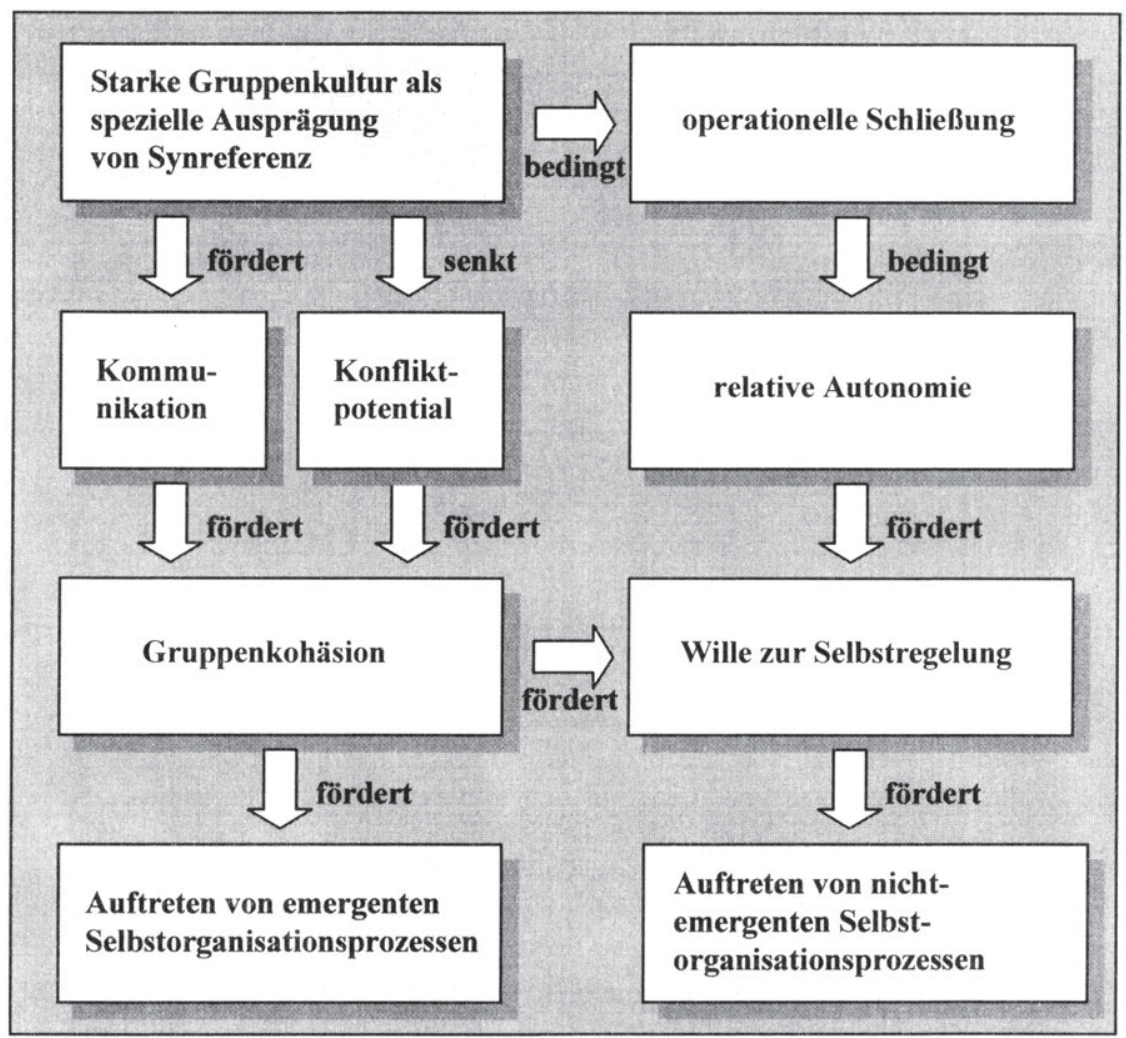

Abb. 4/8: Synreferenz und Selbstorganisationsprozesse

Im Mittelpunkt der organisationstheoretischen Untersuchungen des vorliegenden Kapitels, das Anforderungen an die organisatorische Gestaltung in der lernenden Unternehmung thematisiert, stehen Entscheidungs- und Handlungsautonomie. Die Entscheidungsautonomie stellt auf Möglichkeiten einer Betrachtungseinheit ab, Entscheidungen unabhängig von äußeren Einflüssen zu fällen. Im Gegensatz zu dieser kognitiven und damit abstrakten Aktivität des Entscheidens stellt die Handlungsautonomie auf die Möglichkeiten einer Betrachtungseinheit zu von äußeren Einflüssen unabhängigen beobachtbaren, konkreten Handlungen ab. Beide Autonomiearten sind untrennbar miteinander verbunden. Denn es kommt nicht nur darauf an, daß die 
Betrachtungseinheit die kognitiven Möglichkeiten zu freien Entscheidungen - im Sinne von Entscheidungsautonomie - hat, sondern daß sie diese Entscheidungen - im Sinne von Handlungsautonomie - auch realisieren kann. Umgekehrt ist eine hohe Handlungsautonomie wertlos, wenn sie nicht mit der entsprechenden Entscheidungsautonomie einhergeht. Deshalb werden Entscheidungs- und Handlungsautonomie im folgenden als Einheit behandelt. Die oben beschriebene, auf der partiellen operationellen Schließung des (Sub-) Systems begründete, relative Autonomie bedeutet, daß das (Sub-) System in seinem Verhalten nicht von seiner Umwelt determiniert ist. Dies entspricht dem Begriff der Handlungsautonomie, setzt jedoch zugleich Entscheidungsautonomie voraus. Somit entspricht die im Rahmen der vorliegenden Arbeit thematisierte relative Autonomie der Entscheidungs- und Handlungsautonomie.

Die Entscheidungs- und Handlungsautonomie weist wiederum unterschiedliche Dimensionen auf und wird von verschiedenen Faktoren beeinflußt. So unterscheiden HILl/Fehlbaum/UlRiCH zwischen horizontaler und vertikaler Autonomie. Die horizontale Autonomie bezieht sich auf Art und Intensität der Beziehungen eines Subsystems zu ihm hierarchisch nebengeordneten Einheiten, während die vertikale Autonomie auf das Verhältnis zwischen einander hierarchisch über- bzw. untergeordneten Einheiten abstellt. ${ }^{140}$ FRESE unterscheidet die Einflüsse auf die horizontale Entscheidungs- und Handlungsautonomie in die drei Interdependenzarten: ${ }^{141}$

- Ressourceninterdependenzen,

- Leistungsinterdependenzen und

- Marktinterdependenzen.

Ressourceninterdependenzen bedeuten, daß mehrere Einheiten um die Nutzung knapper Ressourcen konkurrieren. Verbraucht eine Einheit Ressourcen, stehen diese für andere Einheiten nicht mehr zur Verfügung. Zwischen allen Teileinheiten einer Unternehmung bestehen zumindest stets Interdependenzen bezüglich der Nutzung der knappen finanziellen Ressourcen. Leistungsinterdependenzen treten auf, sofern die Entscheidungen und Handlungen einer Einheit die Angebots- oder Nachfragesituation anderer Einheiten beeinflussen, d.h. wenn der Output der Leistungserstellungsprozesse einer Einheit Input derer einer anderen Einheit ist. Marktinterdependenzen liegen z.B. bei Absatzverbünden oder konkurrierenden Produkten vor. Da es sich hierbei um von der organisatorischen Gestaltung nicht beeinflußbare Größen handelt, werden sie im folgenden nicht weiter betrachtet. Dagegen werden sowohl die Ressourcen- als auch die Leistungsinterdependenzen durch Maßnahmen der organisatorischen Gestaltung beeinflußt und sind deshalb Gegenstand der Ausführungen in Abschnitt 4.2 der vorliegenden Arbeit.

$140 \mathrm{Vgl}$. Hill/Fehlbaum/Ulrich (1994), S. 186ff., 224ff.

141 Vgl. dazu und im folgenden Frese (1995), S. $53 \mathrm{ff}$. Im Gegensatz zur Terminologie der vorliegenden Arbeit verwendet Frese den Begriff der Entscheidungsautonomie. 


\subsection{Redundanz}

PROBSTS Argumentation bezüglich der Redundanz als Charakteristikum eines Selbstorganisationsprozesse forderlichen Umfeldes unterscheidet sich grundlegend von der bezüglich der oben genannten Aspekte Komplexităt, Selbstreferenz und relativer Autonomie. Denn hier stellt er - wie im folgenden gezeigt werden wird - nicht länger auf emergente, sondern vielmehr auf nicht-emergente Selbstorganisationsprozesse ab.

Umgangssprachlich verweist der Begriff der Redundanz auf Weitschweifigkeit und Wiederholung bzw. ein 'Mehr als unbedingt notwendig'. In der Wirtschaftsinformatik wird der Begriff der Redundanz insbesondere im Zusammenhang mit der mehrfachen Speicherung derselben Daten verwendet. ${ }^{142}$ In der Managementlehre kann sich Redundanz auf jeden beliebigen Inputfaktor beziehen und wird dann üblicherweise als Organizational Slack bezeichnet. ${ }^{143}$ Organizational Slack sei dabei verstanden als die "die positive Differenz zwischen den Ressourcen, die in einer Periode insgesamt zur Verfúgung stehen und denjenigen Ressourcen, die die Organisation in der Periode tatsächlich zur Erreichung des Anspruchsniveaus ihrer Ziele benötigt"144. Somit handelt es sich bei jedem Mehr als dem unbedingt Notwendigen an Inputfaktoren um Organizational Slack. Der Redundanzbegriff bei PrOBST betrifft über das Phănomen des Organizational Slack hinaus noch weitere Sachverhalte. Grundsătzlich unterscheidet PROBST dabei zwischen den folgenden drei Arten von Redundanz: ${ }^{145}$

- Redundanz der Funktionen,

- Redundanz der Teile und

- Redundanz der Interaktionen.

Er betont die Bedeutung der Redundanz von Funktionen und legt den Schwerpunkt seiner Ausführungen auf die Gestaltung der Făhigkeiten und Möglichkeiten der Mitarbeiter als zentraler Teilaspekte der Redundanz von Funktionen.

Im Mittelpunkt von Probsts Argumentation bezüglich der Möglichkeiten der Mitarbeiter steht die Forderung, daß jeder Mitarbeiter als Teil des (Sub-) Systems potentieller Gestalter sein kann, d.h. organisatorische Regeln formulieren kann. Das bedeutet die Aufhebung der Trennung zwischen Organisator und organisiertem (Sub-) System, die Grundlage von organisatorischer Gestaltung als Fremdorganisation ist. Die Wahrscheinlichkeit für das Auftreten von Selbstorganisationsprozessen wird wiederum dadurch gefördert, daß die Mitarbeiter über die entsprechenden Freiräume bzw. die Legitimation für diese Aktivitäten verfügen. Aufgabe des Managements muß es deshalb

142 Vgl. Gabriel/Rohrs (1995), S. 58; Hansen (1996), S. 190, 942.

143 Vgl. Staehle (1991), S. 314, $321 \mathrm{ff}$. Zwar stellt Staehle dort Redundanz und Organizational Slack nebeneinander. Da seine damit verbundene Begriffsabgrenzung fur die weitere Argumentation der vorliegenden Arbeit jedoch ohne Relevanz ist, soll sie hier nicht weiter verfolgt werden. Scharfenkamp (1987), S. 29.

$145 \mathrm{Vgl}$. dazu und im folgenden Probst (1987), S. 81. 
sein, diese Freiräume für Selbstorganisationsprozesse zu schaffen. Damit stellen die 'Möglichkeiten' der Mitarbeiter auf deren Kompetenzen als fremdorganisatorisch geregelten Sachverhalt ab. Dieser Argumentation liegt die unmittelbar nachvollziehbare Annahme zugrunde, daß der Wille der Mitarbeiter zur Selbstorganisation und damit die Wahrscheinlichkeit für das Auftreten von Selbstorganisationsprozessen umso größer ist, je ausgeprägter der im Rahmen von Fremdorganisationsprozessen gewährte explizite Freiraum dafür ist. Die Möglichkeiten der Mitarbeiter - bzw. in der organisationstheoretischen Terminologie ihre Kompetenzen - als Gegenstand organisatorischer Regeln sind nicht Input des betrieblichen Leistungserstellungsprozesses, sondern auf der Metaebene der Regelung ebendieses Prozesses angesiedelt. Entsprechend handelt es sich bei diesem Teilaspekt der Redundanz von Funktionen nicht um Organizational Slack.

Bezüglich der Fähigkeiten der Mitarbeiter betont PROBST die Bedeutung der entsprechenden Qualifikationen und notwendigen Informationen als Voraussetzungen für das Auftreten von Selbstorganisationsprozessen. Er fordert deshalb den Aufbau von Mehrfachqualifikationen und verweist in diesem Zusammenhang auf das 'Principle of Redundancy of Potential Command', das besagt, daß die Elemente der tiefstmöglichen Ebene des Systems gestaltend und lenkend handeln sollten, die gerade noch über ausreichend Informationen verfügen. ${ }^{146}$ Entsprechendes gilt für die Fähigkeiten der Mitarbeiter, d.h. es gilt, an verschiedenen Stellen im (Sub-) System die Befähigung der Mitarbeiter zur Realisierung von Selbstorganisationsprozessen zu fördern. Je qualifizierter und informierter die Mitarbeiter sind, desto häufiger ist damit zu rechnen, daß Selbstorganisationsprozesse mit hoher Wahrscheinlichkeit zu aus der Sicht des Managements positiven Ergebnissen führen. Da im Rahmen der vorliegenden Arbeit aus Vereinfachungsgründen nicht zwischen der Qualifikation als dem Leistungspotential der Mitarbeiter und ihrer konkreten Arbeitsleistung als dem eigentlichen Inputfaktor unterschieden wird, werden die Fähigkeiten bzw. die Qualifikation der Mitarbeiter hier der Gesamtmenge der Inputfaktoren des betrieblichen Leistungserstellungsprozesses zugerechnet. Entsprechend handelt es sich dabei um einen Teilaspekt des Phänomens Organizational Slack.

Zwar stehen die Fähigkeiten und Möglichkeiten der Mitarbeiter - und damit die Redundanz der Funktionen - im Mittelpunkt der Argumentation bei ProBsT. Darüber hinaus verweist er jedoch auch auf die Bedeutung von Redundanz in den Teilen und Interaktionen. Allerdings beschränkt sich dieser Hinweis bei ProBst auf die Aussage "Eine positive Veränderungsrate der Redundanz wird durch Erhöhung in den Teilen, Beziehungen und Interaktionen erreicht."147 Weitergehende Erläuterungen fehlen. Entsprechend gilt es, im folgenden den von PROBST dort implizierten Zusammenhang zu rekonstruieren.

146 Vgl. Probst (1987), S. 81, 136; Probst (1992), Sp. 2260.

147 Probst (1987), S. 81. 
Redundanz der Teile kann als Überschuß der tatsächlich verfügbaren materiellen Ressourcen im Vergleich zu der für die Leistungserstellung mindestens erforderlichen Menge interpretiert werden und stellt dann eine Ausprägung von Organizational Slack dar. Redundanz der Teile kann sich dabei z.B. auf Rohstoffe und Vorprodukte, aber auch auf Maschinen beziehen. Da redundante Qualifikationen der Mitarbeiter bereits unter den Oberpunkt 'Redundanz der Funktionen' subsumiert wurden, werden Mitarbeiter hier nicht der Kategorie der 'Teile' zugeordnet. ${ }^{148}$

Redundanz der Interaktionen bedeutet, daß die existierenden Interaktionen über das unbedingt notwendige Maß hinausgehen. Auch wenn PROBST nicht explizit darauf verweist, so ist doch davon auszugehen, daß er den Begriff der Interaktion auf Kommunikationsprozesse beschränkt und materielle Austauschprozesse nicht in die Betrachtung einbezieht. Redundanz der Interaktionen bedeutet dann, daß eine Vielzahl von Möglichkeiten für potentielle Kommunikationsprozesse besteht. An die Stelle verbindlich vorgeschriebener Kommunikationswege treten Wahlmöglichkeiten. Das Schaffen solcher Wahlmöglichkeiten durch geeignete organisatorische Rahmenvorgaben kann auch als lose Koppelung bezeichnet werden. Im Gegensatz zu enger Koppelung können dabei die einzelnen Mitarbeiter z.B. auch quer zu den Instanzenwegen kommunizieren und gegebenenfalls auch externen Rat einholen. ${ }^{149}$ Da Kommunikationsprozesse nicht Inputfaktoren des betrieblichen Leistungserstellungsprozesses sind, sondern dem Prozeß selbst zugeordnet werden können, handelt es sich bei der Redundanz von Interaktionen nicht um Organizational Slack, sondern ein darüber hinaus reichendes Phänomen. ${ }^{150}$

Die nähere Analyse des Zusammenhangs zwischen den genannten Arten von Redundanz auf der einen und Selbstorganisationsprozessen auf der anderen Seite zeigt, daß PROBST hier explizit auf einzelne Personen abstellt und Selbstorganisationsprozesse damit nicht länger als „Prozesse, die aus dem Systeme heraus von selbst entstehen und in diesem 'Selbst' Ordnung entstehen lassen"151 und damit als Emergenzphänomene konzipiert. Vielmehr tritt laut PROBST nunmehr jedes einzelne Mitglied der Unternehmung bzw. ihrer Subsysteme als Beteiligter und als Teil des (Sub-) Systems an die Stelle des außerhalb des Systems stehenden organisatorischen Gestalters und stellt organisatorische Regeln auf. ${ }^{152}$ Im Gegensatz zu Komplexität, Selbstreferenz und relativer Autonomie als Charakteristika eines Selbstorganisationsprozesse förderlichen Umfeldes bezieht sich Redundanz somit nicht auf emergente, sondern vielmehr auf nichtemergente Selbstorganisationsprozesse. Diese nicht-emergenten Selbstorganisationsprozesse werden vor allem durch Redundanz der Fähigkeiten und Möglichkeiten der

148 Vgl. Probst (1992), Sp. 2260f., ergänzend Staehle (1991), S. 323.

149 Vgl. Staehle (1991), S. 327ff. Als Instanzen werden in der Organisationstheorie mit Weisungsbefugnissen ausgestattete Stellen bezeichnet.

150 Gleichwohl ist Information als Gegenstand von Kommunikationsprozessen bzw. Interaktionen Ressource. Redundanz der Interaktionen ist damit ein Mittel zur Schaffung von Organziational Slack bezüglich der Ressource Information. Probst (1992), Sp. 2255.

152 Vgl. Probst (1992), Sp. 2260. 
Mitarbeiter, aber auch durch Redundanz der Teile und der Interaktionen gefördert, wie im Folgenden gezeigt werden wird. Bei der Rekonstruktion des - von ProBST postulierten - Zusammenhangs zwischen den verschiedenen Arten von Redundanz und nichtemergenten Selbstorganisationsprozessen kann auf die Ausführungen zur relativen Autonomie in Abschnitt 4.1.3.2.3 Bezug genommen werden:

Betrachtet man zunächst Redundanz der Fähigkeiten und Teile als Ausprägungen von Organizational Slack, so bedeutet das damit verbundene Mehr an verfügbaren Ressourcen eine erhöhte Unabhängigkeit der Mitarbeiter bei der Nutzung ebendieser Ressourcen. Ceteris paribus sinken die Ressourceninterdependenzen des betrachteten (Sub-) Systems mit seinem jeweiligen Umfeld. Diese erhöhte Ressourcenautonomie bedingt wiederum eine höhere Entscheidungs- und Handlungsautonomie der Mitarbeiter des (Sub-) Systems und fördert damit ihre Bereitschaft, selbstorganisierend tätig zu werden. Als Beispiel sei hier auf den konkurrierenden Zugriff mehrerer Subsysteme auf dieselben Betriebsmittel in der Fertigung verwiesen. Man kann hier den Fall, daß die Subsysteme sich die Nutzung der Betriebsmittel teilen müssen, dem Fall gegenüberstellen, in dem Redundanzen dadurch geschaffen werden, daß weitere Betriebsmittel identischer Funktionalität zugekauft und den teilautonomen Fertigungsgruppen exklusiv zugeordnet werden. Die mit der exklusiven Zuordnung bestimmter Betriebsmittel zu einer teilautonomen Fertigungsgruppe verbundene Ressourcenautonomie der teilautonomen Fertigungsgruppe fördert ihre Bereitschaft, ablauforganisatorische Regeln über den Einsatz der Betriebsmittel im konkreten Leistungserstellungsprozeß festzulegen, da sie nicht befürchten müssen, daß ihre Entscheidungen durch solche neben- oder übergeordneter Stellen konterkarriert werden.

Betrachtet man sodann den Zusammenhang zwischen der Redundanz der Möglichkeiten und dem Auftreten nicht-emergenter Selbstorganisationsprozesse, so ist davon auszugehen, daß das explizite Gewähren von Freiräumen für Selbstorganisationsprozesse durch das Management die Bereitschaft der Mitarbeiter, selbstorganisierend tätig $\mathrm{zu}$ werden, fördert. Dies setzt allerdings voraus, daß diese intrinsisch motiviert sind und sich durch die Notwendigkeit der Selbstorganisation nicht überfordert fühlen.

Redundanz der Interaktionen bedeutet schließlich, daß vielfältige Kommunikationsmöglichkeiten bestehen. Je höher die Redundanz der Interaktionen ist, über ein desto höheres Ausmaß an relativer Autonomie bezüglich ihrer Kommunikationsprozesse verfügen die Mitglieder des jeweiligen (Sub-) Systems. Diese erhöhte relative Autonomie wirkt sich wiederum positiv auf ihren Willen aus, selbstorganisierend tätig zu werden.

Auch wenn bei ProBst selbst kein expliziter Zusammenhang zwischen Redundanz und emergenten Selbstorganisationsprozessen hergestellt wird, erscheint er doch zumindest für die Teilphänomene Redundanz der Interaktionen sowie der Fähigkeiten und Teile (als Organizational Slack) plausibel. Geht man nämlich davon aus, daß die vielfältigen Möglichkeiten zur Kommunikation auch genutzt werden, so bedeutet die zunehmende Häufigkeit und Vielfalt der Interaktion bzw. Kommunikation innerhalb 
eines (Sub-) Systems (als eine mögliche Ausprägung der Beziehungen in diesem Subsystem) eine Zunahme des Komplexitätsgrades, der mit einer steigenden Wahrscheinlichkeit für das Auftreten von Emergenz einhergeht. ${ }^{153}$ Aus einem hohen Maß an Organizational Slack resultiert eine höhere Unabhängigkeit der Mitarbeiter bei der Nutzung der Ressourcen, die wiederum deren relative bzw. Entscheidungs- und Handlungsautonomie erhöht und damit - wie in Abschnitt 4.1.3.2.3 aufgezeigt - die Wahrscheinlichkeit für das Auftreten emergenter Selbstorganisationsprozesse erhöht.

\subsection{Zwischenfazit}

Nachdem die vier von PROBST genannten typischen Charakteristika selbstorganisierender Systeme in den Abschnitten 4.1.3.2.1 bis 4.1.3.2.4 vorgestellt, interpretiert und kritisch diskutiert wurden, sollen die dort getroffenen Einzelaussagen bezüglich des Zusammenhangs zwischen diesen Phänomenen und dem Auftreten von Selbstorganisationsprozessen im folgenden zusammengefaßt werden. Insbesondere erfolgt eine Präzisierung der diffusen Aussage von PrOBST, diese Phänomene seien "deutlich untereinander verbunden, überlappen und definieren und produzieren sich gegenseitig"154. Dabei zeigt sich, daß die bei PROBST und vielen anderen Autoren beobachtbare Vagheit der Darstellung, die weder für das Verständnis noch für die Akzeptanz dieser neuen Ausrichtung der Managementlehre förderlich ist, durchaus vermieden werden kann.

Die Thematisierung des Zusammenhangs zwischen den vier genannten Phänomenen und dem Auftreten von Selbstorganisationsprozessen setzt neben der Abgrenzung der vier Phänomene die des Begriffes der Selbstorganisation voraus. Hier kann zum einen an die Ausführungen in Abschnitt 4.1.3.1 der vorliegenden Arbeit angeknüpft werden, da Probst dem dort vorgestellten Autorenkreis zuzurechnen ist, der sich - aufbauend auf den Arbeiten von VON HAYEK zum Emergenzphänomen der spontanen Ordnungsbildung - einer 'Theorie selbstorganisierender Systeme' verpflichtet sieht. Entsprechend beschränkt PROBST seinen Selbstorganisationsbegriff - im Gegensatz zur vorliegenden Arbeit - explizit auf emergente Selbstorganisationsprozesse, indem er feststellt: "In der Einführung dieses Buches habe ich Selbstorganisation so definiert, daß Ordnung an sich und eine 'Verbesserung' der Ordnung vom Beobachter aus emergentes Produkt einer vernetzten Ganzheit ist."155 Zum anderen verweisen aber - wie oben gezeigt - zumindest ProBstS Ausführungen zum Phänomen der Redundanz auf die Existenz nichtemergenter, auf das einzelne Mitglied der Unternehmung bezogener Selbstorganisationsprozesse. Ferner formuliert PrOBST an anderer Stelle sogar explizit: "Ordnung ist das Resultat von Selbstorganisation, die in humanen sozialen Systemen die bewußte

153 BezUglich des Zusammenhangs zwischen der Komplexităt eines Systems sowie dem Auftreten von Emergenzphănomenen siehe Abschnitt 2.1.3 und 4.1.3.2.1 der vorliegenden Arbeit.

155 Probst (1987), S. 76. 
Gestaltung von Strukturen einschließt."156 Diese Ausweitung des Begriffes der Selbstorganisation über Emergenzphänomene hinaus wird insbesondere auch dann deutlich, wenn PROBST aufgrund der Beobachterproblematik die Person des organisatorischen Gestalters stets als Teil des zu organisierenden Systems versteht. Damit löst er den Gegensatz zwischen Fremd- und Selbstorganisation auf und faßt sämtliche Aktivitäten des Aufstellens und Veränderns organisatorischer Regeln unter den Begriff der Selbstorganisation. Jedoch handelt es sich keinesfalls bei sämtlichen organisatorischen Tätigkeiten um Emergenzphänomene, sondern ebenso um nicht-emergente, bewußte Aktivitäten der Mitglieder der Unternehmung. Diese Ausweitung des Begriffes der Selbstorganisation bei PROBST ist m.E. unvereinbar mit seinen häufigen, allein auf Emergenz abstellenden Definitionen bzw. Umschreibungen von Selbstorganisation. Insgesamt erweist sich PrOBSTS Verwendung des Begriffes der Selbstorganisation damit als widersprüchlich und höchst problematisch.

Der Selbstorganisationsbegriff der vorliegenden Arbeit unterscheidet sich sowohl von PROBSTS weitem als auch von seinem engen Begriffsverständnis und ist zwischen beiden angesiedelt. Denn einerseits umfaßt er neben emergenten auch nicht-emergente Selbstorganisationsprozesse. Andererseits werden den Selbstorganisations- durchaus Fremdorganisationsprozesse gegenübergestellt. Entsprechend sind ProBSTS Aussagen bezüglich der oben beschriebenen vier Phänomene an dieses Begriffsverständnis der vorliegenden Arbeit anzupassen. ${ }^{157}$

Abbildung 4/9 zeigt die Ergebnisse der kritischen Diskussion in den Abschnitten 4.1.3.2.1 bis 4.1.3.2.4 bezüglich des Zusammenhangs zwischen den dort thematisierten Systemeigenschaften und dem Auftreten von Selbstorganisationsprozessen.

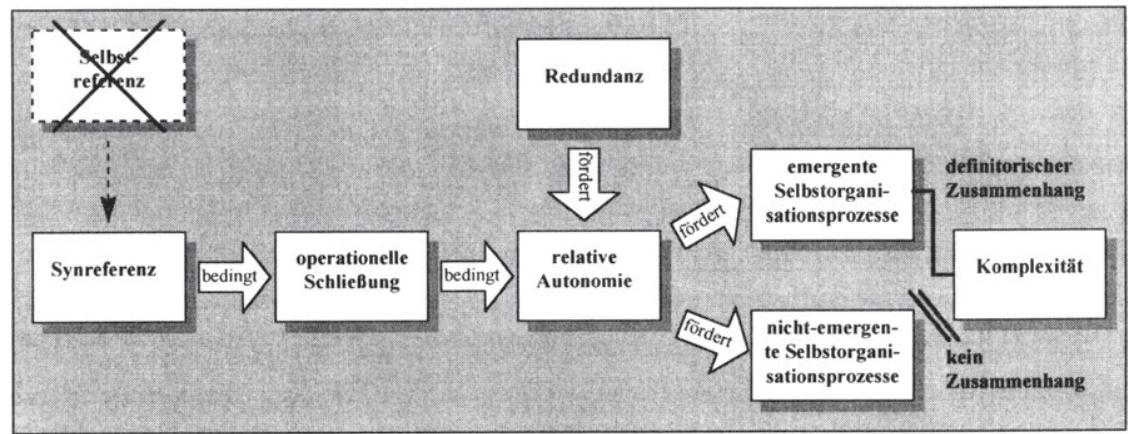

Abb. 4/9: Der Zusammenhang zwischen den verschiedenen Systemeigenschaften und dem Auftreten von Selbstorganisationsprozessen

156 Probst (1987), S. 84.

157 Für eine ausfuhrliche Abgrenzung des Selbstorganisations-Begriffes dieser Arbeit gegenuber alternativen Sichten in der Literatur siehe Abschnitt 4.1.3.1 der vorliegenden Arbeit. 
Bezüglich des Zusammenhangs zwischen Komplexität und emergenten Selbstorganisationsprozessen ist festzustellen, daß das Auftreten von Emergenzphänomenen im allgemeinen und somit auch von emergenten Selbstorganisationsprozessen konstituierendes Merkmal komplexer Systeme ist. Ein System ist komplex, sofern es Emergenzphänomene aufweist. Gleichzeitig treten Emergenzphänomene nur in komplexen Systemen auf. Aufgrund dieser definitorischen Festlegungen der vorliegenden Arbeit sind Komplexität und emergente Selbstorganisationsprozesse innerhalb eines umfassenderen Argumentationszusammenhangs unmittelbar miteinander verknüpft. Komplexität ist weder Voraussetzung noch Folge von emergenten Selbstorganisationsprozessen. Vielmehr treten beide stets gleichzeitig auf. Mehr Komplexität bedeutet somit notwendigerweise ein verstärktes Auftreten von Emergenzphänomenen. Entsprechend fördern die bei ProBst und anderen Autoren genannten komplexitätsfördernden Aktivitäten stets auch das Auftreten emergenter Selbstorganisationsprozesse. Jedoch steht Komplexität dabei auf derselben Ebene wie Emergenz und entsprechend über potentiellen emergente Selbstorganisationsprozesse fördernden Systemeigenschaften. Es macht damit keinen Sinn zu untersuchen, welche organisatorischen Regeln über die Förderung von Komplexität das Auftreten von Selbstorganisationsprozessen fördern.

Ein eindeutiger Zusammenhang zwischen Komplexität und nicht-emergenten Selbstorganisationsprozessen besteht nicht. Nicht-emergente Selbstorganisationsprozesse sind das Ergebnis willentlicher Handlungen einzelner oder mehrerer Mitglieder des Systems Unternehmung. Als Voraussetzungen für ihr Auftreten waren zu Beginn von Abschnitt 4.1.3.2 der Wille der jeweiligen Mitarbeiter sowie entsprechende Kommunikationsmöglichkeiten zwischen ihnen genannt worden. Zwar geht ein hohes Maß an Komplexität eines Systems in der Regel mit einer großen Vielfalt der Kommunikationsbeziehungen in diesem System einher, jedoch handelt es sich bei den Kommunikationsmöglichkeiten nur um eine notwendige, nicht jedoch eine hinreichende Bedingung für das Auftreten nicht-emergenter Selbstorganisationsprozesse. Vielmehr setzen diese einen entsprechenden Willen der Mitarbeiter voraus. Eine eindeutige Spezifikation des Zusammenhangs zwischen diesem Willen und der Komplexität des Systems ist jedoch nicht möglich. Vielmehr konnten in Abschnitt 4.1.3.2.1 sowohl Argumente für eine positive als auch für eine negative Korrelation angeführt werden. Somit kann kein eindeutiger Zusammenhang zwischen der Komplexität des Systems und dem Auftreten nicht-emergenter Selbstorganisationsprozesse hergeleitet werden.

In Abschnitt 4.1.3.2.2 war herausgearbeitet worden, daß weder die Unternehmung als Ganzes noch einzelne ihrer Teilsysteme autopoietische oder selbstreferentielle Systeme sind. Entsprechend macht es weder Sinn, den kausalen Zusammenhang zwischen Autopoiese und Selbstreferenz und emergenten Selbstorganisationsprozessen noch den zwischen Autopoiese und Selbstreferenz und nicht-emergenten Selbstorganisationsprozessen zu untersuchen. 
Dagegen konnte im Rahmen einer gradualistischen Betrachtung aufgezeigt werden, daß eine Erhöhung der Synreferenz der Informationsverarbeitung der Mitglieder eines (Sub-) Systems zur operationellen Schließung des (Sub-) Systems beiträgt. Je ausgeprägter die konsensuellen Bereiche der Mitglieder eines (Sub-) Systems sind, desto stärker ist ihre Abschließung gegenüber ihrer originären Lebenswelt bzw. der Grad ihrer operationellen Schließung und desto weniger wird ihr Verhalten durch äußere Einflüsse determiniert. Stellt man zugleich bei der Definition von relativer Autonomie auf die Unabhängigkeit des Verhaltens eines (Sub-) Systems bzw. seiner Mitglieder von deren Umwelt ab, so bedingt der Grad der operationellen Schließung eines (Sub-) Systems den Grad seiner relativen Autonomie.

Bezüglich des Zusammenhangs zwischen relativer Autonomie und dem Auftreten emergenter Selbstorganisationsprozesse konnte für die Gruppe als einer möglichen Ausprägung eines Subsystems der Unternehmung gezeigt werden, daß ein hohes Maß an Synreferenz in Form einer starken Subkultur, das zugleich ein hohes Maß an operationeller Schließung und relativer Autonomie bedeutet, die Gruppenkohäsion und entsprechend auch das Auftreten emergenter Selbstorganisationsprozesse als typischer Gruppenphänomene fördert. Verallgemeinert man diese gruppenspezifische Argumentation und überträgt sie auf die Gesamtheit der sozialen Subsysteme innerhalb der Unternehmung, so gilt, daß die Wahrscheinlichkeit für das Auftreten von emergenten Selbstorganisationsprozessen positiv mit dem Grad der relativen Autonomie des Subsystems korreliert.

Untersucht man den Zusammenhang zwischen relativer Autonomie und nicht-emergenten Selbstorganisationsprozessen und stellt dabei auf den Willen der Mitarbeiter ab, so ist anzunehmen, daß der Wille der Mitarbeiter in den verschiedenen Subsystemen, bewußt selbstorganisierend tätig zu werden, mit dem von ihnen wahrgenommenen Ausmaß der relativen Autonomie steigt. Je höher also die Synreferenz und die daraus resultierende operationelle Schließung bzw. relative Autonomie sind, desto höher ist die Wahrscheinlichkeit für das Auftreten nicht-emergenter Selbstorganisationsprozesse. Denn je unabhängiger sich die Mitarbeiter als Elemente der Subsysteme der Unternehmung von äußerer Beeinflussung fühlen, desto höher wird ihre Bereitschaft sein, bewußt selbstorganisierend tätig zu werden.

Sowohl zwischen Redundanz und emergenten Selbstorganisationsprozessen als auch zwischen Redundanz und nicht-emergenten Selbstorganisationsprozessen wurde in Abschnitt 4.1.3.2.4 ein positiver Zusammenhang erkannt. Jedoch handelt es sich bei dem Phänomen der Redundanz nicht um einen unabhängigen Einflußfaktor, der neben dem der relativen Autonomie steht. Vielmehr fördern die von PROBST unterschiedenen drei Arten von Redundanz die relative Autonomie des jeweiligen Subsystems. Das erhöhte Ausmaß an relativer Autonomie führt sodann dazu, daß verstärkt emergente und nicht-emergente Selbstorganisationsprozesse auftreten. So gilt für die Möglichkeiten bzw. Kompetenzen der Mitarbeiter eines Subsystems als einem der beiden Teil- 
aspekte der Redundanz der Funktionen, daß die relative Autonomie des jeweiligen Subsystems mit dem Ausmaß der ihm übertragenen Kompetenzen steigt. Sowohl eine verstärkte Redundanz der Fähigkeiten als auch die der Teile als Ausprägungen von Organizational Slack in einem Subsystem verringern die Ressourceninterdependenzen zwischen diesem und seiner Umwelt und erhöhen damit ceteris paribus die relative Autonomie dieses Subsystems. Schließlich bedeutet Redundanz der Interaktionen bzw. der Kommunikation, daß eine Vielzahl von Möglichkeiten für potentielle Kommunikationsprozesse im Sinne einer losen Koppelung besteht. Je höher die Redundanz der Interaktionen ist, über ein desto höheres Ausmaß an relativer Autonomie bezüglich ihrer Kommunikationsprozesse verfügen die Mitglieder des jeweiligen Subsystems. Somit gilt, daß ein hohes Maß an Redundanz der Funktionen, Teile und/oder Interaktionen mit einer hohen Autonomie des Subsystems und damit mit einer hohen Wahrscheinlichkeit für das Auftreten emergenter und nicht-emergenter Selbstorganisationsprozesse einhergeht.

Zusammenfassend haben die obigen Ausführungen gezeigt, daß es sich lediglich bei der relativen Autonomie als einem der vier bei PROBST und den auf seinen Ausführungen aufbauenden Autoren genannten Phänomene um eine Voraussetzung für das Auftreten emergenter und nicht-emergenter Selbstorganisationsprozesse handelt. So müssen die Ausführungen in Abschnitt 4.2 der vorliegenden Arbeit darauf abstellen, welche Ausgestaltung der organisatorischen Regeln als Ergebnis von Fremdorganisationsprozessen die relative Autonomie der sozialen Subsysteme in der Unternehmung fördert. Relative Autonomie resultiert aus der Synreferenz der Informationsverarbeitung der Mitglieder des jeweiligen Subsystems, die mit operationeller Schließung einhergeht. Entsprechend tritt Synreferenz in der obigen Argumentation an die Stelle von Selbstreferenz, die nicht Eigenschaft des sozialen Systems Unternehmung und/oder seiner sozialen Subsysteme sein kann und deshalb keine Berücksichtigung findet. Redundanz im allgemeinen und Organizational Slack im besonderen stellen wiederum eine Möglichkeit dar, um die relative Autonomie der Subsysteme zu fördern und finden deshalb an nachgeordneter Stelle ebenfalls Eingang in die Argumentation in Abschnitt 4.2. Dagegen wird Komplexität aufgrund des definitorischen Zusammenhangs mit Emergenzphänomenen nicht weiter untersucht. Es sei hier darauf hingewiesen, daß die im folgenden vorgenommene Beschränkung der Untersuchung auf relative Autonomie als Charakteristikum eines Selbstorganisationsprozesse förderlichen Umfeldes nicht etwa bedeutet, daß dies die einzig denkbare Voraussetzung für das Auftreten von Selbstorganisationsprozessen ist. Es ist vielmehr davon auszugehen, daß im Rahmen einer - den Rahmen der vorliegenden Arbeit sprengenden - umfassenden Analyse von Selbstorganisationsprozessen weitere Voraussetzungen ermittelt werden könnten. Die folgenden Ausführungen über Möglichkeiten der Förderung organisationalen Lernens im Rahmen von organisatorischer Gestaltung und Informationsmanagement mittels Förderung der relativen Autonomie fokussieren damit nur einen von mehreren grundsätzlich denkbaren Aspekten. 
Greift man beispielhaft das Phänomen des Organizational Slack als eine bestimmte Form von Redundanz heraus, so wird unmittelbar deutlich, daß Aussagen der Art 'das Ausmaß an Organizational Slack in den Subsystemen ist zu erhöhen, um über die damit verbundene Erhöhung ihrer relativen Autonomie die Wahrscheinlichkeit für das Auftreten von Selbstorganisationsprozessen zu erhöhen' als generelle Anforderung an die organisatorische Gestaltung nicht geeignet ist. Da nämlich die in der Unternehmung einsetzbaren Ressourcen stets begrenzt sind, stellt die undifferenzierte Forderung nach einem Mehr an Ressourcen notwendigerweise eine unangemessene Trivialisierung dar. Denn es ist nicht möglich, den Ressourceneinsatz in allen sozialen Subsystemen der Unternehmung über das unbedingt notwendige Maß hinaus zu erhöhen, ohne damit die Existenz der Unternehmung zu gefährden. Vielmehr ist zu spezifizieren, wann und wo ein Mehr an eingesetzten Ressourcen sinnvoll ist und wo nicht. Diese Argumentation bezüglich des Organizational Slack als einer Möglichkeit zur Förderung der relativen Autonomie der Subsysteme in der Unternehmung kann auf die (Sub-) Systemeigenschaft der relativen Autonomie insgesamt ausgedehnt werden. Eine entsprechende Ausdifferenzierung des theoretischen Modells zur Ableitung von Empfehlungen für die organisatorische Gestaltung unter Vermeidung der oben genannten Trivialisierung erfolgt im folgenden Abschnitt 4.1.4.

\subsubsection{Dynamisierte Mehrebenen-Betrachtung}

Der oben aufgezeigte positive Zusammenhang zwischen Synreferenz, operationeller Schließung und relativer Autonomie eines (Sub-) Systems auf der einen und der Wahrscheinlichkeit für das Auftreten emergenter und nicht-emergenter Selbstorganisationsprozesse auf der anderen Seite darf nicht die undifferenzierte Forderung nach einem Maximum an relativer Autonomie der sozialen Subsysteme in der Unternehmung zur Folge haben. Denn einerseits gehen über die Förderung von Selbstorganisationsprozessen hinaus auch andere, negative Konsequenzen mit der zunehmenden operationellen Schließung einher. Andererseits ist nicht jedes Ergebnis von Selbstorganisationsprozessen aus der Sicht des Managements positiv zu bewerten. Dies läßt sich beispielsweise an der intuitiv regelmäßig negativen Bewertung des in Abschnitt 4.1.3.2.2 angeführten Grenzfalls einer Sekte als operationell nahezu geschlossenem System ablesen. Eine theoretische Begründung dieser Bewertung bietet die folgende, systemtheoretisch fundierte Argumentation.

Bereits in Abschnitt 2.2.1.2 der vorliegenden Arbeit wurde die Unternehmung in Mikro-, Meso- und Makroebene gegliedert. Während das einzelne Mitglied der Unternehmung Gegenstand der Mikroebene ist und die Makroebene auf die Unternehmung als Ganzes abstellt, werden auf der Mesoebene verschiedene Subsysteme fokussiert. Innerhalb dieser Perspektive können wiederum durch zunehmende (Dis-) Aggregation unterschiedliche Arten von Subsystemen unterschieden werden. Im Rahmen einer mehrstufigen Systemgliederung kann man das System Unternehmung so in verschie- 
dene Subsysteme unterteilen, die eine Subsystemhierarchie bilden. Dabei können mehrere Subsysteme einer bestimmten Ebene auf der nächsthöheren Ebene zu einem Subsystem zusammengefaßt werden. ${ }^{158}$

Im Mittelpunkt der folgenden Ausführungen dieses Kapitels stehen soziale Subsysteme der Unternehmung als diejenige Teilmenge der Gesamtheit der potentiell unterscheidbaren Subsysteme der Unternehmung, die aus einer Mehrzahl von Personen bestehen. Da organisatorische Regeln per definitionem die arbeitsteilige Aufgabenerfüllung mehrerer Personen betreffen, ist die stelleninterne Abwicklung der Arbeitsaufgaben eines einzelnen menschlichen Aufgabenträgers weder Gegenstand von Fremd- noch von Selbstorganisationsprozessen. ${ }^{159}$ Die Mikroebene des einzelnen Aufgabenträgers wird deshalb im folgenden nicht berücksichtigt. Aber auch die Makroebene wird im folgenden vernachlässigt, weil dort die Unternehmung als Ganzes Betrachtungsobjekt ist und entsprechend bei Verfolgung dieser Perspektive alle organisatorischen Tätigkeiten der Mitglieder der Unternehmung Selbstorganisationsprozesse darstellen. Denn alle Mitglieder der Unternehmung sind dann Teil des relevanten Systems. Somit wären dann auch organisatorische Tätigkeiten des Managements, die aus der Perspektive der Subsysteme Fremdorganisationsprozesse darstellen, selbstorganisierende Tätigkeiten. Die für die Argumentation der vorliegenden Arbeit zentrale Unterscheidung zwischen Selbst- und Fremdorganisation wäre bei Verfolgung der Makroperspektive in dieser Form nicht länger möglich. Da somit Mikro- und Makroebene aus der Betrachtung ausscheiden, ist die Mesoebene der verschiedenen sozialen Subsysteme der Unternehmung Gegenstand der folgenden Untersuchung.

Untersucht man nunmehr das Phänomen der relativen Autonomie der einzelnen Subsysteme innerhalb der Subsystemhierarchie der Mesoebene, so wird folgendes deutlich: Über die verschiedenen Stufen der (Dis-) Aggregation hinweg ist jedes Subsystem der Unternehmung Teil eines übergeordneten (Sub-) Systems. Im Grenzfall der obersten Stufe der Subsystembildung ist es Teil des Systems Unternehmung als Ganzen. Im Rahmen einer zielorientierten Unternehmungsführung ist für jedes einzelne Subsystem sicherzustellen, daß sein Zielbeitrag zum Zielsystem des ihm übergeordneten Subsystems - und damit letztlich zum Zielsystem der Unternehmung als Ganzem - positiv ist. Nur so ist langfristig die Erfüllung des Zielsystems der Unternehmung im allgemeinen und insbesondere die Erfüllung des Ziels der langfristigen Sicherung des Bestehens der Unternehmung gewährleistet. Denn die Existenzsicherung der Unternehmung kann systemtheoretisch als die Aufrechterhaltung der Grenzen des Systems Unternehmung gegenüber einer komplexen Umwelt bezeichnet werden und bedeutet das Ersetzen von Punkt-zu-Punkt-Entsprechungen zwischen der Umwelt und dem System durch komplexitätsreduzierende Verhaltensmuster. ${ }^{160}$ Die Verhaltensmuster bedingen eine relative

158 Siehe Abschnitt 2.1.3 der vorliegenden Arbeit.

159 Siehe Abschnitt 2.2.1.2 der vorliegenden Arbeit.

160 Siehe Abschnitt 3.3.2 der vorliegenden Arbeit. 
Autonomie des Verhaltens des Systems Unternehmung gegenüber Einflüssen aus seiner Umwelt, d.h. das Verhalten des Systems Unternehmung ist nicht durch äußere Einflüsse determiniert. Diese Reinterpretation des Existenzssicherungsziels der Unternehmung als Sicherstellung der relativen Autonomie des Systems Unternehmung als Ganzen gegenüber ihrer Umwelt hat folgende Konsequenz für das Verhältnis der Subsysteme der verschiedenen Stufen der Mesoebene untereinander und für deren Verhältnis zum Gesamtsystem Unternehmung: Auf jeder Stufe der Subsystembildung innerhalb der Unternehmung ist zu gewährleisten, daß die relative Autonomie eines Subsystems nicht die relative Autonomie des nächsthöheren (Sub-) Systems gefährdet. Die Forderung nach einem Mehr an relativer Autonomie der verschiedenen Subsysteme in der Unternehmung ist diesem Mehrebenengedanken entsprechend zu modifizieren. Im Rahmen der Ausführungen in Abschnitt 4.2 zu Möglichkeiten der Förderung des Auftretens von Selbstorganisationsprozessen als Prozessen organisationalen Lernens durch die organisatorische Gestaltung stellt diese mit der Einbettung eines Subsystems in eine Subsystemhierarchie verbundene Begrenzung seiner relativen Autonomie durch die relative Autonomie der ihm übergeordneten Subsysteme ein wichtiges Argument dar.

Für eine nähere Untersuchung dieser Mehrebenen-Betrachtung des Zusammenhangs zwischen der relativen Autonomie der einzelnen Subsysteme innerhalb einer mehrstufigen Gliederung des Systems Unternehmung erweist sich eine Dynamisierung des Modells in Form des Einbeziehens der jeweiligen Lebenszyklusphasen der Subsysteme als sinnvoll. Dabei soll im folgenden anhand der Interpretation der Phasen der Gruppenentwicklung als der Teile eines modifizierten Lebenszykluskonzeptes für Gruppen und der modifizierten Übertragung der damit verbundenen Grundidee auf die Gesamtheit der sozialen Subsysteme in der Unternehmung aufgezeigt werden, daß die Wahrscheinlichkeit für das Auftreten aus der Sicht der Gesamtunternehmung bzw. der nächsthöheren Subsystemebene positiv zu bewertender Selbstorganisationsprozesse auf den verschiedenen Subsystemebenen im Zeitablauf variiert.

Lebenszykluskonzepte stellen allgemein eine Dynamisierung betriebswirtschaftlicher Modellkonstruktionen dar. Sie gehen mit der Vorstellung einher, daß die Entwicklung eines bestimmten Indikators im Zeitablauf in idealtypische Phasen unterteilt werden kann und dabei einem glockenförmigen Verlauf folgt. Einen hohen Bekanntheitsgrad hat z.B. der Produkt-Lebenszyklus des Marketing erlangt, der davon ausgeht, daß die Nachfrage nach einem Produkt am Markt unterschiedliche Sättigungsphasen durchläuft. Grundsätzlich gilt, daß jeder Lebenszyklus eine idealtypische Vereinfachung darstellt, von dem der tatsächlich beobachtete Lebenszyklus im Einzelfall mehr oder weniger stark abweichen kann. Insbesondere können einzelne Phasen übersprungen oder aber durch geeignete Maßnahmen verlängert oder verkürzt werden. Der Umstand, daß damit ex ante nur sehr bedingt Aussagen über den konkreten Kurvenverlauf möglich sind, dieser im Detail vielmehr stets erst ex post ermittelt werden kann, steht im Mittelpunkt der an Lebenszykluskonzepten geübten Kritik. Trotz dieser Kritik stellen Lebenszyklus- 
konzepte dennoch eine interessante Möglichkeit der Dynamisierung betriebswirtschaftlicher Modellüberlegungen dar. ${ }^{161}$

Die Gruppenforschung unterscheidet verschiedene Phasen der Gruppenentwicklung. So differenziert z.B. TUCKMAN, dessen Arbeiten zur Gruppenentwicklung auch heute noch eine weite Verbreitung finden, zwischen den Phasen Forming (Ausprobieren verschiedener Verhaltensweisen), Storming (es treten verstärkt Konflikte auf), Norming (Entwicklung von Gruppenkohäsion) und Performing (konstruktive Aufgabenbearbeitung). ${ }^{162}$ In Erweiterung des Modells von TUCKMAN sollen hier zwei weitere Phasen ergänzt werden, die mit Decline und Deterioration bezeichnet werden. Diese sechs Phasen können als Phasen eines Gruppen-Lebenszyklus interpretiert werden, der den Beitrag der Gruppe zur Zielerreichung des übergeordneten Subsystems im Zeitablauf beschreibt. Dabei stellt die letzte Phase eine Modifikation des üblichen glockenförmigen Verlaufs der Kurve in Lebenszyklus-Konzepten dar, da hier negative Indikatorwerte auftreten. Den Verlauf der Merkmalsausprägung in den einzelnen Phasen des GruppenLebenszyklus visualisiert Abbildung 4/10.163

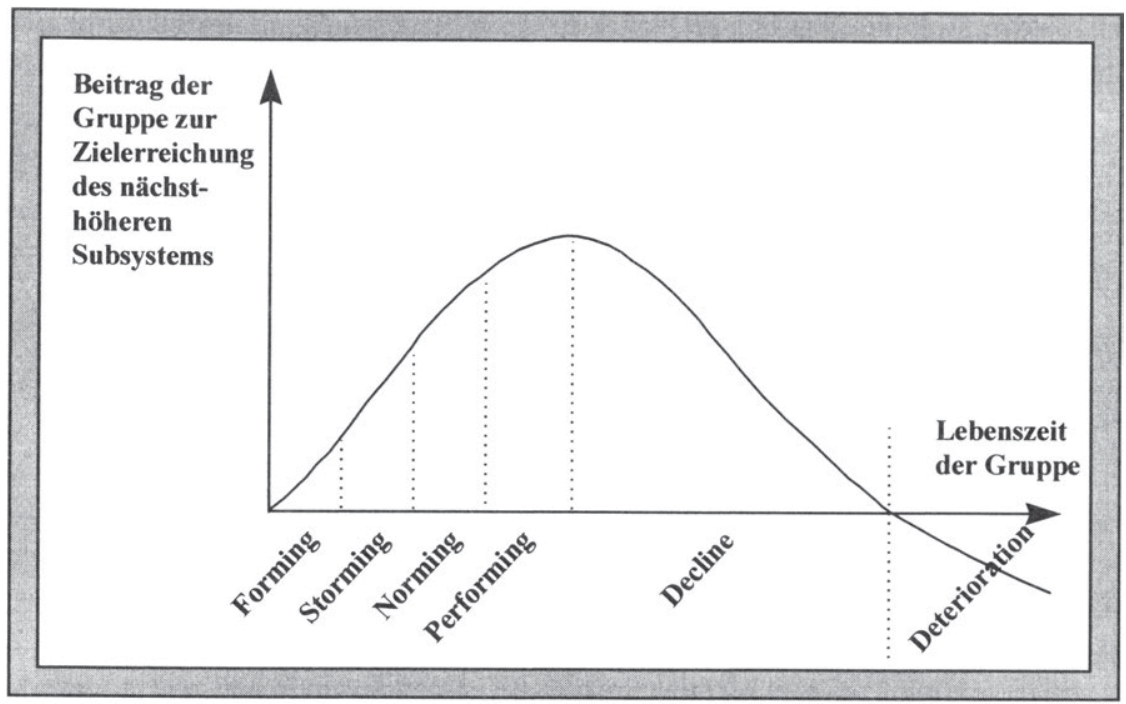

Abb. 4/10: Die Phasen des Gruppen-Lebenszyklus

161 Vgl. ăhnlich Becker (1998), S. 725ff.; Mag (1995), S. 160f.; Meffert (1998), S. 328ff.; Nieschlag/Dichtl/Horschgen (1997), S. 896ff.

162 Vgl. Tuckman (1965), S. 396. Zu den Phasen der Gruppenentwicklung vgl. ferner Scheff (1993), S. 142ff. Für eine Definition von Gruppen siehe Abschnitt 3.2.2.1 der vorliegenden Arbeit.

163 Es sei hier darauf hingewiesen, daß die konkrete Abgrenzung der verschiedenen Phasen (wie z.B. das Ende der Performing-Phase in dem Punkt, in dem der Grenzzielbeitrag Null ist) fur die weitere Argumentation ohne Bedeutung ist. 
Die ersten Phasen des Gruppen-Lebenszyklus sind von Versuch und Irrtum sowie Konflikten zwischen den Gruppenmitgliedern geprägt. Deshalb ist die Produktivität der Gruppe bei der Erfüllung ihrer Teilaufgaben, die als Beitrag der Gruppe zur Zielerreichung des nächsthöheren Subsystems interpretiert werden kann, vergleichsweise gering. Im Zeitverlauf steigen die Gruppenleistung und damit ihr Beitrag zur Zielerreichung des nächsthöheren Subsystems allmählich an. Dieser Zusammenhang kann mit Hilfe der Übertragung der systemtheoretischen Erläuterungen zu Synreferenz, operationeller Schließung und daraus resultierender relativer Autonomie von Subsystemen auf die Gruppe begründet werden. Der Gruppenbildungsprozeß stellt nämlich nichts anderes als das Ausbilden eines immer höheren Maßes an Synreferenz dar: Über die einzelnen Phasen der Gruppenentwicklung hinweg werden die Wahrnehmungen der einzelnen Gruppenmitglieder bezüglich der Gruppe und ihrer Umwelt immer ähnlicher. Die Gruppe (bzw. ihre Mitglieder) entwickelt ein Selbstverständnis, das mit einer zunehmenden Abschließung der Gruppe gegenüber ihrer Umwelt einhergeht. Die Subsystemabgrenzung bzw. -konstitution wird immer mehr zu einer Leistung der Gruppe selbst. Die operationelle Schließung steigt und zugleich auch der Zielbeitrag des Subsystems zu den Zielen des übergeordneten Systems. Denn mit zunehmender Angleichung der Weltsichten und Selbstverständnisse der Gruppenmitglieder steigt die Produktivität der Gruppe zunächst an, da leistungsmindernde gruppeninterne Konflikte abnehmen. Während die zunehmende operationelle Schließung bzw. relative Autonomie des Subsystems so zunächst positiv auf dessen Abstimmung mit der jeweils übergeordneten Subsystemebene wirkt, ist sie ab einem bestimmten Punkt so stark, daß der Zielbeitrag des Subsystems zum Zielsystem des nächsthöheren Subsystems - und im Endeffekt auch zu dem des Gesamtsystems Unternehmung - sinkt. Dabei bleibt er zunächst positiv. Erst in der letzten Phase des Gruppenlebenszyklus wird er negativ und verringert dann die Autonomie des nächsthöheren Subsystems. Denn mit zunehmender Verfestigung von Weltsicht und Selbstverständnis der Gruppe löst diese sich immer mehr von der Perspektive ihrer Umwelt bzw. der des übergeordneten Subsystems. Es findet kein Abgleich der Wahrnehmungen der Gruppenmitglieder mit denen des übergeordneten Subsystems statt. Abweichungen werden nicht korrigiert. Vielmehr führt die zunehmende operationelle Schließung bzw. relative Autonomie des Subsystems dazu, daß dessen Beitrag zur Zielerreichung des nächsthöheren Subsystems immer stärker in den Hintergrund rückt. Unterschiedliche Wahrnehmungen bedingen wiederum, daß die Arbeitsleistung der Gruppe von dieser selbst und ihrer Umwelt unterschiedlich bewertet wird. Ein Ergebnis, das von der Gruppe selbst positiv bewertet wird, kann aus der Sicht ihrer Umwelt eher negativ zu bewerten sein. Diese Reinterpretation und Erweiterung der Phasen der Gruppenentwicklung im Rahmen eines Lebenszykluskonzeptes der Gruppe, das deren Zielbeitrag zum jeweiligen nächsthöheren Subsystem in Beziehung zu der Zeitdauer ihres Bestehens setzt, unterstützt damit die Erkenntnis der modernen Gruppenforschung, die nicht länger - wie in der Vergangenheit verschiedentlich geschehen von einer prinzipiell positiven Korrelation zwischen dem Grad der Gruppenkohäsion 
und der Gruppenleistung ausgeht. ${ }^{164}$ Vielmehr führt eine zu starke Gruppenkohäsion zu einer sinkenden Gruppenleistung.

Zwar können die oben für den Spezialfall der Gruppe (als einer bestimmten Ausprägung von Subsystem in der Unternehmung) getroffenen Aussagen bezüglich der in den einzelnen Phasen des Gruppenlebenszyklus ablaufenden typischen Gruppenprozesse nicht auf die Gesamtheit möglicher sozialer Subsysteme der Unternehmung übertragen werden. Die Abfolge der genannten Phasen des Gruppenlebenszyklus diente dort jedoch vor allem der Begründung des Umstandes, daß der Beitrag der Gruppe zur Zielerreichung des nächsthöheren Subsystems im Zeitablauf variiert. Auch wenn die konkreten Prozesse, die zu im Zeitverlauf zunehmender Synreferenz und operationeller Schließung eines Subsystems führen, ${ }^{165}$ in Abhängigkeit von der Art und insbesondere der Größe des jeweiligen Subsystems u.U. sehr unterschiedlich sein können, erscheint es doch plausibel, auch bei anderen sozialen Subsystemen in der Unternehmung von Veränderungen des Zielerreichungsbeitrages im Zeitablauf auszugehen. Entsprechend werden die obigen Ausführungen bezüglich der Gruppe hier derart auf die Gesamtheit aller sozialen Subsysteme in der Unternehmung übertragen, daß der Zielbeitrag jedes sozialen Subsystems der Unternehmung zu den Zielen des nächsthöheren Subsystems - und letztlich der Gesamtunternehmung - im Zeitablauf variiert. Auf eine konkrete Phasengliederung mit der Zuordnung bestimmter Aktivitäten muß dabei jedoch aufgrund der u.U. großen Unterschiede zwischen den verschiedenen Subsystemen verzichtet werden. Jedoch kann angenommen werden, daß der Zielbeitrag tendenziell im Zeitverlauf zunächst wächst, ein Maximum erreicht und sodann fällt, wobei er ab einem bestimmten Punkt negativ wird. Entsprechend gilt für die Ergebnisse von Selbstorganisationsprozessen innerhalb eines Subsystems, daß deren Auswirkungen auf die Zielerreichung des nächsthöheren Subsystems sowie des Gesamtsystems Unternehmung in Abhängigkeit vom Lebenszyklus des Subsystems sowohl positiv als auch negativ sein können.

Die einzelnen Subsysteme der Unternehmung befinden sich i.d.R. an unterschiedlichen Punkten ihres Lebenszyklus. Zentrales Anliegen der organisatorischen Gestaltung muß es deshalb sein, für jedes einzelne Subsystem zu ermitteln, ob seine relative Autonomie in Harmonie oder in Konkurrenz zur relativen Autonomie der ihm übergeordneten Subsysteme steht. Befindet sich das Subsystem an einem Punkt seines Lebenszyklus, in dem sein Beitrag zur Erfüllung der Ziele des nächsthöheren Subsystems positiv ist und in der nächsten Zukunft weiter zunehmen wird (für die Gruppe: Forming-, Storming-, Norming- und Performing-Phase), so gilt es, über die Förderung seiner relativen Autonomie das Auftreten von emergenten und nicht-emergenten Selbstorganisationsprozessen als Prozessen organisationalen Lernens zu fördern. Befindet es sich dagegen in einem Punkt negativer Zielbeiträge (für die Gruppe: Dete-

164 Vgl. Staehle (1994), S. 264.

165 Von dem Spezialfall im Zeitverlauf sinkender Synreferenz und operationeller Schließung eines Subsystems, der in der betrieblichen Praxis durchaus auftreten kann, wird hier abstrahiert. 
rioration-Phase), so sollte seine relative Autonomie beschränkt werden, da die Ergebnisse der in ihm auftretenden Selbstorganisationsprozesse aus der Sicht der übergeordneten Subsystemebenen negativ zu bewerten sind. Je geringer schließlich der konkrete (positive) Zielbeitrag des Subsystems zum nächsthöheren Subsystem bei gleichzeitiger negativer Ausprägung des Grenzzielbeitrags ist (für die Gruppe: DeclinePhase), desto weniger lohnt es, die relative Autonomie dieses Subsystems - und damit das Auftreten emergenter und nicht-emergenter Selbstorganisationsprozesse - zu fördern. Bis zu welchem Punkt auf der fallenden Kurve des Zielbeitrages des fokussierten Subsystems zum nächsthöheren Subsystem die relative Autonomie dieses Subsystems gefördert und ab wann sie reduziert wird, hängt dabei vom konkreten betrieblichen Einzelfall - und insbesondere vom Vergleich mit anderen Subsystemen der Unternehmung ab.

Über diesen grundsätzlichen Zusammenhang zwischen dem Lebenszyklus eines Subsystems und seinem Beitrag zum Zielsystem des nächsthöheren (Sub-) Systems hinaus können keine Aussagen über die inhaltlichen Ergebnisse der Selbstorganisationsprozesse gemacht werden. PROBST spricht in diesem Zusammenhang davon, daß die Fokussierung selbstorganisierender Prozesse in der Unternehmung einen Perspektivenwechsel weg von der bisherigen Ergebnis- und hin zu einer stärkeren Prozeßorientierung bedeutet. ${ }^{166} \mathrm{Da}$ Lebenszykluskonzepte regelmäßig idealtypische Vereinfachungen darstellen, gilt es zu beachten, daß es sich dabei nur um Tendenzaussagen handeln kann, die im konkreten Einzelfall zu spezifizieren sind. Insbesondere können die im Rahmen von Selbstorganisationsprozessen formulierten organisatorischen Regeln auch in frühen Phasen des Subsystemlebenszklus den Vorstellungen des Managements zuwiderlaufen. ${ }^{167} \mathrm{Ob}$ das Management diese organisatorischen Regeln trotz abweichender Vorstellungen akzeptiert oder gegensteuernd beseitigt, hängt dann vom jeweiligen Einzelfall ab und kann deshalb im Rahmen der vorliegenden Arbeit nicht untersucht werden.

Aus der Erkenntnis darüber, daß bei einer dynamischen Betrachtung der Zielbeitrag des Subsystems zu den Zielen des jeweils übergeordneten (Sub-) Systems variiert, resultiert die Forderung nach einer grundsätzlichen zeitlichen Beschränkung der Lebensdauer von Subsystemen. Dadurch wird vermieden, daß sich das einzelne Subsystem durch ein zu hohes $\mathrm{Ma} ß$ an realisierter relativer Autonomie vom Zielsystem der Unternehmung als Ganzen abkoppelt. Nach der Auflösung des Subsystems bilden dessen bisherige Mitglieder gemeinsam mit Mitgliedern anderer Subsysteme stattdessen ein neues Subsystem. ${ }^{168}$ In diesen Zusammenhang kann auch PROBSTS Forderung nach einem Ersetzen

166 Vgl. Probst (1987), S. 113.

167 Vgl. Strohmeier (1997), S. 174ff.

168 Bei diesem flexiblen Einrichten und Auflösen von Subsystemen innerhalb der Unternehmung ist allerdings die dem Menschen inhärente Disposition zur Gruppenbildung und Abgrenzung zu berücksichtigen, um eine Überforderung und daraus resultierende Demotivation der Mitarbeiter zu vermeiden. Vgl. Wiegand (1996), S. 410. 
der traditionellen Spezialisierung auf Funktionen durch eine Spezialisierung auf die Unternehmung eingeordnet werden. ${ }^{169}$

Faßt man die Konsequenzen der hier vorgestellten dynamisierten MehrebenenBetrachtung für die Argumentation der vorliegenden Arbeit abschließend zusammen, so ist festzuhalten, daß nicht undifferenziert für alle Subsysteme in der Unternehmung ein Mehr an relativer Autonomie (zur Förderung von Selbstorganisationsprozessen) gefordert werden kann. Vielmehr ist eine Abstimmung der relativen Autonomie der Subsysteme der Unternehmung im Rahmen einer mehrstufigen Systemgliederung vorzunehmen. Denn einerseits beschränkt die relative Autonomie des untergeordneten Subsystems die des übergeordneten Subsystems. Andererseits beschränkt die relative Autonomie des übergeordneten Subsystems die des untergeordneten Subsystems. Dabei gilt es zu berücksichtigen, an welchem Punkt seines Lebenszyklus sich das fokussierte Subsystem im relevanten Zeitpunkt befindet. Die folgenden Ausführungen dieser Arbeit beziehen sich auf solche Subsysteme in der Unternehmung, die einen positiven, in der nahen Zukunft weiter wachsenden Zielbeitrag zum Zielsystem des übergeordneten Subsystems leisten und innerhalb derer deshalb das Auftreten von Selbstorganisationsprozessen über die Stärkung ihrer relativen Autonomie gefördert werden soll. Dies erscheint umso wichtiger, als Selbstorganisationsprozesse im Rahmen eines eher traditionellen Managementverständnisses tendenziell zu wenig Berücksichtigung finden.

\subsection{Möglichkeiten der Förderung organisationalen Lernens durch die organisatorische Gestaltung}

Die organisatorische Gestaltung als Managementaktivität hat die präsituative Regelung der arbeitsteiligen Aufgabenerfüllung innerhalb der Unternehmung zum Gegenstand. Nachdem in Abschnitt 4.1 ein theoretischer Bezugsrahmen für die Ableitung von Anforderungen an die organisatorische Gestaltung in der lernenden Unternehmung entwickelt wurde, sollen im folgenden konkrete Möglichkeiten der Förderung organisationalen Lernens durch die organisatorische Gestaltung aufgezeigt werden. Erstens basiert die Argumentation dabei auf der Annahme, daß sowohl fremd- als auch selbstorganisatorische Tätigkeiten als überindividuelle organisationale Lernprozesse höherer Ordnung reinterpretiert werden können. Sie ermöglichen somit grundlegende unternehmungsinterne Wandelprozesse. Da zweitens die Ausgangsproblematik der vorliegenden Arbeit im Ermöglichen häufiger interner Wandelprozesse zwecks Sicherstellung eines Fit zwischen der Unternehmung und ihrer Umwelt besteht, reichen einmalige organisatorische Veränderungen bzw. Lernprozesse nicht aus. Vielmehr gilt es, Deutero Learning als Lernen zu lernen zu ermöglichen. Drittens sind Selbstorganisationsprozesse innerhalb eines bestimmten Subsystems Fremdorganisationsprozessen regelmäßig dann

169 Für eine ausfuhrliche Darstellung des Phănomens der 'Spezialisierung auf die Unternehmung' siehe Abschnitt 4.2.1 der vorliegenden Arbeit. 
überlegen, wenn die unternehmungsexternen Wandelprozesse die spezifischen Teilumwelten der Mitglieder dieses Subsystems betreffen. Denn diese nehmen die Wandelprozesse tendenziell schneller und besser wahr als ein subsystemfremder organisatorischer Gestalter. Aus diesen drei Kernpunkten der bisherigen Argumentation resultiert die Forderung an die organisatorische Gestaltung als Fremdorganisation, einen geeigneten Rahmen zur Förderung künftiger Selbstorganisationsprozesse zu schaffen. Die theoretische Analyse der verschiedenen in der Literatur als Voraussetzungen für Selbstorganisationsprozesse genannten Systemeigenschaften hat ergeben, daß lediglich für die relative Autonomie der Subsysteme ein entsprechender Kausalzusammenhang zum Auftreten emergenter und nicht-emergenter Selbstorganisationsprozesse aufgezeigt werden kann. Entsprechend gilt es im folgenden $\mathrm{zu}$ untersuchen, welche organisatorischen Gestaltungsaktivitäten die relative Autonomie solcher Subsysteme fördern können, innerhalb derer verstärkt Selbstorganisationsprozesse auftreten sollen. Grundhypothese ist dabei, daß das explizite Akzeptieren von Selbstorganisationsprozessen und das Einräumen entsprechender Spielräume durch das Management gegenüber ihrem Ignorieren positive Auswirkungen auf Effektivität und Effizienz der organisatorischen Regeln in der Unternehmung hat.

Zielt man darauf ab, Aussagen über die Ausgestaltung der organisatorischen Regeln als Ergebnis von Fremdorganisation zur Förderung von Selbstorganisationsprozessen zu treffen, so kann entweder ein dimensionaler oder ein typologischer Ansatz gewählt werden. In einem dimensionalen Ansatz werden die organisatorischen Regeln verschiedenen Dimensionen zugeordnet. Sodann werden die Ausprägungen dieser Dimensionen untersucht. Im Rahmen eines typologischen Ansatzes wird dagegen mit Hilfe bestimmter, charakteristischer Merkmalsausprägungen zwischen einer endlichen Anzahl unterschiedlicher Typen von Unternehmungen unterschieden. Voraussetzung für die Typenbildung ist, daß mindestens eines der als relevant erachteten Merkmale abstufbar ist. Die Problematik dieses Ansatzes besteht sodann vor allem darin, aus der großen Fülle möglicher Kombinationen von Merkmalsausprägungen die für den jeweiligen Untersuchungszweck als relevant erachteten auszuwählen. ${ }^{170}$ Ein typischer Vertreter des typologischen Ansatzes ist MINTZBERG, der zwischen den fünf Typen einfache Struktur, Maschinen- und Spezialistenbürokratie, divisionalisierte Struktur und Ad-hoc-Organisation unterscheidet. ${ }^{171}$ Die Beschränkung auf einige wenige Typen als Kombinationen charakteristischer Ausprägungsformen bestimmter Merkmale stellt zwar eine mögliche Herangehensweise für die Betrachtung der organisatorischen Regeln dar. Für die im folgenden angestrebte Ableitung von Anforderungen an das Informationsmanagement erweist sich ein solch grobes Raster jedoch nicht als zweckmäßig, da hierdurch die Isolierung einzelner Wirkungszusammenhänge erschwert wird. Im folgenden wird deshalb ein dimensionaler Ansatz verfolgt, der diese mit der Typenbildung notwendigerweise

170 Vgl. Kosiol (1972), S. 34f.

171 Vgl. Mintzberg (1984), S. 75ff. Eine Weiterentwicklung erfährt der typologische Ansatz in Arbeiten zu Unternehmungskonfigurationen. Vgl. dazu Henselek (1996), S. 49. 
einhergehende sehr Vereinfachung vermeidet und insgesamt eine stärkere Differenzierung zuläßt. Der dimensionale Ansatz erlaubt einerseits die exakte konzeptionelle Abbildung des Zusammenhangs zwischen Anforderungen an die organisatorische Gestaltung und solchen an das Informationsmanagement, andererseits ermöglicht er im Rahmen des Informationsmanagements prinzipiell die Berücksichtigung weiterer Einflußfaktoren, die in einem typologischen Ansatz notwendigerweise zur Bildung zusätzlicher oder modifizierter Typen führen würde. ${ }^{172}$

Im Anschluß an die Entscheidung für einen dimensionalen Ansatz ist nunmehr zu klären, anhand welcher Dimensionẹn der organisatorischen Regeln die Gesamtheit der Aktivitäten der organisatorischen Gestaltung gegliedert werden kann. In der organisationstheoretischen Literatur existiert eine Vielzahl von Systematisierungsmöglichkeiten für die Zuordnung der organisatorischen Regeln zu bestimmten Dimensionen. Viele Autoren unterscheiden zunächst zwischen Arbeitsteilung und Koordination als den beiden zentralen Grundprinzipien organisatorischer Tätigkeiten. Aber auch Konfigurationsund Delegationsaspekte finden regelmäßig Berücksichtigung. ${ }^{173}$ Die von vielen Autoren vorgenommenen Ergänzungen dieses Katalogs zentraler Dimensionen um weitere Aspekte, die von deren jeweiligem Erkenntnis- und Gestaltungsinteresse geprägt werden, ${ }^{174}$ sind für den im Rahmen der vorliegenden Arbeit verfolgten Untersuchungszweck nicht zielführend. So stellen z.B. HILL/FEHLBAUM/UlRICH die Partizipation als eigenständige Dimension neben die Entscheidungsdelegation, während Partizipation im folgenden - aufgrund der damit verbundenen grundsätzlich ähnlichen Konsequenzen für die relative Autonomie der Subsysteme - als Teilaspekt der übergeordneten Dimension der Entscheidungsdelegation behandelt wird. ${ }^{175}$ KIESER/KUBICEK ordnen Fragen der Formalisierung einer eigenen Dimension zu. Aufgrund des spezifischen Erkenntnisinteresses der vorliegenden Arbeit, die die Gestaltung der Informationsstruktur dem Informationsmanagement - und nicht der organisatorischen Gestaltung - zurechnet, findet die Dimension Formalisierung im folgenden keine weitere Berücksichtigung. ${ }^{176}$

172 Vgl. ähnlich Wall (1996), S. 80f.

173 Vgl. z.B. Bleicher (1991), passim; Frese (1995), passim; Kosiol (1962), passim; Mintzberg (1992), passim; Schulte-Zurhausen (1995), passim; Steinmann/Schreyogg (1993), S. 375ff.; Wittlage (1987), S. 567 .

174 Für einen Überblick über die von verschiedenen Forschern untersuchten Dimensionen siehe Breilmann (1989), S. $21 \mathrm{ff}$.

$175 \mathrm{Vgl}$. Hill/Fehlbaum/Ulrich (1994), S. 173ff.

176 Es sei hier darauf hingewiesen, daß der Begriff der Formalisierung bei Kieser/Kubicek sich von dem Begriffsverständnis der vorliegenden Arbeit, wie es in Abschnitt 2.2.1.3 vorgestellt wurde, unterscheidet. So stellt der Begriff der Formalisierung bei Kieser/Kubicek auf Form und Medien der Kommunikation zwischen den Mitgliedern der Unternehmung und insbesondere deren schriftliche Fixierung ab. Innerhalb der Dimension Formalisierung unterscheiden die Autoren zwischen den drei Teilaspekten Formalisierung der organisatorischen Regeln, Formalisierung des Informationsflusses und Formalisierung der Leistungserfassung und -beurteilung. Der Teilaspekt der Formalisierung der organisatorischen Regeln ist dabei - auch nach Kieser/Kubicek - keine eigene Dimension, sondern betrifft die (schriftliche) Form der den anderen Dimensionen zuzuordnenden organisatorischen Regeln. Dagegen stellt der Teilaspekt der Formalisierung des Informationsflusses auf die schriftliche Fixierung der Kommunikationsprozesse ab. Somit handelt es sich hier um eine Dimension der Informationsstruktur als des immateriellen Objektes des Informationsmanagements. Schließlich betrifft der dritte Teilaspekt die schriftliche Fixierung der Aktivităten des disziplinarischen Bereiches. Vgl. Kieser/Kubicek (1992), S. 160ff. sowie Pugh et al. (1968), S. 75ff., 100ff. Auch Schulte-Zurhausen 
Die folgenden Ausführungen beschränken sich auf Arbeitsteilung, Koordination, Leitungssystem und Entscheidungsdelegation als die vier Hauptdimensionen der organisatorischen Gestaltung. Ihre inhaltliche Abgrenzung folgt dabei im wesentlichen dem Ansatz von KIESER/KUBICEK, der in der organisationstheoretischen Literatur eine weite Verbreitung gefunden hat und der - bei Verzicht auf die Dimension Formalisierung - für die Zwecke der vorliegenden Arbeit besonders geeignet ist. ${ }^{177}$

Sieht man von dem Grenzfall der Einpersonen-Unternehmung ab, so ist die arbeitsteilige Erfüllung der Aufgabe der Unternehmung das Ausgangsproblem jeder organisatorischen Tätigkeit. Während nämlich die Kapazität des einzelnen menschlichen Aufgabenträgers begrenzt ist, ist die Gesamtaufgabe der Unternehmung regelmäßig so umfassend, daß sie in Teilaufgaben zerlegt werden muß, die sodann auf mehrere Personen verteilt werden. Die organisatorischen Regeln zur Arbeitsteilung fokussieren die Art und Weise der Zuordnung von Teilaufgabenbündeln zu Subsystemen sowie zu einzelnen Mitgliedern der Unternehmung.

Unmittelbare Folge der arbeitsteiligen Aufgabenerfüllung in der Unternehmung ist die Notwendigkeit zur Koordination der Aktivitäten der verschiedenen Unternehmungsmitglieder bei ihrer jeweiligen Teilaufgabenerfüllung. Diese müssen unter Berücksichtigung des Zielsystems der Unternehmung aufeinander abgestimmt werden, um die optimale Erfüllung der Gesamtaufgabe der Unternehmung zu gewährleisten. Arbeitsteilung und Koordination stellen somit die beiden zentralen Grundprinzipien jeder organisatorischen Tätigkeit dar. Sie können jedoch um weitere Aspekte erweitert werden.

Die der Dimension Konfiguration bzw. Leitungssystem zuzuordnenden organisatorischen Regeln betreffen die Weisungsbefugnisse der Mitglieder der Unternehmung untereinander, d.h. ihre Rechte, anderen Personen Anordnungen zu geben. Die beiden Begriffe Konfiguration und Leitungssystem werden im Rahmen der vorliegenden Arbeit synonym verwendet. Der Begriff der Konfiguration wurde ursprünglich von PUGH ET AL. geprägt und umfaßt die äußere Form des Stellengefüges einer Unternehmung. Da diese äußere Form des Stellengefüges im wesentlichen von den Weisungsbefugnissen der Instanzen geprägt ist, kann sie auch als Leitungssystem bezeichnet werden. ${ }^{178}$ Mit der in den organisatorischen Regeln zum Leitungssystem festgelegten hierarchischen Ordnung der Unternehmungsmitglieder ist zugleich die relative Anordnung der von ihnen zu erfüllenden einzelnen Teilaufgaben(bündel) verbunden. Mitarbeiter und Teilaufgaben können einander dabei über-, unter- oder nebengeordnet werden. Mit den Weisungsbefugnissen betreffen die organisatorischen Regeln zum Leitungssystem eine bestimmte Art von Beziehungen zwischen den Unternehmungsmitgliedern.

bezieht sich auf die ursprunglich von Pugh et al. entwickelte Systematisierung von Formalisierungsphänomenen, ordnet diese jedoch als Unterpunkt der übergeordneten Dimension der Koordination (durch Standardisierung) zu. Vgl. Schulte-Zurhausen (1995), S. 199f.

Vgl. dazu und im folgenden Kieser/Kubicek (1992), S. 74.

178

Vgl. Pugh et al. (1968), passim. 
Die Dimension Entscheidungsdelegation umfaßt die die Entscheidungsbefugnisse der Unternehmungsmitglieder betreffenden organisatorischen Regeln. Delegation bedeutet dabei die dauerhafte Übertragung von Entscheidungsaufgaben sowie der damit verbundenen Kompetenzen und Verantwortung an hierarchisch nachgeordnete Stellen bzw. Subsysteme, d.h. hier wird geregelt, wer berechtigt ist, welche Art von verbindlichen Entscheidungen zu treffen.

Abbildung 4/11 visualisiert den Umstand, daß die folgenden Ausführungen sich an den genannten vier Hauptdimensionen der organisatorischen Gestaltung orientieren und sich entsprechend in Aussagen zur Gestaltung der organisatorischen Regeln zur Arbeitsteilung (Abschnitt 4.2.1), zur Koordination (Abschnitt 4.2.2), zum Leitungssystem (Abschnitt 4.2.3) sowie zur Entscheidungsdelegation (Abschnitt 4.2.4) gliedern. Jede dieser Hauptdimensionen besteht wiederum aus mehreren Teildimensionen, von denen im Rahmen der folgenden Ausführungen diejenigen herausgegriffen werden, bei denen ein Kausalzusammenhang zum Auftreten von Selbstorganisationsprozessen als Prozessen organisationalen Lernens beobachtet werden kann. Das Kapitel schließt mit einer Zusammenfassung der entwickelten Gestaltungsempfehlungen in Abschnitt 4.2.5.

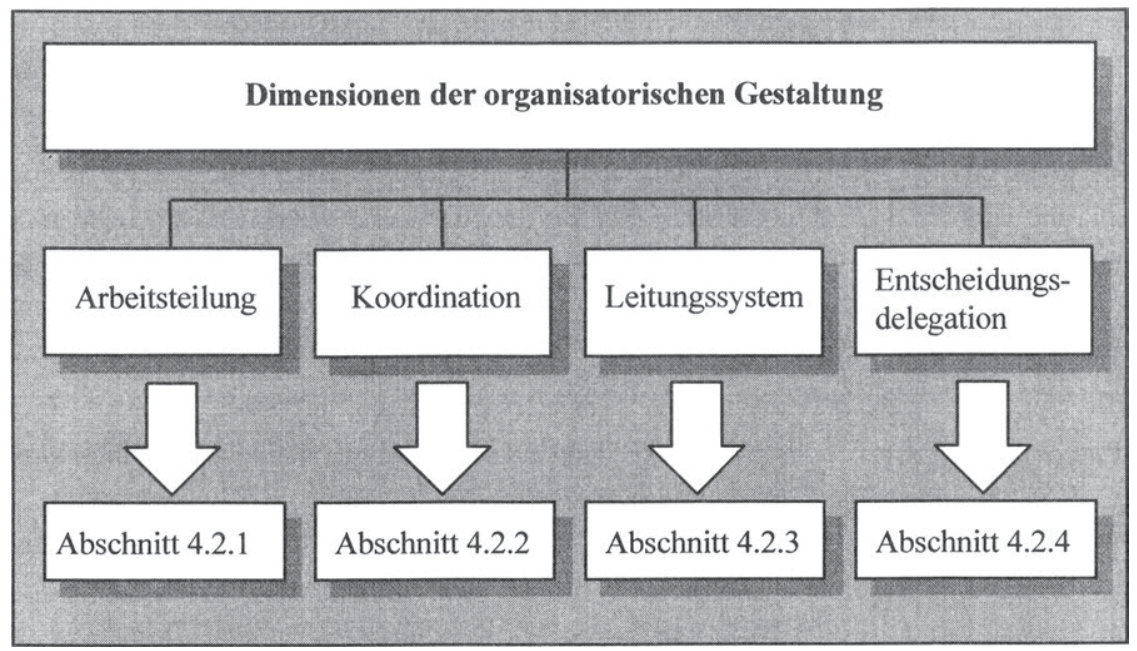

Abb. 4/11: Die Gliederung der Gestaltungsempfehlungen anhand der vier Hauptdimensionen der organisatorischen Gestaltung

\subsubsection{Organisatorische Regeln zur Arbeitsteilung}

Die arbeitsteilige Aufgabenerfüllung in der Unternehmung stellt das zentrale Grundproblem jeder organisatorischen Tätigkeit dar. ${ }^{179}$ Dabei gilt es, die Gesamtaufgabe der

179 Kosiol weist darauf hin, daß der Begriff der Arbeitsteilung damit streng genommen ungenau ist, da es sich um die Verteilung von Teilaufgaben handelt. Vgl. Kosiol (1976), S. 31. 
Unternehmung über mehrere Stufen hinweg auf die verschiedenen Subsysteme und letztendlich auf die einzelnen menschlichen Aufgabenträger zu verteilen. Die vorliegende Arbeit hat Selbstorganisationsprozesse innerhalb solcher Subsysteme zum Gegenstand, deren Beitrag zur Erreichung der Ziele des nächsthöheren Subsystems und letztlich der Gesamtunternehmung positiv ist, und untersucht deshalb, wie die organisatorische Gestaltung die relative Autonomie dieser Subsysteme fördern kann. Dabei wird zwischen intersystemischer und intrasystemischer Arbeitsteilung unterschieden. Während die intersystemische Arbeitsteilung die Verteilung von Teilaufgabenbündeln zwischen verschiedenen Subsystemen betrifft, bezieht sich die intrasystemische Arbeitsteilung auf die Verteilung der Teilaufgabenbündel innerhalb eines einzelnen Subsystems und damit in der Regel auf die Verteilung zwischen den einzelnen Aufgabenträgern als Mitgliedern dieses Subsystems.

Wie bereits in Abschnitt 4.1.3.2.3 beschrieben wurde, sind die einzelnen Subsysteme stets in den Gesamtzusammenhang der Unternehmung eingebettet und deshalb niemals absolut, sondern lediglich relativ autonom. Eine nähere Untersuchung der relativen Autonomie im Sinne von Entscheidungs- und Handlungsautonomie macht die Unterscheidung in die beiden Dimensionen horizontale und vertikale Autonomie sinnvoll. Im Mittelpunkt der Ausführungen über die Gestaltung der organisatorischen Regeln zur Arbeitsteilung steht die horizontale Autonomie. Denn jede Entscheidung für eine bestimmte Form der Arbeitsteilung zwischen einander nebengeordneten Einheiten verstärkt bzw. verringert bestimmte horizontale Interdependenzen zwischen diesen.

Bevor im folgenden die Auswirkungen verschiedener Ausprägungen inter- und intrasystemischer Arbeitsteilung auf die relative Autonomie der jeweiligen Subsysteme herausgearbeitet werden, sollen hier zunächst die verschiedenen Formen der Arbeitsteilung vorgestellt werden: Grundsätzlich bestehen mit der Mengen- und der Artenteilung zwei Möglichkeiten, die Gesamtaufgabe der Unternehmung zu verteilen. Bei der reinen Mengenteilung wird eine Aufgabe in mehrere gleichartige Teilaufgabenbündel zerlegt. Bei der Artenteilung unterscheiden sich die Teilaufgabenbündel dagegen voneinander. Die Aufteilung des Arbeitsvolumens nach der Art der jeweiligen Aufgaben wird auch als Spezialisierung bezeichnet. Im Gegensatz zur Mengenteilung bedeutet Artenteilung bzw. Spezialisierung, daß die Teilaufgabenbündel der Subsysteme sich inhaltlich voneinander unterscheiden. In Abhängigkeit von dem jeweiligen Spezialisierungskriterium kann man grundsätzlich zwischen folgenden zwei Arten der Spezialisierung unterscheiden: ${ }^{180}$

- funktions- bzw. verrichtungsorientierte Spezialisierung,

- objektorientierte Spezialisierung.

180 Vgl. dazu und im folgenden Schulte-Zurhausen (1995), S. 116ff.; Steinmann/Schreyögg (1993), S. $384 \mathrm{ff}$. 
Eine funktions- bzw. verrichtungsorientierte Spezialisierung einzelner Subsysteme oder Aufgabenträger bedeutet, daß der einzelnen Einheit gleichartige Verrichtungen zugeordnet werden. Ein Beispiel für eine funktionsorientierte Spezialisierung ist die Unterscheidung in die Abteilungen Einkauf, Vertrieb, Personal, Rechnungswesen etc. Bei der objektorientierten Spezialisierung wird die Gesamtheit aller Verrichtungen, die ein bestimmtes Objekt bzw. eine abgegrenzte Objektgruppe betreffen, einem Subsystem oder einem Aufgabenträger zugeordnet. Mögliche Objekte sind z.B. Produkte, Kunden oder Absatzregionen. Sofern sie auf der ersten oder zweiten Hierarchieebene der Unternehmung erfolgt, wird eine solche Spezialisierung häufig auch als Divisionalisierung oder Spartengliederung bezeichnet. ${ }^{181}$

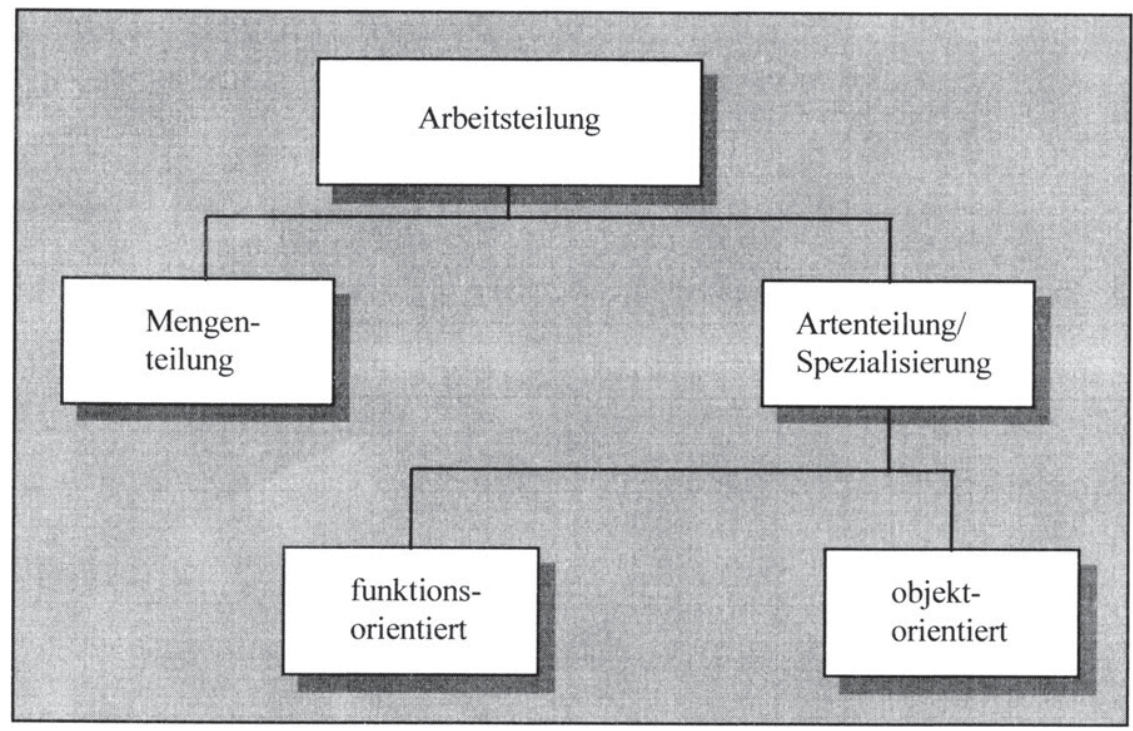

Abb. 4/12: Formen der Arbeitsteilung

Abbildung 4/12 zeigt zusammenfassend die oben genannten Formen der Arbeitsteilung. ${ }^{182}$

181 Einige Autoren weisen die Gliederung nach Regionen und/oder die nach Kundengruppen separat neben der nach Objekten aus und begrenzen die objektorientierte Spezialisierung auf die nach Produkten bzw. Produktgruppen. Vgl. z.B. Hill/Fehlbaum/Ulrich (1994), S. 176ff.; Kieser/Kubicek (1992), S. $87 \mathrm{ff}$. Dieser Sichtweise wird im Rahmen der vorliegenden Arbeit nicht gefolgt.

182 Anstelle der hier vorgestellten Systematisierung, bei der in einem ersten Schritt zwischen Arten- und Mengenteilung unterschieden wird, wobei erstere in einem zweiten Schritt in funktions- und objektorientierte Spezialisierung unterschieden wird, kann im Rahmen einer alternativen Perspektive auf die Unterscheidung von Arten- und Mengenteilung verzichtet werden. Stattdessen wird dann auf der ersten Systematisierungsebene zwischen funktions- und objektorientierter Arbeitsteilung unterschieden und auf der zweiten Ebene bei der objektorientierten Spezialisierung sodann danach differenziert, ob die Unterschiedlichkeit der Objekte dazu fuhrt, daß die Teilaufgabenbündel sich prinzipiell unterscheiden (so variiert z.B. das eingesetzte Marketinginstrumentarium in Abhängigkeit von der jeweiligen Kundengruppe) oder aber, daß sie weitgehend identisch sind (Rechnungsbearbeitung in 
Untersucht man die mit den verschiedenen Formen der Arbeitsteilung verbundene horizontale Autonomie der Subsysteme und unterscheidet dabei in Anlehnung an die Systematisierung von FRESE zwischen Ressourcen- und Leistungsinterdependenzen, ${ }^{183}$ so zeigt sich, daß keine allgemeingültigen Aussagen bezüglich des Zusammenhangs zwischen der Art der Arbeitsteilung und der Stärke der damit verbundenen Ressourceninterdependenzen getroffen werden können. Denn die Stärke der Ressourceninterdependenzen zwischen den verschiedenen Subsystemen hängt von der Knappheit der Ressourcen in den einzelnen Subsystemen ab, die jedoch nicht durch die Wahl einer bestimmten Art der Arbeitsteilung determiniert wird. Vielmehr können alle beschriebenen Arten der Arbeitsteilung sowohl mit einer exklusiven Zuordnung bestimmter Ressourcen zu den jeweiligen Subsystemen als auch mit einem gemeinsamen Zugriff auf ebendiese Ressourcen einhergehen.

Während bezüglich der relativen Vorziehenswürdigkeit von Mengen- und Artenteilung unter dem Aspekt der Ressourcenautonomie keinerlei Aussagen möglich sind, gelangt man beim Vergleich von funktions- und objektorientierter Arbeitsteilung zu folgender Tendenzaussage: Von der prinzipiellen Grundausrichtung her stellt eine funktionale Arbeitsteilung tendenziell stärker als eine objektorientierte auf die effiziente Nutzung der verfügbaren Ressourcen ab. Das zentrale Streben richtet sich bei funktionaler Arbeitsteilung auf den Abbau von Überkapazitäten bzw. die Realisierung von Economies of Scale. Bei der objektorientierten Verteilung von Teilaufgabenbündeln auf Subsysteme müssen diesen dagegen tendenziell mehr Ressourcen zur Verfügung gestellt werden. Die Gefahr von Überkapazitäten ist hier größer als bei funktionaler Arbeitsteilung. Somit wären die Ressourceninterdependenzen zwischen den Subsystemen bei objektorientierter Arbeitsteilung tendenziell geringer als bei funktionsorientierter. ${ }^{184}$ Ceteris paribus bedeutet dies eine höhere relative Autonomie. Allerdings können auch Gegenargumente gegen diese Tendenzaussage angeführt werden: Immer dann nämlich, wenn die objektorientiert organisierten Subsysteme auf gemeinsame Ressourcen zugreifen müssen, sind die Ressourceninterdependenzen hier sehr hoch. So kann die objektorientierte Spezialisierung von Subsystemen mit der Bildung von Zentralbereichen, wie z.B. einem gemeinsamen Rechenzentrum, einer Abteilung Benutzersupport, einer Marktforschungs- oder einer Rechtsabteilung, einhergehen, die Dienstleistungen für die objektorientiert organisierten Subsysteme anbieten und damit von diesen gemeinsam genutzte Ressourcen darstellen. Die mit der Bildung von Zentralbereichen verbundenen

\footnotetext{
Abhăngigkeit vom Datum des Eingangs der Rechnungen). Der letzte Fall entspricht dann der Mengenteilung gemäß dem ersten Klassifikationsschema.

Diese zweite Moglichkeit der Systematisierung verschiedener Arten der Arbeitsteilung vermeidet die mit der Kategorie 'Mengenteilung' verbundene theoretische Unschärfe (denn jede Mengenteilung erfolgt letztlich anhand irgendeines Objektes, wie z.B. dem Namen des Lieferanten oder dem Datum bei der oben erwăhnten Rechnungsbearbeitung). Dennoch konnte sie sich in der organisationstheoretischen Literatur nicht durchsetzen und findet deshalb im Rahmen der Ausfuhrungen der vorliegenden Arbeit keine weitere Berucksichtigung, zumal die genannte Abgrenzungsproblematik für die weiteren Ausfuhrungen nur von geringer Relevanz ist.

184 Vgl. ăhnlich Frese (1993), S. 1006f.
} 
Ressourceninterdependenzen variieren allerdings in Abhängigkeit von deren organisatorischer Ausgestaltung. ${ }^{185}$ Die Argumentation zeigt, daß es nicht sinnvoll ist, allgemeine Aussagen bezüglich der mit den verschiedenen Arten von Arbeitsteilung verbundenen Ressourceninterdependenzen $\mathrm{zu}$ treffen. Entsprechend stellt die folgende Gegenüberstellung der verschiedenen Arten der inter- und intrasystemischen Arbeitsteilung allein auf die damit verbundenen Leistungsinterdependenzen ab.

Zwar können keine eindeutigen Aussagen über den Zusammenhang zwischen den verschiedenen Arten von Arbeitsteilung und den Ressourceninterdependenzen getroffen werden. Jedoch werden durch die organisatorischen Regeln zur Arbeitsteilung Festlegungen bezüglich der Verteilungsbeziehungen als der Zuordnung von Teilaufgaben, abstrakten Aufgabenträgern und abstrakten technischen Hilfsmitteln zueinander bzw. zu Subsystemen der Unternehmung vorgenommen. Diese betreffen unmittelbar das in den Subsystemen realisierte Ausmaß an Organizational Slack. Deshalb ist im Rahmen der Entscheidungen bezüglich der Arbeitsteilung zwischen den Subsystemen der Unternehmung zu prüfen, wo über eine Erhöhung des Organizational Slack die relative Autonomie eines Subsystems und damit das Auftreten von Selbstorganisationsprozessen als Prozessen organisationalen Lernens gefördert werden soll. 186

Die Verstärkung der Ressourcenausstattung über das gemäß dem Minimumprinzip unbedingt notwendige Maß hinaus darf sich allerdings nicht allein auf materielle Ressourcen beschränken, sondern ist insbesondere auch auf den Faktor Zeit auszudehnen. Es gilt, den Mitarbeitern des Subsystems ausreichende Spielräume für Reflexion und interpersonelle Abstimmungsprozesse über grundsätzliche Fragen bezüglich der Abwicklung ihrer Arbeitsaufgaben einzuräumen. Denn ein Mehr an zeitlicher Flexibilität ist ceteris paribus regelmäßig mit dem verstärkten Auftreten von Selbstorganisationsprozessen verbunden. ${ }^{187}$ Tendenziell ist das Problem mangelnder zeitlicher Spielräume auf den oberen Hierarchieebenen weniger stark ausgeprägt als auf unteren Hierarchiebebenen, da dort einerseits weniger detaillierte Vorgaben bezüglich der konkreten Teilaufgabenerfüllung vorliegen, andererseits auf den oberen Hierarchieebenen die Bereitschaft zu einer Ausdehnung der Arbeitszeit in Form von Überstunden in der Regel stärker ausgeprägt ist als auf unteren. Jedoch gewinnt das Problem mangelnder zeitlicher Spielräume in Zeiten starken Kostensenkungsdrucks von Seiten der Unternehmungsführung auch bei Führungskräften stark an Bedeutung. So können z.B. Kürzungen der Etats für Führungskräftetrainings und das mit dem Zusammenlegen von Bereichen verbundene rein quantitative Ausdehnen der Verantwortung einzelner Führungskräfte dazu führen, daß diesen aufgrund der Erfordernisse der Abwicklung des unmittelbaren Tagesgeschäftes die zeitlichen Kapazitäten für konzeptionelle Überlegun-

185 Vgl. Frese (1993), S. 1013ff. Für eine ausfuhrliche Darstellung der unterschiedlichen Typen von Zentralbereichen vgl. Frese/Werder (1993), S. $1 \mathrm{ff}$.

186 Vgl. ăhnlich Gerstner (1995), S. 150.

187 Vgl. Gerstner (1995), S. 222, ăhnlich auch Pautzke (1989), S. $118 \mathrm{ff}$. 
gen im allgemeinen und für Selbstorganisationsprozesse im besonderen fehlen. Zielt man in bestimmten Bereichen auf die Förderung von Selbstorganisationsprozessen $a b$, so muß hier entsprechend gegengesteuert werden. Mangelnde zeitliche Kapazität und Flexibilität als Voraussetzung für das Auftreten von Selbstorganisationsprozessen ist jedoch vor allem ein Problem der unteren Hierarchieebenen. Maßnahmen, wie z.B. das Einrichten von Qualitätszirkeln, stellen eine Möglichkeit dar, diesem Personenkreis mehr zeitliche Freiräume zu gewähren. Im Rahmen von Qualitätszirkeln kommen die Mitarbeiter einer hierarchischen Ebene unter Anleitung eines Moderators in regelmäßigen Abständen zusammen, um Problemstellungen ihres eigenen Arbeitsbereiches zu analysieren und Lösungsvorschläge zu erarbeiten, die sodann von ihnen selbst umgesetzt und kontrolliert werden. ${ }^{188}$ Selbstorganisationsprozesse sind somit Teilmenge der Aktivitäten von Qualitätszirkeln.

Im Anschluß an die obige Diskussion der Ressourceninterdependenzen werden im folgenden die mit den verschiedenen Formen der Arbeitsteilung verbundenen Leistungsinterdependenzen untersucht. Dabei werden in einem ersten Schritt die verschiedenen Formen intersystemischer Arbeitsteilung, d.h. der Arbeitsteilung zwischen dem fokussierten Subsystem, innerhalb dessen die Wahrscheinlichkeit für das Auftreten von Selbstorganisationsprozessen durch die Förderung von dessen relativer Autonomie erhöht werden soll, und anderen, ihm nebengeordneten Subsystemen, betrachtet. In einem zweiten Schritt werden sodann die Konsequenzen der verschiedenen Formen intrasystemischer Arbeitsteilung untersucht.

Grundsätzlich gilt, daß die horizontale relative Autonomie der einzelnen Subsysteme bei Mengenteilung höher ist als bei Artenteilung, da bei Mengenteilung keine Leistungsinterdependenzen zwischen den so organisierten Subsystemen existieren. Betrachtet man nämlich eine bestimmte Menge von Subsystemen mit intersystemischer Mengenteilung, so erfüllt jedes der Subsysteme gleichartige Teilaufgabenbündel, so daß der Output eines Subsystems hier nicht Input eines ihm nebengeordneten Subsystems ist. Die Arbeitsergebnisse dieser Subsysteme stehen vielmehr nebeneinander. Stellt man auf die Erhöhung der relativen Autonomie bestimmter Subsysteme ab, so wäre damit die Mengenteilung der Artenteilung vorzuziehen. Die hohe Komplexität der in der Unternehmung zu bewältigenden Aufgabenstellungen läßt Mengenteilung zwischen Subsystemen jedoch zumeist unrealistisch erscheinen. Spezialisierung im Sinne von Beschränkung der von einem Mitarbeiter bzw. einer Mehrzahl von Mitarbeitern zu erledigenden Teilaufgaben ist vielmehr Voraussetzung für eine effiziente Aufgabenerfüllung und - bis auf wenige Einzelfälle - unabdingbar. Mengenteilung als Form der Arbeitsteilung wird deshalb - trotz der damit verbundenen positiven Effekte auf die relative Autonomie der Subsysteme - im folgenden nicht weiter berücksichtigt. 
Stellt man in einem nächsten Schritt funktions- und objektorientierte Spezialisierung als alternative Formen der Arbeitsteilung zwischen einzelnen Subsystemen einander gegenüber, so sind die Leistungsinterdependenzen bei der objektorientierten Spezialisierung tendenziell geringer als bei der funktionsorientierten: Gliedert man einen bestimmten Bereich der Unternehmung bzw. eine bestimmte Menge von Subsystemen der Unternehmung unter funktionalen Aspekten, so ist das einzelne, funktional spezialisierte Subsystem in der Regel sehr viel stärker auf den Output der anderen Subsysteme als Input seines Leistungserstellungsprozesses angewiesen als bei objektorientierter Arbeitsteilung. Bei einer objektorientierten Spezialisierung verfügen die einzelnen Subsysteme entsprechend tendenziell über mehr horizontale Autonomie als bei funktionsorientierter Spezialisierung. ${ }^{189}$ Daraus resultiert gemäß der Perspektive der vorliegenden Arbeit eine tendenzielle Vorziehenswürdigkeit der objektorientierten Spezialisierung. Das folgende Beispiel verdeutlicht diesen Sachverhalt: Gliedert man die Rechnungsbearbeitung funktional und weist dabei die verschiedenen Verrichtungen wie Rechnungserfassung, Rechnungsprüfung, Buchung sowie Anweisung der Zahlung verschiedenen Subsystemen zu, so hängt beispielsweise die Entscheidung der organisatorischen Einheit bezüglich der Banküberweisung des geforderten Betrages von dem Ergebnis der mit der Rechnungsprüfung befaßten organisatorischen Einheit ab. Aufgrund dieser Abhängigkeit von den Arbeitsergebnissen der jeweils vorgelagerten Subsysteme ist die horizontale Autonomie der einzelnen Subsysteme hier entsprechend gering. Gliedert man die Rechnungsbearbeitung dagegen nach Lieferantengruppen und damit objektorientiert und weist einem Subsystem dabei alle Funktionen der Rechnungsbearbeitung für die Rechnungen einer bestimmten Lieferantengruppe zu, so sind die Entscheidungen und Handlungen der Mitglieder dieses Subsystems tendenziell unabhängiger von den Arbeitsergebnissen der anderen Subsysteme. Die horizontale Autonomie der betroffenen Subsysteme ist damit hier regelmäßig höher als im obigen Fall einer funktionalen Gliederung.

Stellt man Kunden, Produkte und Regionen als die wichtigsten Kriterien zur objektorientierten Spezialisierung für Subsysteme einander gegenüber, so können keine über den spezifischen Einzelfall hinaus gültigen Aussagen über deren aus ihrem jeweiligen Einfluß auf die Leistungsinterdependenzen zwischen den Subsystemen (und damit deren horizontaler Autonomie) resultierende relative Vorteilhaftigkeit gemacht werden. ${ }^{190}$ Die Entscheidung für ein bestimmtes Spezialisierungskriterium setzt vielmehr das Überprü-

$189 \mathrm{Vgl}$. Hill/Fehlbaum/Ulrich (1994), S. 187ff.; Kieser/Kubicek (1992), S. 88f.

Allerdings sind Grenzfalle denkbar, in denen eine funktionale Spezialisierung mit einer höheren horizontalen Autonomie einhergeht. Dies ist umso wahrscheinlicher, je stärkere Interdependenzen zwischen den einzelnen Objekten, nach denen spezialisiert wurde, existieren. Existieren beispielsweise ausgeprägte Absatzverbünde zwischen den Produkten einer Unternehmung, so kann es unter Autonomieaspekten u.U. sinnvoll sein, in bestimmten Bereichen anstelle einer Spezialisierung nach Produkten eine funktionale Gliederung vorzunehmen (oder aber mehrere Produkte zu Produktgruppen als Spezialisierungskriterium zusammenzufassen).

$190 \mathrm{Vgl}$. Kieser/Kubicek (1992), S. $90 \mathrm{ff}$. 
fen der spezifischen Gegebenheiten der konkreten Unternehmung, d.h. der Stärke der jeweiligen Interdependenzen zwischen den Objekten, voraus.

Die Möglichkeiten zur Verringerung von Leistungsinterdependenzen zwischen Subsystemen werden auch unter dem Schlagwort der ganzheitlichen Teilaufgabenzuweisung diskutiert. ${ }^{191}$ Diese kann sich nicht nur auf die einzelnen Aufgabenträger beziehen, sondern auch die verschiedenen Subsysteme in der Unternehmung betreffen. Als ganzheitlich kann ein Teilaufgabenbündel bezeichnet werden, sofern die darin zusammengefaßten Teilaufgaben ein 'sinnvolles Ganzes' darstellen. Bei einem 'sinnvollen Ganzen' sind die Interdependenzen zwischen den einzelnen Teilaufgaben innerhalb des Teilaufgabenbündels regelmäßig stärker ausgeprägt als die zwischen diesem und anderen Teilaufgabenbündeln. Dies ist insbesondere dann der Fall, wenn der aus der Erfüllung des Teilaufgabenbündels resultierende Output eine abgeschlossene Teilleistung, wie z.B. ein vollständiges Zwischen- oder Endprodukt, darstellt. ${ }^{192}$ Als Beispiel für die ganzheitliche Teilaufgabenzuweisung auf der Subsystemebene können teilautonome Fertigungsgruppen ${ }^{193}$ genannt werden.

Teilautonome Fertigungsgruppen bestehen aus einer Mehrzahl von Personen (meist ca. 5-10) mit unterschiedlichen Ausgangsqualifikationen, denen ein bestimmtes, inhaltlich zusammenhängendes Teilaufgabenbündel zugewiesen wird. ${ }^{194}$ Ziel der Bildung teilautonomer Fertigungsgruppen ist es, die Flexibilität der Fertigung sowie die Motivation der Mitarbeiter (Humanisierung der Arbeit) zu erhöhen, indem der Gruppe als Ganzem die Verantwortung für die Erfüllung des von ihr zu erfüllenden Teilaufgabenbündels gemeinsam mit verschiedenen, damit zusammenhängenden Kompetenzen übertragen wird. Dabei bleibt die Feinplanung des Leistungserstellungsprozesses, seine Kontrolle und insbesondere die Verteilung des Teilaufgabenbündels auf ihre einzelnen Mitglieder der Gruppe selbst überlassen. Im Gegensatz zu prozeßintegrierten Arbeitsgruppen im Rahmen von Lean Production-Ansätzen, bei denen eine taktmäßige Fließfertigung erfolgt, werden hier Fertigungs- und Montageinseln eingerichtet, die mit einer deutlich höheren relativen Autonomie der einzelnen Fertigungsgruppe einhergehen. Durch die wechselnde Übernahme bestimmter Teilaufgaben innerhalb der teilautonomen Fertigungsgruppe erlangen deren Mitglieder trotz unterschiedlicher Ausgangsqualifikationen die Fähigkeit zur Erfüllung mehrerer, im Idealfall aller anfallenden Teilaufgaben (Flexibilisierung der Fertigung). Die klare Zuordnung der Verantwortung für ein bestimmtes, in sich möglichst abgeschlossenes Arbeitsergebnis sowie die Übertragung dispositiver Tätigkeiten auf die Mitarbeiter der Gruppe hat positive motivationale Effekte. Als Beispiel sei hier eine teilautonome Fertigungsgruppe in der Automobilindustrie genannt, der die komplette Montage der Karrosserie eines Autos

191 Vgl. Gerstner (1995), S. 221; Kieser (1994), S. 201, 225.

$192 \mathrm{Vgl}$. als vom Grundgedanken her ănnlich, dort jedoch bezüglich der Zuordnung von Teilaufgaben zu einzelnen Stellen Hill/Fehlbaum/Ulrich (1994), S. 306ff.

193 Vgl. Picot (1993), S. 173.

194 Vgl. dazu und im folgenden Bühner/Pharao (1993), S. 46; Grün (1993), S. $50 \mathrm{ff}$. 
übertragen wird. Die Gruppe erhält das Chassis von einem ihr vorgelagerten Arbeitssystem als Input ihres Leistungserstellungsprozesses und muß ihr Arbeitsergebnis an ein ihr nachgelagertes Arbeitssystem als Input für dessen Leistungserstellungsprozeß übergeben. Entsprechend ist ihr Leistungserstellungsprozeß unmittelbar von dem des vorgelagerten Arbeitssystems abhängig (nicht autonom). Innerhalb der Grenzen des ihr zugewiesenen Aufgaben-, Verantwortungs- und Kompetenzbereiches kann sie jedoch frei entscheiden und handeln (Teil- bzw. relative Autonomie). Je ausgeprägter diese relative Autonomie ist, desto höher ist die Wahrscheinlichkeit für das Auftreten emergenter und nicht-emergenter Selbstorganisationsprozesse, die insbesondere ablauforganisatorische Aspekte der Leistungserstellung durch die Gruppe betreffen werden.

Zusammenfassend ist bezüglich der intersystemischen Arbeitsteilung festzustellen, daß die objektorientierte Spezialisierung - und dabei insbesondere eine ganzheitliche Teilaufgabenzuweisung - besser als die funktionale Spezialisierung der Subsysteme geeignet ist, deren relative Autonomie und damit das Auftreten von emergenten und nicht-emergenten Selbstorganisationsprozessen als organisationalem Lernen zu fördern.

Betrachtet man in einem nächsten Schritt die intrasystemische Arbeitsteilung im Sinne der Arbeitsteilung innerhalb eines bestimmten Subsystems und damit zwischen den einzelnen Aufgabenträgern ${ }^{195}$ dieses Subsystems, so muß hier zunächst das Konstrukt der relativen Autonomie eines Subsystems gegenüber einzelnen seiner Mitglieder als weitere Form der relativen Autonomie vorgestellt werden. Die bisherigen Ausführungen der vorliegenden Arbeit bezogen sich auf die relative Autonomie eines Subsystems gegenüber anderen Subsystemen (als seiner Umwelt). Es war gezeigt worden, daß die Wahrscheinlichkeit für das Auftreten von Selbstorganisationsprozessen als Prozessen organisationalen Lernens in einem Subsystem umso höher ist, je ausgeprägter dessen Autonomie gegenüber anderen Subsystemen ist. Darüber hinaus kann jedoch auch die relative Autonomie eines Subsystems gegenüber einzelnen seiner Mitglieder untersucht werden. Diese drückt die Stärke der Abhängigkeit der Entscheidungen und Handlungen eines Subsystems als Ganzen gegenüber einem einzelnen seiner Mitglieder aus. Betrachtet man als Beispiel die Verbreitung bestimmter Qualifikationen innerhalb eines Subsystems, so sind die Entscheidungen und Handlungen des gesamten Subsystems immer dann sehr stark von einem einzelnen seiner Mitglieder abhängig, wenn dieses über eine ansonsten nicht vorhandene, für den Leistungserstellungsprozeß des Subsystems jedoch essentielle Qualifikation verfügt. Bestehen dagegen ausgeprägte Mehrfachqualifikationen in dem Sinne, daß mehrere Mitglieder des Subsystems über dieselbe Qualifikation verfügen, führen personelle Engpässe, z.B. aufgrund von Krank-

195 Aus Grunden der Vereinfachung wird die Argumentation im folgenden auf die Unterscheidung zwischen dem jeweils fokussierten Subsystem der Unternehmung (als multipersoneller Einheit) auf der einen und einzelnen Aufgabenträgern als Elementen dieser multipersonellen Einheit auf der anderen Seite beschrănkt. Grundsătzlich kann ein bestimmtes Subsystem jedoch wiederum aus mehreren multipersonellen Subsystemen bestehen, wie bereits in den Ausfuhrungen zu einer mehrstufigen Systemgliederung in Abschnitt 4.1.4 der vorliegenden Arbeit herausgearbeitet wurde. 
heit, hier weniger zu Problemen, denn die relative Autonomie des Subsystems als Ganzen gegenüber seinen einzelnen Mitgliedern ist hier höher.

Die verschiedenen Formen der intrasystemischen Arbeitsteilung (Mengenteilung, funktions- oder objektorientierte Spezialisierung) haben keine Auswirkungen auf die relative Autonomie des Subsystems gegenüber anderen Subsystemen, da die Leistungs- und Ressourceninterdependenzen zwischen dem Subsystem und anderen Subsystemen von der Art der intrasystemischen Arbeitsteilung unberührt bleiben. Als Beispiel sei hier auf die Interdependenzen zwischen dem Subsystem einer Unternehmung, das mit der Rechnungsbearbeitung betraut ist, und dem, das für die Wareneingangskontrolle zuständig ist, verwiesen. Das Subsystem 'Rechnungsbearbeitung' erhält vom Subsystem 'Wareneingangskontrolle' Daten als Input für die Rechnungsprüfung. Die Intensität dieser Beziehung zwischen den beiden Subsystemen als Ganzen ist unabhängig davon, ob die Rechnungsbearbeitung subsystemintern funktional oder objektorientiert (nach Lieferantengruppen) organisiert wird.

Betrachtet man dagegen die relative Autonomie des Subsystems als Ganzen gegenüber einzelnen seiner Mitglieder, so ergeben sich durchaus Unterschiede zwischen den verschiedenen Formen der intrasystemischen Arbeitsteilung: Reine Mengenteilung zwischen den Mitgliedern des Subsystems bedeutet, daß jedes Mitglied des Subsystems alle diesem zugeordneten Arten von Verrichtungen ausführt und damit einer den anderen ersetzen kann (Dies wäre im obigen Beispiel immer dann der Fall, wenn die Rechnungsbearbeitung subsystemintern nach dem Datum des Rechnungseingangs verteilt würde.). Eine solche Übernahme der Teilaufgaben eines Mitarbeiters durch einen anderen ist bei objekt- und insbesondere bei funktionsorientierter Spezialisierung dagegen in der Regel nicht möglich. Die relative Autonomie des Subsystems gegenüber seinen einzelnen Mitarbeitern ist bei Mengenteilung somit höher als bei Artenteilung.

Im Gegensatz zu der relativen Autonomie eines Subsystems gegenüber anderen Subsystemen der Unternehmung (als seiner Umwelt) kann für eine Erhöhung der Autonomie des Subsystems gegenüber seinen einzelnen Mitarbeitern kein positiver Zusammenhang mit der Wahrscheinlichkeit für das Auftreten von Selbstorganisationsprozessen als Prozessen organisationalen Lernens aufgezeigt werden. Denn das Auftreten emergenter Selbstorganisationsprozesse hängt vom Grad der Synreferenz eines Subsystems bzw. dem Grad seiner operationellen Schließung gegenüber seiner Umwelt ab, die seine relative Autonomie gegenüber dieser Umwelt bedingen, nicht jedoch von der Autonomie des Subsystems gegenüber seinen einzelnen Mitarbeitern. Das Auftreten nichtemergenter Selbstorganisationsprozesse hängt von dem entsprechenden Willen der Mitarbeiter sowie ihren Kommunikationsmöglichkeiten ab, und auch diese werden von der Autonomie des Subsystems gegenüber seinen einzelnen Mitarbeitern nicht beeinflußt. Da intrasystemische Mengenteilung damit das Auftreten von Selbstorganisationsprozessen nicht fördert, findet sie im Rahmen der vorliegenden Arbeit keine weitere Berücksichtigung. 
Vergleicht man zusammenfassend die Ergebnisse der bisherigen Ausführungen bezüglich der verschiedenen Arten der Arbeitsteilung, so gelangt man inter- und intrasystemisch zu unterschiedlichen Ergebnissen: Während intersystemisch eine relative Vorziehenswürdigkeit der objektorientierten Spezialisierung konstatiert wurde, hat die Art der intrasystemischen Arbeitsteilung keinen Einfluß auf die Wahrscheinlichkeit für das Auftreten von Selbstorganisationsprozessen als Prozessen organisationalen Lernens. Geht man von einer hierarchischen Anordnung mehrerer Subsysteme im Rahmen der in Abschnitt 4.1.4 beschriebenen Mehrebenen-Betrachtung aus, so erscheinen diese unterschiedlichen Ergebnisse der inter- sowie der intrasystemischen Betrachtung auf den ersten Blick als problematisch: Denn (fast) jede intrasystemische Perspektive kann auf der nächsttieferen Subsystemebene in eine intersystemische Perspektive überführt werden. Betrachtet man beispielsweise ein bestimmtes Subsystem X, so ist eine funktionsorientierte Arbeitsteilung innerhalb dieses Subsystems (intrasystemisch) unerheblich für die Wahrscheinlichkeit des Auftretens von Selbstorganisationsprozessen in diesem Subsystem. Auf der nächsttieferen Hierarchieebene, auf der das Subsystem X wiederum in die drei Subsysteme a, b und c untergliedert wird, ist der funktionsorientierten Arbeitsteilung dagegen tendenziell eine objektorientierte vorzuziehen, um die Wahrscheinlichkeit für das Auftreten von Selbstorganisationsprozessen innerhalb dieser Subsysteme zu fördern. Dieser scheinbare Widerspruch in den Gestaltungsempfehlungen für die verschiedenen Subsystemebenen wird dadurch aufgelöst, daß im Vorfeld potentieller Gestaltungsaktivitäten in der betrieblichen Praxis zunächst zu klären ist, welche Subsystemebene fokussiert wird bzw. innerhalb welcher Subsysteme der Unternehmung Selbstorganisationsprozesse gefördert werden sollen. Die Gestaltungsempfehlungen unterscheiden sich je nachdem, ob Selbstorganisationsprozesse in $\mathrm{X}$ oder in $\mathrm{a}, \mathrm{b}$ und $\mathrm{c}$ oder in $\mathrm{X}$ und in $\mathrm{a}, \mathrm{b}$ und $\mathrm{c}$ gefördert werden sollen.

Die Unterscheidung zwischen der relativen Autonomie eines Subsystems gegenüber anderen Subsystemen und der gegenüber einzelnen seiner Mitglieder ist wesentlich für die Einordnung des erstmals von PROBST im Zusammenhang mit Selbstorganisationsprozessen diskutierten, aber auch von anderen Autoren aufgegriffenen Phänomens der 'Spezialisierung auf die Unternehmung' in den Argumentationszusammenhang der vorliegenden Arbeit. Dort wird gefordert, die übliche Spezialisierung der Mitarbeiter auf Funktionen durch eine Spezialisierung auf die Unternehmung zu ersetzen. Spezialisierung auf die Unternehmung bedeutet dabei, daß ein Mitarbeiter im Zeitverlauf verschiedene Funktionen innerhalb einer Unternehmung übernimmt und damit einen breiten Überblick über die spezifische Situation dieser einen Unternehmung gewinnt anstatt seine Kenntnisse innerhalb eines bestimmten Teilbereiches der Unternehmung immer weiter zu vertiefen. ${ }^{196}$ Letztlich bedeutet das eine Förderung von (funktionalem) Generalisten- statt (funktionalem) Spezialistentum. Denn interpersonelle Arbeitsteilung muß

196 Vgl. Probst (1987), S. 136f., ferner z.B. Gerstner (1995), S. 149f., 181. Ouchi sieht in dieser Spezialisierung auf die Unternehmung den entscheidenden Unterschied japanischer Karriereverlăufe zu der funktionalen Orientierung amerikanischer Laufbahnen. Vgl. Ouchi (1981), S. 29ff. 
keineswegs ein statisches Phänomen darstellen. Die einmal vorgenommene Zusammenfassung verschiedener Teilaufgaben und deren Zuordnung zu bestimmten Personen kann vielmehr im Zeitablauf variieren. Dies setzt einerseits eine entsprechende Qualifikation und Lernfähigkeit der Mitarbeiter zur Wahrnehmung unterschiedlicher Teilaufgaben voraus, andererseits führt die Wahrnehmung unterschiedlicher Teilaufgaben durch einen Mitarbeiter zu einer Verbreiterung seiner Qualifikation. Es handelt sich hier somit um eine Erhöhung der Redundanz der Funktionen bzw. der Fähigkeiten und Möglichkeiten ${ }^{197}$ der Mitarbeiter. Immer dann, wenn Mitarbeiter innerhalb ein und desselben Subsystems im Zeitverlauf verschiedene Teilaufgaben übernehmen, fördert die daraus entstehende Redundanz der Qualifikationen bzw. dieser Organizational Slack zwar die Autonomie des Subsystems gegenüber seinen einzelnen Mitarbeitern. Positive Auswirkungen auf die Wahrscheinlichkeit für das Auftreten von Selbstorganisationsprozessen resultieren daraus - wie oben gezeigt - jedoch nicht. Lediglich dann, wenn Mitarbeiter im Zeitverlauf unterschiedlichen Subsystemen zugeordnet werden und dort unterschiedliche Teilaufgaben übernehmen, führt ihre daraus resultierende subsystemübergreifende Qualifikation zu einer höheren Autonomie des Subsystems gegenüber eben jenen Subsystemen, deren Know-how nun auch innerhalb des fokussierten Subsystems vorhanden ist. Diese höhere relative Autonomie des Subsystems bedingt wiederum eine höhere Wahrscheinlichkeit für das Auftreten emergenter und nichtemergenter Selbstorganisationsprozesse. Deshalb gilt es, im Rahmen der organisatorischen Gestaltung die Grenzen zwischen den einzelnen Subsystemen der Unternehmung im Zeitverlauf flexibel und durchlässig zu gestalten. ${ }^{198}$ Zusammenfassend ist somit festzustellen, daß der in der Literatur implizierte positive Zusammenhang zwischen der Förderung einer 'Spezialisierung auf die Unternehmung' und dem Auftreten von Selbstorganisationsprozessen nur für den Fall der subsystemübergreifenden Dynamisierung der Arbeitsteilung (und der daraus resultierenden Mehrfachqualifikationen) besteht.

In der Literatur wird ferner auch das Einrichten einer eigenen Forschungs- und Entwicklungsabteilung innerhalb der Unternehmung (im Gegensatz zur unternehmungsexternen Auslagerung der Forschung und Entwicklung) als Maßnahme zur Förderung des Auftretens von Selbstorganisationsprozessen genannt. ${ }^{199}$ Die Argumentation stellt dabei auf die damit verbundene Förderung der Selbst- bzw. gemäß der Terminologie der vorliegenden Arbeit Synreferenz des Systems Unternehmung ab. Diese geht mit einer Förderung der Autonomie der gesamten Unternehmung gegenüber ihrer Umwelt einher. Da bezogen auf das System Unternehmung als Ganzes alle organisatorischen Tätigkeiten innerhalb dieses Systems Selbstorganisationsprozesse sind, eine Abgrenzung zwischen Selbst- und Fremdorganisation hier somit nicht möglich ist, wird diese

197 Siehe Abschnitt 4.1.3.2.4 der vorliegenden Arbeit.

198 Vgl. Probst (1987), S. 142f.

199 Vgl. z.B. Gerstner (1995), S. 190f., $216 \mathrm{ff}$. 
Perspektive im Rahmen der vorliegenden Arbeit nicht verfolgt. ${ }^{200}$ Auf die Autonomie der verschiedenen Subsysteme der Unternehmung, die im Zentrum der vorliegenden Ausführungen steht, hat die Einrichtung einer unternehmungsinternen Forschungs- und Entwicklungsabteilung keinen Einfluß und findet deshalb im folgenden keine weitere Berücksichtigung.

Abbildung 4/13 faßt abschließend die in diesem Abschnitt diskutierten Möglichkeiten zur Förderung organisationalen Lernens in Form von Selbstorganisationsprozessen im Rahmen der Gestaltung der organisatorischen Regeln zur Arbeitsteilung zusammen. Dabei werden jene Gestaltungsempfehlungen in den Vordergrund gestellt, die mögliche Ansatzpunkte für das Informationsmanagement bieten und die entsprechend in Kapitel 5 wieder aufgegriffen werden.

\section{Ressourceninterdependenzen:}

o kein eindeutiger Zusammenhang zwischen Art der Arbeitsteilung und Ressourceninterdependenzen

O Organizational Slack erhöhen, insbesondere bezüglich Faktor Zeit

\section{Leistungsinterdependenzen:}

O intersystemisch:

objektorientierte Arbeitsteilung gegenüber funktionsorientierter

vorzuziehen (z.B. ganzheitliche Teilaufgabenzuweisung, teilautonome Fertigungsgruppen)

O intrasystemisch:

'Spezialisierung auf die Unternehmung' nur bei im Zeitverlauf variierender Zugehörigkeit der Mitarbeiter zu unterschiedlichen Subsystemen

Abb. 4/13: Gestaltungsempfehlungen für die Arbeitsteilung in der lernenden Unternehmung

\subsubsection{Organisatorische Regeln zur Koordination}

Aus der arbeitsteiligen Aufgabenerfüllung in der Unternehmung resultiert die Notwendigkeit, die Aktivitäten der einzelnen Mitarbeiter und Subsysteme untereinander abzustimmen und auf das Zielsystem der Unternehmung auszurichten. Ausgangspunkt für die Betrachtung der Dimension Koordination ist deshalb die Frage, mit Hilfe welcher 
Mechanismen bzw. Instrumente dies erfolgen kann. In Anlehnung an KIESER/KUBICEK kann man anhand des jeweiligen Koordinationsmediums innerhalb der Hauptdimension Koordination folgende vier Teildimensionen bzw. Koordinationsinstrumente unterscheiden:201

- Koordination durch persönliche Weisungen,

- Koordination durch Programme,

- Koordination durch Pläne,

- Koordination durch Selbstregelung.

Diese Systematisierung setzt an den Koordinationsmedien aus der Sicht der koordinierten Mitarbeiter bzw. Subsysteme in der Unternehmung an: Während Koordination durch persönliche Weisungen und Selbstregelung auf unmittelbarer persönlicher Kommunikation beruhen, verselbständigen sich die Medien bei der Koordination durch Programme und Pläne insofern, als die Regelung hier von den Betroffenen nicht mehr als Ergebnis von Entscheidungen bestimmter Personen, sondern als unpersönlich aufgefaßt wird.

Koordination durch persönliche Weisungen beruht auf der unmittelbaren persönlichen Kommunikation. Als Beispiel sei hier auf die Anweisungen eines Werkstattmeisters gegenüber seinen Mitarbeitern verwiesen, die ablauforganisatorische Aspekte der Bearbeitung bestimmter Fertigungsaufträge betreffen.

Ein Programm ist eine intersubjektiv nachvollziehbare Folge von Instruktionen an einzelne menschliche Aufgabenträger oder Subsysteme in der Unternehmung, die standardisierte Vorgaben für deren Handeln enthält. Programme beinhalten damit verbindliche Vorgaben, wie, d.h. nach welchem Verfahren, diese die ihnen zugeordneten Teilaufgabenbündel erfüllen sollen. Häufig werden solche generellen Handlungsanweisungen in Verfahrensrichtlinien oder sogenannten Organisationshandbüchern schriftlich fixiert. Je nach konkreter Ausgestaltung der Programme kann der Standardisierungseffekt bezüglich der durch sie koordinierten Handlungen unterschiedlich stark sein. Ein Beispiel für Koordination durch Programme sind die Arbeitspläne für die Montage der Auspuffanlage eines Kraftfahrzeuges im Fertigungsbereich.

Koordination durch Pläne bedeutet, daß die einzelnen menschlichen Aufgabenträger und Subsysteme periodisch bestimmte Vorgaben erhalten, die ihr Handeln koordinieren. ${ }^{202}$ Im Gegensatz zu Programmen, die die durch sie koordinierten Handlungen auf Dauer festlegen und keine Ziele, sondern konkrete Handlungsanweisungen beinhalten,

201 Vgl. dazu und im folgenden Kieser/Kubicek (1992), S. 95, 103ff. sowie ergänzend Hill/Fehlbaum/Ulrich (1994), S. 266ff. Aufgrund der terminologischen Festlegungen der vorliegenden Arbeit wird hier der von Kieser/Kubicek verwendete Begriff der Selbstabstimmung durch den der Selbstregelung ersetzt. Siehe Abschnitt 4.1.1 der vorliegenden Arbeit.

202 Somit wird hier ein engerer als der von Mag vorgeschlagene weite Planungsbegriff verwendet, der unter Planung die gedankliche Vorbereitung zuküntiger Entscheidungen und Handlungen versteht. Vgl. Mag (1995), S. 2. 
gelten Pläne nur für einen bestimmten Zeitraum und beinhalten stets Ziele. ${ }^{203}$ Als Beispiel sei hier auf Pläne in der Fertigung verwiesen, die vorgeben, daß die Fertigungsgruppe $\mathrm{X}$ in der 3. Kalenderwoche Y Karrosserien des Kraftfahrzeugtyps Z montieren soll.

Selbstregelung stellt schließlich die vierte Koordinationsalternative dar. Im Gegensatz zu Koordination durch persönliche Weisung, durch Programme und durch Pläne als Ausprägungen von Fremdregelung eines Subsystems erfolgt die Regelung des fokussierten Subsystems hier aus diesem selbst heraus. Grundsätzlich umfaßt Selbstregelung einerseits (situative) ad-hoc-Selbstregelung, andererseits (präsituative) Selbstorganisationsprozesse. ${ }^{204} \mathrm{Da}$ im Rahmen der vorliegenden Arbeit davon ausgegangen wird, daß das explizite Akzeptieren von Selbstregelungsprozessen im allgemeinen und Selbstorganisationsprozessen im besonderen durch das Management ihrem Ignorieren vorzuziehen ist, bedeutet das, daß das systematische Schaffen von Freiräumen für Selbstregelungsprozesse eine unmittelbare Alternative $\mathrm{zu}$ den traditionellen Koordinationsmechanismen persönliche Weisung, Programme und Pläne darstellt. Dabei werden den Mitarbeitern von den dazu legitimierten Instanzen explizit Kompetenzen zur Selbstabstimmung eingeräumt, so daß die organisatorischen Regeln, die Ergebnis solcher Prozesse sind, nicht länger nur informalen Charakter haben, sondern formaler Natur, d.h. offiziell legitimiert, sind.

Vergleicht man die genannten vier Koordinationsinstrumente, so ist unmittelbar und ohne jede weitere theoretische Begründung einsichtig, daß das explizite Schaffen von Freiräumen für Selbstregelungsprozesse, zu denen eben auch Selbstorganisationsprozesse zählen, deren Auftreten am meisten fördert. Ebenso unmittelbar einsichtig ist jedoch auch, daß die Gestaltungsempfehlungen bezüglich der zu wählenden Koordinationsmechanismen in der lernenden Unternehmung sich nicht allein auf das Gewähren von Freiräumen für Selbstorganisationsprozesse beschränken können. Denn aufgrund der fehlenden inhaltlichen Vorgaben bestände die Gefahr, daß die damit verbundene Autonomie des fokussierten Subsystems die relative Autonomie des ihm übergeordneten Subsystems und letztlich der Unternehmung als Ganzen gefährdet. ${ }^{205}$ Deshalb gilt es im folgenden, zu Aussagen bezüglich einer geeigneten Kombination der vier Koordinationsinstrumente zu gelangen. Dies setzt ihre Bewertung mit Hilfe eines passenden Kriteriums voraus.

203 Daruber hinaus können Plăne aber auch Verfahren vorgeben. Bezüglich ihrer jeweiligen Inhalte sind Programme und Plăne somit nicht immer trennscharf zu unterscheiden. Im Gegensatz zu der an Kieser/Kubicek orientierten, hier zugrundegelegten Trennung zwischen Programmen und Plănen thematisieren Steinmann/Schreyögg deshalb lediglich die Koordination durch Programme und unterscheiden dabei zwischen Routine- und Zweckprogrammen, wobei Zweckprogramme im wesentlichen den hier vorgestellten Plănen entsprechen. Vgl. Steinmann/Schreyðgg (1993), S. 404.

204 Für eine Gegenuberstellung von Selbst- und Fremdregelung einschließlich der Unterscheidung zwischen ad-hoc-Selbstregelung und Selbstorganisation siehe Abschnitt 4.1.1, fur eine Gegenuberstellung von Selbst- und Fremdorganisation als speziellen Ausprägungen von Selbst- und Fremdregelung siehe Abschnitt 2.2.1.3 der vorliegenden Arbeit.

Siehe Abschnitt 4.1.4 der vorliegenden Arbeit. 
In der Selbstorganisations-Literatur wird regelmäßig die Auflösung starrer Koppelungsbeziehungen in und zwischen Subsystemen und ihr Ersetzen durch lose Koppelung zwecks Förderung von Selbstorganisationsprozessen postuliert. Gewöhnlich fehlt dabei jedoch sowohl eine organisationstheoretisch fundierte Operationalisierung dieser aus der modernen Systemtheorie entlehnten Begriffe als auch die theoretische Begründung für einen Zusammenhang zwischen der Art der Koppelung und dem Auftreten von Selbstorganisationsprozessen. ${ }^{206}$ Diese argumentativen Defizite gilt es im folgenden zu beheben. Starre und lose Koppelung werden hier als Ausprägungen auf dem Kontinuum unterschiedlicher Varietät der koordinierten Handlungen interpretiert. Die Varietät der koordinierten Handlungen bei Einsatz eines bestimmten Koordinationsmechanismus wird ihrerseits definiert als die Anzahl möglicher Verhaltensweisen, die bei der Abwicklung eines bestimmten Prozesses zugelassen sind. ${ }^{207}$ Lose Koppelung im Sinne einer hohen Varietät der Handlungen innerhalb eines bestimmten Bereiches bedeutet, daß hier vielfältige Verhaltensweisen möglich sind. Diese Möglichkeit vielfältiger Verhaltensweisen ist wiederum Ausdruck einer hohen Handlungsautonomie, die - wie in Abschnitt 4.1.3.2.3 begründet - das Auftreten von emergenten und nicht-emergenten Selbstorganisationsprozessen fördert.

Argumentiert man über die mit den verschiedenen Koordinationsinstrumenten verbundene Varietät der koordinierten Handlungen, so bestätigt dies die oben formulierte Präferenz für das explizite Gewähren von Freiräumen für Selbstregelungsprozesse im allgemeinen und Selbstorganisationsprozesse im speziellen. Die Varietät der koordinierten Handlungen ist hier am höchsten, da die Entscheidungen über die organisatorischen Regeln innerhalb des gewährten Freiraumes den Betroffenen selbst überlassen werden. Das Management hat hier keinen Einfluß auf die konkrete Ausgestaltung dieser organisatorischen Regeln. Die relative Autonomie des fokussierten Subsystems - und damit die Wahrscheinlichkeit für das Auftreten von Selbstorganisationsprozessen - ist also dann am höchsten, wenn die dazu legitimierten Instanzen diesem ceteris paribus explizit Freiräume für Selbstabstimmungsprozesse - und damit auch Selbstorganisationsprozesse - einräumen.

Dagegen bedeutet Koordination durch persönliche Weisung, daß eine klare personelle Trennung zwischen Führungs- und Durchführungsaufgaben erfolgt. Die persönlichen Weisungen des außerhalb des fokussierten Subsystems stehenden Vorgesetzten bestimmen die Handlungen der einzelnen Mitarbeiter innerhalb des Subsystems. Die Varietät der so koordinierten Handlungen hängt von der konkreten Ausgestaltung der

Vgl. z.B. Klimecki/Probst/Eberl (1991), S. 144f.; Steinle/Bruch/Müller (1996), S. 651.

$207 \mathrm{Vgl}$. Hill/Fehlbaum/Ulrich (1994), S. 266f., die zur Betonung des Aspektes der mit den verschiedenen Koordinationsinstrumenten verbundenen unterschiedlichen Varietăt der koordinierten Handlungen anstelle der Bezeichnung 'Koordination' für eine der zentralen Dimensionen der organisatorischen Gestaltung die der 'Standardisierung' als der geplanten oder zugelassenen Varietăt bei der Aufgabenerfullung wăhlen. 
persönlichen Weisungen im spezifischen Einzelfall ab. Deshalb wird Koordination durch persönliche Weisung im folgenden nicht weiter berücksichtigt.

Bei der Koordination durch Programme tritt das Programm als generalisierte Handlungsanweisung an die Stelle der persönlichen Weisung des Vorgesetzten. Wie zuvor die persönliche Weisung regeln hier die Wenn-Dann-Aussagen des Programmes das konkrete Verhalten der Mitglieder des Subsystems. Dabei wird das einzelne Problem einer Problemklasse zugeordnet, für die wiederum bestimmte Verfahren zur Problemlösung festgelegt worden sind. Zwar schwankt die Varietät des Verhaltens der Subsystemmitglieder in Abhängigkeit von der konkreten Ausgestaltung der Programme. Tendenziell ist sie aufgrund der Verhaltensvorgaben der Programme jedoch gering. Entsprechend verfügt das Subsystem hier über eine geringe Autonomie. Die Wahrscheinlichkeit für das Auftreten von Selbstorganisationsprozessen ist relativ gering.

Im Gegensatz zur Koordination durch Programme werden bei der Koordination durch Pläne vor allem Zielvorgaben formuliert. Von Ausnahmen abgesehen beziehen sich die Vorgaben hier nicht auf die einzusetzenden Verfahren. ${ }^{208}$ Im Vergleich zu Programmen sind Pläne somit regelmäßig weniger detailliert. Beispielsweise kann für eine unternehmungsinterne Werbeabteilung eines Konsumgüterproduzenten das Ziel formuliert werden, den Bekanntheitsgrad einer Marke $\mathrm{X}$ in dem Kundensegment $\mathrm{Y}$ um $10 \% \mathrm{zu}$ erhöhen. Zugleich obliegt die Wahl der dabei einzusetzenden Mittel, wie z.B. Fernseh-, Zeitungswerbung oder Mailing den Mitarbeitern der Abteilung, d.h. sie können zwischen mehreren alternativen Verhaltensweisen wählen. Varietät und Autonomie des mittels Plan koordinierten Subsystems sind somit höher als bei der Koordination durch Programme. Die Wahrscheinlichkeit für das Auftreten von Selbstorganisationsprozessen ist hier entsprechend höher.

Bei der Ermittlung einer geeigneten Kombination der verbleibenden drei Koordinationsmechanismen anhand der mit diesen verbundenen Varietät der koordinierten Handlungen kann - analog der im Rahmen der Ausführungen zur Arbeitsteilung in Abschnitt 4.2.1 vorgenommenen Unterscheidung zwischen intersystemischer und intrasystemischer Arbeitsteilung - zwischen der Koordination innerhalb des fokussierten Subsystems (intrasystemisch) einerseits und der Koordination zwischen diesem Subsystem und anderen Subsystemen (intersystemisch) unterschieden werden. Beide Arten der Koordination haben Einfluß auf die relative Autonomie eines Subsystems.

Stellt man auf ein bestimmtes Subsystem ab, innerhalb dessen das Auftreten von Selbstorganisationsprozessen gefördert werden soll, so zeigen die obigen Ausführungen, daß es sich bezüglich der intrasystemischen Koordination zunächst einmal anbietet, durch das explizite Einräumen von Freiräumen für Selbstregelungsprozesse im allgemeinen und Selbstorganisationsprozesse im besonderen eine hohe Varietät der koordinierten Handlungen zu ermöglichen. Denn aus dieser hohen Varietät resultiert eine

Vgl. Kieser/Kubicek (1992), S. 114. 
hohe Wahrscheinlichkeit für das Auftreten von Selbstorganisationsprozessen. Ohne die Ergänzung durch andere Koordinationsinstrumente geht dies jedoch mit dem Verlust jeglichen inhaltlichen Einflusses des Managements auf die Ergebnisse der Selbstorganisationsprozesse einher. Zwar bedeutet das eine vergleichsweise hohe relative Autonomie des betroffenen Subsystems, die relative Autonomie des ihm übergeordneten Subsystems - und letztlich der Unternehmung als Ganzen - ist jedoch gefährdet, da ein positiver Beitrag des Subsystems zu deren Zielen nicht sichergestellt ist. Deshalb gilt es, eine klare Abgrenzung des jeweiligen autonomen Bereiches unter expliziter Benennung der gewährten Gestaltungsspielräume vorzunehmen. Einen solchen Rahmen stellen Pläne dar, die Zielvorgaben für die Handlungen und Entscheidungen innerhalb des Subsystems angeben. Diese Zielvorgaben sollten insbesondere die Qualität und Quantität des Subsystemoutputs betreffen. Diese Planung des Subsystemoutputs kann darüber hinaus jedoch auch Basis für eine Budgetplanung sein, so daß die Pläne dann sowohl den Output als auch den Input des Subsystems betreffen. Da die Entscheidungen bezüglich der konkreten Transformation des Inputs in Output im Rahmen des Leistungserstellungsprozesses des Subsystems jedoch den Mitgliedern des Subsystems selbst obliegen, ist hier weiterhin eine vergleichsweise hohe Varietät der so koordinierten Handlungen möglich. Bezüglich der intrasystemischen Koordination ist somit eine Kombination aus dem expliziten Gewähren von Freiräumen für Selbstorganisationsprozesse und Plänen zu fordern, um die Wahrscheinlichkeit für das Auftreten von Selbstorganisationsprozessen als Prozessen organisationalen Lernens zu erhöhen.

Betrachtet man in einem nächsten Schritt die Möglichkeiten zur intersystemischen Koordination, so gilt auch hier zunächst, daß das explizite Gewähren von Freiräumen für Selbstorganisationsprozesse zwischen den Subsystemen deren relative Autonomie und damit das Auftreten von Selbstorganisationsprozessen als Prozessen organisationalen Lernens am stärksten fördert. Bedenkt man jedoch, daß solche Freiräume bereits intrasystemisch gewährt werden, so würde der Verzicht des Managements auf inhaltliche Lenkung der intersystemischen Koordination nicht nur die relative Autonomie übergeordneter Subsysteme bedrohen, sondern u.U. auch ein so hohes Maß an durch die Subsysteme zu verarbeitender Komplexität bedingen, daß diese durch die ihnen gewährten Freiräume überfordert sein könnten. Die intersystemische Koordination durch Pläne und/oder Programme stellt hier eine Möglichkeit dar, um die durch die Subsysteme zu verarbeitende Komplexität zu reduzieren. Das Gewähren von Freiräumen für intrasystemische Selbstorganisationsprozesse in Kombination mit dem Einsatz von auf das einzelne Subsystem bezogenen Plänen wird dann eingebettet in klare Rahmenvorgaben für die intersystemische Koordination in Form von Plänen und Programmen. Dadurch wird dem Subsystem zwar einerseits die Möglichkeit eingeräumt, bezüglich bestimmter, klar definierter Kompetenzbereiche (intrasystemisch) selbstorganisierend tätig zu werden. Gleichzeitig werden jedoch Ziel- bzw. Rahmenvorgaben formuliert, die einerseits den Beitrag des Subsystems zur Zielerreichung des nächsthöheren Subsystems festlegen und andererseits die (intersystemische) Koordination zwi- 
schen dem fokussierten Subsystem und den ihm nebengeordneten Subsystemen regeln. Diese Gestaltungsempfehlung für einen komplementären Einsatz von Koordination durch Selbstregelung, durch Pläne und Programme visualisiert Abbildung 4/14.

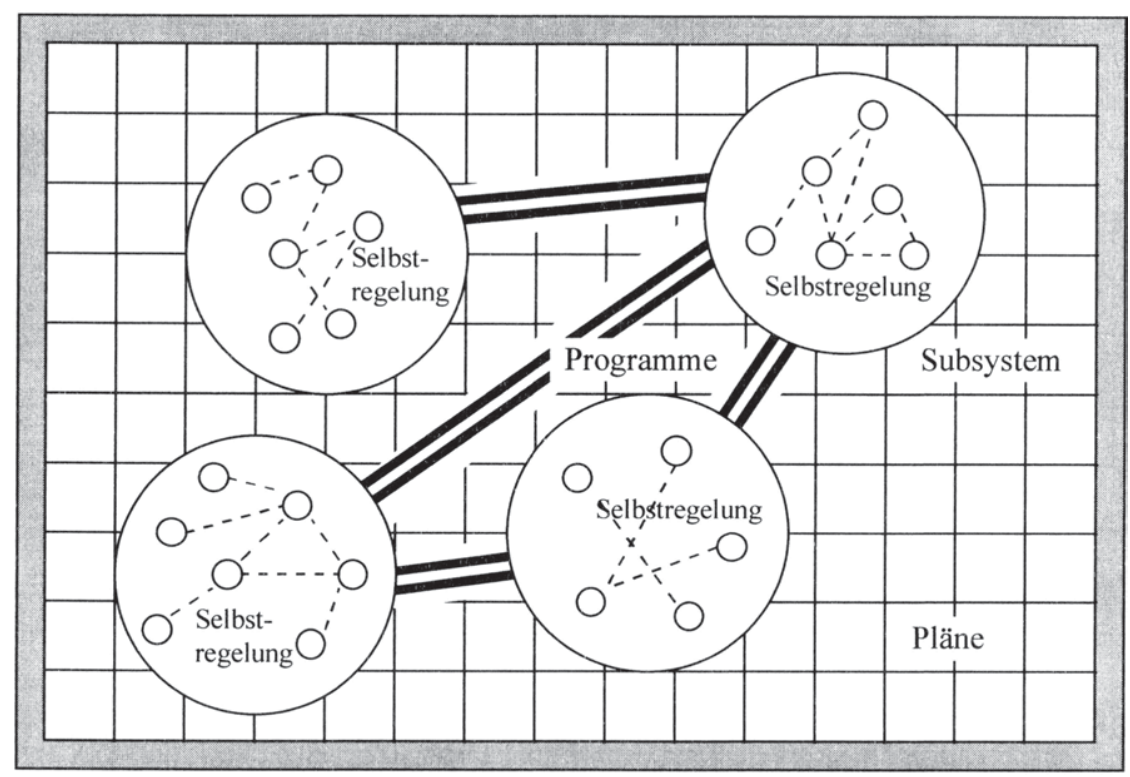

Abb. 4/14: Der komplementäre Einsatz von Koordination durch Selbstregelung, Pläne und Programme

Um die grundsätzliche Forderung nach einem komplementären Einsatz der verschiedenen Koordinationsinstrumente zu konkretisieren, werden im folgenden zunächst unterschiedliche Möglichkeiten der Abgrenzung der Freiräume für intrasystemische Selbstregelungs- bzw. Selbstorganisationsprozesse vorgestellt. Sodann werden Verrechnungspreise thematisiert, die in der Organisationstheorie unter sehr restriktiven Bedingungen als marktmäßiger Koordinationsmechanismus neben die oben genannten organisatorischen gestellt werden, unter den konkreten Bedingungen der betrieblichen Realität jedoch regelmäßig in die Nähe von Plänen rücken.

Die Ausgestaltung der Abgrenzung der Freiräume für Selbstregelungsprozesse im allgemeinen und Selbstorganisationsprozesse im besonderen kann unterschiedlicher Qualität sein. In Anlehnung an die Systematisierung von SCHULTE-ZURHAUSEN soll zwischen den folgenden drei Arten von Selbstorganisation unterschieden werden:209

$209 \mathrm{Vgl}$. dazu und im folgenden ăhnlich Schulte-Zurhausen (1995), S. 195, der sich dort jedoch auf die Gesamtmenge der - präsituativen und situativen - Selbstregelung bezieht (die er Selbstabstimmung nennt), wăhrend sich der Fokus der vorliegenden Arbeit allein die Teilmenge der präsituativen Selbstregelung (als Selbstorganisation) beschrănkt. 
- Selbstorganisation nach eigenem Ermessen,

- themenspezifische Selbstorganisation,

- institutionalisierte Selbstorganisation.

Selbstorganisation nach eigenem Ermessen liegt vor, wenn bestimmte Bereiche im Rahmen der organisatorischen Gestaltung ausgespart werden. In diesen Bereichen fehlen formale organisatorische Regeln, die Ergebnis von fremdorganisatorischen Prozessen sind, so daß dort prinzipiell Freiraum für Selbstorganisation besteht. Es existieren jedoch keine Vorgaben, daß diese Bereiche im Rahmen von Selbstorganisationsprozessen zu regeln sind. Deren Ausmaß und Inhalte obliegt allein dem Ermessen der Subsystemmitglieder. Es ist aber auch denkbar, daß im Rahmen der organisatorischen Gestaltung generelle Vorgaben darüber getroffen werden, bei welchen Problemen bzw. bezüglich welcher Inhalte die Subsystemmitglieder selbstorganisierend tätig werden müssen. Es handelt sich dann um themenspezifische Selbstorganisation. Selbstorganisation wird hier zur Pflicht. Diese Verpflichtung der Subsystemmitglieder reduziert aus der Sicht des Managements das Risiko, daß gemäß deren Perspektive notwendige Regelungsprozesse unterbleiben. Bei der instititutionalisierten Selbstorganisation beziehen sich die Rahmenvorgaben der organisatorischen Gestaltung für potentielle Selbstorganisationsprozesse schließlich auf deren Institutionalisierung innerhalb bestimmter Koordinationsorgane bzw. Kollegien als Teil der Sekundärorganisation der Unternehmung. Die grundsätzlichen Ausgestaltungsmöglichkeiten können dabei stark variieren: So können diese Gremien für einen bestimmten Zeitraum oder unbefristet eingerichtet werden. Sie können in regelmäßigen Abständen oder auf Antrag bestimmter Stellen zusammentreten. Die in den Kollegien behandelten Themen können bei deren Konstituierung festgelegt sein oder offenbleiben und von Fall zu Fall variieren. Typische Beispiele für Koordinationsorgane sind Ausschüsse, Abteilungsleiterkonferenzen und die bereits in Abschnitt 4.2.1 erwähnten Qualitätszirkel. Ausschüsse sind zeitlich befristet, treten regelmäßig oder bei Bedarf zusammen, sind thematisch klar abgegrenzt und dienen der Entscheidungsvorbereitung, der Entscheidung selbst oder der Entscheidungsdurchsetzung, wie z.B. ein Investitions- oder ein Kontrollausschuß. Abteilungsleiterkonferenzen sind zeitlich unbefristet, treten regelmäßig oder bei Bedarf zusammen und sind thematisch offen. Sie dienen vor allem dem Informationsaustausch. ${ }^{210}$

In der organisationstheoretischen Literatur werden häufig Verrechnungspreise als nicht-organisatorischer, marktmäßiger Koordinationsmechanismus den oben genannten organisatorischen Koordinationsmechanismen gegenübergestellt.211 Verrechnungspreise dienen der innerbetrieblichen Leistungsverrechnung zwischen verschiedenen Bereichen einer Unternehmung. Neben der Abrechnungs-, der Planungs- und der Erfolgszuweisungsfunktion kommt ihnen eine Lenkungsfunktion zu. Die Lenkungsauf-

210 Vgl. Picot (1993), S. 130; Steinmann/Schreyögg (1993), S. $410 f$.

211 Vgl. Kieser/Kubicek (1992), S. 118. 
gabe resultiert aus den Koordinationsproblemen, die mit der arbeitsteiligen Aufgabenerfüllung sowie der Dezentralisierung von Entscheidungskompetenzen in der Unternehmung verbunden sind. Verrechnungspreise als Lenkpreise können das Verhalten der einzelnen Subsysteme auf das Zielsystem der Unternehmung als Ganzen ausrichten. Dies kann z.B. dazu führen, daß vorhandene knappe Ressourcen optimal genutzt werden bzw. daß Leistungen für solche Zwecke verwendet werden, die den größten Beitrag zum Erfolg der Unternehmung leisten. ${ }^{212}$

Verrechnungspreise stellen allerdings nur unter den Bedingungen eines (nahezu) vollkommenen Marktes einen nicht-organisatorischen Koordinationsmechanismus dar. Nur dann sind die Verrechnungspreise Marktpreise. Insbesondere dürfen die Verrechnungspreise dann nicht durch eine zentrale Koordinationsinstanz festgelegt werden, sondern sie müssen sich als Ergebnis des Aufeinandertreffens von Angebot und Nachfrage bilden. Ferner darf für keine der beiden Seiten Kontrahierungszwang bestehen. Der zentrale Vorteil von Marktpreisen als Verrechnungspreisen besteht darin, daß sowohl der Gewinn der Unternehmung als Ganzen optimiert werden kann als auch den jeweiligen Subsystemen Teilerfolge zugerechnet werden können. ${ }^{213}$ Die Bedingungen eines (nahezu) vollkommenen Marktes könnten z.B. dann gegeben sein, wenn eine als Profit Center geführte Abteilung 'Inhouse Consulting' ihre Leistungen nicht nur innerhalb der Unternehmung, sondern auch außerhalb anbietet, und die ihre Leistungen nachfragenden Abteilungen der Unternehmung Beratungsleistungen auch bei externen Unternehmungsberatungen nachfragen können. In diesem Fall handelt es sich lediglich bei der - vorgelagerten - Entscheidung für Verrechnungspreise als Koordinationsmechanismus um eine organisatorische Entscheidung, während die Koordination mittels Verrechnungspreisen selbst kein organisatorisches Phänomen darstellt.

In der betrieblichen Praxis sind die Bedingungen eines (nahezu) vollkommenen Marktes eher idealtypischer Natur und nur in den seltensten Fällen erfüllt. Vielmehr werden Verrechnungspreise z.B. häufig zentral festgelegt, oder es besteht Kontrahierungszwang. An die Stelle von Marktpreisen treten dann kostenorientierte Verrechnungspreise, wobei eine Vielzahl unterschiedlicher Verfahren zur Bestimmung dieser Preise existiert. ${ }^{214}$ In diesem Fall rücken Verrechnungspreise als Koordinationsmechanismus in die Nähe traditioneller Pläne. Dies kann anhand des mit grenzkostenorientierten Verrechnungspreisen verbundenen konzeptionellen Dilemmas bei der Erfüllung ihrer Lenkungsfunktion verdeutlicht werden: Zielt man bei der Festlegung der Verrechnungspreise auf das Gesamtoptimum für die gesamte Unternehmung ab, so müssen in einem ersten Schritt zunächst die Grenzkosten in diesem Gesamtoptimum ermittelt werden. Erst in einem zweiten Schritt können dann die optimalen Grenzkosten als Verrechnungspreis festge-

212 Vgl. Beier/Gabriel (1998), S. 51; Coenenberg (1999), S. 523ff.; Kloock (1992), Sp. $2555 f$.

213 Vgl. Coenenberg (1999), S. 534f.

214 Die Spannbreite reicht dabei von den variablen Kosten als Minimum bis zu Vollkosten plus Gewinnaufschlag als Maximum. Vgl. Coenenberg (1999), S. $549 \mathrm{ff}$. 
legt werden. Im Moment dieser Festlegung des Verrechnungspreises ist das Lenkungsproblem damit allerdings bereits gelöst. Verrechnungspreise sind hier somit Ergebnis einer zentral getroffenen Entscheidung und nicht dezentraler Marktprozesse im Sinne des Aufeinandertreffens von Angebot und Nachfrage. ${ }^{215}$ Vielmehr sind Angebot und Nachfrage nach einer bestimmten Leistung hier Resultanten der zentralen Entscheidung über die Höhe des Verrechnungspreises. Dem Verrechnungspreis kommt somit eine ähnliche Funktion wie den oben genannten Plänen zu: Er stellt eine von zentraler Stelle fixierte, das Verhalten der nachfragenden und anbietenden Subsysteme steuernde Vorgabe dar, die deren Verhalten koordiniert, ohne jedoch detaillierte, konkrete Handlungsanweisungen zu beinhalten, wie man sie in Programmen findet. Das mit der Entscheidung über die Höhe der Verrechnungspreise verbundene Prinzip ähnelt also der Vorgabe von Plänen. Verrechnungspreise sind somit nicht nur ein Problem des internen Rechnungswesens, sondern auch ein organisatorisches Problem ${ }^{216}$.

In der Literatur werden im Rahmen der Diskussion um Selbstorganisationsprozesse verschiedentlich sogenannte 'Adhocratien' beschrieben. Adhocratien sind durch ein hohes $\mathrm{Ma} ß$ an ad-hoc-Regelung geprägt. Der relative Anteil der präsituativen Regelung ist hier geringer, der der situativen bzw. ad-hoc-Regelung höher als in traditionellen Unternehmungen. ${ }^{217}$ Da gemäß den Annahmen der vorliegenden Arbeit in den (häufigen, schnellen und diskontinuierlichen) Veränderungen der Umwelt durchaus Muster erkennbar sind, und es deshalb nicht sinnvoll ist, innerhalb der Unternehmung präsituative Regelung verstärkt durch situative zu ersetzen, sondern Selbstorganisationsprozesse als organisationale Lernprozesse höherer Ordnung im Mittelpunkt der Betrachtung stehen, werden Adhocratien hier nicht weiter berücksichtigt. ${ }^{218}$

Abbildung 4/15 faßt abschließend die in diesem Abschnitt diskutierten Möglichkeiten zur Förderung organisationalen Lernens in Form von Selbstorganisationsprozessen im Rahmen der Gestaltung der organisatorischen Regeln zur Koordination zusammen. Dabei werden jene Gestaltungsempfehlungen in den Vordergrund gestellt, die mögliche Ansatzpunkte für das Informationsmanagement bieten und die entsprechend in Kapitel 5 wieder aufgegriffen werden.

215 Vgl. Beier/Gabriel (1998), S. 53.

216 Vgl. Albach (1974), S. 228ff.

217 Vgl. Steinmann/Schreyögg (1993), S. 452.

218 Siehe auch die ausfuhrliche Gegenuberstellung präsituativer und situativer Regelung in Abschnitt 4.1.1 der vorliegenden Arbeit. 
intrasystemische Koordination:

O explizite Freiräume für Selbstorganisationsprozesse in Kombination mit Plänen

O verschiedene Formen der Ausgestaltung der Freiräume für Selbstorganisationsprozesse (nach eigenem Ermessen, themenspezifisch, institutionalisiert)

intersystemische Koordination:

O Kombination von Plänen und Programmen

O Beispiel: kostenorientierte Verrechnungspreise als planähnliches Koordinationsinstrument

Abb. 4/15: Gestaltungsempfehlungen für die Koordination in der lernenden Unternehmung

\subsubsection{Organisatorische Regeln zum Leitungssystem}

Die organisatorischen Regeln zum Leitungssystem legen die Weisungsbeziehungen innerhalb der Unternehmung fest. Immer dann, wenn Entscheidungs- und Durchführungsaufgaben personell getrennt sind, ergibt sich ein Weisungs- bzw. Leitungsverhältnis in Sinne einer hierarchischen Über- bzw. Unterordnung zwischen den jeweiligen Personen oder Subsystemen. Damit stehen hier die vertikalen Beziehungen zwischen Aufgabenträgern und Subsystemen auf verschiedenen Hierarchieebenen der Unternehmung bzw. deren vertikale Autonomie im Mittelpunkt der Ausführungen. Da der Fokus der vorliegenden Arbeit auf solchen Subsystemen der Unternehmung liegt, innerhalb derer Selbstorganisationsprozesse als Prozesse organisationalen Lernens gefördert werden sollen, werden im folgenden die vertikalen Beziehungen zwischen einem solchen Subsystem und ihm übergeordneten Instanzen als Ausdruck seiner vertikalen Autonomie untersucht.

Grundsätzlich kann man im Rahmen der organisatorischen Regeln zum Leitungssystem zwischen Primär- und Sekundärorganisation unterscheiden. ${ }^{219}$

Im Mittelpunkt der Betrachtung der Primärorganisation steht die dauerhafte hierarchische Struktur der Stellen und Instanzen innerhalb der Unternehmung, die aus der stufenweisen Subsystembildung und der Zuordnung von (die Subsysteme sowie die einzelnen Aufgabenträger betreffenden) Weisungskompetenzen zu Instanzen resultiert.

219 Zur Unterscheidung zwischen Primăr- und Sekundărorganisation vgl. Schulte-Zurhausen (1995), S. 205, 221, 247. 
Die Primärorganisation dient er Erfüllung permanenter Teilaufgaben, die im Zeitverlauf immer wieder in ähnlicher Art und Weise auftreten.

Die Konfiguration der Unternehmung kann mit Hilfe von Leitungsspanne und Leitungstiefe sowie verschiedenen Stellenrelationen beschrieben werden. Während die Leitungsspanne die Anzahl der einer Instanz direkt untergeordneten Stellen umfaßt, stellt die Leitungstiefe auf die Zahl der hierarchischen Leitungsebenen in einer Unternehmung ab. Bei gegebener Stellenzahl in einer Unternehmung sinkt die Leitungstiefe mit steigender durchschnittlicher Leitungsspanne (und umgekehrt). Kennzahlen, die bestimmte Arten von Stellen in ein Verhältnis zueinander setzen, werden als Stellenrelationen bezeichnet. Ein Beispiel ist die Leitungsintensität als Relation zwischen Leitungs- und Durchführungsstellen in der Unternehmung. ${ }^{220} \mathrm{Im}$ Rahmen der vorliegenden Arbeit ist von Interesse, ob die Gestaltung der Leitungsspanne, der Leitungstiefe und der verschiedenen Stellenrelationen Auswirkungen auf die relative Autonomie der Subsysteme hat. Diesbezüglich sind jedoch keine Aussagen möglich. Denn die konkrete Ausgestaltung des Leitungssystems einer Unternehmung ist Resultante der Ausprägungen der anderen Dimensionen der organisatorischen Gestaltung und hier vor allem der Entscheidungen bezüglich Arbeitsteilung und Koordination. ${ }^{221}$ Leitungsspanne, Leitungstiefe und die verschiedenen Stellenrelationen sind somit Symptomvariablen mit nur sehr beschränkt instrumentalem Charakter. ${ }^{222}$ Dies kann anhand des Beispiels der Leitungsspanne verdeutlicht werden: Die Leitungsspanne ist tendenziell nämlich umso größer,

- mit je mehr Entscheidungskompetenzen die einzelnen Stellen bzw. Subsysteme ausgestattet sind,

- wenn ein Großteil der Koordination über Programme oder das explizite Einräumen von Freiräumen zur Selbstregelung und nur ein geringer Teil mittels persönlicher Weisungen erfolgt.

Ein verstärktes Auftreten von Selbstorganisationsprozessen ermöglicht somit eine Erhöhung der Leitungsspanne. Die Ausprägungen der Leitungsspanne sind nicht Ursache für, sondern Folge von Selbstorganisationsprozessen. Entsprechend können keine Empfehlungen für eine Gestaltung von Leitungsspanne, Leitungstiefe und diversen Stellenrelationen formuliert werden, die die Wahrscheinlichkeit für das Auftreten von Selbstorganisationsprozessen erhöht.

Im Rahmen der Gestaltung des Leitungssystems der Unternehmung wird regelmäßig zwischen zwei idealtypischen Grundformen unterschieden, dem Einlinien- sowie dem Mehrliniensystem. Dabei werden die Beziehungen zwischen den untergeordneten Stellen bzw. Subsystemen einerseits und den ihnen übergeordneten Instanzen andererseits

Vgl. Hill/Fehlbaum/Ulrich (1994), S. 224. 
als Linien bezeichnet. Bei den von oben nach unten verlaufenden Linien handelt es sich um Weisungen, bei den von unten nach oben verlaufenden Linien um Mitteilungen und Meldungen. In einem Einliniensystem erhält jede untergeordnete Stelle bzw. jedes untergeordnete Subsystem nur von genau einer übergeordneten Instanz Weisungen (Prinzip der Einheit der Auftragserteilung von FAYOL). Dagegen ist die einzelne Stelle bzw. das einzelne Subsystem in einem Mehrliniensystem mehreren spezialisierten Instanzen unterstellt und erhält entsprechend von mehreren Instanzen Weisungen. Das Matrixsystem ist eine spezielle Ausprägung des Mehrliniensystems, bei dem eine untergeordnete Stelle oder ein untergeordnetes Subsystem von genau zwei übergeordneten Instanzen Weisungen erhält. In der Regel ist dabei eine Leitungsdimension funktionsorientiert, die andere objektorientiert. 223

Ein- und Mehrliniensysteme weisen jeweils spezifische Vor- und Nachteile auf. Stellt man auf die mit den beiden Grundformen verbundenen Konsequenzen für die relative Autonomie eines untergeordneten Subsystems ab, so ergibt sich folgende Bewertung: In Einliniensystemen ist der hierarchische Dienstweg stets einzuhalten. Die Informationsbeziehungen verlaufen in zuvor genau definierten Bahnen. Dagegen sind in Mehrliniensystemen vergleichsweise vielfältigere Informationsbeziehungen möglich. Insbesondere ist dadurch eher eine direkte Abstimmung zwischen den im spezifischen Einzelfall betroffenen Einheiten möglich. Diese höhere potentielle Varietät der Informationsbeziehungen in Mehrliniensystemen stellt eine Ausprägung der in Abschnitt 4.1.3.2.4 beschriebenen Redundanz der Interaktionen dar. Eine erhöhte Redundanz der Interaktionen geht wiederum mit einer höheren relativen Autonomie des Subsystems einher. Ein weiteres Argument für die relative Vorziehenswürdigkeit von Mehrliniensystemen resultiert aus den damit verbundenen potentiellen Kompetenzstreitigkeiten ${ }^{224}$ zwischen den verschiedenen Instanzen, die ein und demselben Subsystem für unterschiedliche Fragestellungen vorgesetzt sind. Diese Konfliktträchtigkeit, die gemeinhin als Nachteil von Mehrliniensystemen angesehen wird, erweist sich aus der Perspektive der Förderung der relativen Autonomie des so gesteuerten Subsystems als Vorteil. Denn sie erhöht die Möglichkeit der Subsystemmitglieder, in dem aus ungeklärten bzw. widerstreitenden Kompetenzen resultierenden 'Machtvakuum' selbständig über ihre Arbeit zu bestimmen, ${ }^{225}$ d.h. die relative Autonomie des Subsystems kann hier größer sein als in einem Einliniensystem. Es sei hier darauf hingewiesen, daß der Umstand, daß ein Subsystem innerhalb eines Mehrliniensystems mehreren Instanzen unterstellt ist, nicht vereinfachend dahingehend interpretiert werden kann, daß seine relative Autonomie hier im Vergleich zu einem Einliniensystem geringer sei. Denn vom Grundgedanken her bedeutet ein Mehrliniensystem lediglich die Verteilung derselben Grundgesamtheit von Weisungsbefugnissen auf mehrere statt auf nur eine Instanz.

Vgl. Frese (1995), S. 188ff.

Vgl. Frese (1995), S. 210.

Vgl. ähnlich Hill/Fehlbaum/Ulrich (1992), S. 394. 
Somit ist nicht die bloße Zahl der hierarchischen Beziehungen, sondern ihre inhaltliche Ausgestaltung entscheidend für das Ausmaß der damit einhergehenden Autonomie.

Faßt man die oben genannten Argumente zusammen, so gilt, daß unter dem Aspekt der Förderung der relativen Autonomie eines Subsystems dessen Mehrfachunterstellung in einem Mehrliniensystem einem Einliniensystem vorzuziehen ist. Die Ableitung von Handlungsempfehlungen für die organisatorische Gestaltung in der lernenden Unternehmung darf jedoch nicht nur auf einer solchen partikularen Betrachtung einer Dimension der organisatorischen Gestaltung beruhen. Über den isolierten Vergleich von Einlinien- und Mehrliniensystem als der beiden Grundformen des Leitungssystems hinaus müssen vielmehr auch die Interdependenzen mit Gestaltungsentscheidungen bezüglich der anderen Dimensionen berücksichtigt werden. So beeinflußt die Wahl des Koordinationsinstrumentes die relative Vorziehenswürdigkeit von Einlinien- und Mehrliniensystem erheblich: In Abschnitt 4.2.2 war herausgearbeitet worden, daß das explizite Gewähren von Freiräumen für Selbstorganisationsprozesse zur intrasystemischen Koordination in Kombination mit Plänen das Auftreten von Selbstorganisationsprozessen innerhalb des fokussierten Subsystems am meisten fördert. Idealerweise werden diese intrasystemischen Freiräume mit Plänen und Programmen als Instrumenten der intersystemischen Koordination kombiniert. In diesem Fall erweist sich - entgegen der obigen Argumentation - die Ausgestaltung des Leitungssystems als Einliniensystem als besonders geeignet. Denn das Eröffnen von Gestaltungsspielräumen innerhalb eines Subsystems muß mit klaren Rahmenvorgaben für die Abstimmung des Subsystems mit seiner Umwelt einhergehen, um sicherzustellen, daß der Beitrag des Subsystems zu den Zielen des nächsthöheren Subsystems und letztlich zu den Unternehmungszielen positiv ist. Das Ausmaß der einem bestimmten Subsystem gewährten relativen Autonomie findet seine Begrenzung nämlich regelmäßig in der Sicherstellung der relativen Autonomie des nächsthöheren Subsystems bzw. der Unternehmung als Ganzem.226 Deshalb sollten einerseits im Rahmen der Entscheidungen bezüglich des Koordinationsinstrumentariums die intrasystemisch gewährten Freiräume für Selbstorganisationsprozesse klar definiert sein und in einen durch das Management - vorzugsweise in Form von Plänen - vorgegeben Rahmen eingeordnet werden. Andererseits sollte bezüglich des Leitungssystems sichergestellt werden, daß die das Subsystem betreffenden Weisungsbefugnisse klar und eindeutig geregelt sind, um trotz der gewährten Autonomie die Einordnung des Subsystems in den Gesamtzusammenhang der Unternehmung zu gewährleisten. Aufgrund der in der betrieblichen Praxis regelmäBig auftretenden Probleme bei der Abgrenzung von Zuständigkeiten, Weisungen und Verantwortlichkeiten zwischen den verschiedenen involvierten Instanzen eines Mehrliniensystems und der negativen Auswirkungen der damit verbundenen Kompetenzstreitigkeiten auf die Abstimmung der Aktivitäten des Subsystems mit seinem Umfeld ist hier einem Einliniensystem der Vorzug zu gewähren. 
Als letzte die Primärorganisation betreffende Gestaltungsempfehlung zur Förderung der relativen Autonomie eines Subsystems sei hier die Reintegration der Stabsarbeit in die Linie genannt, die allerdings mit den Instanzen nur eine bestimmte Teilmenge der Gesamtheit der Stellen bzw. Subsysteme in der Unternehmung betrifft. Stabsstellen sind Instanzen zugeordnete Hilfsstellen, die auf bestimmte fachspezifische Aufgaben spezialisiert sind, dabei jedoch nicht über Entscheidungs- und Weisungskompetenzen verfügen, sondern die Entscheidungen und Weisungen der Instanzen durch geeignete Informationsaufbereitung vorbereiten.227 Stellt man auf Aspekte der Arbeitsteilung ab, so ist die Unterscheidung von Linieninstanzen und Stabsstellen ein Spezialfall der Arbeitsteilung nach der Art der Aufgaben, wobei Entscheidungsaufgaben und Entscheidungsunterstützungs- bzw. -vorbereitungsaufgaben einander gegenübergestellt werden. Die Reintegration der Stabsarbeit in die Linie stellt somit eine Möglichkeit der ganzheitlichen Teilaufgabenzuweisung dar. ${ }^{228}$ Übernimmt eine Stabsstelle bestimmte entscheidungsvorbereitende Funktionen für ein Subsystem, so schafft dies eine ausgeprägte Abhängigkeit dieses Subsystems gegenüber der Stabsstelle. Denn aufgrund der hohen fachlichen Qualifikation der Spezialisten im Stab beeinflussen diese die Inhalte der Entscheidungen der Instanz erheblich. Die relative Autonomie der Instanz gegenüber dem Stab ist gering. Zielt man darauf ab, mittels Förderung der relativen Autonomie einer Instanz die Wahrscheinlichkeit für das Auftreten von Selbstorganisationsprozessen als organisationalem Lernen zu erhöhen, so sollte entsprechend auf das Einrichten eines Stabes verzichtet werden und die ihm sonst übergetragene Arbeit stattdessen in die Linie reintegriert werden.

Während die obigen Ausführungen zur Primärorganisation auf auf Dauer angelegte hierarchische Über- und Unterordnungsverhältnisse abstellen, stehen hierarchieübergreifende oder hierarchieergänzende organisatorische Einheiten im Mittelpunkt der Betrachtung der Sekundärorganisation der Unternehmung. Die folgenden Ausführungen beschränken sich auf Projekte als wichtigste Ausprägung der Sekundärorganisation. Konstituierende Charakteristika eines Projektes sind seine zeitliche Begrenzung sowie seine Einmaligkeit (d.h. sein nicht-repetitiver, innovativer Charakter). ${ }^{229}$ Darüber hinaus handelt es sich bei Projekten regelmäßig um klar definierte, durch Umfang, Bedeutung, Kosten und/oder Risiko aus dem üblichen betrieblichen Geschehen herausragende Vorhaben.230 Untersucht man die verschiedenen Arten der aufbauorganisatorischen Einbindung von Projekten, so kann man nach dem Ausmaß der Kompetenzen der Projektleitung gegenüber den Projektmitarbeitern zwischen den folgenden Formen der Projektorganisation unterscheiden:231

227 Vgl. Frese (1995), S. 90ff.

228 Zur ganzheitlichen Teilaufgabenzuweisung siehe Abschnitt 4.2.1 der vorliegenden Arbeit.

229 Vgl. Bleicher (1991), S. 135.

230 Vgl. åhnlich Schulte-Zurhausen (1995), S. 162f.

231 Vgl. dazu und im folgenden Daenzer/Huber (1992), S. 254ff.; Litke (1991), S. 49ff.; Madauss (1990), S. 99ff. 
- Einfluß-Projektorganisation,

- Matrix-Projektorganisation und

- reine Projektorganisation.

Bei der Einfluß-Projektorganisation erhält der Projektleiter keinerlei Entscheidungskompetenzen und Weisungsbefugnisse und hat lediglich Beratungs- und Informationsrechte. Bei der Matrix-Projektorganisation treten seine Weisungsbefugnisse gegenüber den Projektmitarbeitern neben die von deren Linienvorgesetzten. Bei der reinen Projektorganisation schließlich werden die Projektmitarbeiter vollständig aus der Primärorganisation herausgelöst und dem Projektleiter unterstellt. Jede der genannten Formen der Projektorganisation weist spezifische Vor- und Nachteile auf. Stellt man auf die Förderung der relativen Autonomie des Projektes als Subsystem ab, so ist die reine Projektorganisation den anderen beiden Formen der Projektorganisation gegenüber vorzuziehen, da durch das vollständige Herauslösen der Projektmitarbeiter aus der Primärorganisation Konflikte zwischen deren Ansprüchen und denen des Projektes vermieden werden.

Das Herauslösen bestimmter, zeitlich und inhaltlich klar begrenzter Teilaufgaben aus der Primärorganisation und ihre Zuweisung zu Projektteams kann als Ausprägung einer ganzheitlichen Teilaufgabenzuweisung, wie sie bereits im Rahmen der Ausführungen zur Arbeitsteilung in Abschnitt 4.2.1 diskutiert wurde, interpretiert werden. ${ }^{232}$ Dabei werden möglichst viele der projektbezogenen Teilaufgaben aus der Primärorganisation herausgelöst und zu einer eigenständigen organisatorischen Einheit, dem Projektteam, unter einheitlicher Leitung zusammengefaßt. Gegenüber der Abwicklung solcher zeitlich und inhaltlich klar begrenzten Spezialaufgaben innerhalb der Primärorganisation, wodurch u.U. eine Vielzahl verschiedener Subsysteme involviert sind, bietet das Projektteam den Vorteil, daß hier Verantwortungen und Kompetenzen eindeutig zugeordnet werden können und damit eine klare Ergebnisverantwortung besteht. Als Beispiel sei hier auf ein Projekt zur Vereinheitlichung der im internen Rechnungswesen verschiedener Tochterunternehmungen eines Konzerns verwendeten Begrifflichkeiten hingewiesen. Das Herauslösen der mit dieser Projektaufgabe betrauten einzelnen Mitarbeiter aus der Primärorganisation erlaubt diesen die volle Konzentration auf ihre Sonderaufgabe. Die relative Autonomie des Projektteams gegenüber der Primärorganisation ist hier höher als im Fall des Verbleibs der Projektmitarbeiter innerhalb der Primärorganisation. ${ }^{233}$ Stellt man entsprechend Primär- und Sekundärorganisation einander gegenüber, so ist es unter Autonomiegesichtspunkten immer dann sinnvoll, die Sekundärorganisation zu Lasten der Primärorganisation auszudehnen, wenn bestimmte zeitlich begrenzte Sonderaufgaben zu erfüllen sind. Berücksichtigt man ferner, daß der Grad der Synreferenz bzw. der operationellen Schließung und die daraus resultierende relative Autonomie eines Subsystems ab einem bestimmten Punkt dysfunktional in dem Sinne wird, daß

Vgl. Picot (1993), S. 130. 
die relative Autonomie des Subsystems die des nächsthöheren Subsystems gefährdet, ${ }^{234}$ so erweisen sich Projektteams als besonders günstig, da sie per definitionem nur eine begrenzte Lebensdauer haben. Wird die operationelle Abschließung des Subsystems gegenüber seiner Umwelt zu groß, so wird es aufgelöst und die Projektmitarbeiter werden in die Primärorganisation reintegriert oder aber neuen Projekten zugeordnet. Deshalb sollte das Leitungssystem einer lernenden Unternehmung so gestaltet sein, daß es den permanenten Subsystemen der Primärorganisation die Möglichkeit einräumt, im Bedarfsfall Projektteams als temporäre Subsysteme zu bilden.

Eine zentrale Forderung der Selbstorganisationsliteratur - und insbesondere der St. Galler Schule um PROBST - zielt auf die Realisierung sogenannter 'Heterarchien' ab. Diese können sowohl im Rahmen der Primär- als auch der Sekundärorganisation auftreten. Im Gegensatz zu traditionellen hierarchischen Konzepten werden die Über- und Unterordnungsbeziehungen innerhalb der Unternehmung bzw. innerhalb des einzelnen Subsystems im Rahmen des Heterarchie-Konzeptes nicht als statisch, sondern als dynamisch konzipiert. Die hierarchischen Beziehungen werden hier nicht auf Dauer fixiert, sondern verändern sich in Abhängigkeit von den aktuellen Problemstellungen und den Interessen der Beteiligten. Denn sich im Zeitablauf verändernde Fragestellungen verlangen u.U. veränderte personelle Besetzungen. Heterarchie ist somit nicht etwa mit Anarchie zu verwechseln, sondern bezeichnet fluktuierende hierarchische Beziehungen. ${ }^{235}$

Der mit Heterarchien verbundene Grundgedanke ist, daß die mit der arbeitsteiligen Aufgabenerfüllung in der Unternehmung verbundene Zuordnung von Entscheidungs- und Weisungskompetenzen zu bestimmten Stellen, die zur Herausbildung von Entscheidungshierarchien führt, nicht notwendigerweise mit der Bildung von Personenhierarchien einhergehen muß. Eine andere Möglichkeit zur Vermeidung von Personenhierarchien innerhalb eines Subsystems ist, subsystemintern zwar bezüglich der Durchführungsaufgaben arbeitsteilig vorzugehen, bezüglich dispositiver Aktivitäten jedoch eine gemeinschaftliche Teilaufgabenerfüllung durch alle Mitglieder des Subsystems - im Sinne einer Pluralinstanz - zu realisieren. Denn erst wenn man die Leitungsaufgaben dauerhaft bestimmten Personen zuordnet, wird aus einer Stellenhierarchie zugleich eine Personenhierarchie. ${ }^{236}$

234 Siehe Abschnitt 4.1.4 der vorliegenden Arbeit.

235 Vgl. Klimecki/Probst/Eberl (1991), S. 138f.; Probst/Buchel (1998), S. 127ff.; Steinle/Bruch/Muller (1996), S. 651. Die Ausfuhrungen sind dort jedoch zum Teil in sich widerspruchlich bzw. weichen von dem im Rahmen der vorliegenden Arbeit verfolgten Begriffsverständnis ab. So versteht Probst Heterarchie einerseits als polyzentrische Organisationsform und Klimecki/Probst/Eberl verweisen unter Bezugnahme auf Buhl auf das Fehlen einer zentralen Kontrolle. Andererseits verweisen beide Quellen auf fluktuierende Hierarchien und damit durchaus auf die Existenz hierarchischer Über- und Unterordnungsbeziehungen. Es bleibt somit offen, ob Heterarchien dort als das Fehlen von Hierarchie oder deren Veränderung im Zeitablauf verstanden werden, zwei Positionen, die sich gegenseitig ausschließen. Diese Rezeptionsprobleme der Arbeiten von Probst beruhen vor allem auf der von ihm vorgenommenen Einbeziehung des organisatorischen Gestalters in das zu gestaltende System, die mit einer aus der Sicht der vorliegenden Arbeit nicht gewlinschten Aufhebung des Unterschiedes zwischen Fremd- und Selbstorganisation einhergeht und der deshalb hier nicht gefolgt wird.

Vgl. Kieser/Kubicek (1992), S. 86, 97 f. 
Keinesfalls kann das Heterarchie-Konzept in allen Bereichen der Unternehmung angewendet werden. Vor allem die zu erfüllenden Gesetzesvorgaben zur eindeutigen Verantwortungszuordnung bzw. zur Vertretung der Unternehmung nach außen (z.B. durch das Gewähren von Prokura) setzen der Anwendung des Heterarchie-Konzeptes Grenzen. Aber auch in den Bereichen der Repräsentation der Unternehmung nach außen, in denen eine eindeutige und im Zeitablauf stabile Verantwortungszuordnung nicht gesetzlich vorgeschrieben ist, können die Vorteile klassischer hierarchischer Lösungen die der Heterarchie übertreffen. So legen z.B. Kunden in der Regel großen Wert darauf, bei der Bearbeitung ihrer Anfragen stets mit demselben Ansprechpartner in Kontakt zu treten. ${ }^{237}$

Sowohl Heterarchien als auch Pluralinstanzen bedingen, daß Managementleistungen über das gesamte Subsystem verteilt werden. Dies setzt einerseits entsprechende Managementfähigkeiten bei den Mitgliedern des Subsystems voraus. ${ }^{238}$ Andererseits fördert es die Ausbildung ebendieser Fähigkeiten. Untersucht man nunmehr den Zusammenhang zwischen Heterarchien und Pluralinstanzen auf der einen und der Wahrscheinlichkeit für das Auftreten von Selbstorganisationsprozessen innerhalb eines Subsystems als Prozessen organisationalen Lernens auf der anderen Seite, so gelten die im Rahmen der Ausführungen zur Arbeitsteilung bezüglich der Spezialisierung auf die Unternehmung getroffenen Aussagen hier analog:239 Sowohl die im Zeitverlauf erfolgende intrasystemische Veränderung der Zuordnung dispositiver Aktivitäten auf einzelne Aufgabenträger (im Rahmen von Heterarchien) als auch die gemeinschaftliche Wahrnehmung dieser Aufgaben fördern die Redundanz der Funktionen innerhalb des Subsystems im Sinne von Redundanz der Fähigkeiten der Mitglieder des Subsystems. ${ }^{240}$ Diese Mehrfachausprägung von Führungsqualifikationen als Form von Organizational Slack fördert zwar die relative Autonomie des Subsystems gegenüber seinen einzelnen Mitarbeitern. Da die Wahrscheinlichkeit für das Auftreten von Selbstorganisationsprozessen innnerhalb eines Subsystems jedoch nicht mit dessen relativer Autonomie gegenüber einzelnen seiner Mitarbeitern, sondern mit seiner relativen Autonomie gegenüber anderen Subsystemen (als seiner Umwelt) positiv korreliert, gehen damit aber keine positiven Auswirkungen auf die Wahrscheinlichkeit für das Auftreten von Selbstorganisationsprozessen innerhalb des Subsystems einher. Lediglich dann, wenn Heterarchien zugleich mit einer hohen personellen Durchlässigkeit der Grenzen zwischen den verschiedenen Subsystemen verbunden sind und damit Mehrfachqualifikationen über die Subsystemgrenzen hinaus möglich sind, führt dies zu einer höheren relativen Autonomie eines Subsystems gegenüber seiner Umwelt. Vergleicht man Primär- und Sekundärorganisation, so ist die personelle Durchlässigkeit zwischen verschiedenen Subsystemen in der Sekundärorganisation tendenziell stärker ausgeprägt als in der Primärorganisation, da Projekte per

Vgl. Klimecki/Probst/Eberl (1991), S. 139.

Vgl. Gerstner (1995), S. 150; Klimecki/Probst/Eberl (1991), S. 138.

Siehe Abschnitt 4.2.1 der vorliegenden Arbeit.

Vgl. Klimecki/Probst/Eberl (1991), S. 139. 
definitionem eine begrenzte Lebensdauer haben und ihre Mitglieder deshalb regelmäßig nach Auflösung des Projektteams in andere Subsysteme übergehen müssen. Die damit verbundene höhere relative Autonomie liegt jedoch nicht in den wechselnden Unterstellungsverhältnissen, sondern in den veränderten Aufgabenfeldern bzw. Subsystemzugehörigkeiten begründet. Zusammenfassend ist somit festzustellen, daß der in der Literatur verschiedentlich als prinzipiell positiv angenommene Zusammenhang zwischen Heterarchien und der Wahrscheinlichkeit für das Auftreten von Selbstorganisationsprozessen $^{241}$ als organisationalem Lernen nicht konzipiert werden kann.

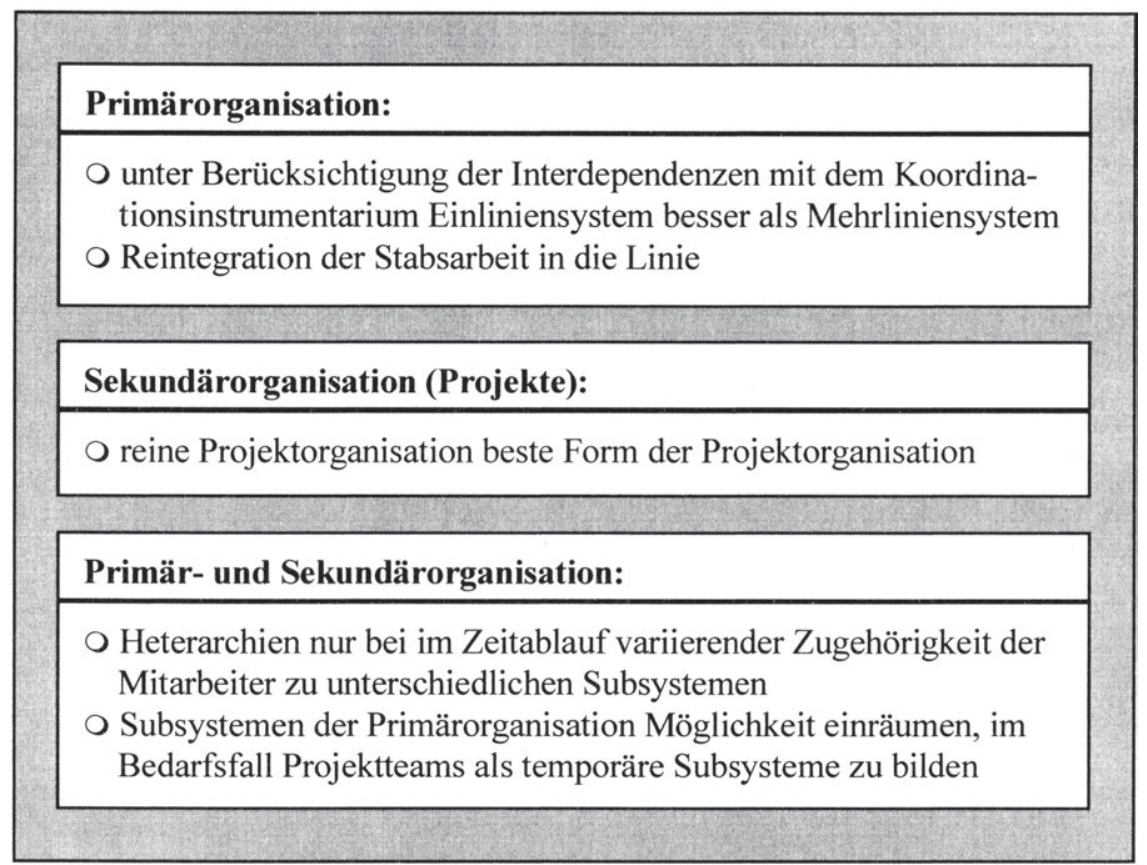

Abb. 4/16: Gestaltungsempfehlungen für das Leitungssystem in der lernenden Unternehmung

Abbildung 4/16 faßt abschließend die in diesem Abschnitt diskutierten Möglichkeiten zur Förderung organisationalen Lernens in Form von Selbstorganisationsprozessen im Rahmen der Gestaltung der organisatorischen Regeln zum Leitungssystem zusammen. Dabei werden jene Gestaltungsempfehlungen in den Vordergrund gestellt, die mögliche Ansatzpunkte für das Informationsmanagement bieten und die entsprechend in Kapitel 5 wieder aufgegriffen werden.

$24 \mathrm{Vgl}$. z.B. Klimecki/Probst/Eberl Steinle/Bruch/Muller (1996), S. 651.

(1991), S. 138f,; Probst/Büchel (1998), S. 127ff.; 


\subsubsection{Organisatorische Regeln zur Entscheidungsdelegation}

Nicht nur die organisatorischen Regeln zum Leitungssystem, sondern auch die zur Entscheidungsdelegation betreffen die vertikalen Beziehungen zwischen einzelnen Aufgabenträgern und Subsystemen auf den verschiedenen Hierarchieebenen der Unternehmung und haben somit unmittelbare Auswirkungen auf deren vertikale Autonomie. Während die organisatorischen Regeln zum Leitungssystem auf die Struktur der Weisungsbeziehungen, nicht jedoch auf deren inhaltliche Ausgestaltung abstellen, steht der inhaltliche Umfang der Entscheidungsbefugnisse der Mitarbeiter und Subsysteme im Mittelpunkt der organisatorischen Regeln zur Entscheidungsdelegation. ${ }^{242}$ Entsprechend kann ein und dieselbe Struktur der Weisungsbeziehungen mit sehr unterschiedlichen inhaltlichen Ausgestaltungen der Entscheidungsbefugnisse einhergehen. Dabei lassen sich die Weisungsbefugnisse aus den Entscheidungsbefugnissen ableiten, da jeder Weisung eine Entscheidung vorgelagert ist. Umgekehrt mündet jedoch nicht jede Entscheidung in eine Weisung.

Der Begriff der Entscheidungsdelegation geht davon aus, daß prinzipiell nur die Eigentümer der Unternehmung bzw. die von diesen entsprechend autorisierte Unternehmungsleitung die Befugnis haben, Entscheidungen zu treffen. Ab einer gewissen Unternehmungsgröße ist dies jedoch nicht mehr möglich. Deshalb werden Entscheidungsaufgaben sowie die damit verbundenen Kompetenzen und Verantwortung dauerhaft von oben nach unten, d.h. an hierarchisch nachgeordnete Stellen bzw. Subsysteme, delegiert. Dabei kann anhand des Grades der Entscheidungsdelegation zwischen den beiden Extremausprägungen vollständige Entscheidungszentralisation und vollständige Entscheidungsdezentralisation unterschieden werden. Während bei der vollständigen Entscheidungszentralisation alle Entscheidungsbefugnisse bei einer zentralen Stelle auf der obersten Hierarchieebene gebündelt sind, bedeutet vollständige Entscheidungsdezentralisation ihre Verteilung auf eine Vielzahl von Stellen auf der untersten Hierarchieebene der Unternehmung. In der Praxis stellen weder vollständige Entscheidungszentralisation noch vollständige Entscheidungsdezentralisation realistische Handlungsoptionen dar. Vielmehr sind die tatsächlichen Ausprägungen des Delegationsgrades auf dem Kontinuum zwischen diesen beiden nur theoretisch relevanten Extrema angesiedelt. ${ }^{243}$

Der Grad der vertikalen Autonomie als Teilaspekt der relativen Autonomie eines Subsystems hängt vom Grad der Entscheidungsdelegation zwischen diesem Subsystem und dem bzw. den ihm übergeordneten Subsystem(en) ab. Der Grad der Entscheidungsdelegation wiederum ist determiniert durch Art und Menge der dem Subsystem übertragenen Entscheidungsbefugnisse. Allerdings kann man hier nicht - wie analog bezüglich Arbeitsteilung, Kordination und Leitungssystem geschehen - bestimmte, grundsätzlich

Vgl. Kieser/Kubicek (1992), S. 155.

Vgl. Schulte-Zurhausen (1995), S. 177. 
unterschiedliche Delegationsarten definieren. Stattdessen lassen sich nur Kriterien dafür aufstellen, wie stark einerseits Kompetenzen delegiert werden und andererseits, welche Arten von Entscheidungsbefugnissen von der Delegation betroffen sind.

Je höher die Anzahl der das Aufgabenfeld eines Subsystems betreffenden Entscheidungen, die dem Subsystem selbst übertragen werden, desto höher ist dessen vertikale Autonomie. Dabei ist einerseits sicherzustellen, daß das Subsystem über eine ausreichende entsprechende Qualifikation verfügt, andererseits, daß die delegierten Entscheidungen auch wirklich delegierbar sind.244 Diese beiden Aspekte begrenzen das Ausmaß der Delegation. Grundsätzlich sollten Entscheidungen dann auf der tiefsten Hierarchieebene getroffen werden, die über die erforderliche Fachkompetenz verfügt. Die jeweils übergeordneten Subsysteme greifen nur dann ein, wenn eine Entscheidung das untergeordnete Subsystem überfordert. ${ }^{245}$ Insbesondere sollte die Trennung von Führungs- und Durchführungsaufgaben so weit wie möglich zugunsten ihrer personellen Zusammenführung aufgegeben werden.

In einem nächsten Schritt ist nunmehr zu prüfen, welche Arten von Entscheidungen bezüglich eines Subsystems existieren, die potentiell an dieses delegiert werden können. In der Literatur finden sich Listen mit verschiedenen Entscheidungsarten, die häufig auf den Überlegungen von GULOWSEN beruhen, der bestimmte Kriterien als Ausdruck der Autonomie von Gruppen entwickelt hat. Dabei werden die aufgelisteten Entscheidungsarten regelmäßig anhand des mit ihrer Delegation verbundenen Ausmaßes an vertikaler Autonomie des betroffenen Subsystems geordnet. Eine Zusammenfassung der verschiedenen Einzelentscheidungen zu übergeordneten Kategorien grundsätzlicher Entscheidungsarten unterbleibt. ${ }^{246}$ Diese würde die Ableitung von Aussagen bezüglich des Zusammenhangs zwischen der Art der delegierten Entscheidungen und dem Grad der vertikalen Autonomie eines Subsystems erleichtern. Abbildung 4/17 zeigt deshalb eine Möglichkeit, die einzelnen Entscheidungsarten den drei übergeordneten Kategorien der zielbildenden, der systemkonstituierenden sowie der prozeßgestaltenden Entscheidungen zuzuordnen. Einerseits sind die drei Kategorien von Entscheidungen von grundsätzlich unterschiedlicher Bedeutung für die vertikale Autonomie eines von ihrer Delegation betroffenen Subsystems, andererseits sind die einzelnen Entscheidungen innerhalb jeder Kategorie wiederum in der Reihenfolge ihrer Nennung mit einem zunehmenden Grad an vertikaler Autonomie des Subsystems verbunden.

244 Vgl. Picot (1993), S. 137 sowie Hill/Fehlbaum/Ulrich (1994), S. 226ff., die zwischen stellen- und entscheidungsbezogenen Kriterien unterscheiden. Stellenbezogene Kriterien sind z.B. die vorausgesetzte Fachkompetenz der Stelle und die bisherige Kompetenz des Stelleninhabers als Ausdruck der Kompetenzmőglichkeiten. Entscheidungsbezogene Kriterien sind dagegen z.B. die zeitliche Reichweite, die Wirkungsbreite, die personellen Wirkungen und das mit einer Entscheidung verbundene Risiko.

245 Vgl. Picot (1993), S. 137; Probst (1987), S. 136; Seidel/Redel (1987), S. 39.

246 Vgl. Gulowsen (1972), S. 376ff., aber z.B. auch Alioth (1978), S. 60ff.; Gomez/Zimmermann (1992), S. 128; Reif-Mosel (1999), o.S. 


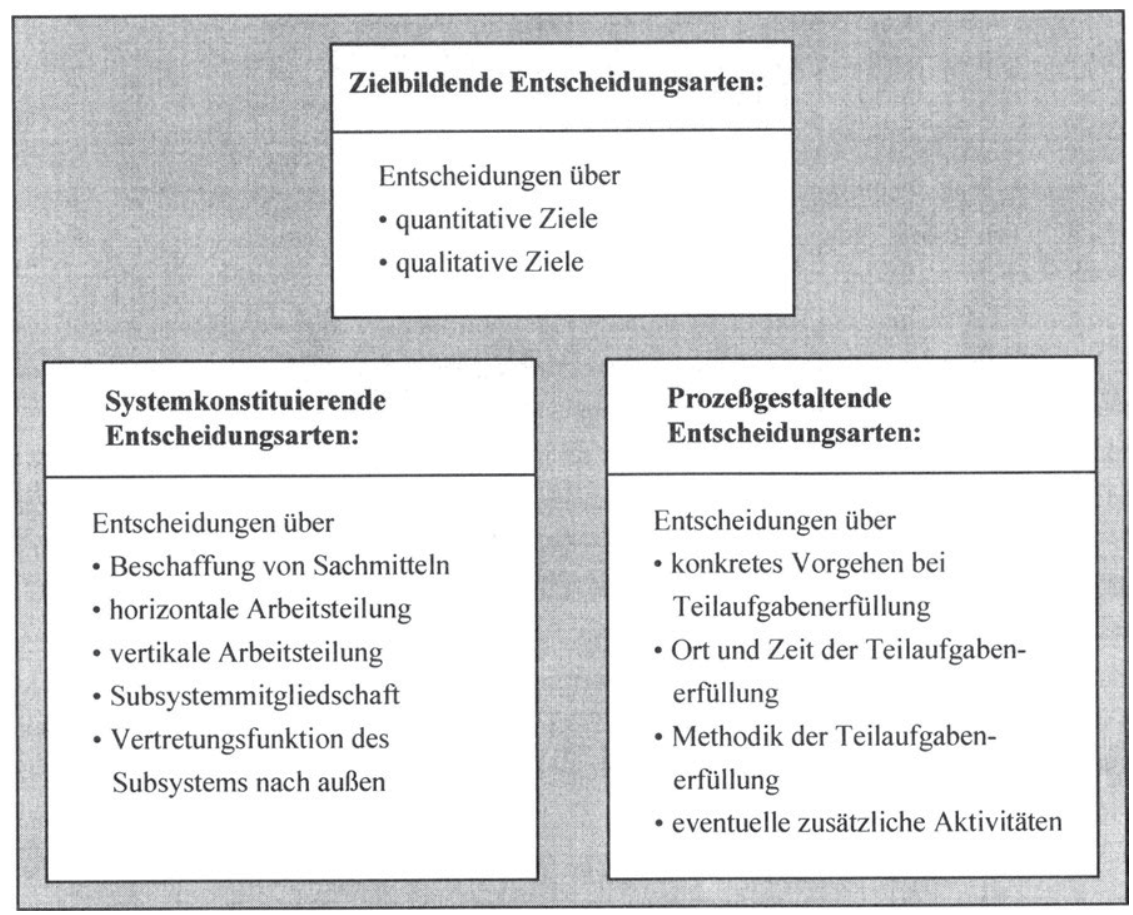

Abb. 4/17: Systematisierung potentiell delegierbarer Entscheidungsarten

Betrachtet man zunächst die prozeßgestaltenden Entscheidungsarten, so ist die Delegation dieser Entscheidungen an ein Subsystem - im unmittelbaren Vergleich zu den systemkonstituierenden und den zielbildenden Entscheidungsarten - mit dem geringsten Grad an vertikaler Autonomie für dieses Subsystem verbunden. Innerhalb dieser Kategorie sind wiederum die Delegation der Entscheidungen bezüglich der konkreten Vorgehensweise bei der Teilaufgabenerfüllung sowie die bezüglich Ort und Zeit der Teilaufgabenerfüllung die einfachsten, d.h. mit dem geringsten Grad an vertikaler Autonomie für das betroffene Subsystem verbundenen, Formen der Delegation. Dabei treffen die Mitglieder des Subsystems innerhalb eines bestimmten, von außen vorgegebenen Rahmens z.B. Entscheidungen über die Reihenfolge der zu bearbeitenden Aufträge sowie die Arbeitszeit- und Pausenregelung. Die Delegation von Entscheidungen über das grundsätzliche Vorgehen bei der Teilaufgabenerfüllung, d.h. bezüglich des Einsatzes bestimmter Produktions- und Arbeitsmethoden, oder über eventuelle zusätzlich durch das Subsystem zu verrichtende Tätigkeiten ist bereits mit vergleichsweise mehr Autonomie für das Subsystem verbunden. Hierzu zählen ablauforganisatorische Regeln, wie z.B. die Auswahl der zur Ausführung eines Arbeitsschrittes geeigneten Maschinen. Grundsätzlich ist dabei davon auszugehen, daß im Falle der Delegation der letztgenannten Entscheidungsarten auch die erstgenannten Entscheidungsarten, die mit vergleichsweise geringeren Autonomieeffekten verbunden sind, an das Subsystem übertragen werden. Denn es erscheint nicht sinnvoll, einem Subsystem Entscheidungs- 
kompetenzen bezüglich der grundsätzlichen Methodik zu gewähren, ohne auch die Entscheidungen bezüglich der konkreten Abwicklung innerhalb des Rahmens dieser Methodik zu delegieren.

Betrachtet man in einem nächsten Schritt die Kategorie der systemkonstituierenden Entscheidungsarten, so gilt auch hier wiederum, daß die verschiedenen Entscheidungsarten in Abbildung 4/17 in sich logisch bedingender Reihenfolge aufgeführt sind, d.h. wird eine bestimmte Entscheidungsart an das Subsystem delegiert, so ist im Regelfall davon auszugehen, daß die zuvor genannten Entscheidungsarten ebenfalls delegiert wurden. Zugleich steigt die mit der Delegation der einzelnen Entscheidungsarten verbundene vertikale Autonomie des Subsystems von Entscheidungsart zu Entscheidungsart. Mit den geringsten Autonomieeffekten ist hier die Delegation der Entscheidungen bezüglich der Beschaffung von Sachmitteln verbunden, wobei die dem Subsystem übertragenen Beschaffungsentscheidungen, z.B. bezüglich der gewünschten Rechnerausstattung einzelner Arbeitsplätze innerhalb des Subsystems, in der Regel durch die zentrale Vorgabe bestimmter Budgets beschränkt werden. Vergleichsweise mehr Autonomie bedingt die Delegation der Entscheidungen bezüglich der subsysteminternen horizontalen Arbeitsteilung oder gar bezüglich eventueller hierachischer Über- oder Unterordnungsverhältnisse zwischen den Mitgliedern des Subsystems (oder des Verzichts auf solche). Darüber hinaus besteht die Möglichkeit, die Entscheidungen über die Mitgliedschaft einzelner Aufgabenträger im Subsystem dem Subsystem selbst zu übertragen. Innerhalb der Kategorie der systemkonstituierenden Entscheidungsarten ist die Delegation der Entscheidung über die personelle Festlegung der Vertretungsfunktion des Subsystems nach außen (oder über den Verzicht auf eine solche) mit dem höchsten Grad an vertikaler Autonomie des Subsystems verbunden.

Zielt man im Rahmen der organisatorischen Gestaltung darauf ab, die Wahrscheinlichkeit für das Auftreten von Selbstorganisationsprozessen als organisationalen Lernprozessen in einem Subsystem zu erhöhen, indem man dessen relative Autonomie stärkt, so gilt es, möglichst weitreichende Entscheidungen auf das Subsystem zu übertragen. Vergleicht man zunächst die prozeßgestaltenden sowie die systemkonstituierenden Entscheidungsarten, so ergeben sich grundsätzliche Unterschiede zwischen diesen beiden Kategorien: Die prozeßgestaltenden Entscheidungsarten betreffen subsysteminterne Abläufe im Sinne des 'Wie?' des Leistungserstellungsprozesses. Input und Output dieses systeminternen Leistungserstellungsprozesses - und damit die Schnittstellen des Subsystems zu seiner Umwelt - sind von diesen Entscheidungen in der Regel nicht betroffen. Die Gefahr ist damit gering, daß eine Erhöhung der relativen Autonomie des Subsystems die relative Autonomie der ihm übergeordneten Subsysteme beeinträchtigt. Entsprechend ist es relativ problemlos möglich, prozeßgestaltende Entscheidungsarten zu delegieren. Die Bewertung der systemkonstituierenden Entscheidungsarten im Rahmen eines Mehrebenen-Ansatzes fällt dagegen differenzierter aus. Während z.B. Entscheidungen über die subsysteminterne horizontale Arbeitsteilung noch vergleichsweise geringe Auswirkungen auf die Umwelt des Subsystems haben, reichen beispielsweise 
die Konsequenzen von Entscheidungen über die Zugehörigkeit einzelner Personen zu einem Subsystem über die Grenzen des Subsystems hinaus und beeinflussen nicht nur dessen relative Autonomie, sondern auch die Autonomie der Subsysteme, die ebenfalls um die Mitgliedschaft dieser Personen konkurrieren. Ordnet man ein Subsystem, innerhalb dessen es das Auftreten von Selbstorganisationsprozessen zu fördern gilt, in einen Mehrebenen-Zusammenhang ein, können entsprechend keine allgemeingültigen Aussagen über den Delegationsgrad der systemkonstituierenden Entscheidungsarten getroffen werden. Vielmehr hängt der Delegationsgrad hier von den Gegebenheiten des spezifischen Einzelfalles ab.

Das Spannungsverhältnis zwischen der relativen Autonomie eines Subsystems und der des nächsthöheren Subsystems (und letztlich der Unternehmung als Ganzen) tritt bei der Untersuchung der Delegationsmöglichkeiten der zielbildenden Entscheidungsarten als der dritten Kategorie besonders deutlich zutage. Die Delegation der Entscheidungen über die vom Subsystem zu erfüllenden quantitativen oder sogar qualitativen Ziele an das Subsystem selbst geht mit der größtmöglichen vertikalen Autonomie für dieses Subsystem einher. Da damit keinerlei inhaltliche Steuerung von außen mehr stattfindet, ist gleichzeitig jedoch die Einbettung des Subsystems in den Gesamtzusammenhang der Unternehmung nicht mehr gewährleistet. Denn die Ziele der einzelnen Mitglieder eines Subsystems stimmen nicht notwendigerweise mit denen der gesamten Unternehmung überein, so daß die Gefahr besteht, daß der fehlende oder negative Zielbeitrag des Subsystems zum Zielsystem der gesamten Unternehmung langfristig deren Existenz gefährdet. Die vollständige Übertragung der zielbildenden Entscheidungen an ein Subsystem ist somit bei Berücksichtigung dieses Mehrebenen-Zusammenhangs nicht sinnvoll. ${ }^{247}$ Hier erweisen sich stattdessen partizipative Lösungen als geeignet.

Partizipation stellt eine spezielle Ausprägung der organisatorischen Regeln zur Entscheidungsdelegation dar. ${ }^{248}$ Während bislang davon ausgegangen wurde, daß bei der Entscheidungsdelegation bestimmte Entscheidungsbefugnisse in der Unternehmungshierarchie von oben nach unten übertragen werden und dabei klar einem bestimmten Aufgabenträger oder Subsystem zugeordnet werden, bedeutet Partizipation, daß die von bestimmten Entscheidungen Betroffenen an den diesbezüglichen Prozessen der Willensbildung und Entscheidung der übergeordneten Hierarchieebenen teilnehmen können. Partizipation bedeutet somit das Recht auf Beteiligung an den Entscheidungen anderer. Bei Partizipation sind deshalb über einen bestimmten Aufgabenträger oder ein bestimmtes Subsystem hinaus mehrere Aufgabenträger oder Subsysteme an einer Entscheidung beteiligt. Dabei können sehr unterschiedliche Formen der Beteiligung, wie

247 Siehe Abschnitt 4.1.4 der vorliegenden Arbeit.

248 In der Literatur finden sich unterschiedliche Standpunkte bezüglich der Abgrenzung von Entscheidungsdelegation und Partizipation: So ordnen z.B. Kieser/Kubicek, denen hier gefolgt wird, ihre Ausfuhrungen zur Partizipation der Hauptdimension Entscheidungsdelegation zu. Schulte-Zurhausen stellt Partizipation dagegen neben Delegation. Vgl. Schulte-Zurhausen (1995), S. 176ff.; Kieser/Kubicek (1992), S. 158f.; Picot (1993), S. 138ff. 
z.B. die bloße Information, die Anhörung, die gemeinsame Beratung, die Mitentscheidung oder das Gewähren eines Vetorechtes, gewählt werden. ${ }^{249}$

Betrachtet man ein bestimmtes Subsystem und untersucht die Auswirkungen von Partizipation auf dessen vertikale Autonomie, so gelangt man zu folgenden Ergebnissen: Partizipieren andere Aufgabenträger oder Subsysteme an den Entscheidungen des fokussierten Subsystems, so senkt dies - in Abhängigkeit von der konkreten Ausgestaltung ihrer Partizipationsmöglichkeiten - die Autonomie dieses Subsystems. Denn die Entscheidung wird dann eben nicht mehr allein durch das Subsystem getroffen, sondern unter Beteilung anderer. Zielt man im Rahmen der organisatorischen Gestaltung darauf $\mathrm{ab}$, die relative Autonomie eines Subsystems zu fördern, um die Wahrscheinlichkeit für das Auftreten von Selbstorganisationsprozessen als Prozessen organisationalen Lernens zu erhöhen, so sollte die Partizipation anderer Aufgabenträger oder Subsysteme an seinen Entscheidungen vermieden werden. Dagegen erhöht die Partizipation des fokussierten Subsystems an den das Subsystem betreffenden Entscheidungen anderer, ihm übergeordneter Aufgabenträger oder Subsysteme seine vertikale Autonomie. ${ }^{250}$ Denn Partizipation führt hier dazu, daß die das Subsystem betreffenden Entscheidungen nicht mehr völlig losgelöst von diesem, sondern unter seiner Einbeziehung getroffen werden.

Vergleicht man die Auswirkungen des anfänglich geschilderten Falles der Entscheidungsdelegation, bei der bestimmte Entscheidungsbefugnisse vollständig auf ein Subsystem übertragen werden, mit dem Spezialfall der Partizipation, bei dem das Subsystem an bestimmten Entscheidungen ihm übergeordneter Instanzen lediglich beteiligt wird, so ist unter dem Aspekt der Förderung der relativen Autonomie eines Subsystems die vollständige Entscheidungsdelegation der Partizipation gegenüber grundsätzlich vorzuziehen. Denn die mit der vollständigen Zuweisung bestimmter Entscheidungsbefugnisse verbundene Stärkung der Autonomie des Subsystems ist hier höher als im Fall der mehr oder weniger ausgeprägten - Beteiligung an den Entscheidungen anderer. Wo immer dies möglich und sinnvoll erscheint, sollten deshalb Entscheidungsbefugnisse an das Subsystem delegiert werden. Insbesondere für die zielbildenden Entscheidungsarten, aber u.U. auch für bestimmte systemkonstituierende Entscheidungsarten, erweist sich dies jedoch aus den oben genannten Gründen als problematisch. Hier stellt die Partizipation des Subsystems an den Entscheidungen der ihm übergeordneten Instanz eine geeignete Möglichkeit dar, die relative Autonomie dieses Subsystems zu erhöhen, ohne dadurch die des nächsthöheren Subsystems (und letztlich der Unternehmung als Ganzen) bzw. die Koordination der verschiedenen Teilbereiche der Unternehmung zu gefährden.

Abbildung 4/18 faßt abschließend die in diesem Abschnitt diskutierten Möglichkeiten zur Förderung organisationalen Lernens in Form von Selbstorganisationsprozessen im 
Rahmen der Gestaltung der organisatorischen Regeln zur Entscheidungsdelegation zusammen. Dabei werden jene Gestaltungsempfehlungen in den Vordergrund gestellt, die mögliche Ansatzpunkte für das Informationsmanagement bieten und die entsprechend in Kapitel 5 wieder aufgegriffen werden.

○ je höher der Delegationsgrad bzgl. eines Subsystems, desto höher seine relative Autonomie

O prozeßgestaltende Entscheidungsarten vergleichsweise problemlos delegierbar

O Art und Ausmaß der Delegation der systemkonstituierenden Entscheidungsarten einzelfallabhängig

O Delegation im Sinne von vollständiger Übertragung der Entscheidungen bei zielbildenden Entscheidungsarten i.d.R. nicht möglich; stattdessen: Partizipation

Abb. 4/18: Gestaltungsempfehlungen für die Entscheidungsdelegation in der lernenden Unternehmung

\subsubsection{Zusammenfassung der Empfehlungen für die organisatorische Gestaltung in der lernenden Unternehmung}

Nachdem in den Abschnitten 4.2.1 bis 4.2.4 im einzelnen untersucht wurde, welche Ausprägungen der organisatorischen Regeln zu Arbeitsteilung, Koordination, Leitungssystem und Entscheidungsdelegation die relative Autonomie der Subsysteme, innerhalb derer Selbstorganisationsprozesse als Prozesse organisationalen Lernens gefördert werden sollen, erhöhen, werden im folgenden die dort entwickelten Gestaltungsempfehlungen zusammengefaßt. Aus ihnen werden in Abschnitt 5.2 wiederum Ausprägungen der Informationsbedarfe und -bereitstellungen der menschlichen Informationsverarbeiter abgeleitet, die Rahmenbedingungen für die auf die informationellen Beziehungen zwischen den menschlichen Informationsverarbeitern abzielenden Gestaltungsaktivitäten des Informationsmanagements sind.

Im Rahmen der Gestaltung der Arbeitsteilung kann zwischen dem Einfluß der diesbezüglichen organisatorischen Regeln auf die Ressourcen- sowie die Leistungsinterdependenzen eines Subsystems unterschieden werden. Für die Ressourceninterdependenzen konnte lediglich aufgezeigt werden, daß es hier gilt, bei der Ausgestaltung der organisatorischen Regeln zur Arbeitsteilung den Organizational Slack eines Subsystems zu fördern. Dabei beschränkt sich die Perspektive der vorliegenden Arbeit im folgenden auf Organizational Slack bezüglich des Faktors Zeit. Bei der Gestaltung der Leistungsinterdependenzen ist zwischen inter- und intrasystemischer Arbeitsteilung zu unterscheiden. Eine Ausrichtung der intersystemischen Arbeitsteilung an Objekten geht 
tendenziell mit geringeren Leistungsinterdependenzen zwischen den Subsystemen und damit einem höheren $\mathrm{Ma} ß$ an relativer Autonomie einher als eine Ausrichtung an Funktionen. Bei der intrasystemischen Arbeitsteilung erweist sich eine 'Spezialisierung auf die Unternehmung' dann als förderlich für die relative Autonomie eines Subsystems, wenn die Mitarbeiter im Zeitverlauf unterschiedlichen Subsystemen angehören und dadurch Know-how über Teilaufgabenbereiche aus anderen Subsystemen erwerben.

Bei der Gestaltung des eingesetzten Koordinationsinstrumentariums ist zwischen intrasystemischer und intersystemischer Koordination zu trennen. Intrasystemische Freiräume werden dabei mit klaren Rahmenvorgaben im intersystemischen Bereich kombiniert: Während innerhalb eines Subsystems explizit gewährte Freiräume für Selbstregelungsprozesse in Kombination mit Plänen ein hohes $\mathrm{Ma} ß$ an Varietät der so koordinierten Handlungen ermöglichen, begrenzt eine Kombination aus Plänen und Programmen zur intersystemischen Koordination gleichzeitig die durch die Subsysteme zu verarbeitende Komplexität und stellt sicher, daß die Erhöhung der relativen Autonomie eines Subsystems nicht zu einer Beeinträchtigung der relativen Autonomie des nächsthöheren Subsystems und letztlich der Unternehmung als Ganzen führt.

Betrachtet man die organisatorischen Regeln zum Leitungssystem, so ist zwischen Primär- und Sekundärorganisation zu differenzieren. Sofern man das eingesetzte Koordinationsinstrumentarium berücksichtigt, ist im Rahmen der Gestaltung der Primärorganisation ein Einliniensystem gegenüber einem Mehrliniensystem vorzuziehen. Denn das Gewähren von Freiräumen für Selbstregelungsprozesse innnerhalb eines Subsystems sollte mit klaren Rahmenvorgaben für die Abstimmung des Subsystems mit seiner Umwelt einhergehen. Ein Einliniensystem vermeidet im Vergleich zu einem Mehrliniensystem die dort häufig auftretenden Kompetenzstreitigkeiten und Abgrenzungsprobleme und ist deshalb besser geeignet, um eindeutige Rahmenbedingungen für das (selbstorganisierende) Subsystem zu schaffen. Für die Primärorganisation gilt ferner, daß die Reintegration von Stabsarbeit in die Linieninstanz deren relative Autonomie fördert. Im Rahmen der Gestaltung der Sekundärorganisation ist die reine Projektorganisation zu präferieren, da sie mit der größten relativen Autonomie des Projektteams einhergeht und damit das Auftreten von Selbstorganisationsprozessen als Prozessen organisationalen Lernens fördert. Sowohl für die Primär- als auch für die Sekundärorganisation gilt, daß Heterarchien als im Zeitverlauf veränderliche Zuordnungen von Führungsaufgaben zu Mitarbeitern nur dann zu einer Erhöhung der relativen Autonomie eines Subsystems führen, wenn die Mitarbeiter im Zeitverlauf Führungsaufgaben in unterschiedlichen Subsystemen übernehmen und dadurch subsystemübergreifendes Know-how erwerben. Schließlich sollte den Subsystemen der Primärorganisation vermehrt die Möglichkeit eingeräumt werden, im Bedarfsfall Projektteams als temporäre Subsysteme zu bilden.

Für die Gestaltung der Entscheidungsdelegation gilt, daß die relative Autonomie eines Subsystems mit dem Umfang der an dieses Subsystem delegierten Entscheidungen steigt. Unterscheidet man zwischen prozeßgestaltenden, systemkonstituierenden und 
zielbildenden Entscheidungsarten, so sind prozeßgestaltende Entscheidungsarten vergleichsweise problemlos delegierbar. Art und Ausmaß der Delegation systemkonstituierender Entscheidungsarten müssen für den spezifischen Einzelfall geprüft werden, während eine vollständige Übertragung der zielbildenden Entscheidungsarten an ein Subsystem regelmäßig nicht möglich ist und hier deshalb gegebenenfalls stattdessen Möglichkeiten zur Partizipation eingeräumt werden können. 
Frauke Streubel - 978-3-631-75510-5

Downloaded from PubFactory at 01/11/2019 04:00:13AM 


\section{Informationsmanagement in der lernenden Unternehmung}

Nach der organisatorischen Gestaltung ist das Informationsmanagement das zweite Aufgabenfeld, das im Rahmen der vorliegenden Arbeit bezüglich seines potentiellen Beitrages zur Förderung häufiger und schneller Prozesse organisationalen Lernens höherer Ordnung analysiert wird. Die Untersuchung von Fremd- und Selbstorganisation als möglicher Ausprägungen organisatorischer Tätigkeiten in Kapitel 4 stellt den notwendigen Zwischenschritt zur Konzeptionalisierung des Zusammenhangs zwischen organisationalem Lernen und Informationsmanagement dar. Denn bei beiden Arten organisatorischer Tätigkeit handelt es sich um organisationale Lernprozesse. Aufgrund der als Ausgangsproblematik der vorliegenden Arbeit konstatierten häufigen, schnellen und grundlegenden Wandelprozesse in den spezifischen Teilumwelten der einzelnen Aufgabenträger der Unternehmung erweisen sich Selbstorganisationsprozesse im Vergleich $\mathrm{zu}$ Fremdorganisationsprozessen als besser geeignet, um entsprechende unternehmungsinterne Wandelprozesse zu gewährleisten. Deshalb gilt es, - im Sinne eines Lernens zu lernen bzw. Deutero Learning - durch Aktivitäten der organisatorischen Gestaltung (als Lernprozesse) das Auftreten künftiger Selbstorganisationsprozesse (als weiterer Lernprozesse) zu fördern. Ziel der organisatorischen Gestaltungsaktivitäten ist es dabei, die relative Autonomie eines Subsystems zu erhöhen, da dies die Wahrscheinlichkeit für das Auftreten emergenter und nicht-emergenter Selbstorganisationsprozesse in eben diesem Subsystem erhöht. Nachdem in Abschnitt 4.2 aufgezeigt wurde, welche Ausgestaltung der organisatorischen Regeln zu Arbeitsteilung, Koordination, Leitungssystem und Entscheidungsdelegation die relative Autonomie eines Subsystems und damit das Auftreten von Selbstorganisationsprozessen fördert, gilt es nunmehr zu untersuchen, welche Konsequenzen daraus für das Informationsmanagement resultieren. Ziel des folgenden Kapitels ist es also, aus den Anforderungen an die organisatorische Gestaltung solche für das Informationsmanagement in der lernenden Unternehmung abzuleiten. Dafür wird in Abschnitt 5.1 zunächst der theoretische Bezugsrahmen für die Ableitung von Anforderungen an das Informationsmanagement vervollständigt. Darauf aufbauend wird in den folgenden beiden Abschnitten im Rahmen eines Zwei-EbenenAnsatzes des Informationsmanagements zwischen der immateriellen Ebene (Abschnitt 5.2) und der materiellen Ebene des computergestützten Informationssystems (Abschnitt 5.3) unterschieden. Es wird aufgezeigt, wie Informationsstruktur und Informationstechnik in der lernenden Unternehmung zu gestalten sind. Dabei wird der jeweils grundsätzlich bidirektionale Zusammenhang zwischen organisatorischen Regeln, Informationsstruktur und Informationstechnik auf eine unidirektionale Argumentationslinie reduziert. Abbildung 5/1 zeigt die Argumentationsstruktur des fünften Kapitels im Überblick. 


\subsection{Theoretischer Bezugsrahmen}

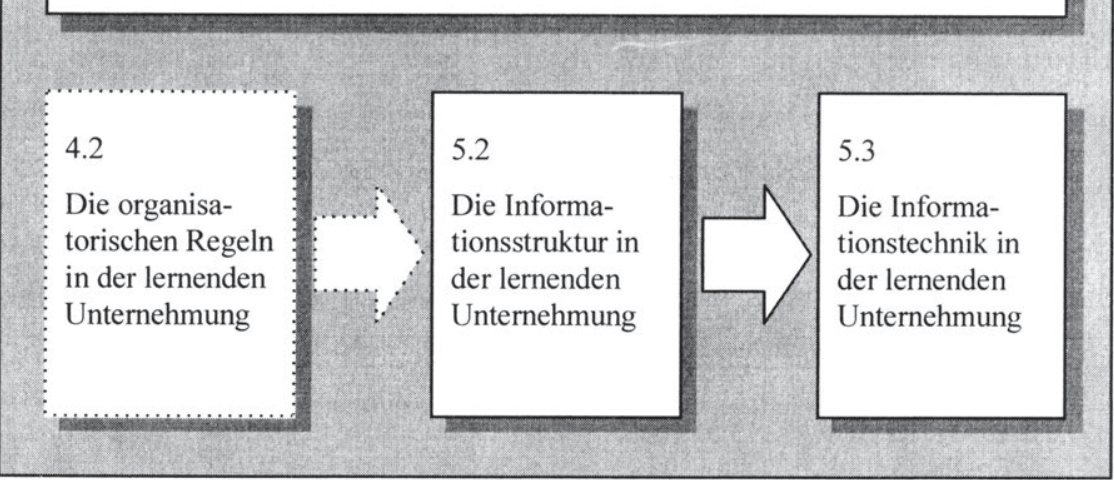

Abb. 5/1: Die Argumentationsstruktur des fünften Kapitels

\subsection{Theoretischer Bezugsrahmen für die Ableitung von Anforderungen an das Informationsmanagement}

Voraussetzung für die systematische Ableitung theoretisch fundierter Anforderungen an das Informationsmanagement in der lernenden Unternehmung ist die Entwicklung eines geeigneten Bezugsrahmens. Denn bei der Rezeption der verfügbaren Literatur erweist es sich als problematisch, daß sowohl das organisationale Lernen als auch das Informationsmanagement vieldiskutierte Phänomene sind, die theoretische Fundierung der Darstellungen jedoch regelmäßig gravierende Mängel aufweist. Treten bereits bei der isolierten Behandlung beider Aspekte Probleme auf, so erweist sich die Konzeptionalisierung des Zusammenhangs zwischen beiden Phänomenen erst recht als problematisch. Trotz der großen Bedeutung des Informationsmanagements im allgemeinen und seiner Einbeziehung in ein umfassendes Managementkonzept organisationalen Lernens im besonderen fehlt in der wissenschaftlichen Literatur bislang eine systematische Aufbereitung dieses Themenkomplexes. Der folgende Abschnitt 5.1.1 bietet eine kritische Würdigung der wenigen verfügbaren deutsch- und englischsprachigen Literatur zum Zusammenhang zwischen organisationalem Lernen und Informationsmanagement. Da sich auch die wenigen dort im Überblick dargestellten Quellen aus der Perspektive der vorliegenden Arbeit in nicht ausreichender Weise mit der Thematik befassen, gilt es im Anschluß daran, einen eigenen Vorschlag zu entwickeln. Dabei wird im wesentlichen auf die Vorarbeiten des zweiten, dritten und vierten Kapitels zurückgegriffen: Zunächst wurde dort aufgezeigt, was unter organisationalem Lernen zu verstehen ist und sodann der Fokus der vorliegenden Arbeit auf bestimmte organisationale Lernprozesse beschränkt, zu denen insbesondere sämtliche organisatorischen Tätigkeiten in der Unternehmung gehören, wobei sich Selbstorganisationsprozesse unter den Prämissen 
dieser Arbeit als besonders geeignet erweisen. Da die organisatorische Gestaltung, die einen Rahmen zur Förderung künftiger Selbstorganisationsprozesse schaffen muß, einen Prozeß organisationalen Lernens darstellt, tritt die Untersuchung des Zusammenhangs zwischen organisatorischer Gestaltung und Informationsmanagement an die Stelle der ursprünglichen Fragestellung nach dem Zusammenhang zwischen organisationalem Lernen und Informationsmanagement. Der in Kapitel 2 entwickelte Zwei-Ebenen-Ansatz des Informationsmanagements dient nicht nur der Abgrenzung dieses Aufgabenfeldes, sondern er stellt darüber hinaus eine geeignete Basis für die Konzeptionalisierung des Zusammenhangs zwischen organisatorischer Gestaltung und Informationsmanagement dar. Die somit bereits in den vorangegangenen Kapiteln entwickelte grundsätzliche Argumentationsstruktur muß im folgenden lediglich spezifiziert werden, um die Ableitung von Anforderungen an das Informationsmanagement in der lernenden Unternehmung aus denen für die organisatorische Gestaltung $\mathrm{zu}$ ermöglichen. Diese Operationalisierung bietet Abschnitt 5.1.2. Sie stellt den letzten Teilschritt zur Erreichung des Zwischenziels der vorliegenden Arbeit dar, den Zusammenhang zwischen organisatorischer Gestaltung und Informationsmanagement zu konzeptionalisieren.

\subsubsection{Stand der Diskussion über den Zusammenhang zwischen organisationalem Lernen und Informationsmanagement in der Literatur}

Bereits zu Beginn der vorliegenden Arbeit wurde einerseits die Bedeutung des Informationsmanagements für ein umfassendes Managementkonzept organisationalen Lernens aufgezeigt, andererseits ein Mangel an entsprechender Literatur konstatiert.' Diese Feststellung soll im folgenden anhand eines kurzen Überblicks über die verfügbare deutsch- und englischsprachige Literatur, die im weitesten Sinne den Zusammenhang zwischen organisationalem Lernen und Informationsmanagement thematisiert, überprüft werden. Dabei werden zunächst die Beiträge eines im Jahre 1995 von ZUCCHERMAGLIO/BAGNARA/STUCKY herausgegebenen Tagungsbandes zum Thema 'Organizational Learning and Technological Change' untersucht. Sodann werden mit ALBRECHT, SCHÜPPEL und GÜLDENBERG wichtige Arbeiten zum Thema Wissensmanagement vorgestellt.

Zwar erheben die von ZuCCHERMAglio/BAgnARA/STUCKY unter dem Titel 'Organizational Learning and Technological Change' zusammengefaßten Beiträge erst gar nicht den Anspruch, das gesamte Aufgabenfeld Informationsmanagement, wie es in der vorliegenden Arbeit abgegrenzt wird, zu behandeln, sondern beschränken sich mit der reinen IT-Gestaltung auf dessen materielle Ebene. Zumindest für diese läßt die Thematik der in dem Sammelband dokumentierten Tagung jedoch die Entwicklung eines systematischen Ansatzes erhoffen. So untersuchen die dem ersten der drei Teile

1 Siehe Abschnitt 1.I der vorliegenden Arbeit. 
des Bandes zugeordneten Beiträge „Organizations as Learning Bodies“2 und haben damit die theoretische Analyse organisationalen Lernens zum Gegenstand. Bei näherer Betrachtung der einzelnen Beiträge ist deren Anteil zur Entwicklung eines theoretischen Bezugsrahmens für die systematische Ableitung von Anforderungen an die Gestaltung der Informationstechnik in der lernenden Unternehmung jedoch eher gering, wie im folgenden beispielhaft anhand der Argumentation bei CLANCEY, ORR und ELKJAER gezeigt wird.

Clancey fokussiert in seinem Beitrag zum Thema 'Practice Cannot be Reduced to Theory: Knowledge, Representations and Change in the Workplace' den Bereich der künstlichen Intelligenz. Er stellt der traditionellen, rationalistischen Perspektive auf den Wissensverarbeitungsprozeß ein interaktionsorientiertes Verständnis menschlichen Verhaltens und menschlicher Kognition gegenüber. Auf diesem aufbauend unterscheidet er zwischen individuellem und Gruppenlernen. Sodann untersucht er die Konsequenzen dieser veränderten epistemologischen Position für Reorganisationsprozesse. $\mathrm{Ob}$ und in welcher Weise organisationales Lernen über interaktionsorientiertes Gruppenlernen hinausreicht, läßt CLANCEY jedoch offen. ${ }^{3}$

ORR untersucht unter dem Titel 'Ethnography and Organizational Learning: In Pursuit of Learning at Work' zunächst das Phänomen des Lernens eines Einzelnen oder einer Gruppe am Arbeitsplatz. In einem nächsten Schritt geht er dann der Frage nach, wie dieses auf einen engen Personenkreis beschränkte und damit lokale Wissen unternehmungsweit verfügbar gemacht werden kann. Unter Verzicht auf eine exakte definitorische Abgrenzung versteht ORR unter organisationalem Lernen damit den Prozeß des Verfügbarmachens individuellen Wissens für einen größeren Personenkreis. ${ }^{4}$

ElkJaer thematisiert unter dem Titel 'Learning is an Active and Personal Process' die Bedeutung von Weiterbildungsmaßnahmen. Dabei unterscheidet sie zwischen der Perspektive des Einzelnen, der die Weiterbildungsmaßnahme als positiv für seine Persönlichkeitsentwicklung sowie seine Funktion als Mitarbeiter in der Unternehmung empfinden kann, und der Perspektive der Unternehmung, aus der es zu untersuchen gilt, ob die Weiterqualifikation des Einzelnen einen positiven Beitrag zur Unternehmungsentwicklung leistet. Tendenziell versteht ELKJAER dabei organisationales Lernen weniger als Lernen der Unternehmung als vielmehr als (individuelles) Lernen in der Unternehmung. ${ }^{5}$

Dieser kurze Überblick über einige der Beiträge des Tagungsbandes zeigt, daß ihre mangelnde Verwertbarkeit in erster Linie in ihrer ungenügenden Konzeptionalisierung

\footnotetext{
Stucky (1995), S. 1.

Vgl. Clancey (1995), S. 20ff.

Vgl. Orr (1995), S. 50ff.

Vgl. Elkaer (1995), S. $82 \mathrm{ff}$.
} 
organisationalen Lernens und insbesondere der mangelnden Trennschärfe der Abgrenzung zwischen organisationalem und individuellem Lernen begründet liegt.

Die unscharfe Abgrenzung von organisationalem und individuellem Lernen in Verbindung mit der Beschränkung des Informationsmanagements auf die Gestaltung der Informationstechnik führt schließlich dazu, daß im dritten Teil des Tagungsbandes einige Beiträge über den Einsatz von Informationstechnik im Bildungsbereich und hier insbesondere in Schulen dem Themengebiet des organisationalen Lernens zugeordnet werden, ${ }^{6}$ d.h. es wird untersucht, wie Informationstechnik individuelles Lernen fördern kann. Aus der Perspektive der vorliegenden Arbeit erscheint ein solches Gleichsetzen von individuellem und organisationalem Lernen nicht sinnvoll. Die dort vorgenommene argumentatorische Verknüpfung von organisationalem Lernen und Informationstechnik bietet damit keine ausreichende konzeptionelle Basis für die Ausführungen der vorliegenden Arbeit.

Während sich in der Literatur keine Aussagen über die Ausgestaltung eines ganzheitlichen Informationsmanagements in der lernenden Unternehmung finden, häufen sich seit ca. Mitte der 90er Jahre Veröffentlichungen zum Wissensmanagement. Da einerseits Wissens- und Informationsmanagement eine große begriffliche Nähe aufweisen, andererseits das Wissensmanagement aber auch häufig in der Tradition von Ansätzen zu organisationalem Lernen steht, gilt es zu prüfen, ob die Arbeiten zum Wissensmanagement Impulse für die im folgenden zu entwickelnden Anforderungen an das Informationsmanagement in der lernenden Unternehmung bieten. Neben einer Fülle eher praxisorientierter Arbeiten, die oft den Eindruck erwecken, als würde hier das populäre Schlagwort des Wissensmanagements vor allem zu Zwecken der Selbstvermarktung verwendet, ohne daß deutlich wird, was das spezifisch Neue der Argumentation ist, ${ }^{7}$ und die deshalb hier nicht weiter berücksichtigt werden, existieren einige theoretisch anspruchsvolle Arbeiten zum Phänomen des Wissensmanagements, von denen im folgenden die von ALBRECHT, SCHÜPPEL und GÜLDENBERG untersucht werden. ${ }^{8}$

ALBRECHT entwickelt unter dem Titel 'Strategisches Management der Unternehmensressource Wissen' zunächst einen allgemeinen Gestaltungsrahmen für ein strategisches Management der Ressource Wissen in der Unternehmung, wobei er nach dem

6 Vgl. Cavalli-Sforza/Lesgold (1995), S. 225ff.; McMahon (1995), S. 254ff.; Newman (1995), S. $212 \mathrm{ff}$. So beschreibt z.B. Newman, wie der Einsatz von Informationstechnik projektbezogenes Lernen im Schulalltag fordern kann.

7 Vgl. z.B. Christmann-Jacoby/Maas (1997), passim; Eppler (1997), passim; Hinkelmann (1997), passim; Lorenz (1998), passim; o.V. (1998), passim; Tödtmann (1997), passim; Wiemann (1998), passim. Vgl. ferner die dort jeweils zu einem Schwerpunktthema 'Wissensmanagement' zusammengefaßten Beitrăge in Information Management, Heft 1, 1998, sowie in Technologie \& Management, Heft 1, 1997, wobei sogar die Darstellung eines Lotus Notes-basierten Besuchsberichtssystems dem Wissensmanagement zugeordnet wird. Vgl. Dieter (1997), passim.

Hier bestătigt sich die von Wollnik bereits 1988 geăußerte Vermutung, daß der damals populäre Begriff des Informationsmanagements in der Zukunft durch einen neuen und damit werbewirksameren Begriff ersetzt werden würde. Vgl. Wollnik (1988), S. 43.

8 Vgl. insbesondere Albrecht (1993), passim; Güldenberg (1997), passim; Pawlowsky (1994), passim; Schüppel (1996), passim, sowie Willke (1995) und (1996), passim. 
Wissensträger zwischen menschlichem und maschinellem Wissen unterscheidet, die im Rahmen eines ganzheitlichen Wissensmanagements zu integrieren sind. Vom Grundgedanken her weist sein Konzept des Wissensmanagements große Ähnlichkeit mit dem Informationsmanagement-Verständnis der vorliegenden Arbeit auf. Denn auch ALBRECHTS zentrales Anliegen besteht darin, die von ihm konstatierte Beschränkung des Informationsmanagements auf rein technische Aspekte im Rahmen eines ganzheitlichen Wissensmanagements zu überwinden. ${ }^{9}$ Dabei unterscheidet er zwischen den folgenden drei Dimensionen des Wissensmanagements: Das WissensressourcenManagement bezieht sich auf die „primäre Ressource Wissen“10, während das HumanRessourcen-Management und das Wissenstechnik-Management (die zum Wissenssystem-Management zusammengefaßt werden können) den Menschen und die Wissenstechnik als „sekundäre Ressourcen“11 bzw. Wissensträger betreffen. ${ }^{12}$ Prinzipiell entspricht diese Systematisierung des Wissensmanagements der Unterscheidung der vorliegenden Arbeit zwischen einer immateriellen und einer materiellen Ebene des Informationsmanagements. Im folgenden wendet ALBRECHT sich dann allerdings im Rahmen der Analyse maschinell gespeicherten Wissens allein dem Bereich der wissensbasierten Systeme als eines Teiles des Forschungsfeldes der Künstlichen Intelligenz zu und beschränkt sich somit auf einen Teilbereich der in der Unternehmung eingesetzten Informationstechnik. ${ }^{13}$ Es scheint, daß diese Verengung der Perspektive die wichtigste Konsequenz des Ersetzens des Informations- durch den Wissensbegriff bei ALBRECHT ist. Als problematisch erweist sich die mangelnde Konzeptionalisierung des Zusammenhangs zwischen dem von ihm entwickelten Gestaltungsrahmen des strategischen Wissensressourcen-Managements und dem strategischen Wissenstechnik-Management. Das Phänomen organisationalen Lernens erwähnt ALBRECHT nur kurz: Die Förderung organisationalen Lernens ordnet er dem Human-Ressourcen-Management und damit dem personalwirtschaftlichen Bereich zu, wodurch die Grenze zwischen individuellem und organisationalem Lernen verwischt.

Insgesamt ähnelt ALBRECHTS Grundansatz eines ganzheitlichen Wissensmanagements dem im Rahmen der vorliegenden Arbeit verfolgten Verständnis von Informationsmanagement. Ähnlich wie hier das Informationsmanagement versteht ALBRECHT das Wissensmanagement als auf die Ressource Wissen bezogenes Aufgabenfeld bzw. als Managementteilaktivität. Da die unbedingte Notwendigkeit für ein Ersetzen des Informations- durch den Wissensbegriff letztlich nicht nachvollziehbar ist, ergibt sich der Eindruck, daß hier ein Modebegriff durch einen noch aktuelleren ersetzt wird. Aus der Sicht der vorliegenden Arbeit erweist sich vor allem die mangelnde Thematisierung

9 Vgl. Albrecht (1993), S. 98. Weshalb es dafur allerdings unbedingt notwendig ist, den Informationsbegriff durch den des Wissens zu ersetzen, ist m.E. nicht wirklich nachvollziehbar.

10 Albrecht (1993), S. 100.

11 Albrecht (1993), S. 100.

12 Vgl. Albrecht (1993), S. 100.

13 Vgl. Albrecht (1993), S. 170ff. 
organisationalen Lernens, das zudem als rein personalwirtschaftlich relevantes Phänomen verstanden wird, als problematisch. ${ }^{14}$ Darüber hinaus sind sowohl die Verengung des Gegenstandsbereiches des strategischen Wissenstechnik-Managements auf wissensbasierte Systeme als auch die mangelnde Konzeptionalisierung des Zusammenhangs zwischen diesem und dem strategischen Wissensressourcen-Management zu kritisieren. Damit stellt AlBRECHT zwar einen interessanten Ansatz für ein ganzheitliches Informationsmanagement vor, für die Ableitung von Anforderungen an das Informationsmanagement in der lernenden Unternehmung bietet seine Arbeit jedoch keine Impulse.

Schon im Titel seiner Arbeit 'Wissensmanagement. Organisatorisches Lernen im Spannungsfeld von Wissens- und Lernbarrieren' stellt SCHüPPEL auf Wissensmanagement und organisationales Lernen ab. In seiner Arbeit entwickelt er zunächst ein Modell organisationalen Lernens. Sodann arbeitet er Wissens- und Lernbarrieren heraus, um schließlich Maßnahmen zur Überwindung dieser Barrieren im Rahmen eines umfassenden Wissensmanagements zu entwickeln. Als umfassendes Managementkonzept rückt sein Verständnis von Wissensmanagement dabei - zumindest vom Grundgedanken her - in die Nähe des Verständnisses der vorliegenden Arbeit von organisationalem Lernen als ebenfalls umfassendem Managementkonzept. Dabei strukturiert er die Maßnahmen des Wissensmanagements anhand der Dimensionen inneres und äußeres Wissenspotential, aktuelles und zukünftiges Wissenspotential sowie explizites und implizites Wissen. Innerhalb dieser von ihm entwickelten Struktur unterscheidet er dann allerdings nicht weiter zwischen organisatorischen und personalwirtschaftlichen Aspekten sowie solchen des Informationsmanagements, sondern stellt die einzelnen diesen drei Bereichen zuordenbaren Maßnahmen ohne weitere Systematisierung nebeneinander. Damit bietet Schüppel zwar ein interessantes Konzept organisationalen Lernens bzw. des Wissensmanagements, der Bezug zum Aufgabenfeld Informationsmanagement geht jedoch über einige exemplarische Aspekte nicht hinaus. Entsprechend sind die Ergebnisse seiner Untersuchung im Rahmen der vorliegenden Arbeit, die auf die Konzeptionalisierung des Zusammenhangs zwischen organisationalem Lernen und Informationsmanagement abstellt, nicht verwertbar. ${ }^{15}$

In seiner Arbeit über 'Wissensmanagement und Wissenscontrolling in lernenden Organisationen' entwirft GüLdENBERG ein Modell der lernenden Unternehmung als wissensbasiertem System. Er versteht Wissen als das Ergebnis von Lernprozessen bzw. als gelernte Information. ${ }^{16}$ Das Wissensmanagement ${ }^{17}$ stellt dann eine umfassende Managementkonzeption zur Förderung von Lernprozessen dar, die GüLDENBERG im

\footnotetext{
Die diesbezüglichen Ausfuhrungen beschrănken sich auf 4 von 230 Textseiten.

Vgl. Schuppel (1996), S. 195ff.

Vgl. Güldenberg (1997), S. 155.

17 Über das Wissensmanagement hinaus betrachtet Guldenberg auch das Wissenscontrolling, das er diesem nicht unter-, sondern nebenordnet. Da diese Unterscheidung für die Argumentation der vorliegenden Arbeit jedoch nicht relevant ist, wird hier auf ihre Darstellung verzichtet.
} 
Verantwortungsbereich der Unternehmungsführung ansiedelt und von rein technisch bzw. personell orientierten Konzeptionen des Wissensmanagements unterscheidet. ${ }^{18}$ Die einzelnen Aktivitäten des Wissensmanagements ordnet er den Bereichen Wissensgenerierung, -speicherung, -transfer und -anwendung zu, innerhalb derer er nicht weiter zwischen personalwirtschaftlichen und organisatorischen Aspekten sowie solchen des Informationsmanagements unterscheidet. Diese mangelnde Differenzierung erweist sich aus der Sicht der vorliegenden Arbeit, die auf die Konzeptionalisierung des Zusammenhangs zwischen organisationalem Lernen und Informationsmanagement abstellt, als problematisch.

Insgesamt unterscheiden sich die Arbeiten von SCHÜPPEL und GÜLDENBERG somit grundlegend von der von ALBRECHT, da sie das Wissensmanagement nicht im Sinne einer auf Wissen bzw. Information bezogenen Ressourcenwirtschaft - und damit ähnlich der Konzeptionalisierung des Informationsmanagements im Rahmen der vorliegenden Arbeit - verstehen, sondern als umfassendes Managementkonzept. Damit rückt ihr Verständnis von Wissensmanagement in die Nähe dessen organisationalen Lernens in der vorliegenden Arbeit. Einige der im Rahmen dieser beiden umfassenden Konzepte formulierten Maßnahmen zur Förderung organisationalen Lernens beziehen sich zwar auf die Gestaltung der Informationstechnik. Aussagen zur immateriellen Ebene des Informationsmanagements fehlen jedoch. Insbesondere unterscheiden weder SCHÜPPEL noch GÜLDENBERG explizit zwischen organisationalen und personalwirtschaftlichen Aspekten sowie solchen des Informationsmanagements. Entsprechend erfolgt auch keine Konzeptionalisierung des Zusammenhangs zwischen Anforderungen an die organisatorische Gestaltung und solchen an das Informationsmanagement, wie sie für die Argumentation der vorliegenden Arbeit notwendig ist. Somit ist festzustellen, daß diese Arbeiten zum Wissensmanagement keine Impulse für die Argumentation der vorliegenden Arbeit bieten.

Abschließend ist nach der Thematisierung des Zusammenhangs zwischen dem Auftreten von Selbstorganisationsprozessen (als einer Form organisationalen Lernens) und den Aktivitäten des Informationsmanagements in der Literatur zu fragen. Es existieren jedoch noch nicht einmal Untersuchungen über den systematischen Zusammenhang zwischen dem Auftreten von Selbstorganisationsprozessen und der reinen Gestaltung der Informationstechnik (unter Abstraktion von den immateriellen Aspekten des Informationsmanagements). In der Literatur zum Phänomen Selbstorganisation finden sich lediglich einige wenige exemplarische Äußerungen über die informationstechnische Unterstützung, die dann zumeist als Teil listenartiger Aufzählungen konkreter Maßnahmen zur Förderung von Selbstorganisationsprozessen undifferenziert neben personalwirtschaftlichen und organisatorischen Maßnahmen stehen. ${ }^{19}$ Der Bezug zwischen

19 Vgl. z.B. Gerstner (1995), S. 223f.; Probst (1987), S. $121 \mathrm{ff}$. 
Selbstorganisationsprozessen und der immateriellen Ebene des Informationsmanagements fehlt vollständig.

Der Überblick über die verfügbare Literatur zeigt, daß der direkte Zusammenhang zwischen organisationalem Lernen und Informationsmanagement dort nicht analysiert wird. Auch bieten die genannten Arbeiten keinerlei Ansatzpunkte für eine solche Konzeptionalisierung. Die folgenden Ausführungen der vorliegenden Arbeit zielen deshalb darauf $a b$, unter Einbeziehung der organisatorischen Gestaltung einen indirekten Zusammenhang zwischen organisationalem Lernen und Informationsmanagement zu entwickeln, um die aufgezeigten konzeptionellen Defizite der Literatur zu überwinden.

\subsubsection{Operationalisierung des Zusammenhangs zwischen organisato- rischer Gestaltung als Prozeß organisationalen Lernens und Informationsmanagement}

Während die grundsätzlichen Argumente zur Konzeptionalisierung des Zusammenhangs zwischen der organisatorischen Gestaltung als einem Proze $ß$ organisationalen Lernens einerseits und dem Informationsmanagement andererseits bereits im zweiten, dritten und vierten Kapitel der vorliegenden Arbeit dargestellt wurden, gilt es nunmehr, die dort entwickelten Annahmen zu operationalisieren. Erst dann können aus den Ausprägungen der organisatorischen Regeln in Abschnitt 4.2 Konsequenzen für das Informationsmanagement abgeleitet werden. Dabei kann auf das von WALL ausgearbeitete Modell zum Zusammenhang zwischen den organisatorischen Regeln und der Architektur der Informationstechnik ${ }^{20}$ zurückgegriffen werden. Es stellt den einzigen in der Literatur verfügbaren systematischen Ansatz zur Verknüpfung organisatorischer Fragestellungen mit solchen der Gestaltung der Informationstechnik dar, der darüber hinaus auch die Informationsbedarfe und -bereitstellungen der menschlichen Informationsverarbeiter als Einflußfaktoren der informationellen Beziehungen zwischen ihnen berücksichtigt. Die Kernpunkte des Modells von WaLL werden in Abschnitt 5.1.2.1 vorgestellt. Im Rahmen dieser reinen Darstellung, die noch keinen expliziten Bezug zur Argumentation der vorliegenden Arbeit herstellt - und entsprechend auch noch keine Bewertung enthält - werden die von WALL gebrauchten Begriffe verwendet, die zum Teil erheblich von der Terminologie der vorliegenden Arbeit abweichen. Erst in Abschnitt 5.1.2.2 erfolgt dann eine kritische Würdigung des Modells von WALL aus der Sicht der vorliegenden Arbeit, und es werden die aus dem hier verfolgten Erkenntnisinteresse und der spezifischen Perspektive resultierenden Modifikationen ihres Ansatzes vorgenommen, die einerseits rein begrifflicher Natur sind, andererseits aber auch bestimmte Modellannahmen betreffen.

20 Wall selbst spricht von dem Zusammenhang zwischen Organisationsstruktur und Architektur des Informationssystems. Da sich die von ihr vorgenommenen Abgrenzungen dieser Begriffe jedoch erheblich von denen der vorliegenden Arbeit unterscheiden, wird hier - und in der Überschrift des folgenden Abschnittes 5.1.2.1 - der Terminologie der vorliegenden Arbeit gefolgt. 


\subsubsection{Das Modell von WALL zum Zusammenhang zwischen organisatorischen Regeln und Architektur der Informationstechnik}

Ziel der Arbeit von WALL ist es, Elemente einer Konstruktionstheorie zur Gestaltung des Informationssystems zu entwickeln. Während sie grundsätzlich auch anderen Faktoren Einfluß auf das Informationssystem zubilligt, beschränkt sie ihre Untersuchung auf die organisatorischen Regeln als Einflußfaktoren der Gestaltung des Informationssystems. ${ }^{21}$ Dem Informationssystem rechnet sie dabei über die in der Unternehmung eingesetzte Informationstechnik hinaus auch die für deren Entwicklung und Betrieb zuständigen Personen zu und stellt damit auf dessen Charakter als Versorgungssystem $a b$, dessen Zweck es ist, die Aufgabenträger in der Unternehmung (die selbst nicht Elemente des Informationssystems sind) mit Informationen zu versorgen..$^{22} \mathrm{Da}$ die systematische Ableitung von organisatorisch bedingten Konstruktionsempfehlungen für das Informationssystem die Konzeptionalisierung des theoretischen Zusammenhangs zwischen organisatorischen Regeln und Informationssystem voraussetzt, entwickelt WALL zunächst ein entsprechendes Modell, das die Formulierung eines geeigneten Konstruktionsziels einschließt. Erst in einem zweiten Schritt leitet sie konkrete Konstruktionsempfehlungen für Informationssysteme ab.

Bei der Konzeptionalisierung des Zusammenhangs zwischen der Organisationsstruktur (als der Summe der organisatorischen Regeln) und dem Informationssystem geht WALL von einem Primat der Organisation aus. Aufgrund dieses Primates der Organisation ist ein Fit zwischen Organisationsstruktur und Informationssystem herzustellen. ${ }^{23}$ Da WALL in der Literatur einen Mangel an Ansätzen zur Operationalisierung dieses auch von anderen Autoren postulierten Fit zwischen Organisationsstruktur und Informationssystem konstatiert, schlägt sie das Konstruktionsziel der Homologie als besonders geeignete Möglichkeit vor, um den Fit zwischen Organisationsstruktur und Informationssystem zu realisieren. ${ }^{24} \mathrm{Im}$ Unterschied zu Analogie, die allein auf Funktionsähnlichkeit abstellt, bezeichnet Homologie zusätzlich Strukturähnlichkeit. Entsprechend gilt, daß ein zur Organisationsstruktur homologes Informationssystem stets auch analoge Ähnlichkeit zu dieser hat, nicht jedoch jedes analoge Informationssystem auch homolog zur Organisationsstruktur ist. Homologie umfaßt dabei einerseits Lageähnlichkeit im Gefüge im Sinne unmittelbarer Strukturähnlichkeiten andererseits qualitative Ähnlichkeiten im Sinne von Übereinstimmungen bei einzelnen Eigenschaften. ${ }^{25}$

Da das Konstruktionsziel Homologie auf die strukturgleiche bzw. -ähnliche Nachbildung der organisatorischen Regeln im Informationssystem abstellt, gilt es, bei der

\footnotetext{
Vgl. Wall (1996), S. 2.

Vgl. Wall (1996), S. 24ff.

Vgl. Wall (1996), S. 52ff.

Vgl. Wall (1996), S. 61, 63.

Vgl. Wall (1996), S. $63 \mathrm{ff}$.
} 
Untersuchung des Informationssystems auf dessen Struktur im Sinne der relativen Anordnung seiner Komponenten zueinander abzustellen. Deshalb fokussiert WALL die Architektur des Informationssystems als die Beschreibung der Anordnung seiner Komponenten auf einem vergleichsweise hohen Abstraktionsniveau. Zwar besteht die Gemeinsamkeit zwischen Organisationsstruktur und Architektur des Informationssystems darin, daß beide Strukturen mit der Bereitstellung von Informationen in der Unternehmung in Zusammenhang stehen, allerdings können beide dennoch nicht direkt miteinander verglichen werden. Deshalb ist es notwendig, mit der Informationsstruktur eine zusätzliche Ebene zwischen organisatorischen Regeln und Informationssystem einzufügen. Diese umfaßt „das Geflecht von Informationsbedarfen und Informationsbereitstellung der Aufgabenträger, das aus der Organisationsstruktur folgt" ${ }^{26}$ und das „Zwangsläufiges Resultat der Organisationsstruktur“27 ist. Denn aus den organisatorischen Regeln lassen sich unmittelbar Aussagen über die organisatorisch determinierten Informationsbedarfe und -bereitstellungen ableiten. Da der Zusammenhang zwischen Organisations- und Informationsstruktur somit deterministischer Natur ist, besteht das eigentliche Konstruktionsproblem erst zwischen der Informationsstruktur auf der einen und der Architektur des Informationssystems auf der anderen Seite. Abbildung 5/2 visualisiert diese Konzeption der Homologie zwischen Organisationsstruktur und Informationssystem-Architektur unter Einbeziehung der Informationsstruktur als Zwischenform zwischen beiden Phänomenen.

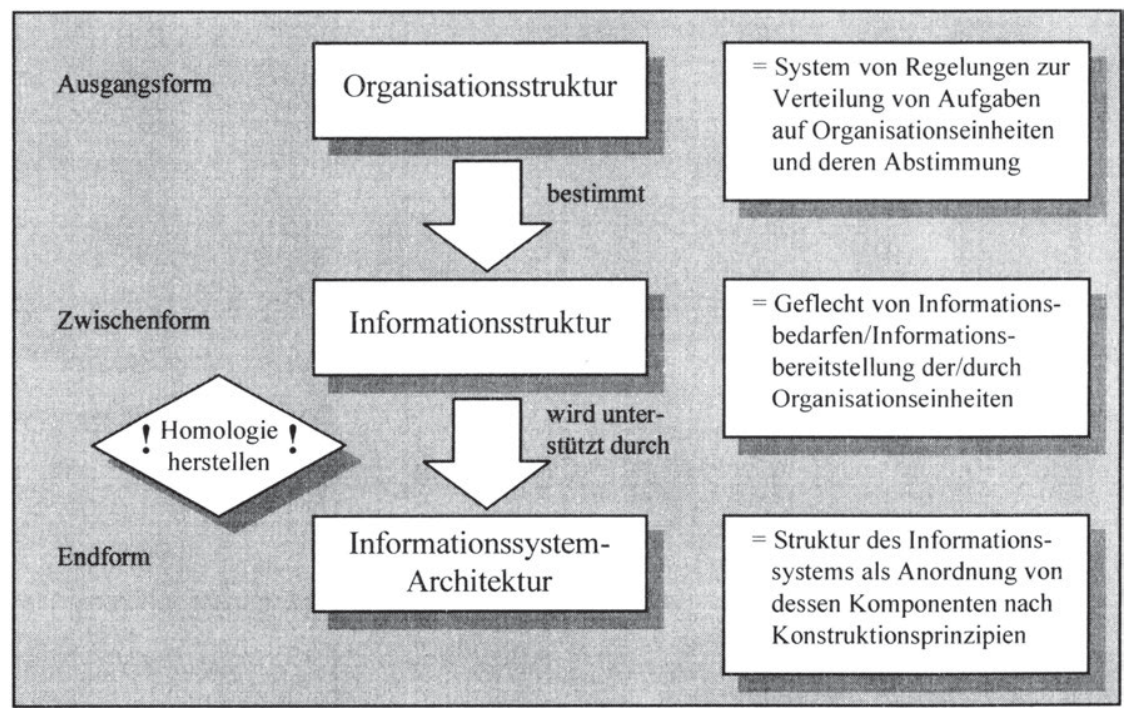

Abb. 5/2: Konzeption der Homologie zwischen Organisationsstruktur und Informationssystem-Architektur bei WALL (Quelle: Wall (1996), S. 69)

27 Wall (1996), S. 69 
Ausgehend von dieser grundsätzlichen Konzeptionalisierung des Zusammenhangs zwischen Organisationsstruktur, Informationsstruktur und Architektur des Informationssystems entwickelt WALL einen dimensionalen Ansatz ${ }^{28}$ zur systematischen Ableitung von Konstruktionsempfehlungen für die Architektur des Informationssystems aus den organisatorischen Regeln. Innerhalb dieses dimensionalen Ansatzes unterscheidet sie für jede der drei Ebenen die in Abbildung 5/3 aufgeführten Dimensionen und diskutiert den Zusammenhang zwischen den Ausprägungen der Dimensionen der drei Ebenen. Im folgenden werden diese Dimensionen vorgestellt.

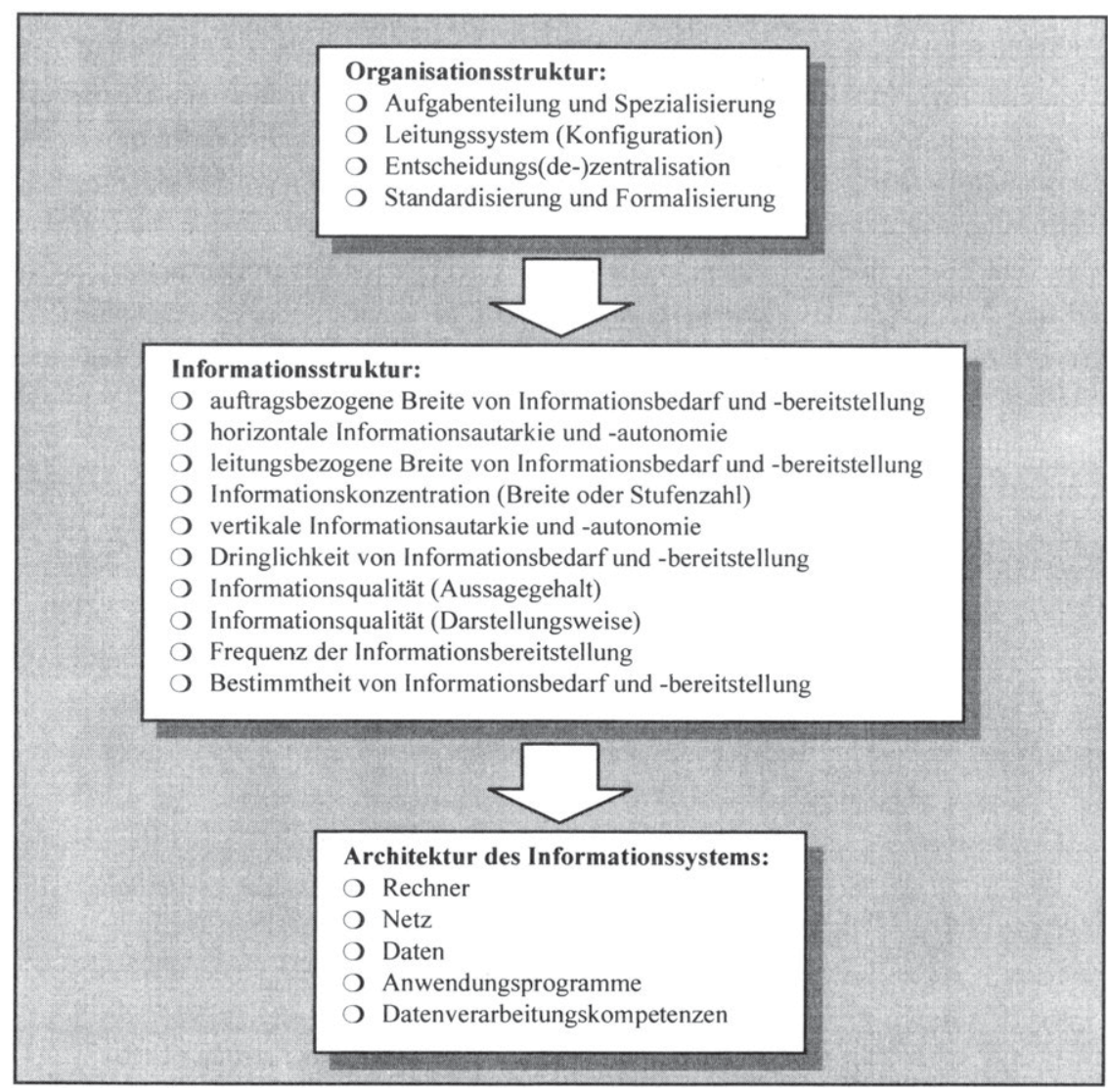

Abb. 5/3: Die Dimensionen von Organisationsstruktur, Informationsstruktur und Architektur des Informationssystems bei WALL

Betrachtet man zunächst die von WALL unterschiedenen Dimensionen der Organisationsstruktur, so entsprechen diese - bei geringfügigen Abweichungen - den in Abschnitt 4.2 der vorliegenden Arbeit untersuchten Hauptdimensionen der organisatorischen 
Gestaltung: 'Aufgabenteilung und Spezialisierung' stehen für 'Arbeitsteilung'. Die Dimensionen 'Leitungssystem' der beiden Arbeiten entsprechen einander in Bezeichnung und Inhalt. Die bei WALL unter der Bezeichnung 'Entscheidungs(de)zentralisation' behandelten Aspekte entsprechen der Dimension 'Entscheidungsdelegation' in der vorliegenden Arbeit. Unter 'Standardisierung' werden Fragen der 'Koordination' thematisiert. Die bei WALL mit der 'Standardisierung' zu einer Dimension zusammengefaßte 'Formalisierung' entfällt in der vorliegenden Arbeit aus den zu Beginn von Abschnitt 4.2 genannten Gründen. Aufgrund der weitgehenden Übereinstimmung zwischen den bei WALL und in der vorliegenden Arbeit unterschiedenen Dimensionen ist eine weitere Erörterung hier nicht notwendig.

Erklärungsbedürftig sind dagegen die von WALL unterschiedenen Dimensionen der Informationsstruktur, die deshalb im folgenden kurz erläutert werden:

Die auftragsbezogene Breite von Informationsbedarf und -bereitstellung dient der inhaltlichen Charakterisierung der von einer organisatorischen Einheit ${ }^{29}$ im Rahmen der Erfüllung ihrer Teilaufgaben benötigten und bereitgestellten Informationen. Geht man davon aus, daß die Gesamtaufgabe der Unternehmung in einzelne Aufträge ${ }^{30}$ zerlegt werden kann, die von unterschiedlichen organisatorischen Einheiten bearbeitet werden, so benötigen diese zur Auftragsbearbeitung Informationen über die Merkmale bzw. Eigenschaften des Auftrages. Zugleich gewinnen sie bei der Auftragsbearbeitung Informationen über den Auftrag. Innerhalb der Dimension 'auftragsbezogene Breite von Informationsbedarf und -bereitstellung' kann zwischen mengenbezogenen und inhaltlichen Teilaspekten unterschieden werden: Die inhaltliche Breite spiegelt wider, wieviele unterschiedliche Informationen über Eigenschaften eines Auftrages von einer organisatorischen Einheit benötigt oder bereitgestellt werden. Sie kann sich auf sämtliche oder nur auf einzelne Auftragseigenschaften erstrecken. Dagegen stellt die mengenbezogene Breite auf die Zahl der Aufträge ab, über die eine organisatorische Einheit Informationen benötigt oder bereitstellt. Sie kann sich auf die gesamte Auftragslast oder kleinere Teil-Auftragsmengen beziehen. Da die menschliche Informationsverarbeitungskapazität beschränkt ist, entwickeln sich inhaltliche und mengenbezogene Breite von Informationsbedarf und -bereitstellung regelmäßig gegenläufig. Je mehr Informationen eine organisatorische Einheit über unterschiedliche Eigenschaften eines Auftrages bearbeitet, desto niedriger ist der Anteil der von ihr bearbeiteten Aufträge an der gesamten Auftragslast, d.h. eine hohe inhaltliche Breite geht mit einer geringen mengenbezogenen Breite von Informationsbedarf und -bereitstellung einher (und umgekehrt). ${ }^{31}$

29 Wall verwendet den neutralen Begriff der organisatorischen Einheit und subsumiert darunter sowohl einzelne Aufgabenträger als auch (multipersonelle) Subsysteme.

30 Wall faßt unter dem Oberbegriff Auftrag so unterschiedliche Phänomene wie die Fertigung eines Endproduktes, das Erstellen eines Kundenangebotes oder das Verfassen eines Berichtes. Vgl. Wall (1996), S. 100.

31 Vgl. Wall (1996), S. 99ff., 143. 
Horizontale Informationsautarkie und -autonomie beschreiben das Ausmaß der informationellen Verflechtungen zwischen einander nebengeordneten organisatorischen Einheiten. Sie hängen zwar eng miteinander zusammen, stellen jedoch auf unterschiedliche Phänomene ab. Die horizontale Informationsautarkie bezieht sich darauf, inwieweit eine organisatorische Einheit bei der Erfüllung ihrer Teilaufgaben auf Informationen von ihr hierarchisch nebengeordneten Einheiten angewiesen ist (oder diese selbst erzeugt). Die horizontale Informationsautonomie stellt dagegen auf die Unabhängigkeit einer organisatorischen Einheit von gleichgeordneten Einheiten bei der Gestaltung ihrer Informationsprozesse ab. Besitzt eine organisatorische Einheit eine geringe horizontale Informationsautarkie, d.h. ist sie im Rahmen ihrer Aufgabenerfüllung in hohem Maße auf Informationen von ihr hierarchisch gleichgeordneten Einheiten angewiesen, so ist regelmäßig auch ihre horizontale Informationsautonomie gering. Da sie nämlich die erhaltenen Informationen auch berücksichtigen muß, ist sie in der Gestaltung ihrer diesbezüglichen Informationsprozesse von den diese Informationen liefernden Einheiten abhängig. Somit ist der Grad der horizontalen Informationsautonomie einer organisatorischen Einheit eine Folge ihres Grades an horizontaler Autarkie. Entsprechendes gilt für die Informationen, die eine organisatorische Einheit an eine andere weitergeben muß.32

Die leitungsbezogene Breite von Informationsbedarf und -bereitstellung betrifft die hierarchiebedingten Informationsbeziehungen zwischen einander über- bzw. untergeordneten organisatorischen Einheiten. Sie können anhand ihrer jeweiligen Richtung einerseits in solche unterschieden werden, in deren Rahmen die hierarchisch untergeordnete organisatorische Einheit Informationen von der ihr übergeordneten Einheit empfängt. Diese können Anordnungscharakter haben oder unterrichtender Natur sein. Andererseits existieren Informationsbeziehungen, in deren Rahmen die untergeordnete organisatorische Einheit der übergeordneten Informationen - insbesondere zu Kontrollzwecken - zur Verfügung stellt. Die Richtung der Informationsbeziehungen ist von großer Bedeutung, da sie deren Charakter maßgeblich beeinflußt. Beide Beziehungsarten können sowohl aus der Perspektive der übergeordneten als auch aus der der untergeordneten Einheit untersucht werden. Grundsätzlich kann im Rahmen der Dimension 'leitungsbezogene Breite von Informationsbedarf und -bereitstellung' zwischen der Zahl der leitungsbedingten Informationsbeziehungen und dem Umfang der übermittelten Informationen unterschieden werden. Dabei ist der Umfang unabhängig von eventuellen Verdichtungsvorgängen. Entsprechend ist z.B. aus der Perspektive der untergeordneten Einheit zu erfassen, welche Informationen sie an wieviele ihr übergeordnete Einheiten weiterleiten muß und von wievielen sie welche Arten von Informationen erhält. ${ }^{33}$ 
Breite und Stufenzahl der Informationskonzentration bedingen einander gegenseitig und werden deshalb zu einer Dimension zusammengefaßt. Die Breite der Informationskonzentration gibt an, von wievielen untergeordneten organisatorischen Einheiten eine übergeordnete Einheit Informationen erhält. Die Verdichtung von detaillierten Informationen zu abstrakteren wird dabei nicht betrachtet, d.h. die Breite der Informationskonzentration ist unabhängig davon, ob die Informationen, die die übergeordnete organisatorische Einheit von den ihr untergeordneten Einheiten zusammenträgt, verdichtet sind oder nicht. ${ }^{34}$ Die Stufenzahl der Informationskonzentration gibt an, auf wievielen hierarchischen Stufen dieselbe Information (in mehr oder weniger detaillierter bzw. abstrakter Form) verwendet wird. Ceteris paribus, d.h. bei gegebener Anzahl organisatorischer Einheiten, entwickeln sich Breite und Stufenzahl der Informationskonzentration gegenläufig: Je höher die Stufenzahl der Informationskonzentration ist, desto niedriger ist die Breite der Informationskonzentration (und umgekehrt). ${ }^{35}$

Vertikale Informationsautarkie und -autonomie beschreiben das Ausmaß der informationellen Verflechtungen zwischen einander über- oder untergeordneten organisatorischen Einheiten. Wie schon bei der oben vorgestellten horizontalen Informationsautarkie und -autonomie handelt es sich auch hier um eng miteinander verbundene, jedoch unterschiedliche Phänomene. Die vertikale Informationsautarkie stellt darauf ab, in wieweit eine organisatorische Einheit auf Informationen ihr über- oder untergeordneter Einheiten angewiesen ist oder diese stattdessen selbst erzeugt. Als vertikale Informationsautonomie wird die Unabhängigkeit einer organisatorischen Einheit von ihr über- oder untergeordneten Einheiten bei der Gestaltung ihrer Informationsprozesse bezeichnet. Damit ist der Grad der vertikalen Informationsautonomie einer organisatorischen Einheit Folge ihres Grades an vertikaler Informationsautarkie. ${ }^{36}$ Obwohl grundsätzlich informationelle Beziehungen in beide Richtungen, also sowohl von unten nach oben als auch von oben nach unten relevant sind, liegt der Schwerpunkt auf der aufwärtsgerichteten Bereitstellung von Informationen, d.h. den Informationen, die einer hierarchisch übergeordneten Einheit durch untergeordnete Einheiten zur Verfügung gestellt werden. Denn bei der Gestaltung der Informationstechnik, auf die die Argumentation von WALL letztlich abzielt, steht traditionellerweise die Weitergabe der Informationen von unten nach oben im Mittelpunkt der Betrachtung. ${ }^{37}$

Die Dringlichkeit von Informationsbedarf und -bereitstellung kann durch den Zeitraum ausgedrückt werden, innerhalb dessen der Informationsbedarf notwendigerweise

34 Der Begriff der Informationskonzentration bei Wall stellt damit allein auf das Sammeln bzw. Zusammentragen von Informationen ab, nicht jedoch auf deren Verdichtung im Sinne einer Abstraktion von Details.

35 Vgl. Wall (1996), S. 118f.; 144.

36 Vgl. Wall (1996), S. 128f., 145.

37 Besonders deutlich zeigen dies Integrationskonzepte wie das der 'Management Support Systems', innerhalb dessen in einer Anwendungssystem-Pyramide hierarchisch höher angesiedelte Systeme auf die Daten der Systeme der unteren Ebenen zugreifen. Vgl. z.B. Gluchowski/Gabriel/Chamoni (1997), passim. 
durch eine entsprechende Informationsbereitstellung zu decken ist. Je kürzer dieser Zeitraum ist und/oder je größer der Schaden ist, der durch ein Überschreiten des Zeitraumes entsteht, desto größer ist die Dringlichkeit von Informationsbedarf und -bereitstellung. ${ }^{38}$

Der Aussagegehalt einer Information ist eine der beiden Dimensionen der Informationsstruktur bei WALL, die auf die Informationsqualität abstellen. Er wird von einer Vielzahl unterschiedlicher Einflußfaktoren beeinflußt. Zu den wichtigsten Einflußfaktoren auf den Aussagegehalt einer Information gehören die Wahrscheinlichkeit, daß die Information wahr ist, ihre Prüfbarkeit, ihre Genauigkeit (im Sinne der Detailliertheit oder Präzision der Abbildung des Informationsobjektes), ihre Vollständigkeit, ihr Wahrheitsgehalt, ihre Aktualität, ihre relative Bedeutung bezüglich einer bestimmten Teilaufgabenerfüllung sowie ihre Objektivität im Sinne von Unpersönlichkeit sowie interpersoneller Nachvollziehbarkeit. ${ }^{39}$

Die Darstellungsweise der Information ist die zweite der beiden von WALL unterschiedenen Dimensionen der Informationsstruktur, die die Informationsqualität betreffen. Auch sie wird von mehreren Faktoren beeinflußt, zu denen ihre Formatierung, ihre Allgemeinverständlichkeit, ihre Dokumentation sowie die Anpassung an das Subjekt zählen. ${ }^{40}$

Die Frequenz der Informationsbereitstellung stellt auf die Häufigkeit der Informationsprozesse ab. Aus ihr resultiert eine bestimmte Übertragungslast, die im Rahmen der Skalierung des Informationssystems (als dessen kapazitätsmäßiger Ausgestaltung) zu beachten ist. Im Gegensatz zur Frequenz der Informationsbereitstellung ist die des Informationsbedarfs unabhängig von der Art der Ausgestaltung der organisatorischen Regeln. Sie resultiert vielmehr aus der Zahl der Wiederholungen der Teilaufgabenerfüllung, so z.B. der Auftragsmenge, und wird deshalb von WALL nicht berücksichtigt. Aber auch die Frequenz der Informationsbereitstellung findet im weiteren Verlauf der Ausführungen von WALL keine Berücksichtigung, da sie Fragen der Skalierung nicht der Gestaltung der Architektur der Informationstechnik zuordnet. ${ }^{41}$

Die Bestimmtheit von Informationsbedarf und -bereitstellung stellt darauf ab, inwieweit Informationsbedarf und -bereitstellung (die beide unmittelbar aus der Teilaufgabenerfüllung der menschlichen Aufgabenträger in der Unternehmung resultieren) vorab, d.h. vor der konkreten Teilaufgabenerfüllung, festgelegt sind. Die Betrachtung kann sich dabei einerseits auf die benötigten und bereitgestellten Informationen als Ergebnis von Informationsprozessen, andererseits auf die Informationsprozesse selbst beziehen. Beide Aspekte sind jedoch nicht unabhängig voneinander. Je höher vielmehr

38 Vgl. Wall (1996), S. 145.

39 Vgl. Wall (1996), S. 23f., $145 \mathrm{f}$.

40 Vgl. Wall (1996), S. 23f., 146.

41 Vgl. Wall (1996), S. 138, 146, 261. 
der Bestimmtheitsgrad eines Informationsprozesses ist, desto höher wird ceteris paribus auch der Bestimmtheitsgrad der benötigten und bereitgestellten Informationen sein (und umgekehrt). ${ }^{42}$

Nach der Organisationsstruktur und der Informationsstruktur unterscheidet WALL auf der dritten Ebene ihres Modells schließlich zwischen folgenden Dimensionen der Architektur des Informationssystems, die sie auch als Architekturen des Informationssystems bezeichnet:

Im Mittelpunkt der Dimension Rechner stehen autonome Rechner, bei denen den Verarbeitungseinheiten (Prozessoren) verschiedene Zentralspeicher sowie mindestens ein externer Speicher exklusiv zugeordnet sind und die von einem eigenen Betriebssystem betrieben werden. Über das Betriebssystem hinaus rechnet WALL auch betriebssystemnahe Software, einschließlich des Datenbankverwaltungssystems, der Dimension Rechner zu. ${ }^{43}$

Im Gegensatz zum üblichen Verständnis von Rechnernetzen, das auch die durch Datenübertragungseinrichtungen und -wege verbundenen Rechner umfaßt, stellt WALL bei ihrer Dimension Netz allein auf die Übertragungseinrichtungen und -wege einschließlich des Netzbetriebssystems sowie der Datenübertragungsprotokolle ab. Ihr Fokus liegt hier somit auf den Einrichtungen zur Übertragung von Daten zwischen autonomen Rechnern. ${ }^{44}$

Die Dimension Daten umfaßt die Gesamtheit der Daten, die WALl explizit als eigenständige Komponente des Informationssystems bezeichnet. Die Datenverwaltung obliegt in der Regel einem Datenbanksystem. Das von ANSI/SPARC vorgeschlagene DreiSchichten-Modell des Datenbankentwurfes spiegelt verschiedene Sichten auf die Daten wider, die von WALL zur Systematisierung ihrer Ausführungen zu dieser Dimension verwendet werden. Sie unterscheidet zwischen externer, konzeptioneller und interner Ebene. Während konzeptionelle und externe Ebene logische Ebenen darstellen, handelt es sich bei der internen Ebene um eine physische Ebene. Die konzeptionelle Ebene betrifft die logische Gesamtstruktur der Daten. Hier wird zunächst in einem semantischen Datenmodell (z.B. Entity-Relationship-Modell) die grundlegende Struktur der Datenbeziehungen in der Unternehmung abgebildet. Das semantische Datenmodell bildet wiederum die Basis für das logische Datenmodell (z.B. Relationenmodell). Im Rahmen der externen Ebene wird die Gesamtsicht der konzeptionellen Ebene in verschiedene Teilsichten zerlegt. Die Zerlegung orientiert sich an der Perspektive einzelner Benutzer bzw. Benutzergruppen und den von ihnen eingesetzten Anwendungsprogrammen. Die interne Ebene dient der Darstellung der physischen Datenorganisation als der implementierungsabhängigen Eigenschaften der Daten. Im Mittelpunkt stehen hier die

\footnotetext{
Vgl. Wall (1996), S. 20f., 139, 1466 .

Vgl. Wall (1996), S. 151.

Vgl. Wall (1996), S. 152.
} 
Art der Datenspeicherung auf physischen Datenträgern sowie geeignete Zugriffsformen auf die gespeicherten Daten. ${ }^{45}$

Der Dimension Anwendungsprogramme ist die Gesamtheit der in der Unternehmung unmittelbar zur Unterstützung betriebswirtschaftlicher Aufgabenstellungen eingesetzten Programme zuzurechnen. Die Anwendungsprogramme sind somit der systemnahen Software gegenüberzustellen, die einerseits der Rechner-, andererseits der Netzarchitektur zugeordnet werden. WALL verweist allerdings auf potentielle Abgrenzungsprobleme, die sich z.B. dadurch ergeben, daß auch Datenbanksysteme komplexe Abfragen unterstützen und damit typische Funktionalitäten von Anwendungsprogrammen umfassen können. ${ }^{46}$

Schließlich stellt die Dimension Datenverarbeitungskompetenzen auf das Aufgabenfeld der mit der Informationstechnik in der Unternehmung betrauten Personen ab. WALL verweist hier auf verschiedene Möglichkeiten, die Gesamtheit dieser Aufgaben zu gliedern und entscheidet sich dann für die Differenzierung in Aufgaben der Erstellung und solche des Betriebes von Informationssystemen. ${ }^{47}$

Wesentliche Voraussetzung für eine systematische Ableitung konkreter Empfehlungen für die Gestaltung des Informationssystems ist laut WALL neben der Unterscheidung in die genannten Architekturen bzw. Dimensionen des Informationssystems die Festlegung bestimmter Gestaltungsprinzipien. In dem Bestreben, für alle Dimensionen des Informationssystems möglichst einheitliche Konstruktionsmaßnahmen abzuleiten und damit eine in sich geschlossene Darstellung zu erreichen, wendet WALL über alle Architekturen des Informationssystems hinweg mit Integration und Differenzierung, wobei sie letztere wiederum in Verteilung und Spezialisierung unterteilt, dieselben Gestaltungsprinzipien an. Fragen der Skalierung, d.h. der kapazitätsmäßigen Ausgestaltung des Informationssystems, finden bei ihr dagegen keine Berücksichtigung. ${ }^{48}$

\subsubsection{Kritische Würdigung und Modifikation des Modells von WALL}

Nachdem die zentralen Aussagen des Modells von WALL vorgestellt wurden, werden sie im folgenden im Hinblick auf das Erkenntnisinteresse der vorliegenden Arbeit einer kritischen Würdigung und Modifikation unterzogen. Dabei wird zwischen der Gegenüberstellung der grundlegenden Modellannahmen bei WALL sowie der vorliegenden Arbeit einerseits (Abschnitt 5.1.2.2.1) und ihrem und dem hier verfolgten, modifizierten dimensionalen Ansatz andererseits (Abschnitt 5.1.2.2.2) unterschieden.

45 Vgl. Wall (1996), S. 152f., ferner Gabriel/Röhrs (1995), S. 104ff., 266ff. Weitere ausfuhrliche Darstellungen des Drei-Schichten-Modells des Datenbankentwurfes bieten z.B. Stucky/Krieger (1990), S. 842ff., sowie Schlageter/Stucky (1983), S. 26ff.

46 Vgl. Wall (1996), S. 153f.

47 Vgl. Wall (1996), S. 155ff.

48 Vgl. dazu und im folgenden Wall (1996), S. 159ff. 


\subsection{Grundlegende Modellannahmen}

Das Modell von WaLl thematisiert - gemäß der von ihr verwendeten Terminologie den Zusammenhang zwischen Organisationsstruktur, Informationsstruktur und Architektur des Informationssystems. Tabelle $5 / 4$ stellt diese drei von WaLL verwendeten Begriffe (bzw. die damit bezeichneten Phänomene) den begrifflichen Abgrenzungen der vorliegenden Arbeit gegenüber.

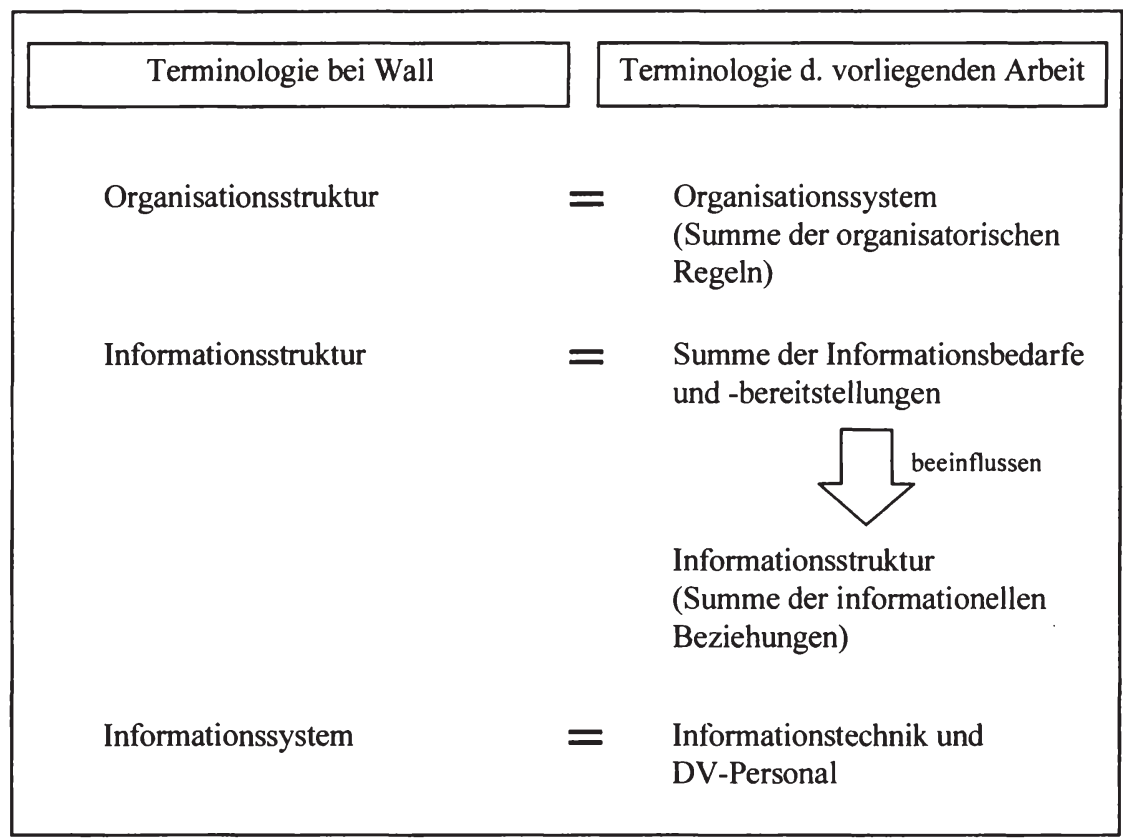

Tab. 5/4: Terminologische Unterschiede zwischen dem Modell von WALL und der vorliegenden Arbeit

Da der Begriff der Organisationsstruktur bei WALL auf die Summe der organisatorischen Regeln abstellt, entspricht er dem des Organisationssystems der vorliegenden Arbeit. ${ }^{49}$ WALLS Informationsstruktur-Begriff umfaßt die Gesamtheit der Informationsbedarfe und -bereitstellungen, die gemäß der Terminologie der vorliegenden Arbeit als Attribute der menschlichen Informationsverarbeiter Einflußfaktoren der informationellen Beziehungen zwischen den menschlichen Informationsverarbeitern sind (deren Summe wiederum in der vorliegenden Arbeit als Informationsstruktur bezeichnet wird). ${ }^{50}$ Auch der Begriff des Informationssystems von WALL unterscheidet sich grundlegend von dem der vorliegenden Arbeit: WALL stellt hier auf die Informationstechnik sowie die mit Entwicklung und Betrieb der Informationstechnik betrauten Mitarbeiter (DV-

49 Zum Begriff des Organisationssystems siehe Abschnitt 2.2.1.2 der vorliegenden Arbeit.

$50 \mathrm{Zu}$ den Begriffen Informationsbedarf und -bereitstellung, informationelle Beziehung sowie Informationsstruktur siehe die Abschnitte 2.2.1.2, 2.2.2.2.4 und 2.2.3 der vorliegenden Arbeit. 
Personal) ab. Berücksichtigt man diese terminologischen Unterschiede, so gilt es nunmehr, die wichtigsten inhaltlichen Probleme herauszuarbeiten, die der Verwendung des Modells von WALL zum Zweck der Operationalisierung des Zusammenhangs zwischen organisatorischer Gestaltung und Informationsmanagement entgegenstehen, sowie die notwendigen Modifikationen vorzunehmen.

Obwohl WALL mit den organisatorischen Regeln, den Informationsbedarfen und -bereitstellungen als Einflußfaktoren der informationellen Beziehungen und der Informationstechnik die zentralen Gegenstandsbereiche der im Rahmen der vorliegenden Arbeit untersuchten Gestaltungsaktivitäten der organisatorischen Gestaltung und des Informationsmanagements betrachtet, ist eine unveränderte Verwendung ihres Modells nicht möglich. Denn ihren Ausführungen fehlt jeder explizite Bezug zum Informationsmanagement. ${ }^{51}$ Entsprechend nimmt sie auch keine Abgrenzung zwischen organisatorischer Gestaltung und Informationsmanagement vor. Allerdings können verschiedene ihrer Aussagen interpretiert und zusammengeführt werden und weisen dann implizit auf eine bestimmte Perspektive hin.

Prinzipiell nimmt WALL an, daß eine Vielzahl von Einflußfaktoren auf die Gestaltung der Informationstechnik in der Unternehmung existieren, berücksichtigt dann aber nur die organisatorischen Regeln. Dabei geht sie von einem strengen Primat der organisatorischen Gestaltung vor der Gestaltung der Informationstechnik aus und unterscheidet sich damit zwar von den Annahmen der vorliegenden Arbeit. Da jedoch auch hier der grundsätzlich als bidirektional angenommene Zusammenhang auf die unidirektionale Ableitung von Aussagen bezüglich der Informationstechnik aus solchen für die organisatorische Gestaltung reduziert wird, ${ }^{52}$ scheinen sich die Vorgehensweisen der beiden Arbeiten auf den ersten Blick zu entsprechen.

In einem nächsten Schritt geht WALL dann jedoch von einem deterministischen Zusammenhang zwischen organisatorischen Regeln und Informationsbedarfen und -bereitstellungen der menschlichen Informationsverarbeiter aus. Anders als die vorliegende Arbeit negiert sie die Existenz situativer und personeller Einflußfaktoren auf Informationsbedarf und -bereitstellung, so daß deren Ausprägungen notwendige Konsequenz der Entscheidungen bezüglich der organisatorischen Regeln sind. Ferner unterscheidet WALL nicht zwischen den Informationsbedarfen und -bereitstellungen als Attributen der menschlichen Informationsverarbeiter und den informationellen Beziehungen zwischen diesen. Implizit geht sie damit davon aus, daß die organisatorisch bedingten Informationsbedarfe und -bereitstellungen die informationellen Beziehungen in der Unternehmung determieren. Somit besteht bei WALL über die organisatorische

51 Lediglich in einer Fußnote zur Systematisierung der DV-Aufgaben der mit Entwicklung und Betrieb der Informationstechnik betrauten Mitarbeiter in der Unternehmung verweist sie kurz auf den Begriff des Informationsmanagements, stellt jedoch keinen Bezug zu den in ihrer Arbeit beschriebenen Gestaltungsaktivităten her. Vgl. Wall (1996), S. 155.

52 Siehe Abschnitt 2.2.3 der vorliegenden Arbeit. 
Gestaltung hinaus keinerlei Gestaltungsspielraum bezüglich der informationellen Beziehungen.

Das Nachzeichnen der mit der Annahme eines deterministischen Zusammenhangs zwischen organisatorischen Regeln auf der einen und Informationsbedarfen und -bereitstellungen auf der anderen Seite verbundenen Argumentationslinie macht die daraus resultierenden problematischen Implikationen für das Informationsmanagement deutlich: Informationsbedarfe und -bereitstellungen und damit auch die informationellen Beziehungen sind bei WALL Resultanten der Entscheidungen der organisatorischen Gestaltung. Es besteht diesbezüglich bei ihr keinerlei eigenständiger Gestaltungsspielraum. Somit kann es bei WALL keine immaterielle Ebene des Informationsmanagements geben, auf der eigenständiges Gestaltungshandeln möglich ist. Vergleicht man ihre Perspektive mit dem in der vorliegenden Arbeit entwickelten Zwei-Ebenen-Ansatz des Informationsmanagements, so wäre das Gestaltungshandeln des Informationsmanagements bei WALL auf die Informationstechnik als die materielle Ebene beschränkt.

Aus der konstruktivistisch geprägten Sicht der vorliegenden Arbeit ist WaLLS Annahme, daß die informationellen Beziehungen in der Unternehmung vollständig durch die organisatorische Gestaltung determiniert werden, abzulehnen, da sie impliziert, daß die Perspektive der organisatorischen Gestaltung die 'einzig wahre und richtige' sei, der folglich allein Gestaltungsspielraum zugestanden wird. Gemäß dem Verständnis der vorliegenden Arbeit sind organisatorische Regeln bezüglich Informationsbedarf und -bereitstellung zwar durchaus Gegenstand der organisatorischen Gestaltung. Sie sind jedoch nur einer von mehreren Einflußfaktoren auf die Informationsbedarfe und -bereitstellungen, zu denen daneben verschiedene situative sowie subjektive, d.h. in den konkreten Personen der Informationsverarbeiter begründete, Faktoren zählen, die gleichberechtigt nebeneinander stehen. So ist z.B. die Verfügbarkeit externer Datenbanken entsprechend spezialisierter Marktforschungsinstitute, die detaillierte Daten über das Konsumverhalten bestimmter Bevölkerungsgruppen bezüglich bestimmter Produktarten zur Verfügung stellen, bei der Gestaltung der informationellen Beziehungen der mit strategischen Fragestellungen der Sortimentsgestaltung befaßten Marketingabteilung eines Konsumgüterherstellers zu berücksichtigen. Aber auch die individuellen Vorlieben einzelner Entscheidungsträger über die Art der Aufbereitung (Tabellen, verschiedene Arten von Grafiken, Fließtext etc.) und den Umfang der benötigten Informationen (als subjektive Faktoren) beeinflussen deren Informationsbedarfe und -bereitstellungen. Die beiden Beispiele machen unmittelbar deutlich, wie wichtig es ist, diese unterschiedlichen Einflußfaktoren bei der Gestaltung der Informationsstruktur zu berücksichtigen. Die Existenz vielfältiger Einflußfaktoren macht die Ermittlung und eventuelle Operationalisierung der Informationsbedarfe und -bereitstellungen im Rahmen des Informationsmanagements als eigenständigem Aufgabenfeld notwendig. Im Anschluß an diese Analysetätigkeiten gilt es sodann, die aus den Informationsbedarfen und -bereitstellungen resultierenden Anforderungen an die informationellen Beziehun- 
gen bei deren Gestaltung zu berücksichtigen (und gegebenenfalls zu modifizieren). Ziel des Informationsmanagements muß es dabei sein, Informationsbedarfe und -bereitstellungen in Einklang zu bringen. ${ }^{53}$ Die Gesamtheit der Aktivitäten zur Ermittlung und Operationalisierung von Informationsbedarfen und -bereitstellungen sowie zur Gestaltung der informationellen Beziehungen werden der immateriellen Ebene des Informationsmanagements als eigenständigem Gestaltungshandeln zugeordnet.

Nach dieser kritischen Würdigung der Modellannahmen von WaLL bezüglich des Zusammenhangs zwischen organisatorischen Regeln und Informationsbedarfen und -bereitstellungen gilt es nunmehr, den von ihr postulierten Zusammenhang zwischen den Informationsbedarfen und -bereitstellungen auf der einen und der Informationstechnik auf der anderen Seite zu untersuchen. Hier erweist sich das von WALL formulierte Konstruktionsziel der Homologie als Möglichkeit der Operationalisierung des geforderten Fit zwischen organisatorischen Regeln und Informationstechnik als problematisch. WALL selbst konzediert, daß ,... aus der Natur der Homologie selbst nicht zwingend hergeleitet werden [kann], daß sie zum 'organizational fit' des Informationssystems führt ..."54, sondern dies lediglich plausibel erscheine. Homologie bedeutet gemäß WALL Strukturgleichheit oder -ähnlichkeit. Ferner stellt sie als Homologiekriterium auf die 'Lageähnlichkeit im Gefüge' in dem Sinne ab, daß die „Zahlen der verschiedenen Komponenten eines Informationssystems und deren Verknüpfungen ... sich grundsätzlich nach der Informationsstruktur [richten], ... im einzelnen aber nach dem Umfang der Prozesse der Informationsbereitstellung und der Intensität der Verknüpfung ausgelegt [werden]." 55 Ihre Argumentation läßt letztendlich jedoch offen, warum gerade diese Lageähnlichkeit im Gefüge besonders geeignet ist, einen Fit zwischen Organisationsstruktur und Architektur der Informationstechnik herzustellen. Auch erscheinen einige der von ihr aufgrund des Konstruktionsziels der Homologie getroffenen Konstruktionsempfehlungen fragwürdig. Als Beispiel sei hier auf den von ihr postulierten Zusammenhang zwischen der horizontalen Informationsautonomie einer organisatorischen Einheit und der Netzsegmentierung verwiesen. WALL fordert: „Je höher der Grad der horizontalen Informationsautonomie ist, um so stärker ist das Netz (in Bezug auf die gewählte Betrachtungsebene) zu segmentieren." 56 Wählt man hier als Beispiele eine Abteilung, eine Arbeits- oder eine Projektgruppe, so würde dies bedeuten, daß diesen zur Förderung ihrer horizontalen Informationsautonomie ein eigenes Subnetz eingerichtet wird. Insbesondere bei den regelmäßig zeitlich befristeten Projektgruppen würde dies bedeuten, daß im Zeitverlauf immer wieder neue

53 Das Auslassen dieser Gestaltungsaktivităt bei Wall impliziert, daß sie von einem quasi 'automatischen' Ausgleich zwischen benötigten und bereitgestellten Informationen im Rahmen der informationellen Beziehungen ausgeht. Diese Annahme widerspricht m.E. fundamental der in der betrieblichen Praxis hăufig zu beobachtenden Realităt fehlender Deckung von Informationsbedarfen und der Bereitstellung nicht benötigter Informationen.

55 Wall (1996), S. 72.

56 Wall (1996), S. 212. 
Netzsegmentierungen vorgenommen werden müßten. Der Abgleich mit der betrieblichen Praxis zeigt m.E., daß es sich hier weder um eine realistische noch eine sinnvolle Gestaltungsoption handelt. Zwar kann es bei einem hohen Grad an Informationsautonomie eines Bereiches wie der Lohn- und Gehaltsabrechnung z.B. aus Datenschutzgründen durchaus geboten sein, eine Netzsegmentierung vorzunehmen. Häufig werden auch technische Restriktionen dies erforderlich machen. Einen regelmäßigen Zusammenhang zwischen beiden Größen in der oben formulierten Weise zu fordern, ist m.E. jedoch für eine Vielzahl der sozialen Subsysteme in der Unternehmung nicht sinnvoll.

Über die geschilderten grundsätzlichen Bedenken gegenüber dem Konstruktionsziel Homologie hinaus, erweisen sich aus der Sicht der vorliegenden Arbeit die daraus resultierenden Konsequenzen für das Informationsmanagement als äußerst problematisch. Denn aus der Forderung nach einer homologen Abbildung der Informationsstruktur (und aufgrund des deterministischen Zusammenhangs zwischen organisatorischen Regeln und Informationsstruktur letztlich auch der organisatorischen Regeln) in der Informationstechnik folgt, daß dem Informationsmanagement bei der Gestaltung der Informationstechnik kaum Freiräume bleiben, da die Vorgaben der organisatorischen Gestaltung unverändert umzusetzen sind, um nicht die geforderte Homologie zu gefährden. Die Modellannahmen von WALL führen somit nicht nur dazu, daß das Informationsmanagement auf die rein materielle Ebene reduziert wird, sondern auch zu einer extremen Einschränkung seiner diesbezüglichen Gestaltungsfreiräume. Informationsmanagement wäre demnach hier letztlich nicht mehr als der auf die konkrete informationstechnische Umsetzung reduzierte 'verlängerte Arm' der konzeptionellen Entscheidungen der organisatorischen Gestaltung. Diese Sichtweise widerspricht der Perspektive der vorliegenden Arbeit fundamental.

Zusammenfassend kann hier festgehalten werden, daß WALL zwar keinen expliziten Bezug zwischen ihrem Modell und dem Aufgabenfeld Informationsmanagement herstellt, daß ein solcher aber durchaus rekonstruiert werden kann. Dabei hat sich gezeigt, daß einige ihrer zentralen Modellannahmen mit der hier vertretenen Grundposition nicht vereinbar sind. Aus der Perspektive der vorliegenden Arbeit ist der Ansatz von WALL von einem unangemessenen Determinismus geprägt. ${ }^{57}$ Dieser betrifft nicht nur ihre Konzeptionalisierung des Zusammenhangs zwischen organisatorischen Regeln und Informationsbedarfen und -bereitstellungen, sondern auch die zwischen Informationsbedarfen und -bereitstellungen und der Architektur der Informationstechnik.

\subsection{Dimensionaler Ansatz}

Trotz der beschriebenen gravierenden Unterschiede in den jeweiligen Grundannahmen bietet die Arbeit von WALL wichtige Impulse für die weitere Vorgehensweise der vorliegenden Arbeit bei der Operationalisierung des Zusammenhangs zwischen organisato-

57 Diese stark deterministische Grundhaltung kommt m.E. auch sehr deutlich in dem Ziel ihrer Arbeit, einen Beitrag zu einer Konstruktionstheorie fur Informationssysteme zu leisten, zum Ausdruck. 
rischer Gestaltung (als organisationalem Lernprozeß, der weitere Lernprozesse in Form von Selbstorganisation ermöglicht) und Informationsmanagement. Diese liegen in der von ihr gewählten Vorgehensweise eines dimensionalen Ansatzes: WALL entwickelt für alle drei von ihr untersuchten Ebenen (organisatorische Regeln, Informationsbedarfe und -bereitstellungen sowie Architektur der Informationstechnik) eine Systematik verschiedener Dimensionen. Anders als bei WALL wird in der vorliegenden Arbeit zwar keinerlei Determinismus unterstellt, jedoch geht es auch hier darum, aus bestimmten Ausprägungen der organisatorischen Regeln Konsequenzen für die Informationsstruktur und die Informationstechnik (als der Gestaltungsobjekte des Informationsmanagements) abzuleiten. Dabei stellen die organisatorischen Regeln zwar grundsätzlich nur einen von mehreren Einflußfaktoren auf die Informationsbedarfe und -bereitstellungen dar. Die Berücksichtigung situativer und subjektiver Einflußfaktoren setzt jedoch eine geeignete Systematisierung ihrer potentiellen Ausprägungen voraus, ${ }^{58}$ die den Rahmen der vorliegenden Arbeit sprengen würde. Deshalb können diese im folgenden nicht berücksichtigt werden. Entsprechend wird auch hier die Argumentation auf die aus den organisatorischen Regeln resultierenden Konsequenzen für Informationsbedarfe und -bereitstellungen reduziert.

Dem Informationsmanagement obliegt es in einem ersten Schritt, die Konsequenzen der organisatorischen Regeln für die Informationsbedarfe und -bereitstellungen zu ermitteln. In einem zweiten Schritt gilt es dann aufzuzeigen, wie das Informationsmanagement im Rahmen seines Gestaltungshandelns dazu beitragen kann, daß es im Rahmen der informationellen Beziehungen in der Unternehmung zu einem Ausgleich zwischen den beschriebenen Informationsbedarfen und -bereitstellungen kommt. Dabei gilt es, einerseits die Deckung der formulierten Informationsbedarfe, andererseits die Verarbeitung der bereitgestellten Informationen sicherzustellen. Auf der materiellen Ebene werden aus den Aussagen bezüglich der Informationsstruktur sodann Konsequenzen für die Gestaltung der verschiedenen Dimensionen der Informationstechnik abgeleitet, die im Rahmen des auf die materielle Ebene bezogenen Gestaltungshandelns des Informationsmanagements umzusetzen sind. Bei dieser Vorgehensweise erweisen sich die von WALL vorgeschlagenen Dimensionen der Informationsbedarfe und -bereitstellungen sowie der Informationstechnik - unter Berücksichtigung einiger in der spezifischen Thematik der vorliegenden Arbeit begründeter Modifikationen - als geeigneter Diskussionsrahmen. Allerdings müssen zwischen Informationsbedarfe und -bereitstellungen auf der einen und die Informationstechnik auf der anderen Seite die informationellen Beziehungen als eigenständiger Aspekt eingefügt werden. Im folgenden wird die in Abschnitt 5.1.2.1 vorgestellte Systematisierung der Dimensionen von WALL aufgegriffen und zu einem geeigneten Bezugsrahmen für die Ableitung der aus den

58 Die konkreten Ausprägungen der situativen und subjektiven Einflußfaktoren und ihre Konsequenzen für die Informationsstruktur können nur für den konkreten betrieblichen Einzelfall untersucht werden. Im Rahmen einer abstrakten Untersuchung wăre es lediglich möglich, die verschiedenen potentiellen Merkmalsausprägungen einer begrenzten Anzahl von Klassen zuzuweisen und fur diese verallgemeinernde Aussagen zu treffen. 
Ausprägungen der organisatorischen Regeln resultierenden Konsequenzen für Informationsstruktur und Informationstechnik in den Abschnitten 5.2 und 5.3 modifiziert.

Bevor die im Rahmen der vorliegenden Arbeit vorgenommene Strukturierung der Dimensionen der Informationsbedarfe und -bereitstellungen im folgenden erläutert wird, sei hier noch auf einen zentralen Unterschied zwischen den Ausführungen von WALL und denen der vorliegenden Arbeit hingewiesen: Im Gegensatz zu WALL stellen die Untersuchungen in den Abschnitten 5.2 und 5.3 explizit auf bestimmte soziale Subsysteme der Unternehmung ab, innerhalb derer durch die Förderung ihrer relativen Autonomie die Wahrscheinlichkeit für das Auftreten von Selbstorganisationsprozessen als Prozessen organisationalen Lernens gefördert werden soll. Somit wird hier explizit die Perspektive eines bestimmten Subsystems gegenüber seinem Umfeld verfolgt und untersucht, welche Ausprägungen dessen Informationsbedarfe und -bereitstellungen aufweisen.

Untersucht man die von WALL unterschiedenen Dimensionen der Informationsbedarfe und -bereitstellungen, ${ }^{59}$ so fällt zunächst auf, daß einige Dimensionen auf prinzipiell ähnliche Sachverhalte abstellen, die deshalb im folgenden zu Gruppen zusammengefaßt werden. Dies gilt erstens für die auftrags- sowie die leitungsbezogene Breite von Informationsbedarf und -bereitstellung, zweitens für die horizontale sowie die vertikale Informationsautarkie und drittens für Aussagegehalt und Darstellungsweise als Teildimensionen der Informationsqualität. Darüber hinaus werden auftrags- und leitungsbezogene Breite von Informationsbedarf und -bereitstellung um weitere Aspekte ergänzt und mit diesen zu einer neuen Dimension 'inhaltlicher Umfang von Informationsbedarf und -bereitstellung' zusammengefaßt. Dagegen entfällt sowohl die Betrachtung der Dimension Frequenz der Informationsbereitstellung als auch die der Informationskonzentration. Somit bilden die in Abbildung 5/5 aufgeführten Dimensionen, die im folgenden näher erläutert werden, die Grundlage der Ausführungen in Abschnitt 5.2.

Sowohl die auftrags- als auch die leitungsbezogene Breite von Informationsbedarf und -bereitstellungen bei WALL ${ }^{60}$ stellen auf den inhaltlichen Umfang von Informationsbedarf und -bereitstellung ab. Zwar unterscheidet sie innerhalb der auftragsbezogenen Breite zwischen inhaltlicher und mengenmäßiger Breite und scheint damit auf den ersten Blick zwischen qualitativen und quantitativen Aspekten zu differenzieren. Beide Teildimensionen haben jedoch den Auftrag bzw. die Aufträge in der Unternehmung als unmittelbare Bezugsgröße. Da WALL von einem sehr weiten Begriffsverständnis für Aufträge ausgeht und diese dabei aus der Zerlegung der Gesamtaufgabe der Unternehmung resultieren, können WALLS Aufträge mit dem Verständnis von Teilaufgaben der vorliegenden Arbeit gleichgesetzt werden. Somit stellt WALL hier auf den inhaltlichen

$59 \mathrm{Vgl}$. dazu und im folgenden Wall (1996), S. 99ff., insbesondere S. $140 \mathrm{ff}$.

$60 \mathrm{Vgl}$. dazu und im folgenden Wall (1996), S. 99ff., 111, $143 \mathrm{f}$. 


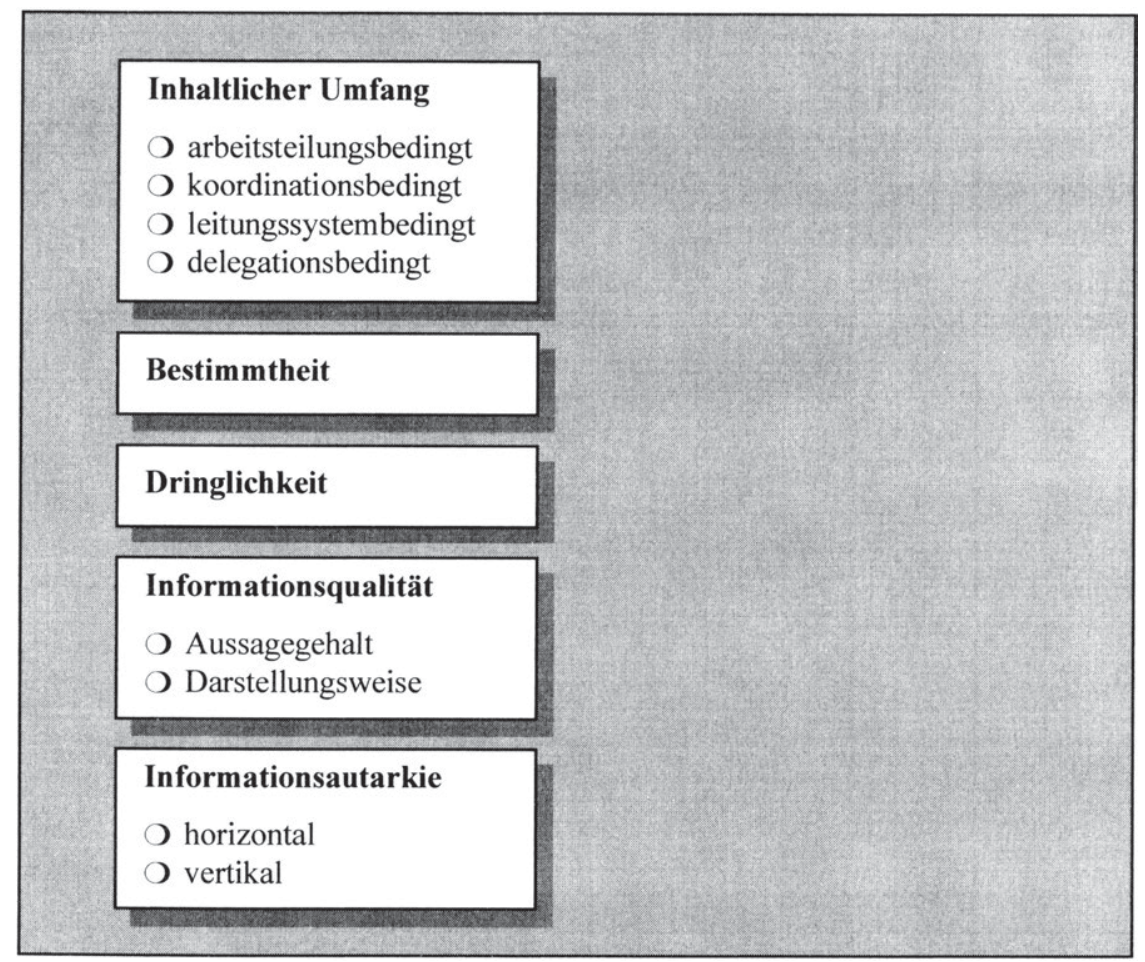

Abb. 5/5: Die Dimensionen der Informationsbedarfe und -bereitstellungen

Bezug von Informationsbedarf und -bereitstellung zu den Teilaufgabenbündeln ab, die im Rahmen der organisatorischen Regeln zur arbeitsteiligen Erfüllung der Gesamtaufgabe der Unternehmung abgegrenzt werden. Sie unterscheidet dabei nach den Inhalten und der Menge der Aufträge - und nicht etwa nach den Inhalten und der Menge der Informationsbedarfe und -bereitstellungen. Somit stellen beide Teildimensionen auf qualitative bzw. inhaltliche Aspekte von Informationsbedarf und -bereitstellung ab. WALLS Dimension der 'auftragsbezogenen inhaltlichen und mengenmäßigen Breite von Informationsbedarf und -bereitstellung' kann deshalb im folgenden als 'arbeitsteilungsbedingter inhaltlicher Umfang von Informationsbedarf und -bereitstellung' reinterpretiert werden. Für eine solche Reinterpretation spricht auch, daß WALL die organisatorischen Regeln zur Arbeitsteilung als einzigen Einflußfaktor auf die auftragsbezogene Breite von Informationsbedarf und -bereitstellung untersucht. Während der leitungssystembedingte Umfang von Informationsbedarf und -bereitstellung der bei WALL formulierten leitungsbezogenen Breite entspricht, stellen koordinations- und delegationsbedingter inhaltlicher Umfang von Informationsbedarf und -bereitstellung zusätzliche Aspekte dar, die bei WALL keine Berücksichtigung finden. In Abschnitt 5.2 wird jedoch aufgezeigt werden, daß sowohl die gewählten Koordinationsinstrumenten als 
auch das Ausmaß der Entscheidungsdelegation den inhaltlichen Umfang von Informationsbedarf und -bereitstellung durchaus beeinflussen.

Die Dimensionen Dringlichkeit und die Bestimmtheit von Informationsbedarf und -bereitstellung werden ohne weitere Modifikation von WALL übernommen.

Aussagegehalt und Darstellungsweise werden als Teildimensionen der Informationsqualität zu einer Dimension zusammengefaßt. Während der Aussagegehalt auf inhaltliche Aspekte der Qualität von Informationsbedarfen und -bereitstellungen abstellt, fokussiert die Darstellungsweise deren formale Seite.

Im Gegensatz zu WALL, die sowohl die Informationsautarkie als auch die Informationsautonomie untersucht, wird im Rahmen der vorliegenden Arbeit lediglich die Informationsautarkie als Dimension der Informationsbedarfe und -bereitstellungen verstanden. Diese drückt das örtliche Zusammen- oder Auseinanderfallen von Informationsbedarf und -bereitstellung aus und stellt dabei darauf ab, in wieweit das Subsystem einerseits bei der Erfüllung seiner Teilaufgaben auf Informationen von anderen Subsystemen $^{61}$ angewiesen ist oder diese selbst erzeugt, und inwieweit es andererseits Informationen für anderere Subsysteme bereitstellen muß. Es kann sich sowohl um hierarchisch über- oder untergeordnete (vertikale Informationsautarkie) als auch um nebengeordnete Subsysteme (horizontale Informationsautarkie) handeln. Die Informationsautarkie fokussiert damit grundlegend andere Sachverhalte als die bisher genannten Dimensionen von Informationsbedarf und -bereitstellung: Während inhaltlicher Umfang, Bestimmtheit, Dringlichkeit und Qualität Dimensionen zur Definition von Informationsbedarf und -bereitstellung sind, geht die Informationsautarkie von bereits definierten Informationsbedarfen und -bereitstellungen aus und stellt den Ort der Bedarfsdeckung in den Mittelpunkt. Es wird untersucht, ob Informationsbedarf und -bereitstellung in demselben Subsystem oder in unterschiedlichen Subsystemen anfallen. Denn nur dann, wenn die Person, die eine Information benötigt, nicht mit der Person übereinstimmt, die diese Information bereitstellt, kommt es zu informationellen Beziehungen in der Unternehmung. Dabei wird die Informationsautarkie von den anderen Dimensionen der Informationsbedarfe und -bereitstellungen beeinflußt.

Die Informationsautonomie stellt auf die Unabhängigkeit eines Subsystems bei der Gestaltung seiner informationellen Beziehungen und damit auf grundlegend andere Sachverhalte als die Informationsautarkie ab. Es handelt sich nicht um eine Dimension der Informationsbedarfe und -bereitstellungen, sondern um ein Ergebnis der die informationellen Beziehungen betreffenden Gestaltungshandlungen des Informationsmanagements. Da im Rahmen der vorliegenden Arbeit im Gegensatz zu WaLL keine deterministische Beziehung zwischen organisatorischen Regeln, Informationsbedarfen

61 Aus Grunden der sprachlichen Vereinfachung wird hier und im folgenden lediglich auf Subsysteme, nicht jedoch auf einzelne Aufgabenträger in der Umwelt des jeweils fokussierten Subsystems (innerhalb dessen Selbstorganisationsprozesse als Prozesse organisationalen Lernens gefördert werden sollen) abgestellt. Die Argumente gelten jedoch grundsătzlich auch für einzelne Aufgabenträger als Umwelt des fokussierten Subsystems. 
und -bereitstellungen sowie informationellen Beziehungen unterstellt wird, die jeglichen von der organisatorischen Gestaltung unabhängigen Gestaltungsspielraum bezüglich der informationellen Beziehungen ausschließt, sind Informationsautarkie und Informationsautonomie hier notwendigerweise unterschiedlichen Argumentationszusammenhängen zuzuordnen. Entsprechend wird die Informationsautarkie als Dimension der Informationsbedarfe und -bereitstellungen in Abschnitt 5.2.1 untersucht, während die Informationsautonomie Gegenstand der gestaltungsorientierten Ausführungen zum Informationsmanagement in Abschnitt 5.2.2 ist.

Untersucht man den Zusammenhang zwischen der in Kapitel 4 thematisierten relativen Autonomie eines Subsystems (deren Erhöhung das Auftreten von Selbstorganisationsprozessen als Prozessen organisationalen Lernens fördert) und dessen Informationsautarkie und -autonomie, so ist festzustellen, daß die Informationsautarkie als Dimension der Informationsbedarfe und -bereitstellungen die Informationsautonomie als Eigenschaft der informationellen Beziehungen beeinflußt, ohne diese jedoch zu determinieren. Je höher nämlich beispielsweise der relative Anteil der subsystemintern gedeckten Informationsbedarfe am Gesamtumfang der Informationsbedarfe eines Subsystems, desto unabhängiger von Einflüssen von außen kann es tendenziell seine informationellen Beziehungen gestalten. Grundsätzlich ist es aber auch möglich, daß das Informationsmanagement bei der Gestaltung der informationellen Beziehungen sehr stark reglementierend eingreift, so daß die Informationsautonomie hier trotz hoher Informationsautarkie gering ist. Umgekehrt hat die Informationsautonomie als Eigenschaft der informationellen Beziehungen keinen Einfluß auf die Informationsautarkie als Dimension der Informationsbedarfe und -bereitstellungen. Betrachtet man nunmehr den Zusammenhang zwischen Informationsautonomie und relativer Autonomie, so handelt es sich bei der Informationsautonomie um einen Teilaspekt der relativen Autonomie eines Subsystems als dem übergeordneten Phänomen. Während im Rahmen der Aussagen in Kapitel 4 zur relativen Autonomie als Unabhängigkeit der Entscheidungen und Handlungen eines Subsystems von äußeren Einflüssen ${ }^{62}$ nicht weiter nach der Art der Entscheidungen und Handlungen differenziert wurde, stellt die Informationsautonomie auf den Spezialfall der Unabhängigkeit bei der Gestaltung der informationellen Beziehungen ab.

Die Dimension der Informationskonzentration findet im folgenden keine Berücksichtigung. Denn Breite und Stufenzahl der Informationskonzentration werden von den Entscheidungen zum Leitungssystem beeinflußt und hängen dabei unmittelbar von den Ausprägungen von Leitungsspanne und Leitungstiefe ab. Für diese wurde jedoch in Abschnitt 4.2.3 herausgearbeitet, daß sie im Zusammenhang mit der Thematik der vorliegenden Arbeit nicht Instrumental-, sondern Symptomvariablen sind, d.h. daß ihre Ausgestaltung die Wahrscheinlichkeit für das Auftreten von Selbstorganisationsprozes- 
sen weder fördert noch verringert, sie selbst vielmehr von dem Auftreten von Selbstorganisationsprozessen beinflußt werden.

Im Gegensatz zu WALL wird in der vorliegenden Arbeit angenommen, daß die organisatorischen Regeln weder die Frequenz der Informationsbedarfe noch die Frequenz der Informationsbereitstellungen beeinflussen. Dies liegt darin begründet, daß WALL nicht zwischen Informationsbedarfen und -bereitstellungen und informationellen Beziehungen unterscheidet. Ihre Aussagen zur Frequenz der Informationsbereitstellungen betreffen gemäß der Sichtweise der vorliegenden Arbeit die der informationellen Beziehungen, die hier Gestaltungsobjekt des Informationsmanagements sind. Während die im folgenden entwickelten Gestaltungsempfehlungen für das Informationsmanagement auch die Häufigkeit der informationellen Beziehungen thematisieren, wird die Frequenz der Informationsbereitstellungen nicht berücksichtigt.

Die hier genannten Dimensionen bilden eine geeignete Systematisierung für die Untersuchung von Informationsbedarfen und -bereitstellungen als Attributen der menschlichen Informationsverarbeiter. Wie in Abschnitt 5.1.2.2.1 herausgearbeitet wurde, wird im Rahmen der vorliegenden Arbeit im Gegensatz zu dem Modell von WaLL explizit zwischen den Informationsbedarfen und -bereitstellungen und den informationellen Beziehungen zwischen den menschlichen Informationsverarbeitern unterschieden und kein deterministischer Zusammenhang angenommen, sondern von einem eigenständigen Gestaltungsfreiraum des Informationsmanagements bezüglich der informationellen Beziehungen ausgegangen. Deshalb müssen neben den obigen Dimensionen der Informationsbedarfe und -bereitstellungen auch Dimensionen der informationellen Beziehungen unterschieden werden. Hierzu eignen sich die in der betriebswirtschaftlichen Literatur verschiedentlich formulierten Kriterien zur hinreichenden Definition der informationellen Beziehungen in der Unternehmung. In geringfügiger Modifikation der Systematisierung von STAEHLE wird im folgenden zwischen

- Informationsinhalt,

- Informationsform,

- Informationsrichtung und

- Informationszeitpunkt

unterschieden. ${ }^{63}$ Die Dimension Informationsinhalt stellt auf die Ausgestaltung der im Rahmen der informationellen Beziehungen übertragenen Informationen als der Strömungsgrößen ab. Dagegen beschreiben die Dimensionen Informationsform und -richtung die Art des Zusammenhangs zwischen Sender und Empfänger. Bei der Untersuchung der Informationsform kann danach unterschieden werden, ob es sich um eine direkte oder eine indirekte Beziehung (unter Zwischenschaltung eines Mittlers) zwi-

63 Vgl. Staehle (1994), S. 548ff. Wăhrend Staehle dort auf die 'Kommunikationsflüsse' in der Unternehmung abstellt, wird dieser Begriff aufgrund der anderen Terminologie der vorliegenden Arbeit hier durch den der informationellen Beziehung ersetzt. 
schen Sender und Empfänger handelt. ${ }^{64}$ Die Informationsrichtung kann entweder einseitig oder wechselseitig sein. Die Dimension Informationszeitpunkt stellt schließlich auf den Zeitpunkt der Aktivierung eines Informationskanals durch eine konkrete informationelle Beziehung ab. Im Rahmen des Informationsmanagements gilt es, die aus den organisatorischen Regeln resultierenden Einflüsse auf die Dimensionen der Informationsbedarfe und -bereitstellungen bei der Gestaltung der Dimensionen der informationellen Beziehungen zu berücksichtigen.

Neben der immateriellen Ebene betreffen die Aktivitäten des Informationsmanagements die materielle Ebene der Informationstechnik. Hier erscheint es sinnvoll, ähnlich der Vorgehensweise von WALL, grundlegende Aspekte anstelle der großen Fülle informationstechnischer Details in den Mittelpunkt der Betrachtung zu rücken. Die Untersuchung wird jedoch nicht allein auf die Gestaltung der Informationstechnik-Architekturen unter Aspekten der Verteilung, der Spezialisierung und der Integration beschränkt. Denn aufgrund der oben genannten Argumente stellt die vorliegende Arbeit zur Operationalisierung des Fit zwischen Informationsstruktur und Informationstechnik bzw. zwischen immaterieller und materieller Ebene des Informationsmanagements nicht auf die von WALL geforderte Homologie und damit allein auf strukturelle Aspekte ab. Vielmehr wird hier untersucht, wie die verschiedenen Dimensionen der Informationstechnik gestaltet werden können, um den Abgleich der Informationsbedarfe und -bereitstellungen zu gewährleisten bzw. die dafür notwendigen informationellen Beziehungen informationstechnisch zu unterstützen.

Bezüglich der untersuchten Dimensionen der Informationstechnik kann die Systematisierung von WALL ${ }^{65}$ weitgehend übernommen werden. Der zentrale Unterschied besteht darin, daß WALL das Informationssystem der Unternehmung betrachtet, das im Sinne eines Versorgungssystems bei ihr auch die mit Entwicklung und Betrieb der Informationstechnik betrauten Personen umfaßt. Deshalb stellt sie auf die Dimension der Datenverarbeitungskompetenzen dieses Personenkreises ab. Da die materielle Ebene des Informationsmanagements gemäß dem in der vorliegenden Arbeit entwickelten ZweiEbenen-Ansatz auf die Informationstechnik beschränkt ist, werden die Datenverarbeitungskompetenzen des DV-Personals im folgenden nicht berücksichtigt. Die Ausführungen zur Informationstechnik in Abschnitt 5.3 gliedern sich in die Dimensionen Daten, Netz, Anwendungsprogramme und Rechner. Im Gegensatz zu WALL werden im folgenden allerdings Aussagen zu den eingesetzten Datenbanksystemen nicht der Dimension Rechner, sondern der der Daten zugeordnet. Als Strömungsgrößen sind die Daten Gegenstand von Beziehungen zwischen Elementen des computergestützten

64 Im Gegensatz dazu ordnet Staehle der Dimension Informationsform Aussagen über die formale Qualităt der übermittelten Informationen zu, die im Rahmen der vorliegenden Arbeit als auf die Strömungsgröße Information bezogene Teilaspekte der Dimension Informationsinhalt zugeordnet werden. Vgl. Staehle (1994), S. 549.

Vgl. dazu und im folgenden Wall (1996), S. 150ff. 
Informationssystems. ${ }^{66}$ Jedoch stehen sie in unmittelbarem Zusammenhang mit den Elementen des Informationssystems, die - wie Datenbanksysteme - ihrer Verarbeitung und Speicherung dienen. Hier wird deutlich, daß die Trennung von Elementen und Beziehungen eines Systems im Rahmen einer systemtheoretisch geprägten Herangehensweise vor allem analytischer Natur ist, beide Aspekte tatsächlich jedoch eng zusammenhängen. Daten und Datenbanksysteme werden deshalb im folgenden zu einer Dimension zusammengefaßt. Im Gegensatz zur immateriellen Ebene des Informationsmanagements, die Informationen bzw. informationelle Beziehungen und damit semantische und pragmatische Aspekte in den Mittelpunkt stellt, werden im Rahmen der Betrachtung der materiellen Ebene des Informationsmanagements dagegen die mit der informationstechnischen Umsetzung verbundenen syntaktischen Aspekte untersucht. Während WALL den Begriff der Anwendungsprogramme auf solche zur Unterstützung betriebswirtschaftlicher Probleme beschränkt, umfaßt er im folgenden grundsätzlich alle - betriebswirtschaftlichen und technischen - Anwendungsprogramme (im Sinne von betrieblichen Anwendungsprogrammen).

\subsection{Die Gestaltung der immateriellen Ebene des computerge- stuitzten Informationssystems in der lernenden Unternehmung}

Nachdem der notwendige theoretische Bezugsrahmen nunmehr vervollständigt ist, kann er im folgenden als Grundlage für die Entwicklung theoretisch fundierter Aussagen bezüglich des Informationsmanagements in der lernenden Unternehmung dienen. Ausgehend von den in Abschnitt 4.2 postulierten Ausprägungen der organisatorischen Regeln zu Arbeitsteilung, Koordination, Leitungssystem und Entscheidungsdelegation werden in Abschnitt 5.2.1 zunächst die daraus resultierenden Konsequenzen für die Informationsbedarfe und -bereitstellungen der menschlichen Informationsverarbeiter in den Subsystemen der Unternehmung ermittelt, deren relative Autonomie zwecks Förderung des Auftretens von Selbstorganisationsprozessen (als Prozessen organisationalen Lernens) gestärkt werden soll. Die hier entwickelten Aussagen über die Dimensionen der Informationsbedarfe und -bereitstellungen stellen Rahmenbedingungen für das Informationsmanagement dar, das im Rahmen der Gestaltung der informationellen Beziehungen gewährleisten muß, daß einerseits den formulierten Informationsbedarfen eine entsprechende Bedarfsdeckung gegenübersteht, andererseits die bereitgestellten Informationen auch tatsächlich verwendet werden. In Abschnitt 5.2.2 werden Möglichkeiten aufgezeigt, wie das Informationsmanagement im Rahmen des ihm verbleibenden Gestaltungsspielraums den aus den organisatorischen Regeln resultierenden Anforderungen bei der Gestaltung der Informationsstruktur begegnen kann. Denn

$66 \mathrm{Zu}$ den Elementen und Beziehungen innerhalb des computergestützten Informationssystems siehe Abschnitt 2.2.2.2.4 der vorliegenden Arbeit. 
sein Gestaltungsspielraum wird durch die organisatorischen Regeln zwar eingeschränkt, nicht jedoch im Sinne eines deterministischen Zusammenhangs zwischen organisatorischen Regeln und informationellen Beziehungen aufgehoben.

\subsubsection{Organisatorisch bedingte Rahmenbedingungen des Informationsmanagements}

Im folgenden wird untersucht, welche Konsequenzen aus den in Abschnitt 4.2 entwickelten Ausprägungen der organisatorischen Regeln für die Informationsbedarfe und -bereitstellungen resultieren. Dabei gliedern sich die Ausführungen anhand der Dimensionen von Informationsbedarf und -bereitstellung in solche zum inhaltlichen Umfang (Abschnitt 5.2.1.1), zur Bestimmtheit (Abschnitt 5.2.1.2) und zur Dringlichkeit von Informationsbedarf und -bereitstellung (Abschnitt 5.2.1.3) sowie zur Informationsqualität (Abschnitt 5.2.1.4) und zur Informationsautarkie (Abschnitt 5.2.1.5). Die Aktivitäten auf der immateriellen Ebene des Informationsmanagements zielen darauf ab, im Rahmen der Gestaltung der informationellen Beziehungen den Abgleich der Informationsbedarfe und -bereitstellungen unter der Berücksichtigung von Wirtschaftlichkeitsaspekten zu gewährleisten. Dabei gilt es, diese aus den organisatorischen Regeln resultierenden Ausprägungen der Dimensionen der Informationsbedarfe und -bereitstellungen zu berücksichtigen. Deshalb stellen die im folgenden abgeleiteten Ausprägungen der Informationsbedarfe und -bereitstellungen Rahmenbedingungen für die Gestaltungsaktivitäten des Informationsmanagements dar.

\subsubsection{Inhaltlicher Umfang von Informationsbedarf und -bereitstellung}

Im folgenden wird gezeigt, daß die Ausprägungen der organisatorischen Regeln zu allen vier Dimensionen der organisatorischen Gestaltung Auswirkungen auf den inhaltlichen Umfang von Informationsbedarf und -bereitstellung haben. Deshalb wird hier zunächst zwischen dem Einfluß von

- Arbeitsteilung,

- Koordination,

- Leitungssystem und

- Entscheidungsdelegation

auf den inhaltlichen Umfang von Informationsbedarf und -bereitstellung unterschieden, bevor eine gesamthafte Betrachtung dieser Dimension von Informationsbedarf und -bereitstellung vorgenommen wird. 


\section{Der Einfluß der Arbeitsteilung auf den inhaltlichen Umfang von Informationsbedarf und -bereitstellung}

Erhöht man den Organizational Slack eines Subsystems, indem man den ihm zur Teilaufgabenerfüllung gewährten zeitlichen Spielraum ausdehnt, um dadurch die Wahrscheinlichkeit für das Auftreten von Selbstorganisationsprozessen als Prozessen organisationalen Lernens zu erhöhen, so kann dies zu einer Erhöhung des inhaltlichen Umfangs von Informationsbedarf und -bereitstellung führen. Immer dann nämlich, wenn Mitarbeiter die ihnen zur Verfügung stehende zusätzliche Zeit für Zwecke der Leistungserstellung nutzen, indem sie mehr und vielfältigere Informationen bei der Leistungserstellung berücksichtigen, z.B. um die zu erfüllenden Teilaufgaben in einen umfassenden Gesamtzusammenhang einzuordnen, erhöht dies den inhaltlichen Umfang des Informationsbedarfs. Der inhaltliche Umfang der von dem Subsystem bereitgestellten Informationen steigt, wenn die Mitarbeiter die zusätzliche Zeit für eine Verbesserung ihres Leistungserstellungsprozesses nutzen und aus diesem verbesserten Leistungserstellungsprozeß umfangreichere Informationen resultieren.

Entscheidet man sich im Rahmen der intersystemischen Arbeitsteilung für eine objektorientierte anstelle einer funktionsorientierten Spezialisierung der Subsysteme, so bedeutet dies, daß das jeweilige Subsystem nur eine bestimmte Teilmenge der Gesamtheit der Auftragslast bearbeitet. Auf die Gesamtmenge der Aufträge bezogen bedeutet objektorientierte Arbeitsteilung somit eine Einschränkung von Informationsbedarf und -bereitstellung. Beispielsweise benötigt das einzelne Subsystem bei der Gliederung des Vertriebsabteilung in kundengruppenorientierte Subsysteme nur Informationen über die von ihm bearbeitete Kundengruppe und stellt entsprechend anderen Subsystemen auch nur Informationen über diese zur Verfügung. Im Gegensatz dazu würde eine funktionsorientierte Arbeitsteilung zwischen den einzelnen Subsystemen der Vertriebsabteilung bedeuten, daß diese die gesamte Menge der Aufträge - allerdings unter Beschränkung auf bestimmte Aspekte - bearbeiten. Damit ist die auf die Auftragslast bezogene mengenmäßige Breite von Informationsbedarf und -bereitstellung bei funktionsorientierter Arbeitsteilung vergleichsweise größer. Zugleich bedeutet die mit der funktionsorientierten Arbeitsteilung verbundene Beschränkung von Informationsbedarf und -bereitstellung auf bestimmte Aspekte der einzelnen Aufträge ein Begrenzung deren inhaltlicher Breite. Bei objektorientierter Spezialisierung ist diese inhaltliche Breite dagegen höher, da Informationsbedarf und -bereitstellung sich hier auf eine Vielzahl unterschiedlicher Aspekte des Auftrages beziehen. ${ }^{67}$ Zusammenfassend bedeutet objektorientierte intersystemische Arbeitsteilung im Vergleich zu funktionsorientierter somit, daß Informationsbedarf und -bereitstellung des betroffenen Subsystems nicht auf die Gesamtmenge der Auftäge, sondern nur auf einen Teil davon abstellen. Insofern ist ihre auf die Menge der Aufträge bezogene Breite (mengenbezogene Breite) geringer. Bezogen auf diese Teilmenge der Aufträge haben 
Informationsbedarf und -bereitstellung hier jedoch eine Vielzahl von Informationen zum Gegenstand, so daß ihre inhaltliche Breite - bezogen auf die bearbeiteten Aufträge deutlich größer ist. Insgesamt ist der inhaltliche Umfang von Informationsbedarf und -bereitstellung bei objektorientierter Arbeitsteilung damit weder größer noch kleiner, sondern anders als bei funktionsorientierter Arbeitsteilung.

Diese allgemeinen Aussagen können analog auf den Spezialfall der ganzheitlichen Teilaufgabenzuweisung zu Subsystemen, wie z.B. teilautonome Fertigungsgruppen, übertragen werden. Auch hier gilt zunächst einmal, daß die Art der Arbeitsteilung nicht notwendigerweise zu einer Ausweitung oder einer Beschränkung des inhaltlichen Umfangs von Informationsbedarf und -bereitstellung führt. Vergleicht man nämlich den mit der Zuweisung einer bestimmten Zahl logisch zusammengehörender Teilaufgaben zu einem Subsystem verbundenen Spezialisierungsgrad ceteris paribus mit dem bei der Zuordnung derselben Zahl logisch nicht miteinander verknüpfter Teilaufgaben, so ist der Spezialisierungsgrad in beiden Fällen gleich groß. Entsprechend ist der inhaltliche Umfang von Informationsbedarf und -bereitstellung im Fall ganzheitlicher Teilaufgabenzuweisung nicht größer, sondern anders als bei nicht-ganzheitlicher Teilaufgabenzuweisung. In der betrieblichen Praxis ist jedoch davon auszugehen, daß - unabhängig von diesen theoretischen Überlegungen - die ganzheitliche Teilaufgabenzuweisung zu einem Subsystem in der Regel mit einer Verringerung von dessen Spezialisierungsgrad einhergeht. Im Vergleich z.B. zu einer funktionsorientierten Arbeitsteilung wird dem Subsystem tendenziell eine höhere Anzahl unterschiedlicher, jedoch inhaltlich zusammengehörender Teilaufgaben zugewiesen. Somit ist eine ganzheitliche Teilaufgabenzuweisung de facto häufig mit einem geringen Spezialisierungsgrad verknüpft, auch wenn dieser Zusammenhang nicht logisch zwingend ist. Da Spezialisierungsgrad und inhaltlicher Umfang von Informationsbedarf und -bereitstellung regelmäßig negativ korrelieren, bedeutet eine ganzheitliche Teilaufgabenzuweisung zu einem Subsystem, daß der inhaltliche Umfang seines Informationsbedarfs und seiner Informationsbereitstellung vergleichsweise hoch ist.

Die 'Spezialisierung auf die Unternehmung' als mögliche Ausprägung der intrasystemischen Arbeitsteilung hat keinen systematischen Einfluß auf den inhaltlichen Umfang von Informationsbedarf und -bereitstellung.

\section{Der Einfluß der Koordination auf den inhaltlichen Umfang von Informationsbedarf und -bereitstellung}

In Abschnitt 4.2.2 war zwischen intrasystemischer und intersystemischer Koordination unterschieden worden. Innerhalb eines bestimmten Subsystems ist das explizite Einräumen von Freiräumen für Selbstorganisationsprozesse in Kombination mit Plänen besonders geeignet, um dessen relative Autonomie zu fördern und damit dort die Wahrscheinlichkeit für das Auftreten von Selbstorganisationsprozessen als Prozessen organisationalen Lernens zu fördern. Um gleichzeitig jedoch die relative Autonomie des nächsthöheren Subsystems und letztlich der Unternehmung insgesamt sicherzustellen, 
sollten Pläne und Programme zur intersystemischen Koordination verwendet werden. Intra- und intersystemisches Koordinationsinstrumentarium haben unterschiedliche Auswirkungen auf den inhaltlichen Umfang von Informationsbedarf und -bereitstellung.

Das intrasystemisch angewendete Koordinationsinstrumentarium geht tendenziell mit einem hohen inhaltlichen Umfang von Informationsbedarf und -bereitstellung einher. Aufgrund des Fehlens bzw. der geringen Ausprägung von externen Rahmenvorgaben ist die durch das Subsystem zu bewältigende Komplexität sehr hoch. Entsprechend umfangreich sind seine Informationsverarbeitungsprozesse sowie deren informationeller Input und Output. Geht man davon aus, daß die einem Subsystem vom Management gewährten Freiräume für Selbstorganisationsprozesse von diesem auch tatsächlich genutzt werden, so ist der damit verbundene inhaltliche Umfang von Informationsbedarf und -bereitstellung im Vergleich zum restlichen Koordinationsinstrumentarium am höchsten und hängt dabei von der gewählten Form der Ausgestaltung der Freiräume für Selbstorganisationsprozesse ab. Denn Selbstorganisation nach eigenem Ermessen, themenspezifische sowie institutionalisierte Selbstorganisation sind wiederum mit unterschiedlich starker Komplexitätsreduktion für das betroffene Subsystem verbunden. So begrenzen z.B. externe Vorgaben bezüglich der Ausgestaltung der zu bildenden Koordinationsorgane oder bezüglich der selbstorganisierend zu regelnden Themen die Komplexität der durch die betroffenen Mitarbeiter zu bewältigenden Situation stärker als das bloße Weglassen fremdorganisatorisch festgelegter organisatorischer Regeln. Der inhaltliche Umfang von Informationsbedarf und -bereitstellung ist somit bei Selbstorganisation nach eigenem Ermessen tendenziell größer als bei themenspezifischer oder gar institutionalisierter Selbstorganisation. Im Vergleich zum Einräumen von Freiräumen für Selbstorganisationsprozesse stellen Pläne eine stärkere Komplexitätsreduktion dar. Allerdings variiert auch diese in Abhängigkeit von der konkreten Ausgestaltung der Pläne. So stellt z.B. die Vorgabe eines bestimmten mengenmäßigen Output für einen Fertigungsbereich einen vergleichsweise wenig konkreten Plan dar, der eine Fülle von Informationsverarbeitungsprozessen mit entsprechend hohem inhaltlichen Umfang von Informationsbedarf und -bereitstellung innerhalb dieses Subsystems zur Folge hat. Im Vergleich dazu ist die mit einem Maschinenbelegungsplan oder einem Personaleinsatzplan für eine bestimmte Periode verbundene Komplexitätsreduktion für diesen Fertigungsbereich erheblich größer. Entsprechend sind Informationsbedarf und -bereitstellung dann tendenziell weniger umfangreich.

Stellt man der intrasystemischen die intersystemische Koordination gegenüber, so gehen die dabei eingesetzten Pläne und vor allem die Programme mit einer vergleichsweise stärkeren Komplexitätsreduktion für die so koordinierten Subsysteme einher. So bedeuten z.B. zentral vorgegebene Verrechnungspreise (als planähnliches Koordinationsinstrument) zur Koordination zwischen einem Subsystem 'Wartung und Reparatur' und verschiedenen Subsystemen der Fertigung eine geringere Komplexitätsreduktion für diese Subsysteme als ein Programm, das Vorgaben über die genauen Wartungsintervalle der einzelnen Maschinen beinhaltet. Denn im ersten Fall ist die Entscheidungssituation 
der Subsysteme weiterhin vergleichsweise komplex, während sie im zweiten Fall durch die detaillierteren Vorgaben der Programme stärker eingeschränkt ist. Entsprechend sind die Informationsverarbeitungsprozesse hier weniger umfangreich, woraus tendenziell ein geringerer inhaltlicher Umfang von Informationsbedarf und -bereitstellung resultiert.

\section{Der Einfluß des Leitungssystems auf den inhaltlichen Umfang von Informationsbedarf und -bereitstellung}

Grundsätzlich kann im Zusammenhang mit der Untersuchung des Einflusses des Leitungssystems auf den inhaltlichen Umfang von Informationsbedarf und -bereitstellung zwischen der Zahl der leitungsbedingten Informationsbeziehungen und dem Umfang der übermittelten Informationen unterschieden werden.

Unter Berücksichtigung der Interdependenzen mit dem Koordinationsinstrumentarium ist die Einbindung eines Subsystems in ein Einliniensystem einem Mehrliniensystem gegenüber vorzuziehen. Aus der Perspektive des Subsystems bedeutet dies, daß die Zahl der leitungsbedingten Informationsbeziehungen genau gleich eins ist. Das Subsystem als untergeordnete Einheit erhält Weisungen nur von einer Instanz und gibt Informationen zu Kontrollzwecken nur an genau diese eine übergeordnete Instanz weiter. Bezüglich des Umfangs der übermittelten Informationen gilt, daß der Informationsbedarf der übergeordneten Instanz sich auf alle führungsrelevanten Aspekte der Teilaufgabenerfüllung durch das ihr untergeordnete Subsystem bezieht. Dessen leitungsbedingter Informationsbedarf wiederum wird in seiner ganzen Breite durch die eine übergeordnete Instanz erfüllt. Somit ist festzustellen, daß im Fall der Einlinienorganisation die Zahl der leitungsbedingten Informationsbeziehungen vergleichsweise gering und zugleich ihr inhaltlicher Umfang groß ist. Im Gegensatz dazu ist das Geflecht der informationellen Beziehungen bei den verschiedenen Formen der Mehrlinienorganisation regelmäßig weitaus komplizierter. Die inhaltliche Beschränkung der einzelnen informationellen Beziehungen geht dort mit einem deutlichen Anstieg ihrer Zahl einher. ${ }^{68}$

Im Endeffekt stellen Einlinien- und Mehrliniensystem jedoch lediglich eine Umverteilung der leitungsbedingten Informationsbedarfe und -bereitstellungen zwischen einem oder mehreren Vorgesetzten dar. Der Gesamtumfang der leitungsbedingten Informationsbedarfe und -bereitstellungen sowohl auf der Seite des untergeordneten Subsystems als auch auf der des bzw. der Vorgesetzten bleibt dagegen gleich. Einzig die mit der bzw. den Personen der Vorgesetzten einhergehenden unterschiedlichen persönlichkeitsbedingten Einflüsse können den inhaltlichen Umfang ihrer Informationsbedarfe und -bereitstellungen verändern. Diesbezüglich kann jedoch keine systematische Wirkungsrichtung festgestellt werden. Geht man nämlich bei einem Mehrliniensystem im Vergleich zu einem Einliniensystem von einem höheren Grad der fachlichen Spezialisierung der Vorgesetzten aus, so kann dieser sowohl zu einer Erhöhung als auch zu einer Verringerung des inhaltlichen Umfangs ihres Informationsbedarfs gegenüber 
dem untergeordneten Subsystem und der von ihnen bereitgestellten Informationen führen. Zusammenfassend gilt somit, daß die Wahl zwischen Ein- und Mehrliniensystem keinen systematischen Einfluß auf den inhaltlichen Umfang der leitungsbedingten Informationsbedarfe und -bereitstellungen hat, sondern lediglich zu deren Umverteilung auf andere informationelle Beziehungen führt.

Die Reintegration der Stabsarbeit in die Linie bzw. das Wegfallen des Stabes als zweite auf die Primärorganisation bezogene Gestaltungsempfehlung geht mit dem Wegfallen der leitungsbedingten Informationsbeziehungen zwischen Instanz und Stab einher.

Die für Ein- und Mehrliniensystem als Ausprägungen der Primärorganisation getroffenen Aussagen können analog auf die Sekundärorganisation übertragen werden: Die hier im Vergleich zu Matrix- oder Einfluß-Projektorganisation präferierte reine Projektorganisation geht mit einer vergleichsweise geringen Zahl leitungsbedingter Informationsbeziehungen einher, deren inhaltlicher Umfang entsprechend groß ist. Der inhaltliche Umfang der leitungsbedingten Informationsbedarfe und -bereitstellungen insgesamt bleibt jedoch unverändert.

Immer dann, wenn den Subsystemen der Primärorganisation verstärkt die Möglichkeit eingeräumt wird, im Bedarfsfall Projektteams als temporäre Subsysteme zu bilden und diese den ihnen gewährten Freiraum tatsächlich nutzen, kommt es zu zusätzlichen Informationsbedarfen und -bereitstellungen. Dabei handelt es sich einerseits um leitungsbedingte Informationsbedarfe und -bereitstellungen im Rahmen der Projektorganisation, die aus den zusätzlichen Weisungsbeziehungen resultieren, andererseits aber auch um unmittelbar aus den Inhalten der konkreten Teilaufgabenerfüllung resultierende Informationsbedarfe und -bereitstellungen. Denn diese sind nicht vollständig durch die organisatorischen Regeln determiniert, sondern variieren in Abhängigkeit von subjektiven und situativen Faktoren. Es ist davon auszugehen, daß die Teilaufgabenerfüllung durch ein eigens dafür gebildetes Projektteam tendenziell sorgfältiger und umfassender erfolgen wird als im Fall des Verbleibs der Teilaufgabenerfüllung in der Primärorganisation. Dies hat einen tendenziell höheren inhaltlichen Umfang von Informationsbedarfen und -bereitstellungen des Projektteams im Vergleich zur Primärorganisation zur Folge.

Das verstärkte Ersetzen im Zeitablauf stabiler hierarchischer Strukturen durch Heterarchien hat keinen systematischen Einfluß auf den inhaltlichen Umfang von Informationsbedarf und -bereitstellung.

\section{Der Einfluß der Entscheidungsdelegation auf den inhaltlichen Umfang von Informationsbedarf und -bereitstellung}

Je höher der Delegationsgrad bezüglich eines Subsystems ist, desto höher ist seine relative Autonomie, die wiederum das Auftreten von Selbstorganisationsprozessen als Prozessen organisationalen Lernens fördert. Unter der Voraussetzung, daß die Mitarbeiter in einem Subsystem die ihnen übertragenen Entscheidungskompetenzen auch tatsäch- 
lich nutzen, steigt der inhaltliche Umfang von Informationsbedarf und -bereitstellung eines Subsystems mit dem Grad der Entscheidungsdelegation. Denn je mehr Entscheidungen einem Subsystem übertragen werden, desto mehr Informationen werden dort einerseits zur Vorbereitung dieser Entscheidungen benötigt. Andererseits sind Entscheidungsprozesse regelmäßig mit der Bereitstellung von Informationen verbunden und stellen Entscheidungen selbst Informationen dar, so daß ceteris paribus auch das Ausmaß der bereitgestellten Informationen mit dem Delegationsgrad zunimmt.

Abbildung 5/6 zeigt abschließend die aus den Ausprägungen der organisatorischen Regeln zu Arbeitsteilung, Koordination, Leitungssystem und Entscheidungsdelegation resultierenden Konsequenzen für den inhaltlichen Umfang von Informationsbedarf und -bereitstellung. Die Pfeile bzw. Schrägstriche im mittleren Feld drücken den Einfluß der jeweils nebenstehend genannten Ausprägungen der organisatorischen Regeln auf den inhaltlichen Umfang von Informationsbedarf und -bereitstellung aus.

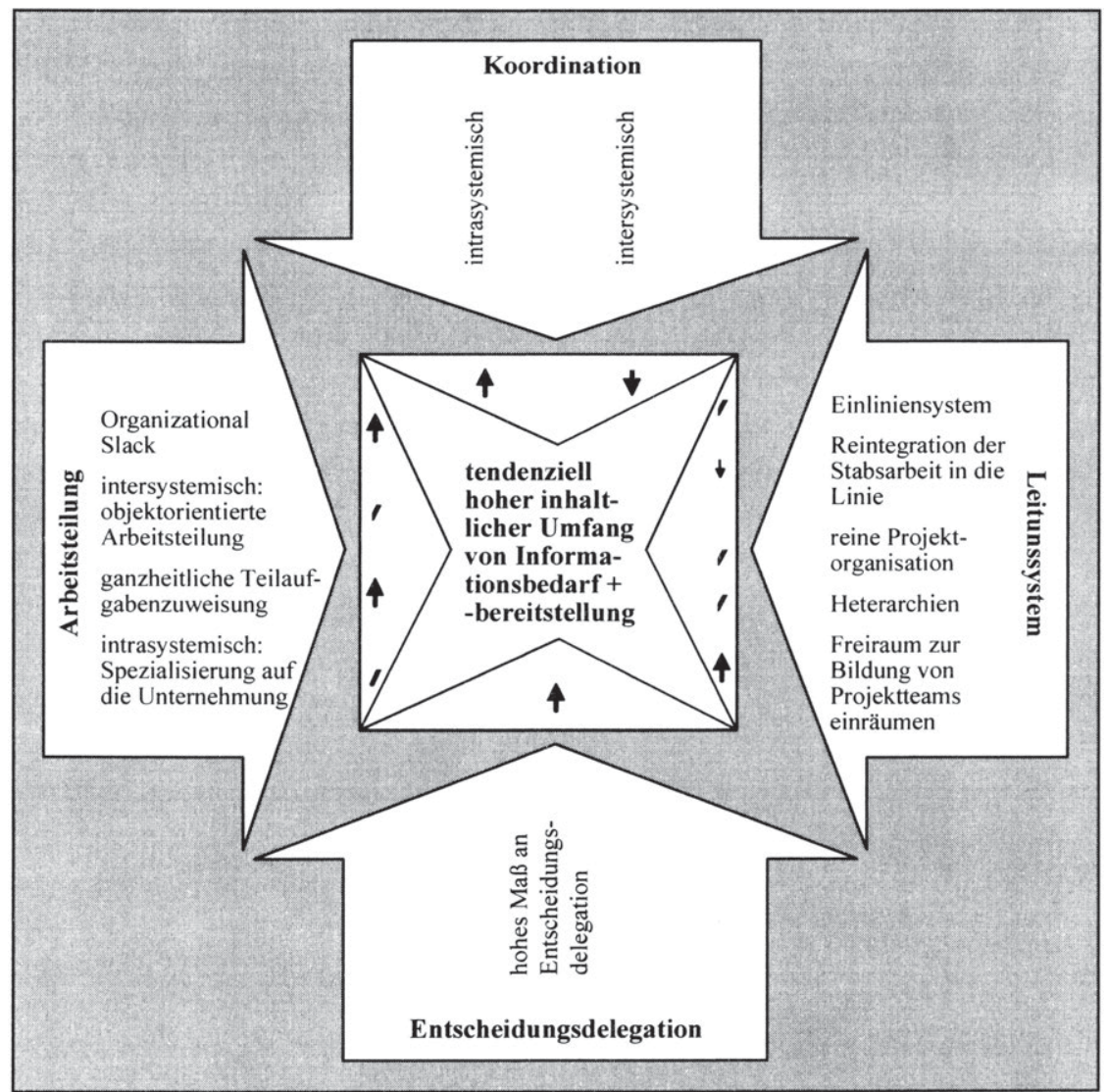

Abb. 5/6: Konsequenzen der Ausprägungen der organisatorischen Regeln für den inhaltlichen Umfang von Informationsbedarf und -bereitstellung 
$\mathrm{Faßt}$ man die aus den verschiedenen Ausprägungen der organisatorischen Regeln resultierenden Konsequenzen für den inhaltlichen Umfang von Informationsbedarf und -bereitstellung zusammen, so führen diese insgesamt tendenziell $\mathrm{zu}$ einem hohen inhaltlichen Umfang von Informationsbedarf und -bereitstellung. Diese Gesamtentwicklung setzt sich allerdings aus mehreren Einzeleinflüssen zusammen, die zum Teil entgegengesetzte Wirkrichtungen aufweisen. Es kann jedoch eine Gewichtung der einzelnen Einflußfaktoren vorgenommen werden, die eindeutige Aussagen über die Gesamtentwicklung des inhaltlichen Umfangs von Informationsbedarf und -bereitstellung erlaubt.

Betrachtet man zunächst die Ausprägungen der organisatorischen Regeln zur Arbeitsteilung, so ergibt sich folgendes Bild: Die Förderung von Organizational Slack bezüglich des Einsatzfaktors Zeit führt tendenziell zu einer Erhöhung des inhaltlichen Umfangs von Informationsbedarf und -bereitstellung. Dagegen führt die objektorientierte Arbeitsteilung im Vergleich zur funktionsorientierten zwar zu einem anderen inhaltlichen Umfang von Informationsbedarf und -bereitstellung. Dieser wird jedoch durch die Art der Arbeitsteilung nicht systematisch kleiner oder größer. Ein unmittelbarer Zusammenhang läßt sich theoretisch nicht begründen. Betrachtet man jedoch die tatsächliche Ausgestaltung des Spezialfalls der ganzheitlichen Teilaufgabenzuweisung in der betrieblichen Praxis, so geht diese Art der Arbeitsteilung häufig mit einem geringeren Grad der Spezialisierung einher. Dieser geringere Spezialisierungsgrad wiederum zieht regelmäßig einen höheren inhaltlichen Umfang von Informationsbedarf und -bereitstellung nach sich. Während somit für objektorientierte Arbeitsteilung im allgemeinen kein systematischer Zusammenhang zum inhaltlichen Umfang von Informationsbedarf und -bereitstellung besteht, ist ein solcher für den Spezialfall einer ganzheitlichen Teilaufgabenzuweisung regelmäßig beobachtbar. Insgesamt führen die Ausprägungen der organisatorischen Regeln zur Arbeitsteilung somit nicht nur zu veränderten, sondern tendenziell auch $\mathrm{zu}$ umfangreicheren Informationsbedarfen und -bereitstellungen.

Die Auswirkungen der organisatorischen Regeln zur Koordination auf den inhaltlichen Umfang von Informationsbedarf und -bereitstellung sind klar in die des intrasystemischen und die des intersystemischen Koordinationsinstrumentariums zu unterscheiden. Während die intrasystemische Koordination mittels explizit autorisierter Selbstorganisationsprozesse und Plänen mit einem hohen inhaltlichen Umfang von Informationsbedarf und -bereitstellung einhergeht, ist der aus der intersystemischen Koordination mittels Plänen und Programmen resultierende vergleichsweise geringer.

Die Entscheidung für ein Einliniensystem anstelle eines Mehrliniensystems und für reine Projektorganisation im Gegensatz zu anderen Formen der Projektorganisation als Ausprägungen der organisatorischen Regeln zum Leitungssystem führen zwar zu einer Umverteilung des inhaltlichen Umfangs der leitungsbedingten Informationsbedarfe und -bereitstellungen auf die informationellen Beziehungen zwischen dem bzw. den Vorge- 
setzten und dem untergeordneten Subsystem, ihr gesamter Umfang bleibt jedoch gleich groß. Diesbezüglich sind somit keine Konsequenzen beobachtbar. Bei der Reintegration der Stabsarbeit in die Linie handelt es sich um eine Gestaltungsoption mit einem sehr engen Einsatzfeld, da die Zahl der Instanzen, denen potentiell Stäbe zugeordnet werden, regelmäßig sehr gering ist. Ferner steht die mit der Reintegration der Stabsarbeit in die Linie verbundene Gefahr der Überlastung der Linieninstanzen häufig der Umsetzung dieser Gestaltungsoption entgegen. Entsprechend bewirkt die Reintegration der Stabsarbeit in die Linie durch den damit verbundenen Wegfall von Weisungsbeziehungen zwar grundsätzlich eine Verringerung des diesbezüglichen inhaltlichen Umfangs von Informationsbedarf und -bereitstellung des betroffenen Subsystems. In der betrieblichen Praxis spielt sie jedoch nur eine untergeordnete Rolle. Die geringe Größe des Pfeils in Abbildung 5/6, der den aus der Reintegration der Stabsarbeit in die Linie resultierenden Einfluß auf den inhaltlichen Umfang von Informationsbedarf und -bereitstellung darstellt, drückt die vergleichsweise geringe Relevanz dieser Gestaltungsoption aus. Im Gegensatz zur Reintegration der Stabsarbeit in die Linie weist der aus dem Gewähren von Freiräumen zur Bildung von Projektteams resultierende Einfluß auf den inhaltlichen Umfang von Informationsbedarf und -bereitstellung eine umgekehrte Wirkungsrichtung auf: Er führt tendenziell zu einem Anstieg des inhaltlichen Umfangs von Informationsbedarf und -bereitstellung. Stellt man diese beiden Gestaltungsoptionen bezüglich des Leitungssystems einander gegenüber, so ist aufgrund der geringen Bedeutung der Reintegration der Stabsarbeit in die Linie davon auszugehen, daß der mit der zweiten Alternative verbundene positive Einfluß auf den inhaltlichen Umfang von Informationsbedarf und -bereitstellung überwiegt.

Im Vergleich zu den organisatorischen Regeln zum Leitungssystem ist der Einfluß der Entscheidungsdelegation auf den inhaltlichen Umfang von Informationsbedarf und -bereitstellung eindeutig. Ein verstärktes $\mathrm{Ma}$ an Entscheidungsdelegation gegenüber einem bestimmten Subsystem führt regelmäßig zu einem entsprechenden Anstieg des inhaltlichen Umfangs von dessen Informationsbedarf und -bereitstellung.

$\mathrm{Fa}$ ßt man die Konsequenzen der Ausprägungen aller vier Dimensionen der organisatorischen Gestaltung zusammen, so gehen sie tendenziell mit einem hohen inhaltlichen Umfang von Informationsbedarf und -bereitstellung einher, der lediglich bezüglich der aus der intersystemischen Koordination resultierenden Informationsbedarfe und -bereitstellungen vergleichsweise geringer ist.

\subsubsection{Bestimmtheit von Informationsbedarf und -bereitstellung}

Untersucht man den Zusammenhang zwischen den Ausprägungen der organisatorischen Regeln zur Arbeitsteilung und der Bestimmtheit von Informationsbedarf und -bereitstellung, so lassen sich bezüglich der objektorientierten Arbeitsteilung im allgemeinen und der ganzheitlichen Teilaufgabenzuweisung im besonderen keine Aussagen treffen. Dagegen bedeutet eine 'Spezialisierung auf die Unternehmung', daß die Mitar- 
beiter im Zeitverlauf verschiedene Teilaufgaben übernehmen. Informationsbedarfe und -bereitstellungen werden nicht nur durch sachliche, in der Art der zu erfüllenden Teilaufgaben begründete Einflüsse geprägt. Vielmehr wirken darüber hinaus auch subjektive, aus der Persönlichkeit des Aufgabenträgers resultierende Einflußfaktoren. Deshalb führen personelle Veränderungen bei der Zuordnung von Teilaufgaben zu Mitarbeitern im Zeitverlauf dazu, daß Informationsbedarfe und -bereitstellungen variieren. Da der konkrete Einfluß der subjektiven Faktoren auf die Informationsbedarfe und -bereitstellungen nicht vollständig antizipiert werden kann, führen personelle Veränderungen bei der Teilaufgabenzuordnung zu einem geringeren Bestimmtheitsgrad von Informationsbedarfen und -bereitstellungen.

Für den Zusammenhang zwischen der Ausdehnung der zur Teilaufgabenerfüllung verfügbaren Zeit im Sinne einer Erhöhung des Organizational Slack und der Bestimmtheit von Informationsbedarf und -bereitstellung kann folgendes angenommen werden: Immer dann, wenn die Mitarbeiter in einem Subsystem die ihnen zur Verfügung stehende zusätzliche Zeit dafür nutzen, um spontan zusätzliche Informationen in die Teilaufgabenerfüllung einzubeziehen, sinkt der Bestimmtheitsgrad ihres Informationsbedarfes. Zugleich können diese Modifikationen bei der Teilaufgabenerfüllung dazu führen, daß zusätzliche und/oder andere Informationen als Ergebnis ihrer Teilaufgabenerfüllung von den Mitarbeitern des Subsystems bereitgestellt werden. Da ex ante nicht vorhersehbar ist, ob und wie die Mitarbeiter die frei verfügbare Zeit nutzen werden und welche Informationsbedarfe und -bereitstellungen aus diesen unvorhersehbaren Aktivitäten resultieren, führt eine Erhöhung des Organizational Slack bezüglich des Faktors Zeit in einem Subsystem zu einer Verringerung des Bestimmtheitsgrades seines Informationsbedarfes und seiner Informationsbereitstellung.

Für die Untersuchung des Zusammenhangs zwischen den organisatorischen Regeln zur Koordination und dem Bestimmtheitsgrad von Informationsbedarf und -bereitstellung kann dieser als Ausdruck der Varietät von Informationsbedarf und -bereitstellung interpretiert werden: Je höher der Bestimmtheitsgrad von Informationsbedarf und -bereitstellung ist, desto geringer ist deren Varietät (und umgekehrt). In Abschnitt 4.2.2 wurde zur Auswahl eines geeigneten Instrumentariums zur intrasystemischen und intersystemischen Koordination auf die mit dessen Einsatz verbundene Varietät der koordinierten Handlungen abgestellt. Aufgrund der daraus resultierenden hohen Varietät der koordinierten Handlungen wurde das explizite Einräumen von Freiräumen für Selbstorganisationsprozesse in Kombination mit Plänen zur intrasystemischen Koordination gefordert. Um zugleich nicht die relative Autonomie des nächsthöheren Subsystems und letztlich die der gesamten Unternehmung zu gefährden, sollten zur intersystemischen Koordination Pläne und Programme verwendet werden. Somit weisen die Handlungen innerhalb des fokussierten Subsystems eine sehr hohe Varietät auf, während die Varietät derjenigen Handlungen, die sich auf den Handlungsraum zwischen den Subsystemen erstrecken, stärker begrenzt wird. Geht man aufgrund des unmittelbaren Zusammenhangs zwischen Entscheidungen und Handlungen auf der einen und Informationsbedar- 
fen und -bereitstellungen auf der anderen Seite davon aus, daß der Grad der Varietät von Informationsbedarf und -bereitstellung sich parallel zu dem der koordinierten Handlungen entwickelt, so ist der Bestimmtheitsgrad der Informationsbedarfe und -bereitstellungen, die mit intrasystemischen Handlungen einhergehen, tendenziell geringer als der der Informationsbedarfe und -bereitstellungen, die aus Handlungen im intersystemischen Aktionsraum resultieren. Dabei variiert der Bestimmtheitsgrad der Informationsbedarfe und -bereitstellungen aber auch bei unterschiedlicher Ausgestaltung des einzelnen Koordinationsinstrumentes. Die Ausführungen in Abschnitt 5.2.1.1, gemäß derer der inhaltliche Umfang von Informationsbedarf und -bereitstellung bei Selbstorganisation nach eigenem Ermessen, themenspezifischer und institutionalisierter Selbstorganisation sowie bei verschiedener Ausgestaltung von Plänen und Programmen variiert, gelten analog für den Bestimmtheitsgrad von Informationsbedarf und -bereitstellung, der ebenfalls mit der Art der Ausgestaltung des einzelnen Koordinationsinstrumentes unterschiedlich stark ausgeprägt sein kann. Tendenziell gilt jedoch, daß die Koordination mittels Programmen mit einem vergleichsweise hohen Bestimmtheitsgrad von Informationsbedarf und -bereitstellung einhergeht, während dieser bei Plänen und insbesondere bei explizit eingeräumten Freiräumen für Selbstorganisationsprozesse geringer ist.

Weder die Entscheidung für ein Einlinien- anstelle eines Mehrliniensystems oder für reine Projektorganisation noch die Reintegration der Stabsarbeit in die Linie als auf das Leitungssystem der Unternehmung bezogene Entscheidungen haben Einfluß auf den Bestimmtheitsgrad von Informationsbedarf und -bereitstellung. Dagegen gelten die oben für das Phänomen 'Spezialisierung auf die Unternehmung' getroffenen Aussagen analog für Heterarchien: Auch hier führt die Zuordnung bestimmter Teilaufgaben (in diesem Fall solche der Mitarbeiterführung) zu im Zeitverlauf wechselnden Personen aufgrund des Einflusses subjektiver Faktoren auf Informationsbedarf und -bereitstellung zu einem geringeren Bestimmtheitsgrad von Informationsbedarf und -bereitstellung. Denn sowohl der Informationsbedarf der Führungskraft als auch die von ihr bereitgestellten Informationen variieren in Inhalt und Umfang in Abhängigkeit von der jeweiligen Person des Vorgesetzten.

Räumt man schließlich Subsystemen der Primärorganisation verstärkt die Möglichkeit ein, im Bedarfsfall Projektteams als temporäre Subsysteme zu bilden und nutzen diese die ihnen gebotenen Möglichkeiten auch tatsächlich, so führt dies ebenfalls zu einem geringeren Bestimmtheitsgrad von Informationsbedarfen und -bereitstellungen. Analog der obigen Argumentation bezüglich Heterarchien und der 'Spezialisierung auf die Unternehmung' gilt nämlich auch hier, daß ex ante schwer vorhersehbare personelle Einflüsse auf die Informationsbedarfe und -bereitstellungen der Projektteams wirken. $\mathrm{Da}$ Informationsbedarfe und -bereitstellungen sich eben nicht deterministisch aus den zu erfüllenden Teilaufgabenbündeln ableiten lassen, sondern neben den organisatorischen Regeln auch von subjektiven und situativen Faktoren beeinflußt werden, unterscheiden sich die Ausprägungen von Informationsbedarfen und -bereitstellungen eines Projekt- 
teams in der Regel von den Ausprägungen, die bei der Teilaufgabenerfüllung innerhalb der Primärorganisation anfallen würden.

Der Grad der Entscheidungsdelegation hat keinen systematischen Einfluß auf die Bestimmtheit von Informationsbedarf und -bereitstellung.

Abbildung 5/7 zeigt abschließend die aus den Ausprägungen der organisatorischen Regeln zu Arbeitsteilung, Koordination, Leitungssystem und Entscheidungsdelegation resultierenden Konsequenzen für die Bestimmtheit von Informationsbedarf und -bereitstellung.

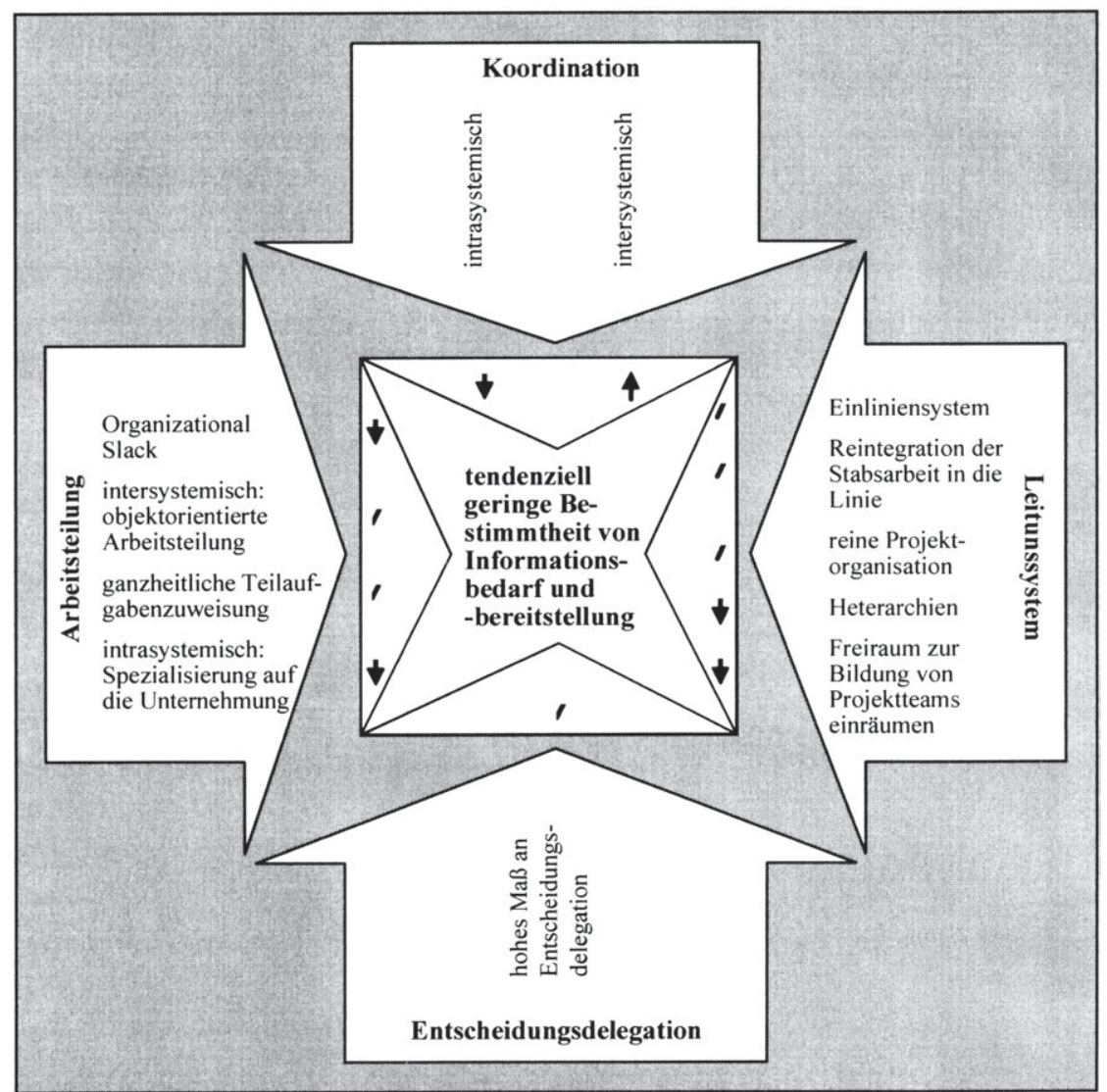

Abb. 5/7: Konsequenzen der Ausprägungen der organisatorischen Regeln für die Bestimmtheit von Informationsbedarf und -bereitstellung

Lediglich die Entscheidungsdelegation hat keinen Einfluß auf die Bestimmtheit von Informationsbedarf und -bereitstellung. Die Auswirkungen der organisatorischen Regeln zur Koordination müssen in intrasystemisch und intersystem eingesetztes Koordinationsinstrumentarium ausdifferenziert werden: Während insbesondere der intersystemi- 
sche Einsatz von Programmen zu einem vergleichsweise hohen Bestimmtheitsgrad von Informationsbedarf und -bereitstellung führt, weist der Einfluß der Ausprägungen der organisatorischen Regeln zu Arbeitsteilung, intrasystemischer Koordination und Leitungssystem weitgehend in dieselbe Wirkrichtung: Sie führen tendenziell $\mathrm{zu}$ einem geringeren Bestimmtheitsgrad von Informationsbedarf und -bereitstellung.

\subsubsection{Dringlichkeit von Informationsbedarf und -bereitstellung}

Betrachtet man die Auswirkungen der organisatorischen Regeln zur Arbeitsteilung auf die Dringlichkeit von Informationsbedarf und -bereitstellung, so hat die Förderung von Organizational Slack beim Einsatz des Faktors Zeit unmittelbare Auswirkungen auf die Dringlichkeit der Informationsbedarfe und -bereitstellungen: Je großzügiger der zeitliche Rahmen für die Leistungserstellung bemessen ist, desto geringer ist die Dringlichkeit der aus dem Leistungserstellungsproze $\beta$ resultierenden Informationsbedarfe und -bereitstellungen. Für andere Einsatzfaktoren besteht kein allgemeingültiger Zusammenhang zwischen Organizational Slack und Dringlichkeit von Informationsbedarf und -bereitstellung. Vielmehr muß dort für jeden Einzelfall geprüft werden, ob der Faktor Zeit durch den jeweiligen Überschußfaktor substituierbar ist. Nur wenn eine solche Substitierbarkeit gegeben ist, kann Organizational Slack bezüglich eines Einsatzfaktors die Dringlichkeit des Informationsbedarfes senken.

Für die Arten der intersystemischen Arbeitsteilung kann der Zusammenhang mit der Dringlichkeit von Informationsbedarf und -bereitstellung unter Zuhilfenahme der mit den verschiedenen Arten der Arbeitsteilung einhergehenden Leistungsinterdependenzen zwischen den Subsystemen begründet werden: Diese sind bei objektorientierter Arbeitsteilung tendenziell geringer als bei funktionsorientierter. Vergleicht man die Auswirkungen, die das Fehlen einer Information in einem Subsystem bei stark ausgeprägten und weniger stark ausgeprägten Leistungsinterdependenzen auf die Leistungserstellung anderer Subsysteme hat, so sind diese um so stärker, je intensivere Leistungsinterdependenzen zwischen den Subsystemen bestehen. Entsprechend ist die Dringlichkeit der Informationsbedarfe und -bereitstellungen um so höher, je stärker die intersystemischen Leistungsinterdependenzen sind. Dies kann mit Hilfe des folgenden Beispiels verdeutlicht werden: Eine fehlende Information in einem von mehreren Subsystemen, die im Rahmen einer funktionsorientiert arbeitsteiligen Fließbandfertigung miteinander verknüpft sind, kann hier leicht zum Stillstand des gesamten Bandes führen und damit schwerwiegende Konsequenzen für die anderen Subsysteme haben. Der diesbezügliche Informationsbedarf weist eine entsprechend hohe Dringlichkeit auf. Dagegen sind die mit dem Fehlen einer Information in einem Subsystem verbundenen Konsequenzen für die anderen Subsysteme bei Zentrenproduktion als einer objektorientierten Organisationsform regelmäßig deutlich weniger gravierend. Die Dringlichkeit des diesbezüglichen Informationsbedarfs sowie der bereitgestellten Information ist hier geringer. Tendenziell ist somit eine objektorientierte Arbeitsteilung im Vergleich zu einer funkti- 
onsorientierten mit einer geringeren Dringlichkeit von Informationsbedarf und -bereitstellung verbunden. ${ }^{69}$ Entsprechendes gilt für eine ganzheitliche Teilaufgabenzuweisung als Spezialfall der objektorientierten intersystemischen Arbeitsteilung.

Weder die 'Spezialisierung auf die Unternehmung' noch die organisatorischen Regeln zur Koordination haben einen systematischen Einfluß auf die Dringlichkeit von Informationsbedarf und -bereitstellung.

Stellt man im Rahmen der Untersuchung des Leitungssystems Einlinien- und Mehrliniensysteme einander gegenüber, so ist die Dringlichkeit des weisungsbezogenen Informationsbedarfs des untergeordneten Subsystems in einem Mehrliniensystem immer dann höher, wenn die Weisungen der Vorgesetzten ausgeprägte Interdependenzen aufweisen und erst in ihrer Gesamtheit vorliegen müssen, bevor der Leistungserstellungsprozeß im untergeordneten Subsystem beginnen kann. Die daraus resultierenden zeitlichen Verzögerungen führen dazu, daß der Informationsbedarf des untergeordneten Subsystems gegenüber der übergeordneten Instanz eine höhere Dringlichkeit als in einem Einliniensystem aufweist. Über diesen Spezialfall hinaus können jedoch keine allgemeingültigen Aussagen über den Zusammenhang zwischen Ein- oder Mehrliniensystem auf der einen und Dringlichkeit von Informationsbedarf und -bereitstellung auf der anderen Seite gemacht werden. ${ }^{70}$

Weder die Form der Projektorganisation, Heterarchien noch das Einräumen der Möglichkeit für Subsysteme der Primärorganisation, im Bedarfsfall Projektteams zu bilden, haben einen systematischen Einfluß auf die Dringlichkeit von Informationsbedarf und -bereitstellung. Die Reintegration der Stabsarbeit in die Linie kann durch die mit dem Wegfallen der informationellen Beziehungen zwischen Stab und Linieninstanz verbundene Zeitersparnis zu einer geringeren Dringlichkeit von Informationsbedarf und -bereitstellung führen. Gleichzeitig kann die Reintegration der Stabsarbeit in die Linie jedoch durch die damit verbundene Ausweitung des Aufgabenfeldes der Linieninstanz zu deren Überlastung und entsprechenden Verzögerungen bei der Teilaufgabenerfüllung führen, die u.U. eine höhere Dringlichkeit von Informationsbedarf und -bereitstellung mit sich bringen. Eine allgemeingültige Aussage über den Zusammenhang zwischen der Reintegration der Stabsarbeit in die Linie und der Dringlichkeit von Informationsbedarf und -bereitstellung ist deshalb nicht möglich.

Betrachtet man schließlich den Einfluß der Entscheidungsdelegation auf die Dringlichkeit der Informationsbedarfe und -bereitstellungen eines Subsystems, so gilt es, die mit der Entscheidungsdelegation einhergehende Veränderung der informationellen Beziehungen zwischen der übergeordneten Instanz und dem dieser Instanz untergeordneten Subsystem zu berücksichtigen, wobei die informationellen Beziehungen anhand ihrer Richtung unterschieden werden können.

69 Vgl. als von der Aussage bezüglich des Zusammenhangs her ähnlich, jedoch mit anderer Begründung Wall (1996), S. 106f.

70 Vgl. Wall (1996), S. 121. 
Je mehr Entscheidungsarten an das Subsystem delegiert werden, desto geringer wird die Zahl der Weisungsbeziehungen als wichtigster Teilmenge der von oben nach unten gerichteten Informationsbeziehungen. Zugleich sinkt ihr Detaillierungsgrad bzw. ihre Nähe zu den operativen Abläufen. Denn regelmäßig werden zunächst solche Entscheidungen delegiert, die in unmittelbarem Zusammenhang mit dem operativen Tagesgeschäft stehen. Erst in einem weiteren Schritt werden dann Entscheidungen von weitreichenderer Relevanz delegiert. Diesen Umstand spiegelt auch die in Abschnitt 4.2.4 entwickelte Systematisierung der potentiell delegierbaren Entscheidungsarten in prozeßgestaltende, systemkonstituierende und zielbildende Entscheidungsarten wider. Ein hoher Grad an Entscheidungsdelegation bedeutet deshalb regelmäßig, daß die verbleibenden Weisungsbeziehungen weniger zeitkritisch als bei einer stärkeren Entscheidungszentralisation sind. Entsprechend sinkt der Dringlichkeitsgrad des weisungsbezogenen Informationsbedarfs des untergeordneten Subsystems mit zunehmender Entscheidungsdelegation.

Zugleich verändert sich aber auch die aufwärtsgerichtete Bereitstellung von Informationen, d.h. derjenigen Informationen, die der hierarchisch übergeordneten Einheit durch das Subsystem als der hierarchisch untergeordneten Einheit zur Verfügung gestellt werden. Je stärker die Entscheidungszentralisation ist, desto mehr Entscheidungen trifft die übergeordnete Instanz selbst. Die ihr vom untergeordneten Subsystem bereitgestellten Informationen dienen dann der Vorbereitung dieser Entscheidungen. Dagegen werden bei stärkerer Entscheidungsdelegation vermehrt Entscheidungen auf der unteren Ebene getroffen. Die von unten nach oben weitergeleiteten Informationen dienen dann nicht der Entscheidungsvorbereitung, sondern der Kontrolle der delegierten Entscheidungen. Tendenziell ist davon auszugehen, daß entscheidungsvorbereitende Informationen - in Abhängigkeit von der Art der Entscheidung - eher zeitkritisch sind als der Entscheidung nachgelagerte Kontrollinformationen. Entsprechend ist die Dringlichkeit der durch das untergeordnete Subsystem der übergeordneten Instanz gegenüber bereitgestellten Informationen bei ausgeprägter Entscheidungszentralisation höher als bei Entscheidungsdelegation.

Ein weiteres Argument unterstützt die These, daß die Dringlichkeit von Informationsbedarf und -bereitstellung bei ausgeprägter Entscheidungsdelegation geringer ist als bei Entscheidungszentralisation: Geht man bei jedem Entscheidungsproblem von einem gegebenen zeitlichen Rahmen zur Problemlösung aus, so ist jeder diese Entscheidung vorbereitende Prozeß der Informationsbeschaffung mit einem bestimmten Zeitverbrauch verbunden. Aufgrund der mit einer ausgeprägten Zentralisation verbundenen Notwendigkeit der Weitergabe von Informationen über mehrere Hierachiestufen hinweg und der daraus resultierenden höheren Anzahl an Informationsprozessen steigt die Dringlichkeit der Informationsbedarfe und -bereitstellungen mit dem Zentralisationsgrad. Dagegen wird die Entscheidungskompetenz bei starker Dezentralisierung der organisatorischen Einheit zugewiesen, bei der auch die entscheidungsvorbereitenden Informationen anfallen. Entsprechend entfällt hier der mit der Weiterleitung der Infor- 
mationen verbundene Zeitverbrauch bzw. er fällt geringer aus. Die Dringlichkeit von Informationsbedarf und -bereitstellung ist dann geringer.

Abbildung 5/8 zeigt abschließend die aus den Ausprägungen der organisatorischen Regeln zu Arbeitsteilung, Koordination, Leitungssystem und Entscheidungsdelegation resultierenden Konsequenzen für die Dringlichkeit von Informationsbedarf und -bereitstellung. Während einige Ausprägungen der organisatorischen Regeln keinen Einfluß auf die Dringlichkeit von Informationsbedarf und -bereitstellung haben, weisen alle diejenigen, für die ein solcher systematischer Einfluß aufgezeigt werden konnte, in dieselbe Wirkrichtung: Sie führen tendenziell zu einem geringen Dringlichkeitsgrad von Informationsbedarf und -bereitstellung.

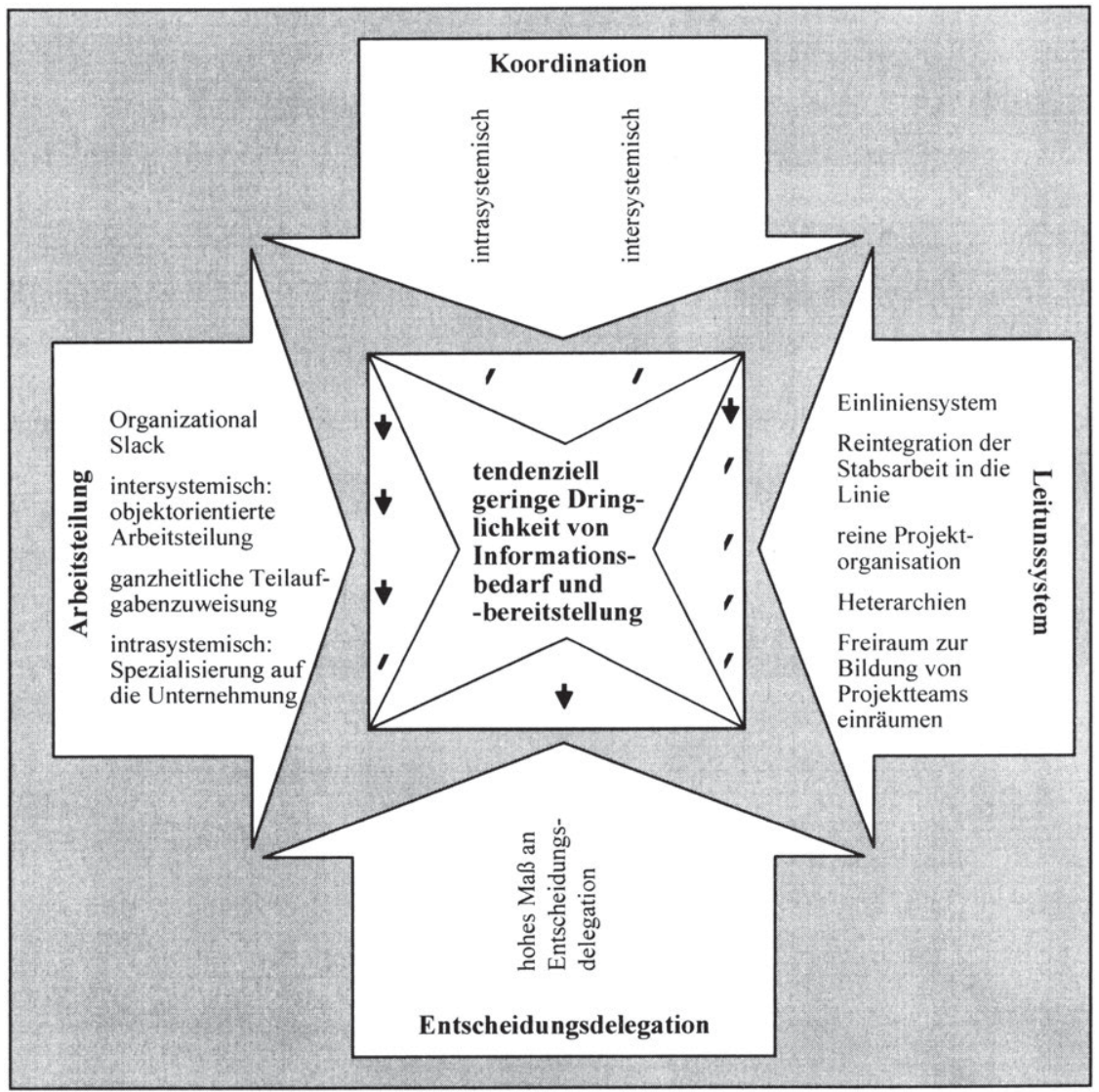

Abb. 5/8: Konsequenzen der Ausprägungen der organisatorischen Regeln für die Dringlichkeit von Informationsbedarf und-bereitstellung 


\subsubsection{Informationsqualität}

Im Rahmen der folgenden Ausführungen wird zwischen inhaltlichen Aspekten der Informationsqualität, die der Teildimension Aussagegehalt zugeordnet werden, sowie formalen Aspekten als der Darstellungsweise unterschieden. ${ }^{71}$ Geht man einerseits davon aus, daß der Qualitätsbegriff auf die Eignung zu einem bestimmten Zweck abstellt und interpretiert die Zweckeignung andererseits als ein graduelles Phänomen, ${ }^{72}$ so steht das Ausmaß der Zweckeignung im Mittelpunkt der Untersuchung der Informationsqualität. Bereits die Definition von Information stellt auf die Zweckorientierung dieser Teilmenge des Wissens ab. ${ }^{73}$ Weder Information noch Informationsqualität sind damit 'an sich' beobachtbare Größen, sondern stets in Bezug zu einem Subjekt zu sehen. Sie sind nicht absolut, sondern immer relativ.

Untersucht man zunächst die organisatorischen Regeln zur Arbeitsteilung, so können keine allgemeingültigen Aussagen über den Zusammenhang zwischen objektorientierter Arbeitsteilung und Informationsqualität getroffen werden. Dies gilt auch für den in der betrieblichen Praxis regelmäßig zu beobachtenden Fall, daß die ganzheitliche Teilaufgabenzuweisung zu einem Subsystem zugleich mit einem geringeren Spezialisierungsgrad einhergeht. Denn die Auswirkung einer Veränderung des Spezialisierungsgrades auf die Qualität der benötigten und vor allem der bereitgestellten Informationen hängt einerseits von der Art der zu erfüllenden Teilaufgaben, andererseits vom bisherigen Ausgangsniveau des Spezialisierungsgrades ab. Die traditionellen tayloristisch geprägten Konzepten zur Arbeitsteilung immanente Grundüberzeugung, daß eine Erhöhung des Spezialisierungsgrades notwendigerweise nicht nur mit einer Erhöhung der Quantität, sondern auch einer Erhöhung der Qualität der Arbeitsergebnisse im allgemeinen und der bereitgestellten Informationen im besonderen einhergeht, kann in dieser Allgemeinheit nicht aufrecht erhalten werden. ${ }^{74}$ Anstelle eines linearen Zusammenhangs zwischen dem Spezialisierungsgrad der Mitarbeiter bei der Teilaufgabenerfüllung und der Qualität der von ihnen bereitgestellten Informationen ist vielmehr häufig davon auszugehen, daß die Informationsqualität zunächst mit zunehmender Spezialisierung steigt, ab einem bestimmten, aufgabenspezifischen Punkt jedoch wieder sinkt.

Für eine Erhöhung des Organizational Slack bezüglich des Faktors Zeit in einem Subsystem ist ein positiver Zusammenhang zur inhaltlichen Teildimension der Informationsqualität konzipierbar. Immer dann nämlich, wenn die Mitarbeiter die ihnen zusätzlich

71 Für eine Übersicht ubber verschiedene Einflußfaktoren auf Aussagegehalt und Darstellungsweise von Informationen siehe die Erläuterungen zu den von Wall vorgeschlagenen Dimensionen von Informationsbedarf und -bereitstellung in Abschnitt 5.1.2.1 der vorliegenden Arbeit.

72 Vgl. Gilles (1999), o.S.

73 Für die Definition von Information mit Hilfe der drei Ebenen der Semiotik siehe Abschnitt 2.2.2.2.2 der vorliegenden Arbeit.

74 Für eine Diskussion der mit einem hohen oder niedrigen Spezialisierungsgrad verbundenen Vor- und Nachteile siehe Kieser/Kubicek (1992), S. 75ff. Anders Wall (1996), S. 108, die ohne weitere Differenzierung auf die mit einem hohen Spezialisierungsgrad verbundene Steigerung der Qualităt der Arbeitsergebnisse einschließlich der bereitgestellten Informationen abstellt. 
zur Verfügung stehende Zeit dafür nutzen, um ihre mit der Leistungserstellung verbundenen Informationsverarbeitungsprozesse zu verbessern, werden sie nicht nur zusätzliche Informationen benötigen, sondern - unter Berücksichtigung von Wirtschaftlichkeitsaspekten - tendenziell auch höhere Anforderungen an deren Aussagegehalt stellen. Dies gilt z.B. für die Detailliertheit (als Teilaspekt der inhaltlichen Informationsqualität) der kundenorientierten Marktforschungsdaten, die die Marketingabteilung eines Konsumgüterherstellers als Grundlage der Entscheidung über die Ausdehnung eines Geschäftsfeldes verwendet. Entsprechendes kann für die Aussagegehalt der von einem Subsystem bereitgestellten Informationen angenommen werden. Denn sofern die verfügbare Zeit - wie in der betrieblichen Praxis häufig zu beobachten ist - und nicht z.B. die mangelnde fachliche Qualifikation der Mitarbeiter den Engpaßfaktor bei der Teilaufgabenerfüllung darstellt, erhöht ein Mehr an verfügbarer Zeit die inhaltliche Qualität der aus den Leistungerstellungsprozessen resultierenden Informationen.

Bei der Untersuchung des Zusammenhangs zwischen der Darstellungsweise als der zweiten hier unterschiedenen Teildimension der Informationsqualität und dem Ausmaß an Organizational Slack bezüglich des Faktors Zeit ist zwischen dem Informationsbedarf des Subsystems, dessen Organizational Slack erhöht wird, und den von diesem bereitgestellten Informationen zu unterscheiden. Während im Fall eines knapp bemessenen zeitlichen Rahmens für die Teilaufgabenerfüllung der Anpassung der formalen Aufbereitung der benötigten Informationen an die spezifischen Erfordernisse dieses Leistungserstellungsprozesses, die Situation sowie die individuellen Bedürfnisse der Mitarbeiter (als Teilaspekt der formalen Informationsqualität) große Bedeutung zukommt, führt ein Mehr an verfügbarer Zeit tendenziell dazu, daß die Erfordernisse an die formale Qualität der benötigten Informationen sinken. Denn die mit einer verbesserten Darstellungsweise einhergehende schnellere Verarbeitung der Informationen ist bei einem erhöhten Ausmaß an Organizational Slack weniger wichtig. Somit sinken die Anforderungen des Informationsbedarfs an die Darstellungsweise der Informationen mit dem Ausmaß an Organizational Slack bezüglich des Faktors Zeit. Betrachtet man die Auswirkungen von Organizational Slack auf die Darstellungsweise der von einem Subsystem bereitgestellten Informationen, so kann - analog zu der Argumentation bezüglich deren Aussagegehalt - davon ausgegangen werden, daß die Mitarbeiter das Mehr an verfügbarer Zeit für eine Verbesserung ihrer Informationsverarbeitungsprozesse verwenden und nicht nur die inhaltliche, sondern auch die formale Qualität der bereitgestellten Informationen entsprechend steigt. Dies gilt z.B. für Aspekte wie die Formatierung oder die Allgemeinverständlichkeit der Informationen. Bezüglich der Anpassung der bereitgestellten Informationen an die Subjekte, die diese benötigen, ist allerdings zu beachten, daß eine solche Anpassung als Teilaspekt der formalen Informationsqualität nur möglich ist, wenn der Empfänger der Informationen und seine Anforderungen an die Art ihrer Aufbereitung bekannt sind. Ein geringer Bestimmtheitsgrad des Informationsbedarfs erschwert somit die individuelle Anpassung der bereitgestellten Informationen als Teilaspekt der formalen Informationsqualität. Grundsätzlich kann 
jedoch von einem positiven Zusammenhang zwischen dem Maß an Organizational Slack bezüglich des Faktors Zeit in einem Subsystem und der formalen Qualität der von diesem bereitgestellten Informationen ausgegangen werden.

Eine verstärkte 'Spezialisierung auf die Unternehmung' im Rahmen der intrasystemischen Arbeitsteilung führt bei hoher personeller Durchlässigkeit der Subsystemgrenzen dazu, daß die Mitarbeiter vermehrt über Kenntnisse bezüglich anderer Subsysteme verfügen. Diese Kenntnisse über andere Arbeitszusammenhänge erlauben ihnen tendenziell sowohl ein gezielteres Formulieren der eigenen Informationsbedarfe als auch eine zielorientiertere Bereitstellung von Informationen gegenüber diesen Subsystemen. So wird z.B. ein Vertriebsmitarbeiter einer Unternehmung des Anlagenbaus, der über ausgeprägte Kenntnisse der Abläufe in der Konstruktionsabteilung verfügt und die Art der dort auftretenden Engpässe kennt, bei den für die Angebotserstellung notwendigen Terminabsprachen diesbezüglich gezielter nachfragen, zugleich aber auch bestrebt sein, die von ihm der Konstruktionsabteilung gegenüber bereitgestellten Informationen auf deren spezifische Informationsbedarfe auszurichten. Somit führen Kenntnisse über die Arbeitszusammenhänge in anderen Subsystemen, die im Rahmen einer 'Spezialisierung auf die Unternehmung' erworben werden, tendenziell zu einer höheren Qualität der Informationsbedarfe und -bereitstellungen gegenüber diesen Subsystemen.

Die organisatorischen Regeln zur Koordination haben keinen systematischen Einfluß auf die inhaltliche und formale Informationsqualität.

Für die organisatorischen Regeln zum Leitungssystem gelten folgende Aussagen: Bei der Gegenüberstellung von Ein- und Mehrliniensystemen wird in der organisationstheoretischen Literatur häufig auf die höhere fachspezifische Qualifikation der Führungskräfte in einem Mehrliniensystem abgestellt. ${ }^{75}$ Daraus könnte gefolgert werden, daß die Informationsqualität der einzelnen Weisungen in einem Mehrliniensystem tendenziell höher ist als in einem Einliniensystem. Denn die Führungskraft ist in ihrem Weisungsverhältnis auf bestimmte (z.B. funktionale) Aspekte beschränkt, die sie entsprechend besser kennt als bei einer inhaltlich breiteren Weisungsbeziehung. ${ }^{76}$ Hier ist jedoch zu beachten, daß die Betrachtung der Informationsqualität der Weisungsbeziehung nicht nur auf den spezifischen Teilaspekt abstellen darf, der im Rahmen dieser Weisungsbeziehung abgebildet wird, sondern die Gesamtheit der aus der Sicht des untergeordneten Subsystems führungsrelevanten Informationen umfassen muß. Aus der Gesamtperspektive des untergeordneten Subsystems kann die Informationsqualität einer Weisung in einem Mehrliniensystem aufgrund der mit der Beschränkung auf bestimmte Aspekte einhergehenden Teiloptimierung unter Vernachlässigung des Gesamtzusammenhangs auch geringer sein als in einem Einliniensystem, in dem die Weisung tendenziell eher eine Gesamtoptimierung sämtlicher für das Subsystem relevanter Weisungsaspekte dar- 
stellt. Entsprechend können keine allgemeingültigen Aussagen darüber getroffen werden, ob die Informationsqualität der Weisungen in einem Einliniensystem im Vergleich zu einem Mehrliniensystem höher oder geringer ist. Denn einerseits hängt die Bewertung der Informationsqualität von der spezifischen Situation ab, andererseits variiert sie in Abhängigkeit von der verfolgten Perspektive.

Betrachtet man in einem nächsten Schritt die verschiedenen Formen der Projektorganisation als Ausprägungen der Sekundärorganisation, so können die Aussagen bezüglich Einlinien- und Mehrliniensystem als verschiedener Formen der Ausgestaltung der Primärorganisation hier nicht analog übertragen werden. Denn unabhängig von der Art der Projektorganisation erhält der einzelne Projektmitarbeiter Weisungen bezüglich der Projektaufgabe stets nur von einem Vorgesetzten. Im Fall der Matrix- und der EinflußProjektorganisation treten neben diese noch weitere Weisungen durch die Linienvorgesetzten, die jedoch nicht die Projektaufgabe betreffen. Die Qualität der projektbezogenen Weisungen ist somit unabhängig von der Form der Projektorganisation. Untersucht man dagegen den Einfluß der Ausgestaltung der Projektorganisation auf die Qualität der durch die Projektmitarbeiter im Rahmen der Erfüllung ihrer Projektaufgaben bereitgestellten Informationen, so ist tendenziell davon auszugehen, daß diese bei reiner Projektorganisation höher ist als bei den anderen Formen der Projektorganisation. Das Herauslösen der Mitarbeiter aus der Primärorganisation führt nämlich dazu, daß die häufig mit den anderen Formen der Projektorganisation verbundene zeitliche Überlastung der Mitarbeiter vermieden wird und diese sich vielmehr vollständig auf ihre Projektaufgaben konzentrieren können. Diese Beschränkung ihres Aufgabenbereiches geht ceteris paribus mit einer höheren inhaltlichen und formalen Qualität der von ihnen bereitgestellten Informationen einher. Zwischen der Qualität ihrer Informationsbedarfe und der Form der Projektorganisation besteht dagegen kein Zusammenhang.

Die Reintegration der Stabsarbeit in die Linie geht in der Regel mit einer geringeren Qualität der bereitgestellten Informationen einher. ${ }^{77}$ Denn einerseits senkt die Auflösung des Stabes regelmäßig den Organizational Slack bezüglich des Faktors Zeit bei den Führungskräften der Linie bzw. führt zu einer erheblich höheren zeitlichen Belastung der Führungskräfte. Andererseits verfügen die Stabsmitarbeiter regelmäßig über ausgeprägtes Spezialwissen, das eine hohe inhaltliche und formale Qualität der von ihnen bereitgestellten Informationen bedingt. Ein systematischer Einfluß auf die Qualität des Informationsbedarfs besteht nicht.

Heterarchien bedeuten, daß die Führungsaufgaben im Zeitverlauf durch wechselnde Mitarbeiter wahrgenommen werden. Diese haben entsprechend durchschnittlich weniger Erfahrung bei der Ausübung der Führungsfunktionen als bei der dauerhaften Teilaufgabenzuweisung zu bestimmten Personen. Die geringere Erfahrung kann mit einer geringeren Informationsqualität ihrer Weisungen einhergehen. Andererseits verfügen sie 
zugleich über vielfältigere Erfahrungen bei der Übernahme anderer Teilaufgaben und kennen insbesondere die Perspektive der geführten Mitarbeiter. Diese Sichtweise kann die Qualität ihrer Weisungen positiv beeinflussen. Es besteht somit kein allgemeingültiger Zusammenhang zwischen Heterarchien und der Informationsqualität der Weisungen.

Gewährt man den Subsystemen der Primärorganisation die Möglichkeit, im Bedarfsfall Projektteams als temporäre Subsysteme der Sekundärorganisation zu bilden, so geht dies tendenziell mit einer Erhöhung der Qualität der im Rahmen ihrer Teilaufgabenerfüllung bereitgestellten Informationen einher. Die obige Argumentation bezüglich der verschiedenen Formen der Projektorganisation gilt hier analog: Je stärker die aus dem Herauslösen der Projektaufgaben aus der Primärorganisation resultierende Konzentration auf diese Teilaufgaben ist, desto höher ist die Qualität der im Rahmen der Teilaufgabenerfüllung bereitgestellten Informationen. Ein systematischer Einfluß auf die Qualität des Informationsbedarfs besteht dagegen nicht.

Der Einfluß der Entscheidungsdelegation auf die Qualität der benötigten und bereitgestellten Informationen beruht auf der mit der Entscheidungsdelegation einhergehenden Veränderung der Perspektive. Gemäß der konstruktivistischen Grundposition der vorliegenden Arbeit ist allgemein von Unterschieden zwischen den Wahrnehmungen verschiedener Personen auszugehen. Dabei unterscheiden sich die Wahrnehmungen der Personen in Abhängigkeit von ihrem Aufgabenfeld und ihrer hierarchischen Position in der Unternehmung. So waren in Abschnitt 4.1.2.2 Unterschiede in der Wahrnehmung von Wandelprozessen in ihren jeweiligen Teilumwelten durch die (selbstorganisierenden) Mitarbeiter und die (fremdorganisierenden) Organisatoren herausgearbeitet worden: Während Veränderungen, die ihr spezifisches Arbeitsumfeld betreffen, im Mittelpunkt der Wahrnehmung der Mitarbeiter stehen, liegt der Fokus der organisatorischen Gestalter eher auf übergeordneten und insbesondere solchen Fragestellungen, die die Unternehmung als Ganzes betreffen.

Verallgemeinert man diese Argumentation für eine Betrachtung der verschiedenen Hierarchieebenen in der Unternehmung, so kann angenommen werden, daß die Einordnung einer Entscheidung in den umfassenden Gesamtzusammenhang des betrieblichen Geschehens auf den oberen Hierarchieebenen der Unternehmung stärker ausgeprägt ist als auf den unteren Hierarchieebenen, die wiederum stärker auf die spezifischen Belange ihres Teilaufgabenbereiches abstellen. Aus diesen unterschiedlichen Perspektiven und unterschiedlichen Informationsständen resultieren Unterschiede in der Qualität der von einzelnen Aufgabenträgern und Subsystemen auf den verschiedenen Hierarchieebenen benötigten und bereitgestellten Informationen.

Betrachtet man zunächst den Aussagegehalt der Informationsbedarfe, so können keine allgemeingültigen Aussagen über die Art der aus der Entscheidungsdelegation resultierenden Veränderung von deren Aussagegehalt getroffen werden. Denn die Anforderungen an Aktualität, Vollständigkeit, Wahrheitsgehalt und sonstige Aspekte der inhaltlichen Qualität der benötigten Informationen ergeben sich nicht aus der hierarchi- 
schen Position der Entscheidungsträger, sondern aus den Entscheidungsinhalten. Dagegen erscheint ein systematischer Einfluß auf die Darstellungsweise als zweite Teildimension der Informationsqualität plausibel. Je weniger die von einem Subsystem benötigten Informationen in unmittelbarem Zusammenhang mit seinem Kernarbeitsbereich stehen, desto höher werden tendenziell die Anforderungen an die Darstellungsweise sein. Je geringer nämlich der ursprüngliche Informationsstand eines Subjektes bezüglich einer bestimmten Art von Informationen ist, d.h. je fremder ihm diese sind, desto höher sind seine diesbezüglichen Anforderungen an eine geeignete und verständliche formale Aufbereitung der benötigten Informationen. So sind die Anforderungen einer Führungskraft bezüglich der formalen Qualität von benötigten Detailinformationen tendenziell höher als die des Subsystems, dessen konkreter Arbeitszusammenhang thematisiert wird, da letzteres einen unmittelbaren inhaltlichen Zugang zu den benötigten Informationen hat. Die Anforderungen eines untergeordneten Subsystems an die formale Qualität von Überblicksinformationen, die in keinem direkten Zusammenhang mit seinem unmittelbaren Arbeitszusammenhang stehen, sind dagegen vergleichsweise hoch.

Betrachtet man in einem nächsten Schritt die Informationsbereitstellungen, so besteht ein systematischer Zusammenhang zwischen der inhaltlichen Qualität der bereitgestellten Informationen und dem Informationsstand des diese bereitstellenden Subsystems. Je höher der Informationsstand eines Subsystems über eine bestimmte Art von Informationen, desto höher ist tendenziell die inhaltliche Qualität der diesbezüglich von ihm bereitgestellten Informationen. Entsprechend ist die inhaltliche Qualität der bei ausgeprägter Entscheidungsdelegation durch ein Subsystem auf der untergeordneten Hierarchieebene bereitgestellten Detailinformationen über sein spezifisches Arbeitsfeld vergleichsweise höher als die entsprechenden Informationen, die bei Entscheidungszentralisation durch das übergeordnete Subsystem bereitgestellt würden. Umgekehrt gilt für Überblicksinformationen, daß bei Entscheidungsdezentralisation eine geringere inhaltliche Qualität der diesbezüglich von dem untergeordneten Subsystem bereitgestellten Informationen angenommen werden muß. Dagegen besteht kein systematischer Zusammenhang zwischen der formalen Qualität der bereitgestellten Informationen und der Hierarchieebene des diese bereitstellenden Subsystems.

Zusammenfassend gilt, daß die verstärkte Delegation von Entscheidungen an Subsysteme auf den unteren Hierarchieebenen einen systematischen Einfluß auf die formale Qualität der Informationsbedarfe und die inhaltliche Qualität der Informationsbereitstellungen hat, wobei jeweils unterschiedliche Auswirkungen auf Überblicks- und Detailinformationen bestehen. Dagegen besteht ein allgemeingültiger Zusammenhang zwischen dem Grad der Entscheidungsdelegation weder bezüglich der inhaltlichen Qualität der Informationsbedarfe noch bezüglich der formalen Qualität der bereitgestellten Informationen.

Abbildung 5/9 zeigt abschließend die aus den Ausprägungen der organisatorischen Regeln zu Arbeitsteilung, Koordination, Leitungssystem und Entscheidungsdelegation 
resultierenden Konsequenzen für die Informationsqualität. Im Gegensatz zu den bisher diskutierten Dimensionen der Informationsbedarfe und -bereitstellungen inhaltlicher Umfang, Bestimmtheit und Dringlichkeit, können die aus den verschiedenen Ausprägungen der organisatorischen Regeln resultierenden einzelnen Konsequenzen hier nicht zu einer allgemeinen Tendenzaussage bezüglich der Art der Veränderung der Informationsqualität zusammengefaßt werden. So können zwar durchaus allgemeingültige Aussagen bezüglich des Einflusses einzelner Ausprägungen der organisatorischen Regeln auf die Informationsqualität gemacht werden. Diese Auswirkungen fallen jedoch häufig für Informationsbedarfe und -bereitstellungen oder für deren formale und inhaltliche Qualität unterschiedlich aus. Oder aber sie gelten jeweils nur für bestimmte Teilmengen der Informationen (wie z.B. Überblicks- und Detailinformationen). Dieser Umstand

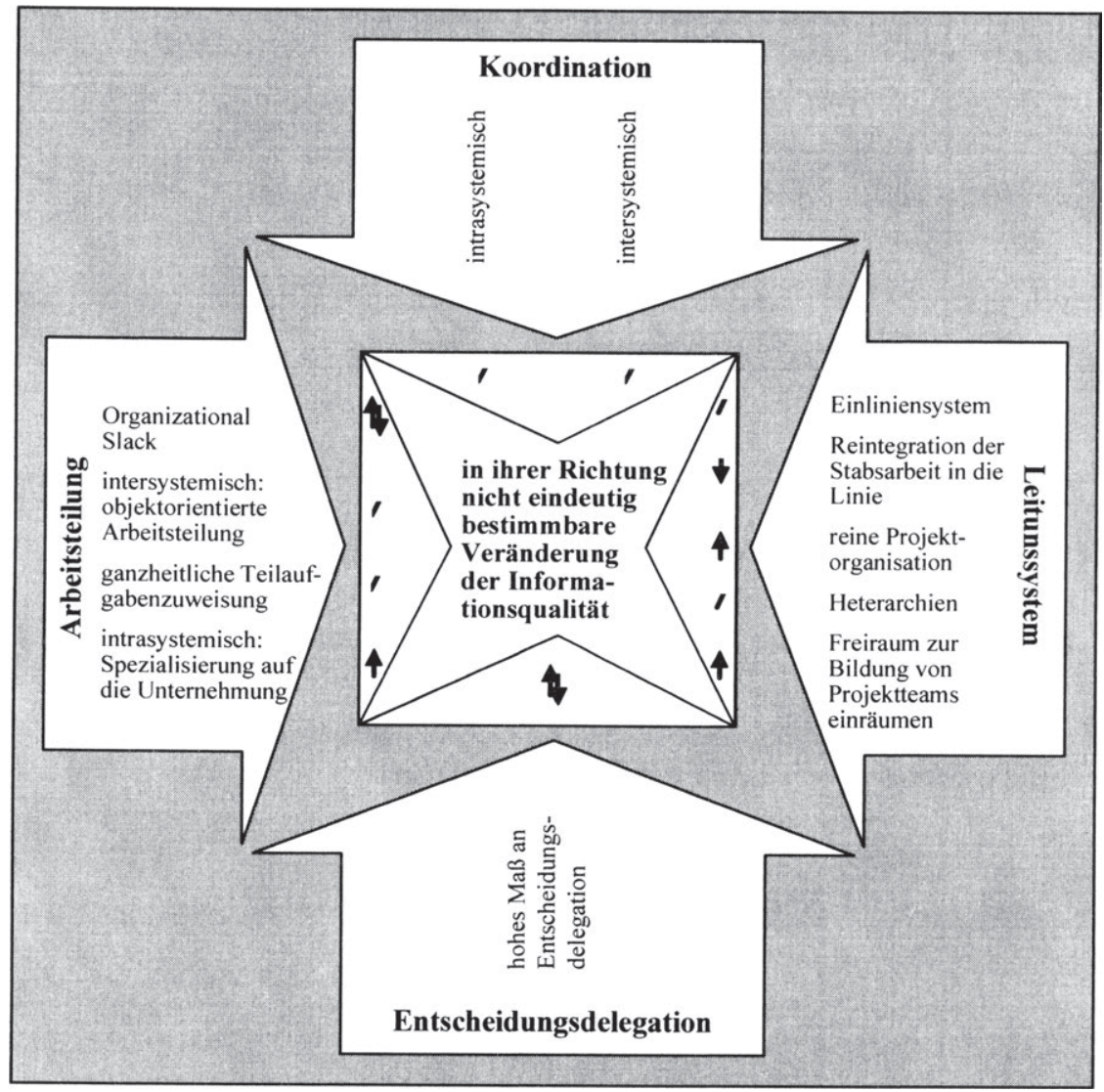

Abb. 5/9: Konsequenzen der Ausprägungen der organisatorischen Regeln für die Informationsqualität

wird in Abbildung 5/9 durch die Verwendung von zwei Pfeilen für die Charakterisierung des Zusammenhangs zwischen einer Ausprägung der organisatorischen Regeln und der Informationsqualität ausgedrückt. So unterscheiden sich z.B. nicht nur die Auswir- 
kungen eines höheren Maßes an Organizational Slack bezüglich des Faktors Zeit auf die Informationsbedarfe zum Teil von denen auf die Informationsbereitstellungen, sondern es kommt auch zu unterschiedlichen Konsequenzen für deren formale und inhaltliche Qualität.

\subsubsection{Informationsautarkie}

Die Informationsautarkie eines Subsystems stellt einerseits darauf ab, inwieweit die Informationsbedarfe dieses Subsystems innerhalb des Subsystems selbst gedeckt werden können oder Informationsbereitstellungen außerhalb des Subsystems notwendig machen. Andererseits beeinflußt aber auch die Verpflichtung des Subsystems, Informationen für andere Subsysteme bereitzustellen, seine Informationsautarkie. Beide Formen des Auseinanderfallens des Ortes von Informationsbedarf und -bedarfsdeckung führen $\mathrm{zu}$ informationellen Beziehungen zwischen dem Subsystem und seinem Umfeld. Anhand des hierarchischen Verhältnisses zwischen den Subsystemen, die Informationen austauschen, kann zwischen der horizontalen und der vertikalen Informationsautarkie unterschieden werden.

Ein Teil der organisatorischen Regeln zur Arbeitsteilung beeinflußt die horizontale Informationsautarkie. Während die Erhöhung des Organizational Slack bezüglich des Faktors Zeit keine Auswirkungen auf die Informationsautarkie hat, geht eine objektorientierte intersystemische Arbeitsteilung im allgemeinen und eine ganzheitliche Teilaufgabenzuweisung im besonderen im Vergleich zur funktionsorientierten Arbeitsteilung tendenziell mit einer höheren Informationsautarkie einher. Denn es kann angenommen werden, daß ein vergleichsweise großer Anteil der mit der Bearbeitung logisch zusammengehörender Teilaufgaben verbundenen Informationsbedarfe durch Informationsbereitstellungen gedeckt wird, die in demselben Arbeitszusammenhang und damit innerhalb desselben Subsystems - anfallen. Stellt man beispielsweise eine funktionale Gliederung der ersten Hierarchieebene einer Unternehmung in Einkauf, Produktion, Vertrieb etc. einer objektorientierten nach Produktgruppen gegenüber, so benötigt bei funktionaler Spezialisierung die Produktionsabteilung bei der Entscheidung über die optimale Produktionsmenge sowohl Absatzinformationen aus der Vertriebsabteilung als auch Informationen über Lagerbestände und Bestellmengen aus der Einkaufsabteilung und weist damit ausgeprägte horizontale informationelle Beziehungen mit diesen Subsystemen auf. Im Gegensatz dazu obliegt die Entscheidung über die optimale Produktionsmenge bei einer Gliederung der ersten Hierarchieebene der Unternehmung nach Produktgruppen demselben Subsystem, das auch über die benötigten Informationen über Absatz und Einkauf verfügt. Die Informationsautarkie dieses Subsystems gegenüber den anderen nach Produktgruppen geordneten Subsystemen ist vergleichsweise groß.

Ein hohes Maß an 'Spezialisierung auf die Unternehmung' bei hoher personeller Durchlässigkeit der Subsystemgrenzen führt dazu, daß in einem Subsystem verstärkt 
Know-how vorhanden ist, das anderen Subsystemen entstammt. Dies wiederum bedingt, daß ein größerer Teil des Informationsbedarfs des Subsystems subsystemintern befriedigt werden kann und nicht zu informationellen Beziehungen des Subsystems zu anderen Subsystemen führt. Die horizontale Informationsautarkie des Subsystems ist entsprechend größer. Als Beispiel sei hier auf eine Controlling-Abteilung verwiesen, die Investitionsrechnungen für potentielle Investitionsvorhaben durchführt. Bei der Gegenüberstellung verschiedener Investitionsalternativen müssen deren jeweilige steuerliche Implikationen in die Investitionsrechnungen einbezogen werden. Über diese Informationen verfügt die Abteilung Steuern, mit der das Controlling entsprechend informationelle Beziehungen unterhalten muß. Sofern ein Mitarbeiter der Controlling-Abteilung jedoch über steuerrechtliche Kenntnisse verfügt, die er zuvor in der Abteilung Steuern erworben hat, besteht keine Notwendigkeit für informationelle Beziehungen zwischen den Abteilungen. Der inhaltliche Umfang des Informationsbedarfs der Controlling-Abteilung bleibt zwar gleich, die Bedarfsdeckung erfolgt nun jedoch innerhalb des Subsystems und geht nicht mit informationellen Beziehungen zu anderen Subsystemen einher. Je mehr die Mitarbeiter eines Subsystems infolge einer ausgeprägten subsystemübergreifenden Spezialisierung auf die Unternehmung über spezifisches Know-how aus anderen Subsystemen verfügen, desto höher ist die horizontale Informationsautarkie des betroffenen Subsystems.

Auch für einen Teil der organisatorischen Regeln zur Koordination kann ein systematischer Zusammenhang mit der horizontalen Informationsautarkie eines Subsystems aufgezeigt werden. Denn Pläne und Programme als intersystemisches Koordinationsinstrumentarium stellen Koordinationsinformationen bereit, die die betroffenen Subsysteme beim Fehlen dieser Formen der Koordination im Rahmen ihrer informationellen Beziehungen untereinander ermitteln müßten. Informationen über Aktivitäten anderer Subsysteme, die ein Subsystem zur Koordination seiner eigenen Aktivitäten mit denen ihm nebengeordneter Subsysteme benötigt, sind bei der Koordination durch Pläne oder Programme nicht Gegenstand informationeller Beziehungen zwischen den Subsystemen, sondern werden durch das Koordinationsinstrumentarium zur Verfügung gestellt. Dies führt dazu, daß die horizontale Informationsautarkie der betroffenen Subsysteme bezüglich dieser Koordinationsinformationen als Teilmenge der Gesamtheit der Informationsbedarfe und -bereitstellungen steigt. Als Beispiel kann die zentrale Vorgabe von Budgets für verschiedene Subsysteme angeführt werden, die dazu führt, daß die zahlreichen Informationsbeziehungen, die mit den politischen Prozessen zwischen den einzelnen Subsystemen im Rahmen ihrer Abstimmung über die Mittelverteilung einhergehen, entfallen.

Stellt man Einlinien- und Mehrliniensystem als Ausprägungen der organisatorischen Regeln zum Leitungssystem einander gegenüber, so hat die Entscheidung für eine Einliniensystem keinen Einfluß auf den Umfang der vertikalen Informationsautarkie eines Subsystems. Während nämlich beim Einliniensystem die Zahl der vertikalen Informationsbeziehungen genau gleich eins und damit geringer als in einem Mehrliniensystem ist, 
ist der inhaltliche Umfang der Weisungsbeziehung im Einliniensystem entsprechend höher, da derselbe Gesamtumfang der Weisungen hier durch eine statt durch mehrere Personen erfolgt. Entsprechendes gilt für die verschiedenen Formen der Projektorganisation, die somit ebenfalls keinen systematischen Einfluß auf die vertikale Informationsautarkie des Projektteams haben.

Aus der Reintegration der Stabsarbeit in die Linie folgt, daß die informationellen Beziehungen zwischen der Linieninstanz und ihrem Stab entfallen. Die von der Linieninstanz benötigten Informationen zur Entscheidungsvorbereitung werden nicht länger vom Stab, sondern von der Linieninstanz selbst bereitgestellt. Dies führt zu einer Erhöhung ihrer Informationsautarkie.

Gehen Heterarchien zugleich mit einer hohen personellen Durchlässigkeit der Subsystemgrenzen einher, so führt die im Zeitverlauf wechselnde Übernahme von Führungsteilaufgaben hier ebenso wie die 'Spezialisierung auf die Unternehmung' zu einer höheren horizontalen Informationsautarkie des Subsystems. Denn das Vorhandensein von Know-how aus anderen Subsystemen ermöglicht die Deckung der diesbezüglichen Informationsbedarfe innerhalb des fokussierten Subsystems. Die entsprechenden informationellen Beziehungen zu anderen Subsystemen können entfallen.

Über den Einfluß auf die horizontale Informationsautarkie der betroffenen Subsysteme haben Heterarchien Einfluß auf die vertikale Informationsautarkie der Führungskräfte und ihrer Mitarbeiter. Denn die wechselnde Ausübung der Führungsaufgaben durch unterschiedliche Personen bedingt, daß deren durchschnittliche Erfahrung mit dieser Teilaufgabenerfüllung geringer ist als bei im Zeitablauf stabilen hierarchischen Beziehungen. Es erscheint plausibel anzunehmen, daß die geringere Erfahrung der Führungskräfte dazu führt, daß sie intensivere informationelle Beziehungen zu ihren Mitarbeitern pflegen, um die fehlende Erfahrung auszugleichen und notwendige Informationen zu erhalten. Aus der Perspektive der Mitarbeiter in dem geführten Subsystem bedeutet dies eine entsprechend höhere Verpflichtung zur Bereitstellung von Informationen gegenüber dem Vorgesetzten. Somit führen Heterarchien tendenziell zu einer geringeren vertikalen Informationsautarkie sowohl der Vorgesetzten als auch ihrer Mitarbeiter.

Gewährt man den Subsystemen der Primärorganisation verstärkt die Möglichkeit, im Bedarfsfall Projektteams als temporäre Subsysteme zu bilden, so bedeutet die damit verbundene Verschiebung der Subsystemgrenzen in Abhängigkeit von den zu erfüllenden Teilaufgaben, daß die horizontale Informationsautarkie der Subsysteme steigt. Denn durch die Zusammenfassung der Projektaufgaben und ihre Zuordnung zu einem Subsystem werden die diesbezüglichen Informationsbedarfe tendenziell eher durch subsystemintern bereitgestellte Informationen gedeckt als dies beim Verbleib der Projektaufgaben in der Primärorganisation der Fall wäre.

Bezüglich der organisatorischen Regeln zur Entscheidungsdelegation ist ein systematischer Einfluß auf die vertikale Informationsautarkie festzustellen. Je höher der Grad der Entscheidungsdelegation ist, desto geringer ist die Zahl der von oben nach unten 
gerichteten Weisungsbeziehungen und desto geringer ist deren inhaltlicher Umfang. An die Stelle der Weisungen durch die übergeordnete Instanz treten hier verstärkt Entscheidungen durch das untergeordnete Subsystem selbst. Zugleich weisen die von unten nach oben weitergegebenen Informationen einen hohen Verdichtungsgrad auf, da sie weniger der Vorbereitung von Entscheidungen durch das übergeordnete Subsystem dienen, sondern vielmehr die Grundlage für deren Kontrollaktivitäten bezüglich der delegierten Entscheidungen bilden. Dies bedingt eine höhere vertikale Informationsautarkie sowohl des geführten als auch des übergeordneten Subsystems.

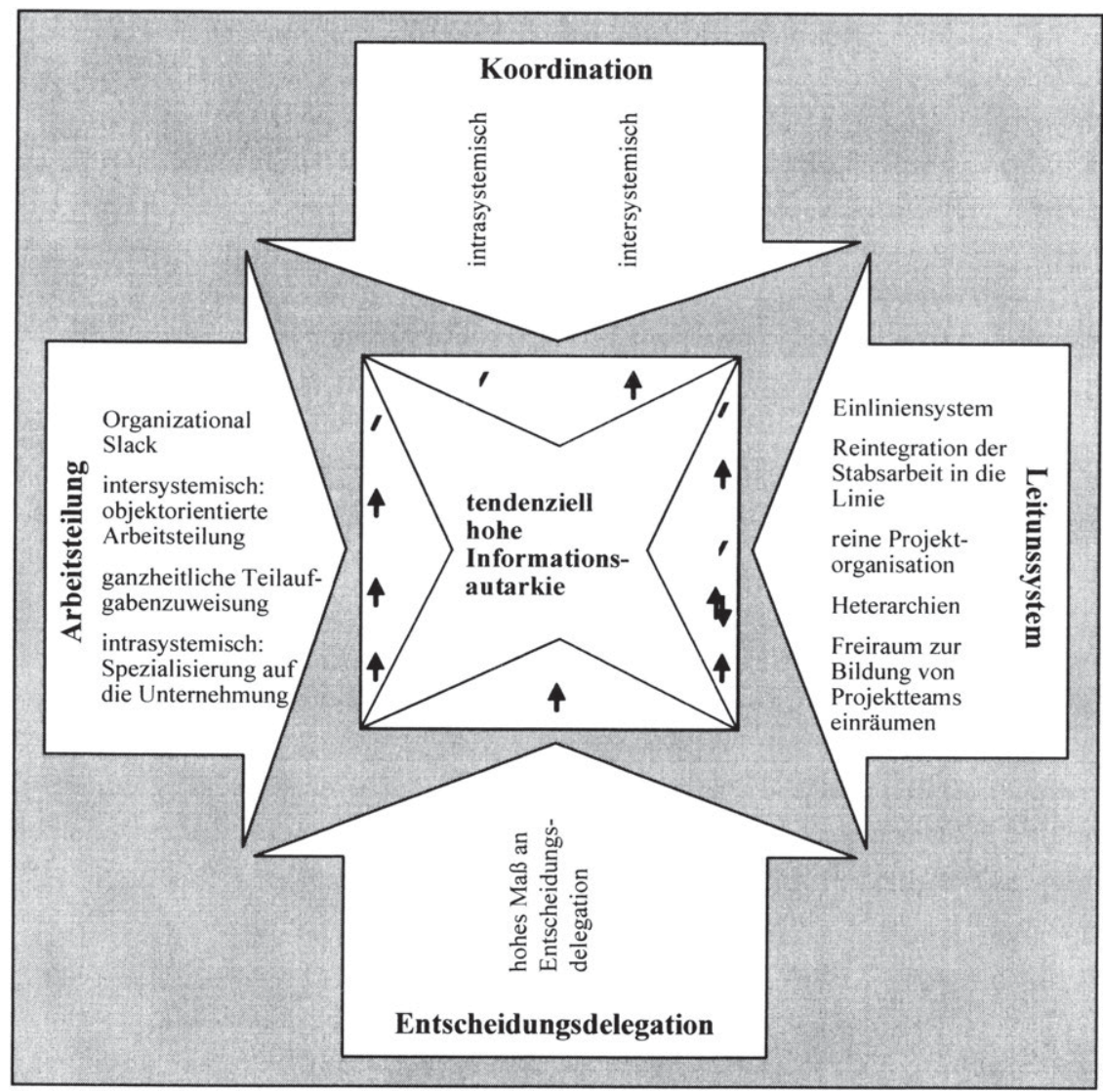

Abb. 5/10: Konsequenzen der Ausprägungen der organisatorischen Regeln für die Informationsautarkie

Abbildung 5/10 zeigt die aus den Ausprägungen der organisatorischen Regeln zu Arbeitsteilung, Koordination, Leitungssystem und Entscheidungsdelegation resultierenden Konsequenzen für die Informationsautarkie. Sieht man von der Ausnahme des Einflusses von Heterarchien auf die vertikale Informationsautarkie ab, weisen alle Ein- 
flußfaktoren, für die ein systematischer Einfluß aufgezeigt werden konnte, in dieselbe Wirkrichtung: Sie führen tendenziell zu einem hohen Maß an Informationsautarkie.

Da die Informationsautarkie auf das örtliche Zusammen- oder Auseinanderfallen von bereits (mit Hilfe der Dimensionen inhaltlicher Umfang, Bestimmtheit, Dringlichkeit und Qualität) definierten Informationsbedarfen und -bereitstellungen abstellt, besteht nicht nur zwischen den Ausprägungen der organisatorischen Regeln und der Informationsautarkie eine Abhängigkeit, sondern auch zwischen dieser und den anderen Dimensionen der Informationsbedarfe und -bereitstellungen. Sowohl ein hoher inhaltlicher Umfang als auch ein geringer Bestimmtheitsgrad von Informationsbedarfen und -bereitstellungen führen tendenziell zu einer geringeren Informationsautarkie des betroffenen Subsystems. Denn es ist davon auszugehen, daß mit zunehmendem inhaltlichen Umfang der durch ein Subsystem verarbeiteten Informationen ceteris paribus die Anzahl derjenigen Informationsbedarfe, die nur außerhalb des Subsystems gedeckt werden können, steigt. Gleichzeitig nimmt auch die Zahl der zur Deckung der Informationsbedarfe anderer Subsysteme bereitgestellten Informationen zu. Entsprechendes gilt für einen geringen Bestimmtheitsgrad bzw. eine hohe Varietät der Informationsbedarfe und -bereitstellungen. Dieser aus den Ausprägungen der anderen Dimensionen der Informationsbedarfe und bereitstellungen resultierende negative Einfluß auf die Informationsautarkie eines Subsystems wirkt den unmittelbaren, positiven Auswirkungen der organisatorischen Regeln auf die Informationsautarkie entgegen. Da eine geringe Informationsautarkie tendenziell mit einer geringen Informationsautonomie einhergeht, die wiederum eine Teilausprägung der relativen Autonomie darstellt, erweist sich dieser gegenläufige Effekt als problematisch. Zielt man nämlich darauf ab, die Wahrscheinlichkeit für das Auftreten von Selbstorganisationsprozessen in einem Subsystem zu fördern, so gilt es, die relative Autonomie dieses Subsystems im allgemeinen und seine Informationsautonomie im besonderen zu fördern. Für das Informationsmanagement folgt daraus, daß es im Rahmen seines Gestaltungshandelns bezüglich der informationellen Beziehungen des Subsystems sicherstellen muß, daß der unmittelbar aus den Ausprägungen der organisatorisatorischen Regeln resultierende positive Einfluß auf die Informationsautarkie nicht durch den mittelbaren negativen Einfluß, der mit dem hohen inhaltlichen Umfang und der geringen Bestimmtheit der Informationsbedarfe und -bereitstellungen einhergeht, überkompensiert wird.

\subsubsection{Die Gestaltung der Informationsstruktur}

Aus den in Abschnitt 4.2 entwickelten Ausprägungen der organisatorischen Regeln resultieren bestimmte Konsequenzen für die Informationsbedarfe und -bereitstellungen. Diese können den in Abschnitt 5.2.1 diskutierten Dimensionen der Informationsbedarfe und -bereitstellungen zugeordnet werden. Sie stellen Rahmenbedingungen für das Informationsmanagement dar, denn das Informationsmanagement muß die Informationsbedarfe der menschlichen Aufgabenträger innerhalb eines Subsystems der Unter- 
nehmung unter Berücksichtigung von Wirtschaftlichkeitsaspekten mit den Informationsbereitstellungen anderer Aufgabenträger aus anderen Subsystemen in Einklang bringen. Es kann nämlich keineswegs davon ausgegangen werden, daß den formulierten Informationsbedarfen - quasi automatisch - eine entsprechende Bedarfsdeckung gegenübersteht. Vielmehr obliegt es dem Informationsmanagement, den Abgleich zwischen Informationsbedarfen und -bereitstellungen durch eine zielorientierte Gestaltung der informationellen Beziehungen zwischen den menschlichen Informationsverarbeitern sicherzustellen.

Im folgenden wird aufgezeigt, wie die organisatorisch bedingten Rahmenbedingungen bei der Gestaltung der Informationsstruktur Berücksichtigung finden können und welche Gestaltungsmöglichkeiten auf der immateriellen Ebene des Informationsmanagements bestehen, um unter Einbeziehung dieser Rahmenbedingungen eine effektive und effiziente Informationsversorgung zu gewährleisten. Die Ausführungen orientieren sich einerseits an den fünf Dimensionen der Informationsbedarfe und -bereitstellungen, andererseits an den Dimensionen der informationellen Beziehungen, wie sie Abbildung 5/11 zeigt.

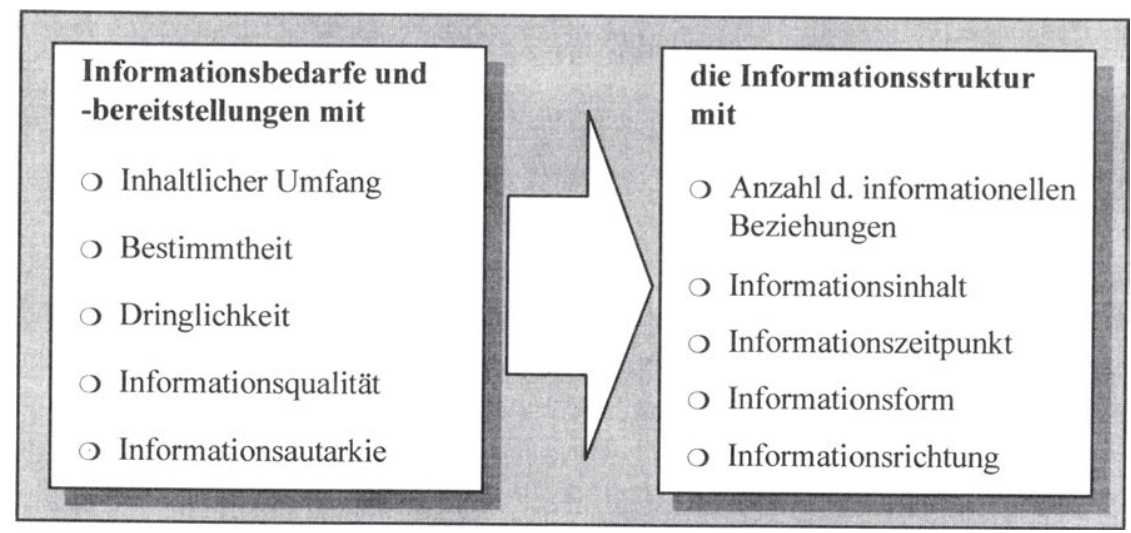

Abb. 5/11: Die Dimensionen der Informationsbedarfe und -bereitstellungen sowie der Informationsstruktur

Über die bereits in Abschnitt 5.1.2.2.2 vorgestellten Dimensionen der informationellen Beziehungen als qualitative Kriterien, die auf die einzelne informationelle Beziehung abstellen, hinaus wird die Anzahl der informationellen Beziehungen als quantitatives Kriterium zur Beschreibung der Informationsstruktur als der Summe der informationellen Beziehungen berücksichtigt. Im Rahmen der folgenden Ausführungen werden somit nacheinander die Anzahl der informationellen Beziehungen, der Informationsinhalt, der Informationszeitpunkt, die Informationsform und die Informationsrichtung untersucht. Dabei werden zunächst die bei der Gestaltung jeder dieser Dimensionen zu berücksichtigenden organisatorisch bedingten Rahmenbedingungen (in Form der Ausprägungen der Dimensionen von Informationsbedarfen und -bereitstellungen) aufgezeigt. 
Sodann werden Gestaltungsmöglichkeiten des Informationsmanagements bezüglich der jeweiligen Dimension herausgearbeitet.

Betrachtet man in einem ersten Schritt das quantitative Phänomen der Zahl der informationellen Beziehungen, so folgt aus dem hohen inhaltlichen Umfang und dem geringen Bestimmtheitsgrad der Informationsbedarfe und -bereitstellungen eines Subsystems, daß die Zahl der durch das Informationsmanagement zur Verfügung gestellten potentiellen Informationskanäle hoch sein muß. Insbesondere der Umstand, daß bei einem geringen Bestimmtheitsgrad der Informationsbereitstellung durch andere Subsysteme u.U. eine Vielzahl von informationellen Beziehungen aufgebaut wird, die nicht zur gewünschten Bedarfsdeckung führen, bis schließlich der geeignete Sender gefunden wird, der den spezifischen Informationsbedarf des Subsystems decken kann, bedingt eine hohes $\mathrm{Ma} ß$ an Kompliziertheit der Informationsverarbeitungsprozesse und der damit verbundenen informationellen Beziehungen der einzelnen menschlichen Informationsverarbeiter eines Subsystems. Zugleich sind sowohl die Informationsverarbeitungskapazität des menschlichen Informationsverarbeiters als auch der verfügbare zeitliche Rahmen regelmäßig beschränkt, so daß ein Anstieg der Zahl der informationellen Beziehungen tendenziell mit der Gefahr der Überforderung einhergeht. Das bloße Ermöglichen einer hohen Zahl von informationellen Beziehungen durch das Informationsmanagement stellt deshalb noch keine ausreichende Gestaltungsalternative dar. Das folgende Beispiel macht dies deutlich: Ausgeprägte Informationsbedürfnisse der Mitarbeiter können das Informationsmanagement veranlassen, eine hohe Anzahl an Informationsbeziehungen dadurch zu ermöglichen, daß allen Mitarbeitern E-mail zur Verfügung gestellt wird. Sofern die Möglichkeit, Verteilerlisten zu definieren und eine E-mail an eine Vielzahl von Empfängern zu versenden, häufig genutzt wird, kommt es $\mathrm{zu}$ einer in der betrieblichen Praxis häufig zu beobachtenden Überlastung der Mitarbeiter durch eine hohe Zahl nur sehr bedingt relevanter E-mails. Entsprechend muß die Gestaltung der Zahl der informationellen Beziehungen durch das Informationsmanagement durch qualitative Gestaltungsmaßnahmen ergänzt werden.

Betrachtet man in einem nächsten Schritt die Gestaltung der Inhalte der informationellen Beziehungen als erste qualitative Dimension, so gilt es, den inhaltlichen Umfang, die Bestimmtheit und bestimmte Teilaspekte der Qualität der Informationsbedarfe und -bereitstellungen zu berücksichtigen. Ziel der die Inhalte der informationellen Beziehungen betreffenden Gestaltungsaktivitäten des Informationsmanagements muß es sein, unter Berücksichtigung der Ausprägungen der drei genannten Dimensionen die Informationsbedarfe der Aufgabenträger und die zu deren Deckung geeigneten Informationsbereitstellungen anderer Aufgabenträger in Einklang miteinander zu bringen.

Aus den organisatorischen Regeln resultiert ein hoher inhaltlicher Umfang der Informationsbedarfe und -bereitstellungen eines Subsystems, innerhalb dessen das Auftreten von Selbstorganisationsprozessen als Prozessen organisationalen Lernens gefördert 
werden soll. Insbesondere ein hohes $\mathrm{Ma}$ an Entscheidungsdelegation bedingt eine Fülle von Informationsverarbeitungsprozessen innerhalb des Subsystems. Diese machen eine große inhaltliche Breite der informationellen Beziehungen notwendig. Das Informationsmanagement muß gewährleisten, daß dem einzelnen Subsystem (bzw. seinen Mitgliedern) die benötigten Informationen zur Verfügung stehen und daß es die aus seinen Informationsverarbeitungsprozessen resultierenden Informationen anderen zur Verfügung stellen kann. Da zugleich jedoch die Informationsverarbeitungskapazität des Menschen regelmäßig begrenzt ist, besteht die Gefahr, daß der große Umfang der Informationen zu einer informationellen Überlastung der Mitarbeiter führt.

Gleichzeitig ist der Bestimmtheitsgrad der Informationsbedarfe und -bereitstellungen des Subsystems vergleichsweise gering. Dies führt dazu, daß die Festlegung bestimmter informationeller Beziehungen ex ante schwierig ist. Ferner besteht immer dann, wenn die zeitpunktbezogene Analyse von Informationsbedarfen und -bereitstellungen die Grundlage für die Festlegung der informationellen Beziehungen für einen bestimmten Zeitraum bildet, die Gefahr, daß diese informationellen Beziehungen die tatsächlichen, im Zeitverlauf veränderten Informationsbedarfe und -bereitstellungen nur unzureichend abbilden. Benötigte Informationen stehen dem Subsystem dann u.U. nicht zur Verfügung, gleichzeitig werden Daten bereitgestellt, die vom Subsystem nicht benötigt werden. Umgekehrt resultieren gegebenenfalls Informationen aus den Informationsverarbeitungsprozessen des Subsystems, die jedoch nicht Gegenstand von informationellen Beziehungen sind und damit nicht an potentielle Empfänger weitergegeben werden. Auch kann der geringe Bestimmtheitsgrad des Informationsbedarfs eines Subsystems dazu führen, daß diesem von anderen prophylaktisch eine Vielzahl potentiell relevanter Informationen zur Verfügung gestellt werden, deren Auswertung die Informationsverarbeitungskapazität des Subsystems überlastet.

Eine Gestaltungsmöglichkeit des Informationsmanagements bezüglich der Inhalte der informationellen Beziehungen, um bei hohem inhaltlichen Umfang und geringem Bestimmtheitsgrad von Informationsbedarf und -bereitstellung die Informationsversorgung eines Subsystems zu gewährleisten, zielt darauf ab, eventuelle Beschränkungen bezüglich der Inhalte der informationellen Beziehungen aufzuheben und somit eine 'Entstandardisierung' der konkreten Inhalte vorzunehmen. Ohne die Ergänzung durch weitere Gestaltungsaktivitäten handelt es sich dabei - insbesondere in Verbindung mit dem oben genannten Ermöglichen einer hohen Anzahl von informationellen Beziehungen - jedoch um eine Scheinlösung. Denn sie verstärkt tendenziell das in der betrieblichen Praxis häufig zu beobachtende Problem der Informationsarmut im Datenüberfluß'78. Dieses Schlagwort stellt darauf ab, daß das enorme Volumen der mit Hilfe der Informationstechnik in der Unternehmung vorgehaltenen Daten nicht notwen-

78 Vgl. ähnlich Nieschlag/Dichtl/Horschgen (1997), S. 1005, 1013. Für eine ausfuhrliche Diskussion dieses Schlagwortes unter Bezugnahme auf die Abgrenzung der Begriffe Wissen, Daten und Information mit Hilfe der drei Ebenen der Semiotik vgl. Streubel (1996), S. 17ff., insbesondere S. 27. 
digerweise mit deren zielorientierter Bereitstellung gegenüber dem informationsverarbeitenden Subjekt einhergeht. Allerdings kommt es hier zu einer Verschiebung bezüglich der betroffenen Hierarchieebenen. Traditionellerweise steht die Datenflut bei gleichzeitiger Informationsarmut auf den oberen Hierarchieebenen der Unternehmung im Mittelpunkt der Gestaltungsaktivitäten des Informationsmanagements. Dieser begegnet man insbesondere durch die starke Verdichtung der von unten nach oben weitergeleiteten Informationen bei gleichzeitigem Einräumen der Möglichkeit des Drilldown auf die auf den unteren Hierarchieebenen anfallenden Detailinformationen mittels vertikaler Integration im Rahmen von Management Support Systems. Da die Argumentation der vorliegenden Arbeit auf selbstorganisierend tätige Subsysteme auf grundsätzlich allen Hierarchieebenen, vor allem aber auf den unteren Hierarchieebenen, abstellt, wird die 'Informationsarmut im Datenüberfluß' hier auch zu einem Problem der Subsysteme der unteren Hierarchieeebenen.

Stellt man obere und untere Hierarchieebenen einander gegenüber, so unterscheiden sich die jeweiligen Ausprägungen der unter dem Schlagwort 'Informationsarmut im Datenüberfluß' subsumierten Probleme. Denn ihre Informationsbedarfe und -bereitstellungen weisen inhaltliche Unterschiede auf, aus denen wiederum unterschiedliche Anforderungen an die formale Qualität resultieren. Im Vergleich zu den oberen Hierarchieebenen verfügen Subsysteme der unteren Hierarchieebenen über mehr Detailwissen bezüglich ihres konkreten Arbeitsumfeldes, gleichzeitig jedoch über weniger Überblickswissen, das ihnen die Einordnung einer an sie delegierten Entscheidung in den Gesamtzusammenhang der nächsthöheren Subsystemebene und letztlich der Unternehmung als Ganzen ermöglicht. Um eine hohe Qualität der delegierten Entscheidungen im Sinne einer Ausrichtung auf das Gesamtoptimum und der Vermeidung teiloptimaler Lösungen, zu gewährleisten, müssen die Gestaltungsaktivitäten des Informationsmanagements verstärkt darauf ausgerichtet werden, den Subsystemen der unteren Hierarchieebenen das notwendige Überblickswissen zur Verfügung zu stellen. Während die Gefahr einer 'Informationsarmut im Datenüberfluß' sich auf den oberen Hierarchieebenen vor allem auf Detailwissen aus den ihnen untergeordneten Subsystemen bezieht, betrifft sie auf den unteren Hierarchieebenen das Überblickswissen. Da die Anforderungen eines Subsystems an die formale Qualität der benötigten Informationen tendenziell um so höher sind, je weniger ihm deren Inhalte vertraut sind, d.h. je weniger sie in einem unmittelbaren Zusammenhang mit seinem Kernarbeitsbereich stehen, ${ }^{79}$ sind die Anforderungen an die formale Qualität dieser Überblicksinformationen auf den unteren Hierarchieebenen stärker ausgeprägt als auf den oberen.

Es wird deutlich, daß die oben vorgeschlagene 'Entstandardisierung' der Inhalte der informationelle Beziehungen nicht ausreicht, um die mit den organisatorisch bedingten Ausprägungen der Informationsbedarfe und -bereitstellungen einhergehenden Herausforderungen an das Informationsmanagement zu bewältigen. Denn aus dieser Gestal- 
tungsmöglichkeit des Informationsmanagement resultiert als Folgeproblem die Ausdehnung der 'Informationsarmut im Datenüberfluß' auf die unteren Hierarchieebenen der Unternehmung. Deshalb werden im folgenden weitere Gestaltungsoptionen für das Informationsmanagement aufgezeigt, die dieses Folgeproblem mildern können.

Eine Möglichkeit, um einerseits den aus dem geringen Bestimmtheitsgrad der Informationsbedarfe und -bereitstellungen der Subsysteme resultierenden Problemen, andererseits dem Problem der 'Informationsarmut im Datenüberfluß' im Rahmen der Gestaltungsaktivitäten des Informationsmanagements $\mathrm{zu}$ begegnen, besteht in einem grundlegenden Perspektivenwechsel des Informationsmanagements. An die Stelle einer eher statischen Sicht auf Informationsbedarfe und -bereitstellungen, die darauf abzielt, den in einem bestimmten Zeitpunkt formulierten Informationsbedarfen eine entsprechende Bedarfsdeckung gegenüberzustellen, tritt eine dynamische Perspektive. Diese geht bei der Gestaltung der informationellen Beziehungen davon aus, daß Informationsbedarfe und -bereitstellungen sich im Zeitverlauf verändern. An die Stelle des Bestrebens, im Rahmen der Gestaltung der informationellen Beziehungen bestimmte, einmal definierte Informationsbedarfe geeignet zu decken, tritt die Überzeugung: 'Das Informationssystem ist nie fertig'. Die häufige Anpassung der informationellen Beziehungen an die tatsächlichen Informationsbedarfe reduziert zwar die Gefahr der mangelnden Übereinstimmung von Informationsbedarfen und Bedarfsdeckungen und damit die 'Informationsarmut im Datenüberfluß', das ständige Neugestalten der informationellen Beziehungen geht jedoch tendenziell mit einer Überforderung des Informationsmanagements einher. Deshalb muß der Fokus der Gestaltungsaktivitäten des Informationsmanagements sich weg von der Gestaltung faktischer informationeller Beziehungen hin zur Schaffung von Potentialen für ex ante inhaltlich nicht determinierte informationelle Beziehungen verschieben.

Eine weitere Möglichkeit, um das Problem der 'Informationsarmut im Datenüberfluß' durch gezielte Gestaltungsaktivitäten des Informationsmanagements zu verringern, besteht darin, formale Standards für die Ausgestaltung der informationellen Beziehungen vorzugeben. Während bezüglich der konkreten Inhalte auf Vorgaben verzichtet wird, erfolgt eine Standardisierung der verwendeten Begriffe und der formalen Aufbereitung der Informationen. Für die Kostenrechnung bedeutet das z.B. eine Vereinheitlichung der inhaltlichen Abgrenzung der verschiedenen Deckungsbeiträge oder der Umsätze, die mit oder ohne Mehrwertsteuer oder Rabatte und andere Erlösminderungen ausgewiesen werden können. Eine erhöhte Transparenz der verwendeten Begriffe und eine höhere Allgemeinverständlichkeit der Informationen aufgrund einer einheitlichen formalen Aufbereitung erleichtert dem einzelnen Subsystem die Verarbeitung einer großen Fülle von Informationen. Benötigte Informationen werden schneller als solche erkannt und können leichter ausgewertet werden.

Aus dem Umstand, daß die extern zu deckenden Informationsbedarfe der (selbstorganisierenden) Subsysteme auf den unteren Hierarchieebenen vor allem Über- 
blickswissen umfassen, folgt für das Informationsmanagement, daß die formalen Standards für dessen Darstellung an den Bedürfnissen dieses Empfängerkreises ausgerichtet sein müssen. Letztlich wird damit die traditionelle Perspektive des Informationsmanagements, die vor allem die Verdichtung von Detailinformationen für die oberen Hierarchieebenen (bottom up) betriff, um eine grundlegend neue 'top-down-Perspektive' erweitert. Diese stellt auf die Informationsversorgung der unteren Hierarchieebenen ab und rückt die Bereitstellung geeignet aufbereiteter Überblicksinformationen für diese in den Mittelpunkt. Die Versorgung unterer Hierarchieebenen mit Überblickswissen setzt auf den oberen Hierarchieebenen die Bereitschaft voraus, dieses Wissen mitzuteilen. Da Wissensvorsprünge häufig als Machtvorsprünge genutzt werden, geht die Umsetzung einer veränderten Perspektive bei der Informationsversorgung hier mit grundlegenden Veränderungen der Unternehmungskultur und insbesondere des Selbstverständnisses der Führungskräfte einher. Die diesbezüglichen Gestaltungsmöglichkeiten des Informationsmanagements setzen somit in einem ersten Schritt entsprechende Überzeugungsarbeit voraus. Erst in einem zweiten Schritt sind sodann Fragen wie die geeignete formale Aufbereitung, das Sicherstellen der Allgemeinverständlichkeit der Informationen sowie das komplexe Problem der Gewährung bzw. Verweigerung von Zugriffsberechtigungen zu klären.

Faßt man die aufgeführten Gestaltungsmöglichkeiten des Informationsmanagements bezüglich des Inhalts der informationellen Beziehungen zusammen, so sind diese durch zwei zentrale Perspektivenwechsel geprägt: Erstens gilt es, im Rahmen einer dynamischen Sichtweise auf die informationellen Beziehungen in der Unternehmung bei jeder Gestaltungsaktivität zu berücksichtigen, daß das Informationssystem nie fertig ist. An die Stelle der Zementierung bestimmter, inhaltlich determinierter informationeller Beziehungen für einen längeren Zeitraum tritt die Schaffung von Potentialen für ex ante inhaltlich nicht determinierte informationelle Beziehungen. Die 'Entstandardisierung' der konkreten Inhalte in Verbindung mit einer formalen Standardisierung erweist sich dabei als geeignete Gestaltungsmaßnahme. Zweitens tritt die Informationsversorgung der unteren Hierarchieebenen, die vor allem auf geeignet aufbereitetes Überblickswissen abstellt, neben die Informationsversorgung der oberen Hierarchieebenen. Insgesamt ist jedoch davon auszugehen, daß die genannten Maßnahmen nicht ausreichen, um das aus der 'Entstandardisierung' der Inhalte resultierende Folgeproblem der 'Informationsarmut im Datenüberfluß' auf den unteren Hierarchieebenen zu bewältigen. Denn trotz hoher Anforderungen an die formale Aufbereitung der Informationen belastet das Trennen notwendiger Informationen von nicht benötigten Daten die Verarbeitungskapazität der einzelnen Aufgabenträger. Deshalb sind über diese Gestaltungsmöglichkeiten bezüglich des Informationsinhalts hinausreichende Aktivitäten des Informationsmanagements notwendig.

Betrachtet man in einem weiteren Schritt die Gestaltungsmöglichkeiten des Informationsmanagements bezüglich des Informationszeitpunktes als Dimension der informationellen Beziehungen, so gilt es wiederum, den hohen inhaltlichen Umfang und den 
geringen Bestimmtheit der Informationsbedarfe und -bereitstellungen als Rahmenbedingungen zu berücksichtigen. Denn aus diesen resultieren hohe Anforderungen an die Gestaltung der Anzahl der informationellen Beziehungen sowie ihre inhaltliche Breite. Der mit den oben beschriebenen diesbezüglichen Gestaltungsaktivitäten des Informationsmanagements verbundenen Gefahr der Verschärfung des Problems der 'Informationsarmut im Datenüberfluß' kann das Informationsmanagement dadurch begegnen, daß es den Zeitpunkt der Informationsbedarfsdeckung durch entsprechende informationelle Beziehungen am Holprinzip ausrichtet, d.h. der potentielle Empfänger der Information entscheidet über den Zeitpunkt der informationellen Beziehung. Die Orientierung am Holprinzip bietet vor allem bei einem geringen Bestimmtheitsgrad des Informationsbedarfes eines Subsystems den Vorteil, daß die Mitglieder des Subsystems im konkreten Einzelfall selbständig entscheiden, ob und welche Informationen sie benötigen. An die Stelle einer standardisierten Bedarfsdeckung in Form einer regelmäBigen Bereitstellung bestimmter Informationen durch den Sender im Rahmen ex ante definierter informationeller Beziehungen treten am konkreten Bedarf ausgerichtete spontane informationelle Beziehungen. Dies führt zu einer Verringerung der Gefahr einer Datenüberflutung. Zugleich ist die Deckung eines Informationsbedarfs jedoch um so eher mit Problemen verbunden, je weniger vorhersehbar sein Auftreten ist. Denn wenn der Informationsbedarf nicht vorhersehbar ist, können im voraus auch keine Aussagen darüber getroffen werden, ob und durch welches Subsystem dieser Informationsbedarf gedeckt werden kann. Die Aktivitäten des Informationsmanagements müssen deshalb einerseits darauf abzielen, dem Informationsempfänger das Aufspüren eines geeigneten Senders zu erleichtern, andererseits die geeignete Informationsbereitstellung durch den Sender sicherstellen. Da die Gestaltungsaktivitäten des Informationsmanagements bezüglich des Zeitpunktes der informationellen Beziehungen keine geeignete Lösung dieser Anforderungen ermöglichen, gilt es im folgenden, die diesbezüglichen Gestaltungsmöglichkeiten bezüglich der verbleibenden Dimensionen der informationellen Beziehungen zu prüfen.

Betrachtet man in einem weiteren Schritt die Gestaltungsmöglichkeiten des Informationsmanagements bezüglich der Informationsform als Dimension der informationellen Beziehungen, so besteht hier ein indirekter Zusammenhang mit dem hohen inhaltlichen Umfang und der geringen Bestimmtheit der Informationsbedarfe und -bereitstellungen. Diese lassen es nämlich wie oben beschrieben sinnvoll erscheinen, im Rahmen der Gestaltungsaktivitäten des Informationsmanagements eine hohe Anzahl informationeller Beziehungen zu ermöglichen. Um die damit einhergehende Gefahr der potentiellen Überlastung der menschlichen Informationsverarbeiter zu reduzieren, kann das Informationsmanagement im Rahmen der Gestaltung der Informationsform verstärkt direkte Informationsbeziehungen durch indirekte ersetzen. Dies geschieht durch das Einfügen eines Mittlers zwischen Sender und Empfänger. Bei diesem Mittler handelt es sich um einen unternehmungsweiten Informationspool. Dieser beinhaltet Meta-Informationen, d.h. Informationen darüber, durch wen in der Unternehmung welche Informationen 
bereitgestellt werden. An die Stelle der einstufigen Beziehung zwischen Sender und Empfänger tritt eine zweistufige Beziehung: In einem ersten Schritt formuliert ein Subsystem seinen Informationsbedarf gegenüber dem Informationspool und erhält von diesem Meta-Informationen darüber, durch wen dieser Informationsbedarf gedeckt werden kann. Erst in einem zweiten Schritt wendet es sich dann direkt an das die Informationen bereitstellende Subsystem. Das Einrichten des Informationspools dient somit dazu, die Transparenz der Informationsbereitstellung zu erhöhen. Es führt nicht nur dazu, daß der Extremfall, für einen bestimmten Informationsbedarf keinerlei Bedarfsdeckung zu finden, deutlich seltener auftritt, sondern reduziert regelmäßig die Suchkosten. Denn an die Stelle u.U. mehrerer vergeblicher informationeller Beziehungen mit einer Vielzahl potentieller Sender tritt - unter Zwischenschaltung des Informationspools - eine einzige zweistufige informationelle Beziehung zwischen Empfänger und Sender. Grundsätzlich handelt es sich bei dem Informationspool und der damit einhergehenden strukturellen Entkoppelung von Sender und Empfänger um eine Gestaltungsmöglichkeit des Informationsmanagements, die den oben geforderten Perspektivenwechsel weg von einer Zementierung bestimmter informationeller Beziehungen hin zur Schaffung von Potentialen für ex ante inhaltlich nicht determinierte informationelle Beziehungen umsetzt.

Eine Variationsmöglichkeit bei der institutionellen Umsetzung der mit der Einrichtung eines unternehmungsweiten Informationspools verbundenen Grundidee der strukturellen Entkoppelung von Sender und Empfänger besteht darin, daß der Informationspool nicht Meta-Informationen über den Ort der Bereitstellung bestimmter Informationen, sondern diese Informationen selbst beinhaltet. Aufgrund der enormen Menge und Vielfalt der in der Unternehmung verfügbaren Informationen erscheint ein solcher Ansatz heute jedoch lediglich bei einer Beschränkung auf bestimmte Teilbereiche, wie z.B. Informationen für Analysezwecke, wie sie im Rahmen eines Data-Warehouse vorgehalten werden, als realistische Gestaltungsoption.

Damit der Informationspool seine Transparenzfunktion erfüllen kann, muß gewährleistet sein, daß sämtliche Subsysteme in der Unternehmung tatsächlich systematisch MetaInformationen über alle Informationen, die sie bereitstellen, in den Informationspool einstellen. Dies ist umso mehr von Bedeutung, je geringer der Bestimmtheitsgrad der Informationsbereitstellungen durch die Subsysteme ist bzw. je stärker deren Informationsbereitstellungen im Zeitverlauf variieren. Da das Bereitstellen der Meta-Informationen in der Regel eine völlig neuartige Teilaufgabe für die Subsysteme darstellt, muß diesen im Rahmen von Schulungen eine geeignete Methodik für die Bereitstellung der Meta-Informationen vermittelt werden, und es müssen formale Standards geschaffen werden, um einerseits das Einfügen der einzelnen Meta-Information in den Informationspool, andererseits den Zugriff auf den Informationspool zu erleichtern. Darüber hinaus muß aber auch ein geeignetes Anreiz- bzw. Sanktionssystem geschaffen werden, das gewährleistet, daß die einzelnen Subsysteme ihrer Informationsbereitstellungsfunktion gegenüber dem Informationspool auch tatsächlich nachkommen. Denn eine Überprüfung der bereitgestellten Informationen auf Vollständigkeit ist letztlich nicht möglich, da 
die Kontrolleinheit ja gerade nicht den tatsächlichen Umfang der in der Unternehmung vorhandenen Informationen kennt und somit über keine Referenzgröße verfügt, mit der sie die tatsächlich bereitgestellten Informationen abgleichen kann. Auch würde der enorme Umfang der unternehmungsweiten Informationssammlung einerseits und der geringe Bestimmtheitsgrad der in den einzelnen Subsystemen bereitgestellten Informationen andererseits eine über Stichproben hinausreichende Kontrolle unter Wirtschaftlichkeitsgesichtspunkten nicht vertretbar erscheinen lassen. Vielmehr muß durch geeignete Maßnahmen gewährleistet werden, daß die mit der Bereitstellung der MetaInformationen verbundenen Kosten des einzelnen Subsystems mit einem entsprechenden Nutzen für das Subsystem einhergehen, so daß sich der Beitrag zum Informationspool aus der Sicht des einzelnen Subsystems letztlich 'lohnt'.

Eine wichtige Gestaltungsmöglichkeit des Informationsmanagements zur Gewährleistung der Bereitstellung von Meta-Informationen durch die Subsysteme betrifft die Informationsrichtung als die letzte der hier zu untersuchenden Dimensionen der informationellen Beziehungen. Die Gesamtheit der informationellen Beziehungen eines Subsystems, die über den Informationspool abgewickelt werden, muß sowohl solche umfassen, innerhalb derer das Subsystem Meta-Informationen für potentielle Empfänger bereitstellt, als auch solche, über die es Meta-Informationen über von anderen Sendern bereitgestellte Informationen zur Deckung seiner spezifischen Informationsbedarfe erhält. Diese Wechselseitigkeit der informationellen Beziehungen trägt dazu bei, den Nutzen des Informationspools für das einzelne Subsystem erlebbar zu machen und damit einen Anreiz zu schaffen, durch die systematische Bereitstellung von MetaInformationen über die durch das Subsystem bereitgestellten Informationen zu dessen Funktionsfähigkeit beizutragen.

Es sei hier darauf hingewiesen, daß der Umstand, daß das Informationsmanagement die Informationsversorgung in der Unternehmung verstärkt am Holprinzip ausrichtet und einen zentralen Informationspool schafft, keinesfalls mit einem generellen Verzicht auf direkte informationelle Beziehungen zwischen Sender und Empfänger einhergeht. Vielmehr ist für jeden spezifischen Einzelfall zu prüfen, ob eine direkte oder eine indirekte, zweistufige Informationsbeziehung unter Zwischenschaltung des Informationspools sinnvoll ist.

Die Ausführungen in Abschnitt 5.2.1.5 der vorliegenden Arbeit haben gezeigt, daß zwar einerseits die mit einer Förderung von Selbstorganisationsprozessen als Prozessen organisationalen Lernens verbundenen Ausprägungen der organisatorischen Regeln tendenziell $\mathrm{zu}$ einem hohen $\mathrm{Ma}$ an Informationsautarkie des betroffenen Subsystems führen, zugleich jedoch der daraus resultierende hohe inhaltliche Umfang sowie der geringe Bestimmtheitsgrad ihrer Informationsbedarfe und -bereitstellungen negative Auswirkungen auf die Informationsautarkie haben. Dieser indirekte Effekt erweist sich deshalb als problematisch, weil eine geringe Informationsautarkie tendenziell mit einer geringen Informationsautonomie einhergeht, die wiederum eine Teilausprägung der in 
Kapitel 4 geforderten relativen Autonomie ist. Da die Gestaltungsempfehlungen der vorliegenden Arbeit auf die Förderung von Selbstorganisationsprozessen als Prozessen organisationalen Lernens abstellen, muß es jedoch Ziel der hier untersuchten Gestaltungsaktivitäten des Informationsmanagements sein, die relative Autonomie eines Subsystems im allgemeinen und seine Informationsautonomie im besonderen zu fördern. Die mit der Schaffung des oben beschriebenen unternehmungsweiten Informationspools in Kombination mit einer Verteilung der Informationen nach dem Holprinzip einhergehende strukturelle Entkoppelung von Sender und Empfänger bedeutet, daß der Empfänger trotz des Auseinanderfallens seines Informationsbedarfs mit dem Ort der Informationsbedarfsdeckung bei der Gestaltung seiner informationellen Beziehungen vergleichsweise unabhängig ist. Somit ist seine Informationsautarkie zwar gering, seine Informationsautonomie jedoch dennoch hoch. Denn der Sender ist - sieht man von eventuellen Zugriffsberechtigungen ab - zur Weitergabe der von ihm bereitgestellten Informationen verpflichtet, aufgrund der Existenz des Informationspools ist sichergestellt, daß der Empfänger den Ort der potentiellen Deckung seines Informationsbedarfs lokalisieren kann, und schließlich ist durch das Holprinzip gewährleistet, daß der Aufbau der informationellen Beziehung auf die Initiative des potentiellen Empfängers hin erfolgt. Somit stellt die Förderung des Holprinzips in Kombination mit dem Einrichten eines Informationspools eine Gestaltungsalternative des Informationsmanagements dar, die mit einer Stärkung der Informationsautonomie einhergeht.

Abschließend sei hier auf die Dringlichkeit der Informationsbedarfe und -bereitstellungen als Restgröße der Analyse verwiesen, die neben inhaltlichem Umfang und Bestimmtheitsgrad eine für die Gestaltung des Zeitpunktes der informationellen Beziehungen relevante Rahmenbedingung darstellt. Überall dort, wo ein systematischer Zusammenhang zwischen den Ausprägungen der organisatorischen Regeln und der Dringlichkeit der Informationsbedarfe und -bereitstellungen angenommen werden kann, folgt daraus eine vergleichsweise geringe Dringlichkeit der Informationsbedarfe und -bereitstellungen in den Subsystemen, in denen das Auftreten von Selbstorganisationsprozessen als Prozessen organisationalen Lernens gefördert werden soll. Ginge man von einem strengen Determinismus zwischen organisatorischen Regeln und Informationsstruktur aus, so müßte daraus gefolgert werden, daß dem Aspekt der Schnelligkeit bei der Gestaltung der informationellen Beziehungen hier deshalb nur eine geringe Bedeutung zukommt. Diese Konsequenz steht in unmittelbarem Widerspruch zu den Erfahrungen der betrieblichen Praxis, gemäß derer die zeitnahe Verfügbarkeit von Informationen heute unverändert eines der zentralen Probleme der Gestaltung der Informationsstruktur darstellt. Der Widerspruch zwischen organisatorisch determinierter Anforderung und praktischer Gestaltungserfahrungen erklärt sich daraus, daß die Dringlichkeit der Informationsbedarfe und -bereitstellungen vor allem situativ bedingt ist, d.h. entscheidend durch die spezifischen Gegebenheiten des Leistungserstellungsprozesses, wie z.B. den Zeitpunkt der Entscheidung, deren Vorbereitung bestimmte Informationen dienen, geprägt wird. Die organisatorischen Regeln wirken hier lediglich ergänzend, 
stellen jedoch nicht den zentralen Einflußfaktor dar. Für das Informationsmanagement bedeutet das, daß der Dringlichkeit der Informationsbedarfe und -bereitstellungen bzw. dem Zeitpunkt der informationellen Beziehung bei der Gestaltung der informationellen Beziehungen keinesfalls weniger Bedeutung zugemessen werden darf. Der mit der Annahme eines deterministischen Zusammenhangs zwischen organisatorischen Regeln und Informationsstruktur einhergehende Verzicht auf einen eigenständigen Gestaltungsspielraum des Informationsmanagements würde hier u.U. zu schwerwiegenden Fehlentscheidungen bei der Gestaltung der informationellen Beziehungen führen. Da davon auszugehen ist, daß der Einfluß situativer Faktoren, die hier jedoch nicht näher untersucht werden, auf den Zeitpunkt der informationellen Beziehungen in der Regel den Einfluß der organisatorisch bedingten Ausprägungen der Dringlichkeit von Informationsbedarfen und -bereitstellungen überkompensiert, findet deren Einfluß auf den Zeitpunkt der informationellen Beziehungen im Rahmen der vorliegenden Ausführungen keine Berücksichtigung.

Faßt man die Ausführungen zu potentiellen Gestaltungsmöglichkeiten des Informationsmanagements unter Berücksichtigung der organisatorisch bedingten Rahmenbedingungen zusammen, so ergeben sich die in Abbildung 5/12 formulierten drei zentralen Gestaltungsempfehlungen, die entsprechend auch im Mittelpunkt der Ausführungen zur Gestaltung der Informationstechnik im folgenden Abschnitt 5.3 stehen.

O Die Fokussierung der Informationsversorgung der unteren Hierarchieebenen muß als zusätzliche 'top-down-Perspektive' neben die Informationsversorgung der oberen Hierarchieebenen treten.

O Die Informationsversorgung ist verstärkt am Holprinzip auszurichten.

O Ein unternehmungsweiter Informationspool ist einzurichten.

Abb. 5/12: Zentrale Gestaltungsempfehlungen für die immaterielle Ebene des computergestützten Informationssystems

\subsection{Die Gestaltung der materiellen Ebene des computer- gestützten Informationssystems in der lernenden Unternehmung}

Grundsätzlich kann das computergestützte Informationssystem als Gestaltungsobjekt des Informationsmanagements in eine immaterielle Ebene, die Gegenstand der Ausführungen in Abschnitt 5.2 war, und eine materielle Ebene, die im folgenden behandelt wird, unterschieden werden. In Abschnitt 5.2 wurde in einem ersten Schritt aufgezeigt, 
welche Konsequenzen die in Abschnitt 4.2 beschriebenen Ausprägungen der organisatorischen Regeln auf die verschiedenen Dimensionen der Informationsbedarfe und -bereitstellungen der menschlichen Informationsverarbeiter haben. Sodann wurde in einem zweiten Schritt untersucht, welche Möglichkeiten das Informationsmanagement hat, um im Rahmen der Gestaltung der verschiedenen Dimensionen der informationellen Beziehungen zwischen den menschlichen Informationsverarbeitern sicherzustellen, daß sowohl den formulierten Informationsbedarfen eine entsprechende Bedarfsdeckung gegenübersteht als auch daß die bereitgestellten Informationen tatsächlich verwendet werden. Dabei zielt es letztlich darauf ab, die Informationsautonomie als einen Teilaspekt der relativen Autonomie derjenigen Subsysteme der Unternehmung, innerhalb derer die Wahrscheinlichkeit für das Auftreten von Selbstorganisationsprozessen erhöht werden soll, zu fördern. Im folgenden wird aufgezeigt, wie auf der materiellen Ebene des Informationsmanagements in der lernenden Unternehmung die Informationstechnik gestaltet werden kann. Im Mittelpunkt der Argumentation steht dabei die informationstechnische Umsetzung der in Abschnitt 5.2.2 entwickelten Gestaltungsempfehlungen für die Informationsstruktur, denen zufolge erstens die Informationsversorgung der unteren Hierarchieebenen als zusätzliche Perspektive neben die der oberen Hierarchieebenen gestellt werden soll. Zweitens ist die Informationsversorgung verstärkt am Holprinzip auszurichten und drittens ist ein unternehmungsweiter Informationspool zu schaffen. Darüber hinaus werden einerseits aber auch die in Abschnitt 5.2.1 aufgezeigten Ausprägungen der Dimensionen der Informationsbedarfe und -bereitstellungen direkt in die Argumentation einbezogen. Andererseits wird unmittelbar auf die mit bestimmten informationstechnischen Gestaltungsoptionen verbundene Informationsautonomie der Subsysteme der Unternehmung Bezug genommen, deren Erhöhung das Auftreten von Selbstorganisationsprozessen als Prozessen organisationalen Lernens fördert. Die Ausführungen gliedern sich nach den Dimensionen der Informationstechnik in solche zu Daten (Abschnitt 5.3.1), Netz (Abschnitt 5.3.2), Anwendungsprogrammen (Abschnitt 5.3.3) und Rechnern (Abschnitt 5.3.4). Abschnitt 5.3.5 faßt abschließend diese auf die materielle Ebene des computergestützten Informationssystems bezogenen Gestaltungsempfehlungen an das Informationsmanagement zusammen.

\subsubsection{Daten}

Betrachtet man die in Abbildung 5/12 genannten drei zentralen Gestaltungsempfehlungen für die immaterielle Ebene des Informationsmanagements, so kann ein unmittelbarer Zusammenhang zwischen dem dort geforderten Informationspool und den Daten als einer Dimension der Informationstechnik hergestellt werden. Denn das Einrichten eines unternehmungsweiten Informationspools macht - unabhängig davon, ob er die Gesamtheit der in der Unternehmung vorhandenen Informationen selbst oder lediglich Metainformationen über diese umfaßt - aufgrund der im Normalfall zu bewältigenden extrem großen Volumina regelmäßig eine informationstechnische Unterstützung unab- 
dingbar. Entsprechend muß es sich bei den dort vorgehaltenen Informationen stets auch um Daten handeln. Der Informationspool muß ein Datenpool sein. ${ }^{80}$

In der betrieblichen Praxis existiert regelmäßig eine Vielzahl unterschiedlicher technischer Systeme zur Speicherung und Verwaltung von Daten nebeneinander. Beispielhaft sei hier auf Datenbanksysteme, Hypertextsysteme, wissensbasierte Systeme und Dokumentenverwaltungssysteme verwiesen. Jede dieser Systemarten stellt auf die spezifischen Erfordernisse der Speicherung und Verwaltung bestimmter Datenarten (z.B. numerische Daten, Grafiken, Volltextdokumente) oder aber auf spezifische Erfordernisse der auf diese Daten zugreifenden Anwendungsprogramme ab. Bei der Entwicklung dieser Systeme wird angestrebt, eine für die jeweilige Datenart bzw. das Anwendungsproblem (möglichst) optimale Lösung zu realisieren. Sieht man von Einzelfällen $a b$, unterbleibt zumeist eine systematische Verknüpfung dieser verschiedenen Teiloptima. Auch multimediale Systeme verbinden zwar verschiedene Datenarten, die Integration bezieht sich jedoch in der Regel auf die Unterstützung einer bestimmten Anwendungsproblematik und stellt deshalb ebenfalls lediglich ein Teiloptimum dar. Als weiteres Beispiel sei hier auf ein Projektmanagementsystem verwiesen. Dieses enthält Ist-Daten über den Verlauf eines spezifischen Projektes, die nicht nur für die Steuerung dieses einen Projektes, sondern auch für die Planung von Projekten durch andere Projektteams von Relevanz sind, diesen in der Regel jedoch nicht zugänglich sind. Das Einrichten eines unternehmungsweiten Datenpools würde dagegen bedeuten, daß entweder sämtliche in der Unternehmung verfügbaren Daten (der verschiedenen Datenarten) selbst oder Metadaten über diese Primärdaten zusammengefaßt werden. Im folgenden werden mit dem Data Warehouse (Abschnitt 5.3.1.1) und dem Knowledge Warehouse (Abschnitt 5.3.1.2) zwei alternative Gestaltungsoptionen für die Umsetzung eines solchen Datenpools vorgestellt.

\subsubsection{Das Data Warehouse}

Die Transaktionsdaten bzw. operativen Daten ${ }^{81}$ als eine Teilmenge der Gesamtheit der in der Unternehmung verarbeiteten Daten werden heute regelmäßig in - zumeist relationalen - Datenbanksystemen gespeichert und verwaltet. In diesen Systemen steht die Abwicklung der operativen Geschäftstätigkeit und das damit einhergehende On-line Transaction Processing (OLTP) als das häufige und schnelle Speichern und Verändern kleiner Datenmengen im Vordergrund. ${ }^{82}$ Dabei ist die betriebliche Praxis regelmäßig von einem Nebeneinander mehrerer operativer Datenbanksysteme ${ }^{83}$ geprägt. Während

80 Für die Abgrenzung der Begriffe Information und Daten siehe Abschnitt 2.2.2.2.1 der vorliegenden Arbeit.

81 Im folgenden werden die Begriffe Transaktionsdaten und operative Daten synonym verwendet.

82 Vgl. Jahnke/Groffmann/Kruppa (1996), S. 321.

83 Im folgenden werden die Begriffe Transaktionsdatenbanksystem, operatives Datenbanksystem und OLTP-Datenbanksystem synonym verwendet. Die auf diese zugreifenden Anwendungsprogramme werden mit den Synonyma operative Anwendungsprogramme oder OLTP-Anwendungen bezeichnet. 
dies für die Abwicklung der operativen Geschäftstätigkeit in der Regel unproblematisch ist, da die operativen Datenbanksysteme ja gerade für eine anforderungsgerechte Abwicklung der betrieblichen Massendatenverarbeitung entwickelt wurden und entsprechend deren Anforderungen genügen, erweist es sich häufig dann als problematisch, wenn die operativen Daten als Basis für analytische Aktivitäten verwendet werden sollen. Als analytische Tätigkeiten werden hier all jene bezeichnet, die darauf abzielen, mit Hilfe der Auswertung von Daten Entscheidungen über zukünftiges Handeln vorzubereiten. Häufig werden dabei vergangenheitsbezogene Daten (insbesondere dort, wo Plan-Ist-Abweichungen analysiert werden) auf UrsacheWirkungs-Zusammenhänge zwischen verschiedenen Größen untersucht, die dann in Form von Ziel-Mittel-Aussagen als Grundlage für zukünftige Entscheidungen dienen. Die Verwendung operativer Datenbanksysteme für analytische Aktivitäten ist einerseits mit technischen, andererseits mit inhaltlichen Problemen verbunden.

Die technischen Probleme resultieren zum einen daraus, daß der Anwender u.U. auf eine Vielzahl heterogener technischer Einzellösungen zugreifen muß. Zum anderen sind die Datenbankstrukturen der operativen Datenbanksysteme für analytische Auswertungen nur sehr bedingt geeignet. Die analytischen Auswertungen, die teilweise sehr hohe Anforderungen an die Leistungsfähigkeit der Hard- und Software stellen, konkurrieren zudem mit den operativen Anwendungen um die knappen IT-Kapazitäten und können zu Störungen des operativen Betriebs führen. Inhaltliche Probleme treten dadurch auf, daß das Auffinden der benötigten Informationen in den enormen Datenvolumina der operativen Systeme aufgrund des fehlenden Überblicks die kognitiven Fähigkeiten der menschlichen Informationsverarbeiter überfordert. Diese Probleme verschärfen sich, sofern keine einheitlichen inhaltlichen Standards bezüglich der verwendeten Begriffe vorgegeben sind. So setzen unterschiedliche Begriffsverständnisse betriebswirtschaftlicher Kennzahlen, wie z.B. der Deckungsbeiträge, umfangreiche inhaltliche Abgrenzungsarbeiten voraus, um Fehlinterpretationen zu vermeiden. ${ }^{84}$

Mit der Entwicklung eines Data Warehouse zielt man darauf ab, die mit der Heterogenität der operativen Datenbanksysteme verbundenen oben geschilderten Probleme zu vermeiden. Unter einem Data Warehouse wird dabei hier ein spezielles Datenbanksystem verstanden, das die replizierten, transformierten und auf verschiedene Weise verdichteten operativen Daten der Unternehmung als Grundlage für darauf aufsetzende analytische Auswertungssysteme bereitstellt. Geht man davon aus, daß jedes Datenbanksystem aus Datenbank ${ }^{85}$, Datenbankverwaltungssystem sowie Datenbankkommunikationsschnittstelle als den drei Kernkomponenten besteht, ${ }^{86}$ so finden sich diese auch in einem Data Warehouse wieder.

84 Vgl. ähnlich Gluchowski (1997), S. 2; Erler/Schelp (1998), S. 20.

85 Die Begriffe Datenbasis und Datenbank werden im folgenden synononym verwendet.

86 Vgl. Gabriel/Röhrs (1995), S. 256ff. 
In der Datenbasis des Data Warehouse werden die replizierten operativen Daten der Unternehmung logisch zentral, einheitlich und konsistent vorgehalten. Diese Datenbasis des Data Warehouse ist thematisch gruppiert, gefiltert sowie nicht-volatil und besteht separat von den Primärdaten der operativen Systeme. ${ }^{87}$ Die dabei vorgenommene syntaktische und semantische Aufbereitung der operativen Daten führt zu einer Fülle von Metadaten, die in einer Metadatenbasis vorgehalten werden. Grundsätzlich ist zwar davon auszugehen, daß in jedem Datenbanksystem Metadaten anfallen (insbesondere setzt die Verwaltung der Daten durch das Datenbankverwaltungssystem solche Metadaten voraus), aufgrund des in der Unterstützung von Analysetätigkeiten begründeten Zwecks des Data Warehouse kommt den Metadaten in einem Data Warehouse jedoch im Vergleich zu operativen Datenbanksystemen eine ungleich höhere Bedeutung zu. Sie umfassen hier nicht nur eine Vielzahl von Metadaten über die Art und Weise der Verwaltung der Daten im Data Warehouse (also syntaktische und ausführliche semantische Beschreibungen der Daten, die für die potentiellen Benutzer von großer Bedeutung sind), sondern insbesondere auch Hinweise auf die Herkunft der Daten und den Datenextraktion-, -transformations- und -integrationsprozeß. Die Metadatenbasis wird deshalb in Abbildung 5/13 gesondert neben ${ }^{88}$ der Datenbasis, die die replizierten, transformierten und verdichteten operativen Daten enthält, ausgewiesen. ${ }^{89}$ Grundsätzlich ist offen, ob bei der praktischen Realisierung eines Data Warehouse Datenbasis und Metadatenbasis physisch voneinander getrennt werden oder ob die veränderten operativen Daten und die Metadaten gemeinsam in einer Datenbank vorgehalten werden. Für die weiteren Ausführungen ist dies jedoch unerheblich. Datenbasis und Metadatenbasis werden von einem Datenbankverwaltungssystem ${ }^{90}$ als einer weiteren Komponente des Data Warehouse verwaltet. Die Kommunikationsschnittstelle steuert schließlich die Kommunikation mit der Hardware und der Systemsoftware, den auf das Data Warehouse zugreifenden Analysetools sowie den Transformationsprogrammen.

Die Transformationsprogramme sind zwar selbst nicht Teil des Data Warehouse als eines Datenbanksystems, jedoch stellen sie eine wichtige Voraussetzung für dessen Existenz dar, da sie der Datengewinnung aus den unterschiedlichen OLTP-Datenbanksystemen dienen. Dabei ist nicht nur die reine Datenextraktion aus in syntaktischer und

87 Vgl. Chamoni/Gluchowski (1998), S. 13ff.; Inmon (1993), S. 29.

88 Aus Gründen der sprachlichen Vereinfachung wird die 'Datenbasis mit den weiterverarbeiteten operativen Daten' im folgenden lediglich als die 'Datenbasis' bezeichnet und der Metadatenbasis gegenubergestellt. Die Gegenubberstellung von Datenbasis und Metadatenbasis verweist somit nicht auf die Subsumtion des Spezialfalls der Metadatenbasis unter die Datenbasis.

89 Vgl. ähnlich Mucksch (1998), S. 134ff., der das Metadatenbanksystem als eigenstăndige Komponente des Data Warehouse neben die Data Warehouse-Datenbasis stellt. Geht man davon aus, daß ein Data Warehouse ein Datenbanksystem ist, so erweist sich jedoch als problematisch, daß bei den von Mucksch genannten Komponeten des Data Warehouse (Data Warehouse-Datenbank, Transformationsprogramme, Archivierungssystem und Metadatenbanksystem) ein Datenbankverwaltungssystem fehlt, so daß angenommen werden muß, daß das Datenbankverwaltungssystem des Metadatenbanksystems diese Funktionalităt nicht nur innerhalb des Metadatenbanksystems, sondern daruber hinaus fur das gesamte Data Warehouse übernimmt.

90 Grundsătzlich können Datenbasis und Metadatenbasis jedoch auch jeweils über ein eigenes Datenbankverwaltungssystem verwaltet werden. Für die weiteren Ausfuhrungen ist auch dies unerheblich. 
semantischer Hinsicht heterogenen Datenbeständen sicherzustellen, sondern auch deren Transformation im engeren Sinne, d.h. ihre Aufbereitung (auf syntaktischer und semantischer Ebene) und Aggregation, sowie der Import der Daten in die Datenbasis des Data Warehouse. ${ }^{91}$ Im Anschluß an das initiale Füllen werden periodisch Updates der Datenbasis des Data Warehouse vorgenommen. Diese periodischen Aktualisierungen sowie die Vielzahl der im Data Warehouse vorgenommenen unterschiedlichen Verdichtungen machen den Einsatz eines Archivierungssystems sowohl zu Datensicherungs- als auch zu Datenarchivierungszwecken notwendig. Das Archivierungssystem dient zur Wiederherstellung der Daten bei Programm- oder Systemfehlern sowie zur Auslagerung der unteren Detaillierungsebenen der historischen Daten (zwecks Performance-Steigerungen). Es stellt damit die Funktionsfähigkeit des Data Warehouse im Zeitverlauf sicher, wird hier jedoch nicht dem Data Warehouse als Datenbanksystem zugerechnet. ${ }^{92}$

Grundsätzlich kann man zwischen den in Abbildung 5/13 visualisierten drei Architekturvarianten eines virtuellen oder eines zentralen Data Warehouse sowie dezentraler Data Marts unterscheiden. ${ }^{93}$

Da die oben vorgenommene Definition des Data Warehouse die Replikation der operativen Primärdaten in einem separaten System voraussetzt, handelt es sich bei dem nur logischen Data Warehouse als der erstgenannten Architekturvariante streng genommen nicht um ein Data Warehouse. Darauf verweist auch die Bezeichnung virtuelles Data Warehouse. Denn hier existiert lediglich ein Metadatenbanksystem, das Metadaten über die Primärdaten der operativen Datenbanksysteme beinhaltet und damit eine logisch einheitliche Sicht der mit Hilfe diverser Analysetools auf die physisch heterogenen Datenbestände zugreifenden Anwender sicherstellt. Eine Replikation der Primärdaten erfolgt nicht. Dennoch sei die Architekturvariante des virtuellen Data Warehouse hier als Vorläufer des Data Warehouse und als einfachste Möglichkeit der Umsetzung des damit verbundenen zentralen Ziels, einen - hier allerdings nur logisch - einheitlichen Zugang zu den operativen Daten für Analysezwecke zu schaffen, angeführt. Denn durch das Zwischenschalten des Metadatenbanksystems 'sehen' die Benutzer - unabhängig von dem physischen Speicherort der operativen Daten - nur eine Datenquelle. Aufgrund der spezifischen Anforderungen der analytischen Auswertungssysteme an die Datenablage, die sich grundlegend von denen der OLTP-Anwendungen unterscheiden, erweist sich der Zugriff auf dieselben physischen Datenbestände jedoch als problematisch, weshalb

91 Vgl. Müller (1998), passim, insbesondere S. 2.

92 Zum Archivierungssystem vgl. Mucksch (1998), S. 133, der dieses dem Data Warehouse-Konzept zurechnet. Hier wird das bei der Rezeption der relevanten Literatur häufig zu beobachtende Problem deutlich, daß sorgfältig zwischen dem Data Warehouse als einem Datenbanksystem und dem Data Warehouse-Konzept als eines Konglomerats verschiedener Themen, die wiederum - wie von Chamoni/Gluchowski vorgeschlagen - unter den Oberbegriff der 'Analytischen Informationssysteme' subsumiert werden konnen, zu unterscheiden ist. Vgl. Chamoni/Gluchowski (1998), S. 5.

Vgl. Schinzer/Bange (1998), S. 43ff. 
man heute in der Regel eine Trennung der Datenbank des Data Warehouse von den OLTP-Datenbanken anstrebt. ${ }^{94}$

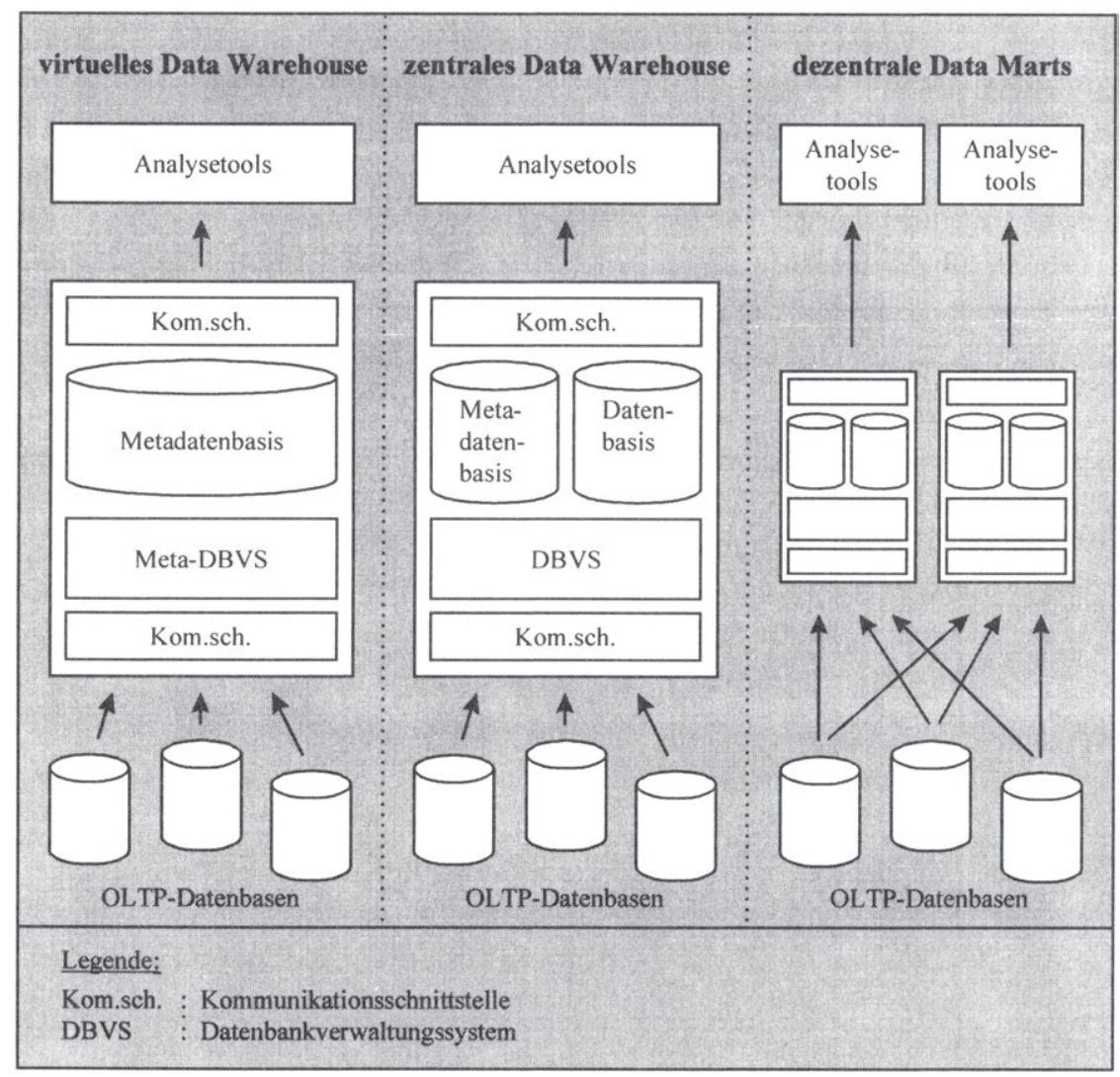

Abb. 5/13: Architekturvarianten für das Data Warehouse

Bei der zweiten Architekturvariante eines zentralen Data Warehouse wird physisch zwischen der Datenbank des Data Warehouse und den OLTP-Datenbanken getrennt. Das Data Warehouse stellt dabei nicht allein eine einfache Replizierung der operativen Primärdaten dar. Darüber hinaus werden dort Daten mit unterschiedlichen Datenformaten zusammengeführt, zur Vermeidung von potentiellen Inkonsistenzen gefiltert und geordnet. Die hier vorgenommenen Verknüpfungen zwischen den Daten unterscheiden sich in der Regel erheblich von denen der operativen Anwendungen, da im Rahmen von Analysetätigkeiten andere Aspekte, wie z.B. eine stärker zeitraumbezogene Sicht, insbesondere aber flexible Auswertungen bezüglich einer Vielzahl von Dimensionen (z.B. beim Umsatz nach Tag, Woche, Monat, Jahr, Kunde, Kundengruppe, Region, Produkt, 
Produktgruppe), im Vordergrund stehen. Zur Verbesserung der Abfragegeschwindigkeit erweist sich insbesondere eine redundante Datenhaltung häufig als sinnvoll. Die Daten des Data Warehouse können grundsätzlich sowohl in objektorientierten, relationalen, mehrdimensionalen als auch hierarchischen Datenbanksystemen vorgehalten werden. Aufgrund der mit dem Handling großer Datenvolumina verbundenen Performance-Probleme der eigens für die Umsetzung von Data Warehouse-Konzepten entwickelten mehrdimensionalen Datenbanksysteme werden heute in der Regel relationale Datenbanksysteme verwendet. ${ }^{95}$

Eine dritte Architekturvariante besteht darin, statt eines zentralen Data Warehouse mehrere dezentrale Data Marts einzurichten. Data Marts sind subjekt- oder abteilungsspezifische Data Warehouses und setzen sich entsprechend aus den gleichen Komponenten wie ein Data Warehouse zusammen. Ihre Vorteile bestehen - bei geeigneter Verteilung der Daten - vor allem in den geringeren Kosten aufgrund der geringeren Projektgröße, der Schnelligkeit des Zugriffs sowie der potentiell größeren Detailliertheit der Darstellung solcher Daten, die nur für bestimmte Personengruppen von Relevanz sind. Aufgrund dieser Vorteile bilden ein Data Mart oder mehrere dezentrale Data Marts heute in der betrieblichen Praxis regelmäßig den Ausgangspunkt für Umsetzungen des Data Warehouse-Konzeptes. Probleme können vor allem aus der Synchronisation zwischen operativen Primärdaten und Data Marts, aber auch aus der Abstimmung zwischen den einzelnen Data Marts resultieren. ${ }^{96}$

Untersucht man vor dem Hintergrund dieser kurzen Einführung in die Thematik des Data Warehouse nunmehr den Zusammenhang zwischen dieser auf die Daten bzw. die Datenverwaltung in der Unternehmung bezogenen technischen Lösung auf der einen und dem in Abschnitt 5.2.2 der vorliegenden Arbeit geforderten unternehmungsweiten Informationspool auf der anderen Seite, so wird deutlich, daß es sich hier in Abhängigkeit von der konkreten Ausgestaltung um eine geeignete Möglichkeit der technischen Umsetzung eines solchen Informations- bzw. Datenpools handelt. Das Data Warehouse bietet die Grundlage für darauf aufsetzende Analysetätigkeiten, die unter Anwendung unterschiedlichster Analysetools auf die Daten des Data Warehouse zugreifen und dabei - in Abhängigkeit von der konkreten Ausgestaltung des Analysetools - gemäß dem Holprinzip anstelle regelmäßig bereitgestellter Daten nur dann Daten nachfragen, wenn sie diese auch tatsächlich benötigen. ${ }^{97}$

Stellt man virtuelles und zentrales Data Warehouse sowie dezentrale Data Marts einander als drei Architekturvarianten gegenüber, so sind lediglich Data Marts als rein dezentrale Architektur für die hier verfolgten Gestaltungsziele nicht geeignet, da die Ausführungen der vorliegenden Arbeit auf die informationstechnische Umsetzung eines

\footnotetext{
Vgl. Hahne (1998), S. 104.

Vgl. Dittmar (1999), o.S.; Schinzer/Bange (1998), S. 45f.

97 Da es sich bei den Analysetools um eine Teilmenge der Anwendungsprogramme der Unternehmung handelt, wird die diesbezügliche Diskussion Abschnitt 5.3.3 der vorliegenden Arbeit zugeordnet.
} 
unternehmungsweiten Informationspools abstellen. Subsystemspezifische Data Marts wären bei einem geringen Bestimmtheitsgrad des Informationsbedarfs des Subsystems häufig eben nicht in der Lage, die Bedarfsdeckung zu gewährleisten. Eine rein dezentrale Architektur ist deshalb aus der hier verfolgten Perspektive nicht sinnvoll. Eine Kombination aus zentralem Data Warehouse und zusätzlichen dezentralen Data Marts ${ }^{98}$ steht den Gestaltungszielen der vorliegenden Arbeit dagegen nicht entgegen, da der gesamte Datenpool hier zentral verfügbar ist und die einzelnen Data Marts letztlich nur 'Abbild des Abbilds' sind. Kann der Informationsbedarf durch den spezifischen Data Mart des Subsystems nicht gedeckt werden, so besteht die Möglichkeit des Zugriffs auf das zentrale Data Warehouse. Damit steht eine solche kombinierte Lösung den hier verfolgten Gestaltungszielen zwar nicht entgegen, es erscheint jedoch fraglich, ob den mit der Einrichtung eines dezentralen Data Marts verbundenen Kosten bei einem geringen Bestimmtheitsgrad des Informationsbedarfs des Subsystems ein entsprechender Nutzen gegenübersteht.

Aufgrund des spezifischen Gestaltungsziels der vorliegenden Arbeit wird hier zentralen Lösungen mit oder ohne eigene, von den Transaktionssystemen getrennte Datenbasis der Vorzug gegeben. ${ }^{99}$ Bei einer hohen Unbestimmtheit der Informationsbedarfe und -bereitstellungen bieten diese eine logisch einheitliche Sicht auf die heterogenen Datenbestände der operativen Datenbanksysteme und ermöglichen den Zugriff auf und die Gewinnung von Analysedaten unter Abstraktion vom physischen Ort ihres Entstehens. Das Data Warehouse bedingt somit eine strukturelle Entkoppelung von Informationsbedarf und -bereitstellung. Das Auffinden benötigter Informationen bzw. der Abgleich zwischen dem Informationsbedarf eines Subsystems und den durch andere Subsysteme bereitgestellten Informationen wird wesentlich erleichtert. Die Informationsautonomie des Subsystems, das Analysedaten benötigt, ist vergleichsweise hoch, obwohl der Ort des Informationsbedarfs nicht mit dem der Bedarfsdeckung übereinstimmt und damit die Informationsautarkie eher gering ist. Beim virtuellen Data Warehouse erfolgt die Bedarfsdeckung durch die operativen Datenbasen, beim Data Warehouse mit eigener, separater Datenbasis erfolgt sie durch die Datenbasis des Data Warehouse.

Vergleicht man in einem nächsten Schritt ein nur logisches bzw. virtuelles Data Warehouse mit einer Lösung, bei der die Primärdaten repliziert und physisch getrennt von den operativen Systemen vorgehalten werden, so ist die Informationsautonomie sowohl des Subsystems, das Informationen benötigt, als auch des Subsystems, das Informationen bereitstellt, im Fall eines virtuellen Data Warehouse tendenziell geringer als bei der

99 Im folgenden wird zwischen den beiden Architekturvarianten eines virtuellen Data Warehouse 'ohne eigene Datenbasis' sowie einem Data Warehouse 'mit eigener, separater Datenbasis' unterschieden. Dabei handelt es sich um eine sprachliche Vereinfachung, da auch ein virtuelles Data Warehouse stets uber eine eigene Datenbasis verfugt. Diese Datenbasis beinhaltet jedoch nicht die Primärdaten der operativen Systeme und deren Verdichtungen, sondern lediglich Metadaten uber diese. Die gewăhlte sprachliche Vereinfachung erhőht jedoch die Lesbarkeit des Textes. 
physischen Replikation der Primärdaten. Denn das Subsystem, das Daten für Analysezwecke benötigt, greift im Falle eines virtuellen Data Warehouse physisch auf die operativen Datenbasen zu. Da der Zugriff nur lesend möglich ist und Daten in transformierter und aggregierter Form in den operativen Datenbanksystemen nicht vorgehalten werden, müssen die notwendigen Verdichtungen jeweils im Zeitpunkt des Bedarfs vorgenommen werden. Die u.U. sehr komplexen Queries können zu einer erheblichen Kapazitätsbelastung der operativen Systeme führen. Die Konkurrenz um knappe IT-Ressourcen führt hier zu einer geringeren relativen Autonomie sowohl des Informationen benötigenden als auch des diese bereitstellenden Subsystems als im Fall des physisch von den operativen Systemen getrennten Data Warehouse. Unter Verfolgung des Gestaltungsziels der vorliegenden Arbeit, die relative Autonomie der Subsysteme in der Unternehmung zu erhöhen, um die Wahrscheinlichkeit für das Auftreten von Selbstorganisationsprozessen als Prozessen organisationalen Lernens zu fördern, ist deshalb ein Data Warehouse mit eigener, separater Datenbasis einem virtuellen Data Warehouse (ohne eigene Datenbasis) gegenüber vorzuziehen.

Faßt man die oben genannten Argumente zusammen, so zielen Data Warehouse-Konzepte schwerpunktmäßig auf die Unterstützung von Analysetätigkeiten ab, die mit bestimmten Formen der Bearbeitung von Daten einhergehen, und stellen deshalb die geeignete Aufbereitung der Transaktionsdaten in den Mittelpunkt. Denn erstens stellen die OLTP-Anwendungen regelmäßig andere Anforderungen an die Verwaltung der Daten als Analysetools im allgemeinen und die heute verstärkt eingesetzten OLAPTools im besonderen, ${ }^{100}$ zweitens werden die Transaktionsdaten in einer Vielzahl unterschiedlicher operativer Datenbanksysteme vorgehalten, so daß übergreifende Analysen u.U. umfangreiche Anpassungen sowohl auf der syntaktischen als auch auf der semantischen Ebene notwendig machen. Als Grundlage für vielfältige, auf unterschiedliche Dimensionen abstellende Analysen enthält die Datenbasis des Data Warehouse drittens über die bloße Replikation der Transaktionsdaten hinaus zahlreiche Verdichtungen dieser Primärdaten. Aus diesen drei Gründen folgt, daß eine eigene, physisch von den operativen Datenbanken getrennte Datenbasis des Data Warehouse im Mittelpunkt des Data Warehouse-Konzeptes steht. Ein virtuelles Data Warehouse stellt regelmäßig nur die zweitbeste Lösung dar.

Data Warehouses können anhand ihres Adressatenkreises einerseits in solche, die die Unterstützung von Managemententscheidungen in den Mittelpunkt stellen, ${ }^{101}$ andererseits in solche, die auf breitere Nutzergruppen abzielen, ${ }^{102}$ unterschieden werden. Während das Data Warehouse häufig in der Tradition von Konzepten für Management Support Systems gesehen wird und auf die Bewältigung der damit einhergehenden tech-

100 Vgl. Chamoni (1998), S. 233ff.

101 Vgl. insbesondere die hăufig zitierte Definition von Inmon (1993), S. 29, der explizit auf die Unterstützung von Managemententscheidungen abstellt. Vgl. ferner z.B. Hahne/Schelp (1997), S. 1.

102 Vgl. z.B. Hansen (1996), S. 976f.; Mucksch (1998), S. 134. 
nischen und inhaltlichen Probleme bei der Analyse von großen Datenmengen abstellt, betonen andere Autoren, daß ein Data Warehouse der Entscheidungsunterstützung „,von Mitarbeitern aller Bereiche und Ebenen“ 103 in der Unternehmung dienen kann. Aus der Sicht der vorliegenden Arbeit, die die Informationsversorgung der unteren Hierarchieebenen als zusätzliche Perspektive neben die der oberen Hierarchieebenen stellt, sollte der Kreis der Nutzer eines Data Warehouse über das Management und hochspezialisierte Fachkräfte in den Stabsabteilungen hinaus ausgedehnt werden. Vielmehr sollte jeder Mitarbeiter potentieller Nutzer des Data Warehouse sein. Denn je höher das Ausmaß der Entscheidungsdelegation an die Subsysteme der unteren Hierarchieebenen ist, um damit das Auftreten von Selbstorganisationsprozessen als Prozessen organisationalen Lernens zu fördern, desto mehr Überblicksinformationen müssen deren Mitgliedern tendenziell zur Verfügung gestellt werden, um ihnen die Einordnung der zu treffenden Entscheidung in übergeordnete Zusammenhänge zu erleichtern. Der Zugriff auf ein unternehmungsweites Data Warehouse mittels geeigneter Analyse-Tools leistet einen wichtigen Beitrag zu Erlangung dieser Überblicksinformationen. Ein Data Warehouse für alle Mitarbeiter in der Unternehmung bedeutet jedoch nicht etwa, daß allen Mitarbeitern sämtliche Daten verfügbar gemacht werden. Vielmehr sind hier umfassende Konzepte zur Definition von Zugriffsrechten notwendig.

Wie eingangs erwähnt, handelt es sich bei den Daten der Transaktionsdatenbanken nur um eine Teilmenge der Gesamtheit der in der Unternehmung verfügbaren Daten, die wiederum lediglich eine Teilmenge des in der Unternehmung verfügbaren Wissens darstellen. Zwar werden verschiedentlich weitreichende Anforderungen an die Fähigkeit eines Data Warehouse gestellt, auch äußerst heterogene Datenarten verarbeiten zu können, so daß dieses prinzipiell über die operativen Daten hinaus auch andere Daten umfassen könnte. So fordern z.B. Gluchowski/GABRIEL/ChAmONI: „Es soll jede Art von Datenmaterial behandelt werden können, so z.B. strukturierte relationale Daten, unstrukturierte Texte, multidimensionale Daten oder Multimedia-Material wie Grafiken oder Daten in Ton- und Videoform."104 Als theoretisches Konzept stellt ein Data Warehouse also keineswegs allein auf die Transaktionsdaten ab. In der betrieblichen Praxis sind die bis heute realisierten Data Warehouses jedoch regelmäßig auf Transaktionsdaten bzw. deren Transformation und Aggregation beschränkt. Die auf den Daten des Data Warehouse aufsetzenden Analysetools haben zwar regelmäßig auch andere Datenarten zum Ergebnis (so transformieren sie z.B. numerische Daten in Grafiken), die Datenbasis des Data Warehouse ist jedoch auf Transaktionsdaten und deren Verdichtung beschränkt. Darüber hinaus werden Data Warehouses heute typischerweise für bestimmte betriebliche Funktionsbereiche wie das Controlling oder den Vertrieb (und hier insbesondere das Direkt-Marketing) eingerichtet, ${ }^{105}$ wobei die Grenze zu dezentralen

103 Hansen (1996), S. 976.

104 Gluchowski/Gabriel/Chamoni (1997), S. 267.

105 Vgl. Dittmar (1999), o.S. 
Data Marts häufig fließend ist. Die heute in der betrieblichen Praxis anzutreffenden Umsetzungen des Data Warehouse-Konzeptes stellen somit lediglich eine Teillösung bei der informationstechnischen Realisierung des hier postulierten unternehmungsweiten Informations- bzw. Datenpools dar. Im folgenden Abschnitt wird deshalb das Knowledge Warehouse als eine weitere informationstechnische Gestaltungsoption des Informationsmanagements vorgestellt.

\subsubsection{Das Knowledge Warehouse}

Jüngste Forschungsbestrebungen am Ende der 90er Jahre zielen auf die Entwicklung eines Knowledge Warehouse ab, das das Auffinden von Wissen innerhalb der Unternehmung und über diese hinaus erleichtern soll. ${ }^{106}$ Die derzeit verfügbaren Arbeiten gehen allerdings über erste konzeptionelle Überlegungen in einigen wenigen Veröffentlichungen im Internet nicht hinaus. ${ }^{107}$ Sie sind weit davon entfernt, ein in sich geschlossenes Knowledge Warehouse-Konzept anzubieten, sondern stellen stets nur Partialbetrachtungen dar. Deshalb werden im folgenden unter Berücksichtigung zentraler Aussagen dieser Ansätze im Hinblick auf das Gestaltungsinteresse der vorliegenden Arbeit Anforderungen an ein zu entwickelndes Knowledge Warehouse formuliert.

Einerseits handelt es sich beim Knowledge Warehouse um eine Weiterentwicklung des im Rahmen von Data Warehouse-Konzepten verfolgten grundsätzlichen Einsatzziels der Schaffung eines unternehmungsweiten Datenpools. Diese inhaltliche Nähe spiegelt sich auch in den verwendeten ähnlichen Begrifflichkeiten wider. Andererseits ist beim Knowledge Warehouse im Vergleich zum Data Warehouse jedoch eine Verschiebung der Perspektive zu beobachten, die im folgenden aufgezeigt wird.

Im Gegensatz zum Data Warehouse steht beim Knowledge Warehouse-Konzept nicht die Aufbereitung von Daten, sondern das Auffinden von Wissen ${ }^{108}$ in der Unternehmung und über diese hinaus im Mittelpunkt. Dem Knowledge Warehouse kommt somit eine umfassende Transparenzfunktion zu, die es nur dann erfüllen kann, wenn der Umfang des ausgewerteten Wissens hier über die Transaktionsdaten hinaus auf die Gesamtheit des in der Unternehmung verfügbaren Wissens und über die Grenzen der Unternehmung hinaus auch auf potentiell relevante Teile des unternehmungsextern

106 Vgl. Dataware Technologies (1999a), S. 11.

107 Einen guten Überblick uber die im Internet verfugbare Literatur zum Thema Knowledge Warehouse im Zusammenhang des Knowledge Management bietet die Linksammlung der 'Arbeitsgemeinschaft Wissensmanagement Kaiserslautern' unter http://www.cck.uni-kl.de/wmk/.

Dabei ist bezuglich des Knowledge Management im allgemeinen und des Knowledge Warehouse im besonderen die fur modische Schlagworte im IT-Bereich typische Entwicklung zu beobachten, daß Anbieter von IT-Produkten und -Dienstleistungen das aktuelle Schlagwort in der Hoffnung auf die damit verbundene absatzfordernde Wirkung für altbekannte Sachverhalte, wie z.B. Dokumentenverwaltungssysteme, Helpdesk-Systeme oder Internet-Suchmaschinen, verwenden.

$\mathrm{Zu}$ den wenigen, eher konzeptionell ausgerichteten Arbeiten zählen insbesondere Dataware Technologies (1999a), passim; Dataware Technologies (1999b), passim; Vucovich/Ladley (1999), passim.

108 Fur eine Abgrenzung der Begriffe Wissen und Daten siehe Abschnitt 2.2.2.2.1 der vorliegenden Arbeit. 
verfügbaren Wissens ausgedehnt wird. Aufgrund dieser Transparenzfunktion kommt der Metadatenbasis hier eine noch größere Bedeutung zu als beim Data Warehouse. Denn die Metadaten beantworten die mit dem Auffinden des Wissens verbundenen Fragen nach dem 'Wo?', 'Wer?', 'Was?', 'Wann?' und 'Wie?' der Wissensbereitstellung und ermöglichen damit die Lösung des informationslogistischen Problems. Während die Deckung von Informationsbedarfen mit einem hohen Bestimmtheitsgrad regelmäßig im Rahmen standardisierter, für einen längeren Zeitraum ex ante definierter informationeller Beziehungen erfolgt und ein Intermediär zwischen Bedarf und Bedarfsdeckung deshalb nicht notwendig ist, kommt dem Knowledge Warehouse immer dann eine wichtige Transparenzfunktion zu, wenn Informationsbedarfe und -bedarfsdeckungen mit einer hohen Varietät in Übereinstimmung zu bringen sind. Diese Zielsetzung des Knowledge Warehouse-Konzeptes stimmt unmittelbar mit der Zielsetzung der in Abschnitt 5.2.2 der vorliegenden Arbeit formulierten Gestaltungsempfehlungen für das Informationsmanagement überein. Denn das verstärkte Auftreten von Selbstorganisationsprozessen in den Subsystemen der Unternehmung macht bestimmte Ausprägungen der organisatorischen Regeln, wie insbesondere ein hohes $\mathrm{Ma} ß$ an Entscheidungsdelegation, notwendig, die wiederum mit einem geringen Bestimmtheitsgrad von Informationsbedarfen und -bereitstellungen einhergehen. Deshalb muß es Ziel der Gestaltungsaktivitäten des Informationsmanagement sein, durch die geeignete informationstechnische Unterstützung der informationellen Beziehungen trotz ihrer hohen Unbestimmtheit die Deckung der Informationsbedarfe sicherzustellen.

Untergliedert man den Prozeß der Informationsverarbeitung in mehrere Teilaktivitäten bzw. -phasen, so schließt sich an das Auffinden benötigter Informationen regelmäßig der Zugriff auf diese Informationen an. Über das bloße Auffinden des Wissens hinaus besteht eine zweite potentielle Funktion des Knowledge Warehouse somit darin, den Zugriff auf das lokalisierte Wissen zu erleichtern. Dabei sind jedoch zwei Probleme zu beachten: Erstens erstreckt sich die Transparenzfunktion des Knowledge Warehouse über Daten als maschinenverarbeitbares Wissen hinaus auch auf nicht maschinenverarbeitbares Wissen, wie z.B. personengebundenes Wissen. Der Zugriff auf dieses personengebundene Wissen ist in erster Linie keine informationstechnische Fragestellung, die durch das Knowledge Warehouse als informationstechnische Komponente des computergestützten Informationssystems der Unternehmung unterstützt werden könnte. Zweitens ist der Bestimmtheitsgrad des Informationsbedarfs, der mit Hilfe des Knowledge Warehouse gedeckt werden soll, gering, so daß ex ante nicht vorhersehbar ist, welche Art der Informationsverarbeitung angestrebt wird. Entsprechend ist eine benutzergerechte Aufbereitung der Informationen ex ante nicht möglich und aufgrund der hohen Varietät der informationellen Beziehungen unter Wirtschaftlichkeitsgesichtspunkten auch nicht sinnvoll. Eben diese hohe Varietät der informationellen Beziehungen, aus der die Ausrichtung auf das Auffinden des Wissens als dem zentralen Einsatzziel des Knowledge Warehouse resultiert, führt damit zugleich dazu, daß hier im 
Gegensatz zum Data Warehouse der nutzungsgerechten Aufbereitung des Wissens keine große Bedeutung zukommt.

Überträgt man die in Abschnitt 5.3.1.1 für das Data Warehouse unterschiedenen drei Architekturvarianten auf das Knowledge Warehouse, so stellt die virtuelle Variante des Knowledge Warehouse ein reines Metadatenbanksystem dar. Bei der zentralen Lösung mit eigener, separater Datenbasis umfaßt das Knowledge Warehouse über die Metadatenbasis hinaus auch die Replikation sämtlicher in der Unternehmung verfügbaren Daten sowie bestimmter unternehmungsexterner Daten, die auch hier wiederum vereinfachend als die Datenbasis bezeichnet werden soll, ein Datenbankverwaltungssystem und eine Kommunikationsschnittstelle. Die dezentrale Variante würde aus einer Mehrzahl nebeneinanderstehender, vom Umfang auf bestimmte Teilaspekte beschränkter Knowledge Warehouses bestehen, deren Komponenten mit denen der zentralen Knowledge Warehouse-Variante mit eigener, separater Datenbasis übereinstimmen.

Vergleicht man die drei Architekturvarianten für das Knowledge Warehouse, so gelangt man vor dem Hintergrund der obigen Ausführungen zur Transparenzfunktion des Knowledge Warehouse zu folgender Bewertung: Das unternehmungsweite Auffinden von Daten wird durch eine zentrale logische Struktur des Knowledge Warehouse wesentlich erleichtert. Eine dezentrale Architektur - in Analogie zu den Data Marts - ist hier tendenziell nicht sinnvoll, da sie das Suchen in mehreren (dezentralen) Metadatenbanken erfordert.

Vergleicht man in einem nächsten Schritt eine virtuelle Lösung, bei der das Knowledge Warehouse ein Metadatenbanksystem darstellt, mit einem Knowledge Warehouse mit Metadatenbank sowie eigener, separater Datenbasis, so spricht sowohl die Gegenüberstellung von Kosten und Nutzen als auch die technische Machbarkeit gegen eine eigene, separate Datenbasis des Knowledge Warehouse.

Der wichtigste Vorteil einer eigenen Datenbasis des Knowledge Warehouse besteht in der damit einhergehenden Integration. Durch das Zusammenführen unterschiedlichster Daten(arten) in einem technischen System werden bislang existierende Schnittstellenprobleme zwischen heterogenen Einzelsystemen beseitigt, so daß der Zugriff auf die Daten deutlich vereinfacht wird. Bei einer geringen Bestimmtheit der informationellen Beziehungen stellt der Zugriff auf die Daten jedoch regelmäßig erst den zweiten Schritt dar. Im Mittelpunkt steht dagegen die Problematik des Auffindens der benötigten Daten. Das Auffinden von Daten setzt eine Strukturierung der Daten sowie Kenntnisse über diese Strukturierung voraus. Strukturierung bedeutet dabei eine Abstraktionsleistung von der Fülle der Einzeldaten und eine Reduktion der Perspektive auf die zentralen $\mathrm{Zu}$ sammenhänge. Im Sinne eines informationslogistischen Problems sind das die oben genannten Fragen nach dem 'Wo?', 'Wer?', 'Was?', 'Wann?' und 'Wie?' der Informationsbereitstellung, wie sie die Metadaten der Metadatenbasis beantworten. Somit bildet die Metadatenbasis die notwendige Voraussetzung zum Auffinden benötigter Daten. Eine replizierte Datenbasis mit den Daten selbst erleichtert zwar den Zugriff auf die 
Daten und dadurch indirekt auch die die Erlangung von Metadaten, als 1:1-Abbildung der Quelldaten leistet sie jedoch keinen direkten Beitrag zum Auffinden der benötigten Informationen. Der mit ihrer Existenz verbundene Nutzen dürfte deshalb regelmäßig deutlich geringer sein als die mit der Replikation sämtlicher Daten in der Unternehmung verbundenen Kosten.

Berücksichtigt man ferner den Stand der technischen Entwicklung, so stellt ein unternehmungsweit einheitliches, d.h. vollintegriertes Datenverwaltungssystem, das sämtliche in der Unternehmung vorhandenen Daten umfaßt, heute für die meisten Unternehmungen keine realistische Handlungsoption dar. Wäre eine solche vollintegrierte unternehmungsweite Datenverwaltung technisch möglich, so sollte sie jedoch sinnvollerweise im Rahmen der Quellsysteme realisiert werden. Der einheitliche Zugriff auf alle Daten sowie die damit verbundene einfachere Generierung von Metadaten wäre dann auch ohne Replikation der Daten in einem separaten Knowledge Warehouse möglich. Letztlich würden hier Knowledge Warehouse und Quellsysteme zusammenfallen.

Faßt man diese Argumente zusammen, so sollte es sich beim Knowledge Warehouse stets um ein reines Metadatenbanksystem und damit in Analogie zum virtuellen Data Warehouse um eine virtuelle Architekturvariante handeln, innerhalb derer lediglich Metadaten über die Gesamtheit des in der Unternehmung verfügbaren Wissens und über Teile des unternehmungsexternen Wissens verwaltet werden, wie sie Abbildung 5/14 zeigt. Eine Replikation der Primärdaten und ihre Vorhaltung in einer separaten Datenbasis stellt weder eine realistische noch eine sinnvolle Gestaltungsoption dar.

Stellt man das Knowledge Warehouse dem Data Warehouse gegenüber, so resultieren aus der zu beobachtenden Verschiebung der Perspektive unterschiedliche architekturbezogene Gestaltungsempfehlungen: Während die analyseorientierte Aufbereitung der Daten eine eigene, separate Datenbasis des Data Warehouse sinnvoll macht, stellt eine reine Metadatenbank innerhalb eines Knowledge Warehouse die geeignete Unterstützung für das Auffinden unterschiedlichster Wissensarten dar. Abbildung 5/14 zeigt, daß das Knowledge Warehouse über diese Metadatenbasis hinaus aus einem Metadatenbankverwaltungssystem und einer Komunikationsschnittstelle besteht. Es liefert Metadaten über die jeweils benötigten Teile des unternehmungsinternen oder -externen Wissens an die Anwendungsprogramme. Das unternehmungsinterne und -externe Wissen kann sowohl in Form von Daten, als personengebundenes Wissen oder aber auch in papiergebundener Form vorliegen.

Im folgenden werden aus seiner umfassenden Transparenzfunktion bezüglich des gesamten in der Unternehmung vorhandenen Wissens und bezüglich Teilen des unternehmungsextern verfügbaren Wissens resultierende Anforderungen an die Funktionalität des Knowledge Warehouse entwickelt. Dabei wird zwischen den Anforderungen an Inhalt, Darstellung, Generierung und Verwaltung der Metadaten sowie solchen an den Umfang des auszuwertenden Wissens unterschieden. 


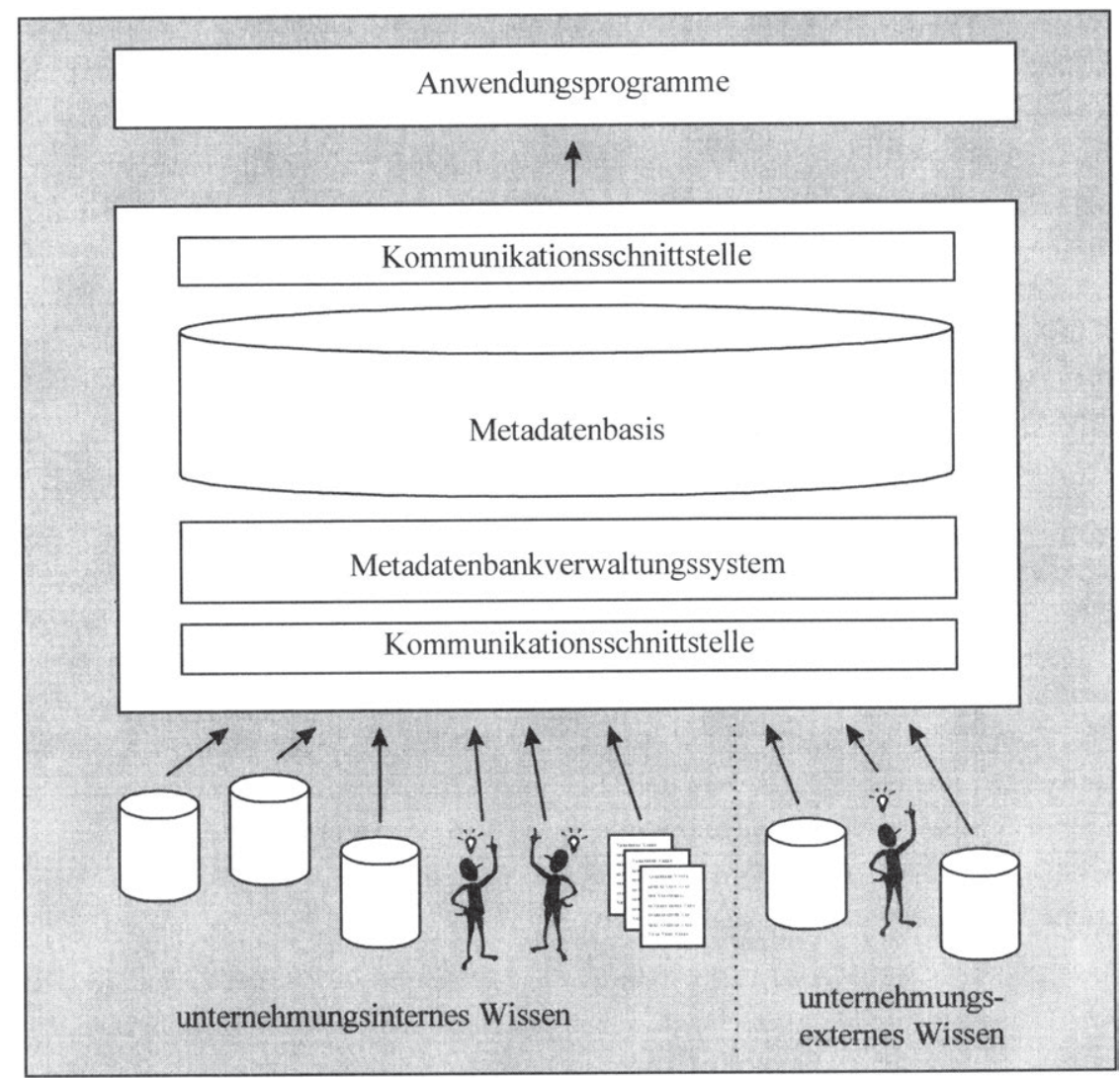

Abb. 5/14: Das Knowledge Warehouse als Metadatenbanksystem

Zunächst gilt es, die Inhalte der Metadaten zu klären. Oben war bereits ausgeführt worden, daß die Metadaten die Fragen nach dem 'Wo?', 'Wer?', 'Was?', 'Wann?' und 'Wie?' der Informationsbereitstellung beantworten. Sie geben somit Auskunft darüber,

- in welchen Datenspeichern, wie z.B. relationalen Datenbanksystemen, Hypertextoder Dokumentenverwaltungssystemen, Daten vorgehalten werden,

- um welche Datenarten es sich handelt (z.B. numerische Daten, alphanumerische Zeichenketten, Volltext, Grafik, Foto, Bewegtbild, Ton),

- durch wen dieses Wissen ursprünglich bereitgestellt wurde (bereitstellende Person, Ergebnis der Transformationsschritte eines bestimmten Anwendungsprogramms),

- zu welchem Zeitpunkt das Wissen bereitgestellt wurde,

- welchen Themengebieten das Wissen zugeordnet werden kann bzw. zur Lösung welcher Fragestellungen es einen Beitrag leisten kann. 109 
Die größte Herausforderung bei der Gestaltung der Metadaten bezieht sich auf den letztgenannten Punkt. Es gilt, geeignete Möglichkeiten zu finden, um Wissensinhalten Kategorien zuzuweisen, die den Zugriff auf diese Wissensinhalte bei der themenorientierten Suche ermöglichen. So ist z.B. zwar davon auszugehen, daß die undifferenzierte Suche nach Informationen über eine bestimmte Produktgruppe oder einen Lieferanten zunächst vergleichsweise problemlos verläuft, da es sich um gängige Wissenskategorien handelt. Jedoch besteht regelmäßig die Gefahr, daß der Benutzer mit einer riesigen Fülle an Hinweisen auf diesbezügliches Wissen konfrontiert wird, die seine Informationsverarbeitungskapazität bei weitem überfordert und deshalb von geringem Nutzen ist. Dieser Fall ist mit dem Suchen mittels Suchmaschinen im Internet vergleichbar, das in Abhängigkeit vom eingegebenen Suchbegriff häufig dazu führt, daß der Benutzer Hunderte von Hinweisen auf Links erhält, ohne daß eine geeignete Sortierung dem Benutzer die systematische Erschließung dieser potentiellen Informationsquellen erleichtert. Aufgrund der großen Fülle des in einem Knowledge Warehouse ausgewerteten Wissens müssen die Kategorien zur Systematisierung der Inhalte dieses Wissens detailliert genug sein, um eine bedarfsorientierte Informationsbereitstellung zu ermöglichen und eine Überflutung mit irrelevantem Wissen zu vermeiden. Gleichzeitig müssen diese Kategorien flexibel genug sein, um bei einem geringen Bestimmtheitsgrad von Informationsbedarfen und -bereitstellungen, wie er aus den in Abschnitt 4.2 entwickelten Ausprägungen der organisatorischen Regeln resultiert, auf ex ante nicht bekannte Wissensbestandteile anwendbar zu sein.

Die Frage nach der geeigneten Darstellung der Metadaten ist unmittelbar mit der nach ihren Inhalten verknüpft. Aktuelle Forschungsbemühungen über Möglichkeiten der Darstellung richten sich auf die Entwicklung sogenannter Knowledge Maps. ${ }^{110}$ Dabei handelt es sich um vorgefertigte Schemata zur Klassifikation der Wissensbestände. Grundsätzlich wird zwischen physischen und qualitativen Knowledge Maps unterschieden. Die physischen Knowledge Maps stellen auf die Art des Datenspeichers ab und dienen damit der Abbildung der oben genannten Metadaten über Datenspeicher (und evtl. die Datenarten). Im Mittelpunkt der qualitativen Knowledge Maps steht die inhaltliche Darstellung der durch das Knowledge Warehouse ausgewerteten Wissensbestände. Hier kann wiederum zwischen prozeßorientierten, funktionalen und themenorientierten Knowledge Maps unterschieden werden. Prozeßorientierte Knowledge Maps orientieren sich an den Teilphasen des betrieblichen Leistungserstellungsprozesses bzw. an der damit verbundenen Abfolge von Informationsverarbeitungsaktivitäten, wie z.B. Anfragebearbeitung, Angebotserstellung, Auftragserfassung und Auftragsbearbeitung. Funktionale Knowledge Maps sind auf eine funktionale Gliederung der Unternehmung in Abteilungen wie Beschaffung, Lager, Produktion etc. ausgerichtet. Themenorientierte Knowledge Maps ermöglichen den Zugriff auf die funktionsübergreifend zu einem bestimmten Thema verfügbaren Wissensbestände, wie z.B. die in der Unternehmung ge- 
machten Erfahrungen mit einer bestimmten Unternehmungsberatungsgruppe oder einem Gutachter.

Snowledge Map

๑. Topics of Interest

G. Sopartments

(1) Strategy \& Planning

$\oplus$ Jinance

$\boxplus$ Human Resources

(†) Information Systems

Ф) Marketing

๑) Sales

由. Customer Service

G. Physical Information Systems

(1) Relational Databases

(1) Groupware Databases

(1) Text Repositories

Abb. 5/15: Beispielhafte Hierarchie möglicher Knowledge Maps (Quelle: Data Technologies (1999a), S.5)

Abbildung 5/15 zeigt beispielhaft eine von DATAWARE TECHNOLOGIES vorgeschlagene Struktur möglicher Knowledge Maps. Das Fehlen einer weiteren Untergliederung des Punktes 'Topics of Interest' verweist darauf, daß hier noch vielfältiger Forschungsbedarf notwendig ist. Das Aufstellen solcher themenorientierten Knowledge Maps stellt eine der großen Herausforderungen bei der Gestaltung des Knowledge Warehouse dar, da es hier gilt, ex ante, d.h. vor der Formulierung des tatsächlichen Informationsbedarfs durch die Nutzer des Knowledge Warehouse, Systematisierungen für das verfügbare Wissen zu formulieren, die ein flexibles Auffinden der benötigten Informationen ermöglichen. Das Aufstellen themenorientierter Knowledge Maps erweist sich dabei als umso schwieriger, je geringer der Bestimmtheitsgrad der Informationsbedarfe und -bereitstellungen in der Unternehmung ist und je wichtiger damit zugleich die Funktion des Knowledge Warehouse als Intermediär zur strukturellen Entkoppelung von Informationsbedarf und -bereitstellung ist. Da die Eignung einer Knowledge Map unmittelbar von den spezifischen Nutzungszielen und Präferenzen des jeweiligen Nutzers abhängt, gibt es hier nicht eine beste Art der Darstellung, sondern es gilt regelmäßig, eine Vielzahl unterschiedlicher Knowledge Maps zur Verfügung zu stellen. ${ }^{111}$

111 Vgl. Dataware Technologies (1999a), S. 5, 13. 
Betrachtet man den Umfang des durch ein Knowledge Warehouse auszuwertenden Wissens, so muß das Knowledge Warehouse aufgrund seiner unternehmungsweiten und über die Unternehmung hinausreichenden Transparenzfunktion im Unterschied zum Data Warehouse neben den Transaktionsdaten auch andere in der Unternehmung anfallende Datenarten auswerten. Neben gut strukturierten sind damit auch schwach strukturierte Daten, wie z.B. multimediale Daten und Volltextdokumente, zu berücksichtigen. Ferner liegt ein Großteil des in der Unternehmung vorhandenen Wissens nicht in Form von Daten, sondern z.B. als personengebundenes Wissen oder auch personenungebunden in Papierform vor. Schließlich sollte die Transparenzfunktion des Knowledge Warehouse auch potentiell relevante Teile des unternehmungsextern verfügbaren Wissens abdecken, da die Informationsbedarfe der Mitarbeiter sich regelmäßig nicht auf innerhalb der Unternehmung verfügbare Informationen beschränken, sondern unternehmungsextern verfügbares Wissen heute immer stärker an Bedeutung gewinnt.

Aus dem großen Umfang des durch ein Knowledge Warehouse auszuwertenden Wissens, das über unterschiedliche Datenarten hinaus auch vielfältiges nicht maschinenverarbeitbares Wissen einschließt, folgt, daß regelmäßig unterschiedliche Möglichkeiten zur Generierung von Metadaten über dieses Wissen nebeneinander zum Einsatz kommen. Grundsätzlich besteht einerseits die Möglichkeit, Metadaten automatisch zu generieren, andererseits können die Metadaten von den Mitarbeitern zur Verfügung gestellt werden.

Die Funktionalität informationstechnischer Lösungen zur Generierung von Metadaten ist heute zwar noch sehr begrenzt und erstreckt sich vor allem auf Metadaten über Datenspeicher und -formate sowie die das Wissen bereitstellende Person bzw. das Anwendungsprogramm, aus dem dieses Wissen resultiert. Intensive Forschungsbemühungen im Bereich 'Softwareagenten' zielen jedoch darauf ab, vermehrt auch die inhaltliche Auswertung der Daten zu automatisieren. Softwareagenten können nicht nur zur Generierung von Metadaten für das Knowledge Warehouse, sondern von den Benutzern des Knowledge Warehouse auch zur Informationssuche innerhalb des Knowledge Warehouse sowie für den Zugriff auf die Daten der Quellsysteme eingesetzt werden. ${ }^{112}$ Deshalb werden sie im Rahmen der vorliegenden Arbeit den Ausführungen zu den Anwendungsprogrammen zugeordnet und in Abschnitt 5.3.3 thematisiert.

Die Generierung von Metadaten muß erstens überall dort durch die menschlichen Informationsverarbeiter selbst erfolgen, wo die Wissensbestände nicht zugleich auch Daten sind, d.h. nicht in maschinenverarbeitbarer Form vorliegen. Dies trifft insbesondere für die wichtige Teilmenge des personengebundenen Wissens $\mathrm{zu}$. An eine bestimmte Person gebundenes Wissen ist nur dann für andere Mitarbeiter verfügbar, wenn diese im Bedarfsfall die entsprechende Person auffinden können. Die Metadatenbank des Knowledge Warehouse ist hier somit eine Weiterentwicklung der in der Vergangen-

112 Vgl. Dataware Technologies (1999a), S. 14. 
heit verschiedentlich realisierten 'Skills Databases'113, die darauf abzielen, die Frage nach dem 'wer weiß was?' in der Unternehmung zu beantworten. Eine solche Metadatenbank setzt voraus, daß bei den Mitarbeiter der Unternehmung die Bereitschaft besteht, ihr Wissen durch die Angabe entsprechender Metadaten transparent zu machen und gegebenfalls mit anderen zu teilen.

$\mathrm{Da}$ - wie oben bereits erwähnt - der automatischen Generierung von Metadaten zur thematischen Einordnung von Datenbeständen heute noch enge Grenzen gesetzt sind, erfolgt die Generierung von Metadaten zweitens dann, wenn sie aufwendige Interpretationsleistungen erfordert, regelmäßig durch die Mitarbeiter. Eine Unterstützung durch das Informationsmanagement kann hier darin bestehen, standardisierte Formen für die Erfassung dieser Metadaten, wie z.B. Formulare, zur Verfügung zu stellen. ${ }^{14} \mathrm{Um}$ die Funktionsfähigkeit des Knowledge Warehouse sicherzustellen, müssen darüber hinaus Anreize geschaffen werden, damit die Personen, im Rahmen deren Teilaufgabenerfüllung die Datenbestände anfallen, diese systematisch um die notwendigen Metadaten ergänzen. Neben den Mitarbeitern, innerhalb deren Arbeitsbereich die Datenbestände anfallen, kann die Generierung von Metadaten auch durch den für das Knowledge Warehouse verantwortlichen 'Content Manager' erfolgen.

Der 'Content Manager' 115 ist für die Verwaltung der Metadaten im Knowledge Warehouse verantwortlich. Er muß sicherstellen, daß entweder von anderen geeignete Metadaten zur Verfügung gestellt werden oder aber diese selbst generieren. Ohne eine solche Institutionalisierung der Überwachungsfunktion besteht die Gefahr, daß das Knowledge Warehouse seine Aufgabe, Intermediär zwischen Informationsbedarfen und -bedarfsdeckungen zu sein, nur ungenügend erfüllt, da die Metadaten nicht aktuell sind oder aber keine geeignete, allgemein verständliche Systematisierung der Wissensbestände ermöglichen. Nur eine hohe Qualität der Metadaten gewährleistet, daß das Knowledge Warehouse das Problem der 'Informationsarmut im Datenüberfluß' verringert und nicht umgekehrt dazu beiträgt, es zu vergrößern.

Betrachtet man den Adressatenkreis des Knowledge Warehouse, so erscheint eine Einschränkung des Kreises seiner potentiellen Nutzer nicht sinnvoll. Die Funktion eines Intermediärs zwischen Informationsbedarf und -bereitstellung sollte es vielmehr für alle Mitarbeiter der Unternehmung übernehmen. Dies bedeutet jedoch nicht etwa, daß alle Metadaten von allen Mitarbeitern der Unternehmung gleichermaßen ausgewertet werden können. So können beispielsweise Kennzahlen über die Produktivität anderer Subsysteme im Sinne von Benchmarks wichtige Informationen für eine teilautonome Fertigungsgruppe darstellen. Gleichzeitig ist dies jedoch tendenziell dann problematisch, wenn dadurch Mitarbeiter die Leistung anderer Mitarbeiter nachvollziehen und bewerten können. Entsprechend ist hier ein sorgfältiges Abwägen der Vor- und Nachteile der

113 Vgl. Dataware Technologies (1999b), S. 14.

114 Vgl. Dataware Technologies (1999b), S. 12.

115 Vgl. dazu und im folgenden Dataware Technologies (1999a), S. 14. 
Informationsbereitstellung notwendig. Das Einrichten eines Knowledge Warehouse setzt deshalb regelmäßig ausgefeilte Konzepte für die Definition von Zugriffsrechten voraus.

Faßt man abschließend die Ausführungen zum Knowledge Warehouse zusammen und stellt Data Warehouse und Knowledge Warehouse einander gegenüber, so stellen beide auf die Daten als Dimension der Informationstechnik bzw. die Datenverwaltung bezogene Gestaltungsoptionen dar, um die für die immaterielle Ebene des computergestützten Informationssystems aufgestellten Anforderungen an das Informationsmanagement informationstechnisch umzusetzen. Denn beide ermöglichen erstens über die Informationsversorgung des Managements hinaus die aller Mitarbeiter in der Unternehmung. Zweitens stellen beide einen Datenpool dar, der eine Entkoppelung von Informationsbedarf und -bereitstellung ermöglicht und drittens eine stärkere Ausrichtung der Informationsversorgung am Holprinzip erlaubt. Dabei erweist sich das Knowledge Warehouse allerdings dadurch als geeigneter, daß es über die Menge der (Transaktions-) Daten hinaus auf die Gesamtheit des Wissens in der Unternehmung und auf Teile unternehmungsexternen Wissens abstellt und dabei deren Auffinden in den Mittelpunkt stellt, während beim Data Warehouse syntaktische und semantische Fragen der Aufbereitung von (Transaktions-) Daten zu Analysezwecken im Mittelpunkt stehen. Die Begriffe Data Warehouse und Knowledge Warehouse können damit vor dem Hintergrund der Abgrenzung von Wissen und Daten, wie sie in der vorliegenden Arbeit vorgenommen wurde, ${ }^{116}$ durchaus auch als Hinweis auf konzeptionelle Unterschiede verstanden werden.

Das folgende Beispiel verdeutlicht den Beitrag des Knowledge Warehouse zur Förderung organisationaler Lernprozesse: Stellt sich einem oder mehreren Mitarbeitern in der Unternehmung ein Problem, zu dessen Lösung ihnen bestimmtes Spezialisten-Knowhow fehlt, so unterstützen die Metadaten des Knowledge Warehouse sie bei der Suche nach einer geeigneten Person, die über dieses Wissen verfügt. Sie gründen selbstorganisatorisch ein Projekt zur Bearbeitung der Problemstellung. Aus den Projektergebnissen resultiert ein neuer Prozeß, für dessen Umsetzung über die Dauer des ursprünglichen Projektes hinaus ein Mitarbeiter die Verantwortung übernimmt. Diese Veränderung der organisationalen Handlungstheorien stellt einen organisationalen Lernprozeß höherer Ordnung dar, der ein schnelles Agieren und Reagieren der Unternehmung in einer sich rasch verändernden Umwelt ermöglicht.

\subsubsection{Netz}

Die folgende Betrachtung des Netzes als der Dimension der Informationstechnik, die die Übertragung von Daten zwischen autonomen Rechnern ermöglicht, stellt auf die Übertragungseinrichtungen und -wege einschließlich des Netzbetriebssystems sowie der

116 Siehe Abschnitt 2.2.2.2.1 der vorliegenden Arbeit. 
Datenübertragungsprotokolle ab. ${ }^{117}$ Das Netz bildet damit die informationstechnische Grundlage der informationellen Beziehungen. Die Untersuchung des Einflusses der organisatorischen Regeln auf die informationellen Beziehungen der Subsysteme der Unternehmung, innerhalb derer das Auftreten von Selbstorganisationsprozessen als Prozessen organisationalen Lernens gefördert werden soll, in Abschnitt 5.2 hat folgendes ergeben: Mit den in Abschnitt 4.2 beschriebenen Ausprägungen der organisatorischen Regeln gehen tendenziell ein hoher inhaltlicher Umfang und ein geringer Bestimmtheitsgrad der Informationsbedarfe und -bereitstellungen einher. Um Informationsbedarfe und -bereitstellungen dennoch zur Übereinstimmung $\mathrm{zu}$ bringen, sollte das Informationsmanagement auf das Ermöglichen einer großen Zahl von informationellen Beziehungen, die zudem ex ante nicht determiniert sind, abzielen. Da im voraus häufig weder Sender und Empfänger noch Art und Umfang der übertragenen Daten feststehen, müssen die auf die materielle Ebene des computergestützten Informationssystems bezogenen Gestaltungsaktivitäten des Informationsmanagements darauf abzielen, flexible technische Potentiale zu schaffen. Für die Gestaltung des Netzes bedeutet das, daß die Aktivitäten des Informationsmanagements auf eine unternehmungsweite Integration aller Computerarbeitsplätze abzielen sollten. ${ }^{118}$

Berücksichtigt man ferner die Ausführungen zum Data Warehouse in Abschnitt 5.3.1, so setzen die Extraktion der Primärdaten aus den operativen Datenbanken, ihre Aufbereitung und ihr Import in die Datenbank des Data Warehouse die Vernetzung der operativen Datenbanksysteme mit dem Data Warehouse voraus. Eine Vernetzung ist jedoch auch für den Zugriff der Endbenutzer mit verschiedenen Analysetools auf das Data Warehouse wichtig. Somit setzt die Realisierung eines Data Warehouse als einer möglichen Ausprägung eines Datenpools zur Entkoppelung von Informationsbedarf und -bereitstellung die Vernetzung der Beteiligten voraus. Ähnliches gilt für das unternehmungsweite Knowledge Warehouse: Die automatische Erweiterung bzw. Aktualisierung der Metadatenbank durch Softwareagenten ${ }^{119}$ setzt die Vernetzung zwischen Knowledge Warehouse und sämtlichen Datenspeichern in der Unternehmung voraus. Aber auch das Einstellen von Metadaten über in ihrem Arbeitsbereich verfügbare Informationen durch die Mitarbeiter in das Knowledge Warehouse wird durch eine Vernetzung wesentlich erleichtert. Auch aus der in Abschnitt 5.2.2 formulierten Anforderung an das Informationsmanagement, einen unternehmungsweiten Informationspool einzurichten, folgt somit für die Gestaltung des Netzes die Empfehlung einer unternehmungsweiten Integration.

Darüber hinaus steigt heute in vielen Teilbereichen der Unternehmung der relative Anteil der Informationsbedarfe, der nur durch unternehmungsextern verfügbare Datenbe-

117 Siehe Abschnitt 5.1.2.1 in Verbindung mit 5.1.2.2.2 der vorliegenden Arbeit.

118 Situative Einflußfaktoren, wie z.B. Sicherheits- oder Datenschutzüberlegungen, erfordern eine Berücksichtigung im konkreten Fall, die der grundsătzlichen Konzeption jedoch nachgelagert ist. Sie finden deshalb hier keine explizite Berucksichtigung.

119

Siehe Abschnitt 5.3.3 der vorliegenden Arbeit. 
stände gedeckt werden kann. Dies gilt insbesondere dort, wo - wie in Abschnitt 3.1.1 als Ausgangsproblematik der vorliegenden Arbeit beschrieben - häufige, schnelle und diskontinuierliche Wandelprozesse in der Umwelt bestimmter Subsysteme der Unternehmung zu beobachten sind. Deshalb ist eine Vernetzung über die Unternehmungsgrenzen hinaus, die einen Zugang zum Internet mit seinen enormen Leistungspotentialen bei der Erlangung unterschiedlichster Daten ermöglicht, die zweite zentrale Anforderung an die netzbezogenen Gestaltungsaktivitäten des Informationsmanagements.

Der Einsatz eines Intranet mit Anbindung an das Internet stellt eine geeignete Gestaltungsoption dar, um die unternehmungsweite Integration aller Computerarbeitsplätze sowie die Vernetzung über die Grenzen der Unternehmung hinaus zu ermöglichen. Ein Intranet sei hier definiert als ein unternehmungsinternes Netz, das auf den TCP/IP-Protokollen beruht. ${ }^{120}$ Es kann, muß jedoch nicht über einen Zugang zum Internet als einem globalen, offenen, allgemein zugänglichen Rechnernetz auf TCP/IPBasis $^{121}$ verfügen. Aus der Sicht der vorliegenden Arbeit besteht der wichtigste Vorteil eines Intranet in der mit dem Einsatz der TCP/IP-Protokollfamilie verbundenen Standardisierung. TCP/IP ist ein in vier Schichten aufgebauter Satz von herstellerneutralen Anwendungs- und Transportprotokollen, die sich durch ihren einfachen Aufbau und ihre große Flexibilität auszeichnen. Das 'Internet Protocol' (IP) regelt den Transfer sowie die Zerteilung der Daten in Pakete und stellt sicher, daß der richtige Rechner die angeforderten Daten-Pakete erhält. Das 'Transmission Control Protocol' (TCP) regelt die Zusammensetzung der Daten-Pakete in der richtigen Reihenfolge. ${ }^{122}$ Das TCP/IP-Protokoll wird heute von allen gängigen Hardware-Plattformen unterstützt und stellt damit eine kostengünstige Möglichkeit für die Datenübertragung zwischen Rechnern unterschiedlicher Hersteller dar. Früher notwendige aufwendige Maßnahmen zur nachträglichen Anpassung verschiedener Übertragungsprotokolle der unterschiedlichen Rechner in einem heterogenen Netzwerk durch Protokollkonverter entfallen. ${ }^{123}$

Die mit der Festlegung auf die TCP/IP-Protokollfamilie verbundene Standardisierung schafft ein hohes Maß an Offenheit bei der Gestaltung des Rechnernetzes in der Unternehmung. So können im Zeitverlauf z.B. zusätzliche Clients oder Server in das Netz eingefügt werden. Technisch ist die Datenübertragung zwischen jedem in das Intranet integrierten Rechner möglich. Dies fördert die Informationsautonomie der Subsysteme als deren Unabhängigkeit bei der Gestaltung ihrer informationellen Beziehungen. Sieht man von der Notwendigkeit der Berücksichtigung des vorgegebenen Protokollstandards ab, können die einzelnen Mitarbeiter sowie die Subsysteme ihre informationellen Beziehungen (unter Berücksichtigung potentieller situativer Restriktionen) prinzipiell frei

120 Vgl. z.B. Greer (1997), S. 2; Kortzfleisch/Winand (1997), S. 30; Pott (1998), S. 2; Schelp (1997), S. 9.

121 Vgl. Hansen (1996), S. 380.

122 Vgl. Eckel/Steen (1997), S. 7f.

123 Vgl. Kyas (1997), S. 26; Seifert (1997), S. 40. 
gestalten. Gleichzeitig wird damit durch das Schaffen eines Intranet die in Abschnitt 5.2.2 geforderte Veränderung der Perspektive des Informationsmanagements hin zu der Überzeugung, 'das Informationssystem ist nie fertig', für die Dimension Netz der Informationstechnik umgesetzt.

Über die oben beschriebene unternehmungsinterne Standardisierung hinaus bietet ein Intranet den Vorteil, daß es auf den Protokollen des Internet basiert und damit eine Anbindung an das Internet über ein Gateway technisch vergleichsweise unproblematisch möglich ist. ${ }^{124}$ Diese Anbindung an das Internet ermöglicht den Mitarbeitern erstens den Zugang zu einer enormen Fülle an unternehmungsextern bereitgestellten Daten. Zweitens können mehrere räumlich getrennte Teile eines Intranet über das Internet verbunden werden. Dabei kann es sich sowohl um einzelne Mitarbeiter (z.B. im Vertrieb) als auch um Subsysteme verschiedener Größe (z.B. Zweigniederlassungen, Tochterunternehmungen im Konzern) handeln. Die mit der Nutzung des Internet verbundenen Einsparungen bei den Leitungskosten stellen einen weiteren Faktor bei der Erhöhung der Informationsautonomie dar, da sie flexible Lösungen auch über große räumliche Distanzen hinweg ermöglichen.

Abschließend sei hier darauf hingewiesen, daß die aus der Verwendung einheitlicher Protokolle resultierenden oben beschriebenen Vorteile nicht an das Produkt TCP/IP gebunden sind, sondern grundsätzlich auch mit anderen Produkten realisiert werden könnten. In der Zukunft könnte eine ebensolche Standardisierung also auch auf andere Protokolle abstellen.

\subsubsection{Anwendungsprogramme}

Im Mittelpunkt der folgenden Ausführungen zu den Anwendungsprogrammen als der dritten hier untersuchten Dimension der Informationstechnik steht die informationstechnische Umsetzung der in Abschnitt 5.2.2 entwickelten drei zentralen Gestaltungsempfehlungen für die immaterielle Ebene des computergestützten Informationssystems. Zunächst werden jedoch unmittelbar aus der hohen Anzahl der informationellen Beziehungen einerseits sowie dem geringen Bestimmtheitsgrad von Informationsbedarfen und -bereitstellungen andererseits resultierende Anforderungen an die Gestaltung der Anwendungsprogramme aufgezeigt. Erst danach werden die Implikationen der Einrichtung eines unternehmungsweiten Informationspools in Kombination mit einer verstärkten Ausrichtung der Informationsversorgung am Holprinzip für die Anwendungsprogramme aufgezeigt, wobei zwischen den Anwendungsprogrammen im Kontext des Data Warehouse einerseits und denen im Kontext des Knowledge Warehouse andererseits unterschieden wird. Schließlich gilt es zu untersuchen, welche Möglichkeiten das Informationsmanagement bei der Gestaltung der Anwendungsprogramme in der

Vgl. Servati/Bremner/Iasi (1997), S. 93f. 
Unternehmung hat, um die Informationsversorgung der unteren Hierarchieebenen als zusätzliche 'top-down-Perspektive' neben die der oberen Hierarchieebenen zu stellen.

In Abschnitt 5.2.2 war herausgearbeitet worden, daß aufgrund der organisatorisch bedingten Ausprägungen der Informationsbedarfe und -bereitstellungen in den Subsystemen der Unternehmung, in denen das Auftreten von Selbstorganisationsprozessen als Prozessen organisationalen Lernens gefördert werden soll, das Informationsmanagement dort eine hohe Anzahl von informationellen Beziehungen ermöglichen sollte. Für die informationstechnische Dimension der Anwendungsprogramme bedeutet das, daß dem Einsatz von E-mail und anderer Groupware hier eine große Bedeutung zukommt, da das Informationsmanagement dadurch potentielle Informationskanäle schafft. Groupware dient der Computerunterstützung kooperativer Arbeitsformen in sozialen Subsystemen, wobei regelmäßig vor allem auf Gruppen als eine Teilmenge möglicher Subsysteme abgestellt wird. ${ }^{125}$ Selbstorganisationsprozesse als Prozesse organisationalen Lernens in einem sozialen Subsystem der Unternehmung machen eine Vielzahl von informationellen Beziehungen zwischen den Mitgliedern des Subsystems notwendig. Hier bieten Groupware-Anwendungen geeignete Unterstützungsmöglichkeiten, wobei die verschiedenen Anwendungen anhand der beiden Dimensionen 'Zeit' und 'Raum' systematisiert werden können, d.h. Groupware unterstützt Mitarbeiter, die sich zu gleicher oder anderer Zeit am gleichen Ort oder an unterschiedlichen Orten befinden. ${ }^{126}$ Beispielhaft sei hier auf Electronic Meeting Systems, Videokonferenzsysteme sowie E-mail hingewiesen. Electronic Meeting Systems unterstützen Mitarbeiter, die sich zur selben Zeit am selben Ort befinden und helfen dabei, Besprechungen $\mathrm{zu}$ strukturieren sowie den Abstimmungs-, Konsensfindungs- und Dokumentationsproze $\beta \mathrm{zu}$ vereinfachen. ${ }^{127}$ Videokonferenzsysteme unterstützen informationelle Beziehungen zwischen Mitarbeitern, die sich zur selben Zeit an unterschiedlichen Orten befinden, durch die Übertragung unterschiedlicher Datenarten einschließlich Bewegtbild und Ton. ${ }^{128}$ Am weitesten verbreitet sind schließlich E-mail-Anwendungen, ${ }^{129}$ auf die deshalb im folgenden näher eingegangen wird.

Erstens unterstützt E-mail die informationellen Beziehungen zwischen Mitarbeitern, die sich zur selben Zeit oder zu verschiedenen Zeiten am selben Ort oder an verschiedenen Orten befinden. Zweitens unterstützen E-mail-Anwendungen regelmäßig alle drei Grundformen informationeller Beziehungen, d.h. 1:1-, 1:n- und m:n-Informationsprozesse. ${ }^{130}$ Deshalb stellen sie immer dann, wenn die informationstechnische Abwicklung

125 Vgl. Nastansky (1991), S. 6. Für eine Übersicht uber verschiedene Groupware-Definitionen siehe Scholer (1998), S. 16f.

$126 \mathrm{Vgl}$. Fuchs/Pankoke-Babatz/Prinz (1994), S. 32; Krcmar (1992), S. 7f. Für eine ausführliche Diskussion verschiedener Groupware-Anwendungen siehe Reif-Mosel (1999), o.S.

127 Vgl. Petrovic (1992), S. 20; Scholer (1998), S. 50.

128 Vgl. Broßmann (1998), S. 56; Färber (1993), S. 45ff.; Hasenkamp/Syring (1994), S. $28 \mathrm{f}$.

129 Vgl. Teufel et al. (1995), S. 80f.

$130 \mathrm{Vgl}$. Hansen (1996), S. 385, der dort allerdings aufgrund anderer begrifflicher Abgrenzungen anstelle von informationellen Beziehungen auf Kommunikationsprozesse abstellt. 
einer hohen Zahl von informationellen Beziehungen notwendig ist, eine zentrale Gestaltungsoption des Informationsmanagements dar. Während m:n-Informationsprozesse in der Unternehmung heute eher eine untergeordnete Rolle spielen, ${ }^{131}$ stehen dort 1:1Informationsprozesse, bei denen ein Sender an genau einen Empfänger Informationen überträgt, sowie 1:n-Informationsprozesse, bei denen ein Sender an eine Mehrzahl von Empfängern Informationen überträgt, im Mittelpunkt.

Ein bereits in Abschnitt 5.2.2 erwähntes Problem der weiten Verbreitung von E-mail in Unternehmungen geht mit der Möglichkeit der Definition von Verteilerlisten einher, die 1:n-Informationsprozesse deutlich erleichtert und die Anwender häufig dazu veranlaßt, Wissensbestandteile prophylaktisch an eine Vielzahl potentiell interessierter Empfänger zu versenden. Eine solche Überflutung mit E-mails geringer Relevanz wird zudem häufig als Ausdruck einer informationsorientierten bzw. auf das Teilen von Informationen ausgerichteten Unternehmungskultur mißverstanden. Ceteris paribus ist bei zunehmender Akzeptanz von E-mail-Anwendungen durch die Benutzer in Zukunft mit einer Verschärfung dieser Problematik zu rechnen. Die Aktivitäten des Informationsmanagements müssen hier deshalb auf ein verändertes Problembewußtsein der Anwender abzielen. Nicht das undifferenzierte Übertragen von Wissensbestandteilen an eine Vielzahl von Personen muß im Mittelpunkt informationeller Beziehungen stehen, sondern die bedarfsorientierte Bereitstellung von Informationen. Das wenig zielgenaue Streuen von Wissen wird insbesondere immer dann überflüssig, wenn ein unternehmungsweites Knowledge Warehouse als Intermediär zwischen Informationsbedarfen und -bereitstellungen existiert. An die Stelle der Übertragung der Wissensbestandteile selbst an eine Vielzahl potentieller Interessenten im Rahmen von 1:n-Informationsprozessen tritt die Übertragung von Metadaten über diese Wissensbestandteile an das Knowledge Warehouse im Rahmen einer 1:1-Beziehung. Die Aktivitäten des Informationsmanagements müssen dabei nicht nur auf die Bereitstellung von Informationskanälen abstellen, sondern auch Überzeugungsarbeit bei den Benutzern leisten, um eine zielorientierte Nutzung der Informationstechnik zu gewährleisten.

Alle beschriebenen Groupware-Anwendungen setzen die Vernetzung der beteiligten Mitarbeiter voraus. Während sich die Anforderungen an die Vernetzung bei Electronic Meeting Systems auf einen entsprechend ausgestatteten Electronic Meeting Room ${ }^{132}$ beschränken, bildet ein Intranet eine geeignete Grundlage für Videokonferenzsysteme ${ }^{133}$ sowie E-mail. Der verstärkte Einsatz von Groupware-Anwendungen stellt somit ein zusätzliches Argument dar, um die in Abschnitt 5.3.2 diskutierte unternehmungsweite Vernetzung aller Mitarbeiter zu fordern.

131 M:n-Informationsprozesse finden sich vor allem unternehmungsübergreifend in Form von News Groups im Internet. Vgl. dazu Pott (1998), S. 234.

132 Vgl. Petrovic/Krickl (1993), S. 121.

133 Auf eine Untersuchung der zur Gewăhrleistung akzeptabler Geschwindigkeiten mit Videokonferenzsystemen verbundenen Anforderungen an die Bandbreite des Netzwerks wird hier verzichtet. 
Untersucht man die Gestaltungsempfehlungen bezüglich der Anwendungsprogramme, die aus dem organisatorisch bedingten geringen Bestimmtheitsgrad von Informationsbedarfen und -bereitstellungen resultieren, so ist hier einerseits die verstärkte Möglichkeit der Anpassung der Anwendungsprogramme durch die Benutzer selbst, andererseits die Ermöglichung des potentiellen Zugriffs der Mitarbeiter auf eine Vielzahl von Anwendungsprogrammen zu fordern. Je weniger nämlich die Informationsverarbeitungsprozesse ex ante determiniert sind und je weniger vorhersehbar damit zugleich die Anforderungen der Benutzer an die Anwendungsprogramme sind, desto flexibler müssen diese handhabbar sein. Die Möglichkeit individueller Anpassungen durch die Benutzer selbst fördert ihre Unabhängigkeit gegenüber einer zentralen Abteilung Informationswirtschaft als einen Teilaspekt ihrer Informationsautonomie und erhöht damit ihre relative Autonomie. Dies führt wiederum zu einer erhöhten Wahrscheinlichkeit für das Auftreten von Selbstorganisationsprozessen als Prozessen organisationalen Lernens. Die Forderung nach der Ermöglichung eines potentiellen Zugriffs der Mitarbeiter auf eine Vielzahl von Anwendungsprogrammen stellt darauf $a b$, daß ihnen über die regelmäßig im Rahmen der Abwicklung des Tagesgeschäftes genutzten Anwendungsprogramme hinaus zusätzlich ein Instrumentarium zur Deckung ad hoc formulierter Informationsbedarfe zur Verfügung gestellt werden sollte. Dieser Aspekt wird im Rahmen der folgenden Ausführungen zu den Anwendungsprogrammen im Kontext von Data Warehouse und Knowledge Warehouse wieder aufgegriffen werden.

Im Rahmen der Ausführungen zu der Dimension Daten in Abschnitt 5.3.1 wurden das Data Warehouse und insbesondere das Knowledge Warehouse als geeignete Gestaltungsoptionen des Informationsmanagements zur Umsetzung der auf der immateriellen Ebene geforderten verstärkten Ausrichtung der Informationsversorgung am Holprinzip in Kombination mit einem unternehmungsweiten Informationspool vorgestellt, die zudem eine verstärkte Fokussierung der Informationsversorgung der unteren Hierarchieebenen ermöglichen. Im folgenden gilt es nunmehr $\mathrm{zu}$ prüfen, mit welchen Gestaltungsempfehlungen bezüglich der Anwendungsprogramme die Umsetzung eines Data Warehouse einerseits und eines Knowledge Warehouse andererseits verbunden ist.

Das Data Warehouse dient als Datenpool für sehr unterschiedliche, auf die Transaktionsdaten der Unternehmung bezogene Analyseaktivitäten. Die eingesetzten Analysetools sind entsprechend von unterschiedlicher Funktionalität und Komplexität und reichen von einfachen Berichtswerkzeugen über OLAP-Tools bis zu Data Mining-Tools. ${ }^{134}$ Im unmittelbaren Vergleich zu OLAP- und Data Mining-Tools ist die Funktionalität der traditionellen Berichtswerkzeuge zwar eher begrenzt, dennoch leisten sie beim Aufbau des betrieblichen Berichtswesens gute Dienste und decken die Bedarfe vieler Anwender ausreichend ab. Anhand der jeweiligen Funktionalität der Berichtswerkzeuge kann zwischen einfachen Abfragegeneratoren, Berichtsgeneratoren und Managed Query Envi-

Vgl. Gluchowski (1998), S. 179. 
ronments unterschieden werden. Mittels einfacher Abfragewerkzeuge können Abfragen formuliert werden, um Extrakte aus umfangreichen Datenbeständen zu erstellen. Mit vergleichsweise geringem Aufwand dienen sie vor allem zur Deckung ad hoc formulierter Informationsbedarfe. Über die reine Abfragefunktionalität hinaus verfügen Berichtsgeneratoren und insbesondere Managed Query Environments über vielfältige Gestaltungs- und Berechnungsoptionen und dienen damit dem systematischen Aufbau eines betrieblichen Berichtswesens, wobei Managed Query Environments auf eine unternehmungsweite Abstimmung des Berichtswesens abstellen, um aus einer unkoordinierten dezentralen Berichtserstellung resultierende hohe und im Zeitverlauf ungleichmäßige Anforderungen an die Hardware- und Netzkapazität zu vermeiden. ${ }^{135}$

Als OLAP-Tools werden Analysewerkzeuge bezeichnet, die multiperspektivische Auswertungen von Daten ermöglichen, wobei das betriebswirtschaftliche Zahlenmaterial einerseits nach unterschiedlichen Dimensionen, wie z.B. Zeit, Region, Produkt oder Lieferant, andererseits auf verschiedenen Verdichtungsstufen, wie z.B. Tag, Woche, Monat, Quartal oder Jahr, analysiert werden kann. Im Vergleich zu traditionellen Berichtswerkzeugen zeichnen sich die OLAP-Tools durch die große Vielfalt möglicher Auswertungen bei kurzen und stabilen Antwortzeiten aus. ${ }^{136}$

Data Mining-Tools zielen darauf ab, Beziehungsmuster in Daten zu identifizieren und durch logische oder funktionale Beziehungszusammenhänge abzubilden und dadurch die Explizierung implizit in den Datenbeständen vorhandenen Wissens zu ermöglichen. ${ }^{137}$ Als Beispiel sei hier auf die Analyse der mittels Scannerkassen im Einzelhandel erfaßten Daten über die Zusammensetzung der Warenkörbe der Kunden (explizites Wissen) verwiesen. Durch die Anwendung statistischer Verfahren lassen sich Verbundkäufe (implizites Wissen) ermitteln.

Im Anschluß an diesen kurzen Überblick über die unterschiedlichen Gruppen von Anwendungsprogrammen im Kontext des Data Warehouse gilt es nunmehr, diesbezügliche Gestaltungsempfehlungen für das Informationsmanagements aufzuzeigen. In Abschnitt 4.2.4 war herausgearbeitet worden, daß ein hohes Maß an Entscheidungsdelegation die relative Autonomie der Subsysteme und damit das Auftreten von Selbstorganisationsprozessen als Prozessen organisationalen Lernens fördert. Die zunehmende Delegation von Entscheidungen an Subsysteme unterer Hierarchieebenen führt dort zu veränderten Informationsbedarfen, die insbesondere auf Überblickswissen zur Einord-

135 Vgl. Gluchowski (1998), S. 188ff.

$136 \mathrm{Vgl}$. Gluchowski/Gabriel/Chamoni (1997), S. 276ff., insbesondere S. 282.

Es existieren unterschiedliche Architekturkonzepte uber den Zusammenhang zwischen OLAP und Data Warehouse. Grundsätzlich sollte zwischen den hier genannten OLAP-Frontends als Clients sowie den OLAP-Servern unterschieden werden. Diese OLAP-Server stehen zwischen der bloßen Datenhaltung durch das Data Warehouse auf der einen und der Analysefunktionalităt der Frontends auf der anderen Seite. Grundsătzlich können sie jedoch auch der Datenhaltungsseite zugeordnet werden und stellen dann zusătzlich zum Data Warehouse existierende Data Marts dar. Da OLAP-Server für die Argumentation der vorliegenden Arbeit ohne Relevanz sind, finden sie hier keine Berücksichtigung. Vgl. ăhnlich Chamoni (1998), S. $238 f f$.

137 Vgl. Düsing (1998), S. 295, 298. 
nung der zu treffenden Entscheidungen in einen übergeordneten Gesamtzusammenhang abstellen. ${ }^{138}$ Die verschiedenen oben genannten Analysetools bieten vielfältige Funktionalitäten zur Generierung und geeigneten Aufbereitung solchen Überblickswissens. Ihr Einsatz stellt damit eine wichtige Gestaltungsoption des Informationsmanagements bezüglich der Dimension der Anwendungsprogramme dar. In der betrieblichen Praxis stellen die Analysetools solches Überblickswissen heute typischerweise Managern zur Verfügung und firmieren dann unter Bezeichnungen wie z.B. Executive Information System. Aufgabe des Informationsmanagements muß es sein, die Funktionalitäten dieser Analysetools zur Gewinnung von Überblickswissen auch den Mitarbeitern auf unteren Hierarchieebenen zur Verfügung zu stellen. Da Mitarbeiter und Führungskräfte in Abhängigkeit von ihren jeweiligen Arbeitsumfeldern u.U. sehr verschiedene Anforderungen an Inhalt und formale Aufbereitung der Informationen haben, können nicht etwa dieselben Anwendungen jetzt auch den unteren Hierarchieebenen verfügbar gemacht werden, sondern sie müssen an deren spezifische Informationsbedarfe angepaßt werden. Als problematisch erweist sich hier, daß die mit umfangreichen Systemanpassungen verbundenen Kosten im Vergleich zu dem daraus resultierenden Nutzen vergleichsweise hoch sind, da anders als beim Management Analysetätigkeiten auch bei ausgeprägter Entscheidungsdelegation auf den unteren Hierarchieebenen in der Regel nicht im Mittelpunkt der Aktivitäten stehen, sondern nur einen Teilaspekt der Tätigkeiten der Subsysteme darstellen. Entsprechend stellen ausgefeilte Lösungen hier unter Wirtschaftlichkeitsgesichtspunkten regelmäßig keine realistische Handlungsoption dar. Aber bereits einfache Abfragewerkzeuge, die auf die Datenbank eines Data Warehouse zugreifen, können gerade bei der Deckung ad hoc formulierter Informationsbedarfe, wie sie für einen geringen Bestimmtheitsgrad der Informationsverarbeitungsprozesse typisch sind, wertvolle Dienste leisten und sollten deshalb den Subsystemen der unteren Hierarchieebenen vom Informationsmanagement systematisch zur Verfügung gestellt werden.

Anders als bei den analyseorientierten Anwendungsprogrammen im Kontext des Data Warehouse, bei denen das Informationsmanagement vor allem darauf abstellen muß, unter Berücksichtigung von Wirtschaftlichkeitsaspekten die heute bereits vielfach für das Management eingesetzten Anwendungsprogramme mit ihrer breiten Funktionalität an die spezifischen Bedarfe unterer Hierarchieebenen anzupassen und diesen zur Verfügung zu stellen, sollten für die Anwendungsprogramme im Kontext des Knowledge Warehouse Lösungen gefunden werden, die die damit verbundene Retrieval-Funktionalität allen Mitarbeitern in der Unternehmung gleichermaßen zur Verfügung stellen, d.h. die keine individuellen Anpassungen der Funktionalität an den einzelnen Benutzer erfordern. Während auf der Ebene der Datenverwaltung durch die Definition von $\mathrm{Zu}$ griffsrechten festzulegen ist, wem Zugriff auf welche Wissenbestände gewährt wird, ${ }^{139}$

138 Siehe Abschnitt 5.2.1.4 der vorliegenden Arbeit.

139 Siehe Abschnitt 5.3.1.2 der vorliegenden Arbeit. 
und damit eine Identifikation des Nutzers der Benutzung der Anwendungsprogramme vorausgehen muß, sollte die auf der Ebene der Anwendungsprogramme bereitgestellte Suchfunktionalität unternehmungsweit identisch sein.

Aufgrund ihrer großen Bedeutung bei der Realisierung der Retrieval-Funktionalität stehen Softwareagenten als Teilmenge der Anwendungsprogramme im Mittelpunkt der folgenden Ausführungen. Darüber hinaus wird auf die Bedeutung eines Query Broker verwiesen. Bei Softwareagenten handelt es sich um „Dienstleister, die eine wohldefinierte Tätigkeit ausführen und sofern gewünscht das Resultat ihrer Aktion an ihren Auftraggeber zurückmelden. ... Softwareagenten erbringen zumindest einen Teil ihrer Dienstleistung asynchron, ohne ständig mit ihrem Auftraggeber in Kontakt zu stehen." "140 Im Kontext des Knowledge Warehouse können sie für folgende Aufgabenfelder eingesetzt werden:

- automatische Generierung von Metadaten für das Knowledge Warehouse aus den Quelldatenbeständen,

- Zugriff des Nutzers auf die Metadaten des Knowledge Warehouse,

- Zugriff des Nutzers auf die Quelldatenbestände (unter Berücksichtigung der durch das Knowledge Warehouse zur Verfügung gestellten Metadaten).

Die Metadatenbasis des Knowledge Warehouse umfaßt Metadaten über sehr unterschiedliche Wissensbestände. Neben verschiedenen Datenarten wird insbesondere auch personengebundenes Wissen sowie unternehmungsexternes Wissen (das wiederum nicht nur in Form von Daten, sondern auch als personengebundenes Wissen vorliegen kann) ausgewertet und in der Metadatenbasis z.B. mit Hilfe von Knowledge Maps dargestellt. Während eine automatische Generierung von Metadaten über personengebundenes Wissen regelmäßig nicht möglich ist, besteht die Möglichkeit, mit Hilfe des Einsatzes von Softwareagenten Metadaten über die verschiedenen Datenbestände innerhalb der Unternehmung und darüber hinaus automatisch zu generieren. Dabei kann zwischen fest programmierten, für bestimmte Aufgaben programmierbaren und intelligenten Softwareagenten, die ihr Verhalten selbständig weiterentwickeln können, unterschieden werden. ${ }^{141}$

In Abhängigkeit von der auszuwertenden Datenart sowie der Art der zu erlangenden Metadaten sind die technischen Möglichkeiten hier heute sehr unterschiedlich weit entwickelt. So existieren zwar verschiedene Anwendungsprogramme für die inhaltliche Auswertung von Volltextdokumenten. Der Beitrag ihrer Funktionalität zur Erreichung der zentralen Ziele eines Knowledge Warehouse ist jedoch aus der Sicht der vorliegenden Arbeit begrenzt. Sie ermöglichen z.B. die Suche nach bestimmten Schlagworten und untersuchen Texte danach, ob einzelne Begriffe, die vom Benutzer vorzugeben sind, häufig in unmittelbarer Nähe zueinander genannt werden, was darauf schließen

140 Hartroth/Kottmann (1996), S. 92.

141 Vgl. Fischbach (1996), S. 148ff.; Hartroth/Kottmann (1996), S. 93. 
läßt, daß der durch sie charakterisierte Themenkreis in dem Dokument behandelt wird. Weiterentwicklungen sollten hier darauf abzielen, daß Softwareagenten die Texte selbständig nach solchen potentiellen inhaltlichen Bezüge zwischen Schlagworten bzw. den damit verbundenen Themenbereichen untersuchen, ohne daß Vorgaben der Benutzer über diese Schlagworte notwendig sind. Erst dadurch könnten ohne menschliches Eingreifen Metadaten über die Inhalte von Volltextdokumenten automatisch generiert werden.

Untersucht man in einem nächsten Schritt die Funktionalität von Softwareagenten zur Unterstützung des Zugriffs des Nutzers auf die Metadaten des Knowledge Warehouse, so bieten intelligente Softwareagenten hier vor allem dem Vorteil einer Kombination von Hol- und Bringprinzip bzw. von Pull- und Push-Effekten. Während der Benutzer beim reinen Holprinzip seinen aktuellen Informationsbedarf gegenüber dem Anwendungsprogramm formuliert und ein allein darauf bezogenes Ergebnis erhält, erstellen intelligente Softwareagenten ein Benutzerprofil. Da der Zugriff auf die Suchfunktionalität stets mit der Identifikation des Benutzers einhergeht, besteht die Möglichkeit der systematischen inhaltlichen Auswertung der von einem bestimmten Benutzer im Zeitverlauf getätigten Suchabfragen, die in einem Benutzerprofil zusammengefaßt werden. Auf der Basis dieses Benutzerprofils werden dem Benutzer sodann aktiv Wissensbestände zur Verfügung gestellt, ohne daß er diese explizit angefordert hat. Je differenzierter das erstellte Benutzerprofil ist, desto höher ist die Wahrscheinlichkeit, daß die bereitgestellten Wissensbestände für den Benutzer auch tatsächlich Informationen in dem Sinne darstellen, daß er sie im Rahmen seiner Teilaufgabenerfüllung verwenden kann. Ferner muß eine enge quantitative Beschränkung der aktiv bereitgestellten Wissensbestände vorgenommen werden, um eine Datenüberflutung zu vermeiden.

Ein Beispiel für eine solche Kombination von Pull- und Push-Effekten findet sich bei AMAZON, einer international tätigen Buchversandhandelsunternehmung. ${ }^{142}$ Die Kunden können sich über die WWW-Seiten von AMAZON über deren Buchangebot informieren und die gewünschten Bücher online bestellen. Da bei der Bestellung notwendigerweise die Identität des Bestellers erfaßt wird, kann ein Benutzerprofil über die von einer Person im Zeitverlauf bestellten Bücher erstellt werden, wobei die einzelnen Titel bestimmten Themengruppen zugeordnet werden. Aufbauend auf der Auswertung dieses Benutzerprofils wird dem Kunden bei seiner nächsten Anmeldung auf den WWW-Seiten von AMAzON eine eng begrenzte Auswahl von Titeln der ihn potentiell interessierenden Themengruppen angeboten.

In Abhängigkeit von der konkreten Ausgestaltung der jeweiligen Anwendungen kann die Kombination von Pull- und Push-Effekten gegenüber einer allein am Holprinzip orientierten Lösung vorteilhaft sein. Denn erstens wirkt sie der Problematik entgegen,

142 Die Präsentation von Amazon einschließlich der Electronic Commerce-Funktionalität findet sich im Internet unter http://www.amazon.de. 
daß die Informationssuche einer Person stark von ihren Annahmen über die verfügbaren Wissensbestände geprägt ist. Geht eine Person davon aus, daß bestimmte Informationen nicht erhältlich sind, bezieht sie diese häufig auch nicht in die Formulierung ihrer Suchanfrage ein. Zweitens kann sie zu einer Erweiterung der kognitiven Strukturen ${ }^{143}$ des Benutzers führen, indem sie diesem - basierend auf den in dem Softwareagenten abgebildeten kognitiven Strukturen, die von denen des Benutzers abweichen - Wissensbestände zur Verfügung stellt, die dieser von sich aus nicht in die Problemlösung einbezogen hätte. ${ }^{144}$ Ausgefeilte ${ }^{145}$ Push-Effekte bieten somit zusätzliche Funktionalität bei der Informationsbedarfsdeckung.

Das Lokalisieren einer benötigten Information mit Hilfe der Auswertung der Metadaten des Knowledge Warehouse stellt stets nur den ersten Schritt auf dem Weg zu ihrer Verwendung im Rahmen der menschlichen Informationsverarbeitung dar. Den zweiten Schritt bildet der Zugriff auf die Information. Während sich personengebundenes Wissen einem informationstechnisch gestützten Zugriff entzieht, sollten die Anwendungsprogramme im Kontext des Knowledge Warehouse idealerweise nicht nur die Lokalisierung bestimmter Daten, sondern auch den Zugriff auf diese unterstützen. Der Zugriff auf die Quelldatenbestände stellt somit die dritte Einsatzmöglichkeit für Softwareagenten im Kontext des Knowledge Warehouse dar. ${ }^{146}$ Neben residenten Agenten, die nur auf einem bestimmten Wirtssystem ablaufen, und beweglichen Agenten, die auf mehreren ex ante festgelegten Systemen ablaufen, kommen dabei insbesondere auch mobile Softwareagenten zum Einsatz, bei denen die Menge der potentiellen Wirtssysteme ex ante nicht festgelegt wird. ${ }^{147}$ Dies setzt jedoch das Vorhandensein einer Agentenablaufumgebung auf den potentiellen Wirtssystemen voraus. ${ }^{148}$ In Abhängigkeit von der Datenart der jeweiligen Quelldaten können sich beim Zugriff eines Softwareagenten auf die Quelldaten semantische Probleme ergeben, wie am Beispiel von relationalen Datenbanksystemen gezeigt werden kann. Denn die in einer bestimmten Relation gespeicherten Daten umfassen u.U. eine umfangreiche Liste mit Schlüsseln, die auf in anderen Relationen gespeicherte Daten verweisen (Fremdschlüssel). Der Zugriff auf diese Relationen setzt die Interpretation dieser Schlüssel bzw. die Bewertung der inhaltlichen Relevanz der Daten, auf die diese verweisen, voraus. Denn es ist regelmäßig davon auszugehen, daß nicht sämtliche Felder eines Datensatzes aus der Perspektive

143 Siehe Abschnitt 3.2.1.2 der vorliegenden Arbeit.

144 In der Praxis verschwimmt hier allerdings die Trennlinie zwischen den mit der möglichen Erweiterung der individuellen kognitiven Strukturen verbundenen Chancen und der Gefahr der Datenüberflutung des Individuums.

145 Das insbesondere in der populärwissenschaftlichen Literatur in diesem Zusammenhang häufig verwendete Adjektiv 'intelligent' wird hier bewußt vermieden. Ebenso folgt die Bezeichnung 'intelligenter Softwareagenten' in erster Linie dem gängigen Sprachgebrauch zur Kennzeichnung einer bestimmten Teilmenge der Softwareagenten. Die Frage, ob die Übertragung des bei Lebewesen beobachtbaren Phănomens der Intelligenz auf Software als technisches System angemessen ist, soll hier nicht diskutiert werden.

146 Vgl. Dataware Technologies (1999a), S. 10, 14.

$147 \mathrm{Zu}$ den verschiedenen Arten von Softwareagenten vgl. Hartroth/Kottmann (1996), S. 93.

148 Vgl. Wagner (1997), S. 238f. 
der jeweiligen Abfrage Informationen darstellen. Um eine Überflutung des Benutzers mit irrelevanten Wissensbestandteilen zu vermeiden, kommt der Funktionalität auf der semantischen Ebene große Bedeutung zu.

Die Fülle der im Zusammenhang mit einem Knowledge Warehouse notwendigen Suchund Zugriffsfunktionalität wird regelmäßig nicht von einem einzelnen, sondern einer Vielzahl unterschiedlicher Anwendungsprogramme zur Verfügung gestellt. Insbesondere für den gelegentlichen Benutzer kann die Konfrontation mit diesen unterschiedlichen Anwendungen leicht zu einer Überforderung führen. Deshalb besteht eine zentrale Gestaltungsempfehlung an das Informationsmanagement darin, diese unterschiedlichen Funktionalitäten bzw. Anwendungsprogramme unter der einheitlichen Benutzungsoberfläche eines Query Broker zusammenzufassen. Dabei kann es sich z.B. um einen Browser handeln. Während unterschiedliche Softwareagenten die in der Datenbasis des Knowledge Warehouse vorgehaltenen Metadaten auswerten und gegebenenfalls den Zugriff auf die relevanten Teile der Quelldatenbestände unterstützen, werden die Ergebnisse dieser Retrieval-Aktivitäten dem Benutzer dann unter der einheitlichen und leicht verständlichen Oberfläche eines Browsers zur Verfügung gestellt. ${ }^{149}$

Zusammenfassend ist hier festzuhalten, daß bezüglich der Anwendungsprogramme im Kontext des Knowledge Warehouse zwar erste Partiallösungen verfügbar sind, die z.B. die benutzergesteuerte inhaltliche Auswertung von Volltextdokumenten ermöglichen. Ingesamt besteht hier jedoch noch weitreichender Forschungs- und Entwicklungsbedarf, der nicht nur auf eine verbesserte Funktionalität der einzelnen Lösungen, sondern insbesondere auch auf deren Zusammenführung in einem umfassenden Gesamtkonzept abstellen sollte.

\subsubsection{Rechner}

Zielt man darauf ab, die Informationsautonomie der Subsysteme in der Unternehmung zu fördern, innerhalb derer das Auftreten von Selbstorganisationsprozessen als Prozessen organisationalen Lernens gefördert werden soll, so ist einer dezentralen Rechnerarchitektur gegenüber einer zentralen der Vorzug zu geben. Denn die Zuordnung bestimmter Rechnerkapazitäten zu einem Subsystem gewährleistet eine hohe Verfügbarkeit dieser Rechnerkapazität für das fokussierte Subsystem, die nicht durch die Inanspruchnahme dieser Kapazität durch andere Subsysteme gemindert wird. ${ }^{150}$ Die dezentrale Rechnerarchitektur sollte sinnvollerweise mit einer Dezentralisierung der Entscheidungskompetenzen bezüglich der Rechnerausstattung verbunden werden, d.h. den einzelnen Subsystemen wird ein bestimmtes Budgets für ihre informationstechnische Ausstattung zugewiesen, über dessen Verwendung sie frei entscheiden können. Die Gestaltungsaktivitäten des Informationsmanagements beschränken sich auf die Formu- 
lierung unternehmungsweiter Standards, die trotz der Dezentralisierung der Entscheidungskompetenzen die subsystemübergreifende Integration gewährleisten sollen. Aus der Forderung nach der Erhöhung der Informationsautonomie der Subsysteme resultiert somit unmittelbar, daß bezüglich der dezentralen Rechner keine weitergehenden Gestaltungsempfehlungen getroffen werden können, da die Ausgestaltung der eingesetzten Rechnerkapazität nicht durch das Informationsmanagement, sondern durch die Subsysteme selbst erfolgen sollte. Die Gestaltungsaktivitäten des Informationsmanagements sollten sich vielmehr auf die Schaffung von Rahmenbedingungen für diese Freiräume durch die Formulierung von Standards beschränken.

Die Forderung nach einer Dezentralisierung der Rechnerarchitektur ist aufgrund vielfältiger Einflußfaktoren zu relativieren. Einen Aspekt bilden die in Abschnitt 5.3.1 thematisierten Datenbanksysteme Data Warehouse und Knowledge Warehouse, die regelmäßig auf zentral bereitgestellter Rechnerkapazität basieren sollten. In beiden Fällen erfolgt die Datenhaltung sinnvollerweise auf einem zentralen Datenbankserver, auf den die Analyse- bzw. Retrieval-Tools der Endbenutzer als dezentrale Clients zugreifen. Die zentrale Datenhaltung bietet gerade auch bezogen auf die benötigte Rechnerkapazität große Vorteile gegenüber einer dezentralen Lösung. So würde eine lokale Datenablage regelmäßig eine immense Verschwendung von Rechnerkapazität bedeuten. ${ }^{151}$ Zusammenfassend stellt die auf die Rechnerarchitektur bezogene Gestaltungsempfehlung an das Informationsmanagement hier deshalb auf eine Kombination zentraler und dezentraler Rechnerkapazitäten ab.

Ein geringer Bestimmtheitsgrad der Informationsbedarfe und -bereitstellungen bzw. der Informationsverarbeitungsprozesse macht das Vorhalten von Organizational Slack bezüglich der Rechnerkapazität notwendig, da unvorhergesehene Informationsverarbeitungsprozesse zusätzliche Rechnerkapazität beanspruchen können. Aufgrund der oben getroffenen Aussagen bezüglich einer dezentralen Rechnerarchitektur, die zugleich mit einer Dezentralisierung der auf die informationstechnische Ausstattung der Subsysteme bezogenen Entscheidungskompetenzen einhergeht, obliegt die Verantwortung für das Vorhalten solcher Überschußkapazitäten zwar prinzipiell den Subsystemen selbst. Gleichzeitig gilt jedoch, daß derselbe Puffereffekt des Organizational Slack bei einer zentralen, subsystemübergreifenden Bereitstellung dieser Überschußkapazitäten im Vergleich zu einer dezentralen Lösung tendenziell mit weniger Organizational Slack und damit kostengünstiger realisiert werden kann. Deshalb kann es sich aus der Perspektive der gesamten Unternehmung als sinnvoll erweisen, die dezentrale Verantwortung der einzelnen Subsysteme für das Schaffen von Organizational Slack bezüglich der Rechnerkapazität mit einer zentralen Lösung zu kombinieren. Potentiell problematisch ist dabei jedoch, daß Daten, Hard- und Software nicht beliebig getrennt und aufgeteilt werden können. Ein zeitlich begrenzter Engpaß an dezentraler Rechnerkapazität kann zumeist nicht einfach durch das 'Dazuschalten' zentral vorgehaltener

151 Vgl. ăhnlich Gluchowski (1998), S. 188. 
Slack-Ressourcen ausgeglichen werden. Zentral bereitgestellte Überschußkapazität bietet deshalb nur in sehr engen Grenzen eine Entlastung der dezentralen Rechnerkapazität. Zwei mögliche Beispiele hierfür stellen das Data Warehouse sowie das Knowledge Warehouse dar. Denn wie oben dargestellt wurde erfolgt die Datenhaltung hier regelmäBig auf einem zentralen Datenbankserver. Da ex ante häufig unbestimmt ist, welche Analyse- und Retrieval-Funktionalität wann zu welcher Belastung der Rechnerkapazität führen wird, führt die zentrale Bereitstellung der Kapazität im Vergleich zur dezentralen hier regelmäßig zu einer besseren Auslastung und stellt deshalb die kostengünstigere Alternative dar.

\subsubsection{Zusammenfassung der informationstechnischen Gestaltungs- empfehlungen in der lernenden Unternehmung}

In den Abschnitten 5.3.1 bis 5.3.4 wurde im einzelnen untersucht, welche Gestaltungsoptionen bezüglich der informationstechnischen Dimensionen Daten, Netz, Anwendungsprogramme und Rechner bestehen, um die für die immaterielle Ebene des computergestützten Informationssystems formulierten Anforderungen einer verstärkten Fokussierung der Informationsversorgung der unteren Hierarchieebenen sowie des Einrichtens eines unternehmungsweiten Informationspools in Kombination mit einer verstärkten Ausrichtung der Informationsversorgung am Holprinzip auf der materiellen Ebene umzusetzen. Die Gestaltungsempfehlungen zielen darauf ab, die Informationsautonomie (als Teilausprägung der relativen Autonomie) der Subsysteme zu fördern, innerhalb derer das Auftreten von Selbstorganisationsprozessen als Prozessen organisationalen Lernens gefördert werden soll. Abbildung 5/16 zeigt die wichtigsten der dort entwickelten Gestaltungsempfehlungen im Überblick. Im folgenden werden diese auf die einzelnen informationstechnischen Dimensionen bezogenen Gestaltungsempfehlungen zu einigen dimensionenübergreifenden Anforderungen an die Gestaltung der Informationstechnik in der lernenden Unternehmung zusammengeführt.

Im Mittelpunkt der auf die Informationstechnik bezogenen Gestaltungsempfehlungen an das Informationsmanagement stehen das Data Warehouse sowie das Knowledge Warehouse. Dabei sollte nicht allein auf die bloßen Datenbanksysteme abgestellt werden, sondern im Sinne eines umfassenden informationstechnischen Ansatzes müssen auch Aspekte, die die anderen informationstechnischen Dimensionen betreffen, in die Argumentation einbezogen werden.

Im Kontext des Data Warehouse existiert heute bereits eine Vielzahl informationstechnischer Systeme, so daß das Informationsmanagement hier aus der Fülle der vorhandenen kommerziellen Lösungen auswählen und diese an die spezifischen Erfordernisse der jeweiligen Unternehmung anpassen kann. Der Fokus muß dabei einerseits auf der Schaffung einer zentralen, unternehmungsweiten Lösung, andererseits auf der Bereitstellung flexibler, bedarfsgerechter Analysefunktionalität auch für die unteren Hierarchieebenen der Unternehmung liegen. Denn dezentrale Data Marts stellen 


\section{Daten:}

O Data Warehouse

Knowledge Warehouse

Anwendungsprogramme:

O Groupware

O Anpassung durch Benutzer

O Zugriff auf Vielzahl von Anwendungsprogrammen

O Data Warehouse: benutzerspezifische Analysetools auch auf unteren Hierachieebenen

O Knowledge Warehouse: einheitliche Suchfunktionalität für alle
Netz:

O Standardisierung durch globale Protokolle: Intranet mit Anbindung an das Internet

\section{Rechner:}

O Kombination von zentraler und dezentraler Rechnerkapazität

Delegation der Entscheidungskompetenz für dezentrale Rechnerkapazität an Subsysteme

Abb. 5/16: Zentrale Gestaltungsempfehlungen für die materielle Ebene des computergestützten Informationssystems

nicht nur den typischen ersten Schritt im Rahmen eines von der Überzeugung 'think big, start small' geprägten Data Warehouse-Einführungsprozesses dar. Vielmehr verharren viele Data Warehouse-Projekte heute auf dieser ersten Stufe und beschränken sich auf die Unterstützung einzelner Funktionsbereiche, wie z.B. des Controlling. Entsprechend ähneln die in der Praxis anzutreffenden sogenannten Data Warehouse-Lösungen regelmäßig eher dezentralen, funktionsbereichsspezifischen Data Marts als dem postulierten zentralen, bereichsübergreifenden Data Warehouse. ${ }^{152}$ Immer dann, wenn man die Deckung von Informationsbedarfen mit einem geringen Bestimmtheitsgrad anstrebt, erweisen sich solche dezentralen Lösungen jedoch als problematisch. Die Deckung hochvariabler Informationsbedarfe der selbstorganisierenden Subsysteme in den unterschiedlichsten Bereichen der Unternehmung erfordert vielmehr eine zentrale, unternehmungsweite Data Warehouse-Lösung. Die Datenhaltung erfolgt dabei typischerweise auf einem zentralen Datenbankserver, auf den die verschiedenen Analysetools der Anwender als dezentrale Clients zugreifen. Diese Architekturlösung erfordert unmittelbar eine unternehmungsweite Vernetzung. Auf der Ebene der

Vgl. die empirische Untersuchung in Dittmar (1999), o.S. 
Analysetools muß das Informationsmanagement deren benutzerspezifische Anpassung sowie eine möglichst einfache, intuitive Handhabung gewährleisten. Denn der Einsatz von Executive Information Systems hat gezeigt, daß die einfache Bedienung ein zentraler Erfolgsfaktor bei der Verwendung von Analysetools ist. Diese Erfahrungen können von der Ebene der Führungskräfte auf alle Mitarbeiter übertragen werden, die solche Analysetools zur Deckung unregelmäßig auftretender, ex ante nicht determinierter Informationsbedarfe nutzen. Unter Berücksichtigung dieser Anforderungen besteht der wichtigste Nutzen eines Data Warehouse aus der Perspektive der vorliegenden Arbeit darin, daß den Mitarbeitern der selbstorganisierenden Subsysteme eine große Fülle an Überblickswissen bezüglich der Transaktionsdaten zur Verfügung gestellt wird, das es ihnen erlaubt, die an sie delegierten Entscheidungen über die engen Grenzen ihres eigenen Arbeitsbereiches hinaus in einen umfassenden Gesamtzusammenhang einzuordnen.

Da Data Warehouse-Lösungen sich in der Praxis regelmäßig auf die Transaktionsdaten als eine Teilmenge der in der Unternehmung verfügbaren Daten beschränken und der Schwerpunkt auf der Analysefunktionalität liegt, stellen sie nur einen ersten Schritt bei der informationstechnischen Umsetzung des postulierten unternehmungsweiten Informationspools dar. Die Gestaltungsaktivitäten des Informationsmanagements sollten deshalb über ein Data Warehouse hinaus auf die Umsetzung des Knowledge Warehouse-Ansatzes abstellen. Jüngste Forschungsbestrebungen in diesem Zusammenhang streben die Bereitstellung einer umfassenden Suchfunktionalität an. Diese erstreckt sich nicht nur über die Transaktionsdaten hinaus auf die Gesamtheit aller in der Unternehmung verfügbaren (stark und schwach strukturierten) Daten, sondern einerseits auch auf Wissensbestände außerhalb der Unternehmung, andererseits auf Wissensbestände, die nicht in maschinenverarbeitbarer Form vorliegen. So können z.B. Metadaten darüber vorgehalten werden, welcher unternehmungsexterne oder -interne Experte über welches Know-how verfügt, oder Suchmaschinen ermöglichen das Suchen nach im Internet verfügbaren Daten. Erst dadurch wird eine umfassende Unterstützung der Mitarbeiter in selbstorganisierenden Subsystemen bei der Deckung unterschiedlichster, spontan formulierter Informationsbedarfe möglich. Zugleich stellt die systematische Gewinnung von Metadaten über in der Unternehmung verfügbares Wissen sicher, daß die Existenz von Wissensbeständen, die im Rahmen der flexibel gestalteten Leistungserstellungs- und Informationsverarbeitungsprozesse der selbstorganisierenden Subsysteme entstehen, anderen potentiellen Nutzern gegenüber transparent ist. Da über das Auffinden der Wissensbestände hinaus idealerweise auch der Zugriff auf diese unterstützt werden sollte, müssen den Anwendern hier vielfältige Such- und Zugriffsfunktionalitäten mittels verschiedener Retrieval-Tools zur Verfügung gestellt werden. Um eine Überforderung - gerade auch des gelegentlichen Nutzers - zu vermeiden, sollten die unterschiedlichen Funktionalitäten den Anwendern unter der einheitlichen Benutzungsoberfläche eines Browsers im Sinne eines Query Broker zur Verfügung gestellt werden. Dieser gewährleistet die Zusammenführung und die 
einheitliche Aufbereitung der Ergebnisse der unterschiedlichen Retrieval-Tools, die für den Anwender (weitgehend) 'unsichtbar' bleiben sollten. Da Forschung und Entwicklung bezüglich potentieller Knowledge Warehouse-Lösungen sich heute noch in den Anfängen befinden, besteht hier umfassender Forschungsbedarf, um dem mit diesem Konzept verbundenen hohen Anspruch gerecht $\mathrm{zu}$ werden und dem Informationsmanagement als betrieblichem Aufgabenfeld schlüssige Konzepte und funktionale Tools zur Verfügung zu stellen, die es sodann an die spezifischen Besonderheiten der jeweiligen Unternehmungssituation anzupassen gälte. 
Frauke Streubel - 978-3-631-75510-5

Downloaded from PubFactory at 01/11/2019 04:00:13AM 


\section{Zusammenfassung und Ausblick}

Unternehmungen können lernen. Die zu Beginn der vorliegenden Arbeit gestellte Frage ist mit ' $\mathrm{ja}$ ' $\mathrm{zu}$ beantworten. Es existieren originär organisationale Lernprozesse, die eindeutig von individuellen Lernprozessen in der Unternehmung unterscheidbar sind. Unternehmungen können jedoch nicht nur lernen, sie müssen lernen, um in einer durch häufige, schnelle und diskontinuierliche Wandelprozesse geprägten Umwelt zu bestehen. Die Förderung organisationaler Lernprozesse durch geeignete Managementaktivitäten stellt somit eine unmittelbare Notwendigkeit dar, um die Wettbewerbsfähigkeit der Unternehmung im Zeitverlauf zu gewährleisten. Das Informationsmanagement, das als Querschnittsfunktion sämtliche Bereiche der Unternehmung betrifft und dort die informationellen Beziehungen sowie deren informationstechnische Unterstützung gestaltet und damit eine zentrale Teilmenge der Managementaktivitäten darstellt, kann und muß einen entsprechenden Beitrag zur Förderung organisationalen Lernens leisten. Zentrales Ziel der vorliegenden Arbeit war es, diesen Beitrag der Gestaltungsaktivitäten des Informationsmanagements zur Förderung organisationalen Lernens aufzuzeigen. Die Ableitung theoretisch fundierter Gestaltungsempfehlungen war jedoch bislang aufgrund vielfältiger Forschungsdefizite nicht möglich. Die im ersten Kapitel formulierten vier Zwischenziele der vorliegenden Arbeit zielten deshalb auf die Überwindung dieser Forschungsdefizite ab. Erst danach konnten Gestaltungsempfehlungen für das Informationsmanagement in der lernenden Unternehmung entwickelt werden.

Die der vorliegenden Arbeit zugrundeliegende Ausgangsproblematik besteht in häufigen, schnellen und diskontinuierlichen unternehmungsexternen Wandelprozessen, die unter der Annahme eines herzustellenden Fit zwischen Unternehmung und Umwelt entsprechende unternehmungsinterne Wandelprozesse notwendig machen. Organisationales Lernen als geistige Veränderung bildet die Voraussetzung für unternehmungsinterne Wandelprozesse als materielle Veränderungen. Die Befähigung der Unternehmung zu häufigen, schnellen und diskontinuierlichen unternehmungsinternen Wandelprozessen stellt deshalb das Effizienzkriterium zur Bewertung organisationaler Lernprozesse dar. Somit wird organisationales Lernen hier nicht - wie in der Literatur oft zu beobachten - als universelles Allheilmittel für sämtliche betrieblichen Probleme angesehen, sondern vor dem Hintergrund einer spezifischen Problematik bewertet.

In der Literatur ist häufig ein Theoriedefizit bezüglich der Abgrenzung des Phänomens organisationalen Lernens festzustellen, das sich insbesondere in einer mangelnden Unterscheidung zwischen organisationalen Lernprozessen und individuellen äußert. Die Ableitung von Gestaltungsempfehlungen für das Informationsmanagement in der lernenden Unternehmung setzt jedoch eine theoretische Abgrenzung des Phänomens organisationalen Lernens unmittelbar voraus. Versteht man die Ausführungen der vorliegenden Arbeit als Bausteine eines Managementkonzeptes organisationalen Lernens, so besteht ein erster Baustein aus der geeigneten Abgrenzung des Phänomens or- 
ganisationalen Lernens. Organisationales Lernen wird hier als Veränderung der organisationalen Wissensbasis definiert. Die Gesamtheit der Prozesse organisationalen Lernens schließt dabei sowohl Veränderungen der individuellen Teile der organisationalen Wissensbasis als auch Veränderungen der überindividuellen Teile der organisationalen Wissensbasis ein. Während erstere vor allem individuelle Lernprozesse darstellen, sind letztere regelmäßig von grundlegend anderer Qualität. Sie umfassen das identische Lernen mehrerer Individuen, das emergente Lernen eines Kollektivs sowie die Veränderung des institutionalisierten Wissens in der Unternehmung. Insbesondere letzteres ist klar von individuellen Lernprozessen einzelner Mitarbeiter der Unternehmung unterscheidbar und stellt einen originär organisationalen Lernprozeß dar. Anhand des Inhalts des veränderten organisationalen Wissens können diese Lernprozesse wiederum in einfache (Single-loop Learning) und höhere (Double-loop Learning) Prozesse organisationalen Lernens sowie solche des Lernens zu lernen (Deutero Learning) unterschieden werden. Zur Bewältigung des beschriebenen unternehmungsexternen Wandels sind häufige und schnelle Prozesse eines organisationalen Double-loop Learning, die zur Gewährleistung der Lernfähigkeit im Zeitverlauf in ein Deutero Learning einzubetten sind, notwendig.

Organisatorische Regeln begrenzen die Freiheitsgrade der Handlungen der Mitglieder des Systems Unternehmung und haben damit komplexitätsreduzierende Funktion. Deshalb können sie als Analogon der kognitiven Strukturen des einzelnen Individuums, die als Wahrnehmungsfilter der Komplexitätsreduktion der vom Individuum wahrgenommenen Umwelt dienen, konzipiert werden. So wie die kognitiven Strukturen des Individuums die Tiefenstruktur der individuellen Wissensbasis darstellen, bilden die organisatorischen Regeln als organisationale Handlungstheorien die Tiefenstruktur der organisationalen Wissensbasis. Jede organisatorische Tätigkeit stellt damit einen organisationalen Lernprozeß höherer Ordnung bzw. Double-loop Learning dar. Die Konzeptionalisierung des Zusammenhangs zwischen organisationalem Lernen und organisatorischer Gestaltung als einem zweiten Zwischenziel der vorliegenden Arbeit bzw. einem weiteren Baustein eines Managementkonzeptes organisationalen Lernens ergibt also, daß alle organisatorischen Tätigkeiten - und so auch die organisatorische Gestaltung - organisationale Lernprozesse darstellen. Zugleich bilden die organisatorischen Regeln als Gegenstand organisatorischer Tätigkeiten neben situativen und subjektiven Aspekten die zentralen Einflußfaktoren von Informationsbedarf und -bereitstellung als Attributen der menschlichen Informationsverarbeiter, die wiederum Gegenstand der immateriellen Ebene des Informationsmanagements sind. Deshalb stellt die Untersuchung organisatorischer Tätigkeiten den notwendigen Zwischenschritt zur Konzeptionalisierung des Zusammenhangs zwischen organisationalem Lernen und Informationsmanagement dar, und die Analyse organisationaler Lernprozesse höherer Ordnung verengt sich auf die Teilmenge der organisatorischen Tätigkeiten.

Stellt man Selbst- und Fremdorganisationsprozesse als alternative Ausprägungen organisatorischer Tätigkeiten einander mit ihren jeweiligen Vor- und Nachteilen gegenüber, 
so erweisen sich Selbstorganisationsprozesse regelmäßig dann denen der organisatorischen Gestaltung als überlegen, wenn - wie in dieser Arbeit angenommen - häufige und schnelle Wandelprozesse in den Teilumwelten der Mitarbeiter in den verschiedenen Subsystemen der Unternehmung auftreten. Denn die Mitarbeiter nehmen Veränderungen in der relevanten Teilumwelt ihres Subsystems in der Regel schneller und besser wahr als ein Organisator als außerhalb dieses Subsystems Stehender. Da organisatorische Regeln als Ergebnis von Fremdorganisationsprozessen regelmäßig den Rahmen für Selbstorganisationsprozesse bilden, müssen die Aktivitäten der organisatorischen Gestaltung - im Sinne eines Deutero Learning bzw. Lernens zu lernen - auf die Schaffung geeigneter Rahmenbedingungen zur Förderung des Auftretens von Selbstorganisationsprozessen abzielen. Denn organisatorische Regeln als organisationales Wissen sind nicht nur Ergebnis organisationaler Lernprozesse, sondern bilden auch den Ausgangspunkt weiteren organisationalen Lernens.

Die Literatur zum Thema Selbstorganisation wird stark von den Arbeiten von PROBST und anderen St. Galler Autoren geprägt. Mit geringfügigen Abweichungen thematisieren sie regelmäßig Phänomene wie Komplexität, Selbstreferenz, Autopoiese, relative Autonomie, operationelle Geschlossenheit und Redundanz als Voraussetzungen für das Auftreten von Selbstorganisationsprozessen. Der näheren Untersuchung hält diese schillernde Begriffswelt jedoch nicht Stand. In der vorliegenden Arbeit kann aufgezeigt werden, daß lediglich die relative Autonomie eines Subsystems das Auftreten emergenter und nicht-emergenter Selbstorganisationsprozesse fördert. Darüber hinaus erhöhen Synreferenz als eine Modifikation von Selbstreferenz, die die operationelle Schließung eines Subsystems bedingt, sowie Redundanz die relative Autonomie eines Subsystems und tragen damit indirekt zu einem verstärkten Auftreten emergenter und nicht-emergenter Selbstorganisationsprozesse bei. Entsprechend muß die Erhöhung der relativen Autonomie eines Subsystems im Mittelpunkt der Aktivitäten der organisatorischen Gestaltung stehen, die auf die Förderung von Selbstorganisationsprozessen als Prozessen organisationalen Lernens abstellen.

Die Operationalisierung des Zusammenhangs zwischen Selbst- und Fremdorganisation erfolgt mit Hilfe eines dimensionalen Ansatzes, innerhalb dessen aufgezeigt wird, welche Ausprägungen der organisatorischen Regeln zur Arbeitsteilung, zur Koordination, zum Leitungssystem sowie zur Entscheidungsdelegation als Ergebnis von Fremdorganisationsprozessen die relative Autonomie eines Subsystems und damit das Auftreten von Selbstorganisationsprozessen fördern. Die wichtigsten Empfehlungen für die organisatorische Gestaltung stellen auf eine verstärkt objektorientierte intersystemische Arbeitsteilung, die Gewährung expliziter Freiräume zur Selbstregelung in Kombination mit Plänen für die intrasystemische Koordination, Pläne und Programme für die intersystemische Koordination, die Einrichtung eines Einliniensystems sowie ein hohes Maß an Entscheidungsdelegation ab. 
Die Analyse des Zusammenhangs zwischen organisatorischer Gestaltung und Informationsmanagement setzt die Konzeptionalisierung des Informationsmanagements voraus. Die Ausführungen zur Erreichung dieses Zwischenziels der vorliegenden Arbeit bilden einen weiteren Baustein eines Managementkonzeptes organisationalen Lernens. Die Untersuchung der verfügbaren Literatur zeigt ein Theoriedefizit bezüglich eines über die reine Technikgestaltung hinausreichenden, auch betriebswirtschaftlich orientierten Informationsmanagements. Deshalb wird in der vorliegenden Arbeit ein ZweiEbenen-Ansatz des Informationsmanagements entwickelt, der explizit zwischen der Gestaltung der immateriellen und der materiellen Ebene des computergestützten Informationssystems unterscheidet. Die immaterielle Ebene umfaßt die informationellen Beziehungen zwischen den menschlichen Informationsverarbeitern mit ihren auf die Informationsverarbeitung als immaterielles Phänomen bezogenen Attributen. Dazu zählen insbesondere die Informationsbedarfe und -bereitstellungen, die neben situativen und subjektiven Faktoren von den organisatorischen Regeln beeinflußt werden. Die auf die immaterielle Ebene bezogenen Gestaltungsaktivitäten des Informationsmanagements haben zunächst die Ermittlung der Informationsbedarfe und -bereitstellungen zur Aufgabe und zielen sodann darauf ab, Informationsbedarfe und -bereitstellungen im Rahmen geeignet zu gestaltender informationeller Beziehungen in Einklang miteinander $\mathrm{zu}$ bringen. Auf der materiellen Ebene des computergestützten Informationssystems wird die Informationstechnik als das physische Trägermedium des immateriellen Phänomens Information gestaltet.

Dieser Zwei-Ebenen-Ansatz des Informationsmanagements bietet einerseits die Möglichkeit, die Gestaltung der Informationstechnik in einen umfassenderen Kontext einzuordnen, andererseits stellt er eine geeignete Basis für die Konzeptionalisierung des Zusammenhangs zwischen organisatorischer Gestaltung und Informationsmanagement dar. Dabei handelt es sich um das letzte der zu untersuchenden Zwischenziele, dessen Erreichung die Voraussetzung für die Untersuchung des Beitrags des Informationsmanagements zur Förderung organisationalen Lernens als des zentralen Ziels der vorliegenden Arbeit bildet. Hierfür wird der grundsätzlich bidirektionale Zusammenhang zwischen dem Organisationssystem, der Informationsstruktur und der Informationstechnik auf die unidirektionale Ableitung von Gestaltungsempfehlungen für die Informationstechnik aus solchen für die Informationsstruktur, die wiederum durch die auf die organisatorischen Regeln bezogenen Gestaltungsempfehlungen beeinflußt werden, reduziert.

Die Operationalisierung des Zusammenhangs zwischen den Aktivitäten der organisatorischen Gestaltung und denen des Informationsmanagements erfolgt mit Hilfe eines dimensionalen Ansatzes. Den Anstoß dazu liefert die Arbeit von WALL, die den einzigen im deutschsprachigen Raum verfügbaren Ansatz zur systematischen Verknüpfung von organisatorischen Fragestellungen mit solchen der Gestaltung der Informationstechnik darstellt und die zudem die Informationsbedarfe und -bereitstellungen der menschlichen Informationsverarbeiter berücksichtigt. Allerdings geht WALL von einem 
deterministischen Zusammenhang zwischen organisatorischen Regeln, Informationsbedarfen und -bereitstellungen sowie der Informationstechnik aus, der dem Informationsmanagement auf der immateriellen Ebene keinerlei und auch auf der materiellen Ebene nur einen geringen Gestaltungsspielraum einräumen würde. Dagegen werden dem Informationsmanagement gemäß dem Verständnis der vorliegenden Arbeit nicht nur bei der Gestaltung der Informationstechnik, sondern auch bei der Gestaltung der informationellen Beziehungen in der Unternehmung weitreichende Freiräume eingeräumt. Daraus folgt, daß hier explizit zwischen den Auswirkungen der organisatorischen Regeln auf Informationsbedarfe und -bereitstellungen einerseits und den vom Informationsmanagement zu gestaltenden informationellen Beziehungen andererseits unterschieden wird. Deshalb stellen die Annahmen von WALL zwar den Ausgangspunkt der diesbezüglichen Ausführungen der vorliegenden Arbeit dar, erfahren hier jedoch eine starke Modifikation.

Die auf die immaterielle Ebene des computergestützten Informationssystems bezogenen Aktivitäten des Informationsmanagements betreffen zunächst die Ermittlung der Konsequenzen für Informationsbedarfe und -bereitstellungen, die aus den oben genannten Ausprägungen der organisatorischen Regeln zu Arbeitsteilung, Koordination, Leitungssystem und Entscheidungsdelegation resultieren. Die Empfehlungen an die organisatorische Gestaltung führen tendenziell zu einem hohen inhaltlichen Umfang, einer geringen Bestimmtheit und Dringlichkeit von Informationsbedarfen und -bereitstellungen sowie einem hohen $\mathrm{Ma} ß$ an Informationsautarkie. Eine allgemeine Aussage bezüglich der Informationsqualität ist aufgrund der Vielzahl unterschiedlicher Einflüsse der organisatorischen Regeln nicht möglich.

Die aus den organisatorisch bedingten Ausprägungen der Informationsbedarfe und -bereitstellungen resultierenden Empfehlungen für die Gestaltung der informationellen Beziehungen als der zweiten auf die immaterielle Ebene des computergestützten Informationssystems bezogenen Aktivität des Informationsmanagements werden anhand der Dimensionen der Informationsstruktur in solche bezüglich Anzahl der informationellen Beziehungen, Informationsinhalt, -zeitpunkt, -form und -richtung gegliedert. Die wichtigsten Gestaltungsempfehlungen zielen hier auf das Einrichten eines unternehmungsweiten Informationspools in Kombination mit einer verstärkten Ausrichtung der Informationsversorgung am Holprinzip sowie die Fokussierung der Informationsversorgung der unteren Hierarchieebenen als zusätzliche 'top-down-Perspektive' ab.

Aus den formulierten Gestaltungsempfehlungen bezüglich der immateriellen Ebene resultieren solche für die Informationstechnik als der materiellen Ebene des computergestützten Informationssystems, die anhand der Dimensionen Daten, Netz, Anwendungsprogramme und Rechner gegliedert werden können. Im Mittelpunkt der Gestaltungsempfehlungen stehen hier das Data Warehouse und vor allem das Knowledge Warehouse als mögliche informationstechnische Umsetzungen des auf der imma- 
teriellen Ebene geforderten Informationspools. Für die Anwendungsprogramme im Kontext des Data Warehouse wird eine benutzerspezifische Bereitstellung auch für die unteren Hierarchieebenen gefordert, während die Anwendungsprogramme im Kontext des Knowledge Warehouse eine einheitliche Suchfunktionalität für alle Mitarbeiter der Unternehmung bereitstellen sollten. Bezüglich der Dimension Netz erweist sich die mit der Verwendung globaler Protokolle verbundene unternehmungsinterne und -übergreifende Standardisierung als sinnvoll, wie sie durch den Einsatz eines Intranet mit Anbindung an das Internet erfolgt. Schließlich ist für die Dimension Rechner bei einer Kombination von zentraler und dezentraler Rechnerkapazität vor allem die Delegation der Entscheidungskompetenz für die dezentrale Rechnerkapazität an die jeweiligen Subsysteme zu fordern.

Die Überwindung der Theoriedefizite bezüglich der Konzeptionalisierung des organisationalen Lernens, des Aufgabenfeldes Informationsmanagement, des Zusammenhangs zwischen organisatorischer Gestaltung und Selbstorganisation sowie des Zusammenhangs zwischen organisatorischer Gestaltung und Informationsmanagement im Rahmen der Ausführungen der vorliegenden Arbeit macht somit schließlich die Ableitung theoretisch fundierter Gestaltungsempfehlungen für das Informationsmanagement in der lernenden Unternehmung möglich. Damit sind die Voraussetzungen geschaffen, um in zukünftigen Forschungsarbeiten einerseits die Rolle des Informationsmanagements bei der Förderung organisationalen Lernens innerhalb des hier entwickelten theoretischen Rahmens weitergehenden Untersuchungen zu unterziehen. Andererseits gälte es, die modelltheoretischen Rahmenbedingungen der vorliegenden Arbeit als Ausgangspunkt für die Entwicklung weiterer Bausteine eines Managementkonzeptes organisationalen Lernens zu verwenden und diese letztlich mit den hier entwickelten Bausteinen zu einem integrierten Ansatz zur Förderung organisationalen Lernens in der Unternehmung zusammenzuführen.

So wäre bezüglich des Informationsmanagements die Entwicklung eines Implementierungsansatzes wünschenswert, der unter Verfolgung einer dynamischen Perspektive auf den Prozeß der Schaffung und Aufrechterhaltung geeigneter Rahmenbedingungen zur Förderung organisationalen Lernens abstellt. Dieser müßte insbesondere über die Ausprägungen der organisatorischen Regeln hinaus die systematische Berücksichtigung der konkreten situativen und subjektiven Einflußfaktoren auf Informationsbedarfe und -bereitstellungen der Mitarbeiter bei der Gestaltung der informationellen Beziehungen ermöglichen. Ferner besteht auf der Ebene der Informationstechnik umfangreicher Forschungsbedarf. Während nämlich das Data Warehouse seit einigen Jahren im Mittelpunkt der Forschungs- und Entwicklungsbemühungen von Wissenschaft und Praxis steht und hier vielfältige, ausgefeilte informationstechnische Lösungen verfügbar sind, existieren zum Knowledge Warehouse zur Zeit nur einige wenige konzeptionelle Arbeiten. Entsprechend ist eine Intensivierung der diesbezüglichen Forschungs- und Entwicklungsarbeit zu fordern. Diese sollten einerseits auf die automatische Generierung von Metadaten aus den heterogenen Datenbeständen sowie deren geeignete Darstellung 
und Verwaltung in der Metadatenbank abzielen. Andererseits müssen auf der Anwendungsseite geeignete Tools geschaffen werden, die den einfachen Zugriff auf die Metadaten erlauben und idealerweise mit dem Zugriff auf die Originaldaten auch den zweiten Schritt, der einer Verarbeitung dieser Daten vorausgeht, unterstützen.

Über die organisatorische Gestaltung und das Informationsmanagement hinaus können auch andere Managementaktivitäten in der Unternehmung zu einer Förderung organisationalen Lernens beitragen. So war z.B. im Rahmen der obigen Ausführungen zum Informationsmanagement darauf hingewiesen worden, daß es gilt, die Bereitschaft der Mitarbeiter zu erhöhen, ihr Wissen mit anderen zu teilen. Letztlich handelt es sich dabei um eine Veränderung heute typischer Unternehmungskulturen, die häufig auf dem Grundsatz 'Wissen ist Macht' basieren, hin zu einer Unternehmungskultur, die das bedarfsgerechte Teilen von Wissen in den Vordergrund stellt. Hier ist neben dem Informationsmanagement insbesondere die Personalwirtschaft gefordert. So können z.B. durch die Definition geeigneter Kriterien zur Personalbeurteilung und darauf aufsetzender Beförderungsentscheidungen Anreize für ein entsprechendes Verhalten der Mitarbeiter geschaffen werden. Über die Personalwirtschaft hinaus sollte prinzipiell jede Managementaktivität in der Unternehmung auf ihren potentiellen Beitrag zur Förderung organisationalen Lernens in der Unternehmung untersucht werden. Versteht man diese Einzeluntersuchungen anderer Aufgabenfelder als weitere Bausteine eines Managementkonzeptes organisationalen Lernens, so könnten die in der vorliegenden Arbeit entwickelten Bausteine stufenweise zu einem die gesamte Unternehmung umfassenden Managementkonzept organisationalen Lernens ergänzt werden. 
Frauke Streubel - 978-3-631-75510-5

Downloaded from PubFactory at 01/11/2019 04:00:13AM 


\section{Literaturverzeichnis}

Ackoff, Russell L. (1961): Systems, Organizations and Interdisziplinary Research, in: Eckmann, Donald P. (Hrsg.): Research and Design, New York/London 1961, S. $26-42$

Albach, Horst (1974): Innerbetriebliche Lenkpreise als Instrument dezentraler Unternehmensführung, in: Zeitschrift für betriebswirtschaftliche Forschung, Heft 3/4, 1974, S. 216-242

Albrecht, Frank (1993): Strategisches Management der Unternehmensressource Wissen. Inhaltliche Ansatzpunkte und Überlegungen zu einem konzeptionellen Gestaltungsrahmen, Dissertation Technische Universität Berlin, Frankfurt am Main u.a. 1993

Alioth, Andreas (1978): Entwicklung und Einführung alternativer Arbeitsformen, Dissertation Hochschule St. Gallen, Bern 1978

Anderson, Peter W. (1972): More Is Different. Broken Symmetry and the Nature of the Hierarchical Structure of Science, in: Science, Heft 4047, 1972, S. 393-396

Angermeyer, Hans Christoph (1993): Die Einführung von Informations-Management - eine Führungsaufgabe, in: Zeitschrift Führung und Organisation, Heft 4, 1993, S. $235-241$

Ansoff, Harry I./Declerck, Roger P./Hayes, Roger L. (1997): From Strategic Planning to Strategic Management, in: Hahn, Dietger/Taylor, Bernard (Hrsg.): Strategische Unternehmungsplanung - Strategische Unternehmensführung, 7. Auflage, Heidelberg/Wien 1997, S. 719-756

Argyris, Chris/Schön, Donald A. (1978): Organizational Learning, Reading (Massachusetts) 1978

Ashby, W. Ross (1974): Einführung in die Kybernetik, Frankfurt am Main 1974

Baetge, Jörg (1974): Betriebswirtschaftliche Systemtheorie, Opladen 1974

Balzert, Helmut (1982): Die Entwicklung von Software-Systemen: Prinzipien, Methoden, Sprachen, Werkzeuge, Zürich 1982

Bandura, Albert (1979): Sozial-kognitive Lerntheorie, Stuttgart 1979

Baumöl, Ulrike (1998): Die (R-) Evolution im Informationsmanagement. So beschleunigen Sie den Informationsfluß im Unternehmen. Mit vielen Beispielen, Wiesbaden 1998

Becker, Jochen (1998): Marketing-Konzeption: Grundlagen des strategischen und operativen Marketing-Managements, 6. Auflage, München 1998

Beier, Dirk/Gabriel, Roland (1998): Methoden und Organisation des Informationsmanagements, Arbeitsbericht Nr. 98-28 des Lehrstuhls für Wirtschaftsinformatik der Ruhr-Universität Bochum, Bochum 1998

Beier, Dirk/Gabriel, Roland/Streubel, Frauke (1997): Ziele und Aufgaben des Informationsmanagements, Arbeitsbericht Nr. 97-23 des Lehrstuhls für Wirtschaftsinformatik der Ruhr-Universität Bochum, Bochum 1997

Bell, Daniel (1985): Die nachindustrielle Gesellschaft, Frankfurt am Main u.a. 1985

Benson, Robert J./Parker, Marilyn M. (1985): Enterprise-wide Information Management - An Introduction to the Concepts, IBM Los Angeles Scientific Center Report Nr. G 320-2768, Los Angeles 1985 
Bernskötter, Hanns (1997): Lernende Organisationen. Schlagwort oder mehr?, in: Marketing Journal, Heft 1, 1997, S. 30-32

Bertalanffy, Ludwig von (1968): General Systems Theory, New York 1968

Berthel, Jürgen (1975): Betriebliche Informationssysteme, Stuttgart 1975

Berthel, Jürgen (1992): Informationsbedarf, in: Frese, Erich (Hrsg.): Handwörterbuch der Organisation, 3. Auflage, Stuttgart 1992, Sp. 872-886

Beutel-Wedewardt (1991): Multiplikatorenkonzepte - ein Einstieg in die lernende Organisation?, in: Sattelberger, Thomas (Hrsg.): Die lernende Organisation: Konzepte für eine neue Qualität der Unternehmensentwicklung, Wiesbaden 1991, S. $245-259$

Bierfelder, Wilhelm (1991): Entwicklungsdynamik von Unternehmen - Gestaltung von Übergängen und Selbstorganisation, Wiesbaden 1991

Biethahn, Jörg/Mucksch, Harry/Ruf, Walter (1994): Ganzheitliches Informationsmanagement, Band 1: Grundlagen, 3. Auflage, München/Wien 1994

Bleicher, Knut (1985): Meilensteine auf dem Weg zur Vertrauensorganisation, in: Thexis, Heft 4, 1985, S. 2-7

Bleicher, Knut (1991): Organisation. Strategien - Strukturen - Kulturen, 2. Auflage, Wiesbaden 1991

Bleicher, Knut (1992a): Leitbilder, Stuttgart 1992

Bleicher, Knut (1992b): Organisatorische(n) Gestaltung, Theorie der, in: Frese, Erich (Hrsg.): Handwörterbuch der Organisation, 3. Auflage, Stuttgart 1992, Sp. 1883-1900

Bleicher, Knut (1993): Organisation, in: Bea, Franz Xaver/Dichtl, Erwin/Schweitzer, Marcell (Hrsg.): Allgemeine Betriebswirtschaftslehre, Band 2: Führung, 6. Auflage, Stuttgart/Jena 1993, S. 103-186

Bleicher, Knut (1994): Betriebswirtschaftslehre - Disziplinäre Lehre vom Wirtschaften in und zwischen Betrieben oder interdisziplinäre Wissenschaft vom Management?, in: Wunderer, Rolf (Hrsg.): Betriebswirtschaftslehre als Managementund Führungslehre, 3. Auflage, Stuttgart 1994, S. 91-120

Bleicher, Knut (1995a): Vertrauen als kritischer Faktor einer Bewältigung des Wandels, in: Zeitschrift Führung und Organisation, Heft 6, 1995, S. 390-395

Bleicher, Knut (1995b): Das Konzept Integriertes Management, 3. Auflage, Frankfurt am Main 1995

Bleicher, Knut/Meyer, Erik (1976): Führung in der Unternehmung, Reinbek bei Hamburg 1976

Boaden, R./Lockett, G. (1991): Information Technology, Information Systems and Information Management: Definition and Development, in: European Journal of Information Systems, Heft 1, 1991, S. 23-32

Bode, Jürgen (1997): Der Informationsbegriff in der Betriebswirtschaftslehre, in: Zeitschrift für betriebswirtschaftliche Forschung, Heft 5, 1997, S. 449-468

Boehm, Barry W. (1986): Wirtschaftliche Software-Produktion, Wiesbaden 1986

Bredenkamp, Karin/Bredenkamp, Jürgen (1976): Was ist Lernen?, in: Weinert, Franz E. (Hrsg.): Pädagogische Psychologie. Band 5, Weinheim/Basel 1976, S. $1-19$ 
Breilmann, Ulrich (1989): Die Berücksichtigung der strategischen Wahl im Rahmen eines neokontingenztheoretischen Ansatzes, Dissertation Universität Bochum, Frankfurt am Main 1990

Brenner, Walter (1994): Konzepte des Informationssystem-Managements, Heidelberg 1994

Brenner, Walter/Hamm, Volker (1994): Wege zu einem schlanken Informationsmanagement, in: Handbuch Moderner Datenverarbeitung, Heft 179, 1994, S. 8-25

Brockhaus, Rainer (1992): Informationsmanagement als ganzheitliche, informationsorientierte Gestaltung von Unternehmen, Dissertation Universität Göttingen, Göttingen 1992

Bronner, Rolf (1992): Komplexität, in: Frese, Erich (Hrsg.): Handwörterbuch der Organisation, 3. Auflage, Stuttgart 1992, Sp. 1121-1130

Broßmann, Michael (1998): Multipointkonferenzen. Spontane Meetings auf dem Schirm, in: Office Management, Heft 5, 1998, S. 56-57

Bühl, Walter L. (1984): Die Ordnung des Wissens, Berlin 1984

Bühner, Rolf (1994): Betriebswirtschaftliche Organisationslehre, 7. Auflage, München/Wien 1994

Bühner, Rolf/Pharao, Iris (1993): Erfolgsfaktoren integrierter Gruppenarbeit, in: VDI Zeitschrift, Heft 1/2, 1993, S. 46-57

Busse von Colbe, Walther/Laßmann, Gert (1991): Betriebswirtschaftstheorie, Band 1: Grundlagen, Produktions- und Kostentheorie, 5. Auflage, Berlin/Heidelberg 1991

Cangelosi, Vincent E. /Dill, William R. (1965): Organizational Learning Observations Toward a Theory, in: Administrative Science Quarterly, Heft 2, 1965, S. 175203

Carnall, Colin A. (1990): Managing Change in Organizations, New York u.a. 1990

Cavalli-Sforza, Violetta/Lesgold, Alan (1995): Intelligent Learning by Doing Tools for Technical and Dialectical Knowledge, in: Zucchermaglio, Cristina/Bagnara, Sebastiano/Stucky, Susan U. (Hrsg.) (1995): Organizational Learning and Technological Change, Proceedings of the NATO Advanced Research Workshop on Organizational Learning and Technological Change (Siena, 22.26.9.1992), Berlin/Heidelberg 1995, S. 225-253

Chamoni, Peter (1998): Entwicklungslinien und Architekturkonzepte des On-Line Analytical Processing, in: Chamoni, Peter/Gluchowski, Peter (Hrsg.): Analytische Informationssysteme. Data Warehouse, On-Line Analytical Processing, Data Mining, Berlin/Heidelberg u.a. 1998, S. 231-250

Chamoni, Peter/Gluchowski, Peter (1998): Analytische Informationssysteme - Einordnung und Überblick, in: Chamoni, Peter/Gluchowski, Peter (Hrsg.): Analytische Informationssysteme. Data Warehouse, On-Line Analytical Processing, Data Mining, Berlin/Heidelberg u.a. 1998, S. 3-25

Chmielewicz, Klaus (1994): Forschungskonzeptionen der Wirtschaftswissenschaft, 3. Auflage, Stuttgart 1994

Christmann-Jacoby, Hans/Maas, Robert (1997): Wissensmanagement im Projektumfeld auf Basis von Internet-Technologien, in: Information Management, Heft 3, 1997, S. 16-26 
Chrobok, Reiner (1997): ZfO-Stichwort: Selbstorganisation, in: Zeitschrift Führung und Organisation, Heft 2, 1997, S. 114-115

Churchman, Charles W. (1973): Perspektiven des Systemansatzes, in: Hentsch, Benedict/Malik, Fredmund (Hrsg.): Systemorientiertes Management, Bern 1973

Clancey, William J. (1995): Practice Cannot be Reduced to Theory: Knowledge, Representations and Change in the Workplace, in: Zucchermaglio, Cristina/Bagnara, Sebastiano/Stucky, Susan U. (Hrsg.) (1995): Organizational Learning and Technological Change, Proceedings of the NATO Advanced Research Workshop on Organizational Learning and Technological Change (Siena, 22.26.9.1992), Berlin/Heidelberg 1995, S. 16-46

Coenenberg, Adolf G. (1999): Kostenrechnung und Kostenanalyse, 4. Auflage, Landsberg am Lech 1999

Corsten, Hans: Komponenten und Instrumente der produktionswirtschaftlichen Flexibilität, in: WISU-Studienblatt, Beilage zu: Das Wirtschaftsstudium, Heft 10, 1988, o.S.

Cyert, Richard M./ March, James G. (1963): A Behavioral Theory of the Firm, Englewood Cliffs (New Jersey) 1963

Daenzer, Walter F./Huber, Fritz (1992): Systems Engineering. Methodik und Praxis, 7. Auflage, Zürich 1992

Dataware Technologies (1999a): Knowledge Management. Linking People to Knowledge for Bottom Line Results, in: http://www.dataware.com/km/linking.pdf (Stand: April 1999)

Dataware Technologies (1999b): Corporate Executive Briefing. Seven Steps to Implementing Knowledge Management in Your Organization, in: http://www.dataware.com/km/7steps.pdf (Stand: April 1999)

De Geus, Arie P. (1988): Planning as Learning, in: Harvard Business Review, Heft 1, 1988, S. 70-74

Delfmann, Werner (1993): Planungs- und Kontrollprozesse, in: Wittmann, Waldemar et al. (Hrsg.): Handwörterbuch der Betriebswirtschaft, Teilband 2, 5. Auflage, Stuttgart 1993, Sp. 3232-3251

Delhees, Karl H. (1990): Die Lern- und Entwicklungsfähigkeit älterer Mitarbeiter, in: Die Unternehmung, Heft 1, 1990, S. 2-10

Deppe, Joachim (1992): Quality Circle und Lernstatt. Ein integrativer Ansatz, 3. Auflage, Wiesbaden 1992

Dieter, Thomas (1997): Besuchsberichtssystem auf Basis von Lotus Notes, in: Technologie \& Management, Heft 1, 1997, S. 18-25

Dittmar, Carsten (1999): Einführungsstrategien für Data Warehouse-Projekte, Arbeitsbericht des Instituts für Unternehmungsführung und Unternehmensforschung der Ruhr-Universität Bochum, in Vorbereitung

Dodgson, Mark (1993): Organizational Learning: A Review of Some Literatures, in: Organization Studies, Heft 3, 1993, S. 375-394

Döring, Klaus W. (1983): Lehren in der Erwachsenenbildung, Weinheim/Basel, 1983

Drucker, Peter Ferdinand (1969): The Age of Discontinuity. Guidelines to Our Changing Society, London 1969 
Dülfer, Eberhard (1993): Management in fremden Kulturen, in: Wittmann, Waldemar et al. (Hrsg.): Handwörterbuch der Betriebswirtschaft, Teilband 2, 5. Auflage, Stuttgart 1993, Sp. 2647-2663

Düsing, Roland (1998): Knowledge Discovery in Databases und Data Mining, in: Chamoni, Peter/Gluchowski, Peter (Hrsg.): Analytische Informationssysteme. Data Warehouse, On-Line Analytical Processing, Data Mining, Berlin/Heidelberg u.a. 1998, S. 291-299

Duncan, Robert/Weiss, Andrew (1979): Organizational Learning: Implications for Organizational Design, in: Staw, Barry M. (Hrsg.): Research in Organizational Behavior, Band 1, Greenwich (Connecticut) 1979, S. 75-123

Eckel, George/Stehen, William (1997): Intranets: Technik, Aufbau und effektiver Nutzen im Unternehmen, München/Wien 1997

Elkjaer, Bente (1995): Learning is an Active and Personal Process, in: Zucchermaglio, Cristina/Bagnara, Sebastiano/Stucky, Susan U. (Hrsg.) (1995): Organizational Learning and Technological Change, Proceedings of the NATO Advanced Research Workshop on Organizational Learning and Technological Change (Siena, 22.-26.9.1992), Berlin/Heidelberg 1995, S. 75-95

Emery, Frederick E./ Trist, Eric L. (1965): The Causal Texture of Organizational Environments, in: Human Relations, Heft 1, 1965, S. 21-32

Eppler, Martin J. (1997): Praktische Instrumente des Wissensmanagements - Wissenskarten: Führer durch den „Wissensdschungel“, in: Gablers Magazin, Heft 8, 1997, S. 10-13

Erler, Thomas/Schelp, Joachim (1998): Das Data Warehouse im Kontext der strategischen Bedeutung betrieblicher Informationssysteme, Arbeitsbericht Nr. 98-32 des Lehrstuhls für Wirtschaftsinformatik der Ruhr-Universität Bochum, Bochum 1998

Eschenröder, Gerhard (1985): Planungsaspekte einer ressourcenorientierten Informationswirtschaft, Dissertation Universität Köln 1984, Bergisch Gladbach 1985

Felsch, Anke (1996): Personalentwicklung und Organisationales Lernen. Mikropolitische Perspektiven zur theoretischen Grundlegung, Dissertation Universität Hamburg, Hamburg 1996

Fiol, C. Marlene/Lyles, Marjorie A. (1985): Organizational Learning, in: Academy of Management Review, Heft 4, 1985, S. 803-813

Fischbach, Rainer (1996): Verständige Schlapphüte. Für und Wider: Intelligente Softwareagenten, in: iX Magazin für professionelle Informationstechnologie, Heft 4, 1996, S. 146-155

Föhr, Silvia/Lenz, Hansrudi (1992): Unternehmenskultur und ökonomische Theorie, in: Staehle, Wolfgang H./Conrad, Peter (Hrsg.): Managementforschung, Band 2, Berlin/New York 1992, S. 111-162

Foerster, Heinz von (1984): Principles of Self-Organization - In a Socio-Managerial Context, in: Ulrich, Hans/Probst, Gilbert J.B. (Hrsg.): Self-Organization and Management of Social Systems. Insights, Promises, Doubts and Questions, Berlin u.a. 1984, S. 2-24

Foerster, Heinz von (1988): Das Konstruieren einer Wirklichkeit, in: Watzlawick, Paul (Hrsg.): Die erfundene Wirklichkeit, 5. Auflage, München (1988), S. 39-60

French, Wendell/Bell, Cecil H. (1994): Organisationsentwicklung. Sozialwissenschaftliche Strategien zur Organisationsveränderung, 4. Auflage, Bern 1994 
Frese, Erich (1992): Organisationstheorie, in: Frese, Erich (Hrsg.): Handwörterbuch der Organisation, 3. Auflage, Stuttgart 1992, Sp. 1706-1733

Frese, Erich (1993): Geschäftssegmentierung als organisatorisches Konzept - zur Leitbildfunktion mittelständischer Strukturen für Großunternehmungen -, in: Zeitschrift für betriebswirtschaftliche Forschung, Heft 12, 1993, S. 999-1024

Frese, Erich (1995): Grundlagen der Organisation. Konzept - Prinzipien - Strukturen, 6. Auflage, Wiesbaden 1995

Frese, Erich/Werder, Axel von (1993): Zentralbereiche. Organisatorische Formen und Effizienzbeurteilung, in: Frese, Erich/Werder, Axel von/Maly, Werner (Hrsg.): Zentralbereiche. Theoretische Grundlagen und praktische Erfahrungen, Stuttgart 1993, S. 1-50

Fuchs, Herbert (1973): Systemtheorie und Organisation. Die Theorie offener Systeme als Grundlage zur Erforschung und Gestaltung betrieblicher Systeme, Wiesbaden 1973

Fuchs, Ludwin/Pankoke-Babatz, Uta/Prinz, Wolfgang (1994): Ereignismechanismen zur Unterstützung der Orientierung in Kooperationsprozessen, in: Hasenkamp, Ulrich (Hrsg.): Einführung von CSCW-Systemen in Organisationen, Tagungsband der D-CSCW '94, Braunschweig/Wiesbaden 1994, S. 31-45

Gabriel, Roland (1992): Wissensbasierte Systeme in der betrieblichen Praxis, Hamburg/New York 1992

Gabriel, Roland (1994) et al.: Büroinformations- und -kommunikationssysteme. Aufgaben - Systeme - Anwendungen, Heidelberg 1994

Gabriel, Roland/Röhrs, Heinz-Peter (1995): Datenbanksysteme. Konzeptionelle Datenmodellierung und Datenbankarchitekturen, 2. Auflage, Berlin/Heidelberg 1995

Gage, Nathaniel L./Berliner, David C. (1986): Pädagogische Psychologie, 4. Auflage, München 1986

Garratt, Bob (1990): Creating a Learning Organization, Cambridge 1990

Gaugler, Eduard (1994): Zur Weiterentwicklung der Betriebswirtschaftslehre als Management- und Führungslehre, in: Wunderer, Rolf (Hrsg.): Betriebswirtschaftslehre als Management- und Führungslehre, 3. Auflage, Stuttgart 1994, S. 251-264

Gebhardt, Wilfried (1996): Organisatorische Gestaltung durch Selbstorganisation. Konzept - Ökonomische Fundierung - Praktische Umsetzung, Dissertation Universität Eichstätt, Wiesbaden 1996

Geißler, Harald: Vom Lernen in der Organisation zum Lernen der Organisation, in: Sattelberger, Thomas (Hrsg.): Die lernende Organisation: Konzepte für eine neue Qualität der Unternehmensentwicklung, Wiesbaden 1991, S. 79-96

Gemünden, Hans Georg (1993): Information: Bedarf, Analyse und Verhalten, in: Wittmann, Waldemar et al. (Hrsg.): Handwörterbuch der Betriebswirtschaft, Teilband 2, 5. Auflage, Stuttgart 1993, Sp. 1725-1735

Gerstner, Thomas S. (1995): Die Bewältigung organisatorischer Übergänge. Vom Management zum Mastering, Dissertation Universität Stuttgart, Wiesbaden 1995 
Geyer, Erich (1997): Innovatives, kreatives und selbstbestimmtes Lernen in der lernenden Organisation, in: Dr. Wieselhuber \& Partner (Hrsg.): Handbuch Lernende Organisation. Unternehmens- und Mitarbeiterpotentiale erfolgreich erschließen, Wiesbaden 1997, S. 117-127

Giddens, Anthony (1981): A Contemporary Critique of Historical Materialism, Band 1: Power, Property and the State, London/Berkeley (California) 1981

Gilles, Ralf (1999): Qualitätsmanagement auf der Grundlage eines betriebswirtschaftlichen Qualitätsinformationssystems, Dissertation Universität Bochum, in Vorbereitung

Glaserfeld, Ernst von (1997): Erklärung der American Society for Cybernetics, in: Glaserfeld, Ernst von (Hrsg.): Radikaler Konstruktivismus. Ideen, Ergebnisse, Probleme, Frankfurt am Main 1997, S. 238-245

Gloede, Dieter (1991): Strategische Personalplanung in multinationalen Unternehmungen, Dissertation Universität Bochum, Wiesbaden 1991

Gluchowski, Peter (1997): Data Warehouse - Konzepte, Produkte und Einsatzmöglichkeiten, in: Gabriel, Roland (Hrsg.): Data Warehouse -Einsatzmöglichkeiten in der Praxis, Beiträge zu einem Workshop am 20.11.1997, Arbeitsbericht Nr. 70 des Instituts für Unternehmungsführung und Unternehmensforschung der RuhrUniversität Bochum, Bochum 1997

Gluchowski, Peter (1998): Techniken und Werkzeuge zum Aufbau betrieblicher Berichtssysteme, in: Chamoni, Peter/Gluchowski, Peter (Hrsg.): Analytische Informationssysteme. Data Warehouse, On-Line Analytical Processing, Data Mining, Berlin/Heidelberg u.a. 1998, S. 179-200

Gluchowski, Peter/Gabriel, Roland/Chamoni, Peter (1997): Management Support Systeme. Computergestützte Informationssysteme für Führungskräfte und Entscheidungsträger, Berlin/Heidelberg u.a. 1997

Göbel, Elisabeth (1993): Selbstorganisation - Ende oder Grundlage rationaler Organisationsgestaltung?, in: Zeitschrift Führung und Organisation, Heft 6, 1993, S. 391-395

Gomez, Peter (1988): Die Organisation der Autonomie. Neue Denkmodelle für die Unternehmensführung, in: Zeitschrift Führung und Organisation, Heft 6, 1988, S. 389-393

Gomez, Peter/Müller-Stewens, Günter (1994): Corporate Transformation: Zum Management fundamentalen Wandels großer Unternehmen, in: Gomez, Peter et al. (Hrsg.): Unternehmerischer Wandel: Konzepte zur organisatorischen Erneuerung, Wiesbaden 1994, S. 135-197

Gomez, Peter/Probst Gilbert J.B. (1985): Organisationelle Geschlossenheit im Management sozialer Institutionen - ein komplementäres Konzept zu den Kontingenz-Ansätzen, in: Delfin. Deutsche Zeitschrift für Konstruktion, Analyse und Kritik, Heft 5, 1985, S. 22-29

Gomez, Peter/Zimmermann, Tim (1992): Unternehmensorganisation. Profile, Dynamik, Methodik, Frankfurt 1992

Greer, Tyson (1997): Intranets verstehen. Ein Leitfaden für Entscheidungsträger, 13. Auflage, Unterschleißheim 1997

Griese, Joachim (1990): Ziele und Aufgaben des Informationsmanagements, in: Kurbel, Karl/Strunz, Horst (Hrsg.): Handbuch der Wirtschaftsinformatik, Stuttgart 1990, S. 641-657 
Grochla, Erwin (1978): Einführung in die Organisationstheorie, Stuttgart 1978

Grochla, Erwin (1982): Grundlagen der organisatorischen Gestaltung, Stuttgart 1982

Grothe, Martin (1997): Ordnung als betriebswirtschaftliches Phänomen. Die Bedeutung von Koordination und Komplexität, Dissertation Wissenschaftliche Hochschule für Unternehmensführung Koblenz, Wiesbaden 1997

Grün, Josef (1993): Qualifizierung und verbesserte betriebliche Qualifikation durch Gruppenarbeit, in: IO Management Zeitschrift, Heft 6, 1993, S. 50-55

Grün, Oskar (1980): Informale Organisation, in: Grochla, Erwin (Hrsg.): Handwörterbuch der Organisation, 2. Auflage, Stuttgart 1980, Sp. 881-889

Güldenberg, Stefan (1997): Wissensmanagement und Wissenscontrolling in lernenden Organisationen. Ein systemtheoretischer Ansatz, Dissertation Wirtschaftsuniversität Wien, Wiesbaden 1997

Güldenberg, Stefan/Eschenbach, Rolf (1996): Organisatorisches Wissen und Lernen erste Ergebnisse einer qualitativ-empirischen Erhebung, in: Zeitschrift Führung und Organisation, Heft 1, 1996, S. 4-9

Gulowsen, Jon (1972): A Measure of Work-Group Autonomy, in: Davis, Louis E./Taylor, James C. (Hrsg.): Design of Jobs, Harmondsworth (Middlesex) 1972, S. 374-390

Gutenberg, Erich (1962): Unternehmensführung - Organisation und Entscheidung, Wiesbaden 1962

Gutenberg, Erich (1983): Grundlagen der Betriebswirtschaftslehre. Erster Band: Die Produktion, 24. Auflage, Berlin/Heidelberg 1983

Hahn, Dietger (1989): Strategische Unternehmungsführung - Stand und Entwicklungstendenzen unter besonderer Berücksichtigung US-amerikanischer Konzepte, in: Seidel, Eberhard/Wagner, Dieter (Hrsg.): Organisation. Evolutionäre Interdepenzen von Kultur und Struktur der Unternehmung, Wiesbaden 1989, S. $55-78$

Hahn, Dietger (1994): Unternehmungsziele im Wandel, in: Gomez, Peter/Hahn, Dietger/Müller-Stewens, Günter/Wunderer, Rolf: Unternehmerischer Wandel. Konzepte zur organisatorischen Erneuerung, Wiesbaden 1994, S. 59-83

Hahn, Dietger/Laßmann, Gert (1993): Produktionswirtschaft - Controlling industrieller Produktion, Band 3, Zweiter Teilband: Informationssystem, Heidelberg 1993

Hahne, Michael (1998): Logische Datenmodellierung für das Data Warehouse. Bestandteile und Varianten des Star Schemas, in: Chamoni, Peter/Gluchowski, Peter (Hrsg.): Analytische Informationssysteme. Data Warehouse, On-Line Analytical Processing, Data Mining, Berlin/Heidelberg u.a. 1998, S. 103-122

Hahne, Michael/Schelp, Joachim (1997): Semantische und logische Modellierung mehrdimensionaler Datenstrukturen, Arbeitsbericht Nr. 97-26 des Lehrstuhls für Wirtschaftsinformatik der Ruhr-Universität Bochum, Bochum 1997

Hansen, Hans Robert (1996): Wirtschaftsinformatik I, Grundlagen betrieblicher Informationsverarbeitung, 7. Auflage, Stuttgart 1996

Harbrecht, Wolfgang (1993): Bedürfnis, Bedarf, Gut, Nutzen, in: Wittmann, Waldemar et al. (Hrsg.): Handwörterbuch der Betriebswirtschaft, Teilband 1, 5. Auflage, Stuttgart 1993, Sp. 266-280 
Hartroth, Jörn/Kottmann, Dietmar (1996): Mobile Softwareagenten: Entwicklungsstand und Einsatzperspektiven, in: Handbuch Moderner Datenverarbeitung, Heft 190, 1996, S. 91-107

Hasenkamp, Ulrich/Syring, Michael (1990): Bibliographie zum Thema Anwendungsarchitektur, in: Wirtschaftsinformatik, Heft 5, 1990, S. 446-450

Hasenkamp, Ulrich/Syring, Michael (1994): CSCW (Computer Supported Cooperative Work) in Organisationen - Grundlagen und Probleme, in: Hasenkamp, Ulrich/Kirn, Stefan/Syring, Michael (Hrsg.): CSCW - Computer Supported Cooperative Work, Informationssysteme für dezentrale Unternehmensstrukturen, Bonn/Paris 1994, S. 15-37

Hayek, Friedrich August von (1945): The Use of Knowledge in Society, in: The American Economic Review, Heft 4, 1945, S. 519-530

Hayek, Friedrich August von (1969a): Bemerkungen über die Entwicklung von Systemen von Verhaltensregeln, in: Hayek, Friedrich August von (Hrsg.): Freiburger Studien - Gesammelte Aufsätze, Tübingen 1969, S. 144-160

Hayek, Friedrich August von (1969b): Die Ergebnisse menschlichen Handelns, aber nicht menschlichen Entwurfs, in: Hayek, Friedrich August von (Hrsg.): Freiburger Studien - Gesammelte Aufsätze, Tübingen 1969, S. 97-107

Hayek, Friedrich August von (1972): Die Theorie komplexer Phänomene, Tübingen 1972

Hayek, Friedrich August von (1991): Spontaneous ('grown') order and organized ('made') order, in: Thompson, Grahame et al. (Hrsg.): Markets, Hierarchies and Networks. The Coordination of Social Life, London/Newbury Park/New Delhi 1991, S. 293-301

Hedberg, Bo (1981): How Organziations Learn and Unlearn, in: Nystrom, Paul C./Starbuck, William H. (Hrsg.): Handbook of Organizational Design, Band 1, New York 1981, S. 3-27

Heilmann, Heidi (1989): Integration: Ein zentraler Begriff aus der Wirtschaftsinformatik im Wandel der Zeit, in: Handbuch Moderner Datenverarbeitung, Heft 150, 1989 , S. $46-58$

Heinen, Edmund/Fank, Matthias (1997): Unternehmenskultur. Perspektiven für Wissenschaft und Praxis, 2. Auflage, München 1997

Heinrich, Lutz J. (1996): Informationsmanagement. Planung, Überwachung und Steuerung der Informationsinfrastruktur, 5. Auflage, München/Wien 1996

Heinrich, Lutz J./Burgholzer, Peter (1987): Informationsmanagement. Planung, Überwachung und Steuerung der Informationsinfrastruktur, 1. Auflage, München/Wien 1987

Heinze, Burger (1985): Lernen und Lerntheorien, in: Sarges, Werner/Fricke, Rainer (Hrsg.): Psychologie für die Erwachsenenbildung/Weiterbildung, Göttingen u.a. 1986 , S. $350-354$

Hejl, Peter M. (1982): Sozialwissenschaft als Theorie selbstreferentieller Systeme, Frankfurt am Main/New York 1982

Hejl, Peter M. (1983): Kybernetik 2. Ordnung, Selbstorganisation und Biologismusverdacht. Aus Anlaß der Kontroverse um das "Evolutionäre Management", in: Die Unternehmung, Heft 1, 1983, S. 41-62 
Hejl, Peter M. (1984): Towards a Theory of Social Systems: Self-Organization and Self-Maintenance, Self-Reference and Syn-Reference, in: Ulrich, Hans/Probst, Gilbert J.B. (Hrsg.): Self-Organization and Management of Social Systems. Insights, Promises, Doubts and Questions, Berlin u.a. 1984, S. 60-78

Henselek, Hilmar F. (1996): Das Management von Unternehmungskonfigurationen, Dissertation Universität Bochum, Wiesbaden 1996

Hesse, W. et al. (1994): Terminologie der Softwaretechnik. Ein Begriffssystem für die Analyse und Modellierung von Anwendungssystemen. Teil 1: Begriffssystematik und Grundbegriffe, in: Informatik-Spektrum, Heft 1, 1994, S. 39-47

Hildebrand, Knut (1992): Ein Referenzmodell für Informationssystem-Architekturen, in: Information Management, Heft 3, 1992, S. 6-12

Hildebrand, Knut (1993): Zur Begriffsvielfalt bei Informationssystem-Architekturen: Ein Vorschlag für eine einheitliche Terminologie, in: Reichel, Horst (Hrsg.): Informatik - Wirtschaft - Gesellschaft, 23. GI-Jahrestagung, Berlin u.a. 1993, S. $74-80$

Hildebrand, Knut (1995): Informationsmanagement, München/Wien 1995

Hilgard, Ernest R./Bower, Gordon H. (1973): Theorien des Lernens, Band 2, 2. Auflage, Stuttgart 1973

Hill, Wilhelm (1994): Betriebswirtschaftslehre als Managementlehre, in: Wunderer, Rolf (Hrsg.): Betriebswirtschaftslehre als Management- und Führungslehre, 3. Auflage, Stuttgart 1994

Hill, Wilhelm/Fehlbaum, Raymond/Ulrich, Peter (1992): Organisationslehre 2. Theoretische Ansätze und praktische Methoden der Organisation sozialer Systeme, 4. Auflage, Bern/Stuttgart 1992

Hill, Wilhelm/Fehlbaum, Raymond/Ulrich, Peter (1994): Organisationslehre 1. Ziele, Instrumente und Bedingungen der Organisation sozialer Systeme, 5. Auflage, Bern/Stuttgart/Wien 1994

Hinkelmann, Knut (1997): Unterstützung des Wissensmanagements durch ein Organizational Memory, in: Technologie \& Management, Heft 1, 1997, S. 26-30

Hoch, Marc (1997): Kompaß der Kopflosen. Das Modell der „Lernenden Organisation" hilft Unternehmen in der grundlegend geänderten Wirtschaftswelt, in: Personalkonzepte. Beilage der Süddeutschen Zeitung Nr. 122, 31.5/1.6.1997, S. P1

Hoffmann, Friedrich (1976): Entwicklung der Organisationsforschung, 3. Auflage, Wiesbaden 1976

Hoffmann, Friedrich (1980): Organisation, Begriff der, in: Grochla, Erwin (Hrsg.): Handwörterbuch der Organisation, 2. Auflage, Stuttgart 1980, Sp. 1425-1431

Hoffmann, Friedrich (1992): Aufbauorganisation, in: Frese, Erich (Hrsg.): Handwörterbuch der Organisation, 3. Auflage, Stuttgart 1992, Sp. 208-221

Homans, George Caspar (1965): Theorie der sozialen Gruppe, 2. Auflage, Köln/Opladen 1965

Hoppen, Dirk (1992): Organisation und Informationstechnologie. Grundlagen für ein Konzept zur Organisationssystemgestaltung, Dissertation Universität Bielefeld, Hamburg 1992

Horton, Forest W. (1981): The Information Management Workbook - IRM made simple, Washington DC 1981 
Huber, George P. (1991): Organizational Learning: The Contributing Processes and the Literature, in: Organization Science, Heft 2, S. 88-115

Hutchison, Terence W. (1972): Theoretische Ökonomie als Sprachsystem, in: Albert, Hans (Hrsg.): Theorie und Realität, 2. Auflage, Tübingen 1972, S. 191-202

Inmon, William H. (1993): Building the Data Warehouse, New York u.a. 1993

Jahnke, Bernd/Groffmann, Hans-Dieter/Kruppa, Stephan (1996): On-line Analytical Processing (OLAP), in: Wirtschaftsinformatik, Heft 3, 1996, S. 321-324

Jantsch, Erich (1978): Erkenntnistheoretische Aspekte der Selbstorganisation natürlicher Systeme, in: Peter M. Hejl/Köck, Wolfram K./Roth, Gerhard (Hrsg.): Wahrnehmung und Kommunikation, Frankfurt am Main 1978, S. 99-127

Jelinek, Mariann (1979): Institutionalizing Innovation. A Study of Organizational Learning Systems, New York u.a. 1979

Kakabadse, Andrew/Fricker, John (1991): Anreize und Pfade zur lernenden Organisation, in: Sattelberger, Thomas (Hrsg.): Die lernende Organisation: Konzepte für eine neue Qualität der Unternehmensentwicklung, Wiesbaden 1991, S. $67-77$

Kasper, Helmut (1990): Die Handhabung des Neuen in organisierten Sozialsystemen, Berlin u.a. 1990

Kasper, Helmut (1991): Neuerungen durch selbstorganisierende Prozesse, in: Staehle, Wolfgang H. /Sydow, Jörg (Hrsg.): Managementforschung, Band 1, Berlin/New York 1991, S. 1-74

Kasper, Helmut (1995): Vom Management der Organisationskulturen zur Handhabung lebender sozialer Systeme, in: Kasper, Helmut (Hrsg.): Post-graduate-Management-Wissen, Wien 1995, S. 193-228

Kerres, Michael (1998): Multimediale und telemediale Lernumgebungen. Konzeption und Entwicklung, München 1998

Kieser, Alfred (1992): Organisationstheorie, evolutionsorientierte, in: Frese, Erich (Hrsg.): Handwörterbuch der Organisation, 3. Auflage, Stuttgart 1992, Sp. 1758-1777

Kieser, Alfred (1993): Der situative Ansatz, in: Kieser, Alfred (Hrsg.): Organisationstheorien, Stuttgart 1993, S. 161-191

Kieser, Alfred (1994): Fremdorganisation, Selbstorganisation und evolutionäres Management, in: Zeitschrift für betriebswirtschaftliche Forschung, Heft 3, 1994, S. $199-228$

Kieser, Alfred (1996): Moden \& Mythen des Organisierens, in: Die Betriebswirtschaft, Heft 1, 1996, S. 21-39

Kieser, Alfred/Kubicek, Herbert (1978): Organisationstheorien I: Wissenschaftstheoretische Anforderungen und kritische Analyse klassischer Ansätze, Stuttgart u.a. 1978

Kieser, Alfred/Kubicek, Herbert (1992): Organisation, 3. Auflage, Berlin/New York 1992

Kim, Daniel H. (1993): The Link between Individual and Organizational Learning, in: Sloan Management Review, Heft 4, 1993, S. 37-50

Kirsch, Werner (1990): Unternehmenspolitik und strategische Unternehmensführung, München 1990 
Kirsch, Werner (1992): Kommunikatives Handeln, Autopoiese, Rationalität. Sondierungen zu einer evolutionären Führungslehre, München 1992

Kirsch, Werner/Knyphausen, Dodo zu (1991): Unternehmungen als „autopoietische“ Systeme?, in: Staehle, Wolfgang/Sydow, Jörg (Hrsg.): Managementforschung, Band 1, Berlin/New York 1991, S. 75-101

Kleinhans, Andreas M. (1989): Wissensverarbeitung im Management. Möglichkeiten und Grenzen wissensbasierter Managementunterstützungs-, Planungs- und Simulationsansätze, Dissertation Universität Stuttgart, Frankfurt am Main u.a. 1989

Klimecki, Rüdiger/Probst, Gilbert J.B./Eberl, Peter (1991): Systementwicklung als Managementproblem, in: Staehle, Wolfgang H./Sydow, Jörg (Hrsg.): Managementforschung, Band 1, Berlin/New York 1991, S. 103-162

Klimecki, Rüdiger/Probst, Gilbert J.B./Eberl, Peter (1994): Entwicklungsorientiertes Management, Stuttgart 1994

Kloock, Josef (1992): Verrechnungspreise, in: Frese, Erich (Hrsg.): Handwörterbuch der Organisation, 3. Auflage, Stuttgart 1992, Sp. 2554-2572

Kluwe, Rainer H. (1995): Wissen, in: Sarges, Werner (Hrsg.): Management-Diagnostik, 2. Auflage, Göttingen u.a. 1995, S. 218-224

Knof, Heide-Lore (1992): CIM und organisatorische Flexibilität, Dissertation Universität Bochum, München 1992

Knyphausen, Dodo zu (1988): Unternehmungen als evolutionsfähige Systeme. Überlegungen zu einem evolutionären Konzept für die Organisationstheorie, Dissertation Universität München, München 1988

Knyphausen, Dodo zu (1991): Selbstorganisation und Führung. Systemtheoretische Beiträge zu einer evolutionären Führungskonzeption, in: Die Unternehmung, Heft 1, 1991, S. 47-63

Knyphausen-Aufseß, Dodo zu (1995): Theorie der strategischen Unternehmensführung. State-of-the-Art und neue Perspektiven, zugleich: Habilitationsschrift Universität München, Wiesbaden 1995

König, Wolfgang (1994): Profil der Wirtschaftsinformatik. Beschluß der Wissenschaftlichen Kommission Wirtschaftsinformatik im Verband der Hochschullehrer für Betriebswirtschaft e.V. vom 6.10.1993, in: Wirtschaftsinformatik, Heft 1, 1994, S. 80-81

Kortzfleisch, Harald von/Winand, Udo (1997): Kooperieren und Lernen im Intranet, in: Information Management, Heft 2, 1997, S. 28-35

Kosiol, Erich (1962): Organisation der Unternehmung, Wiesbaden 1962

Kosiol, Erich (1972): Die Unternehmung als wirtschaftliches Aktionszentrum, Reinbek bei Hamburg 1972

Kosiol, Erich (1976): Organisation der Unternehmung, 2. Auflage, Wiesbaden 1976

Krcmar, Helmut (1990): Bedeutung und Ziele von Informationssystem-Architekturen, in: Wirtschaftsinformatik, Heft 5, 1990, S. 395-402

Krcmar, Helmut (1991): Annäherungen an Informationsmanagement - Managementdisziplin und/oder Technologiedisziplin, in: Staehle, Wolfgang H./Sydow, Jörg (Hrsg.): Managementforschung, Band 1, Berlin 1991, S. 163-203

Krcmar, Helmut (1992): Computer Aided Team - Ein Überblick, in: Information Management, Heft 1, 1992, S. 6-9 
Krcmar, Helmut (1997): Informationsmanagement, Berlin/Heidelberg 1997

Krüger, Wilfried (1994): Organisation der Unternehmung, 3. Auflage, Stuttgart/Berlin/Köln 1994

Krüger, Wilfried/Bach, Norbert (1997): Lernen als Instrument des Unternehmungswandels, in: Dr. Wieselhuber \& Partner (Hrsg.): Handbuch Lernende Organisation. Unternehmens- und Mitarbeiterpotentiale erfolgreich erschließen, Wiesbaden 1997, S. 23-31

Krüger, Wilfried/Pfeiffer, Peter (1991): Eine konzeptionelle und empirische Analyse der Informationsstrategien und der Aufgaben des Informationsmanagements, in: Zeitschrift für betriebswirtschaftliche Forschung, Heft 1, 1991, S. 21-43

Küppers, Bert (1981): Betriebliche Aus- und Weiterbildung, München 1981

Küppers, Günter/Krohn, Wolfgang (1992): Selbstorganisation. Zum Stand einer Theorie in den Wissenschaften, in: Krohn, Wolfgang/Küppers, Günter (Hrsg.): Emergenz: Die Entstehung von Ordnung, Organisation und Bedeutung, Frankfurt am Main 1992, S. 7-26

Kuhn, Alfred (1990): Unternehmensführung, 2. Auflage, München 1990

Kyas, Othmar (1997): Unternehmensstrategie Intranet, in: Online, Heft 2, 1997, S. $22-28$

Lattmann, Charles (1975): Führungsstil und Führungsrichtlinien, Bern/Stuttgart 1975

Lehner, Franz/Maier, Ronald (1994): Information in Betriebswirtschaftslehre, Informatik und Wirtschaftsinformatik, Forschungsbericht Nr. 11 der Schriftenreihe des Lehrstuhls für Wirtschaftsinformatik und Informationsmanagement der Wissenschaftlichen Hochschule für Unternehmensführung - Otto-BeisheimHochschule, Koblenz 1994

Levitt, Barbara/March, James G. (1988): Organizational Learning, in: Annual Review of Sociology, 1988, S. 319-340

Lewin, Kurt (1958): Group Decision and Social Change, in: Maccoby, Eleanor E./Newcomb, Theodore M./Hartley, Eugene L. (Hrsg.): Readings in Social Psychology, 3. Auflage, New York 1958, S. 197-211

Litke, Hans-Dieter (1991): Projektmanagement. Methoden, Techniken, Verhaltensweisen, München/Wien 1991

Löwe, Hans (1974): Einführung in die Psychologie des Erwachsenenalters, 5. Auflage, Berlin 1974

Lorenz, Wolf-Dietrich (1998): Wissen richtig managen, in: Information Management, Heft 1, 1998, S. 99-100

Lübbe, Hermann (1987): Zeit-Erfahrung als Faktor kultureller Evolution, in: Hierholzer, Klaus/Wittmann, Heinz-Günter (Hrsg.): Phasensprünge und Stetigkeit in der natürlichen und kulturellen Welt, Stuttgart 1987, S. 283-304

Luhmann, Niklas (1981): Organisation und Entscheidung, in: Luhmann, Niklas (Hrsg.): Soziologische Aufklärung, 3. Auflage, Opladen 1981, S. 335-389

Luhmann, Niklas (1984): Soziologische Aspekte des Entscheidungsverhaltens, in: Die Betriebswirtschaft, S. 591-603

Luhmann, Niklas (1986): Organisation, in: Küpper, Willi/Ortmann, Günther (Hrsg.): Mikropolitik: Rationalität, Macht und Spiele in Organisationen, Opladen 1986, S. $165-185$ 
Luhmann, Niklas (1991): Soziale Systeme. Grundriß einer allgemeinen Theorie, 4. Auflage, Frankfurt am Main 1991

Madauss, Bernd J. (1990): Handbuch Projektmanagement, 3. Auflage, Stuttgart 1990

Mag, Wolfgang (1971): Grundfragen einer betriebswirtschaftlichen Organisationstheorie, 2. Auflage, Opladen 1971

Mag, Wolfgang (1975): Informationsbeschaffung, in: Grochla, Erwin/Wittmann, Waldemar (Hrsg.) Handwörterbuch der Betriebswirtschaft, 2. Auflage, Stuttgart 1975, Sp. 1882-1894

Mag, Wolfgang (1978): Die Unternehmung als Organisation, in: Drukarczyk, Jochen/Müller-Hagedorn, Lothar (Hrsg.): Betriebswirtschaftslehre. Eine Einführung in die Theorie der Unternehmung, Band 2, Wiesbaden 1978, S. 247-308

Mag, Wolfgang (1983): Bringt die „organisatorische Gestaltung“ neue Ideen für die Organisationstheorie und Organisationspraxis?, in: Zeitschrift für betriebswirtschaftliche Forschung, Heft 11/12, 1983, S. 1026-1039

Mag, Wolfgang (1990): Grundzüge der Entscheidungstheorie, München 1990

Mag, Wolfgang (1992): Die Funktionserweiterung der Unternehmensführung, in: Wirtschaftswissenschaftliches Studium, Heft 2, 1992, S. 60-64

Mag, Wolfgang (1993): Planung, in: Bitz, Michael et al. (Hrsg.): Vahlens Kompendium der Betriebswirtschaftslehre, Band 2, 3. Auflage, München 1993, S. 1-58

Mag, Wolfgang (1995): Unternehmungsplanung, München 1995

Malik, Fredmund (1989): Strategie des Managements komplexer Systeme. Ein Beitrag zur Management-Kybernetik evolutionärer Systeme, 3. Auflage, Bern/Stuttgart 1989

Malik, Fredmund/Probst, Gilbert J.B. (1981): Evolutionäres Management, in: Die Unternehmung, Heft 2, 1981, S. 121-140

Mandl, Heinz/Spada, Hans (Hrsg.) (1988): Wissenspsychologie, München/Weinheim 1988

March, James G./Olsen, Johan P. (1976): Ambiguity and Choice in Organizations, Bergen u.a. 1976

Marchand, Donald A. (1989): Information Management: Strategies and Tools in Transition, in: Information Management Review, Heft 3, 1989, S. 27-34

Marchand, Donald A./Horton, Forest W. (1986): Infotrends. Profiting from your Information Resources, New York 1986

Maturana, Humberto R. (1981): Autopoiesis, in: Zeleny, Milan (Hrsg.): Autopoiesis: A Theory of Living Organization, New York 1981, S. 21-33

Maturana, Humberto R. (1982): Biologie der Kognition, in: Maturana, Humberto R. (Hrsg.): Erkennen: Die Organisation und Verkörperung von Wirklichkeit. Ausgewählte Arbeiten zur biologischen Epistemologie, Braunschweig/Wiesbaden 1982, S. $32-80$

Maturana, Humberto R./Varela, Francisco J. (1979): Autopoiesis and Cognition, Boston 1979

Maturana, Humberto R./Varela, Francisco J. (1987): Der Baum der Erkenntnis. Die biologischen Wurzeln des menschlichen Erkennens, Bern/München 1987 
Maturana, Humberto R./Varela, Francisco J./Uribe, Ricardo B. (1982): Autopoiese: die Organisation lebender Systeme, ihre nähere Bestimmung und ein Modell, in: Maturana, Humberto R. (Hrsg.): Erkennen: Die Organisation und Verkörperung von Wirklichkeit, Braunschweig/Wiesbaden 1982, S. 157-169

McMahon, Harry (1995): The Use of Computer-Mediated Role Play in Management Training, in: Zucchermaglio, Cristina/Bagnara, Sebastiano/Stucky, Susan U. (Hrsg.) (1995): Organizational Learning and Technological Change, Proceedings of the NATO Advanced Research Workshop on Organizational Learning and Technological Change (Siena, 22.-26.9.1992), Berlin/Heidelberg 1995, S. $254-268$

Meffert, Heribert (1998): Marketing. Grundlagen marktorientierter Unternehmensführung. Konzepte, Instrumente, Praxisbeispiele, 8. Auflage, Wiesbaden 1998

Meik, Frank (1997): Informationsmanagement reicht nicht. Die Datenbank als Führungsinstrument, in: IO Management Zeitschrift, Heft 5, 1997, S. $42-47$

Mertens, Peter (1997a): Integrierte Informationsverarbeitung 1. Administrations- und Dispositionssysteme in der Industrie, 11. Auflage, Wiesbaden 1997

Mertens, Peter (1997b): WI - Für Sie gelesen: Building a Corporate Memory: Experiences From Three Case Studies von Otto Kühn und Andreas Abecker, in: Wirtschaftsinformatik, Heft 2, 1997, S. 177-180

Mertens, Peter/Holzner, Jochen (1992): Eine Gegenüberstellung von Integrationsansätzen der Wirtschaftsinformatik, in: Wirtschaftsinformatik, Heft 1, 1992, S. 525

Mertens, Peter/Plattfaut, Eberhard (1986): Informationstechnik als strategische Waffe, in: Information Management, Heft 2, 1986, S. 6-17

Meyer, Alan D./Goes, James B. /Brooks, Geoffrey R. (1993): Organizations Reacting to Hyperturbulence, in: Huber, George P./Glick, William H. (Hrsg.): Organizational Change and Redesign, New York/Oxford 1993, S. 66-111

Meyer, Petra (1988): Entwicklungslinien der Organisationswissenschaft im deutschsprachigen Raum, in: Zeitschrift Führung und Organisation, Heft 3, 1988, S. $192-199$

Miller, James G.(1978): Living Systems, New York u.a. 1978

Mintzberg, Henry (1984): A Typology of Organizational Structure, in: Miller, Danny/Friesen, Peter H./Mintzberg, Henry (Hrsg.): Organizations: A Quantum View, Englewood Cliffs (New Jersey) 1984, S. 68-86

Mintzberg, Henry (1994): The Rise and Fall of Strategic Planning, New York u.a. 1994

Mohr, Niko (1997): Kommunikation und organisatorischer Wandel. Ein Ansatz für ein effizientes Kommunikationsmanagement im Veränderungsprozeß, Dissertation Universität Trier, Wiesbaden 1997

Montada, Leo (1970): Die Lernpsychologie Jean Piagets, Stuttgart 1970

Morgan, Gareth/Smircich, Linda (1980): The Case of Qualitative Research, in: Academy of Management Review, 1980, S. 491-500

Mucksch, Harry (1998): Das Data Warehouse als Datenbasis analytischer Informationssysteme. Architektur und Komponenten, in: Chamoni, Peter/Gluchowski, Peter (Hrsg.): Analytische Informationssysteme. Data Warehouse, On-Line Analytical Processing, Data Mining, Berlin/Heidelberg u.a. 1998, S. 123-140 
Müller, Jochen (1998): Datenversorgung für das Data Warehouse. Ein dreistufiges Modell zur Transformation operativer Daten, Arbeitsbericht Nr. 98-29 des Lehrstuhls für Wirtschaftsinformatik der Ruhr-Universität Bochum, Bochum 1998

Müller-Merbach, Heiner (1992): Vier Arten von Systemansätzen, dargestellt in Lehrgesprächen, in: Zeitschrift für Betriebswirtschaft, Heft 8, 1992, S. 853-876

Nastansky, Ludwig (1991): Gruppenarbeit - Workgroup Computing, in: Office Management, Heft 6, 1991, S. 6-13

Nawatzki, Jürgen (1994): Integriertes Informationsmanagement. Die Koordination von Informationsverarbeitung, Organisation und Personalwirtschaft bei der Planung, Durchführung, Kontrolle und Steuerung des Einsatzes neuer Informationstechnologie in der Unternehmung, Dissertation Universität Münster, Bergisch Gladbach/Köln 1994

Newman, Denis (1995): The School as a Workplace, in: Zucchermaglio, Cristina/Bagnara, Sebastiano/Stucky, Susan U. (Hrsg.) (1995): Organizational Learning and Technological Change, Proceedings of the NATO Advanced Research Workshop on Organizational Learning and Technological Change (Siena, 22.26.9.1992), Berlin/Heidelberg 1995, S. 212-224

Nieschlag, Robert/Dichtl, Erwin/Hörschgen, Hans (1997): Marketing, 18. Auflage, Berlin 1997

Nonaka, Ikujiro (1994): A Dynamic Theory of Organizational Knowledge Creation, in: Organization Science, Heft 1, 1994, S. 14-37

Nordsieck, Fritz (1960): Organisation, in: Seischab, Hans/Schwantag, Karl (Hrsg.): Handwörterbuch der Betriebswirtschaftslehre, Teilband 3, 3. Auflage, Stuttgart 1960, Sp. 4235-4242

Nystrom, Paul C./Starbuck, William H. (1984): To Avoid Organizational Crisis Unlearn, in: Organizational Dynamics, Heft 1, 1984, S. 53-65

Oberschulte, Hans (1994): Organisatorische Intelligenz. Ein integrativer Ansatz des organisatorischen Lernens, Dissertation Universität Saarbrücken, München/Mering 1994

Oelsnitz, Dietrich von der (1995): Individuelle Selbststeuerung - der Königsweg "moderner" Unternehmungsführung?, in: Die Betriebswirtschaft, Heft 6, 1995, S. 707-720

Österle, Hubert (1995): Business Engineering, Band 1: Entwurfstechniken, Berlin u.a. 1995

Österle, Hubert/Brenner, Walter/Hilbers, Konrad (1992): Unternehmensführung und Informationssystem. Der Ansatz des St. Galler Informationssystem-Management, 2. Auflage, Stuttgart 1992

Orr, Julian E. (1995): Ethnography and Organizational Learning: In Pursuit of Learning at Work, in: Zucchermaglio, Cristina/Bagnara, Sebastiano/Stucky, Susan U. (Hrsg.) (1995): Organizational Learning and Technological Change, Proceedings of the NATO Advanced Research Workshop on Organizational Learning and Technological Change (Siena, 22.-26.9.1992), Berlin/Heidelberg 1995, S. $47-60$

Ortner, Erich (1991): Informationsmanagement - wie es entstand, was es ist und wohin es sich entwickelt, in: Informatik-Spektrum, Heft 4, 1991, S. 315-327 
Osterloh, Margit/Grand, Simon (1994): Modelling oder Mapping? Von Rede- und Schweigeinstrumenten in der betriebswirtschaftlichen Theoriebildung, in: Die Unternehmung, Heft 4, 1994, S. 277-294

Otten, Klaus W. (1993): Trends des Informationsmanagements in den USA. Informationsorientiertung der amerikanischen Wirtschaft, in: Office Management, Heft 12,1993, S. $14-19$

Ouchi, William G. (1981): Theory Z - How American Business Can Meet the Japanese Challenge, Reading (Massachusetts) 1981

o.V. (1998): Wissensmanagement - Service für Kunden und Consultants, in: Information Management, Heft 2, 1998, S. 89-90

Pawlowsky, Peter (1992): Betriebliche Qualifikationsstrategien und organisationales Lernen, in: Staehle, Wolfgang H./Conrad, Peter (Hrsg.): Managementforschung, Band 2, Berlin/New York 1992, S. 177-237

Pawlowsky, Peter (1994): Wissensmanagement in der lernenden Organisation, unveröffentlichte Habilitationsschrift Universität Paderborn, o.O., 1994

Pautzke, Gunnar (1989): Die Evolution der organisatorischen Wissensbasis. Bausteine zu einer Theorie des organisatorischen Lernens, Dissertation Universität München, Herrsching 1989

Pedler, Mike/Boydell, Tom/Burgoyne, John (1991): Auf dem Weg zum "Lernenden Unternehmen", in: Sattelberger, Thomas (Hrsg.): Die lernende Organisation: Konzepte für eine neue Qualität der Unternehmensentwicklung, Wiesbaden 1991, S. 57-65

Perich, Robert (1993): Unternehmungsdynamik. Zur Entwicklungsfähigkeit von Organisationen aus zeitlich-dynamischer Sicht, 2. Auflage, Dissertation Hochschule St. Gallen 1992, Bern/Stuttgart/Wien 1993

Petrovic, Otto (1992): Groupware - Systemkategorien, Anwendungsbeispiele, Problemfelder und Entwicklungsstand, in: Information Management, Heft 1, 1992, S. $16-22$

Petrovic, Otto/Krickl, Otto (1993): Traditionell-moderiertes vs. Computergestütztes Brainstorming. Eine vergleichende Betrachtung, in: Wirtschaftsinformatik, Heft 2, 1993, S. 120-128

Pfeiffer, Peter (1990): Technologische Grundlage, Strategie und Organisation des Informationsmanagements, Dissertation Universität Gießen, Berlin 1990

Piaget, Jean (1983): Meine Theorie der geistigen Entwicklung, Frankfurt am Main 1983

Picot, Arnold (1975): Zur Frage der Ableitung von empirisch überprüfbaren Aussagen aus systemtheoretischen Ansätzen der Organisationsforschung, in: Jehle, Egon (Hrsg.): Systemforschung in der Betriebswirtschaftslehre, Stuttgart 1975, S. 88105

Picot, Arnold (1993): Organisation, in: Bitz, Michael (Hrsg.): Vahlens Kompendium der Betriebswirtschaftslehre, 3. Auflage, München 1993, S. 101-174

Picot, Arnold/Franck, Egon (1988): Die Planung der Unternehmensressource Information (Teil I und II), in: Das Wirtschaftsstudium, Heft 10 und 11, 1988, S. 544549 und 608-614 
Picot, Arnold/Maier, Matthias (1992): Informationssysteme, computergestützte, in: Frese, Erich (Hrsg.): Handwörterbuch der Organisation, 3. Auflage, Stuttgart 1992, Sp. 923-936

Pohl, Wilfried (1997): Individuelle Informationsverarbeitung, in: Mertens, Peter et al. (Hrsg.): Lexikon der Wirtschaftsinformatik, 3. Auflage, Berlin/Heidelberg 1997, S. 194-195

Polanyi, Michael (1985): Implizites Wissen, Frankfurt am Main 1985

Pomberger, Gustav/Blaschek, Günther (1993): Grundlagen des Software Engineering - Prototyping und objektorientierte Software-Entwicklung, München/Wien 1993

Popper, Karl R. (1995): Auf der Suche nach einer besseren Welt, 8. Auflage, München/Zürich 1995

Porter, Lyman/Lawler, Edward E./Hackman, John R. (1975): Behavior in Organizations, New York 1975

Porter, Michael E./Millar, Victor E. (1986): Wettbewerbsvorteile durch Information. Die Informationstechnik revolutioniert Branchen und Märkte, in: Harvard Manager, Heft 1, 1986, S. 26-35

Pott, Oliver (1998): SmartBooks Intranet-Bibel. Das Standardwerk zur Intranet-Praxis, Kilchberg 1998

Prim, Rolf (1968): Über die Grenzen methodologischer Auseinandersetzungen, in: Zeitschrift für Betriebswirtschaft, Heft 2, 1968, S. 127-131

Probst, Gilbert J. B. (1986): Der Organisator im selbstorganisierenden System. Aufgaben, Stellung und Fähigkeiten, in: Zeitschrift Führung und Organisation, Heft 6, 1986, S. 395-399

Probst, Gilbert J. B. (1987): Selbst-Organisation. Ordnungsprozesse in sozialen Systemen aus ganzheitlicher Sicht, Berlin/Hamburg 1987

Probst, Gilbert J. B. (1992): Selbstorganisation, in: Frese, Erich (Hrsg.): Handwörterbuch der Organisation, 3. Auflage, Stuttgart 1992, Sp. 2255-2269

Probst, Gilbert J. B. (1994): Organisationales Lernen und die Bewältigung von Wandel, in: Gomez, Peter et al. (Hrsg.): Unternehmerischer Wandel, Wiesbaden 1994, S. 295-319

Probst, Gilbert J.B./Büchel, Bettina (1998): Organisationales Lernen: Wettbewerbsvorteil der Zukunft, Wiesbaden 1998

Probst, Gilbert J.B./Gomez, Peter (1982): New („Second-ORDER“) Cybernetics against Mismanagement, in: Trappl, Robert (Hrsg.): Cybernetics and Systems Research, Proceedings of the Sixth European Meeting on Cybernetics and Systems Research (St. Gallen, 13.-16.4.1982), Amsterdam/New York/Oxford 1982, S. 437-447

Probst, Gilbert J.B./Scheuss, Ralph-W. (1984): Resultat von Organisieren und Selbstorganisation, in: Zeitschrift Führung und Organisation, Heft 8, 1984, S. $480-488$

Prokesch, Steven E. (1997): Unleashing the Power of Learning: An Interview with British Petroleum's Jon Browne, in: Harvard Business Review, Heft 5, 1997, S. $147-168$

Pugh, Derek S. et al. (1968): Dimensions of Organization Structures, in: Administrative Science Quarterly, Heft 1, 1968, S. 65-105 
Raffée, Hans (1974): Grundprobleme der Betriebswirtschaftslehre, Band 1, 8. unveränderter Nachdruck, Göttingen 1974

Reber, Gerhard (1992): Lernen, organisationales, in: Frese, Erich (Hrsg.): Handwörterbuch der Organisation, 3. Auflage, Stuttgart 1992, Sp. 1239-1255

Reichardt, Ingo (1998): Lernende Unternehmen. Intelligenten Organisationen gehört die Zukunft, in: Office Management, Heft 4, 1998, S. 64-67

Reif-Mosel, Ane-Kristin (1999): Computergestützte Kooperation im Büro. Empfehlungen für die Gestaltung unter Berücksichtigung aufgabenbezogener, struktureller, technischer und personeller Aspekte, Dissertation Universität Bochum, in Vorbereitung

Reinhardt, Rüdiger (1995): Das Modell Organisationaler Lernfähigkeit und die Gestaltung Lernfähiger Organisationen, Dissertation Universität Kassel 1993, 2. Auflage, Frankfurt am Main 1995

Reiß, Michael/Morelli, Frank (1994): Informationsmanagement bedeutet auch „Subkultur-Management", in Online, Heft 5, 1994, S. 104-106

Reuter, Edzard (1993): Manager, in: Wittmann, Waldemar et al. (Hrsg.): Handwörterbuch der Betriebswirtschaft, Teilband 2, 5. Auflage, Stuttgart 1993, Sp. $2663-$ 2679

Ringlstetter, Max (1988): Auf dem Weg zu einem evolutionären Management. Konvergierende Tendenzen in der deutschsprachigen Führungs- und Managementlehre, Dissertation Universität München, Müchen 1988

Ropella, Wolfgang (1988): Synergie als strategisches Ziel der Unternehmung, Dissertation Universität Bochum, Berlin/New York 1988

Roth, Gerhard (1986): Selbstorganisation - Selbsterhaltung - Selbstreferentialität: Prinzipien der Organisation der Lebewesen und ihre Folgen für die Beziehung zwischen Organismus und Umwelt, in: Dress, Andreas/Hendrichs, Hubert/Küppers, Günter (Hrsg.): Selbstorganisation. Die Entstehung von Ordnung in Natur und Gesellschaft, München 1986, S. 149-180

Roth, Gerhard (1996): Erkenntnis und Realität: Das reale Gehirn und seine Wirklichkeit, in: Schmidt, Siegfried J. (Hrsg.): Der Diskurs des Radikalen Konstruktivismus, 7. Auflage, Frankfurt am Main 1994

Rudolph, Hagen (1997): Wie lernt das „lernende Unternehmen“?, in: Zeitschrift Führung und Organisation, Heft 4, 1997, S. 202-205

Ryle, Gilbert (1949): The Concept of Mind, London 1949

Sattelberger, Thomas (1991): Die lernende Organisation im Spannungsfeld von Strategie, Struktur und Kultur, in: Sattelberger, Thomas (Hrsg.): Die lernende Organisation: Konzepte für eine neue Qualität der Unternehmensentwicklung, Wiesbaden 1991, S. 11-55

Schäffer, Utz (1996): Koordination durch Selbstabstimmung, in: Das Wirtschaftsstudium, Heft 12, 1996, S. 1096-1101

Schanz, Günther (1992): Organisation, in: Frese, Erich (Hrsg.): Handwörterbuch der Organisation, 3. Auflage, Stuttgart 1992, Sp. 1459-1470

Schanz, Günther (1994): Organisationsgestaltung. Management von Arbeitsteilung und Koordination, 2. Auflage, München 1994 
Scharfenkamp, Norbert (1987): Organisatorische Gestaltung und wirtschaftlicher Erfolg. Organizational Slack als Ergebnis und Einflußfaktor der formalen Organisationsstruktur, Berlin/New York 1987

Scheer, August-Wilhelm (1993): Betriebs- und Wirtschaftsinformatik, in: Wittmann, Waldemar et al. (Hrsg.): Handwörterbuch der Betriebswirtschaft, Teilband 1, 5. Auflage, Stuttgart 1993, Sp. 390-408

Scheer, August-Wilhelm (1997): Wirtschaftsinformatik. Referenzmodelle für industrielle Geschäftsprozesse, 7. Auflage, Berlin/Heidelberg 1997

Scheer, August-Wilhelm (1998): ARIS - Vom Geschäftsprozeß zum Anwendungssystem, 3. Auflage, Berlin/Heidelberg 1998

Scheff, Josef (1993): Business Teams - Implikationen für die Personalplanung, in: Kraus, Herbert/Scheff, Josef/Gutschlhofer, Alfred (Hrsg.): Neue Ansätze in der Personalarbeit, Wien 1993, S. 131-152

Schein, Edgar H. (1992): Organizational Culture and Leadership, 2. Auflage, San Francisco (California) u.a. (1992)

Schein, Edgar H. (1993): How can Organizations Learn Faster? The Challenge of Entering the Green Room, in: Sloan Management Review, Heft 2, 1993, S. 8592

Schelp, Joachim (1997): Datenautobahnen für das Unternehmen: Internet und Intranet, in: Gabriel, Roland/Müller, Jochen/Schelp, Joachim: Trends in der Wirtschaftsinformatik: Intranet und Warehousing, Arbeitsbericht Nr. 66 des Instituts für Unternehmungsführung und Unternehmensforschung der Ruhr-Universität Bochum, Bochum 1996, S. 7-18

Schiemenz, Bernd (1993): Systemtheorie, betriebswirtschaftliche, in: Wittmann, Waldemar et al. (Hrsg.): Handwörterbuch der Betriebswirtschaft, Teilband 3, 5. Auflage, Stuttgart 1993, Sp. 4127-4140

Schinzer, Heiko D./Bange, Carsten (1998): Werkzeuge zum Aufbau analytischer Informationssysteme. Marktübersicht, in: Chamoni, Peter/Gluchowski, Peter (Hrsg.): Analytische Informationssysteme. Data Warehouse, On-Line Analytical Processing, Data Mining, Berlin/Heidelberg u.a. 1998, S. 41-58

Schischkoff, Georgi (1982): Philosophisches Wörterbuch, 21. Auflage, Stuttgart 1982

Schlageter, Gunter/Stucky, Wolffried (1983): Datenbanksysteme: Konzepte und Modelle, 2. Auflage, Stuttgart 1983

Schmidt, Siegfried J. (1982): Unsere Welt - und das ist alles, in: Merkur, Heft 36, 1982, S. 356-365

Schmidt, Siegfried J. (1996a): Der Radikale Konstruktivismus: Ein neues Paradigma im interdisziplinären Diskurs, in: Schmidt, Siegfried J. (Hrsg.): Der Diskurs des Radikalen Konstruktivismus, 7. Auflage, Frankfurt am Main 1996, S. 1188

Schmidt, Siegfried J. (1996b): Vorbemerkung, in: Schmidt, Siegfried J. (Hrsg.): Der Diskurs des Radikalen Konstruktivismus, 7. Auflage, Frankfurt am Main 1996, S. 7-9

Schmitz, Paul (1989): Informations- und Kommunikations-System, Planung des, in: Szyperski, Norbert (Hrsg.): Handwörterbuch der Planung, Stuttgart 1989, Sp. 684-692 
Schneider, Dieter (1987): Allgemeine Betriebswirtschaftslehre, 3. Auflage, München/Wien 1987

Schneider, Dieter (1995): Betriebswirtschaftslehre. Band 1: Grundlagen, 2. Auflage, München 1995

Schöne, Katrin (1997): Controlling der Informationsinfrastruktur. Entwicklungsstand Gestaltungskonzeption - Perspektiven, Dissertation Universität Dresden, Wiesbaden 1997

Schönpflug, Wolfgang/Schönpflug, Ute (1983): Psychologie. Allgemeine Psychologie und ihre Verzweigungen in die Entwicklungs-, Persönlichkeits- und Sozialpsychologie, München/Wien/Baltimore 1983

Scholer, Stefan (1998): Groupware und Informatikabteilungen: Untersuchung des Einsatzes von Groupware und der damit verbundenen Veränderungen der Aufgaben, Organisation und künftigen Bedeutung von Informatikabteilungen, Dissertation Hochschule St. Gallen, Bamberg 1998

Schreyögg, Georg (1989): Zu den problematischen Konsequenzen starker Unternehmungskulturen, in: Zeitschrift für betriebswirtschaftliche Forschung, Heft 2, 1989, S. 94-113

Schreyögg, Georg (1995): Umwelt, Technologie und Organisationsstruktur. Eine Analyse des kontingenztheoretischen Ansatzes, 3. Auflage, Bern/Stuttgart/Wien 1995

Schreyögg, Georg/Noss, Christian (1994): Hat sich das Organisieren überlebt? Grundfragen der Unternehmenssteuerung in neuem Licht, in: Die Unternehmung, Heft 1, 1994, S. 17-33

Schreyögg, Georg/Noss, Christian (1995): Organisatorischer Wandel: Von der Organisationsentwicklung zur lernenden Organisation, in: Die Betriebswirtschaft, Heft 2, 1995, S. 169-185

Schüler, Wolfgang (1989): Informationsmanagement: Gegenstand und organisatorische Konsequenzen, in: Spremann, Klaus/Zur, Eberhard (Hrsg.): Informationstechnologie und strategische Führung, Wiesbaden 1989

Schüppel, Jürgen (1996): Wissensmanagement. Organisatorisches Lernen im Spannungsfeld zwischen Wissens- und Lernbarrieren, Dissertation Hochschule St. Gallen, Wiesbaden 1996

Schütte, Reinhard (1997): Für eine gemäßigt konstruktivistische Orientierung der Wirtschaftsinformatik, unveröffentlichter Diskussionsbeitrag zur Tagung 'Wirtschaftsinformatik und Wissenschaftstheorie. Bestandsaufnahme und Perspektiven', Münster, 10.-11. Oktober 1997, o.O. 1997

Schulte-Zurhausen, Manfred (1995): Organisation, München 1995

Schulze-Wischeler, Britta (1995): Lean Information. Computergestützte Systeme in der mittelständischen Industrie, Dissertation Universität Göttingen, Wiesbaden 1995

Schwarze, Jochen (1990): Betriebswirtschaftliche Aufgaben und Bedeutung des Informationsmanagements, in: Wirtschaftsinformatik, Heft 2, 1990, S. 104-115

Schwarzer, Bettina (1994a): Prozeßorientiertes Informationsmanagement in multinationalen Unternehmen. Eine empirische Untersuchung in der Pharmaindustrie, Dissertation Universität Hohenheim, Wiesbaden 1994 
Schwarzer, Bettina (1994b): Die Rolle der Information und des Informationsmanagements in Business Process Re-Engineering-Projekten, in: Information Management, Heft 1, 1994, S. 30-35

Scott, William Richard (1992): Organizations. Rational, Natural and Open Systems, 3. Auflage, Englewood Cliffs (New Jersey) 1992

Scott Morton, Michael S. (Hrsg.) (1991): The Corporation of the 1990s. Information Technology and Organizational Transformation, New York/Oxford 1991

Segler, Tilman (1985): Die Evolution von Organisationen. Ein evolutionstheoretischer Ansatz zur Erklärung der Entstehung und des Wandels von Organisationsformen, Frankfurt u.a. 1985

Seibt, Dietrich (1990): Ausgewählte Probleme und Aufgaben der Wirtschaftsinformatik, in: Wirtschaftsinformatik, Heft 1, 1990, S. 7-19

Seibt, Dietrich (1993): Begriff und Aufgaben des Informationsmanagement - ein Überblick, in: Preßmar, Dieter B. (Hrsg.): Informationsmanagement, Wiesbaden 1993, S. 3-30

Seibt, Dietrich (1997): Anwendungssystem, in: Mertens, Peter et al. (Hrsg.): Lexikon der Wirtschaftsinformatik, 3. Auflage, Berlin/Heidelberg 1997, S. 38-39

Seidel, Eberhard (1986): Grundbegriffe der betrieblichen Organisationslehre, in: Das Wirtschaftsstudium, Heft 5, 1986, S. 225-231

Seidel, Eberhard/Redel, Wolfgang (1987): Führungsorganisation, München/Wien 1987

Seifert, Manfred (1997): Intranet und Extranet. Nur intern oder mit Kunden und Partnern, in: Unternehmer-Magazin, Heft 9, 1997, S. 38-41

Senge, Peter M. (1990): The Leader's New Work: Building Learning Organizations, in: Sloan Management Review, Heft 3, 1990, S. 7-23

Senge, Peter M. (1996): Die fünfte Disziplin. Kunst und Praxis der lernenden Organisation, 3. Auflage, Stuttgart 1996

Servati, Al/Bremner, Lynn/Iasi, Anthony (1997): Die Intranet Bibel. Technische und wirtschaftliche Grundlagen - Entscheidungshilfe und Amortisationsberechnung - Fallstudien, Feldkirchen 1997

Shrivastava, Paul (1983): A Typology of Learning Systems, in: Journal of Management Studies, Heft 1, 1983, S. 7-20

Smircich, Linda (1983): Concepts of Culture and Organizational Analysis, in: Administrative Science Quarterly, Heft 3, 1983, S. 339-358

Smith, Richard E.: A Historical Overview of Computer Architecture, in: Annals of the History of Computing, Heft 4, 1989, S. 277-303

Specht, Günter (1993): Technologiemanagement, in: Wittmann, Waldemar et al. (Hrsg.): Handwörterbuch der Betriebswirtschaft, Teilband 3, 5. Auflage, Stuttgart 1993, Sp. 4154-4168

Staehle, Wolfgang H. (1991): Redundanz, Slack und lose Kopplung in Organisationen: Eine Verschwendung von Ressourcen?, in: Staehle, Wolfgang H./Sydow, Jörg (Hrsg.): Managementforschung, Band 1, Berlin/New York 1991, S. 313-345

Staehle, Wolfgang H. (1994): Management. Eine verhaltenswissenschaftliche Perspektive, 7. Auflage, München 1994 
Staerkle, Robert (1985): Wechselwirkungen zwischen Organisationskultur und Organisationsstruktur, in: Probst, Gilbert J.B./Siegwart, Hans (Hrsg.): Integriertes Management. Bausteine des systemorientierten Managements, Bern/Stuttgart 1985, S. 529-553

Stahlknecht, Peter/Hasenkamp, Ulrich (1997): Einführung in die Wirtschaftsinformatik, 8. Auflage, Berlin/Heidelberg 1997

Steiner, Gerhard (1992): Lerntheorien, in: Gaugler, Eduard/Weber, Wolfgang: Handwörterbuch des Personalwesens, 2. Auflage, Stuttgart 1992, Sp. 1264-1274

Steinle, Claus (1985): Organisation und Wandel, Berlin/New York 1985

Steinle, Claus/Bruch, Heike/Müller, Petra (1996): Selbstorganisation - Ansätze und Implikationen für Organisation und Personalführung, in: Das Wirtschaftsstudium, Heft 7, 1996, S. 648-655

Steinmann, Horst/Schreyögg, Georg (1993): Management. Grundlagen der Unternehmensführung. Konzepte - Funktionen - Fallstudien, 3. Auflage, Wiesbaden 1993

Steinmüller, Wilhelm (1981): Eine sozialwissenschaftliche Konzeption der Informationswissenschaft (Informationstechnologie und Informationsrecht I), in: Nachrichten für Dokumentation, Heft 2, 1981, S. 69-80

Steinmüller, Wilhelm (1993): Informationstechnologie und Gesellschaft: Einführung in die Angewandte Informatik, Darmstadt 1993

Strauß, Ralf E. (1996): Determinanten und Dynamik des Organizational Learning, Dissertation Universität Freiburg im Breisgau, Wiesbaden 1996

Streubel, Frauke (1996): Theoretische Fundierung eines ganzheitlichen Informationsmanagements, Arbeitsbericht Nr. 96-21 des Lehrstuhls für Wirtschaftsinformatik der Ruhr-Universität Bochum, Bochum 1996

Strohmeyer, Stefan (1997): Selbstorganisation und Betriebswirtschaftslehre - Eine wissenschaftstheoretische und fachpraktische Gratwanderung?, in: Kahle, Egbert (Hrsg.): Betriebswirtschaftslehre und Managementlehre, Wiesbaden 1997, S. $143-185$

Stucky, Susan U. (1995): Part I: Organizations as Learning Bodies, Introduction, in: Zucchermaglio, Cristina/Bagnara, Sebastiano/Stucky, Susan U. (Hrsg.) (1995): Organizational Learning and Technological Change, Proceedings of the NATO Advanced Research Workshop on Organizational Learning and Technological Change (Siena, 22.-26.9.1992), Berlin/Heidelberg 1995, S. 1-3

Stucky, Wolffried/Krieger, Rudolf (1990): Datenbanksysteme, in: Kurbel, Karl/Strunz, Horst (Hrsg.): Handbuch Wirtschaftsinformatik, Stuttgart 1990, S. 837-856

Sydow, Jörg (1992): Strategische Netzwerke und Transaktionskosten - Über die Grenzen einer transaktionskostentheoretischen Erklärung der Evolution strategischer Netzwerke, in: Staehle, Wolfgang H./Conrad, Peter (Hrsg.): Managementforschung, Band 2, Berlin/New York 1992, S. 239-311

Synott, William R./Gruber, William H. (1981): Information Resource Management Opportunities and Strategies for the 1980s, New York u.a. 1981 
Teubner, Gunther (1987a): Hyperzyklus in Recht und Organisation: Zum Verständnis von Selbstbeobachtung, Selbstkonstitution und Autopoiese, in: Haferkamp, Hans/Schmid, Michael (Hrsg.): Sinn, Kommunikation und soziale Differenzierung. Beiträge zu Luhmanns Theorie sozialer Systeme, Frankfurt am Main 1987 , S. 89-128

Teubner, Gunther (1987b): Episodenverknüpfung. Zur Steigerung von Selbstreferenz im Recht, in: Baecker, Dirk et al. (Hrsg.): Theorie als Passion, Frankfurt am Main 1987, S. 423-446

Teufel, Stephanie et al. (1995): Computerunterstützung für die Gruppenarbeit, Bonn 1995

Thom, Norbert (1992): Stelle, Stellenbildung und -besetzung, in: Frese, Erich (Hrsg.): Handwörterbuch der Organisation, 3. Auflage, Stuttgart 1992, Sp. 2321-2333

Thompson, James D. (1967): Organizations in Action, New York 1967

Tödtmann, Claudia (1997): Wissensmanagement. Großes Defizit, in: Wirtschaftswoche, Heft 35, 1997, S. 64-66

Trauth, Eileen M. (1984): Research-Oriented Perspective on Information Management, in: Journal of Systems Management, Heft 1, 1984, S. 12-17

Trauth, Eileen M. (1989): The Evolution of Information Resource Management, in: Information \& Management, Heft 5, 1989, S. 257-268

Trott zu Solz, Clemens von (1992): Informationsmanagement im Rahmen eines ganzheitlichen Konzeptes der Unternehmensführung, Dissertation Universität Göttingen 1991, Göttingen 1992

Trott zu Solz, Clemens von (1992a): Grundlagen eines strategischen Informationsmanagements, in: Mucksch, Harry/Roesenthal, Wolfgang/Ruf, Walter (Hrsg.): Entwicklungstendenzen der Informationsverarbeitung in Klein- und Mittelbetrieben, Lünen 1992, S. 25-49

Tuckman, Bruce W. (1965): Development Sequence in Small Groups, in: Psychological Bulletin, Heft 6, 1965, S. 384-369

Türk, Klaus (1980): Pathologie der Organisation, in: Grochla, Erwin (Hrsg.): Handwörterbuch der Organisation, 2. Auflage, Stuttgart 1980, Sp. 1855-1864

Türk, Klaus (1989): Neuere Entwicklungen in der Organisationsforschung, Stuttgart 1989

Tulowitzki, Ulrich (1991): Anwendungssystemarchitekturen im strategischen Informationsmanagement, in: Wirtschaftsinformatik, Heft 2, 1991, S. 94-99

Twardy, Martin (1985): Lernpsychologische Bedingungen und didaktische Konsequenzen zur Realisierung computerunterstützten Unterrichts, in: Seibt, Dietrich/Szyperski, Norbert/Hasenkamp, Ulrich (Hrsg.): Angewandte Informatik, Braunschweig 1985, S. 305-322

Ulrich, Hans (1968): Die Unternehmung als produktives soziales System, Bern/Stuttgart 1968

Ulrich, Hans (1978): Der systemorientierte Ansatz in der Betriebswirtschaftslehre, in: Schweitzer, Marcell (Hrsg.): Auffassungen und Wissenschaftsziele in der Betriebswirtschaftslehre, Darmstadt 1978, S. 270-291

Ulrich, Hans (1993): Überlegungen zu den konzeptionellen Grundlagen der Unternehmungsführung, in: Krulis-Randa, Jan S.; Staffelbach, Bruno/Wehrli, Hans Peter (Hrsg.): Führen von Organisationen, Bern/Stuttgart/Wien 1993, S. 37-54 
Ulrich, Hans (1994): Reflexionen über Wandel und Management, in: Gomez, Peter et al. (Hrsg.): Unternehmerischer Wandel: Konzepte zur organisatorischen Erneuerung, Wiesbaden 1994, S. 5-29

Ulrich, Peter/Fluri, Edgar (1992): Management. Eine konzentrierte Einführung, 6. Auflage, Bern/Stuttgart 1992

Varela, Francisco J. (1979): Principles of Biological Autonomy, New York/Oxford 1979

Varela Francisco J. (1984): Two Principles for Self-Organization, in: Ulrich, Hans/Probst, Gilbert J.B. (Hrsg.): Self-Organization and Management of Social Systems. Insights, Promises, Doubts and Questions, Berlin u.a. 1984, S. 25-32

Venkatraman, N. (1991): IT-Induced Business Reconfiguration, in: Scott Morton, Michael S. (Hrsg.): The Corporation of the 1990s. Information Technology and Organizational Transformation, New York/Oxford 1991, S. 122-158

Vollmer, Gerhard (1994): Evolutionäre Erkenntnistheorie, 6. Auflage, Stuttgart 1994

Vucovich, Donn/Ladley, John (1999): Where is the Bridge from Data Warehouse to Knowledge Warehouse?, in: http://knowledgeinterspace.com/article/article1. html

Wagner, Gerd (1997): Software mit Managerqualitäten. Agenten - Programme mit Überzeugungen und Absichten, in: c't Magazin für Computertechnik, Heft 15, 1997, S. 234-243

Wahren, Heinz-Kurt (1996): Das lernende Unternehmen. Theorie und Praxis des organisationalen Lernens, Berlin/New York 1996

Wall, Friederike (1996): Organisation und betriebliche Informationssysteme. Elemente einer Konstruktionstheorie, zugleich: Habilitationsschrift Universität Hamburg, Wiesbaden 1996

Weick, Karl E. (1977): Organization Design: Organizations as Self-Designing Systems, in: Organizational Dynamics, Heft 2, 1977, S. 31-46

Weick, Karl E. (1991): The Nontraditional Quality of Organizational Learning, in: Organization Science, Heft 1, 1991, S. 116-124

Weick, Karl E. (1993): Organizational Redesign as Improvisation, in: Huber, George P./Glick, William H. (Hrsg.): Organizational Change and Redesign, New York/Oxford 1993, S. 346-379

Weick, Karl E./Bougon, Michel G. (1986): Organizations as Cognitive Maps. Charting Ways to Success and Failure, in: Sims, Henry P./Gioia, Dennis A.: The Thinking Organization, San Francisco (California) 1986, S. 102-135

Widmer, Rolf (1990): Informationstechnologien und Organisationsspielräume. Ein Beitrag zur Analyse der Veränderung von organisatorischen Gestaltungsspielräumen durch den Einsatz von Informationstechnologien, Dissertation Universität Zürich, Bern/Frankfurt am Main 1990

Wiegand, Martin (1996): Prozesse Organisationalen Lernens, Dissertation Freie Universität Berlin, Wiesbaden 1996

Wiemann, Klaus (1998): Wissensmanagement: Netzwerke zum Aufbau von neuem Wissen, in: Gablers Magazin, Heft 2, 1998, S. 22-25

Wild, Jürgen (1982): Grundlagen der Unternehmungsplanung, 4. Auflage, Opladen 1982 
Willke, Helmut (1987): Systemtheorie I: Eine Einführung in die Grundprobleme der Theorie sozialer Systeme, 2. Auflage, Stuttgart/Jena 1987

Willke, Helmut (1995): Systemtheorie III: Steuerungstheorie: Grundzüge einer Theorie der Steuerung komplexer Sozialsysteme, Stuttgart/Jena 1995

Willke, Helmut (1996): Dimensionen des Wissensmanagements - Zum Zusammenhang von gesellschaftlicher und organisationaler Wissensbasierung, in: Schreyögg, Georg/ Conrad, Peter (Hrsg.): Wissensmanagement, Managementforschung, Band 6, Berlin/New York 1996, S. 263-304

Wittlage, Helmut (1987): Die Organisation mittelständischer Unternehmen, in: Betriebswirtschaftliche Forschung und Praxis, Heft 6, 1987, S. 562-583

Wittmann, Waldemar (1959): Unternehmung und unvollkommene Information, Köln/Opladen 1959

Wolfsteiner, Wolf D. (1995): Das Management der Kernfähigkeiten - Ein ressourcenorientierter Strategie- und Strukturansatz, Dissertation Hochschule St. Gallen, Rosch-Buch/Hallstadt 1995

Wollnik, Michael (1986): Implementierung computergestützter Informationssysteme. Perspektive und Politik informationstechnologischer Gestaltung, Dissertation Universität Köln, Berlin/New York 1986

Wollnik, Michael (1988): Ein Referenzmodell des Informationsmanagements, in: Information Management, Heft 3, 1988, S. 34-43

Wunderer, Rolf (Hrsg.): Betriebswirtschaftslehre als Management- und Führungslehre, 3. Auflage, Stuttgart 1994

Zachman, John A. (1987): A Framework for Information Systems Architecture, in: IBM Systems Journal, Heft 3, 1987, S. 276-292

Zahn, Erich (1991): Auf der Suche nach Erfolgspotentialen: Strategische Optionen in turbulenter Zeit, Stuttgart 1991

Zahn, Erich (1993): Informationstechnologie und Informationsmanagement, in: Bea, Franz Xaver/Dichtl, Erwin/Schweitzer, Marcell (Hrsg.): Allgemeine Betriebswirtschaftslehre, Band 2: Führung, Stuttgart/Jena 1993, S. 225-290

Zucchermaglio, Cristina/Bagnara, Sebastiano/Stucky, Susan U. (Hrsg.) (1995): Organizational Learning and Technological Change, Proceedings of the NATO Advanced Research Workshop on Organizational Learning and Technological Change (Siena, 22.-26.9.1992), Berlin/Heidelberg 1995 


\section{Bochumer Beiträge zur Unternehmungsführung und Unternehmensforschung}

Herausgegeben vom Direktorium des Instituts für Unternehmungsführung und Unternehmensforschung der Ruhr-Universität Bochum

Band 1 Busse von Colbe, Walther/Mattessich, Richard (Hrsg.): Der Computer im Dienste der Unternehmungsführung (1968)

Band 2 Busse von Colbe, Walther/Meyer-Dohm, Peter (Hrsg.): Unternehmerische Planung und Entscheidung (1969)

Band 3 Anthony, Robert N.: Harvard-Fälle aus der Praxis des betrieblichen Rechnungswesens. Herausgegeben von Richard V. Mattessich unter Mitarbeit von Klaus Herrnberger und Wolf Lange (1969)

Band 4 Mattessich, Richard: Die wissenschaftlichen Grundlagen des Rechnungswesens (1970)

Band 5 Schweim, Joachim: Integrierte Unternehmungsplanung (1969)

Band 6 Busse von Colbe, Walther (Hrsg.): Das Rechnungswesen als Instrument der Unternehmungsführung (1969)

Band 7 Domsch, Michel: Simultane Personal- und Investitionsplanung im Produktionsbereich (1970)

Band 8 Leunig, Manfred: Die Bilanzierung von Beteiligungen. Eine bilanztheoretische Untersuchung (1970)

Band 9 Franke, Reimund: Betriebsmodelle. Rechensystem für Zwecke der kurzfristigen Planung, Kontrolle und Kalkulation (1972)

Band 10 Wittenbrink, Hartwig: Kurzfristige Erfolgsplanung und Erfolgskontrolle mit Betriebsmodellen (1975)

Band 11 Lutter, Marcus (Hrsg.): Recht und Steuer der internationalen Unternehmensverbindungen (1972)

Band 12 Niebling, Helmut: Kurzfristige Finanzrechnung auf der Grundlage von Kosten- und Erlösmodellen (1973)

Band 13 Perlitz, Manfred: Die Prognose des Unternehmenswachstums aus Jahresabschlüssen deutscher Aktiengesellschaften (1973)

Band 14 Niggemann, Walter: Optimale Informationsprozesse in betriebswirtschaftlichen Entscheidungssituationen (1973)

Band 15 Reichardt, Harald: Der aktienrechtliche Abhängigkeitsbericht unter ökonomischen Aspekten (1974)

Band 16 Backhaus, Klaus: Direktvertrieb in der Investitionsgüterindustrie - Eine Marketing-Entscheiung (1974)

Band 17 Plinke, Wulff: Kapitalsteuerung in Filialbanken (1975)

Band 18 Steffen, Rainer: Produktionsplanung bei Fließbandfertigung (1977)

Band 19 Kolb, Jürgen: Industrielle Erlösrechnung - Grundlagen und Anwendungen (1978)

Band 20 Busse von Colbe, Walther/Lutter, Marcus (Hrsg.): Wirtschaftsprüfung heute: Entwicklung oder Reform? (1977)

Band 21 Uphues, Peter: Unternehmerische Anpassung in der Rezession (1979) 
Band 22 Gebhardt, Günther: Insolvenzprognosen aus aktienrechtlichen Jahresabschlüssen (1980)

Band 23 Domsch, Michel: Systemgestützte Personalarbeit (1980)

Band 24 Schmied, Volker: Alternativen der Arbeitsgestaltung und ihre Bewertung (1982)

Band 25 Wäscher, Gerhard: Innerbetriebliche Standortplanung bei einfacher und mehrfacher Zielsetzung (1982)

Band 26 Weber, Martin: Entscheidungen bei Mehrfachzielen - Verfahren zur Unterstützung von Individual- und Gruppenentscheidungen (1983)

Band 27 Kroesen, Alfred: Instandhaltungsplanung und Betriebsplankostenrechnung (1983)

Band 28 Plinke, Wulf: Erlösplanung im industriellen Anlagengeschäft (1985)

Band 29 Chamoni, Peter: Simulation störanfälliger Systeme (1986)

Band 30 Arning, Andreas: Die wirtschaftliche Bewertung der Zentrenfertigung - Dargestellt am Beispiel einer Fertigungsinsel (1987)

Band 31 Gebhardt, Günther: Finanzielle Planung und Kontrolle bei internationaler Untemehmenstätigkeit

Band 32 Markiewicz, Michael: Ersatzteildisposition im Maschinenbau - Betriebswirtschaftliche Methoden der Planung und Überwachung (1988)

Band 33 Pellens, Bernd: Der Informationswert von Konzernabschlüssen - Eine empirische Untersuchung deutscher Börsengesellschaften (1989)

Band 34 Mrotzek, Rüdiger: Bewertung direkter Auslandsinvestitionen mit Hilfe betrieblicher Investitionskalküle (1989)

Band 35 Deppe, Joachim: Quality Circle und Lernstatt - Ein integrativer Ansatz (1989, 3. Auflage 1993)

Band 36 Rademacher, Michael: Arbeitszeitverkürzung und -flexibilisierung - Formen und betriebliche Auswirkungen (1990)

Band 37 Kaiser, Klaus: Kosten- und Leistungsrechung bei automatisierter Produktion (1991, 2. Auflage 1993)

Band 38 Müller, Hermann: Industrielle Abfallbewältigung - Entscheidungsprobleme aus betriebswirtschaftlicher Sicht (1991)

Band 39 Schörner, Peter: Gesetzliches Insiderhandelsverbot - Eine ordnungspolitische Analyse (1991)

Band 40 Bentler, Martin: Grundsätze ordnungsmäßiger Bilanzierung für die Equitymethode (1991)

Band 41 Brüggerhoff, Jürgen: Management von Desinvestitionen (1992)

Band 42 Bröker, Erich W.: Erfolgsrechnung im industriellen Anlagengeschäft - Ein dynamischer Ansatz auf Zahlungsbasis - (1993)

Band 43 Frankenberg, Peter: Transnationale Analyse US-amerikanischer und deutscher Jahresabschlüsse - Eine theoretische und empirische Untersuchung (1993)

Band 44 Kleinaltenkamp, Michael: Standardisierung und Marktprozeß - Entwicklungen und Auswirkungen im CIM-Bereich (1993)

Band 45 Pellens, Bernhard: Aktionärsschutz im Konzern - Empirische und theoretische Analyse der Reformvorschläge der Konzernverfassung (1994)

Band 46 Reckenfelderbäumer, Martin: Marketing-Accounting im Dienstleistungsbereich - Konzeption eines prozeßkostengestützten Instrumentariums (1995) 
Band 47 Knittel, Friedrich: Technikgestützte Kommunikation und Kooperation im Büro. Entwicklungshindernisse - Einsatzstrategien - Gestaltungskonzepte (1995)

Band 48 Riezler, Stephan: Lebenszyklusrechnung - Instrument des Controlling strategischer Projekte (1996)

Band 49 Schulte, Jörn: Rechnungslegung und Aktienkursentwicklung - Erklärung und Prognose von Aktienrenditen durch Einzel- und Konzernabschlußdaten (1996)

Band 50 Muhr, Martin: Zeitsparmodelle in der Industrie - Grundlagen und betriebswirtschaftliche Bedeutung mehrjähriger Arbeitszeitkonten (1996)

Band 51 Brotte, Jörg: US-amerikanische und deutsche Geschäftsberichte. Notwendigkeit, Regulierung und Praxis jahresabschlußergänzender Informationen (1997)

Band 52 Gersch, Martin: Vernetzte Geschäftsbeziehungen. Die Nutzung von EDI als Instrument des Geschäftsbeziehungsmanagement (1998)

Band 53 Währisch, Michael: Kostenrechnungspraxis in der deutschen Industrie. Eine empirische Studie (1998)

Band 54 Völkner, Peer: Modellbasierte Planung von Geschäftsprozeßabläufen (1998)

Band 55 Fülbier, Rolf Uwe: Regulierung der Ad-hoc-Publizität. Ein Beitrag zur ökonomischen Analyse des Rechts (1998)

\section{Band 1 - 55 erschienen beim Gabler Verlag Wiesbaden}

Band 56 Ane-Kristin Reif-Mosel: Computergestützte Kooperation im Büro. Gestaltung unter Berücksichtigung der Elemente Aufgabe, Struktur, Technik und Personal (2000)

Band 57 Claude Tomaszewski: Bewertung strategischer Flexibilität beim Unternehmenserwerb. Der Wertbeitrag von Realoptionen (2000)

Band 58 Thomas Erler: Business Objects als Gestaltungskonzept strategischer Informationssystemplanung (2000)

Band 59 Joachim Gassen: Datenbankgestützte Rechnungslegungspublizität. Ein Beitrag zur Evolution der Rechnungslegung (2000)

Band 60 Frauke Streubel: Organisatorische Gestaltung und Informationsmanagement in der lernenden Unternehmung. Bausteine eines Managementkonzeptes organisationalen Lernens (2000) 


\section{Informationsmanagement im Wandel}

\section{Praxisorientierte Lösungsansätze und Managementmodelle zur Bewältigung von Veränderungen im Informationsma- nagement}

Frankfurt/M., Berlin, Bern, New York, Paris, Wien, 1999.

LXVIII, 410 S., zahlr. Tab. u. Graf.

Europäische Hochschulschriften: Reihe 5,

Volks- und Betriebswirtschaft. Bd. 2422

ISBN 3-631-34212-8 • br. DM 128.-*

Die seit Jahren zu beobachtende Beschleunigung der Veränderungen in unseren Arbeits- und Wirtschaftsprozessen verlangt vom Informationsmanagement ein Umdenken. Das in dieser Arbeit geforderte veränderungsorientierte, strategisch-dynamische Informationsmanagement versucht, die vielfachen Schwächen des Informationsmanagements in der Unternehmenspraxis zu heilen und die erkannten Schwächen in Stärken umzukehren. Auf Basis von Situationen, Schwachstellen und Veränderungen im Informationsmanagement werden praxisorientierte Lösungsansätze und Managementmodelle erarbeitet. Diese sind eine Orientierungsleitlinie für Geschäftsfeldund IT-Manager und erleichtern den Übergang von einem status-quoorientierten zu einem veränderungsorientierten Informationsmanagement.

Aus dem Inhalt: Informationsmanagement im Wandel · Grundlagen für das Informationsmanagement - Situation und Schwachstellen des Informationsmanagements in der Praxis - Veränderungen im Informationsmanagement . Lösungsansätze zur Bewältigung von Veränderungen im Informationsmanagement · Managementmodelle zur Bewältigung von Veränderungen im Informationsmanagement

Frankfurt/M - Berlin - Bern - New York · Paris - Wien

Auslieferung: Verlag Peter Lang AG

Jupiterstr. 15, CH-3000 Bern 15

Telefax (004131) 9402131

*inklusive Mehrwertsteuer

Preisänderungen vorbehalten 